\title{
OSTI
}

The Effect of Chromium Oxide on the Properties of Simulated Nuclear Waste Glasses
O. Vojtech
M. Maryska
P. Havel
J. Sussmilch
J. Had
T. Cervinka
Z. Urbanec
V. Krestan
E. Stejskalova
P. Novy
P. Exnar
Z. Baloun
J. Hlavac
L. Bauer
T. Zizka
V. Hulinsky
J. Rusek

February 1996

Prepared for

the U.S. Department of Energy under Contract DE-AC06-76RLO 1830

Pacific Northwest National Laboratory Richland, Washington 99352 
PNNL-10986

UC-810

Project Technical Information

\section{The Effect of Chromium Oxide on the Properties of Simulated Nuclear Waste Glasses}
O. Vojtech
M. Maryska
P. Havel
J. Sussmilch
J. Had
T. Cervinka
Z. Urbanec
V. Krestan
E. Stejskalova
P. Novy
P. Exnar
Z. Baloun
J. Hlavac
L. Bauer
T. Zizka
V. Hulinsky
J. Rusek

February 1996

Prepared for

the U.S. Department of Energy

under Contract DE-AC06-76RLO 1830

Pacific Northwest National Laboratory

Richland, Washington 99352 


\title{
DISCLAIMER
}

This report was prepared as an account of work sponsored by an agency of the United States Government. Neither the United States Government nor any agency thereof, nor Battelle Memorial Institute, nor any of their employees, makes any warranty, express or implied, or assumes any legal liability or responsibility for the accuracy, completeness, or.usefulness of any information, apparatus, product, or process disclosed, or represents that its use would not infringe privately owned rights. Reference herein to any specific commercial product, process, or service by trade name, trademark, manufacturer, or otherwise does not necessarily constitute or imply its endorsement, recommendation, or favoring by the United States Government or any agency thereof, or Battelle Memorial Institute. The views and opinions of authors expressed herein do not necessarily state or reflect those of the United States Government or any agency thereof.

\author{
PACIFIC NORTHWEST NATIONAL LABORATORY \\ operated by \\ BATTELLE \\ for the \\ UNITED STATES DEPARTMENT OF ENERGY \\ under Contract DE-AC06-76RLO 1830
}

Printed in the United States of America

Available to DOE and DOE contractors from the

Office of Scientific and Technical information, P.O. Box 62, Oak Ridge, TN 37831;

prices available from (615) 576-8401.

Available to the public from the National Technical Information Service, U.S. Department of Commerce, 5285 Port Royal Rd.p Springfield, VA 22161 


\section{DISCLAMMER}

Portions of this document may be illegible in electronic image products. Images are produced from the best available original document. 


\title{
The Effect of Chromium Oxide
}

\section{on the Properties of Simulated Nuclear Waste Glasses \\ (Final Report)}

\author{
July, 1995 \\ Prepared for \\ Battelle Memorial Institute, \\ Pacific Northwest Laboratory \\ under Contract No. 209344-A-F1
}

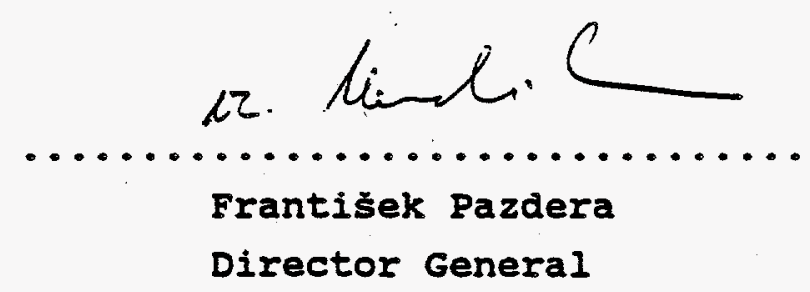

Nuclear Research Institute Rež, plc 


\section{ABSTRACT}

A study of the effect of chromium on the properties of selected glasses was performed in the frame of a contract between Battelle, Pacific Northwest Laboratories and Nuclear Research Institute, Rez (Contract No. 209344-A-FI). In the period from July 1994 to June 1995 two borosilicate glasses of special composition were prepared according to the PNL procedure and their properties were studied. Physical and structural characteristics of glasses were studied by a team consisting of the staff of laboratories of Nuclear Research Institute in Rez, University of Chemical Technology in Prague, Glass Institute (State Testing Laboratory) in Hradec Králové and svus (former Glass Research Institute) Hradec Králové.

The properties. measured for two baseline glasses included temperature dependence of the viscosity, temperature dependence of the electrical conductivity, crystallinity (measured by $\mathrm{X}-\mathrm{ray}$ diffraction analysis, $S E M$ analysis, optical microscopy incl. image analysis), dilatometry, liquidus temperature, chemical analysis of glasses and properties of the respective batches during the heat treatment.

Two special heat treatments of both glasses (corresponding to the centerline cooling temperature decrease and to a treatment with uncontrolled cooling) were used for both baseline glass compositions, and the crystallinity study of the products was performed.

The behavior of chromium compounds during the heat treatment of batches of baseline compositions was studied by the analysis of samples obtained in gradient furnaces and by studies at constant temperatures. The dependencies of the $\mathrm{Cr}$ (VI) content in batches on the temperature and on the residence time of the heat treatment were mathematically described. 
The effect of changes in the glass compositions on the chromium behavior was studied by changes of glasses acidobasicity and changes in concentrations of alkali oxides and of alumina.

On the request of PNL a supplemental program was included in the project. Five special glasses were prepared.for the study of Fe, 25 , Ni and in effect on the crystallinity of the baseline glass.

Both baseline glasses, with lower and higher waste loading, contained crystal phases. Glass 1 contained agglomerates and individual crystals of eskolaite, Glass 2 contained eskolaite and. beta-eucryptite as major phases and nepheline and spinel as minor phases. Glass 1 is relatively stable, Glass 2 is very sensitive to thermal history and concentration changes.

From the point of view of measured physico-chemical properties (viscosity, electrical conductivity) Glass 1 exhibited regular (non-anomalous) behavior. In case of Glass 2 , because of high crystallization ability, problems in the measurement of respective properties occured.

Chemical durability of the Glass 1 is essentially higher than that of the Glass 2 .

Heat treatment study of the respective batches indicated the ranges of temperatures where CrVI is formed. Mathematical description of the CrVI formation kinetics was performed as well.

Two prescribed heat treatment procedures were used for both baseline glasses, which simulated some technological steps. Crystallinity study of products showed that Glass 1 exhibits lower tendency to crystallization than Glass 2. Eskolaite and beta-eucryptite were found as dominant phases again. Only small proportions of other crystalline phases appeared in the Glass 2. procedure simulating the cooling of a Glass 2 block (Canister Centerline cooling procedure) led to almost fully crystalline product.

Changes in the content of some glass constituents ( $\mathrm{L} i, \mathrm{Na}$; $s i$ and $B)$ affecting the acidobasicity of the glass showed that 
decrease of the glass basicity leads to lower CrVI/Cr ratio and to a decrease of the chromium leached from the glass.

A series of glasses with increased concentration of $\mathrm{Fe}, \mathrm{Ni}$. $\mathrm{Mn}$ and $\mathrm{Zr}$ was prepared according to special heat treatment procedures. As a dominant phase in the majority of glasses eskolaite crystals and its agglomerates were found. Only the glass enriched by Mno did not crystallize at all after thermal exposure at the melting temperature, and only small spinel crystals appeared after the exposure $100^{\circ} \mathrm{C}$ lower.

This Final Report contains a vast documentation on the properties of all glasses studied. For the preparation of the respective technology more detailed study of physico-chemical properties and crystalinity of investigated systems would be desirable. 


\section{SUMLARY}

A study of the chromium effect on the glass behavior during the melting process and on the vitrification product próperties was performed within a PNL project realized in the frame of the contract No. $209344-A-F 1$.

Studies necessary for the fulfillment of the objectives were performed at the Nuclear Research Institute kez, plc (as a leading organization), at the Glass Institute-state Testing Laboratory, Hradec Kralove, at the University of Chemical Technology, Prague (Department of Glass and Ceramics) and at svus, Hradec Králové (former Glass Research Institute).

Group of specialists from the above institutions represented an optimum combination of research workers with an experience in the glass and nuclear research, theoreticians working in the field of silicate sciences and specialists of the state Testing Laboratory working on a necessary QA level.

As a basis for the study two types of glasses were prepared differing in the waste loading. From the point of view of the chromium content Glass 1 contained theoretically 4.14 weight of $\mathrm{Cr}_{2} \mathrm{O}_{3}$ and Glass 2 contained 6.215 weight of $\mathrm{Cr}_{2} \mathrm{O}_{3}$. (For the glasses preparation chromium hydroxide prepared according to a special PNL recommended procedure was used).

Both glasses were prepared using a "quenched and annealed" procedure (melting temperature of Glass 1 was $1150{ }^{\circ} \mathrm{C}$, of Glass $21450^{\circ} \mathrm{C}$ ) and respective samples were used for the determination of physico-chemical and chemical properties. These properties included crystallinity (X-ray diffraction analysis, scanning electron microscopy and optical microscopy with image analysis), temperature dependence of viscosity and electrical conductivity, liquidus temperature, dilatometric constants, chemical analysis and durability. 
Crystallinity

Glass 1 contained tabular crystals of eskolaite $\left(\mathrm{Cr}_{2} \mathrm{O}_{3}\right)$ and agglomerates of eskolaite as the only crystalline phase in the glassy matrix. Eskolaite crystals contained variable amounts of $\mathrm{Fe}_{2} \mathrm{O}_{3}$ and $\mathrm{Al}_{2} \mathrm{O}_{3}$ as admixtures presumably in solid solution. The agglomerates were apparently relicts of chromium hydroxide used for the preparation.

The prevailing primary crystalline phases in the Glass 2 were eskolaite and beta-eucryptite, as minor phases nepheline and spinel were found. Very small spinel particles were more concentrated in the bottom part of the glass block. The Glass 2 was very sensitive to the conditions of preparation and components concentration changes.

Inhomogeneities were found in various parts of the cast blocks.

\section{Viscosity and electrical conductivity}

Both viscosity and electrical conductivity data were succesfully interpreted for the Glass 1 using vogel-FulcherTammann (VFT) equation. The Glass 1 can be considered as a good glass not exhibiting apparent anomalies. Particles of eskolaite apparently did not affect the measurements and interpretation of data. In case of Glass 2 difficulties occured during the viscosity and electrical conductivity measurements, caused by the lower stability of the glass and crystallization of phases other than eskolaite in the measured sample. Changes in crystallinity were responsible for inadequate fit of viscosity data with the VFT equation and for bad repeatability of electrical conductivity measurements.

\section{Thermal expansion and transformation temperature}

The coefficient of thermal expansion and transformation temperature for Glass 1 has shown good repeatability.

In case of Glass 2 the same problems appeared as in the measurements of viscosity and electrical conductivity. Repeated measurements of thermal expansion led to different results for 
the same sample and even for different parts of the sample. The latter effect can be explained by different content of beta-eucryptite, which exhibits a negative expansion coefficient. Expansion coefficient $\alpha_{(20-300)} c^{10^{6}}$ for Glass 1 was about 8.1 , for Glass 2 in the range of 5.2 to 8.1 . Dilatometric transformation temperature for Glass 1 was $472{ }^{\circ} \mathrm{C}$, for Glass 2 was in the range $421-455^{\circ} \mathrm{C}$.

\section{Chemical analysis}

Qualitative and quantitative chemical analysis confirmed the expected composition of both baseline glasses. Special attention was given to the content of different valence states of chromium and iron. The content of CrVI in case of Glass 1 was about 0.38 wt.f (expressed as $\mathrm{CrO}_{3}$ ) compared to total $\mathrm{Cr}_{2} \mathrm{O}_{3}$ content 3.82 wt. $\%$. The content of CrVI in Glass 2 was 0.36 wt.7 (total $\mathrm{Cr}_{2} \mathrm{O}_{3} 5.76$ wt. $\%$ ). The concentration of divalent iron in dissolved glassy phase was below the detection limit 0.01 wt. $\%$.

\section{Durability}

The determination of chemical durability according to Iso-719 standard (one hour exposure of glass grain at $98^{\circ} \mathrm{C}$ ) proved that the Glass 2 exhibits a very poor hydrolytical - resistance, probably due to a high content of various crystalline phases. Glass 1 belongs to the durability class HGB 3 , corresponding to relatively good stable glasses, whereas Glass 2 is out of the limits of durability classes.

Batch heat treatment studies

The behavior of the batch during the heat treatment was studied by gradient furnace experiments and by experiments at constant temperatures. Special attention was given to the valence state of chromium during the process of batch heating and thermal exposures.

The beginning of the CrVI formation in case of Glass 1 was found at approx. $200^{\circ} \mathrm{C}$. A significant increase in $\mathrm{Cr}$ oxidation rate was stated at $600^{\circ} \mathrm{C}$ and at residence times longer than 1 hour. This effect was more significant for Glass 2 . Higher 
temperatures $\left(650^{\circ} \mathrm{C}\right)$ or prolonged residence time caused decrease of the CrVI formation rate, evidently because of the melt formation approx. at $670^{\circ} \mathrm{C}$.

In case of Glass 2 the beginning of the CrVI formation was at $170^{\circ} \mathrm{C}$. Mathematical models for the CrVI formation were proposed for temperature intervals $200{ }^{\circ} \mathrm{C}-550^{\circ} \mathrm{C}$ and $550^{\circ} \mathrm{C}$ - $700^{\circ} \mathrm{C}$. The $\mathrm{CrVI}$ formation rate is higher for the latter interval case.

The formation of CrVI is significant for early stages of glass preparation, formation of a liquid phase in the melt hinders the CrVI formation process. The separation of the chromate layer was not found in the systems studied under the conditions used for melting.

Special heat treatment

Glasses of both types were heat treated according to two special procedures, one of which simulated cooling conditions in the canister (glasses marked CCC - Canister Centerline cooling scheme), the other followed the 24 hours treatment at melting temperatures, two hours residence time at $500^{\circ} \mathrm{C}$ and uncontrolled cooling in the furnace (products marked TEM). Products gained by these two treatments were studied using $x$-ray diffraction analysis and optical microscopy for the presence of crystal phases and possible settling properties.

The results were following: Glass 1 exhibits lower tendency to crystallization than Glass 2, heat treatment according to the CCC schedule leads to products with higher degree of crystallization. Glass 1, treated by TEM procedure, contained eskolaite as the only crystal phase. CCC procedure led to the formation of beta-eucryptite (dominant phase) and eskolaite.

Glass 2, treated by the TEM procedure, contained also beta-eucryptite as dominant phase, crystals of eskolaite and Li-Al-disilicate. Relatively small proportion of amorphous glass phase was present. Canister Centerline cooling procedure produced a product with amorphous phase only in thin layers on the crystal 
boundaries, with beta-eucryptite dominant phase, nepheline and eskolaite.

No distinct differencies between the phase composition near to the surface and to the bottom were found. Settling effect or segregation were not oberved during the heat treatment performed in this study.

Following conclusions can be made from experiments performed with Glasses 1 and 2 , with respect to melting behaviour and product properties:

Both glasses can be melted at technologically acceptable temperatures. For Glass 1 which was prepared at $1150^{\circ} \mathrm{C}$ the optimum melting temperature was found in the range 1295 to $1340^{\circ} \mathrm{C}$ (extrapolation of the VFT equations). Higher viscosity and lower temperature used for the Glass 1 preparation are probably the reasons why agglomerates of $\mathrm{Cr}_{2} \mathrm{O}_{3}$ did not dissolve in the melt to such an extent as in Glass 2 which was melted at $1450^{\circ} \mathrm{C}$ and viscosity lower than $6 \mathrm{~Pa} . \mathrm{s}$. (The extrapolated value of the melt temperature corresponding to the $6 \mathrm{~Pa} . \mathrm{s}$ viscosity is in case of Glass $21420^{\circ} \mathrm{C}$ ).

Alkali chromate is formed during heating the batch within the medium range of temperatures in oxidizing conditions. with the method of melting used in this study, macroscopic liquid phase separation of sodium chromate was not observed although reducing agents were not introduced into the batch.

Agglomerates of $\mathrm{Cr}_{2} \mathrm{O}_{3}$ (eskolaite) were found in both glasses with particle size corresponding to the as-batched chromium hydroxide which apparently did not dissolve at the melting temperature. Individual crystals of eskolaite are formed very quickly during cooling without affecting the regular behavior of the melt and presumably will not influence considerably the chemical and physical properties of the product required for the waste vitrification. 
Crystals formation (esp. beta-eucryptite) in the Glass 2 and. the respective high liquidus temperature deserves more detailed study of the crystals morphology and modified measurements of the liquidus temperature.

When considering the suitability of Glasses 1 and 2 for waste vitrification, Glass 2 exhibits several undesirable properties: very high crystallization ability has unacceptable consequences in the physical properties (irregularities in viscosity and electrical conductivity, low mechanical strength) and esp. in hydrolytic resistance which is 2 orders of magnitude lower according to leached quantity: than that found for Glass 1. For future studies changes of the composition of the glasses can be recommended in the direction of decreased $\mathrm{Li}_{2} \mathrm{O}$ and alumina and increased silica content.

As to the influence of the CrVI on the glass system, its content, which is by an order of magnitude lower than CrIII, seems to be sufficient to suppress the content of Feo to negligible values. More detailed study of this problem will be useful.

The detailed study of the above vitrification system was enhanced by the investigation of the effect of glass acidobasicity on the chromium behavior, in glasses and of the increased concentration of alkali elements and lower content of aluminium.

The decrease of glass basicity caused by the decrease of Li content and simultaneous increase of $S i$ and $B$ content led to a lower crVI/Cr ratio in glasses studied for two chromium concentrations examined in these experiments. The lower CrVI/Cr ratio is supposed to be a reason for a decrease of chromium leached from the glasses in the tested region.

The decrease of $\mathrm{Al}_{2} \mathrm{O}_{3}$ content which was substituted by $\mathrm{Na}_{2} \mathrm{O}$ had a large effect on the increase of CrVI/Cr ratio in the glass and subsequently on the increase of the amount of chromium leached from the glass. This effect can be explained also by the 
higher basicity resulted from such composition changes. Nevertheless, chemical durability has acceptable values after composition changes studied in this glass system.

\section{Glasses of the Series $C$}

On special request of the PNL laboratory a special series of glasses was prepared (series c) to study changes in crystallinty caused by the increase of following elements: iron, zirconium, manganese and nickel. The content of chromium oxide was reduced to about 1.1 weight $t$.

Two special heat tireatment were used for the preparation of glasses, simulating technological conditions. For the proper heat treatment schedule the temperature dependence of melt viscosity and glass transformation temperatures were determined.

Glasses marked $c-c$ were prepared at their respective melting temperatures, corresponding to the viscosity of $6 \mathrm{~Pa} . \mathrm{s}$ (residence time was 24 hours), Glasses $D-C$ at temperatures $100^{\circ} \mathrm{C}$ bellow the melting temperatures with the same residence time.

Most glass samples contained individual crystals and agglomerates of eskolaite. Only in glassses with the increased content of manganese the eskolaite crystals were not present, but spinel precipitated at the lower temperature of heat treatment. spinel phase was found also in the glass with the increased content of nickel. The spinel phase found in all experiments performed in this study always contained $\mathrm{Ni}, \mathrm{kn}$ or $\mathrm{zn}$ in the position of divalent cations. The increase of $\mathrm{Fe}$ oxides in the glass $c 2$ apparently did not affect the spinel formation.

Most individual eskolaite crystals (presumably formed by secondary crystallization from supersaturated melt) contained iron in solid solution. The solubility of chromium in the glasses studied is supposed to be between $0.5-1.0$ weight $*$

The glasses of this series represent a very promising type of glass for waste vitrification. However, it should be necessary to perform more detailed studies of the following problems: 
a) Liquidus temperature, crystallization ability and viscosity changes induced by changes of the baseline composition $\mathrm{Cl}$ with the aim to optimize the properties. special attention should be paid to the participation of divalent cations (incl. MgII) on the spinel formation.

b) Crystallinity after heat treatment at high as well as at lower temperatures (ccc-type schedule) with respect to possible settling effects and to the effect of phase composition on chemical durability and mechanical properties.

c) Melting behavior of batches, incl. volatilization, homogenization, redox reactions and conditions for the reduction of chromates.

d) Chemical durability tests and studies of long-time interactions of glass with aqueous solutions for as prepared glass as well as for crystallized products, preferably using continuous dynamic (flow-through) tests.

Detailed study of such systems would be necessary in case glasses with the increased content of specific elements (such as in series C) will be the subject of the proposed technology. It is supposed that the increased content of certain elements can affect not only the quality of the vitrification product but can cause problems during the melting in ceramic melters. 
ABSTRACT

page

i

SUMARARY iv

LIST OF FIGURES $\quad x$

IIST OF TABLES $\quad$ EXIi

1. INTRODUCTION 1

2. CHROMIUM CONTAINING GLASSES

3. PREPARATION AND PROPERTIES OF CHROMIUM HYDROXIDE 5

3.1. PREPARATION 6

3.2. PROPERTIES . 7

4. CHARACTERIZATION OF GLASSES 1 AND $2 \quad 12$

4.1. PREPARATION 12

4.2. PROPERTIES 20

4.2.1. CRYSTALIINITY 20

4.2.1.1. X-Ray Diffraction Analysis 20

4.2.1.2. Optical Microscopy 24

4.2.1.3. Electron Microanalysis 30

4.2.1.4. Conclusions. 63

4.2.2. PHYSICO-CHEMICAI PROPERTIES 64

4.2.2.1. Density 64

4.2.2.2. Temperature Dependence of Viscosity 65

4.2.2.3. Temperature Dependence of Electrical Conductivity

4.2.2.4. Dilatometry

4.2.2.5. Liquidus Temperature

4.2.2.6. Discussion and Conclusions 75

4.2.3. CHEMICAL PROPERTIES

4.2.3.1. Chemical Analysis of Glasses 77

4.2.3.2. Nondestructive Analysis 82

4.2.3.3. Chemical Durability 85

4.2.3.4. Discussion of Results 87

4.2.4. BATCH HEAT TREATMENT 87

4.2.4.1. Gradient Furnace Experiments 88

4.2.4.2. Experiments at Constant Temperature 92

4.2.4.3. Chemical Analysis of Batches 95

4.2.4.4. Mathematical Evaluation of Experiments 98

4.2.4.5. Discussion of Results . 107

4.2.5. CONCLUSIONS

108

5. GLASSES WITH SPECIAL THERMAL TREATMENT 111

5.1. PREPARATION OF GLASSES 111 
5.2. CHARACTERIZATION

5.2.1. VISUAL EVALUATION OF SAMPLES

5.2.2. CRYSTALIINITY

5.2.2.1. X-Ray Diffraction Analysis

5.2.2.2. Optical Microscopy

5.3. DISCUSSION AND CONCLUSIONS

114

114

1.15

115

118

129

6. THE INFLUENCE OF GLASS BASICITY AND CONTENT OF SOME CONSTITUENTS ON THE CHROMIUM BEHAVIOR IN GLASSES

6.1. INTRODUCTION

6.2. EFFECT OF ACIDOBASICITY

6.2.1. INTRODUCTION

6.2 .2 . PREPARATION OF GLASSES

6.2.3. ANALYSIS OF LEACHATES

6.3. EFFECT OF LOWER AI CONTENT AND OMISSION OF Li FROM ADDITIVES

6.3.1. INTRODUCTION

6.3.2. PREPARATION OF GLASSES

6.3.3. ANALYSIS OF LEACHATES

6.4. ANALYSIS OF GLASSES

6,5. PHYSICO-CHEMICAI PROPERTIES OF GLASSES

6.6. DISCUSSION AND CONCLUSIONS

7. THE EFFECT OF Fe,Mn,Ni AND $\mathrm{Zr}$ ON SPECIAL GLASS PROPERTIES

7.1. PREPARATION OF GLASSES OF SERIES $C$

7.2. PHYSICO-CHEMICAL PROPERTIES OF GLASSES

179

184

190

7.3. STRUCTURAL CHARACTERISTICS OF GLASSES

7.4. DISCUSSION AND CONCLUSIONS

223

226

231

9. QUALITY ASSURANCE

234

EXPERIMENTS NOT INCLUDED IN THE TEST PLAN

PREPARATION AND PROPERTIES OF CHROMIUM HYDROXIDE I

PREPARATION AND PROPERTIES OF GLASSES A, B, A/TEM, A/CCC, B/TEM AND B/CCC

ANNEX A3

PREPARATION OF GLASSES WITH LOWER CONTENT OF CHROMIUM OXIDE

250

ANNEXES B

METHODS AND PROCEDURES

ANNEX B1

QUANTITATIVE CHEMICAL ANALYSES OF CHROMIUM HYDROXIDE 
ANNEX B2

METHODS FOR THE DETERMINATION OF TOTAL AND HEXAVALENT CHROMIUM

IN CHROMIUM GLASSES AND LEACHING SOLUTIONS

ANNEX 83

DETERMINATION OF IIQUIDUS TEMPERATURE

ANNEX B4

DETERMINATION OF VISCOSITY BY ROTARY VISCOMETER

ANNEX B5

DETERMINATION OF ELECTRIC CONDUCTIVITY OR SPECIFIC ELECTRIC

RESISTANCE OF GLASS MEITS AT HIGH TEMPERATURES

ANNEX B6

DETERMINATION OF DENSITY

ANNEX $\mathrm{B7}$

DETERMINATION OF MEAN COEFFICIENT OF IINEAR THERMAI EXPANSION

AND DILATOMETRIC TRANSFORMATION TEMPERATURE

ANNEX B8

X-RAY DIFFRACTION IDENTIFICATION OF CRYSTALLINE PHASES

ANNEX B9

PHOTODOCUMENTATION AND ANALYSIS IN ELECTRON SCANNING MICROSCOPE

ANNEX B10

DETERMINATION OF THE SUM OF $\mathrm{Nd}_{2} \mathrm{O}_{3}+\mathrm{La}_{2} \mathrm{O}_{3}+\mathrm{ZrO}_{2}$

ANNEX BII

TOTAL CHROMIUM DETERMINATION IN WATER-GLASS LEACHATES USING FLAME-AAS

ANNEX B12

MEASUREMENT OF CASTING ABILITY

ANNEX B13

PREPARATION AND LEACHING OF CRUSHED GLASS

ANREXES C

TABLES AND FIGURES NOT INCLUDED IN THE TEXT OF FINAL REPORT

273

ANNEXES D

IISTS OF DOCUNENTS AND SAMPLES

ANNEX DI

LIST OF CLOSING REPORTS

ANNEX D2

IIST OF ARCHIVED SAMPLES

ANNEX $\mathbf{E}$

STATEMENT OF WORK 
Figure 3-1: Chromium Hydroxide II Observed in SEM Mode, Magn. 100

Figure 3-2: Chromium Hydroxide II Observed in SEM Mode, Magn.450

Figure 4-1: Polished surface of a Cross-section of the Glass Block 2/5(3) Successively Investigated in scanning Electron Microscope (the Bottom Edge of the Figure Corresponds to the Bottom Sample Area, Magn. 15)

Figure 4-2: Diffractogram of Glass 1/5, Centre

Figure 4-3: Diffractogram of Glass 2/5, Centre

Figure 4-4: Diffractogram of Glass 2/5, Bottom

Figure 4-5: Glass 1/5, Objective 3.2, Surface Area of the Dark Phase 51 :

Figure 4-6: Glass 1/5, Objective 50, Plates of Eskolaite, Detail of a Small Agglomerate and its Vicinity

Figure 4-7: Glass 2/5, Objective 3.2, Surface Area of the Dark Phase $44 \%$

Figure 4-8a: Glass 2/5, Objective 50, Plates of Escolaite (Es) and Hexagonal Crystals of Beta Eucryptite (Eu)

Figure 4-8b: Glass 2/5, Escolaite and Eucryptite Crystals, Combination of Image in Polarized Light and Crossed Polarizing Filters Arrangement

Figure 4-9: Glass 1/5. Section View in the Bottom Area and Central Part of the Block ( $0 \mathrm{~mm})$

Figure 4-10: Glass 1/5. Section View in the surface Block Part $(15 \mathrm{~mm})$

Figure 4-11: Glass 1/5. Detail of the Section of the Bottom Area and Central Block Part $(0-5 \mathrm{~mm})$

Figure 4-12: Glass 1/5. Detail of the section of the Bottom Area and Central Block Part (16-20 mm)

Figure 4-13: Glass 1/5. Grain Irregular Particle with Marked Area and Local Analyses. Normal Section (16-20 mm)

Figure 4-14: Glass 1/5. Grain Irregular Particle. X-Ray Distribution of $\mathrm{Na}, \mathrm{Al}, \mathrm{Cr}, \mathrm{Fe}$ and $\mathrm{Si}$ in the Area Shown in Figure 4-13. Normal Section (16-20 $\mathrm{mm})$. Program MAPPING 
Figure 4-15: Glass 1/5. Eskolaite Crystal Clusters with Narked Area and Local Analyses. Normal Section $(0-5 \mathrm{~mm})$

Figure 4-16: Glass 1/5. Eskolaite Crystal Cluster. X-Ray Distribution of $\mathrm{Na}, \mathrm{Al}, \mathrm{Si}, \mathrm{Fe}$ and $\mathrm{Cr}$ in the Area Show in Figure 4-15. Normal Section $(0-5 \mathrm{~mm})$. Program MAPPING

Figure 4-17: Glass 1/5. Eskolaite Crystal Cluster. Normal Section $(16-20 \mathrm{~mm})$

Figure 4-18: Glass 1/5. Eskolaite Crystal Cluster. X-RaY Distribution of $\mathrm{Na}, \mathrm{Al}, \mathrm{Si}, \mathrm{Fe}$ and $\mathrm{Cr}$ in the Area Shown in Figure 4-i7. Normal section (16-20 mm). Progran KAPPING

Figure 4-19: Glass 1/5. Isolated Eskolaite Crystals. Normal Section $(0-5 \mathrm{~mm})$

Figure 4-20: Glass 1/5. Isolated Eskolaite Crystals. Normal Section $(16-20 \mathrm{~mm})$

Figure 4-21: Glass 1/5. Isolated Eskolaite Crystals, X-Ray Distribution of $\mathrm{Na}, \mathrm{Al}, \mathrm{Si}, \mathrm{Fe}$ and $\mathrm{Cr}$ in the Range Shown in Figure 4-20. Normal section (16-20 mm). Program MAPPING

Figure 4-22: Glass 2/5. Section View of the Bottom Block Zone $(0 \mathrm{~mm})$

Figure 4-23: Glass 2/5. Detail of the section of the Surface Layer of the Bottom Block Zone $(0-1 \mathrm{~mm})$

Figure 4-24: Glass 2/5: Detail of the section in the Area between Bottom Zone and Central Block Part $(3-4 \mathrm{~mm})$

Figure 4-25: Glass 2/5. Detail of the section in the Central Block Part $(5-10 \mathrm{~mm})$

Figure 4-26: Glass 2/5. Detail of the section of the Central Block Part $(11-15 \mathrm{~mm})$

Figure 4-27: Glass 2/5. Eskolaite Crystal cluster. Normal Section $(1-3 \mathrm{~mm})$

Figure 4-28: Glass 2/5. Eskolaite Crystal Cluster with Marked Surface Analysis. Normal Section (16-20 mm)

Figure 4-29: Glass 2/5. Eskolaite Crystal Cluster. X-Ray Distribution of $\mathrm{Na}, \mathrm{Al}, \mathrm{Si}, \mathrm{Fe}$ and $\mathrm{Cr}$ in the Area Shown in Figure 4-28. Normal Section (16-20 mm). Program MAPPING 
Figure 4-30: Glass 2/5. Eskolaite Crystal Cluster (Detail) with Marked Local Analyses of the Crystal (Point 1) and the Intercrystal space (Point 2). Normal Section $(16-20 \mathrm{~mm})$

Figure 4-31: Glass 2/5. Eskolaite Crystal Cluster (Detail). X-Ray Distribution of $\mathrm{Na}, \mathrm{Al}, \mathrm{Si}, \mathrm{Fe}$ and $\mathrm{Cr}$ in the Area Shown in Figure 4-30. Normal section (16-20 mm). Program MAPPING

Figure 4-32: Glass 2/5. Isolated Eskolaite Crystals with Marked Local Analyses of Crystal (Point 1) and Matrix (Point 2). Normal Section (16-20 mm)

Figure 4-33: Glass 2/5. Isolated Eskolaite Crystals with Marked Local Analysis of Eucryptite Crystal (Point E). Normal section (11-15 mm)

Figure 4-34: Glass 2/5. Isolated Eskolaite crystals with Eucryptite crystals. Normal Section (16-20 mm)

Figure 4-35: Glass 2/5. Isolated Eskolaite Crystals with Eucryptite Crystals. X-Ray Distribution of Na, Al, Si, Fe, and $\mathrm{Cr}$ in the Area Shown in Figure 4-34. Normal section $(16-20 \mathrm{~mm})$. Program MAPPING

Figure 4-36: Glass 2/5. Isolated Eskolaite Crystals with Eucryptite (Points 3 and 4 ) and Nepheline (Points 1, 2, 5 and 6) Crystals. Normal Section (0-1 $\mathrm{mm})$

Figure 4-37: Glass 2/5. Isolated Eskolaite Crystals with Eucryptite and Nepheline Crystals.X-Ray Distribution of $\mathrm{Na}, \mathrm{Al}, \mathrm{Si}, \mathrm{Fe}$, and $\mathrm{Cr}$ in the Area shown in Figure 4-36. Normal section $(0-1 \mathrm{~mm})$. Program MAPPING

Figure 4-38: Glass 2/5. Small spherical Particles. Normal Section $(1-3 \mathrm{~mm})$

Figure 4-39: Glass 2/5. Small Spherical Particles. Normal Section $(16-20 \mathrm{~mm})$

Figure 4-40: EDS Spectra of Glass 2/5: Upper Part-Particles Lower Part-Glass Matrix

Figure 4-41: The Cr2p Line of the Sample UJV-2-6

Figure 4-42: The Cr2p Iine of the Sample 2/5

Figure 4-43: Appearance of the Boat with Batch 1 after Thermal Treatment in the Gradient Furnace during 1 and 6 Hours

Figure 4-44: Appearance of the Boat with Batch 1 after Thermal Treatment in the Gradient Furnace during 24 and 48 Hours 
Figure 4-45: Appearance of the Boat with Batch 2 after Thermal Treatment in the Gradient Furnace during 1 and 6 Hours

Figure 4-46: Appearance of the Boat with Batch 2 after Thermal Treatment in the Gradient Furnace during 24 and 48 Hours

Figure 4-47: Comparison of experimental values with calculated dependence courses for the Batch 1. See text for more details

Figure 4-48: Comparison of experimental values with calculated dependence courses for the Batch 2. See text for more details

Figure 5-1: Diffractograms of Tempered Specimens of Glass 1

Figure 5-2: Diffractograms of Tempered Specimens of Glass 2

Figure 5-3: Glass 1/6/TEM Surface, Surface Area of the Dark Phase 31.3 \&

Figure 5-4: Glass 1/6/TEM Surface, Plates of Eskolaite, Detail of a Small Agglomerate and its Vicinity

Figure 5-5: Glass 1/6/CCC Surface, Surface Area of the Dark Phase 33 \&

Figure 5-6: Glass 1/6/CCC Surface, Plates of Eskolaite and Crystals of Another Crystalline Phase of Dendritic Appearance

Figure 5-7: Glass 2/6/TEM Surface, Surface Area of the Dark Phase $52 \%$, Inhomogeneous Distribution of Eskolaite

Figure 5-8: Glass 2/6/TEM Surface, Crystals of Eskolaite (Es) and beta-eucryptite (EU), Glass Phase (GI) and New Dendritic Phase

Figure 5-9: Glass 2/6/TEM Bottom, Surface Area of the Dark Phase $35 \%$, Inhomogeneous Distribution of Eskolaite

Figure 5-10: Glass 2/6/CCC Surface, Surface Area of the Dark Phase $40 \%$, Inhomogeneous Distribution of Eskolaite

Figure 5-11: Glass 2/6/CCC Surface, Crystalline Structure (Nepheline, Eskolaite, beta-eucryptite), only Small Amount of Glass Phase on Crystal Boundaries

Figure 5-12: Glass 2/6/CCC surface at Higher Magnification, Crystaliine Structure with small Amount of Intercrystalline Glass Phase 
Figure 5-13: Glass 2/6/CCC Bottom, Crystalline Composed structure of Eskolaite, Nepheline and beta-eucryptite, Small Amount of Glass Phase at Interphases

Figure 5-14: Glass 2/6/CCC Bottom, Crystalline Structure of Figure 5-13 in Crossed Nicols

Figure 6-1: Variation of $\mathrm{B}_{2} \mathrm{O}_{3}$ and $\mathrm{Li}_{2} \mathrm{O}$ Content in Glasses

Figure 6-2: Glass $x$. Grain Irregular Particle with Marked Area Analysis. Normal section $(0-4 \mathrm{~mm})$

Figure 6-3: Glass R. Grain Irregular Particle with Marked Area Analysis. Normal Section $(0-4 \mathrm{~mm})$

Figure 6-4: Glass L. Grain Particle with Marked Area Analysis. Normal Section $(0-5 \mathrm{~mm})$

Figure 6-5: Glass M. Detail Section View in a Bottom Block Part $(0-5 \mathrm{~mm})$

Figure 6-6: Glass M. Grain Particle with Marked Area Analysis. Normal Section $(0-5 \mathrm{~mm})$

Figure 6-7: Glass M. Grain Particle. Normal Section (10-15 mm)

Figure 6-8: Temperature Ranges for Glass Casting

Figure 6-9: Cr Leached from Grains of Glass 1 Modifications ( 30 \% Waste Loading)

Figure 6-10: Relationship Between $\mathrm{Cr}^{6+} / \mathrm{Cr}$ Ratio in Leachate and Basicity for the Z-U-S-Y Series of Composition

Figure 6-11: Relationship Between $\mathrm{Cr}^{6+} / \mathrm{Cr}$ Ratio in Leachate and Basicity for the Z-T-R-X Series of Composition

Figure 6-12: Results of Leachate Analyses (45 \% Waste Loading)

Figure 6-13: Effect of $\mathrm{Cr}$ Doubling in Waste

Figure 6-14: Results of Leachate Analyses (Lower Al,Li;Higher Na)

Figure 6-15: Cr Analysis in Glass (4.14 of $\mathrm{Cr}_{2} \mathrm{O}_{3}$ )

Figure 6-16: Cr Analysis in Glass (7.28 of $\mathrm{Cr}_{2} \mathrm{O}_{3}$ )

Figure 6-17: Cr Analysis of Glass with Partial $\mathrm{Al}_{2} \mathrm{O}_{3}$ Substitution and/or Complete substitution of $\mathrm{Li}_{2} \mathrm{O}^{2}$ for $\mathrm{Na}_{2} \mathrm{O}$

Figure 7-1: Glass $\mathrm{C}-\mathrm{Cl}$. Detail Section View in a Central Block Part (6-10 mm)

Figure 7-2: Glass C-Cl. Crystal cluster with Marked Local Analysis. Normal section (6-10 mm)

$$
\mathbf{x i x}
$$


Figure 7-3: Glass C-Cl. Isolated Eskolaite Crystal with Marked

Local Analysis. Normal Section (6-10 mm)

Figure 7-4: Glass D-C1. Crystal Cluster.

Normal section $(6-10 \mathrm{~mm})$

Figure 7-5: Glass D-CI. Isolated Eskolaite Crystals with Marked Local Analysis. Normal Section (6-10 mm)

Figure 7-6: Glass C-C2. Crystal Cluster with Marked Local

Analysis. Normal Section $(6-10 \mathrm{~mm})$

Figure 7-7: Glass C-C2. Isolated Eskolaite Crystals with Marked Local Analysis. Normal Section (6-10 mm)

Figure 7-8: Glass D-C2. Recrystallized Grain Particle. Normal Section $(6-10 \mathrm{~mm})$

Figure.7-9: Glass D-C2. Recrystallized Grain Particle. Normal section $(6-10 \mathrm{~mm})$

Figure 7-10: Glass D-C2. Isolated Eskolaite Crystals with Marked Local Analysis. Normal Section $(6-10 \mathrm{~mm})$

Figure 7-11: Glass D-C3. Spinel Phase Crystals

in a Central Block Part $(6-10 \mathrm{~mm})$

Figure 7-12: Glass D-C3. Spinel Phase Crystals in a Central Block Part with Marked Local Analysis (6-10 mm)

Figure 7-13: Glass C-C4. Crystal Cluster. Normal section $(6-10 \mathrm{~mm})$

Figure 7-14: Glass C-C4. Isolated Eskolaite Crystals with Marked Local Analysis. Normal Section $(6-10 \mathrm{~mm})$

Figure 7-15: Glass D-C4. Eskolaite Crystal Cluster and Spinel Phase Crystals in a Central Block Part (6-10 mm)

Figure 7-16: Glass D-C4. Grain Particle, Eskolaite Crystal Cluster and Isolated Spinel Phase Crystals in a Central Block Part $(6-10 \mathrm{~mm})$

Figure 7-17: Glass D-C4. Grain Particle, Eskolaite Crystal Cluster and Isolated Spinel Phase Crystals. $X-R a y$ Distribution of $\mathrm{Cr}, \mathrm{Fe}$ and $\mathrm{Si}$ in the Area Given in Figure 7-16. Normal section (6-10 $\mathrm{mm}$ ). Program MAPPING

Figure 7-18: Glass D-C4. Grain Particle, Eskolaite Crystal Cluster and Isolated Spinel Phase Crystals. $X-R a y$ Distribution of $\mathrm{Na}, \mathrm{Al}, \mathrm{Zn}$ and $\mathrm{Ni}$ in the Area Given in Figure 7-16. Normal Section (6-10 mm). Program MAPPING 
Figure 7-19: Glass C-C5. Grain Recrystallized Particles. Normal Section $(6-10 \mathrm{~mm})$

Figure 7-20: Glass C-C5. Crystal Cluster. Normal Section $(6-10 \mathrm{~mm})$

Figure 7-21: Glass D-C5. Detail section View in a Central Block Part $(6-10 \mathrm{~mm})$

Figure 7-22: Glass D-C5. Recrystallized Grain Particle with Marked Local Analysis. Normal Section (6-10 mm)

Figure 7-23:'Glass D-C5. Crystal Cluster. Normal Section $(6-10 \mathrm{~mm})$

Figure 7-24: Glass'D-C5. Isolated Eskolaite Crystals with Marked Local Analysis. Normal Section (6-10 mm)

Figure 7-25: Glass C-Cl, Isolated Crystals and an Agglomerate of Eskolaite (Area Fraction of Agglomerates $3 \%$ )

Figure 7-26: Glass D-Cl, Eskolaite Crystals and Agglomerates $(5$ f). Preffered Horizontal orientation of Isolated Eskolaite Crystals

Figure 7-27: Glass C-C2, Eskolaite Crystals and Agglomerates, (Area Fraction of Agglomerates $2.5 \%$ )

Figure 7-28: Glass D-C2, Eskolaite Crystals and Agglomerates, (Area Fraction of the Dark Phase $12 \%$ )

Figure 7-29: Glass D-C3, Crystals of a Spinel Phase, (Area Fraction $4.7 \%$ )

Figure 7-30: Glass C-C4, Eskolaite Crystals and Agglomerates, (Area Fraction of the Dark Phase 8 f)

Figure 7-31: Glass D-C4, an Agglomerate of Eskolaite Crystals and Crystals of a Spinel Phase (Area Fraction of the Dark Phase 10 \%)

Figure 7-32: Glass C-C5, Agglomerates and Crystals of Eskolaite

Figure 7-33: Glass D-C5, Agglomerates and Isolated Crystals of Eskolaite

Figure A1-1: Cumulative Mass Percent Finer vs. Diameter, for the Chromium Hydroxide I

Figure A1-2: Mass Population vs. Diameter for the Preparation of Chromium Hydroxide I

Figure A3-1: B1/CR. Normal section (NS 0-2 mm)

Figure $A 3-2: B 1 / C R$. Normal section (NS 16-20 mm) 


\section{IIST OF TABLES}

Table 3-1: Results of the Determination of the Specific Surface "A" of Chromium Hydroxide II

Table 3-2: The Results of Optical Emission Spectrographic Analysis of Chromium Hydroxide II

Table 3-3: Results of Quantitative Chemical Analysis. of Chromium Hydroxide II

Table 4-1: As-batched Composition of Glasses 1 and 2

Table 4-2: Chemical Composition of Batching Materials (Analysis)

Table 4-3: Weight Aliquots for the Preparation of $100 \mathrm{~g}$ of Glass 1 and 2

Table 4-4: The Melting Procedure

(Used for the Preparation of Glasses 1 and 2)

Table 4-5: A Comparison of Intensities of the most Intensive Diffraction Iines of Crystalline Phases (According to their Relative Height at Corresponding Conditions)

Table 4-6: Statistical Evaluation of Agglomerates in Glasses $1 / 5$ and $2 / 5$ (Image Analysis)

Table 4-7: A Summary of Analyses Results of a Sample of Quenched and Annealed Glass $1 / 5$

Table 4-8: A Summary of Analyses Results of Eskolaite Crystal Clusters in a Sample of Quenched and Annealed Glass $1 / 5$

Table 4-9: A Summary of Area Analyses Results of Eskolaite Crystal clusters in the Sample of Quenched and Annealed Glass $2 / 5$

Table 4-10: A Summary of Analyses Results of Eskolaite Crystals from Clusters and Isolated Crystals from a sample of Quenched and Annealed Glass $2 / 5$

Table 4-11: A Summary of Local Analyses Results of Eucryptite and Nepheline Crystals in Glass 2/5

Table 4-12: A Summary of Local Analyses Results of Spherical Particles in the Sample of Quenched and Annealed Glass $2 / 5$

Table 4-13: A Summary of Local Determinations Results of the $\mathrm{B}_{2} \mathrm{O}_{3}$ Content in selected Areas of the Samples of Glasses $1 / 5$ and $2 / 5$

Table 4-14: Composition of Selected Areas and crystals in Samples $1 / 5$ and $2 / 5$ xxii 
Table 4-15: Comparison of Experimental and Caiculated viscosity Values for Glass $1 / 5$

Table 4-16: Comparison of Experimental and Calculated viscosity Values for Glass $2 / 5$

Table 4-17: Comparison of Experimental and Calculated Viscosity Values for Glass $1 / 5$ (wide Range Temperature Curve)

Table 4-18: Comparison of Experimental and Calculated Viscosity Values for Glass 2/5 (Wide Range Temperature Curve)

Table 4-19: Comparison of Experimental and Calculated Values of the Specific Electric Resistance for Glass $1 / 5$

Table 4-20: Comparison of Experimental and Calculated Values of the Specific Electric Resistance for Glass $2 / 5$

Table 4-21: Mean Coefficient of Linear Thermal Expansion, Dilatometric Transformation Temperature $t_{g}$ and Dilatometric Softening Point $t_{d}$ of Glasses $1 / 5$ and $2 / 5$

Table 4-22: The Results of Optical. Emission Spectrographic Analysis

Table 4-23: The Results of Chromium Redox states Determination

Table 4-24: The Results of Iron Redox States Determination

Table 4-25: The Results of Quantitative Chemical Analyses

Table 4-26: The Results of Hydrolytic Resistance of Tested Samples According to the ĆSN ISO 719

Table 4-27: Classification of Tested Samples According to the CSN ISO 719

Table 4-28: Visual Evaluation of Specimen Appearance of the Batch 1 after Thermal Treatment

Table 4-29: Visual Evaluation of Gradient Boats Appearance with Batch 2 after Thermal Treatment

Table 4-30: Tests Survey with Thermally Treated Batch 1 at a Constant Temperature and their visual Evaluation

Table 4-31: Tests Survey with a Thermally Treated Batch 2 at a Constant Temperature and their Visual Evaluation

Table 4-32: $\mathrm{Cr}^{6+}$ content (Expressed as wt. $\%$ of $\mathrm{CrO}_{3}$ ) in Thermally Treated Samples of Batch 1

Table 4-33: $\mathrm{Cr}^{6+}$ Content (Expressed as wt. of $\mathrm{CrO}_{3}$ ) in Thermally Treated Samples of Batch 2 
Table 5-1: Uncontrolled Cooling of Samples Marked TEM

Table 5-2: Canister Centerline cooling (CCC) schedules

Table 5-3: Statistical Evaluation of Large Agglomerates (1/6/TEM Surface, Bottom)

Table 5-4: Statistical Evaluation of Large Agglomerates (1/6/Cce surface, Bottom)

Table 6-1: Sanderson's Acidobasicity of Glasses

Table 6-2a: Composition of Prepared Glasses Modification of Glass 1 ( 30 waste Loading), 1.Part

Table 6-2b: Composition of Prepared Glasses Modification of Glass 1 ( 30 \% Waste Loading), 2.Part

Table 6-3: Composition of Prepared Glasses Modification of Glass 2 ( 45 \% Waste Loading)

Table 6-4: Composition of Glasses Prepared from Waste with Doubled Content of Chromium

Table 6-5: Chemical Compounds Used for Preparation of Glasses

Table 6-6: Melting and Casting List of Glass 1 Modifications ( 30 \& Waste Loading)

Table 6-7: Melting and Casting List of Glass 2 Modifications ( 45 \& Waste Loading)

Table 6-8: Melting and Casting List of Glasses with Doubled Cr Content in Waste

Table 6-9: Results of Leachate Analyses for Products of Glass 1 Modifications with 30 * Waste Loading

Table 6-10: Results of Ieachate Analyses for Products of Glass 2 Modifications with 45 Waste Loading

Table 6-11: Results of Leachate Analyses (Doubled Cr Content in Waste)

Table 6-12: Composition of Glasses with Lower Al and Li content Simultaneously Compensated by Increase of Na Content

Table 6-13: Melting and Casting (List of Glasses with Lower Al, Ii and Higher $\mathrm{Na}$ )

Table 6-14: Results of Leachate Analyses (Lower AI, $\mathrm{Li}$ and Higher $\mathrm{Na}$ )

Table 6-15: Chemical Analysis of Glass 1 Modjfications (Concentration of Total $\mathrm{Cr}$ and $\mathrm{Cr}^{6+}$ in wt. $\frac{\text { f }}{\text { ) }}$ 
Table 6-16: Comparison of Experimental and Calculated Viscosity Values for Glass $X$

Table 6-17: Comparison of Experimental and Calculated Viscosity Values for Glass $R$

Table 6-18: Survey of Analyses Results of the Glass $x$

Table 6-19: Survey of Analyses Results of the Glass $R$

Table 6-20: Survey of Analyses Results of the Glass I

Table 6-21: Survey of Area Analyses Results of Glass $M$

Table 6-22: Survey of Local Analyses Results of Glass $M$

Table 6-23: The Results of Determination of Water Resistance of Glasses $X, I$, and $M$ at $98^{\circ} \mathrm{C}$

Table 6-24: Limiting Values of Water Resistance by Grain Method According to the ESN ISO 719

Table 6-25: Chromium Redox State in Glasses $X$; and $R$

Table 7-1: As-batched Compositions of Glasses $\mathrm{Cl}_{1}, \mathrm{C2}_{2}, \mathrm{C3}, \mathrm{C4}$ and $\mathrm{C5}_{5}$

Table 7-2: Melting Conditions for the Preparation of Glasses $C-C_{1}$ to $C-C 5$ and $D-C 1$ to $D-C 5$

Table 7-3: Comparison of Experimental and Calculated Viscosity Values for Glass $\mathrm{Cl}$

Table 7-4: Comparison of Experimental and Calculated Viscosity Values for Glass $\mathrm{C2}_{2}$

Table 7-5: Comparison of Experimental and Calculated Viscosity Values for Glass C3

Table 7-6: Comparison of Experimental and Calculated Viscosity Values for Glass $C_{4}$

Table 7-7: Comparison of Experimental and Calculated viscosity Values for Glass C5

Table 7-8: Determination Results of Medium Coefficient of Iinear Thermal Expansion, Dilatometric Transformation Temperature $t_{g}$ and Dilatometric softening Point $t_{d}$ of Glasses $\mathrm{Cl}$ to $\mathrm{C5}$

Table 7-9: Survey of Analyses Results of the Glass Sample C-Cl

Table 7-10: Survey of Analyses Results of the Glass sample D-Cl

Table 7-11: Survey of Analyses Results of the Glass Sample C-C2 
Table 7-12: Suryey of Analyses Results of the Glass Sample D-C2

Table 7-13: Survey of Analyses Results of the Glass Samples C-C3 and $\mathrm{D}-\mathrm{C} 3$

Table 7-14: Survey of Analyses Results of the Glass Sample C-C4

Table 7-15: Survey of Analyses Results of the Glass Sample D-C4

Table 7-16: Survey of Analyses Results of the Glass Sample C-C5

Table 7-17: Survey of Analyses Results of the Glass Sample D-C5

Table 7-18: Size Distribution of the Spinel Phase in a) D-C3 and

Table Al-1: Granulometry of Chromium Hydroxide I

b) $\mathrm{D}-\mathrm{C} 4$

Table Al-2: Results of Chromium Hydroxide I Quantitative Analysis

Table A1-3: Results of Quantitative Chemical Analysis

of Chromium Hydroxide - Black Form

Table A2-1: As-batched Compositions of Glasses 1, A, 2 and B

Table A2-2: Results of Determinations of Medium Coefficient of Iinear Thermal Expansion, Dilatometric Transformation Temperature $t_{\mathrm{g}}$ and Dilatometric Softening Point $t_{d}$ of Experimental Glasses

Table A2-3: Summaxy of Analyses Results of Annealed Glass AI

Table A2-4: Summary of Analyses Results of Crystal Clusters in Annealed Glass Al

Table A2-5: Summary of Analyses Results of Crystal Clusters in the Lower Part of the Block (NS $0-2 \mathrm{~mm}$ ) of Annealed Glass $B 1$

Table A2-6: Summary of Analyses Results of Crystal Clusters in the Upper Part of the Block (NS 6-20 mm) of Anealed Glass B1

Table A2-7: Summary of Analyses Results of the Matrix in Annealed Glass B1

Table A2-8: Summary of Analyses Results of Spherical Particles from the Lower Part of the Block (NS $0-2 \mathrm{~mm}$ ) and Isolated Crystal

Table A3-1: As-batched Compositions of Glasses Al/Cr and BI/Cr

Table A3-2: Summary of Analytical Results of Glass $\mathrm{A} / \mathrm{Cr}$ and Comparison with As-batched Composition

Table A3-3: Summary of Analyses Results of Annealed Glass $B 1 / C r$ xxvi 
1. INTRODUCTION

The present report contains results and their discussion relating to activities carried out in the frame of the contract No. 209344-A-F1, signed in June 1994, between Battelle Memorial Institute, Pacific Northwest Laboratories and Nuclear Research Institute Rež, pcl, and contained in the respective Test Plan.

The basis for the preparation of the Test Plan, which represented a guideline for all coritract activities, were statement of work, prepared by PNL (see Annex E), and the respective Proposal for the contract, prepared by NRI. The activities of the Test Plan were divided into several Tasks (Task 1 to Task 8), all of them containing detailed and precise information about individual experiments and goals.

some data and information gained during the work on this project led to the conclusion that the important goal of the general task (behavior of chromium in the glass and the way to the mitigation of its negative influence) is not of so vital importance as it was expected at the beginning of the project.

It was agreed that Task $6 \mathrm{C}$ and Task 8 in the Test Plan could be canceled and on the request of PNL new Task 9 was introduced. This Task has dealt with the preparation of a new glass system followed by the characterization of the product structures. This task was oriented towards the effect of the elevated concentration of several metal elements ( $\mathrm{Fe}, \mathrm{Mn}, \mathrm{Ni}$ and $\mathrm{Zr}$ ) on the characteristics of glasses.

The aim of the basic part of the research was to prepare several glasses and study their physical, physico-chemical and chemical properties. The goals for individual tasks are explained in respective sections.

The report contains data gained during the research, accompanied by corresponding.tables, diagrams, photographs etc, with results explanation and respective discussion. 
Because of a great number of data gained during this research, only main results are presented in this report, detailed information was handed over to PNL in the form of several Closing Reports, together with Monthly Reports (Iist of closing Reports is included in the Annex Di).

Monthly Progress Reports which were regularly sent to PNL described the research progress and data gained during the respective period.

During the whole work communication between our laboratory and PNL was established, using telephone, fax and especially e-mail connection. In such a way running of the project could be followed and occasionally corrected by the PNL specialists.

Relatively wide scope of goals has promoted a cooperation between several teams of respective institutions working in the field of radioactive waste management and in some areas of glass research. The specific situation in the czech Republic, with a long and wide experience in the glass research and manufacturing, enabled to form a team covering several professions necessary for the adequate solution of the task.

Besides the Nuclear Research Institute in kez it were the university of Chemical Technology, Prague (Department of Glass and Ceramics), Glass Institute, State Testing Laboratory No. 237 In Hradec Králové and svus a.s. (former Glass Research Institute) also in Hradec Králové who closely cooperated during the whole period of the 1994 and 1995 years.

The cooperation was conducted by a small team of head specialists who controlled the basic activities and by a special scientific council, which discussed research problems and was looking for final explanation of results.

As already mentioned above this Final Report is not the only. deliverable and non deliverable result of the research. In the Annex of this report following documents are presented: list of closing reports, selected laboratory procedures used in this work and list of samples in institutional archives. 
Laboratory reports and some closing Reports, which exist only in Czech language, are deposited in respective laboratories, as well as the majority of glass samples. The same is valid for special procedures used in the course of the research.

\section{CHROMIUM CONTAINING GLASSES}

(An introductory review of practical experience)

Chromium is a well known colour generating element which has been used in glass manufacture since long time. Small amount of $\mathrm{Cr}^{3+}$ (about 0.1 wt. $* \mathrm{Cr}_{2} \mathrm{O}_{3}$ ) colours glass green.

In glasses of usual composition $\mathrm{Cr}^{3+}$ is mostly the prevailing state, esp. due to reducing conditions. With common soda-lime glasses not more than $60 \%$ of $\mathrm{Cr}$ can be fixed in the oxydized hexavalent form generating lemon-coloured glass. In glasses with higher alkali content (esp. of $k_{2} \mathrm{O}$ ) yellow or yellow-green colouration is obtained according to the ratio of $\mathrm{Cr}^{3+} / \mathrm{Cr}^{6+}$ ratio. The presence of boric oxide shifts the ratio to a higher value. A strongly reducing effect can be attained by admixture to the batch of $\mathrm{As}_{2} \mathrm{O}_{3}$ or $\mathrm{Sb}_{2} \mathrm{O}_{3}$ (commonly used refining agents), or Feo. The oxidation states of $\mathrm{Cr}$ in glass can be distinguished by spectrometric measurements in the UV region (Bamford, 1977; Weyl, 1951).

Higher temperatures and longer melting favour the reduction to $\mathrm{Cr}^{3+}$. The composition of the basic glass has only a limited effect on the colour. Alkali oxides promote yellower shades, $\mathrm{B}_{2} \mathrm{O}_{3}$ supports dark green tones. Some lead glasses produce reddish colour due to the formation of polychromate anions or due to the crystallization of finely dispersed lead chromate (Volf, 1984).

Complicated chemical equilibria are established in the glass during melting in the presence of several polyvalent cations. According to the stability and "oxidation potential", oxides can be arranged into the series:

$$
\mathrm{Cr}_{2} \mathrm{O}_{3}-\mathrm{Mn}_{2} \mathrm{O}_{3}-\mathrm{CeO}_{2}-\mathrm{V}_{2} \mathrm{O}_{5}-\mathrm{CuO}-\mathrm{As}_{2} \mathrm{O}_{3}-\mathrm{Sb}_{2} \mathrm{O}_{3}-\mathrm{Fe}_{2} \mathrm{O}_{3}
$$


For example, $\mathrm{As}_{2} \mathrm{O}_{3}$ exhibits reducing effect upon Cuo and other oxides preceding it in the series (Volf, 1984, p. 515, see also kühl et al., 1938). A similar series based on the kühl s work indicates the stability of higher valency states of various multivalent ions in increasing order (Bamford, 1977), 1.e.

$$
\mathrm{Cr}^{6+} / \mathrm{Cr}^{3+}-\mathrm{Mn}^{3+} / \mathrm{Mn}^{2+}-\mathrm{Ce}^{4+} / \mathrm{Ce}^{3+}-\mathrm{As}^{5+} / \mathrm{As}^{3+}-\mathrm{Sb}^{5+} / \mathrm{Sb}^{3+}-\mathrm{Fe}^{3+} / \mathrm{Fe}^{2+}
$$

The ionic equilibrium of any particular element in the series will be shifted in the direction of increased proportion of the higher valency by any element listed before it and vice versa. The oxidation of ferrous ion by hexavalent chromium would be anticipated to be particularly marked. It is a practical rule that ferrous ions and hexavalent chromium are incompatible together in the same glass (Bamford, 1977, p. 83).

The above shown series is in good agreement with the results of more recent studies concerning redox states of polyvalent oxides in glasses. The sequence of oxidation potentials can be derived from the dependence of the ratio "reduced/oxidized" form on the oxygen partial pressure. In a graphical $\log -\log$ plot, the dependencies for various oxides are represented by straight lines with various positions and slopes, in accord with the stoichiometry of the reaction (see e.g. Schreiber et al., 1986). It can be shown that esp. oxides of $A s, F e$ and $U$ produce a strong effect on $\mathrm{Cr}^{3+} / \mathrm{Cr}^{6+}$ equilibrium during glass melting, in accord with practical experience.

Potassium bichromate or $\mathrm{BaCrO}_{4}$ are mostly used as colouring agents because they dissolve in glass better than chromium oxide or hydroxide. There is a common experience that alkali chromates have a tendency to phase separation in the liquid state because of their low melting point and low density. Therefore, $\mathrm{BaCrO}_{4}$ is preferred for melting of commercial glasses (Kocik and Nebřenský, 1978).

- The limiting value of glass saturation with dissolved $\mathrm{Cr}_{2} \mathrm{O}_{3}$ is about 1.2 wt. for potassium glasses and about 2.0 for lead glasses (Volf, 1952). At higher concentrations, in usual silicate 
glasses, $\mathrm{Cr}_{2} \mathrm{O}_{3}$ precipitates from glass during cooling as a result of increasing supersaturation. Thin emerald green hexagonal plates are formed and the product is called aventurine glass.

Aventurine glass was produced esp. at the turn of the century as a fashionable ware. originally, aventurine is a finegrained reddish-brown or green variety of quartz with a glossy appearance due to the presence of mica inclusions. Aventurine glass simulates this appearance by precipitated crystals of copper (more usual) or $\mathrm{Cr}_{2} \mathrm{O}_{3}$. Besides copper and chrome aventurine, also chrome-iron aventurine is known (Beyersdorfer, 1943).

Chrome aventurine is the only commercial glass with $\mathrm{Cr}_{2} \mathrm{O}_{3}$ content exceeding its saturation limit, i.e. 2-7 \%. Apparently, the crystals of $\mathrm{Cr}_{2} \mathrm{O}_{3}$ are fully compatible with the glass matrix and do not affect the mechanical and chemical integrity of the glass.

Whereas literature concerning chromium containing coloured glasses is quite numerous, publications dealing with chrome aventurine can be found only rarely and they are mostly of earlier date. Some more recent papers appeared in the Russian literature with practical orientation to the exploitation of the aventurine colouring effect for glasses based on cheap natural or waste raw materials (e.g. Polyushkin, 1979, 1983, 1983).

The broad spectrum of chrome aventurine glass compositions indicates that silicate and borosilicate glasses represent promising media for immobilization of radioactive waste containing chromates.

\section{PREPARATION AND PROPERTIES OF CHROMIUM HYDROXIDE.}

Chromium hydroxide presented among all components used for the glass preparations a special substance. The effect of chromium on the glass properties belonged to main tasks of the project and thus the behaviour of chromium hydroxide during the 
thermal treatment of the batch played an important role. That was the reason why this substance was prepared according to a procedure which was a part of the PNL request and was separately described in the Test Plan.

During the first period of experiments a portion of chromium hydroxide was prepared, but before its use for the Glass 1 and 2 preparation slightly higher temperature during the drying procedure led to a product with different properties. This product was used for preparation of some glasses (A and $B$ ) and lately analyzed. Description of this product (called Chromium Hydroxide - black form) and of the initial Chromium Hydoxide - I, with their respective evaluation is in the Arnex Al:

A new product (Chromium Hydroxide II) was prepared, using the procedure of the Test Plan (see Closing Report STL No. 1/95) and used for the preparation of glasses which were studied in this project.

\subsection{PREPARATION}

For the hydroxide - preparation chromium nitrate $\left(\mathrm{Cr}\left(\mathrm{NO}_{3}\right)_{3} \cdot 9 \mathrm{H}_{2} \mathrm{O}\right.$, analytically pure) was used.

$3750 \mathrm{~g}$ of chromium nitrate was added to 151 of distilled water and mixed till total dissolving of salt. Reaction mixture was stirred and sodium hydroxide was added by drops. After adding of stoichiometric volume of sodium hydroxide, the suspension was carefully mixed and free sedimentation of solid particles began. After sedimentation the $\mathrm{pH}$ of a clear supernatant liquid was measured and $\mathrm{pH}$ value $10 \pm 0.1$ was adjusted by adding of sodium hydroxide or nitric acid.

The suspension was carefully mixed and sedimented through the night. Next day the clear supernatant liquid was decanted and distilled water added in volume equivalent to 3 times of volume of decanted suspension. After careful mixing the suspension sedimented freely through the night. Then the clear supernatant liquid was decanted and the washing process using distilled water was repeated once more in the same way. 
After decanting of the supernatant liquid, the rest of suspension was introduced on a.filter paper of Büchner funnel and the liquid phase was separated. The precipitate on the filter was washed by 3 parts of distilled water, every time in volume corresponding approximately to the precipitate volume. The final filtrate exhibited neutral pH on litims paper.

Filter cake of the precipitate was dried (on Al tray) in an electric drier at the temperature $105^{\circ} \mathrm{C}$ for $24^{\text {hours. }}$

Dried precipitate was ground in a jar mill. After 8 hours grinding the product was hand sieved through a metal sieve (mesh diameter $0.18 \mathrm{~mm}$ ). Undersize fraction was put inside of a preliminary washed and dried wide-neck bottle with screw cap. oversize fraction was repeatedly ground.

The processes; incl. the preparation of chromium hydroxide precipitate, its drying, grinding, sieving, was repeated, to the consumption of the whole amount of the chromium nitrate.

Ground product was homogenized in rotating homogenizer during 2 hours and submitted to physico-chemical analysis. The yield of this preparation was $3020 \mathrm{~g}$.

Detailed description of the chromium hydroxide preparation is in the closing Report STL No. $1 / 95$.

\subsection{PROPERTIES}

Following properties of the chromium hydroxide were examined:

- density

- granulometry

- specific surface

- crystalinity

- loss by ignition

- qualitative and semiquantitative analysis (optical emission spectrography

- chemical analysis ( $\mathrm{Cr}, \mathrm{Na}, \mathrm{Al}, \mathrm{FeIII}, \mathrm{NO}_{3}$ )

Detailed description of analyses is in the closing Report STL No. $2 / 95$. 
The product was dark green powder, marked "Chromium hydroxide, $\mathrm{Cr}_{2} \mathrm{O}_{3} \times \mathrm{nH}_{2} \mathrm{O}$, Dec. 5, 1994", hereinafter called "Chromium hydroxide II".

\section{Density}

Density of the product was measured according to the:

Internal regulation F-11-93 Density determination on AUTOPYCNOMETER 1320 (Micromeritics, USA).

The sample was measured in original state after drying in turbulent drier at the temperature $105 \pm 2{ }^{\circ} \mathrm{C}$ to the constant weight and then lodged in desiccator.

Sample density of chromium hydroxide II was $2.551 \mathrm{~g} \cdot \mathrm{cm}^{-3}$.

\section{Granulometry}

For granulometric analysis following regulation was used: Internal regulation F-09-93 Granulometric analysis by sedimentation method on SEDIGRAPH 5100 (Micromeritics, USA).

Dispersion of the sample in $75 \mathrm{ml}$ of denatured ethanol was realized in an ultrasonic apparatus Laborette 19 for 3 minutes.

Testing results are summarized in Annex $C$. Sample granulometry is characterized by a cumulative mass percent finer vs. diameter (see Annex C15) and Mass population vs. diameter (Annex C16). Granulometric data are given in Table $C$ 14. Data on measuring conditions are written in the heading of the table.

Specific surface

Internal regulation F-10-93 Determination of specific surface by nitrogen adsorption on the apparatus FLOWSORB II 2300 (Micromeritics, USA).

Determination was based on nitrogen adsorption and desorption on the surface of measured sample. Two measurements of the sample were done, from which the mean value and the respective value range were calculated. The calibration of the apparatus was performed for $1 \mathrm{ml}$ of $\mathrm{N}_{2}$.

Testing result is presented in Table 3-1. 
Table 3-1: Results of the Determination of the specific surface "A" of Chromium Hydroxide II

\begin{tabular}{|c|c|c|}
\hline Sample & A $\left[\mathrm{m}^{2} \mathrm{~g}^{-1}\right]$ & Range $\left[\mathrm{m}^{2} \mathrm{~g}^{-1}\right]$ \\
\hline Chromium Hydroxide II & 9.5 & 0.7 \\
\hline
\end{tabular}

\section{X-ray identification of crystal phases}

Internal regulation $F-12-93$. X-ray diffraction analysis on the apparatus Siemens $U$ 13-008.

The prepared sample of chromium hydroxide is roentgenographically amorphous. In spite of an adjustment of experimental conditions to a maximum sensitivity no diffraction line was found.

Qualitative and semiquantitative optical emission spectrographic analysis

Internal regulation $\mathrm{CH}-46-92$ Qualitative optical emission spectroscopy. Spectrography.

Testing results are summarized in Table 3-2.

Table 3-2: Results of Optical Emission Spectrographic Analysis of Chromium Hydroxide II

\begin{tabular}{|c|c|}
\hline $\begin{array}{c}\text { Identificated } \\
\text { Component }\end{array}$ & $\begin{array}{c}\text { Concentration } \\
\text { Range }\end{array}$ \\
\hline $\mathrm{Cr}$ & $\mathrm{MC}$ \\
$\mathrm{Na}$ & $\mathrm{SC}$ \\
$\mathrm{Al}$ & $\mathrm{AC}$ \\
$\mathrm{Fe}$ & $\mathrm{AC}$ \\
$\mathrm{Ca}$ & $\mathrm{AC}$ \\
\hline
\end{tabular}

Notes: Symbol

corresponding concentration range

MC, main component

... $10-100$ wt. \%

sC, secondary component $\ldots 1$ - 10 wt. \&

$A C$, accompanying component ... 1 wt. \&

Quantitative chemical analysis

chemical analyses of chromium hydroxide II was performed using following standards and regulations:

CSN 720103 Basic method of silicate analysis. Determination of the loss on ignition.

CsN 700626 Part1. Chemical analysis of glass. Determination of iron(III) oxide by a photometric method with 2.2 ' dipyridil. 
CSN 720108 Basic method of silicate analysis. Determination of oxides of ammonia group by a gravimetric method.

Internal regulation $\mathrm{CH}-42 \mathrm{a}-92$ Testing method of glass. Methods of atomic absorption and emission flame spectrometry. Determination of sodium oxide.

Internal regulation CH-21b-92 Testing method of glass. Methods of optical emission spectrometry with microwave generated capacity bonded plasma. Determination of aluminium oxide.

Testing procedures are given in ANNEX B1. Testing results are summarized in Table 3-3.

Table 3-3: Results of Quantitative Chemical Analysis of Chromium Hydroxide II

\begin{tabular}{|c|c|c|}
\hline $\begin{array}{l}\text { Determined } \\
\text { Component }\end{array}$ & $\begin{array}{l}\text { Chromium } \\
\text { Hydroxide II } \\
\text { [wt. \&] }\end{array}$ & Used Method \\
\hline $\begin{array}{l}\text { Loss by Ignition * } \\
\mathrm{Cr}_{2} \mathrm{O}_{3} \\
\mathrm{Sum} \mathrm{of}_{2} \mathrm{O}_{3} \text { Expressed } \\
\text { as } \mathrm{Cr}_{2} \mathrm{O}_{3} \\
\mathrm{Na}_{2} \mathrm{O} \\
\mathrm{Al}_{2} \mathrm{O}_{3} \\
\mathrm{Fe}_{2} \mathrm{O}_{3} \\
\mathrm{NO}_{3}\end{array}$ & $\begin{array}{l}27.0 \\
63.4 \\
63.8 \\
5.05 \\
0.11 \\
0.18 \\
4.54\end{array}$ & $\begin{array}{l}\text { CSN } 720103 \\
\text { Experimental Part } \\
\text { CSN } 720108 \\
\text { Int.Regulat. CH-42a-92 } \\
\text { Int.Regulat. CH-21b-92 } \\
\text { CSN } 700626 \text { Part } 1 \\
\text { Experimental Part }\end{array}$ \\
\hline
\end{tabular}

* at $1100{ }^{\circ} \mathrm{C}$ to a Constant Weight

Notes: - Test results are related to a sample dried at $105^{\circ} \mathrm{C}$ to a constant weight.

- Analyzed sample shows hygroscopic properties.

- The given value of loss by ignition is only informative considering that forms and time stability of nitrates at given temperature are not known.

\section{Electron microanalysis}

Additionally the chromium hydroxide II was observed in SEM mode. Figure 3-1 represents this powder at the magnification 100 . The size of greatest particles was nearly identical with the size of observed agglomerates in sample glass $1 / 5$. More detailed Figure 3-2 at the magnification 450 shows the compact body of the particle $\mathrm{Cr}(\mathrm{OH})_{3}$ that is covered by fine particles. EDS analysis has shown that the sodium oxide content is about 3.9 wt. I while the content of sodium oxide in fine particles is about $10.4 \mathrm{wt}$. $\%$. 


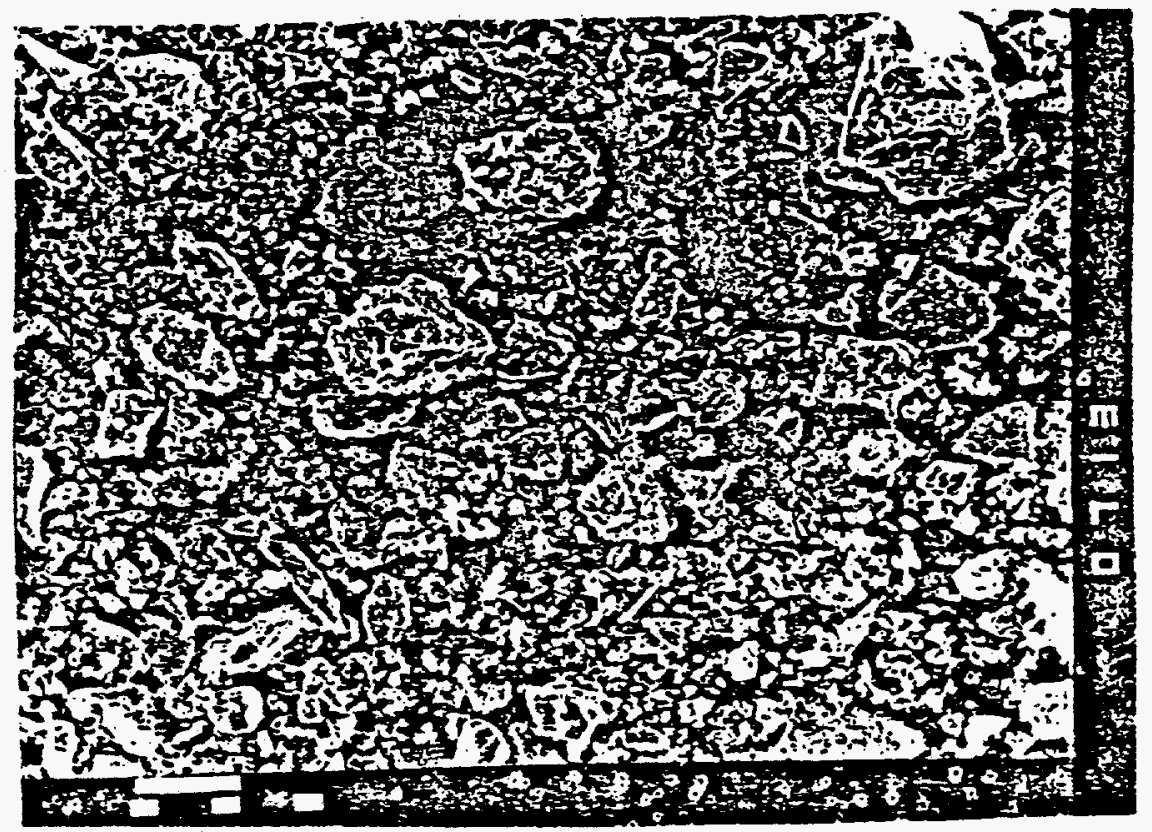

Figure 3-1: Chromium Hydroxide II Observed in SEM Mode, Magn. 100

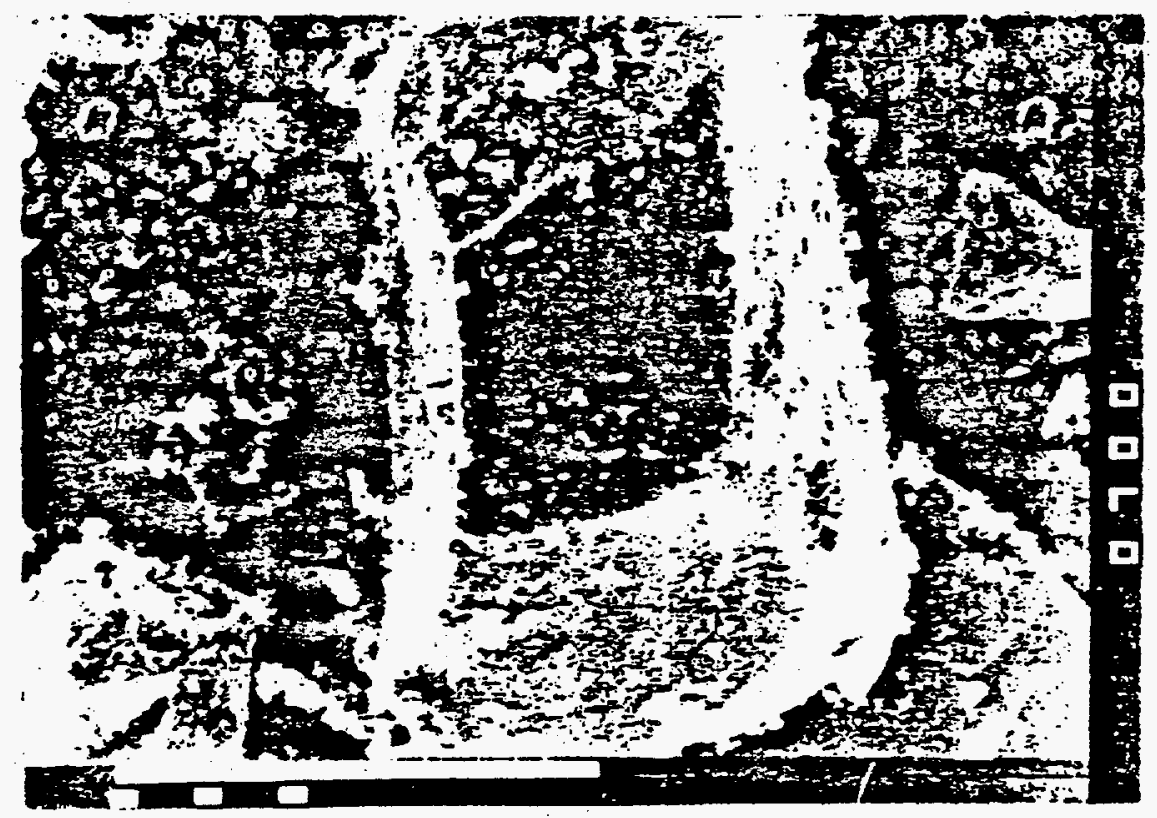

Figure 3-2: Chromium Hydroxide II Observed in SEM Mode, Magn. 450 
4. CHARACTERIZATION OF GLASSES 1 AND 2

According to the Task 2 two glasses (Glass 1 and Glass 2) were prepared. The composition of both glasses is given in Table 4-1.

Table 4-1: As-batched Composition of Glasses 1 and 2 [wt. f]

\begin{tabular}{|c|c|c|}
\hline Component & Glass 1 & Glass 2 \\
\hline $\begin{array}{l}\mathrm{SiO}_{2} \\
\mathrm{~B}_{2} \mathrm{O}_{3} \\
\mathrm{Na}_{2} \mathrm{O} \\
\mathrm{LI}_{2} \mathrm{O} \\
\mathrm{CaO} \\
\mathrm{MgO} \\
\mathrm{Fe}_{2} \mathrm{O}_{3} \\
\mathrm{Al}_{2} \mathrm{O}_{3} \\
\mathrm{ZrO}_{2} \\
\mathrm{Cr}_{2} \mathrm{O}_{3} \\
\mathrm{P}_{2} \mathrm{O}_{5} \\
\mathrm{SO}_{3} \\
\mathrm{Nd}_{2} \mathrm{O}_{3} \\
\mathrm{La}_{2} \mathrm{O}_{3} \\
\mathrm{~K}_{2} \mathrm{O}_{3} \\
\mathrm{~F} \\
\mathrm{MnO}_{2} \\
\mathrm{MoO} \\
\mathrm{NiO} \\
\mathrm{Cl} \\
\mathrm{ZnO}\end{array}$ & $\begin{array}{r}46.752 \\
17.070 \\
6.245 \\
6.685 \\
0.186 \\
0.018 \\
1.399 \\
16.213 \\
0.021 \\
4.143 \\
0.108 \\
0.057 \\
0.060 \\
0.021 \\
0.075 \\
0.027 \\
0.411 \\
0.108 \\
0.090 \\
0.123 \\
0.186\end{array}$ & $\begin{array}{r}40.239 \\
9.188 \\
9.367 \\
6.334 \\
0.279 \\
0.027 \\
2.099 \\
24.319 \\
0.032 \\
6.215 \\
0.162 \\
0.086 \\
0.090 \\
0.032 \\
0.113 \\
0.041 \\
0.617 \\
0.162 \\
0.135 \\
0.185 \\
0.279\end{array}$ \\
\hline
\end{tabular}

The composition of respective glasses is in weight percents of oxides expected in the final glass, not taking into account losses during the preparation (volatilization).

\subsection{PREPARATION}

The preparation of Glasses 1 and 2 is described in the svus protocol No. 5 .

For the preparation of both glasses chemicals of different purity were used. The chemical analysis is given in Table 4-2. 
Table 4-2: Chemical Composition of Batching Materials (Analysis) [wt. \&]

\begin{tabular}{|c|c|c|c|c|c|c|c|c|c|c|c|}
\hline CaBuicals & PURITY & $\mathrm{SiO}_{2}$ & $\mathrm{~B}_{2} \mathrm{O}_{3}$ & $\mathrm{Ne}_{2} \mathrm{O}$ & $\mathrm{Li}_{2} \mathrm{O}$ & $\mathrm{CaO}$ & $\mathrm{MgO}$ & $\mathrm{A}_{2} \mathrm{O}_{3}$ & $\mathrm{TiO}_{2}$ & $\mathrm{P}_{2} \mathrm{O}_{5}$ & Nio \\
\hline 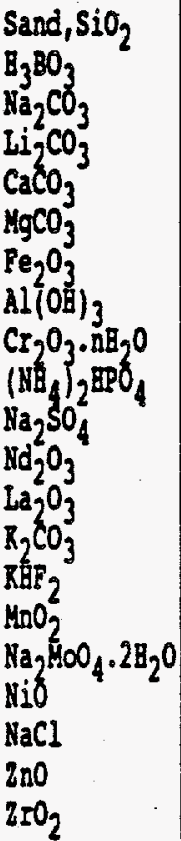 & $\begin{array}{r}99.83 \\
100.00 \\
99.90 \\
100.00 \\
98.75 \\
96.86 \\
99.70 \\
99.62 \\
\\
99.92 \\
100.00 \\
99.90 \\
98.10 \\
98.94 \\
82.30 \\
100.00 \\
85.60 \\
100.00 \\
100.00 \\
100.00\end{array}$ & 5.18 & 56.3 & $\begin{array}{c}0.007 \\
58.44 \\
\\
0.15 \\
5.05 \\
43.67\end{array}$ & $\mid 40,44$ & $\begin{array}{l}55.3 \\
0.65\end{array}$ & $\left|\begin{array}{c}0.003 \\
46.30\end{array}\right|$ & $\mid \begin{array}{c}0.055 \\
\\
\\
65.15 \\
0.11\end{array}$ & 0.026 & $50.50 \mid$ & $85.6 \mid$ \\
\hline
\end{tabular}

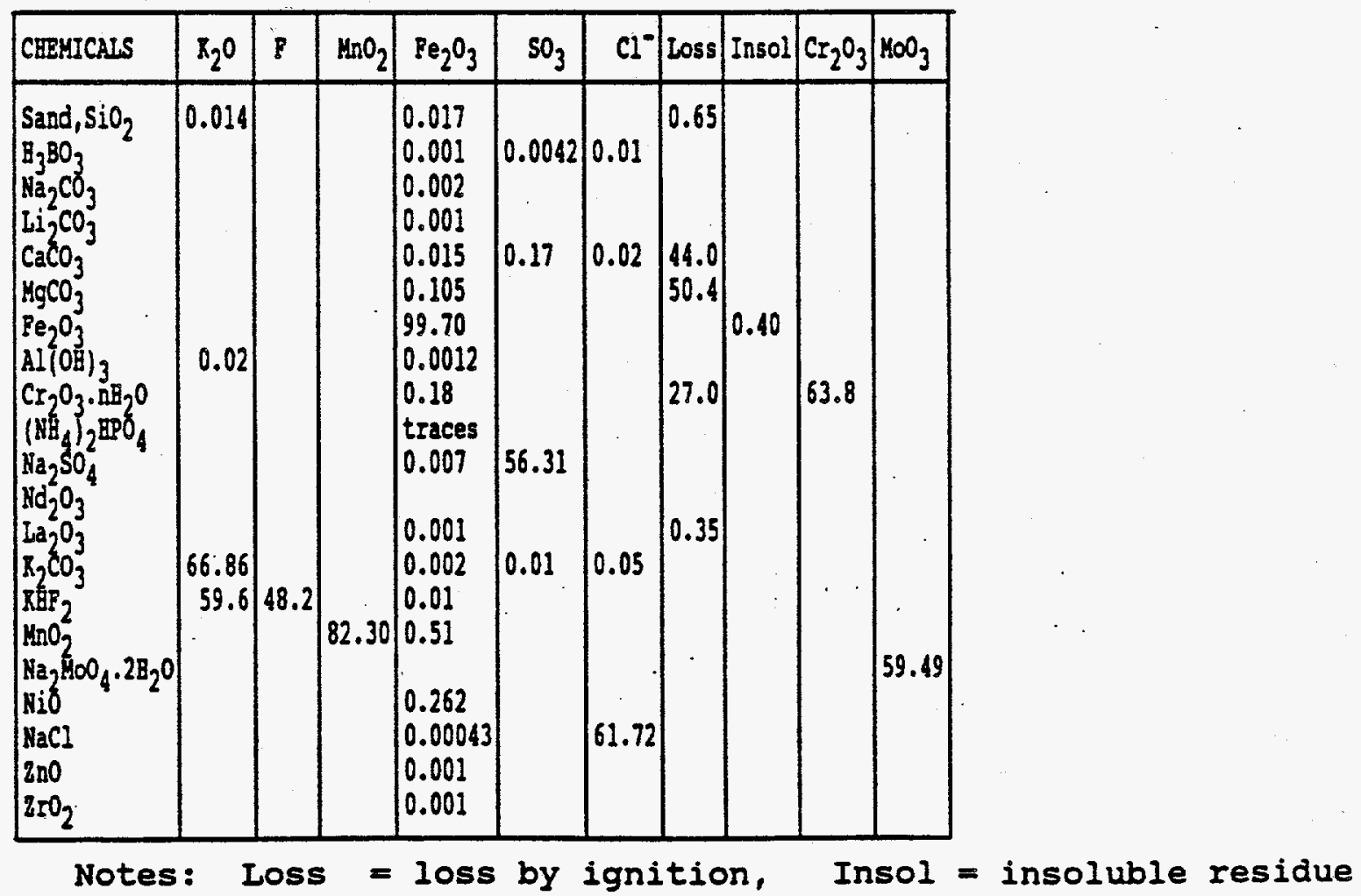


The purity of the chromium hydroxide product was checked after its preparation and is mentioned in the section 3.2 .

Before each weighing of the chromium hydroxide product, drying at $105^{\circ} \mathrm{C}$ was performed. The weights for the batches preparation with corresponding component values are in Table 4-3.

Table 4-3: Weight Aliquots for the Preparation

of $100 \mathrm{~g}$ of Glass 1 and 2

\begin{tabular}{|c|c|c|}
\hline Chemicals & $\begin{array}{l}\text { Weights for } \\
1 / 5,1 / 6\end{array}$ & $\begin{array}{c}100 \mathrm{~g} \text { Glass } \\
2 / 5,2 / 6\end{array}$ \\
\hline 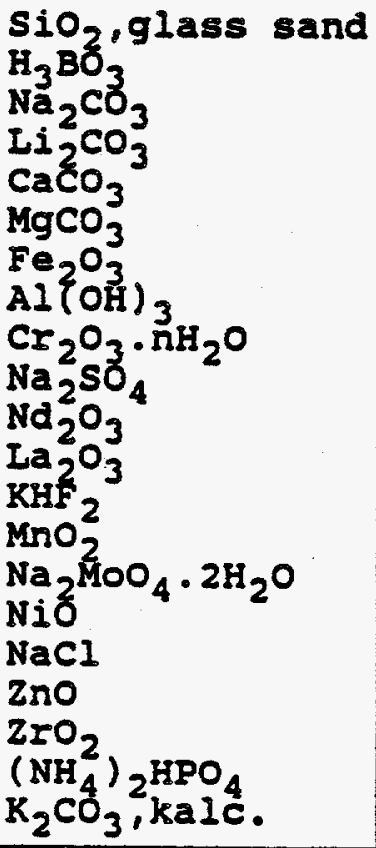 & $\begin{array}{r}46.806 \\
30.320 \\
9.752 \\
16.530 \\
0.329 \\
0.037 \\
1.379 \\
24.835 \\
6.494 \\
0.076 \\
0.060 \\
0.021 \\
0.055 \\
0.499 \\
0.182 \\
0.105 \\
0.194 \\
0.186 \\
0.021 \\
0.214 \\
0.046\end{array}$ & $\begin{array}{r}40.268 \\
16.320 \\
14.594 \\
15.663 \\
0.498 \\
0.056 \\
2.075 \\
37.277 \\
9.741 \\
0.140 \\
0.090 \\
0.032 \\
0.085 \\
0.750 \\
0.272 \\
0.158 \\
0.297 \\
0.279 \\
0.032 \\
0.321 \\
0.073\end{array}$ \\
\hline Total & 238.141 & 139.021 \\
\hline
\end{tabular}

Note: Glasses $1 / 5$ and $1 / 6$, and Glasses $2 / 5$ and $2 / 6$ mean two separate melts of Glass 1 and Glass 2 resp.

The weighing of respective chemicals was performed using balances METLER (weights up to $1 \mathrm{~g}$ ), OWA LABOR (up to $10 \mathrm{~g}$ ) and SARTORIUS 3808 MP 8-1 (above $10 \mathrm{~g}$ ).

The respective mixtures of chemicals were put in a wide-neck bottle and homogenized by shaking. The homogenized mixtures were sifted using 100 mesh sieve. Bigger pieces of the 
mixture were ground and sifted again. After this procedure the mixture was homogenized for the second time. The homogenization degree was evaluated visually (according to the granulometry and colourl.

\section{Glass melting}

The melting was performed in the superkanthal program regulated furnace with a mechanical stirrer (see Test Plan Appendix $A$ ). The measurement of the temperature was enabled by a thermoelement placed in the vicinity of the crucible. Material of the crucible was PtRh208 (No. 2845).

From the batches to give $1050 \mathrm{~g}$ of glass, $50 \mathrm{~g}$ were used for elemental analysis, the rest for the preparation of $1000 \mathrm{~g}$ of glass.

The melting of glasses $1 / 5$ and $1 / 6$ was carried out at the temperature $1150{ }^{\circ} \mathrm{C}$ and glasses $2 / 5$ and $2 / 6$ at $1450^{\circ} \mathrm{C}$.

The melting procedure is schematically described in Table 4-4.

Table 4-4: The Melting Procedure

(Used for the Preparation of Glasses 1 and 2 )

\begin{tabular}{|c|l|}
\hline Time Interval [min] & Procedure step \\
\hline 0 & 1st charge loading \\
30 & 2nd charge loading \\
15 & 3d charge loading \\
15 & 4th charge loading \\
15 & loading of the rest \\
15 & 1st sample, start of stirring \\
45 & 2nd sample \\
45 & 3d sample \\
15 & stop of stirring, casting \\
\hline 195 & total time of melting \\
\hline
\end{tabular}

First loading was performed into a cold crucible, other loadings on the surface of the melt. The course of melting was checked by fibres arawn from the melt, using a platinum wire, in intervals given in Table 4-4. 
The samples were visualy evaluated, are archived and photographs of glass and crucibles are enclosed in respective laboratory reports. The fibre samples exhibited rough surface and their appearence did not change during the whole course of melting. The melting of both kinds of glasses was quick and with only slight foaming.

Molten glass was poured in bars, sizes of which were :

$$
\text { - } \quad 10 \times 10 \times 2 \mathrm{~cm}
$$

Casting moulds were made of cast iron, special modules enabled the preparation of forms of various sizes and shapes. The casting sheet was preheated (using a gas burner) so that the temperature of base plate was $200{ }^{\circ} \mathrm{C}$, the temperature of walls was $120^{\circ} \mathrm{C}$.

The preheating of the casting surface should prevent a temperature gradient between the center and the edge of the glass bar (prevention of cracks in the edge parts of the bar).

Annealing of the glass bars was performed in a muffle lehr type kHS. Starting temperature was $530^{\circ} \mathrm{C}$, residence time at this temperature was one hour, temperature decrease changed according to following values:

\begin{tabular}{cc} 
Time [hours] & Temp. Decrease $\left[{ }^{\circ} \mathrm{C} / \mathrm{h}\right.$ ] \\
\hline $0-2$ & 60 \\
$2-3$ & 40 \\
$3=6$ & 25 \\
$6-18$ & 12
\end{tabular}

Description of samples

Samples of Glasses 1 and 2 were visualy evaluated and prepared for testing. Detailed description and respective photographs are in Closing Report STI No. 37/95, glass fibres are in the archive of svus.

Visual evaluation

The Glasses $1 / 5$ and $1 / 6$ contained bubbles (diam. approx. $1.5-2.0 \mathrm{~mm}$ ) in the bulk of glass and on the surface. The 
glasses $2 / 5$ and $2 / 6$ did not contain bubbles. The mean yield of the casted glass (corresp. to $1000 \mathrm{~g}$ of the expected amount of glass) was $818 \mathrm{~g}$ for the Glass 1 and $823 \mathrm{~g}$ for the Glass 2.

In case of Glass $1 / 5$ and $1 / 6$ no visible surface crystallization has been observed, in the bulk of glass tiny crystals were visible.

The Glasses $2 / 5$ and $2 / 6$ devitrified on the surface and also a brown layer was observed on the surface: The same layer was in a great extent also in the bottom part of samples.

During the cutting and grinding processes the Glasses I proved to be harder than the Glasses 2 .

Preparation of samples for examination of their physical properties and an evaluation of their respective appearence.

Physical properties of glasses were studied at the state Testing Laboratory (STL) and at the Technical University (VSCHT) . Blocks of glasses, described in the section 4.1. were divided into two parts, so that the cut area studied in both institutions corresponded to each other. As an example description of samples performed in the STL is given:

\section{Glass $1 / 5$}

The sample was composed of two parts. The greater one in the form of a cut off block part, dimensions $5.7 \times 9.7 \mathrm{~cm}$, height approximately $2 \mathrm{~cm}$ and weight $319 \mathrm{~g}$ was further cut to several portions by a diamond-charged saw and used for various tests. A schematic division of the block and the number marking of separate portions is given in the Annex Cl.

The smaller part of the sample in the form of a cut off block part, dimension $2.3 \times 9.7 \mathrm{~cm}$, height approx. $1 \mathrm{~cm}$ and weight $87 \mathrm{~g}$ was used as a whole for viscosity and specific electric resistance measurement.

on both blocks there was well recognisable surface area $(5.7 \times 9.7 \mathrm{~cm}$ and $2.3 \times 9.7 \mathrm{~cm}$, resp.) with a different surface character, herein called "bottom area" which was in contact with 
a metal plate during casting. The distance from this area into the interior of the block and towards the surface area was measured in cases. when it was necessary to define this position for the investigation purposes. The appearance of the cutting surface was macroscopically homogeneous.

Glass $2 / 5$

The sample had two parts. The greater one in the form of a cut off block part, dimensions $6.5 \times 9.7 \mathrm{~cm}_{6}$ height app. $2 \mathrm{~cm}$ and weight $362 \mathrm{~g}$ was further cut to several portions by a diamond-charged saw and used for various tests. The division of the block to separate portions and their number marking is shown in Annex C1. The smaller part of the sample in the form of a cut off block part, dimensions $2.3 \times 9.7 \mathrm{~cm}$, height approximately $I \mathrm{~cm}$ and weight $87 \mathrm{~g}$ was used as a whole for viscosity and specific electric resistance measurement.

on both blocks there was a well recognisable area $(6.5 \times 9.7 \mathrm{~cm}$ and $2.3 \times 9.7 \mathrm{~cm}$; resp.) with a different surface character, herein called "bottom area" which was in contact with the metal plate during casting. The position of individual layers is designated by the distance from the bottom in the same way as in the block of glass $1 / 5$.

on the section of the greater block, its inhomogeneity was well recognisable and the block was considerably cracked. In the distance 0 - $1 \mathrm{~mm}$ from the bottom area there was a visible glass layer, herein called "surface layer of bottom zone" which merged continuously into the crystallized layer in the distance 1 - $3 \mathrm{~mm}$ from the bottom area, herein called "bottom zone". The upper surface part of the bottom zone was sharply demarcated from the central. part of the block and in the area of this boundary a great number of cracks was observed. Towards the surface, there tas a visually homogeneous layer of glass (distance 3-20 mm from the bottom area). 'For the purpose of description during some tests, this layer was still divided to central part (the block centre) and surface part (glassy layer part adjacent to the surface area). The crystallized layer of the corresponding 
character to the bottom zone was present also on side walls of the block which were in contact with a metal mould during casting. The appearance of the block cutting surface which was successively investigated by electron scanning microscope is documented in Figure 4-1.

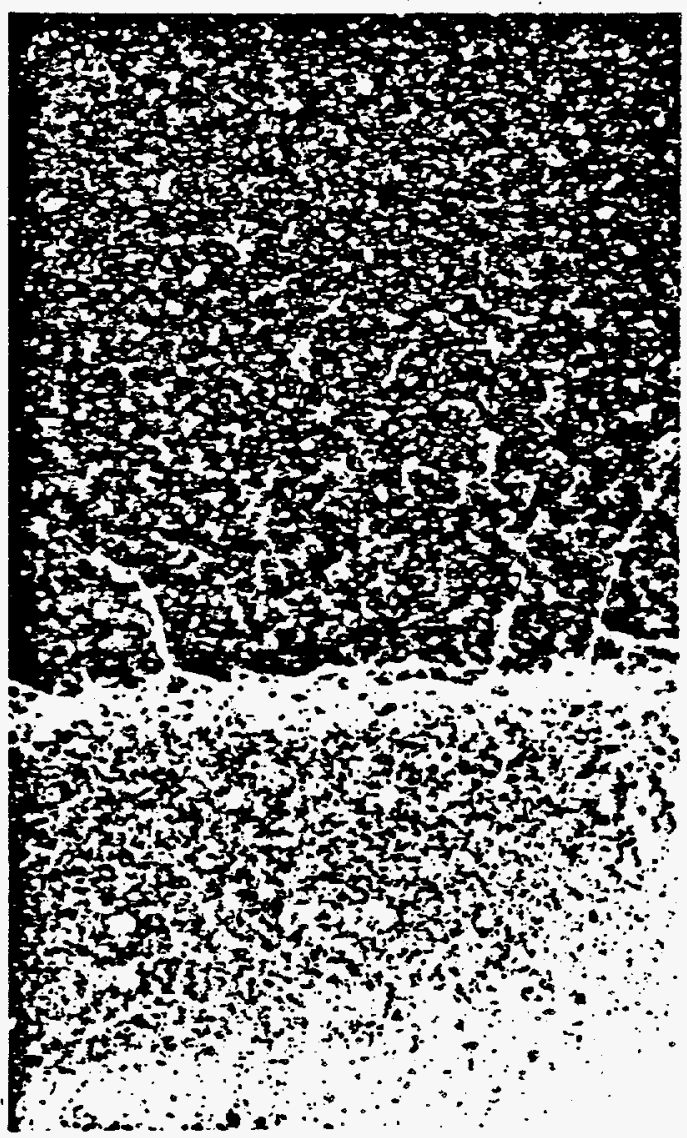

Figure 4-1: Polished Surface of a Cross-section of the Glass Block $2 / 5(3)$ Successively Investigated in Scanning Electron Microscope (The Bottom Edge of the Figure Corresponds to the Bottom Sample Area, Magn. 15)

It was typical for the sample $2 / 5$ that it cracked very intensively in various directions during cutting and this property is considered to be typical. 


\subsection{PROPERTIES}

Glasses 1 and 2 were characterized by a number of physical, physico-chemical and chemical properties, description and resulting data of which are given in following sections.

Detailed study of crystallinity was realized by X-ray diffraction analysis, optical microscopy and electron microanalysis (section 4.2.1.). Measurements of temperature dependence of viscosity and electrical conductivity of melts, dilatometry and determination of typical glass constants is described in section 4.2.2. Chemical analysis of glasses, their chemical durability is given in section 4.2.3. and research. on chromium behaviour during the batch heat treatment in section 4.2 .4 .

\subsubsection{CRYSTALIINITY}

The glasses are called as quenched and annealed because they were prepared by pouring the molten glass onto a metal table with successive thermal treatment (annealing) to remove internal stress (see procedure desribed in the Test Plan and Section 4.1).

\subsubsection{X-RAY DIFFRACTION ANAIYSIS}

The specimens of Glasses 1 and 2 , marked as $1 / 5$ and $2 / 5$ according to the sequence of melts, were cut from cast plates having the size $97 \times 42 \times 23 \mathrm{~mm}$, namely from the central part not influenced by the surface. Both cast samples as received from the svis exhibit dark greenish and glassy appearance. In the sample 2/5, a less coloured bottom layer can be seen of about $3 \mathrm{~mm}$ thickness on the vertical section. Therefore, the analysis was performed not only from the central, but also from the bottom part of the original plate.

The X-ray powder patterns were obtained with Seifert $x$-ray diffractometer (XRD 3OOOP) using CuK(alfa) radiation and graphite monochromator. The measured values of d-spacing were compared with PDF 2 data (Powder Diffraction File of the JCPDS). For the phase analysis only those elements were taken into consideration, the concentration of which was in units or decades of percent, i.e. Si, O, Al, CI, Fe, Na, $L i$ and B. Before evaluation, 
smoothing of diffractograms and background separation was performed for better identification of weak diffraction lines. However, the background separation was performed in such a way not to influence elevated area characteristic of the amorphous phase. In the enclosed records, diffractograms are compared with a scale factor which enables evaluation of very weak diffraction lines, even when cutting off was performed of the most intensive lines. From the same reason, graphic comparisons of diffractograms with PDF 2 data were performed with scale factor 5 , when necessary.

E v a l u a $t$ i o n

Specimen $1 / 5$ centre

High content of amorphous phase, distinct lines of well crystalline $\mathrm{Cr}_{2} \mathrm{O}_{3}$ (eskolaite, Card No. 38-1479) exhibiting good coincidence of lattice parameters with tabulated values. jols: 1-GCicDN referenr.t. mew outive bus: 2

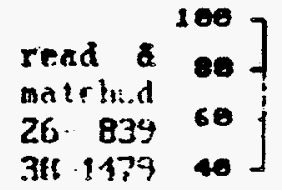
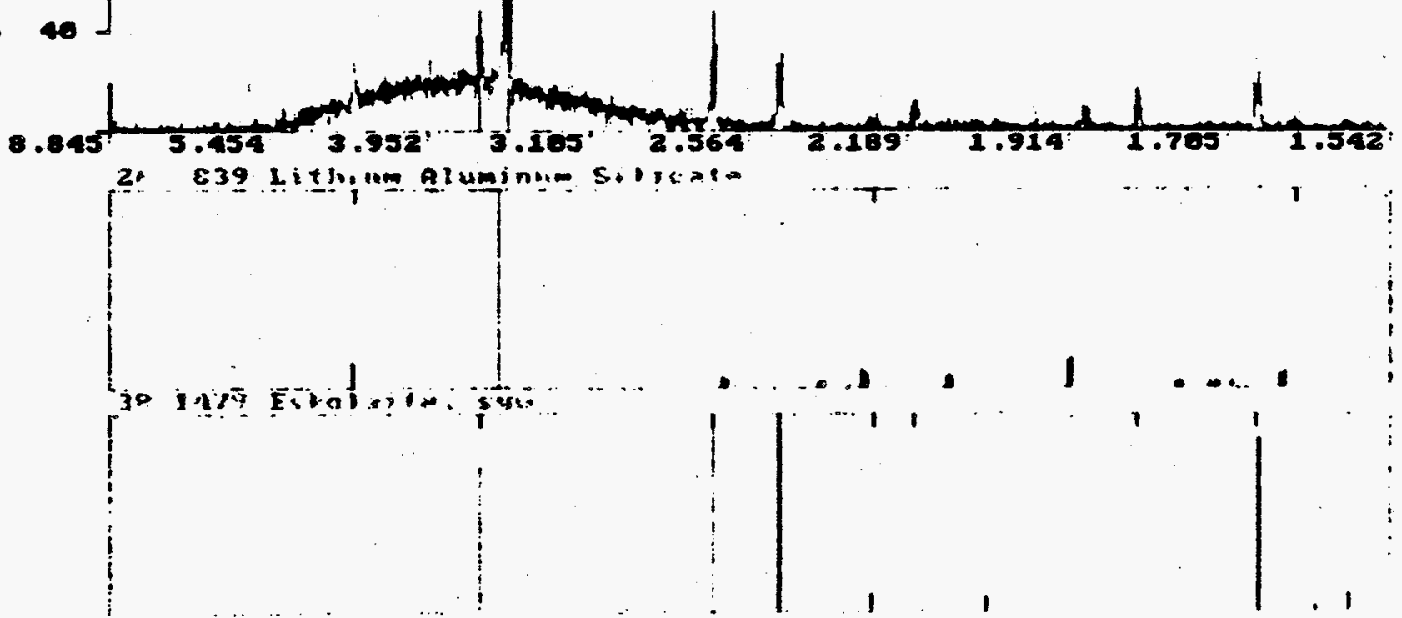

Figure 4-2: Diffractogram of Glass $i / 5$ (Centre)

Specimen $2 / 5$ centre

The amount of amorphous phase is distinctly lower than in the preceding sample. Distinct lines of well crystalline $\mathrm{Cr}_{2} \mathrm{O}_{3}$ in good accord with tabulated values. Beta-LiAlsio 4 (betaeucryptite*) is the dominant phase exhibiting lattice parameters shifted to lower values in comparison with tabulated ones (Card 
No. 26-839), presumably due to the formation of solid solutions in the series $\mathrm{LiAlsiO}_{4}-\mathrm{SiO}_{2}$. Less distinct lines correspond to the phase $\mathrm{Li}_{2} \mathrm{Al}_{2} \mathrm{Si}_{2} \mathrm{O}_{8}$ (No. 40-62), named $\mathrm{Li}-\mathrm{Al}$ disilicate in the following text.

- In the literature on glass-ceramics, beta-eucryptite and beta-quartz represent high-temperature polymorphs and alpha are low-temperature forms, according to mineralogical usage. JCPDS tables include 3 forms of lithium aluminum silicate: alpha$\mathrm{LiAlSiO}_{4}$ (Card No. 14-667, eucryptite, not found in the samples studied here), beta-LiAlsio 4 (No. 26-839, designated as beta-eucryptite in this study) and $\mathrm{Ii}_{2} \mathrm{Al}_{2} \mathrm{Si}_{2} \mathrm{O}_{8}$ (No. 40-62, designated as Li-Al-disilicate in this study).

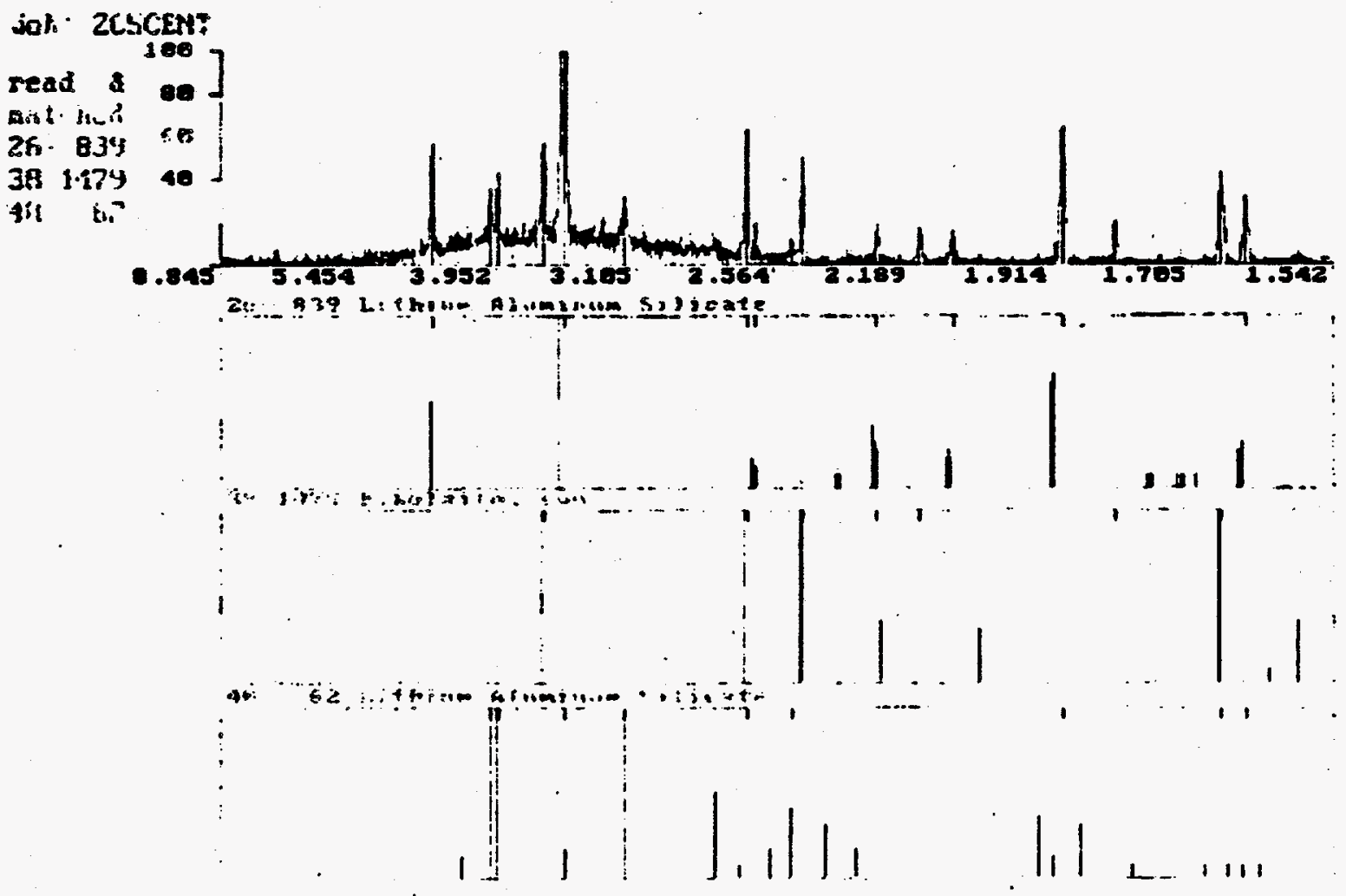

Figure 4-3: Diffractogram of Glass $2 / 5$, Centre

Specimen $2 / 5$ bottom

Phase composition similar to the centre, Li-Al-disilicate lines are very weak, almost unidentifiable. Two very weak lines can be attributed to chromium oxide of uncertain formula (Card 
No. 6-532). Several other lines near the limit of resolution correspond well to nepheline (Card No. 35-424) which is a sodium analogy of eucryptite.

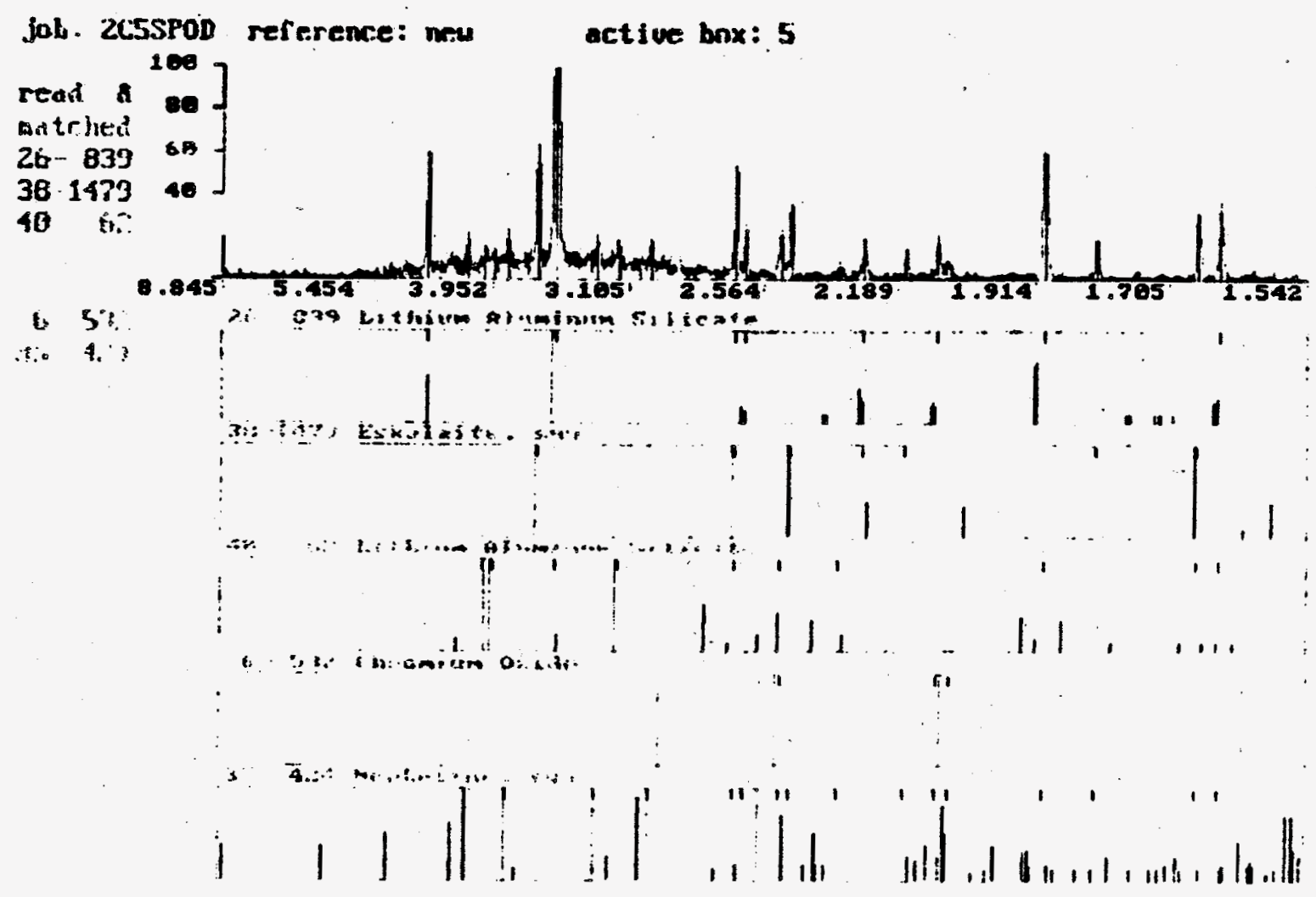

Figure 4-4: Diffractogram of Glass 2/5, Bottom

Independent investigation of phase composition by $x$-ray diffraction, using the specimens of $2 / 5$ taken from the same block (near to the cut surface, similarly as in the study by VŠcHT) was performed by. STL Hradec Kralove which confirmed the above shown results. Nepheline was fourd in the bottom zone. Moreover, a crystalline phase with spinel structure corresponding to chromite $\mathrm{FeO} . \mathrm{Cr}_{2} \mathrm{O}_{3}$ (No. 3-0873) was identified as a minor phase both in the bottom and upper parts of the block of glass $2 / 5$. The presence of the spinel phase will be discussed later. 
The contents ratio of crystalline phases in separate areas of the sample $2 / 5$ is very variable and it is, very approximately, given by the intensity of their main diffraction lines.

In Table 4-5 a comparison is made of intensities of the most intensive diffraction lines of crystalline phases present in the samples including their comparison with the intensity of the main diffraction line of synthetic high temperature eucryptite (see Report STL No. 254/94, Part 5).

Table 4-5: A Comparison of Intensities of the Most Intensive Diffraction Iines of Crystalline Phases (According to their Relative Height at Corresponding Conditions)

\begin{tabular}{|c|c|c|c|c|c|}
\hline & $\begin{array}{l}\text { High Tempe- } \\
\text { rature } \\
\text { Eucryptite } \\
\quad d=3,51\end{array}$ & $\begin{array}{l}\text { Esko- } \\
\text { laite } \\
d=2,66\end{array}$ & $\begin{array}{l}\text { Spine1- } \\
\text { type } \\
\text { Chromite } \\
d=2,51\end{array}$ & $\begin{array}{l}\text { Nephe- } \\
\text { line } \\
d=3,00\end{array}$ & $\begin{array}{l}\text { Li-AI- } \\
\text { disili- } \\
\text { cate } \\
d=4,01\end{array}$ \\
\hline $\begin{array}{l}1 / 5 \\
2 / 5 \\
\text { Bottom zone } \\
\text { Central Part } \\
\text { Surface Part } \\
\text { High Temperat. } \\
\text { Eucryptite } \\
\text { Synthetic }\end{array}$ & $\begin{array}{r}- \\
2567 \\
8.50 \\
1270 \\
5520\end{array}$ & $\begin{array}{l}131 \\
165 \\
166 \\
219\end{array}$ & $\begin{array}{c}- \\
76 \\
41 \\
32\end{array}$ & $\begin{array}{r}- \\
37 \\
-\end{array}$ & $\begin{array}{r}- \\
94 \\
62\end{array}$ \\
\hline
\end{tabular}

\subsubsection{OPTICAL MICROSCOPY}

Samples of glasses 1 and 2 , marked $1 / 5$ and $2 / 5$ were cut from plates $97 \times 42 \times 23 \mathrm{~mm}$, namely from the central part of the plate not affected by the surface, i.e. the same part as for $X-r a y$ diffraction.

only measurements with thin sections were performed because they give more information than those with polished sections in incident light.

Thin sections were prepared in petroleum and observations were performed in polarized light. Image analysis system IUCIA was used for evaluation.

The results are shown in Table $4-6$ and in Figures 4-5 to $4-8 a, b$. 
Table 4-6: Statistical Evaluation of Agglomerates in Glasses $1 / 5$ and $2 / 5$ (Image Analysis)

$1 / 5$

Number of Fields $\quad 1$

Number of Objects 26

Objects per Field 26

Measured Area $\quad 3.93371\left[\mathrm{~mm}^{*} \mathrm{~mm}\right]$

Objects per Area $\quad 6.60954 /\left[\mathrm{mm}^{*} \mathrm{~mm}\right]$

Area Fraction 0.0332092

$\begin{array}{llllll}\text { Feature } & \text { Mean } & \text { St.Dev } & \text { Minimum } & \text { Maximum } & \\ \text { EqqDiameter } & 0.070956 & 0.024977 & 0.045657 & 0.1563 & \mathrm{~mm}\end{array}$

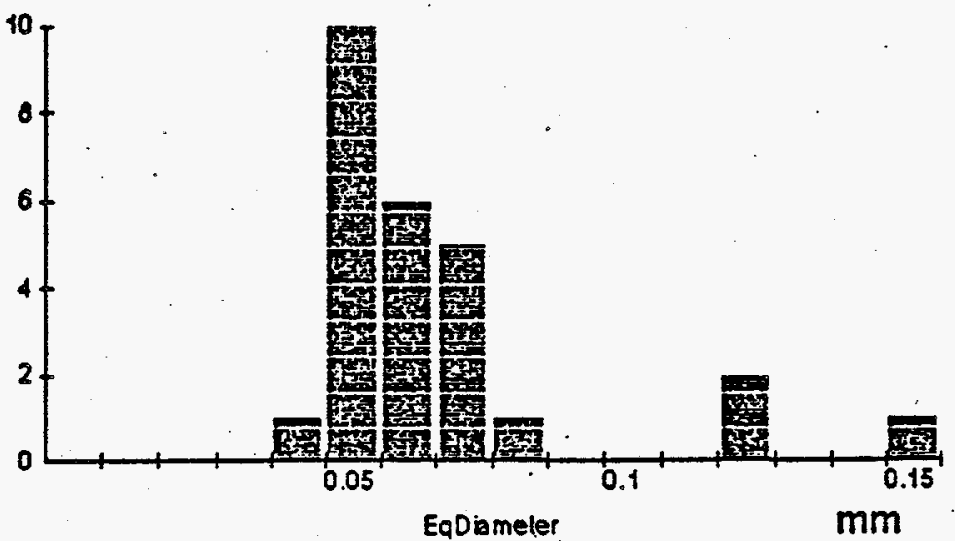

$2 / 5$

Number of Fields 1

Number of Objects 8

Objects per Field

Measured Area $\quad 3.93371\left[\mathrm{~mm}^{*} \mathrm{~mm}\right]$

Objects per Area $\quad 2.0337 /\left[\mathrm{mm}^{*} \mathrm{~mm}\right]$

Area Fraction 0.012298

$\begin{array}{llllll}\text { Feature } & \text { Mean } & \text { St.Dev } & \text { Minimum } & \text { Maximum } & \\ \text { EqDiameter } & 0.086122 & 0.016805 & 0.069039 & 0.12529 & \mathrm{~mm}\end{array}$

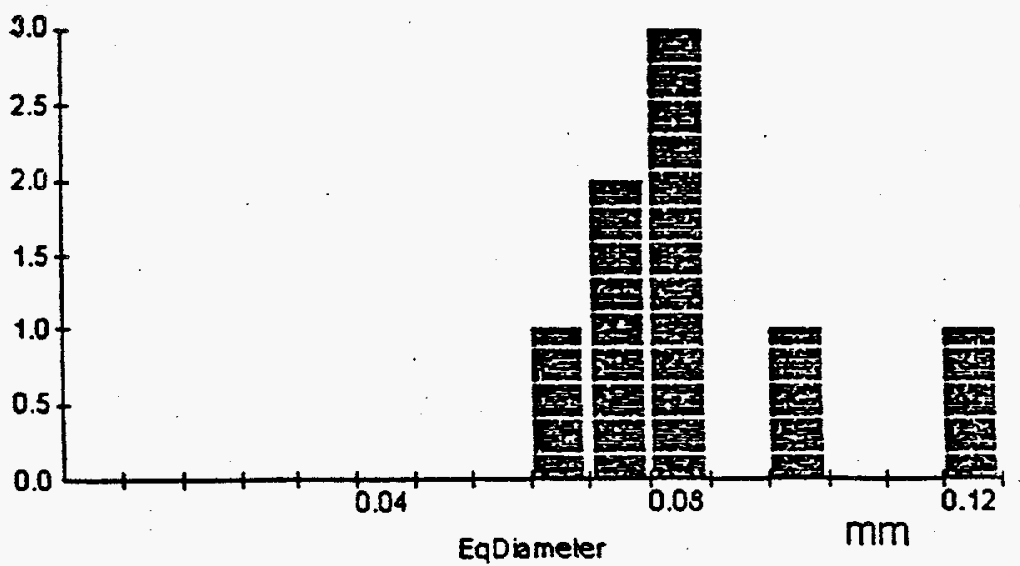




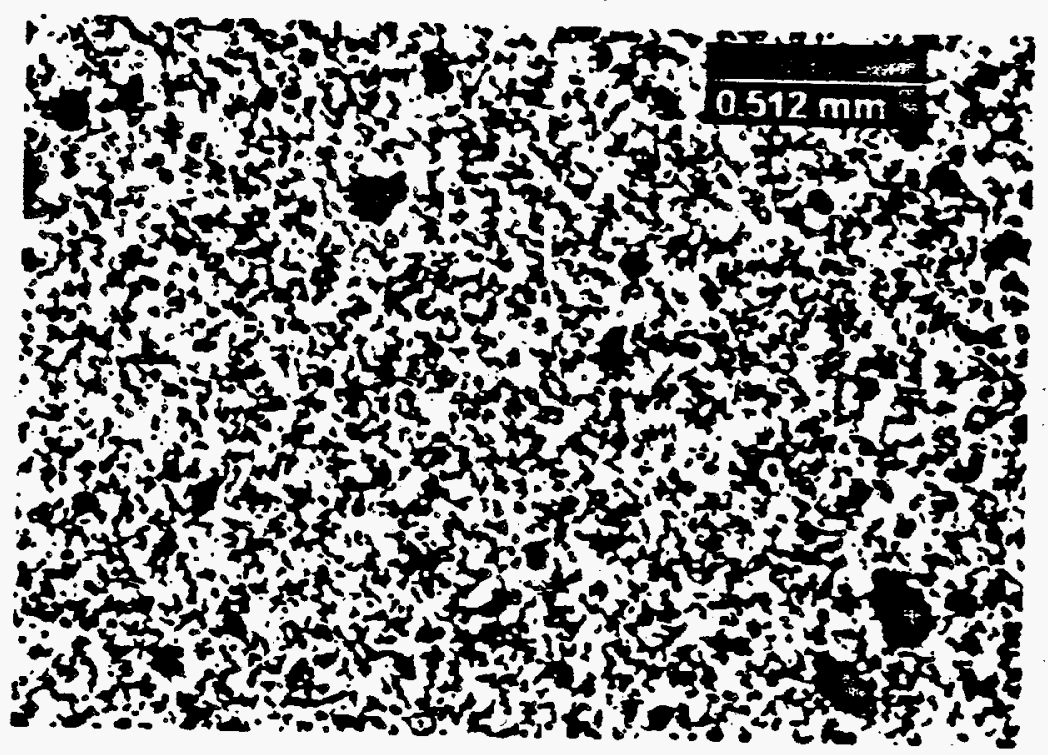
Figure 4-5: Glass $1 / 5$, Objective 3.2, Surface Area of the Dark
Phase $51:$

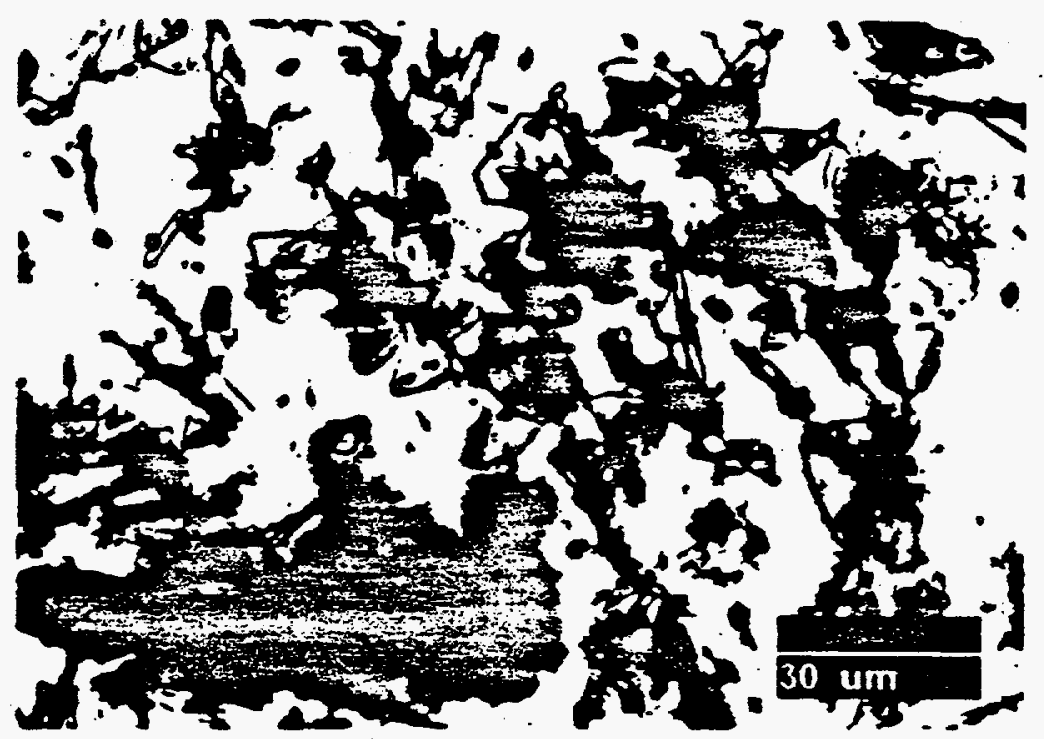

Figure 4-6: Glass 1/5, Objective 50, Plates of Eskolaite, Detail of a Small Agglomerate and its Vicinity 


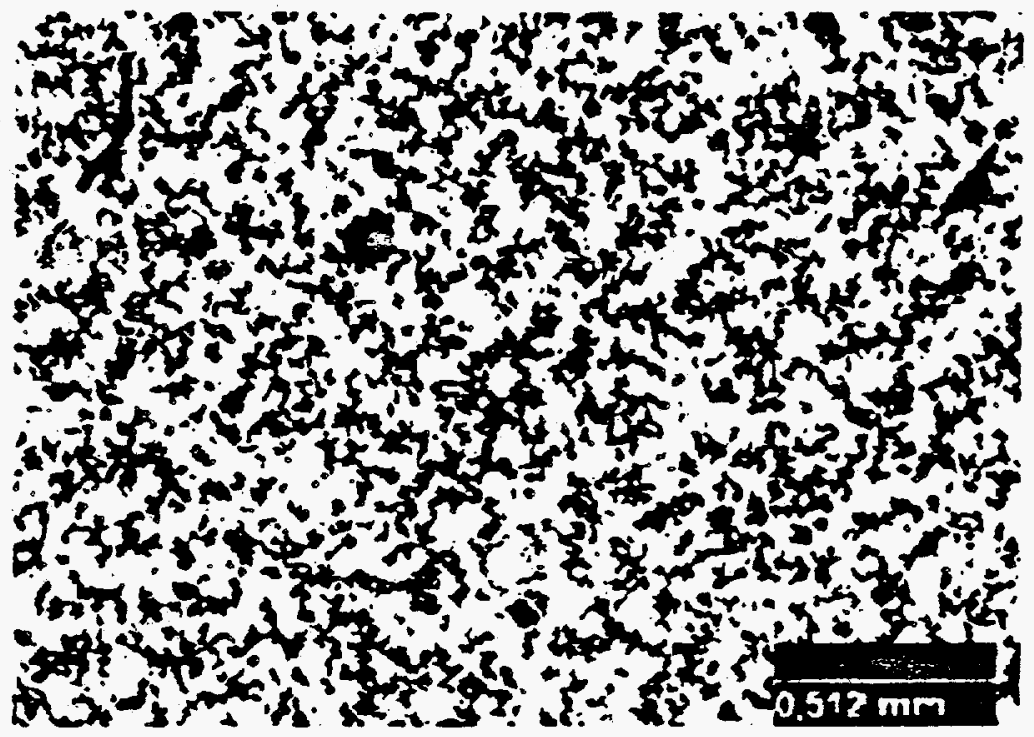

Figure 4-7: Glass 2/5, Objective 3.2, Surface Area of the Dark Phase $44 \%$

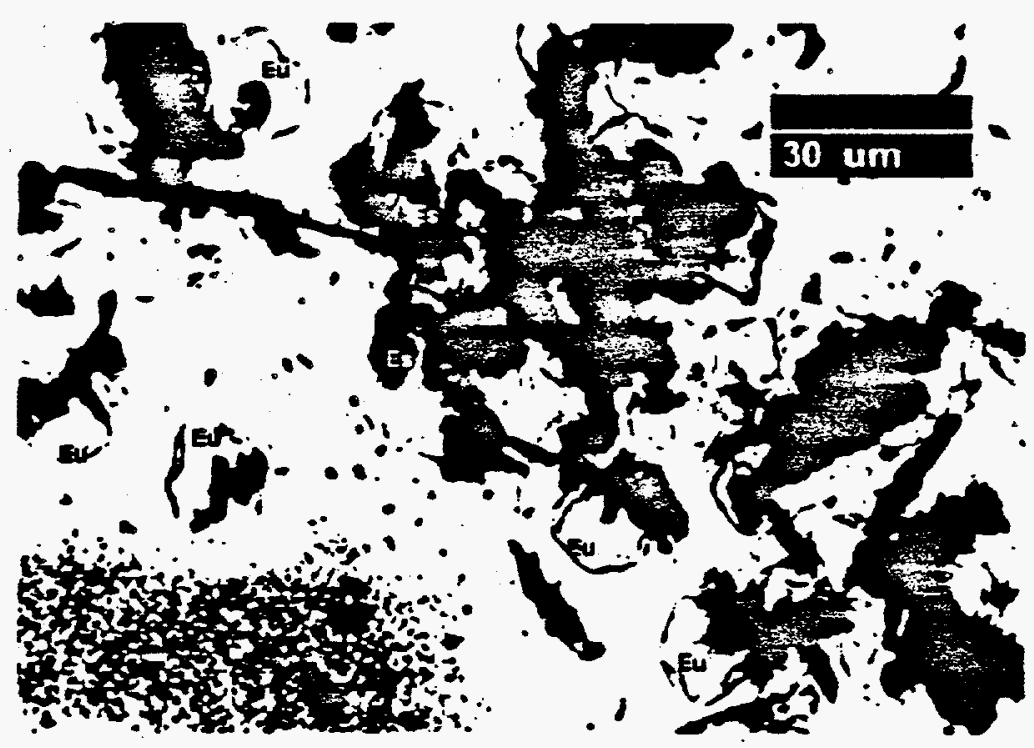

Figure 4-8a: Glass 2/5, Objective 50, Plates of Escolaite (Es) and Hexagonal Crystals of Beta Eucryptite (Eu) 


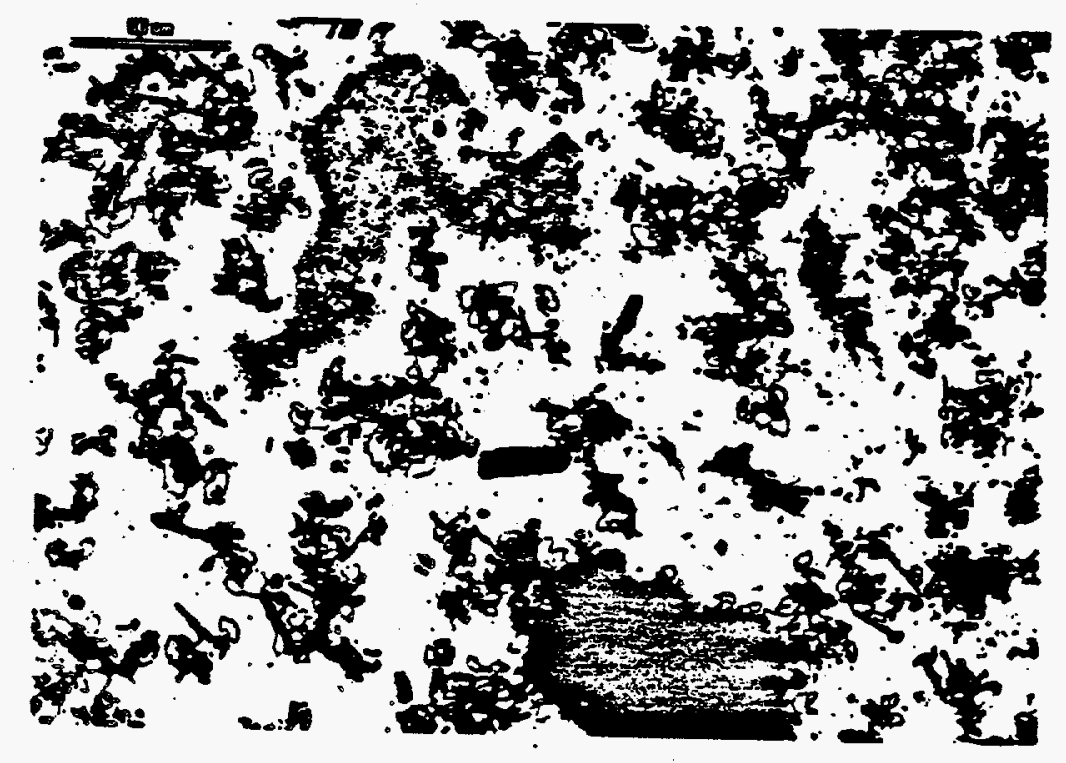

Figure 4-8b: Glass 2/5, Eskolaite and Eucryptite Crystals, Combination of Image in Polarized Light and Crossed polarizing filters Arrangement

Specimen $1 / 5$

The specimen contains large agglomerates of $\mathrm{Cr}_{2} \mathrm{O}_{3}$ (eskolaite) with mean diameter of $0,070 \mathrm{~mm}$ (see Table 4-6 and Figure 4-5). small dark particles in Figure 4-5 are individual crystals and small agglomerates of eskolaite.

Surface area of the dark phase $(51$ \%) indicates the proportion of eskolaite in a layer about $0,03 \mathrm{~mm}$ thick, so that it is not a direct measure of the volume fraction. Detail of an agglomerate (dark region in the lower part) is shown in Figure 4-6. Plates of eskolaite surrounding the agglomerate have 15 - 30 microns diameter and about 1 micron thickness (or less). Some plates are green, representing pure $\mathrm{Cr}_{2} \mathrm{O}_{3}$, other plates are of brown colour which presumably implies the solid solution with $\mathrm{Fe}_{2} \mathrm{O}_{3}$. The presence of solid solution was not apparent from the results of $X$-ray diffraction (see the preceeding section). 
Specimen $2 / 5$

The agglomerates have similar size as in the preceding case (see Table 4-6 and Figures 4-7 and 4-8a,b). Figure 4-7 shows dark particles composed of large and small agglomerates occupying about 44 of surface area. Moreover, there are grey regions in Figure 4-7 consisting of very small agglomerated particles of unidentified nature.

A detail in Figure 4-8a shows plates of eskolaite, again green or brown due to $\mathrm{Fe}_{2} \mathrm{O}_{3}$ in solid solution. In addition, there are hexagonal crystals of beta-eucryptite, estimated from the crystal symmetry and refractive index. In the lower left harid corner of Figure 4-8a, there can be seen the above mentioned agglomerate. of very small particles which may represent another phase not yet found in the samples studied here and which can not be identified by optical microscopy (identified as a spinel phase by EMA - see later).

Identical phases can be seen in Figure 4-8b. A large eskolaite agglomerate is situated at the bottom of the figure. Irregular isotropic shape of grey-blue color in the upper part of the figure corresponds to the agglomerate of very small particles of unidentified composition. The Figure 4-8b was obtained by combination of image in polarized light (without using the analysator) and that with crossed polarizing filters arrangement. In this case eucryptite appears as blue crystals; the blue color has been arificially created using the image analysis system. Eucryptite crystals exhibit significant birefringence. Eskolaite crystals are colored brown to brown-green.

\section{optical microscopy summary}

The content of large eskolaite agglomerates is higher in $1 / 5$ than in 2/5. The individual plates of eskolaite in both glasses have the diameter 15 - 30 microns and thickness 1 micron or less. Some of them contain $\mathrm{Fe}_{2} \mathrm{O}_{3}$ in solid solution (brown color) and exhibit birefringence when oriented perpendicullary to the surface of the thin section. 
Glass $2 / 5$ contains another phase of hexagonal symmetry which corresponds to beta-eucryptite. The diameter of the crystals is about 15 microns. Beta-eucryptite crystals are situated near to eskolaite boundaries. This finding implies heterogenous nucleation on the boundaries of eskolaite crystals.

In Glass $2 / 5$ regions can be observed exhibiting deeper colour where large crystals are not present. They are composed of very small unidentified particles.

The size of large agglomerates of eskolaite in both glasses is in good relation to the dimensions of agglomerates in chromium hydroxide which was used as raw material for the batch. It can be concluded, that large agglomerates of eskolaite represent pseudomorphic formations of altered hydroxide (see Chapter 3.2).

\subsubsection{ELECTRON MICROANALYSIS}

The laboratory of the Glass Institute used:

Internal regulation F-18-94 Methods of nondestructive analysis of solid substances in the apparatus complex:

Camscan 4-DV - LINK AN 10000 - Microspec WDX-2A for the electron microanalysis of Glass 1 and 2 samples

\section{Preparations of resting samoles}

For investigating in scanning electron microscope the portions $1 / 5(3)$ and $2 / 5(3)$ of glass samples $1 / 5$ and $2 / 5$ (see Annex (1) were used, i.e. original cutting surface of blocks representing the perpendicular sections through blocks. The section surface was polished, at first on polishing device and then on an equipment using free diamond (DSM 2/1 Pramet and PWD 3-I Wolters) on a brass support plate.

Before inserting into apparatus, surfaces of samples were coated by carbon in a high vacuum equipment B 302 .

\section{Experimental part}

Samples were located into a chamber of electron scanning microscope Camscan 4-DV with energy dispersive analyzer LINK AN 10000 and wave dispersive analyzer Microspec WDX-2A. 
Pictures taken in back scattered electrons (BSE) or secondary electrons (SEI) were carried out using following conditions: accelerating voltage $20 \mathrm{kV}$, working distance $29 \mathrm{~mm}$, shield 2, resolution 4. There were documented and analyzed typical texture motives detected in analyzed glasses. The dependence of the presence of such structural motives on the distance from the bottom part of a block was investigated. This distance is given in $\mathrm{mm}$ and it corresponds to the distance from lower edge of the picture. The upper edge of the picture is in the direction to the upper edge of the block.

Further on, EDX spectra of selected areas of texture motives and matrix by energy dispersive analyzer LINK AN 10000 were performed. Both area analyses (a surface of analyzed area is documented in pictures) or local analyses (a diameter of analyzed place appr. $1.5 \mathrm{Nm}$ ) were carried out. The gained spectra were quantitatively evaluated by a correction programme ZAF-4/FLS, which is a part of programme equipment of the analyzer, and statistically evaluated. The complement of analyses to $100 \mathrm{wt}$. is created by minor components (in particular cases statistically unprovable, the values are lower than 2 c) and by $\mathrm{B}_{2} \mathrm{O}_{3}$ and $\mathrm{Li}_{2} \mathrm{O}$ which cannot be determined by the analytical method used.

Using the MAPPING programme, $\mathrm{x}$-ray distributions of selected elements $\mathrm{Si}, \mathrm{Cr}, \mathrm{Fe}, \mathrm{Na}$ and $\mathrm{Al}$ were made.

The wave dispersive analyzer Microspec WDX-2A was used for verification of $\mathrm{B}_{2} \mathrm{O}_{3}$ presence in selected sample places.

Testing results

Glass $1 / 5$

In Figures 4-9 and 4-10 the texture of Glass $1 / 5$ is documented at a small magnification.

Even at greater magnification (see Figures 4-11 and 4-12) no texture changes in dependence on a position of relevant place in the direction to the bottom area of block were found. 


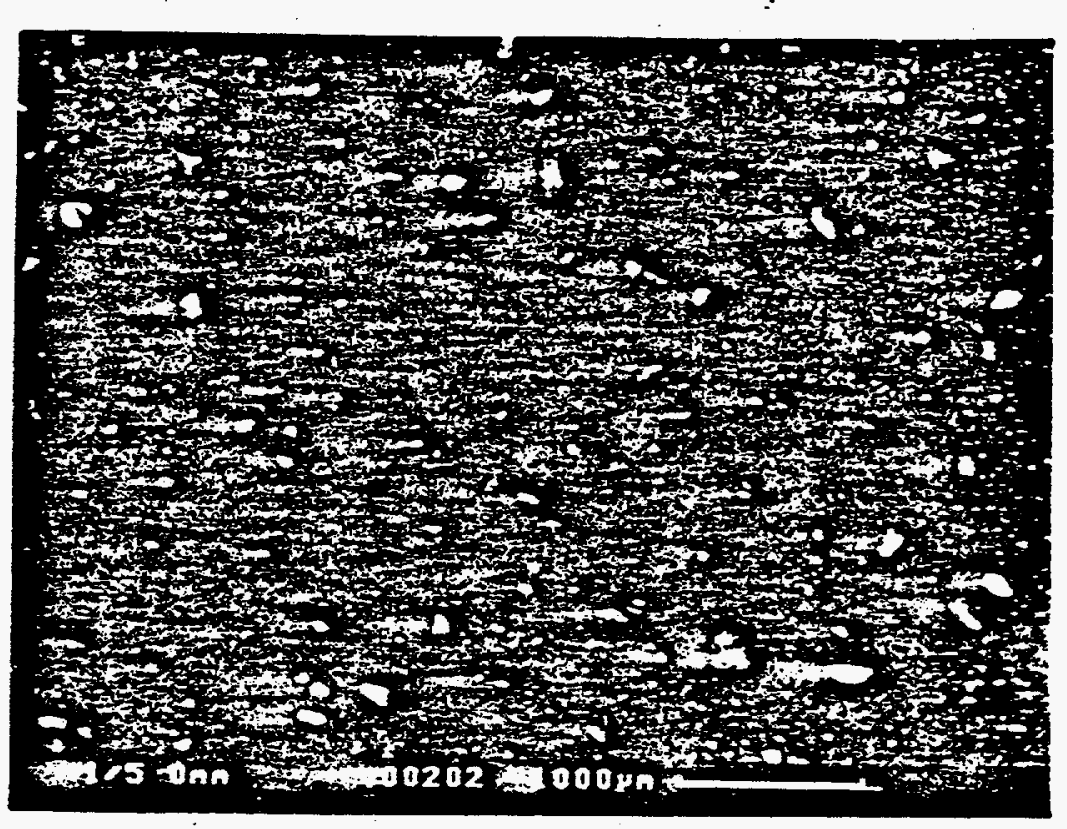

Figure 4-9: Glass 1/5. Section View in the Bottom Area and Central Part of the Block (0 mm). Microscope Camscan 4-DV, BSE.

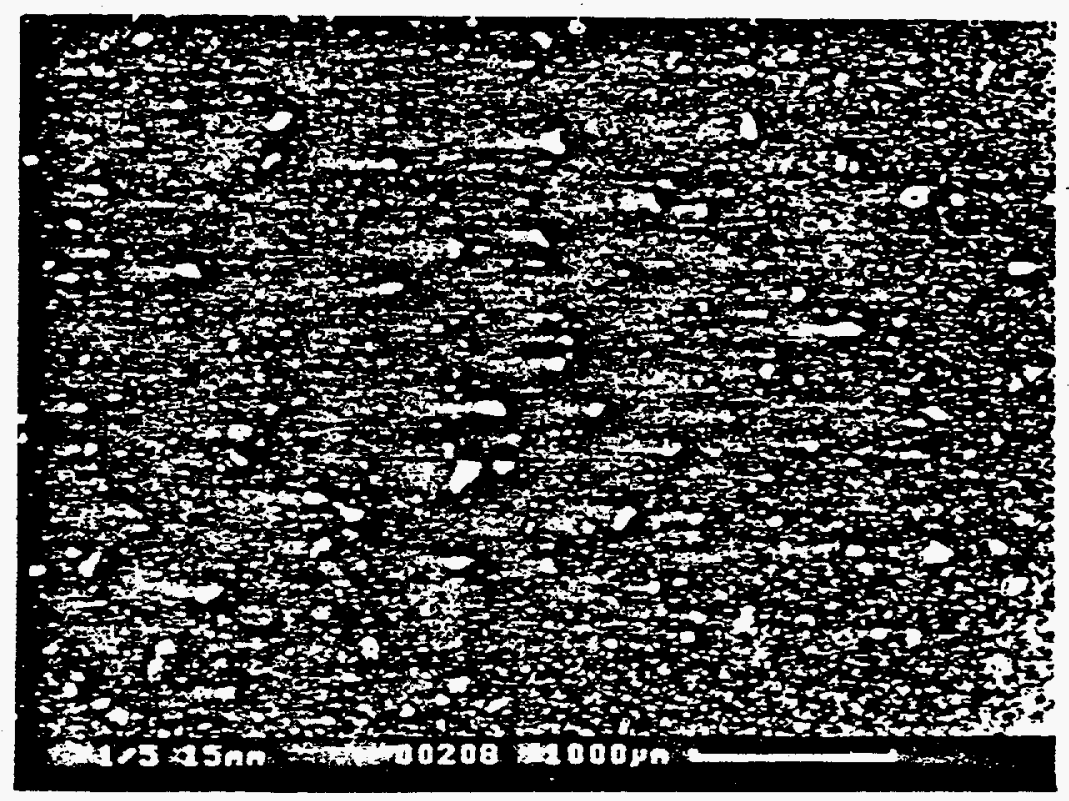

Figure 4-10: Glass 1/5. Section View in the Surface Block Part (15 mm). Microscope Camscan 4-DV, BSE. 


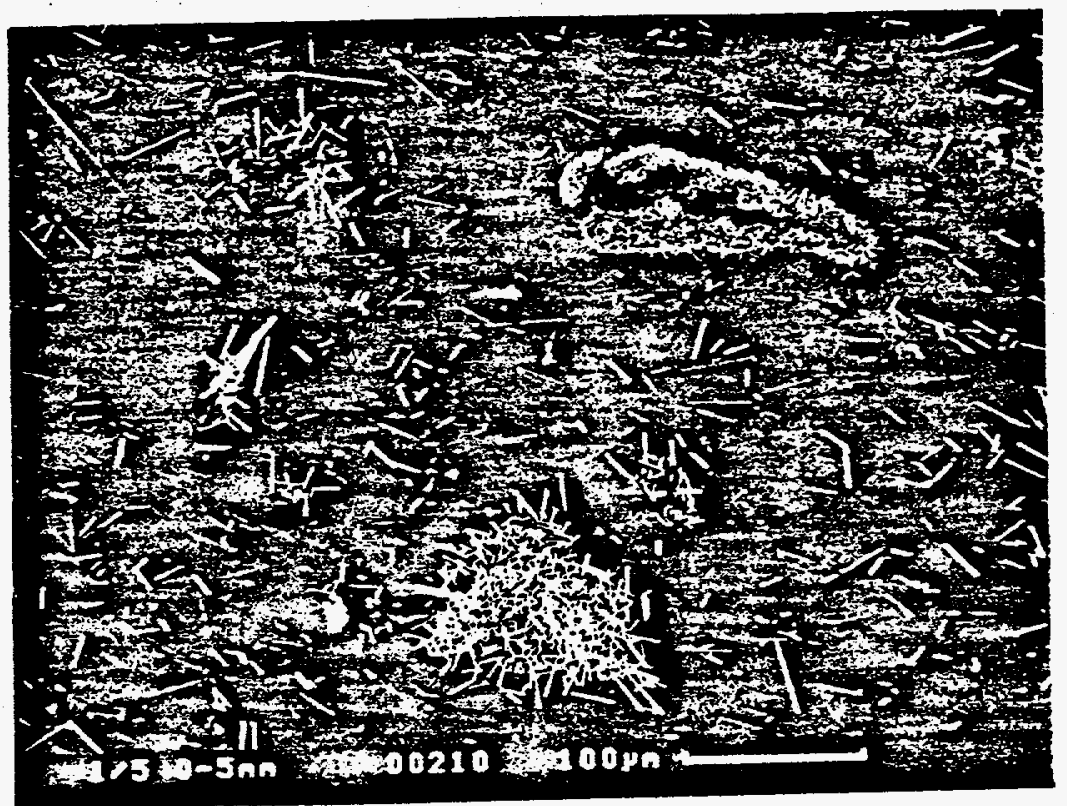

Figure 4-11: Glass 1/5. Detail of the section of the Bottom Area and Central Block Part $(0-5 \mathrm{~mm})$. Microscope Camscan 4-DV, BSE.

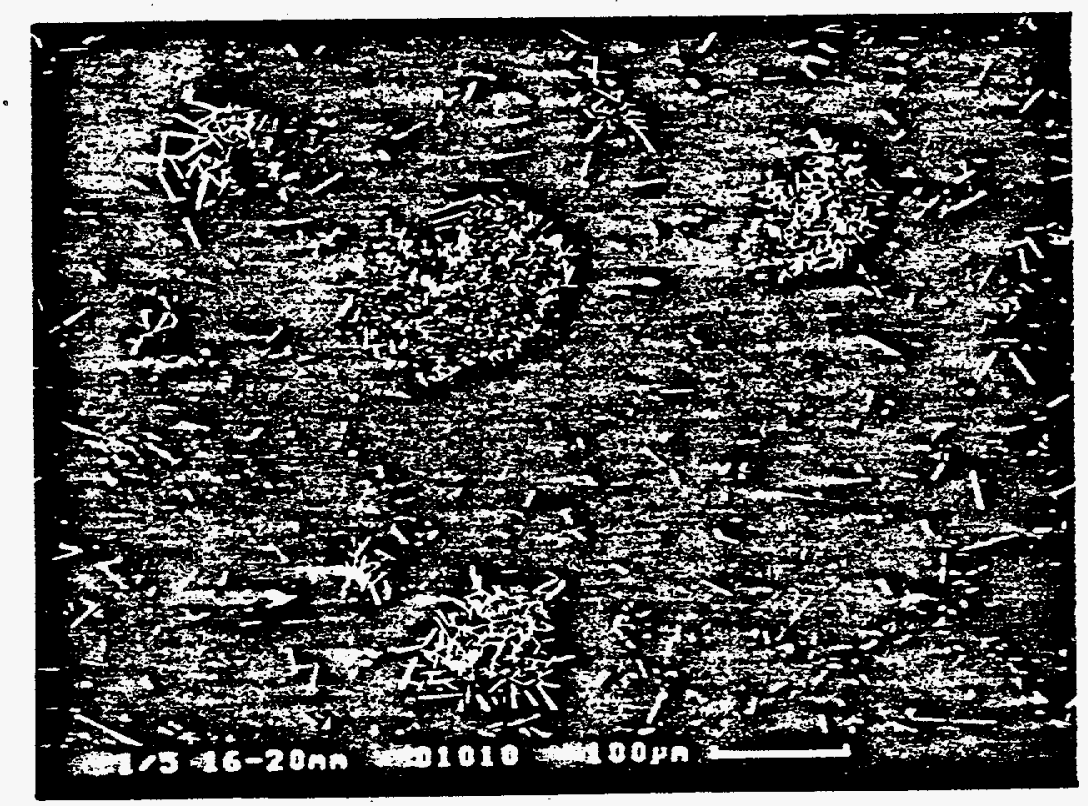

Figure 4-12: Glass 1/5. Detail of the Section of the Bottom Area and Central Block Part (16-20 mm). Microscope Camscan 4-DV, BSE. 
There were detected several types of texture motives in the whole analyzed sample area. Grained irregular particles (typical example is in Figure 4-13) were analyzed either by area analysis or by local analysis.

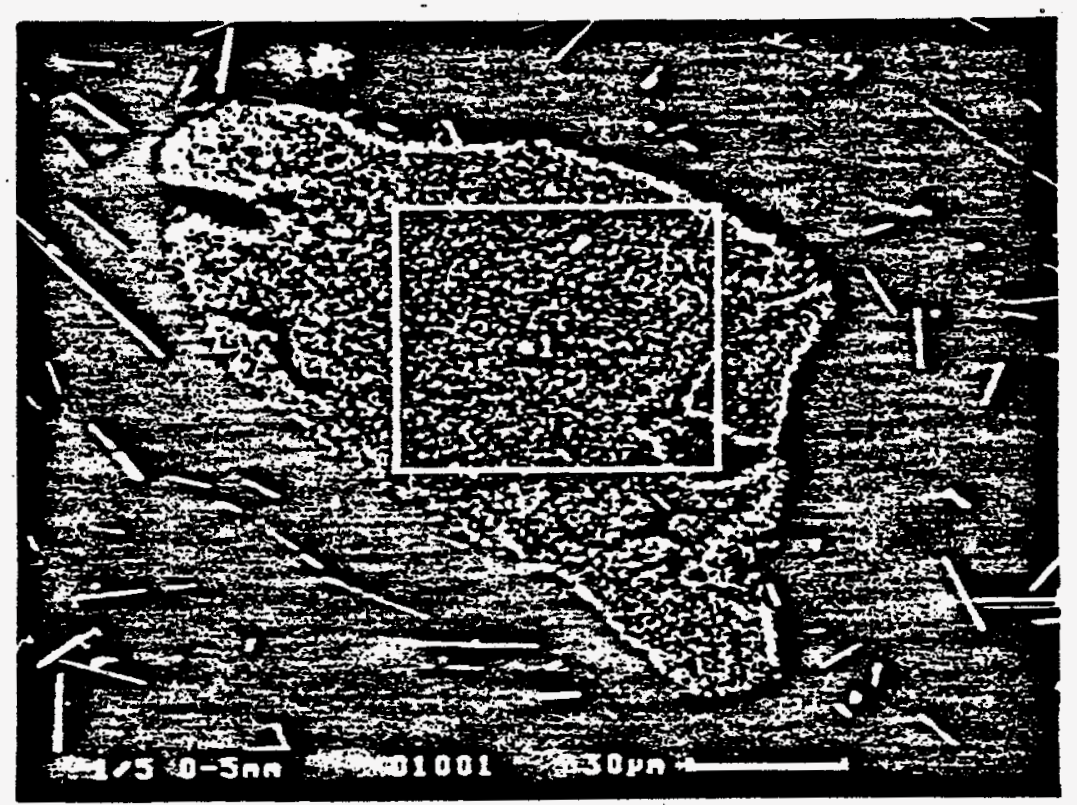

Figure 4-13: Glass 1/5. Grain Irregular Particle with Marked Area and Local Analyses. Normal Section (16-20 mm). Microscope Camscan 4-DV, BSE.

The local analysis of different places of grained particles confirmed their chemically homogeneous composition and corresponded to the area analyses results.

The respective analytical results are given in Table 4-7. 
Table 4-7: A Summary of Analyses Results of a Sample of Quenched and Annealed Glass $1 / 5$

(IINK AN 10000, Expressed in wt. z)

\begin{tabular}{|c|c|c|c|c|c|c|}
\hline $\begin{array}{l}\text { Analyzed } \\
\text { Area }\end{array}$ & \multicolumn{2}{|c|}{$\begin{array}{l}\text { Grained } \\
\text { Particles }\end{array}$} & \multicolumn{2}{|c|}{$\begin{array}{l}\text { Isolated } \\
\text { Crystals }\end{array}$} & \multicolumn{2}{|c|}{ Matrix } \\
\hline $\mathbf{n}$ & \multicolumn{2}{|c|}{20} & \multicolumn{2}{|c|}{8} & \multicolumn{2}{|c|}{20} \\
\hline & $\overline{\mathbf{x}}$ & $\sigma$ & $\overline{\mathbf{x}}$ & $\sigma$ & $\overline{\mathbf{x}}$ & $\sigma$ \\
\hline $\begin{array}{l}\mathrm{Na}_{2} \mathrm{O} \\
\mathrm{Al}_{2} \mathrm{O}_{3} \\
\mathrm{SiO}_{2} \\
\mathrm{Fe}_{2} \mathrm{O}_{3} \\
\mathrm{Cr}_{2} \mathrm{O}_{3} \\
\mathrm{MnO}_{2} \\
\mathrm{NiO} \\
\mathrm{ZnO}\end{array}$ & $\begin{array}{r}4,8 \\
10,6 \\
28,7 \\
2,0 \\
35,1 \\
a \\
a \\
a\end{array}$ & $\begin{array}{l}0,7 \\
0,7 \\
2,3 \\
0,2 \\
4,1\end{array}$ & $\begin{array}{l}0,9 \\
3,4 \\
5,8 \\
5,4 \\
73,4 \\
a \\
a \\
a\end{array}$ & $\begin{array}{l}0,6 \\
0,3 \\
0,9 \\
0,3 \\
1,6\end{array}$ & $\begin{array}{c}6,8 \\
16,6 \\
48,2 \\
1,2 \\
0,57 \\
0,34 \\
a \\
a\end{array}$ & $\begin{array}{l}0,4 \\
0,3 \\
0,5 \\
0,2 \\
0,07 \\
0,08\end{array}$ \\
\hline sum & 81,2 & & 88,9 & & 73,71 & \\
\hline
\end{tabular}

Notes: $n \ldots$ number of independent analyses

$\overline{\mathbf{x}}$... arithmetical mean

$\sigma$... standard deviation

a ... value less than 20

Chemical homogeneity of grained particles is confirmed by a selected elements distribution in an area of these particles see Figure 4-14.

The other type of texture motives are clusters of eskolaite crystals. Their characteristic appearance is documented in Figures 4-15 and 4-17. In this case area and local analyses were carried out as well. 


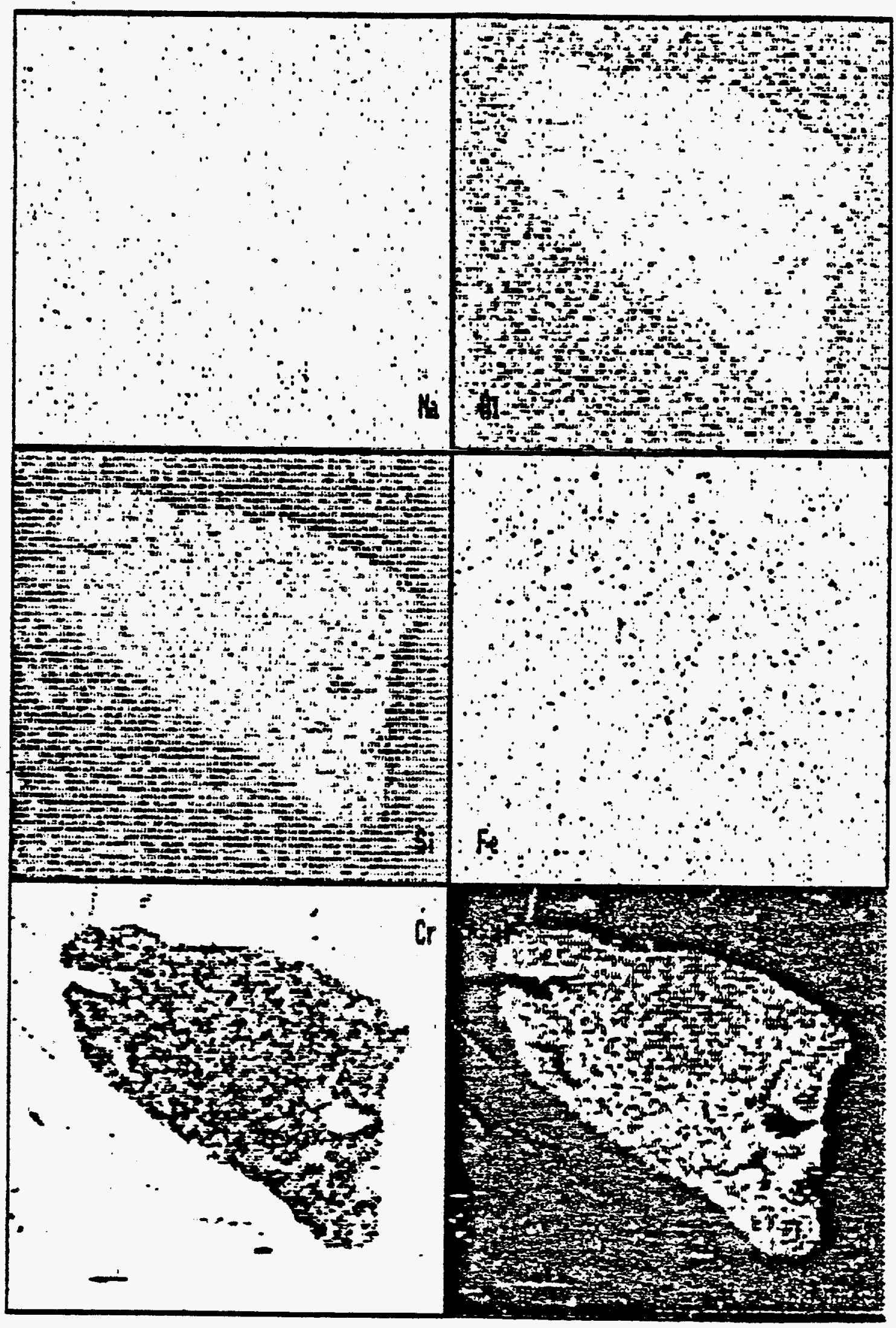

Figure 4-14: Glass 1/5. Grain Irregular Particle. $X$-Ray Distribution of $\mathrm{Na}, \mathrm{Al}, \mathrm{Cr}, \mathrm{Fe}$ and $\mathrm{Si}$ in the Area Shown in Figure 4-13. Normal Section (16-20 mm). Microscope Camscan 4-DV, Programme MAPPING. 


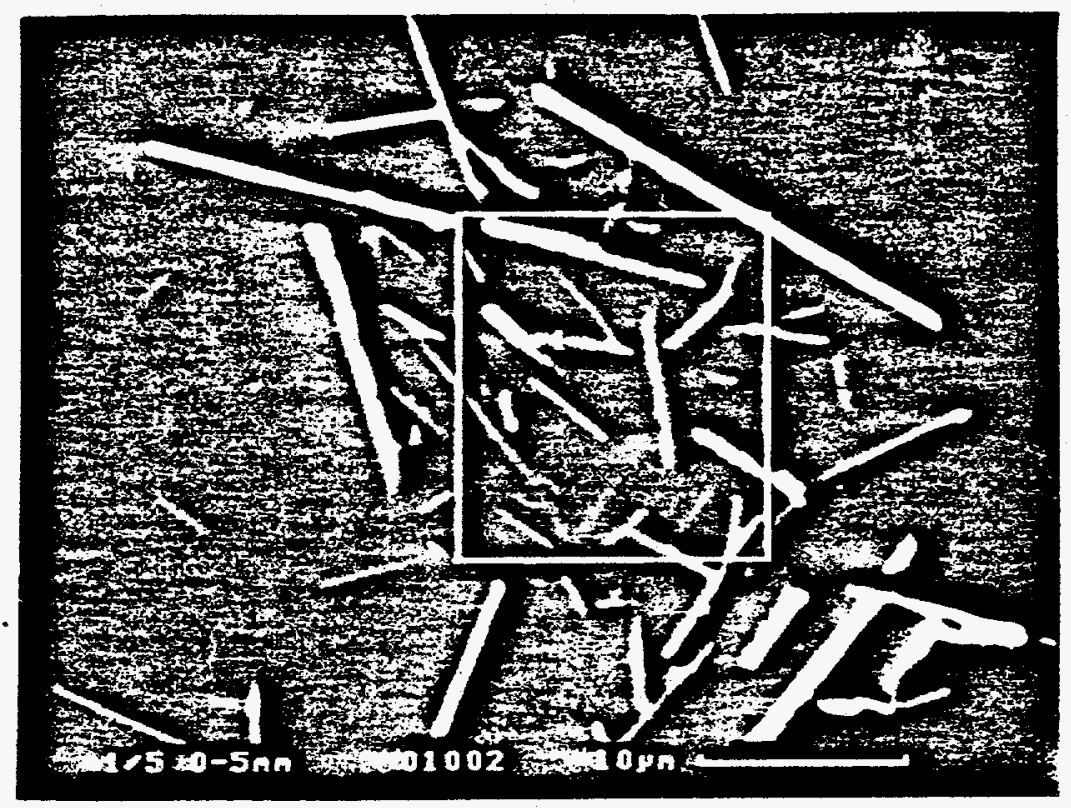

Figure 4-15: Glass 1/5. Eskolaite Crystal Clusters with Marked Area and Local Analyses. Normal section $(0-5 \mathrm{~mm})$. Microscope Camscan 4-DV, BSE.

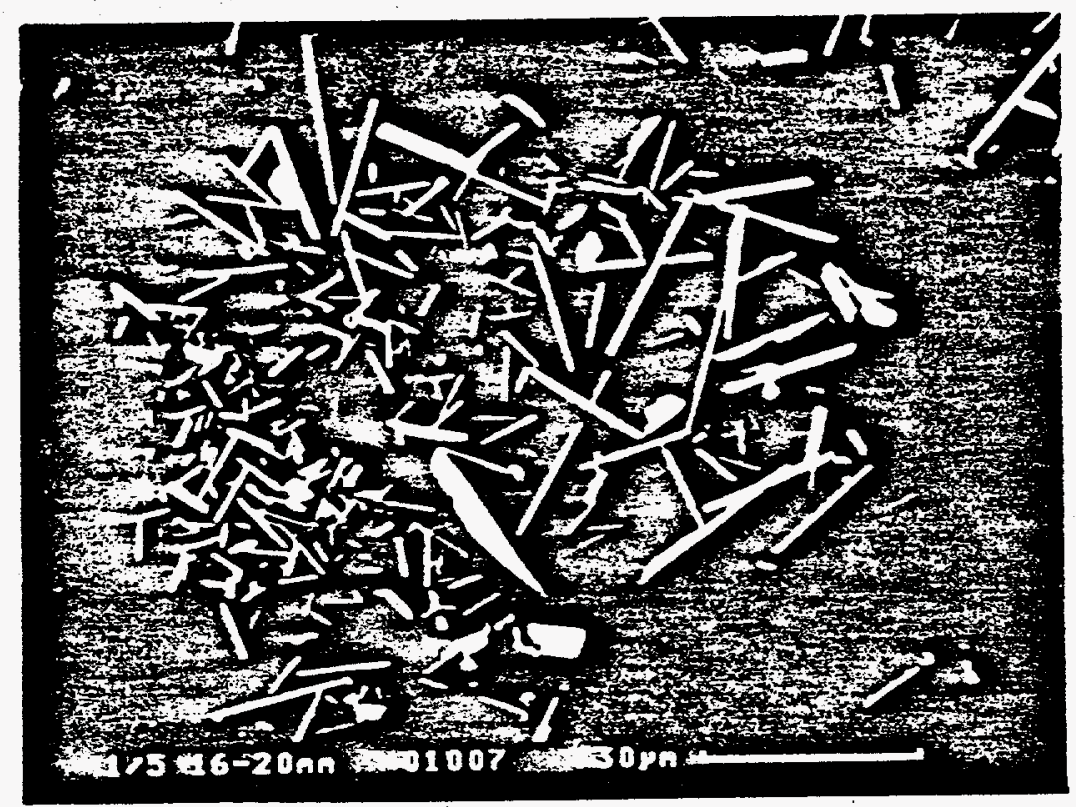

Figure 4-17: Glass 1/5. Eskolaite Crystal Cluster. Normal Section $(16-20 \mathrm{~mm})$. Microscope CamScan 4-DV, BSE.

Area analyses and local analysis of crystals in clusters and an intercrystalline space were statistically evaluated and summarized in Table 4-8. In Figures 4-16 and 4-18 selected elements distribution in the area of crystal clusters is shown. 
Table 4-8: A Summary of Analyses Results of Eskolaite Crystal Clusters in a Sample of Quenched and Annealed Glass $1 / 5$ (LINR AN 10000, Expressed in wt. t)

\begin{tabular}{|c|c|c|c|c|c|c|}
\hline $\begin{array}{l}\text { Analyzed } \\
\text { Area }\end{array}$ & \multicolumn{2}{|c|}{$\begin{array}{l}\text { Area } \\
\text { Analysis }\end{array}$} & \multicolumn{2}{|c|}{$\begin{array}{l}\text { Eskolaite } \\
\text { Crystals }\end{array}$} & \multicolumn{2}{|c|}{$\begin{array}{l}\text { Intercrystal } \\
\text { Space }\end{array}$} \\
\hline ก & \multicolumn{2}{|c|}{20} & \multicolumn{2}{|c|}{4} & \multicolumn{2}{|c|}{14} \\
\hline & $\overline{\mathbf{x}}$ & 0 & $\bar{x}$ & $\sigma$ & $\bar{x}$ & $\sigma$ \\
\hline $\begin{array}{l}\mathrm{Na}_{2} \mathrm{O}^{\circ} \\
\mathrm{Al}_{2} \mathrm{O}_{3} \\
\mathrm{SiO}_{3} \\
\mathrm{Fe}_{2} \mathrm{O}_{3} \\
\mathrm{Cr}_{2} \mathrm{O}_{3} \\
\mathrm{MnO}_{2} \\
\mathrm{NiO}_{2} \\
\mathrm{ZnO}\end{array}$ & $\begin{array}{r}5,7 \\
12,1 \\
32,2 \\
2,6 \\
31,2 \\
a \\
a \\
a\end{array}$ & $\begin{array}{l}0,5 \\
0,7 \\
2,5 \\
0,6 \\
5,0\end{array}$ & $\begin{array}{c}1,2 \\
3,9 \\
5,9 \\
5,4 \\
77,2 \\
a \\
a \\
a\end{array}$ & $\begin{array}{l}0,4 \\
0,8 \\
0,8 \\
0,4 \\
1,7\end{array}$ & $\begin{array}{l}6,8 \\
16,0 \\
46,1 \\
1,4 \\
4,7 \\
a \\
a \\
a\end{array}$ & $\begin{array}{l}0,4 \\
0,5 \\
1,5 \\
0,15 \\
1,7\end{array}$ \\
\hline sum & 83,8 & & 93,6 & & 75,0 & \\
\hline
\end{tabular}

Notes: see Table 4-7 


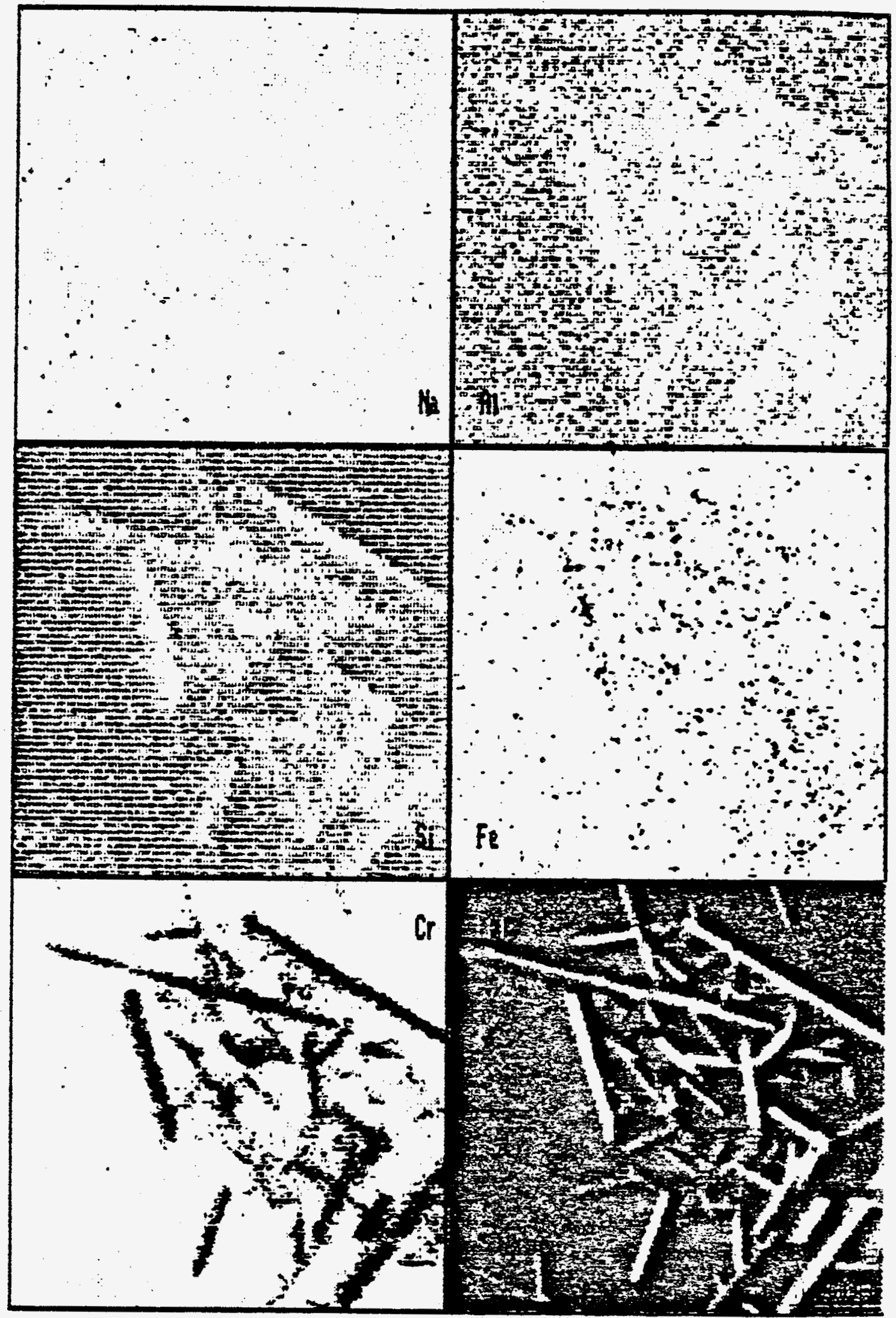

Figure 4-16: Glass 1/5. Eskolaite Crystal Cluster. X-Ray Distribution of $\mathrm{Na}, \mathrm{Al}, \mathrm{Si}, \mathrm{Fe}$ and $\mathrm{Cr}$ in the Area Shown in Figure 4-15. Normal Section $(0-5 \mathrm{~mm})$. Microscope Camscan 4-DV, Programme MAPPING. 


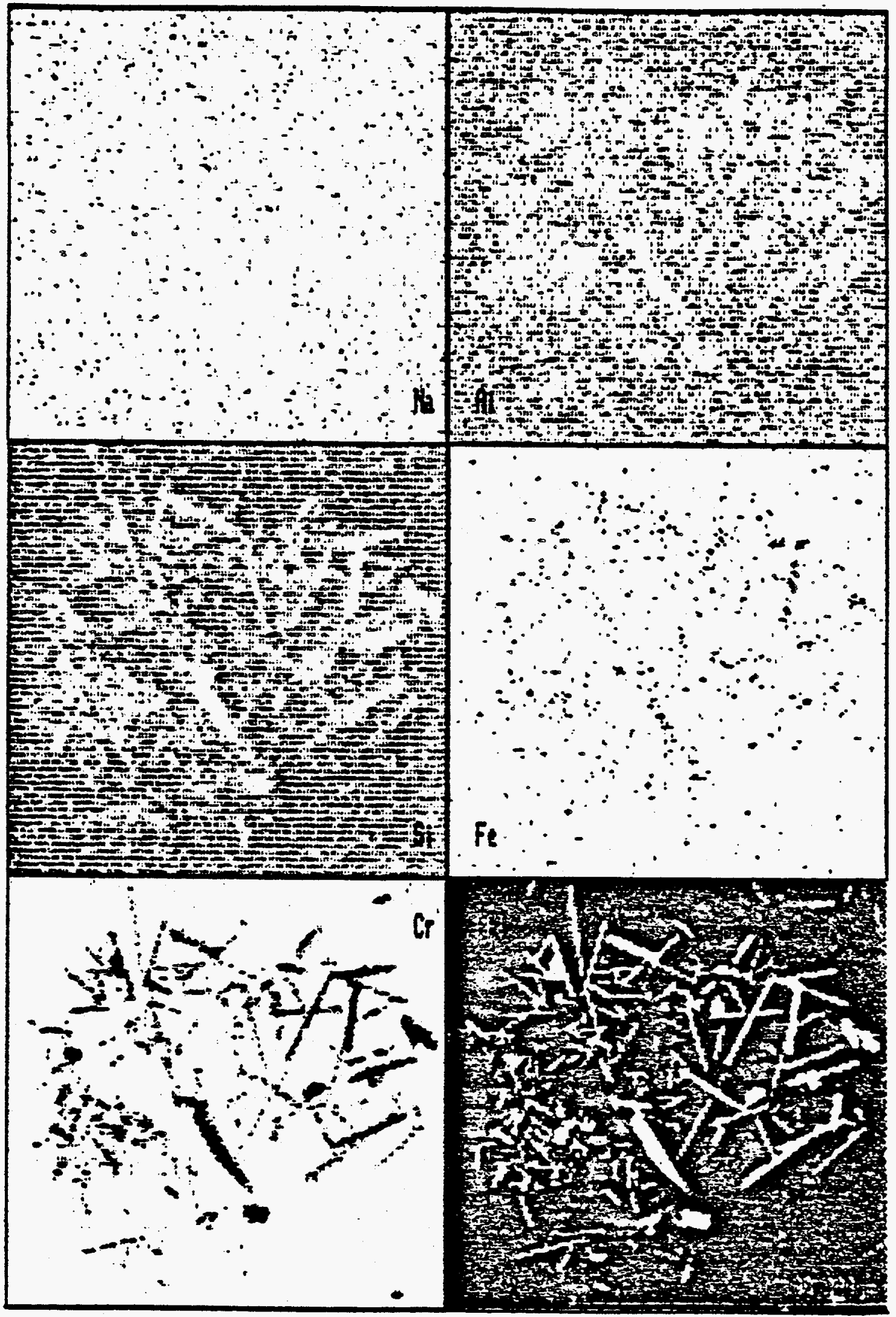

Figure 4-18: Glass 1/5. Eskolaite Crystal Cluster. X-Ray Distribution of $\mathrm{Na}, \mathrm{Al}, \mathrm{Si}, \mathrm{Fe}$ and $\mathrm{Cr}$ in the Area Shown in Figure 4-17. Normal Section (16-20 $\mathrm{mm})$. Microscope Camscan 4-DV, Programme MAPPING. 
There were detected also transition particles between both previous types of texture motives irespective figures are in Annex $\mathrm{C} 2$ and $\mathrm{C3}$ ).

In the whole sample area isolated crystals of eskolaite were observed. Their shape is documented in Figures 4-19 and 4-20. The distribution of selected elements in the area of separate crystals indicates the presence of small concentration of Fe (Figure 4-21). The results of the statistical evaluation of local analyses of these crystals and surrounding glass (matrix) are summarized in Table 4-7.

No substantial diference was found between bottom, centre and surface of the samples.

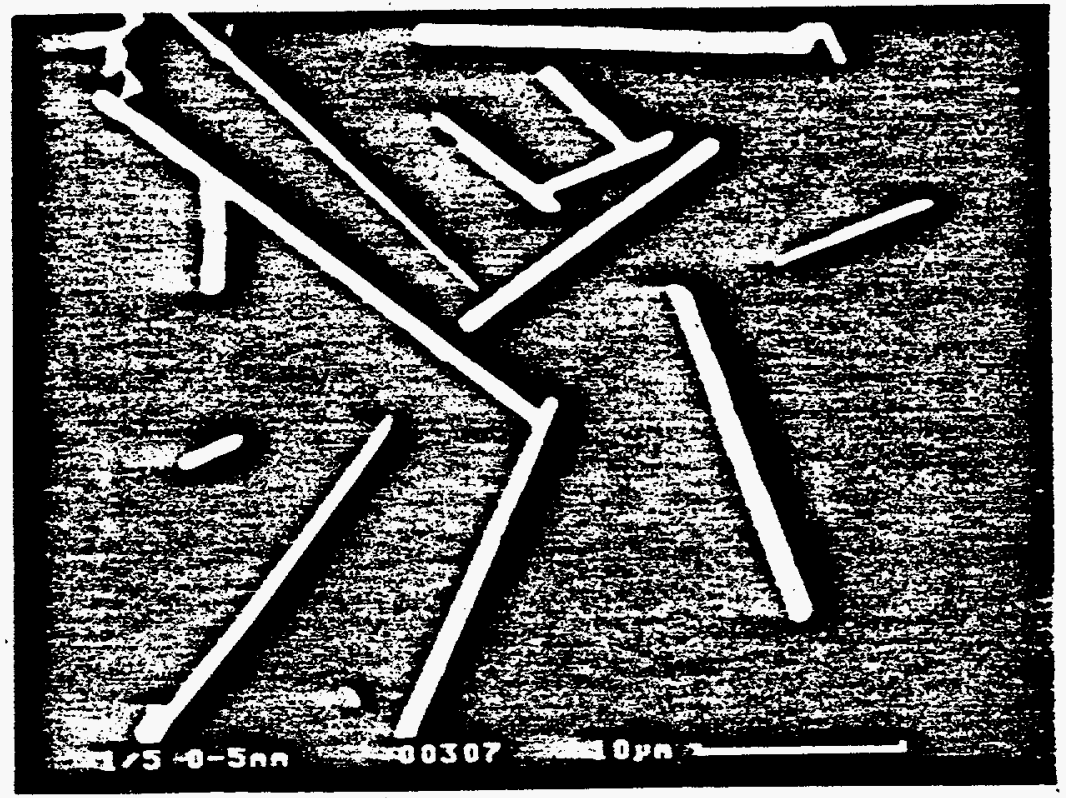

Figure 4-19: Glass 1/5. Isolated Eskolaite Crystals. Normal Section $(0-5 \mathrm{~mm})$. Microscope Camscan 4-DV, BSE. 


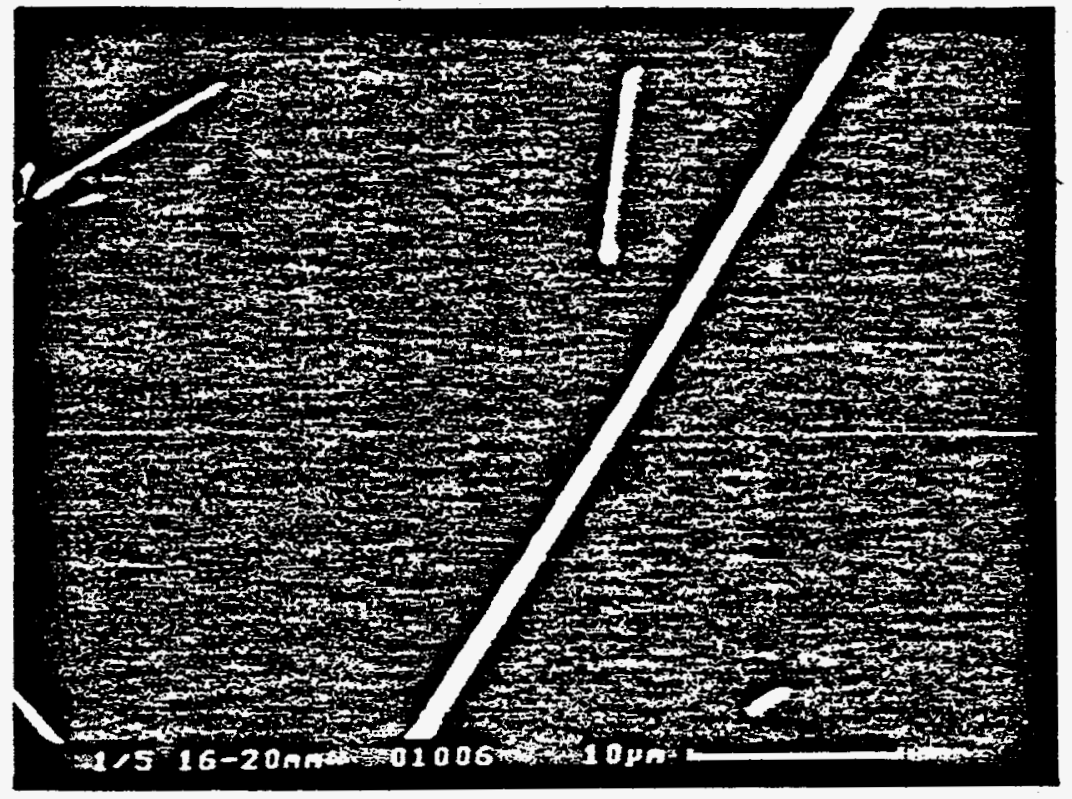

Figure 4-20: Glass 1/5. Isolated Eskolaite Crystals. Normal. Section $(16-20 \mathrm{~mm})$. Microscope Camscan 4-DV, BSE. 


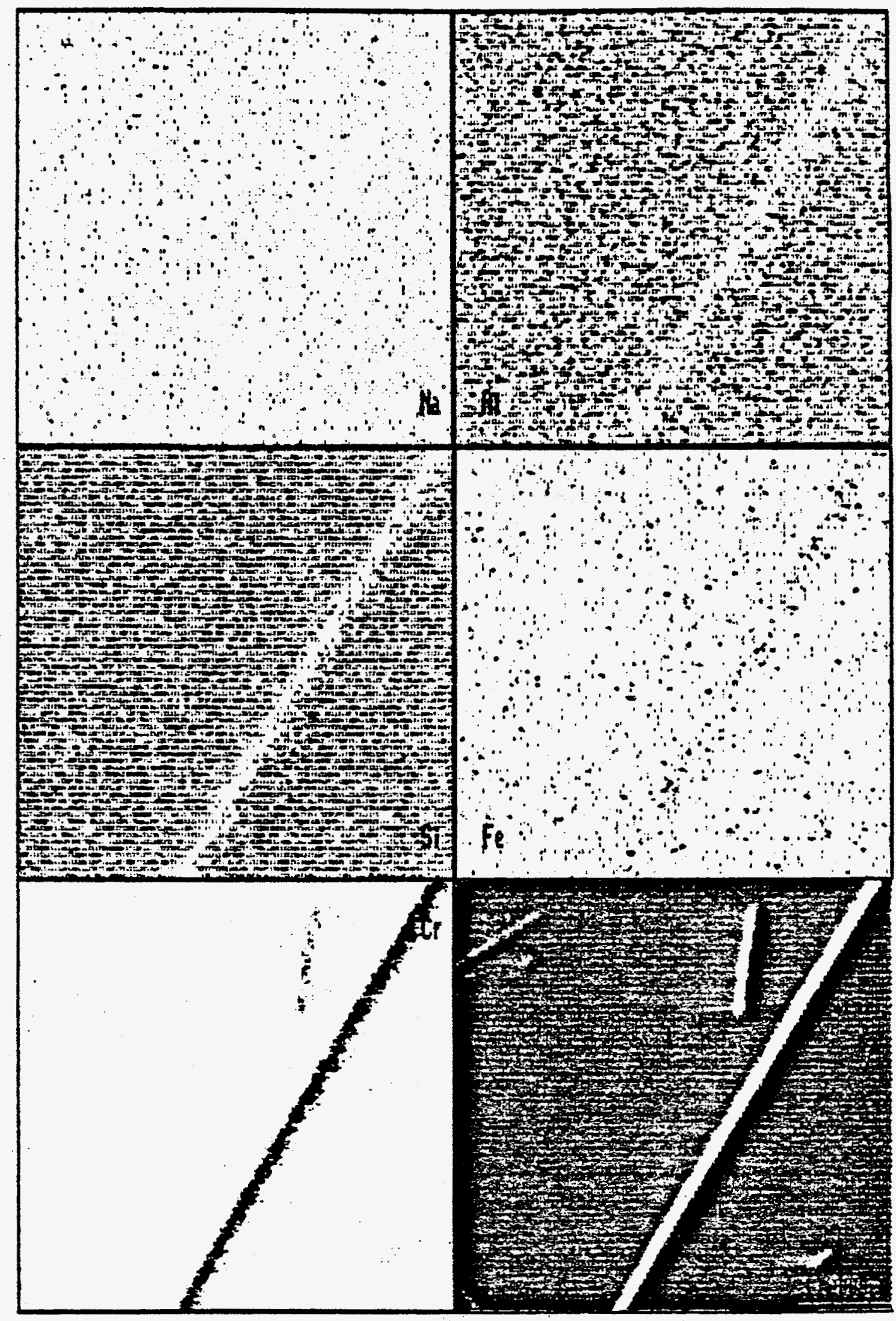

Figure 4-21: Glass 1/5. Isolated Eskolaite Crystals. X-Ray Distribution of $\mathrm{Na}, \mathrm{Al}, \mathrm{Si}, \mathrm{Fe}$ and $\mathrm{Cr}$ in the Range Shown in Figure 4-20. Normal section $(16-20 \mathrm{~mm})$. Microscope Camscan 4-DV, Programme MAPPING. 


\section{Glass $2 / 5$}

In Figure 4-22 a Glass 2/5 texture is documented at a small magnification. The difference in texture character between bottom, centre and surface was not found at this magnification..

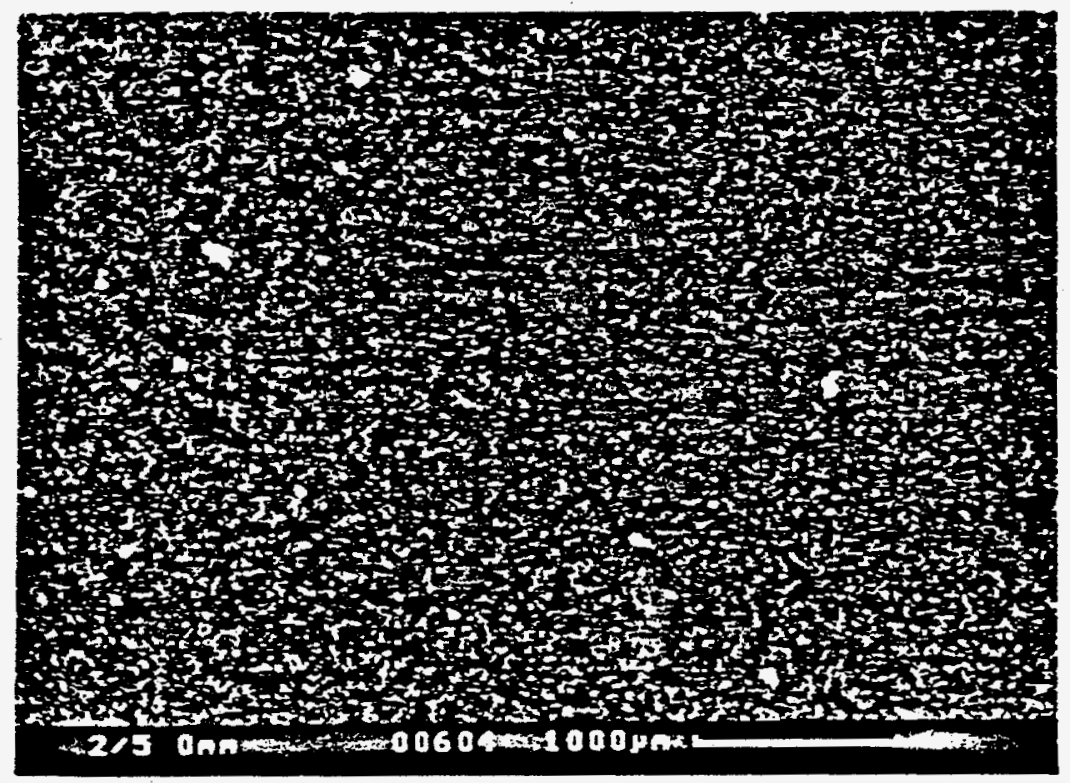

Figure 4-22: Glass 2/5. Section View of the Bottom Block Zone $(0 \mathrm{~mm})$. Microscope CamScan 4-DV, BSE.

The differences in glass texture motives in dependence on the distance from the bottom block area can be seen using a greater magnification (see Figures 4-23,4-24,4-25, 4-26). 


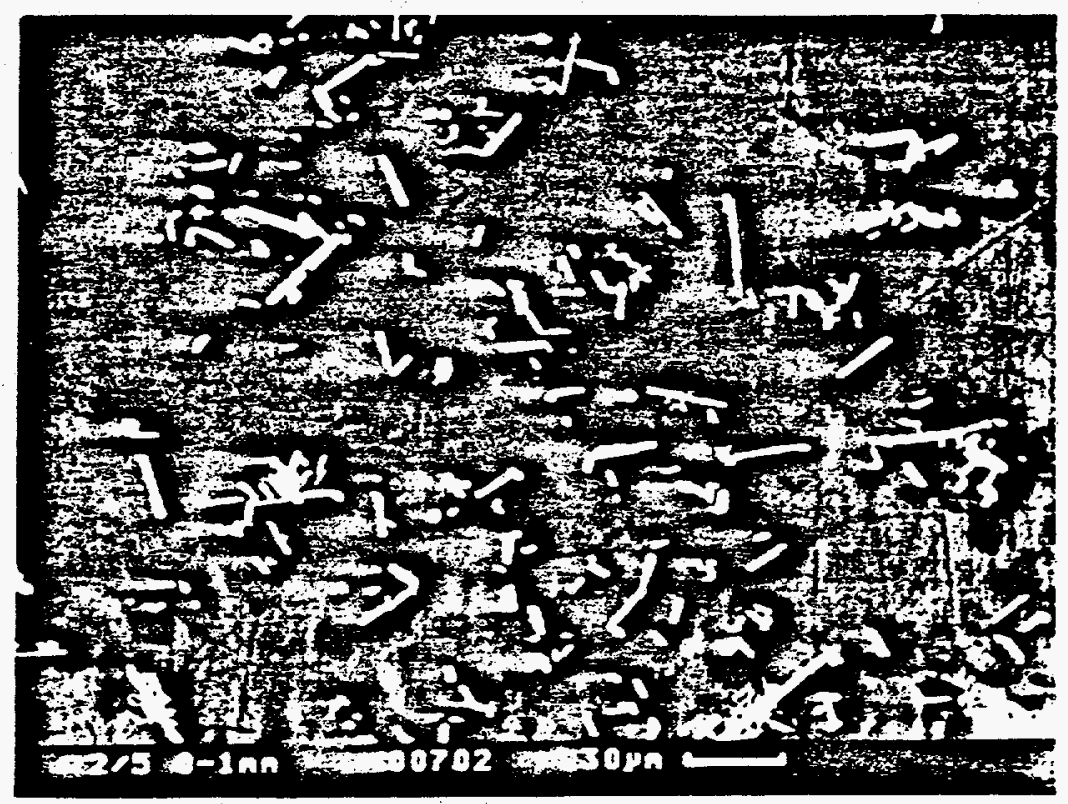

Figure 4-23: Glass 2/5. Detail of the Section of the surface Layer of the Bottom Block Zone $(0-1 \mathrm{~mm})$. Microscope Camscan 4-DV, BSE.

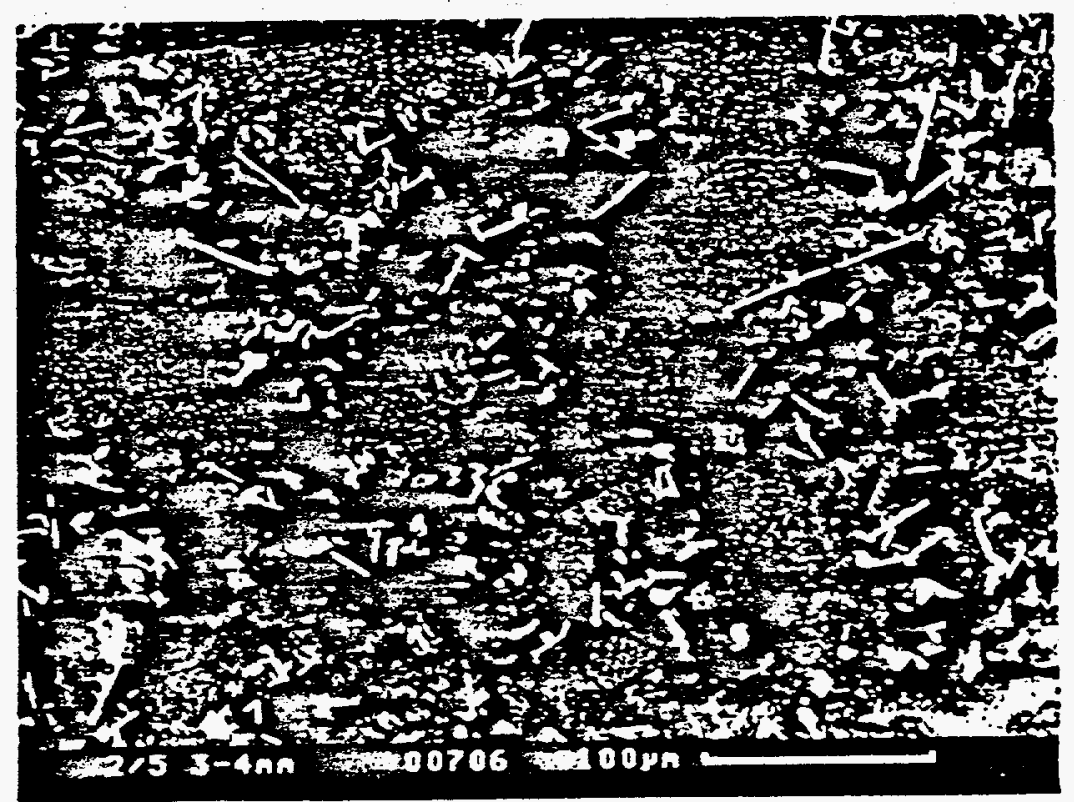

Figure 4-24: Glass 2/5. Detail of the section in the Area Between Bottom zone and Central Block Part (3-4 mm). Microscope Camscan 4-DV, BSE. 


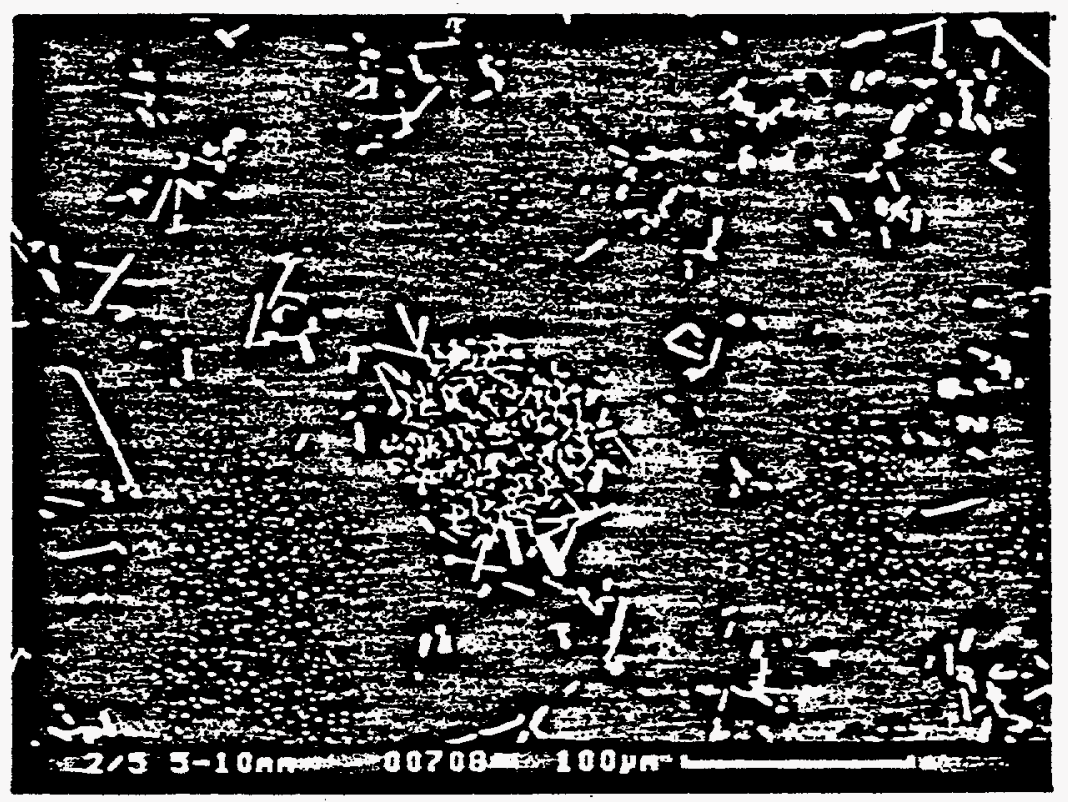

Figure 4-25: Glass 2/5. Detail of the Section in the Central Block Part $(5-10 \mathrm{~mm})$. Microscope Camscan 4-DV, BSE.

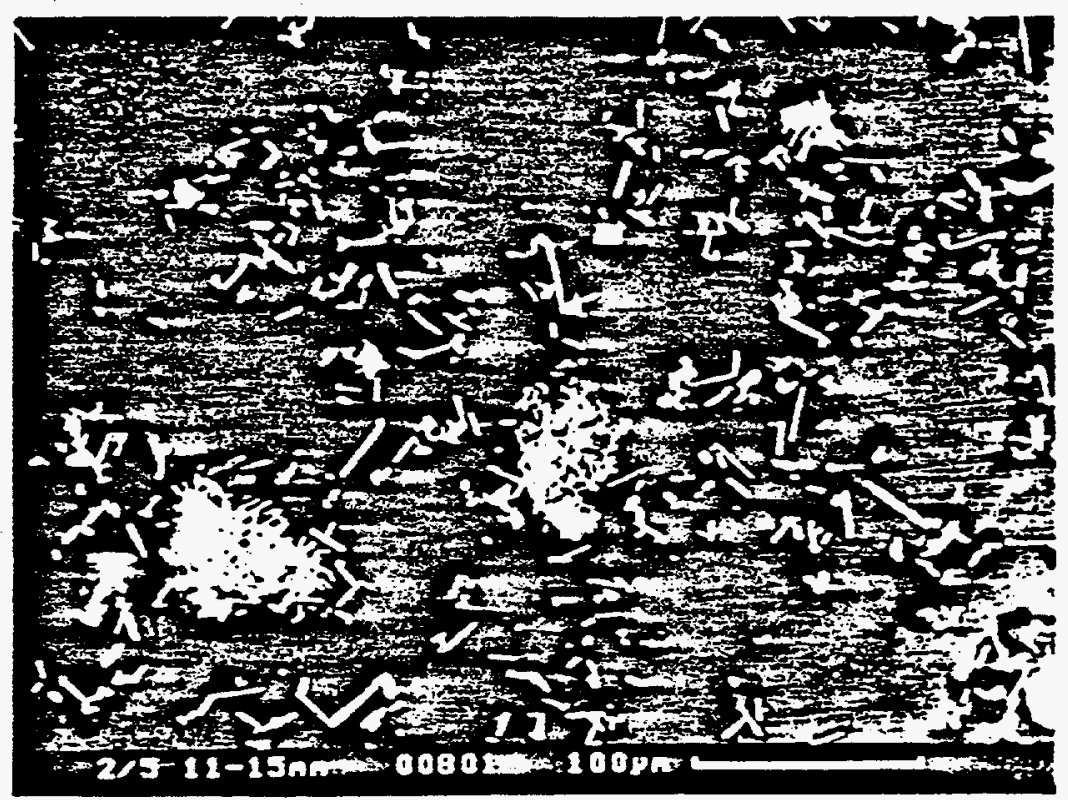

Figure 4-26: Glass 2/5. Detail of the section of the Central Block Part (11-15 mm). Microscope Camscan 4-DV, BSE. 
An intensive matrix crystalization not only around isolated crystals of eskolaite and their clusters but in the whole area is documented in the bottom zone. The presence of cracks and (exceptionally in the surface layer of the bottom zone) small spherical particles in matrix, which are probably spinel-type crystals (see below), is typical. On the other hand, in the central and surface part of the block is the eucryptite crystallization limited to a tight closeness of isolated crystals and eskolaite crystal clusters. In the central part also small spherical particles are seen, their number is, however, lower than in the bottom zone. Their number decreases further on in the surface part.

Clusters of needle shaped or thin tabular eskolaite crystals (Figures 4-27, 4-28, 4-30) are typical texture motives presented in the whole sample area.

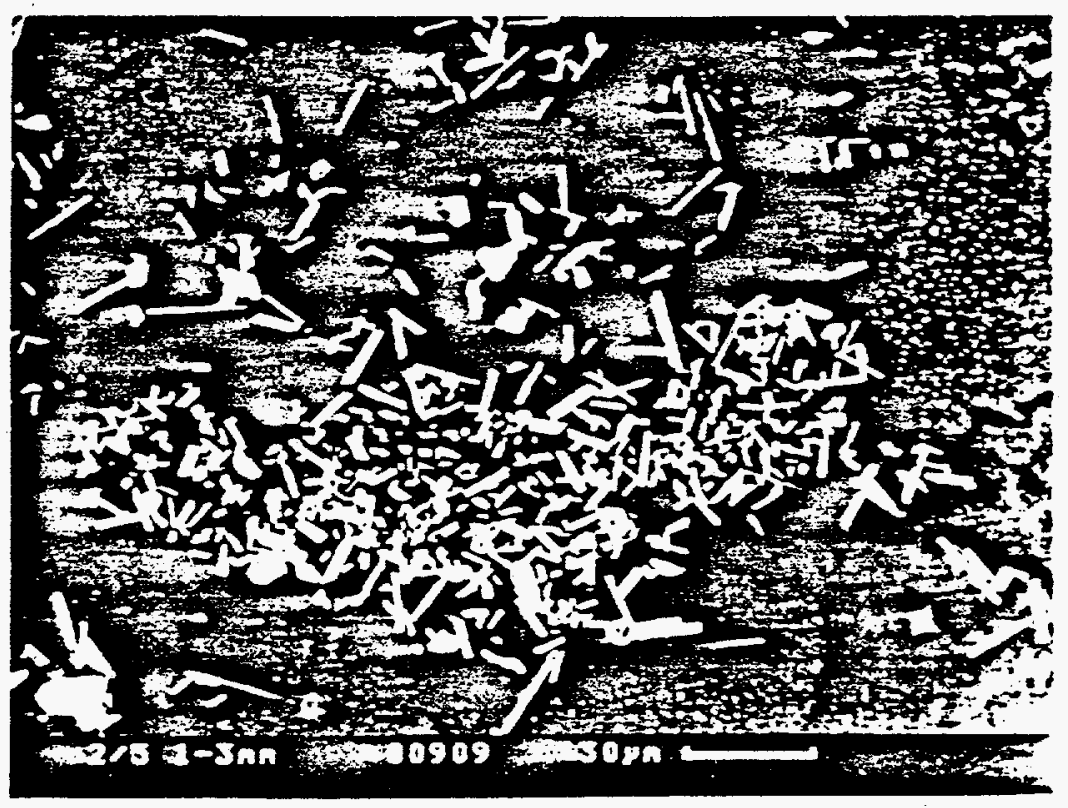

Figure 4-27: Glass 2/5. Eskolaite Crystal Cluster. Normal Section $(1-3 \mathrm{~mm})$. Microscope Camscan 4-DV, BSE. 


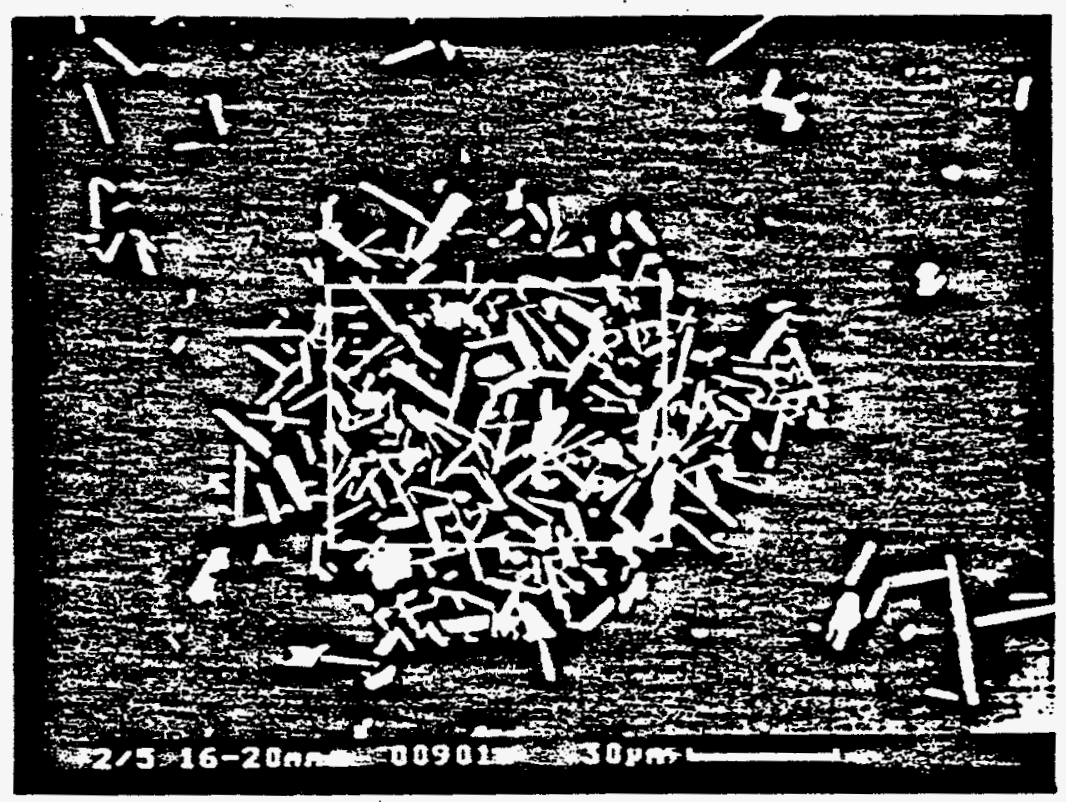

Figure 4-28: Glass 2/5. Eskolaite Crystal Cluster with Marked Surface Analysis. Normal Section (16-20 mm). Microscope Camscan 4-DV, BSE.

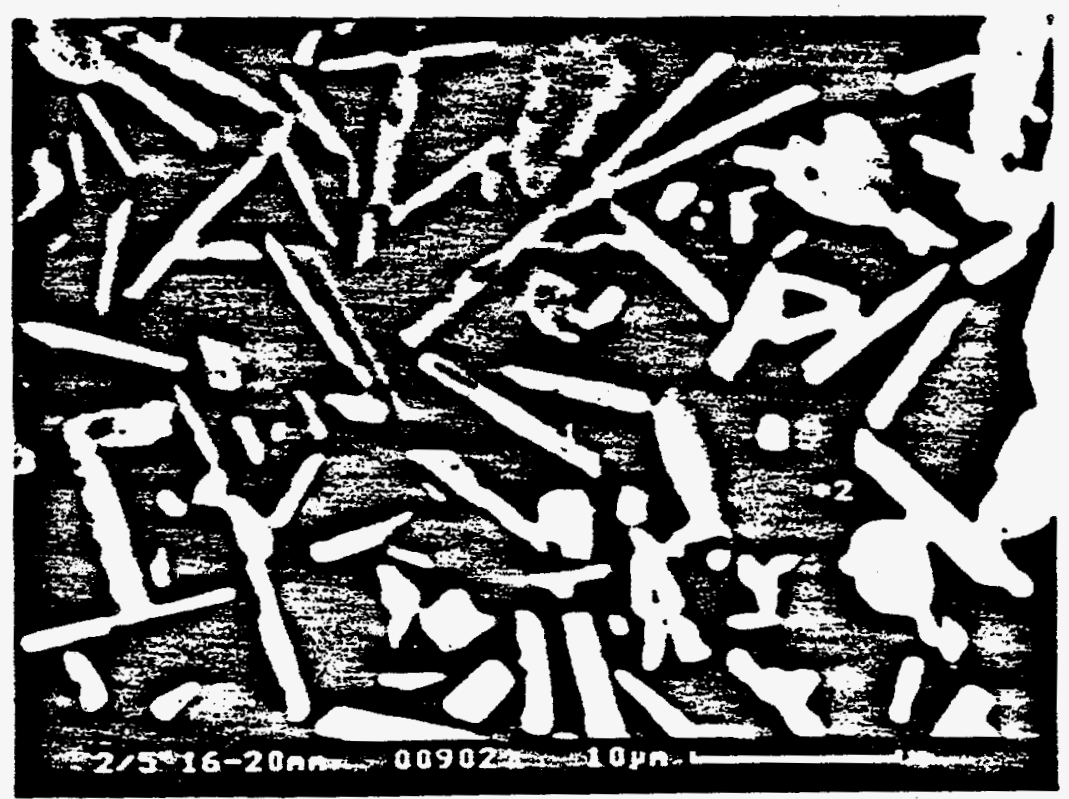

Figure 4-30: Glass 2/5. Eskolaite Crystal Cluster (Detail) with Marked Iocal Analyses of the Crystal (Point 1) and the Intercrystalline Space (Point 2). Normal section (16-20 mm). Microscope Camscan 4-DV, BSE. 


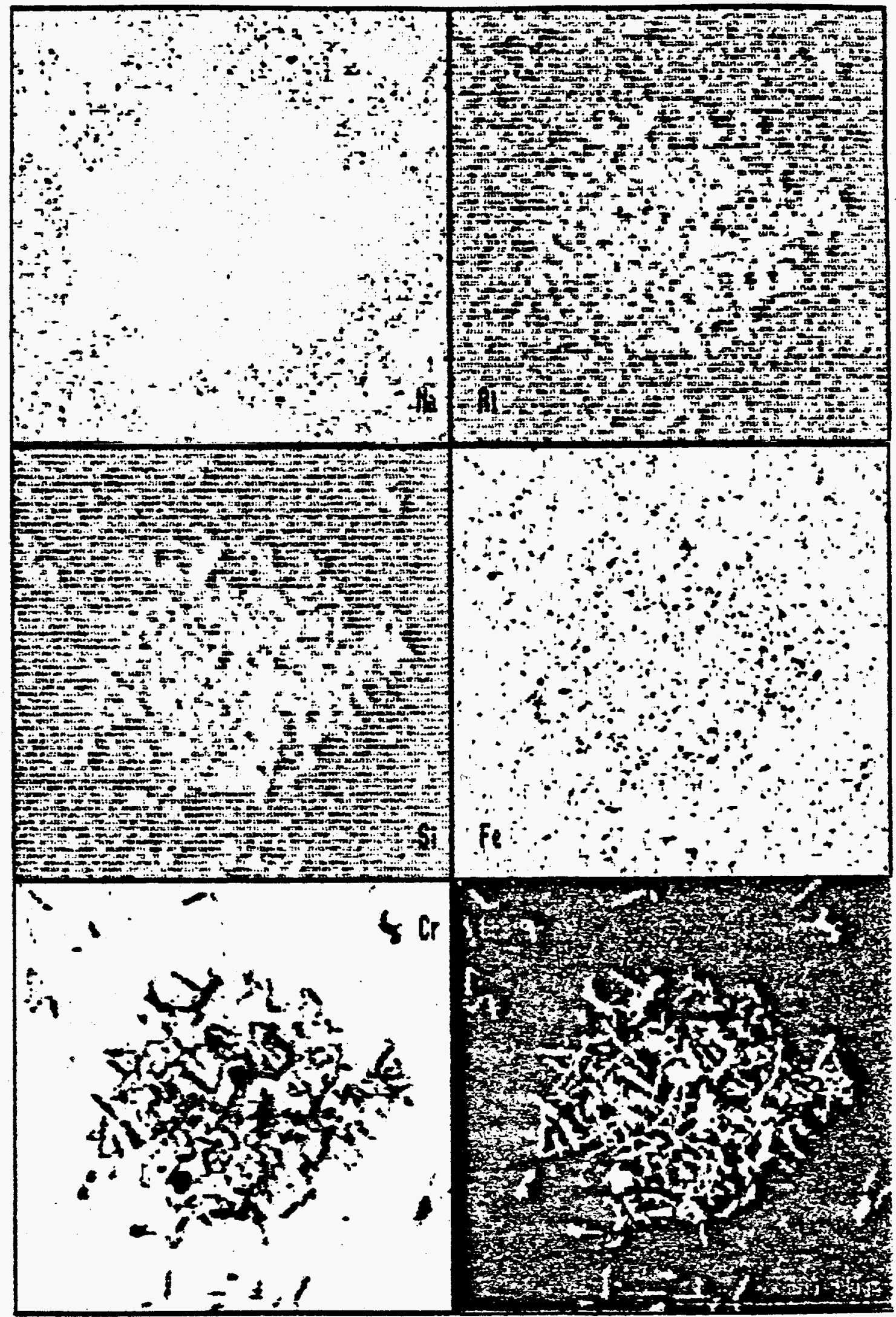

Figure 4-29: Glass 2/5. Eskolaite Crystal Cluster. X-Ray Distribution of $\mathrm{Na}, \mathrm{AI}, \mathrm{Si}, \mathrm{Fe}$ and $\mathrm{Cr}$ in the Area Shown in Figure 4-28. Normal section (16-20 mm). Microscope Camscan 4-DV, Programme MAPPING. 


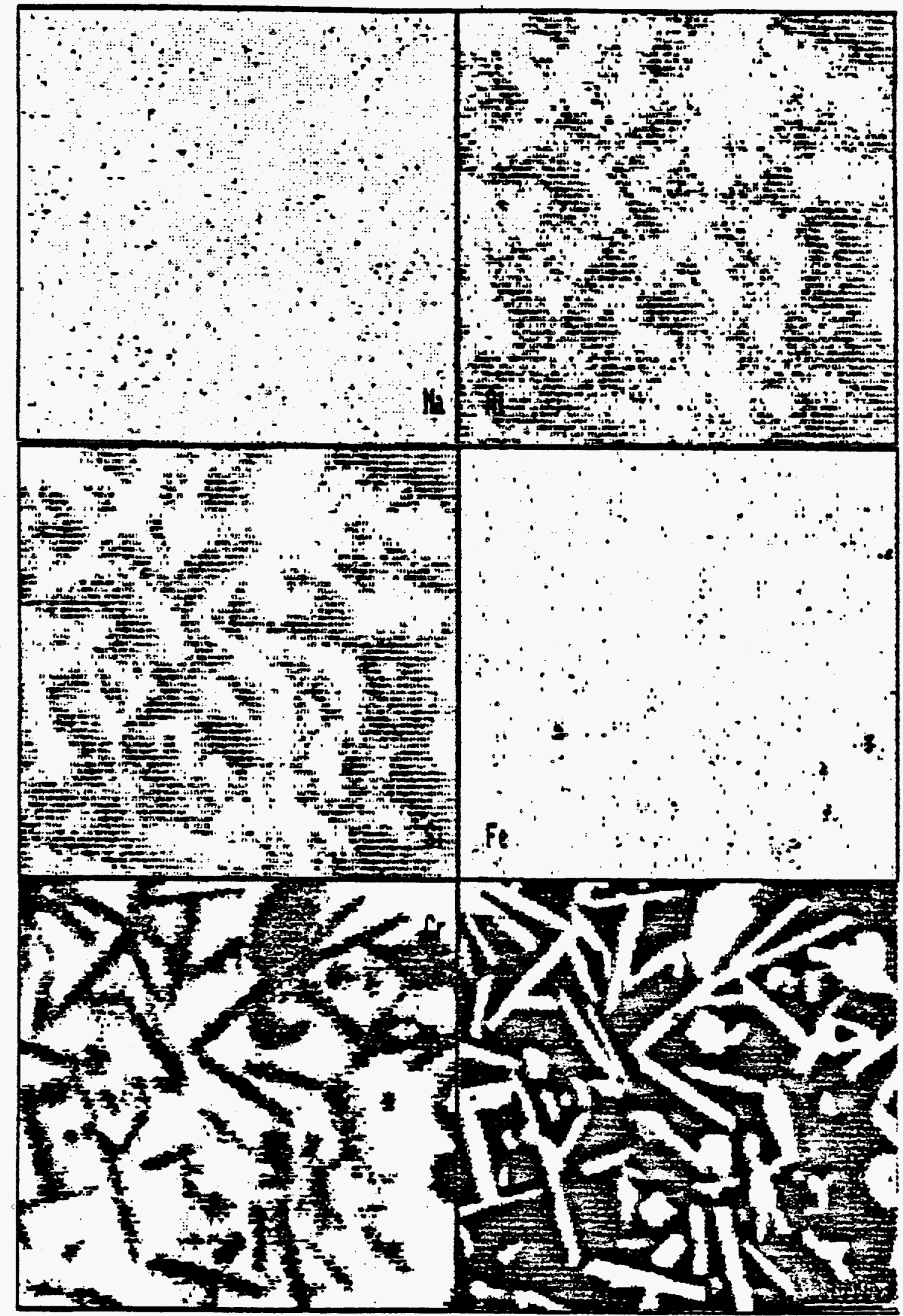

Figure 4-31: Glass 2/5. Eskolaite Crystal Cluster (Detail). X-Ray Distribution of $\mathrm{Na}, \mathrm{Al}, \mathrm{Si}, \mathrm{Fe}$, and $\mathrm{Cr}$ in the Area Shown in Figure 4-30. Normal section (16-20 mm). Microscope Camscan 4-DV, Programme MAPPING. 
The results of the area analysis of the clusters from the bottom zone and from the central to surface part of the sample are summarized in Table 4-9. (The method and dimensions of the area analysis are seen in Figure 4-28). Distributions of selected elements in the area of these clusters are shown in Figures 4-29 and 4-31. The area analyses were completed by local analyses of eskolaite crystals in clusters and intercrystalline space. The analysis of eskolaite crystals from clusters did not show any dependence on a distance from the bottom block area and, therefore, they were processed together. The results of intercrystalline space analysis in crystal clusters vary in a broad range of chemical compositions. Therefore, it was not possible to do serious statistical evaluation and the results are not presented.

Table 4-9: A Summary of Area Analyses Results of Eskolaite Crystal Clusters in the Sample of Quenched and Annealed Glass $2 / 5$ (IINK AN 10000, Expressed in wt. 8 )

\begin{tabular}{|c|c|c|c|c|}
\hline $\begin{array}{l}\text { Analyzed } \\
\text { Area }\end{array}$ & \multicolumn{2}{|c|}{$\begin{array}{c}\text { Area Analysis } \\
1-3 \mathrm{~mm}\end{array}$} & \multicolumn{2}{|c|}{$\begin{array}{c}\text { Area Analysis } \\
6-20 \mathrm{~mm}\end{array}$} \\
\hline $\mathbf{n}$ & \multicolumn{2}{|c|}{5} & \multicolumn{2}{|c|}{15} \\
\hline & $\overline{\mathbf{x}}$ & $\sigma$ & $\overline{\boldsymbol{x}}$ & $\sigma$ \\
\hline $\begin{array}{l}\mathrm{Na}_{2} \mathrm{O} \\
\mathrm{Al}_{2} \mathrm{O}_{3} \\
\mathrm{SiO}_{2} \\
\mathrm{Fe}_{2} \mathrm{O}_{3} \\
\mathrm{Cr}_{2} \mathrm{O}_{3} \\
\mathrm{MnO}_{2} \\
\mathrm{NiO} \\
\mathrm{ZnO} \\
\mathrm{CaO}\end{array}$ & $\begin{array}{c}4,9 \\
19,7 \\
27,7 \\
2,8 \\
34,0 \\
a \\
a \\
a \\
0,30\end{array}$ & $\begin{array}{l}0,5 \\
1,6 \\
3,1 \\
0,3 \\
5,2\end{array}$ & $\begin{array}{c}1,7 \\
18,9 \\
24,7 \\
3,1 \\
41,1 \\
a \\
a \\
a \\
0,24\end{array}$ & $\begin{array}{l}0,6 \\
1,3 \\
2,6 \\
0,6 \\
5,6\end{array}$ \\
\hline sum & 89,4 & & 89,74 & \\
\hline
\end{tabular}

Notes: see Table 4-7.

In the whole sample area the dispersed eskolaite crystals were observed. Their appearance is shown in Figures 4-32 to 4-34. A number of results (e.g. the point 1 in the Figure 4-32) was gained by the local analysis of such crystals. 


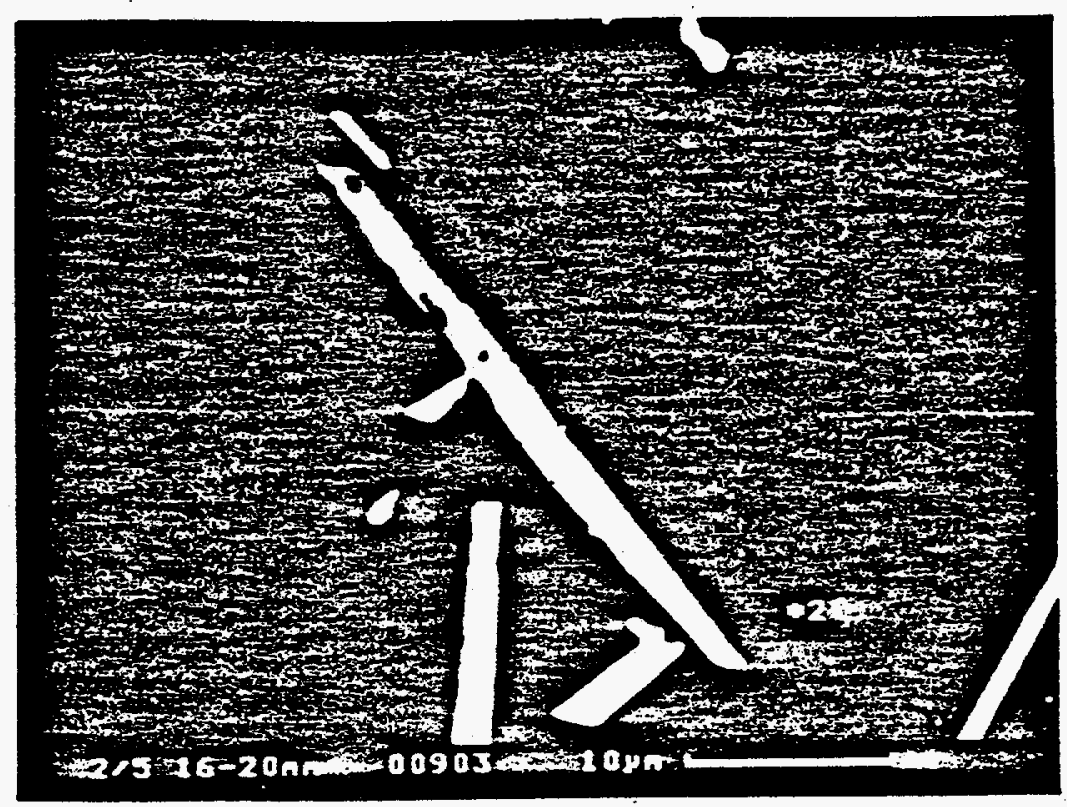

Figure 4-32: Glass 2/5. Isolated Eskolaite Crystals with Marked Local Analyses of Crystal (Point 1) and Matrix (Point 2). Normal Section $(16-20 \mathrm{~mm}$ ) . Microscope Camscan 4-DV, BSE.

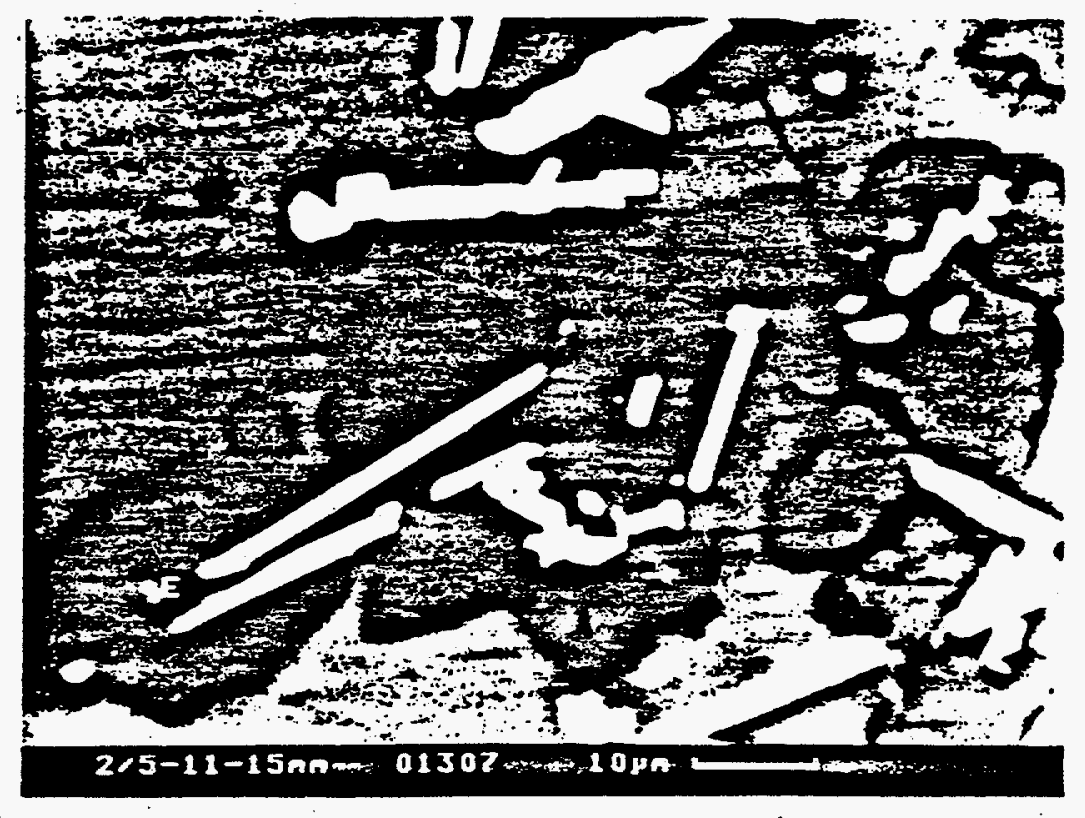

Figure 4-33: Glass 2/5. Isolated Eskolaite Crystals with Marked Local Analysis of Eucryptite Crystal (Point E). Normal Section (11-15 mm). Microscope Camscan 4-DV, BSE. 


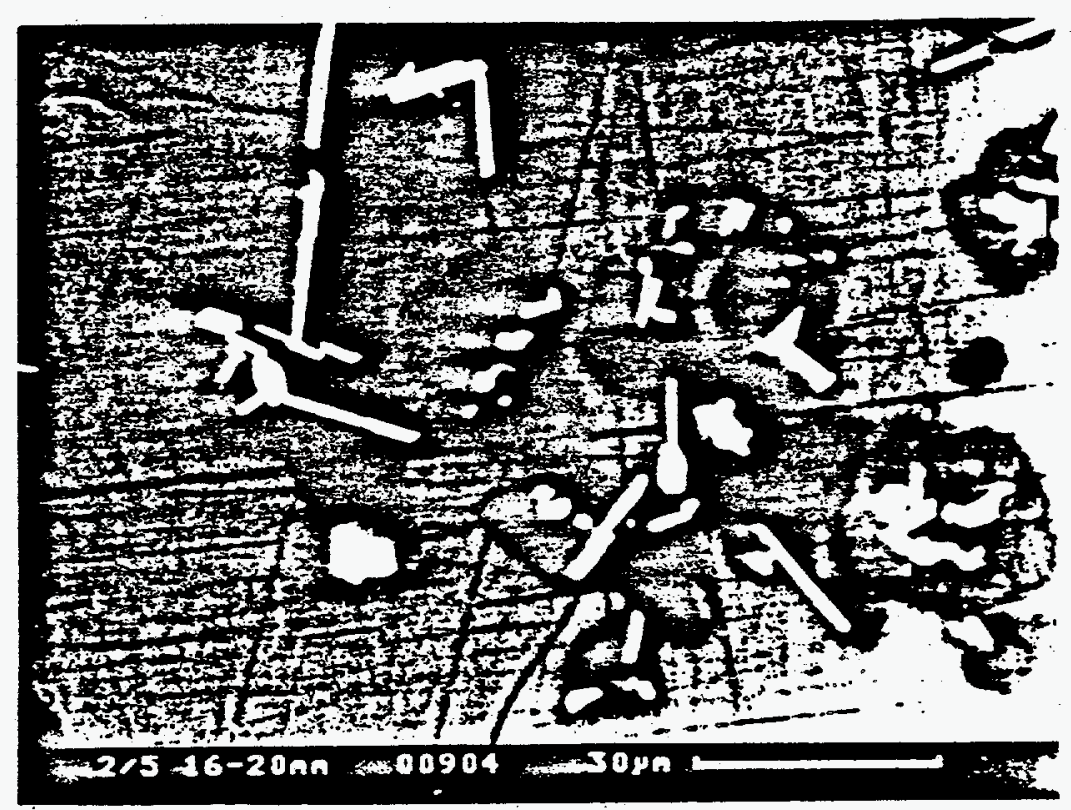

Figure 4-34: Glass 2/5. Isolated Eskolaite Crystals with Eucryptite Crystals. Normal section (16-20mm) Microscope Camscan 4-DV, BEI.

The dependence of chemical composition of the crystals on the distance from the bottom block area was not statistically documented and, therefore, all analyses were processed together (see Table 4-10). 
Table 4-10: A Summary of Analyses Results of Eskolaite Crystals from Clusters and Isolated Crystals from a sample of Quenched and Annealed Glass $2 / 5$

(LINK AN 10000, Expressed in wt. *)

\begin{tabular}{|c|c|c|c|c|}
\hline $\begin{array}{l}\text { Analyzed } \\
\text { Area }\end{array}$ & \multicolumn{2}{|c|}{$\begin{array}{l}\text { Crystals in } \\
\text { Clusters }\end{array}$} & \multicolumn{2}{|c|}{$\begin{array}{l}\text { Isolated } \\
\text { Crystals }\end{array}$} \\
\hline $\mathbf{n}$ & \multicolumn{2}{|c|}{8} & \multicolumn{2}{|c|}{20} \\
\hline & $\overline{\mathbf{x}}$ & $\sigma$ & $\overline{\boldsymbol{x}}$ & 0 \\
\hline $\begin{array}{l}\mathrm{Na}_{2} \mathrm{O} \\
\mathrm{Al}_{2} \mathrm{O}_{3} \\
\mathrm{SiO}_{2} \\
\mathrm{Fe}_{2} \mathrm{O}_{3} \\
\mathrm{Cr}_{2} \mathrm{O}_{3} \\
\mathrm{MnO}_{2} \\
\mathrm{NiO} \\
\mathrm{znO}\end{array}$ & $\begin{array}{c}a \\
6,7 \\
0,8 \\
2,7 \\
86,8 \\
a \\
a \\
a\end{array}$ & $\begin{array}{l}1,4 \\
0,5 \\
1,7 \\
2,5\end{array}$ & $\begin{array}{c}a \\
6,0 \\
1,0 \\
4,9 \\
87,4 \\
a \\
a \\
a\end{array}$ & $\begin{array}{l}1,4 \\
0,8 \\
0,7 \\
2,9\end{array}$ \\
\hline sum & 97.0 & & 99,3 & \\
\hline
\end{tabular}

Notes: see Table 4-7.

On the basis of photodocumentation, local analyses and distributions of selected elements the presence of other areas with chemical composition different from initial glass, especially near eskolaite crystals is evident. It was confirmed by results of $X$-ray diffraction analysis (see section 4.2.1.1. of this Report) and local analyses that these areas contain crystalline phases: high temperature eucryptite IiAlsio 4 and nepheline $\mathrm{NaAlSiO}_{4}$. Crystals of the high temperature eucryptite are in the whole sample area. Their abundance is bonded to a closeness of eskolaite crystals in the central and surface sample part. on the other hand, in the bottom zone they appear also in matrix. In the bottom zore also nepheline was detected near the eskolaite crystals. Above mentioned facts are documented in Figures 4-33 to 4-37. 


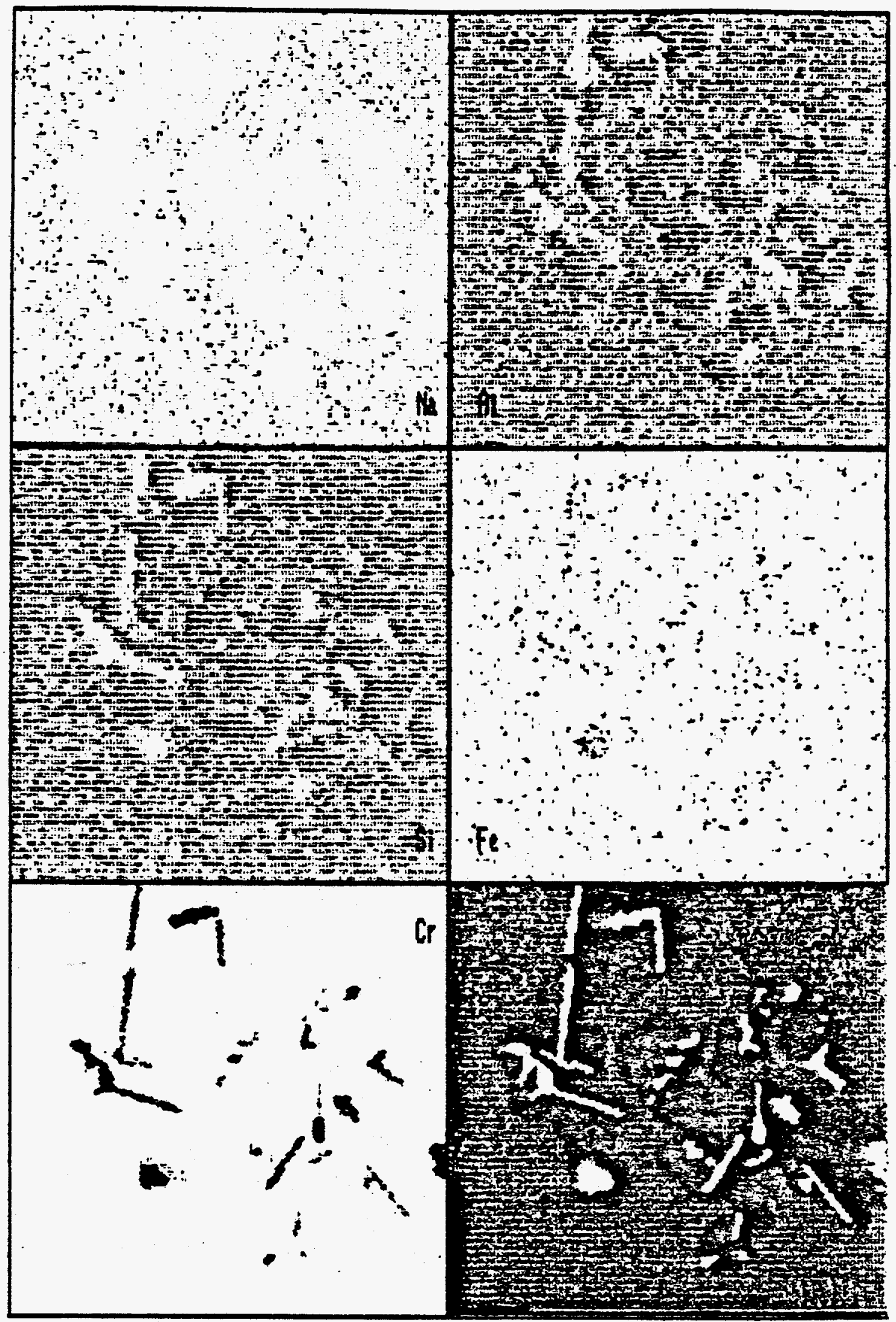

Figure 4-35: Glass 2/5. Isolated Eskolaite Crystals with Eucryptite Crystals. X-Ray Distribution of $\mathrm{Na}, \mathrm{Al}$, $\mathrm{Si}, \mathrm{Fe}$, and $\mathrm{Cr}$ in the Area Shown in Figure 4-34. Normal Section $(16-20 \mathrm{~mm})$. Microscope Camscan 4-DV, Programme MAPPING. 


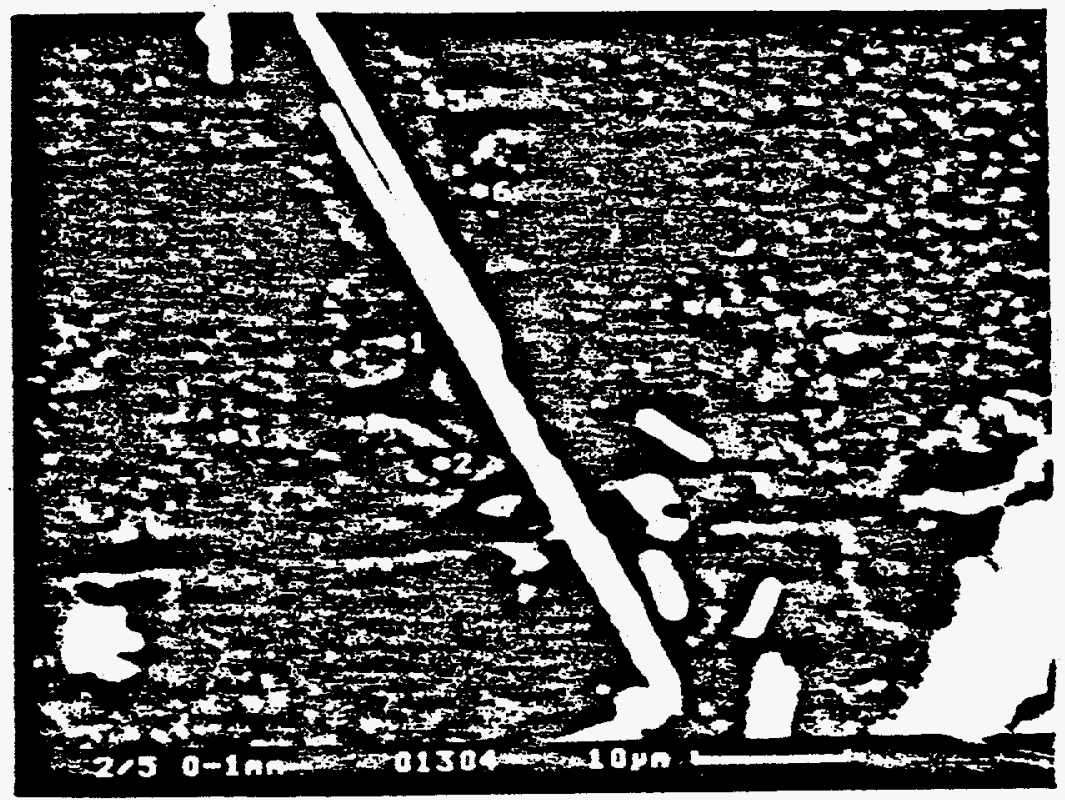

Figure 4-36: Glass 2/5. Isolated Eskolaite Crystals with Eucryptite (Points 3 and 4 ) and Nepheline (Points 1. 2, 5 and 6) Crystals. Normal section $(0-1 \mathrm{~mm})$. Microscope Camscan 4-DV, BSE. 


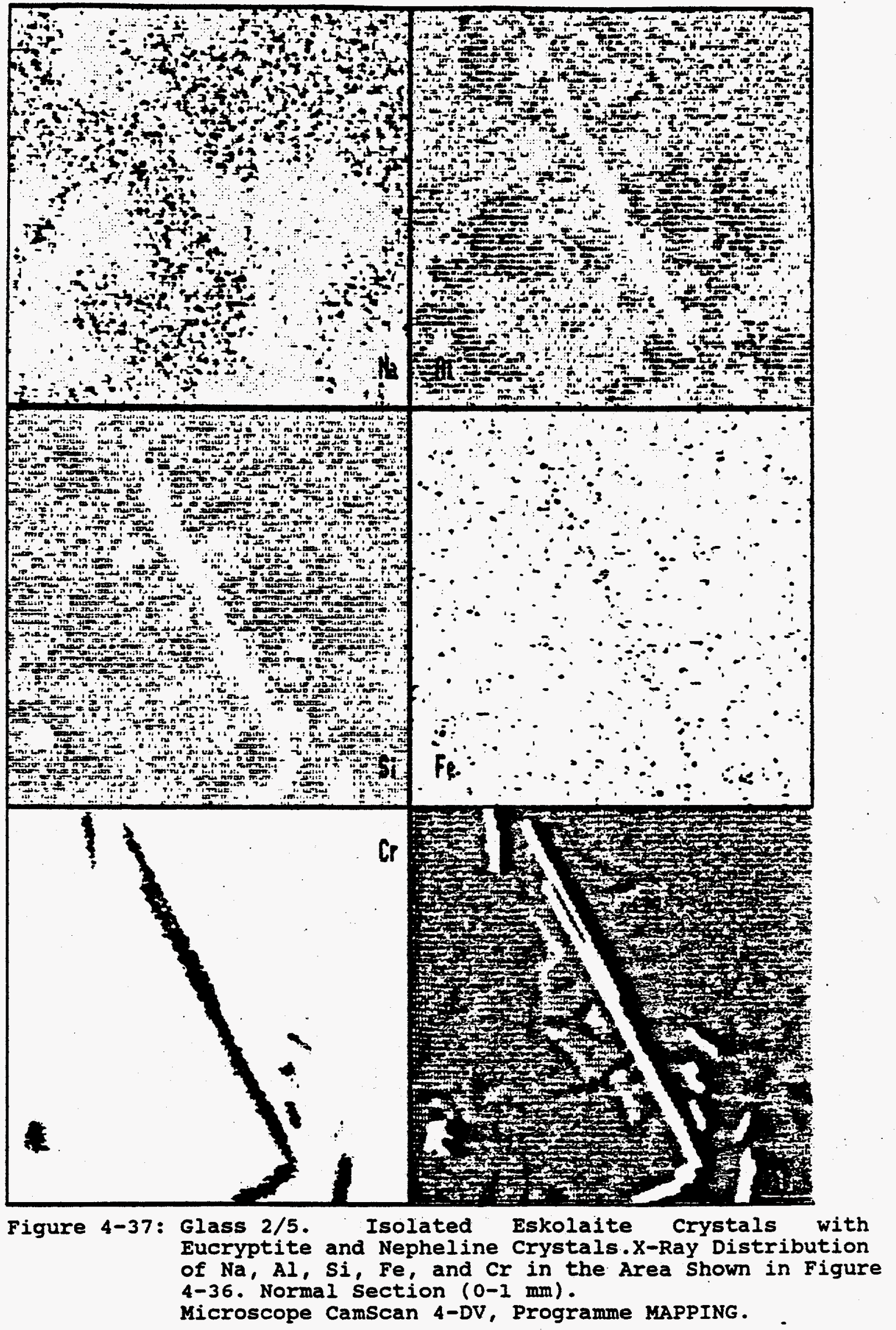


The results of high temperature eucryptite and nepheline analyses are summarized in Table 4-11.

Table 4-11: A Sumary of Local Analyses Results of Eucryptite and Nepheline Crystals in Glass 2/5 (IINK AN 10000, Expressed in wt. \&)

\begin{tabular}{|c|c|c|c|c|}
\hline $\begin{array}{l}\text { Analyzed } \\
\text { Area }\end{array}$ & \multicolumn{2}{|c|}{$\begin{array}{l}\text { Eucryptite } \\
0-20 \mathrm{~mm}\end{array}$} & \multicolumn{2}{|c|}{$\begin{array}{l}\text { Nepheline } \\
0-3 \mathrm{~mm}\end{array}$} \\
\hline $\boldsymbol{\Omega}$ & \multicolumn{2}{|c|}{15} & \multicolumn{2}{|c|}{8} \\
\hline . & $\overline{\mathbf{x}}$ & $\sigma$ & $\bar{x}$ & $\sigma$ \\
\hline $\begin{array}{l}\mathrm{Na}_{2} \mathrm{O} \\
\mathrm{Al}_{2} \mathrm{O}_{3} \\
\mathrm{SiO}_{2} \\
\mathrm{Fe}_{2} \mathrm{O}_{3} \\
\mathrm{Cr}_{2} \mathrm{O}_{3} \\
\mathrm{MnO}_{2} \\
\mathrm{NiO} \\
\mathrm{znO} \\
\mathrm{CaO} \\
\mathrm{K}_{2} \mathrm{O}\end{array}$ & $\begin{array}{l}a \\
38,7 \\
50,7 \\
1,1 \\
a \\
a \\
a \\
a \\
a \\
a \\
\end{array}$ & $\begin{array}{l}1,2 \\
1,9 \\
0,2\end{array}$ & $\begin{array}{l}18,6 \\
32,2 \\
46,9 \\
1,8 \\
1,2 \\
0,47 \\
a \\
a \\
a \\
0,37\end{array}$ & $\begin{array}{l}0,3 \\
0,7 \\
1,5 \\
0,2 \\
0,2 \\
0,17 \\
\\
0,06\end{array}$ \\
\hline sum & 90,5 & & 101,54 & \\
\hline
\end{tabular}

Notes: see Table 4-7.

The above mentioned small spherical particles which are probably crystals of spinel-type phase with a substitution of divalent and trivalent ions of nickel, zinc, manganese, iron, chromium and aluminium, are documented in Figures 4-38 and 4-39.

During the analyses (see Table 4-12 for results) the substantial differences in chemical composition in the bottom zone and in the surface part were found.

The interpretation of the results was difficult due to the great share of surrounding glass in the analysis and small size of respective particles. 


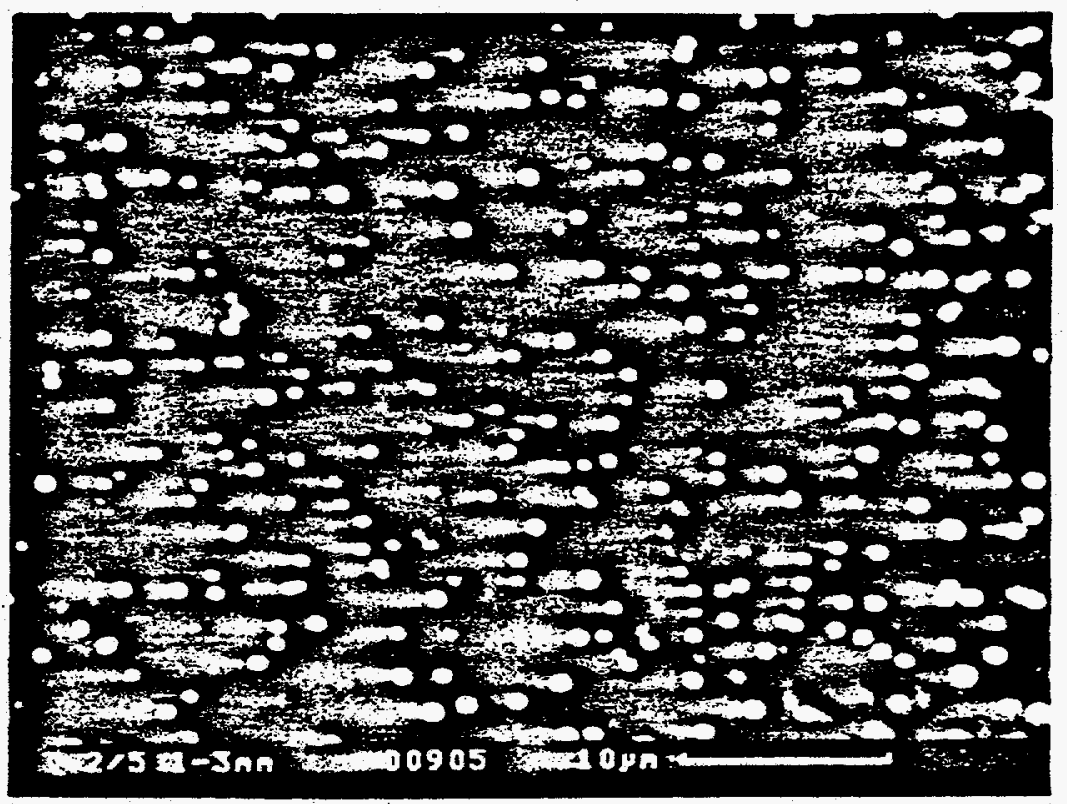

Figure 4-38: Glass 2/5. Small Spherical Particles. Normal Section $(1-3 \mathrm{~mm})$. Microscope Camscan 4-DV, BSE.

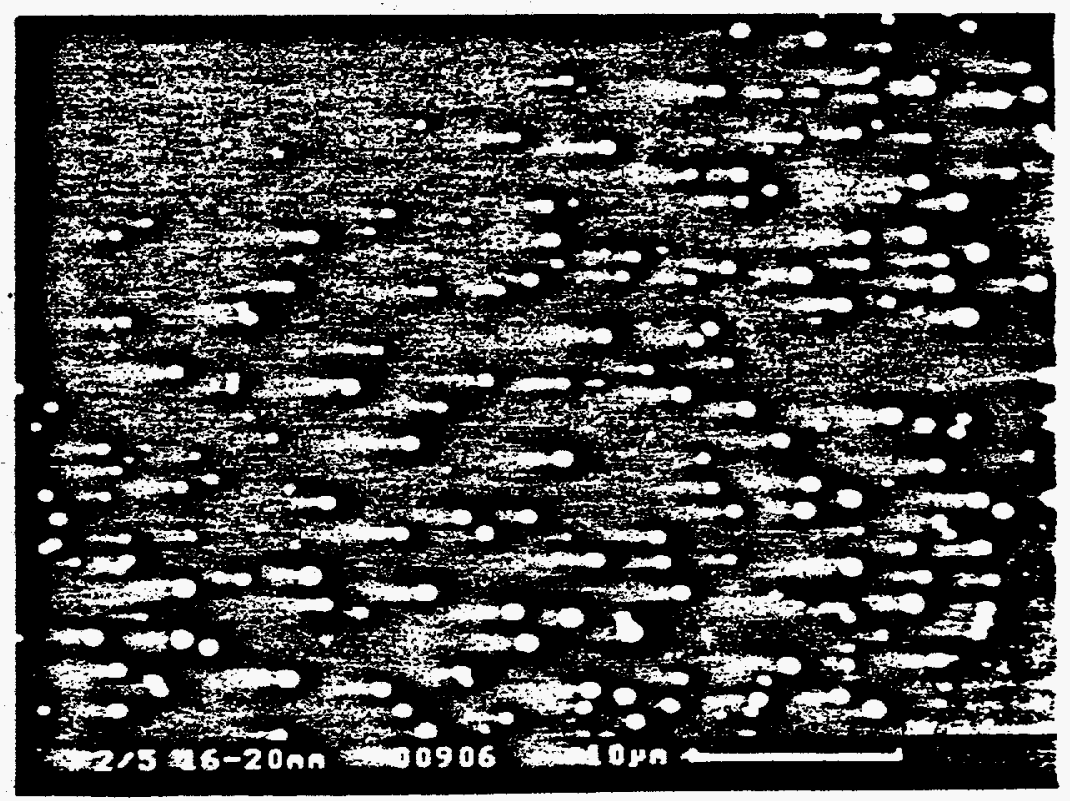

Figure 4-39: Glass 2/5. Small Spherical Particles. Normal Section $(16-20 \mathrm{~mm})$.

Microscope Camscan 4-DV, BSE. 
Table 4-12: A Summary of Local Analyses Results of Spherical Particles in the Sample of Quenched and Annealed Glass 2/5 (LINK AN 10000, Expressed in wt. \%)

\begin{tabular}{|c|c|c|c|c|}
\hline \multirow{3}{*}{$\frac{\begin{array}{l}\text { Analyzed } \\
\text { Area }\end{array}}{n}$} & \multicolumn{2}{|c|}{$\begin{array}{l}\text { Spherical Parti- } \\
\text { cles } 1-3 \mathrm{~mm}\end{array}$} & \multicolumn{2}{|c|}{$\begin{array}{l}\text { Spherical Parti- } \\
\text { cles } 16-20 \mathrm{~mm}\end{array}$} \\
\hline & \multicolumn{2}{|c|}{5} & \multicolumn{2}{|c|}{5} \\
\hline & $\overline{\mathbf{x}}$ & $\boldsymbol{\sigma}$ & $\overline{\mathbf{x}}$ & $\sigma$ \\
\hline $\begin{array}{l}\mathrm{Na}_{2} \mathrm{O} \\
\mathrm{Al}_{2} \mathrm{O}_{3} \\
\mathrm{SiO}_{2} \\
\mathrm{Fe}_{2} \mathrm{O}_{3} \\
\mathrm{Cr}_{2} \mathrm{O}_{3} \\
\mathrm{MnO}_{2} \\
\mathrm{NiO} \\
\mathrm{ZnO} \\
\mathrm{CaO}\end{array}$ & $\begin{array}{c}12,6 \\
22,9 \\
34,8 \\
7,9 \\
9,7 \\
3,9 \\
2,1 \\
2,8 \\
0,39\end{array}$ & $\begin{array}{l}3,3 \\
1,8 \\
1,4 \\
1,1 \\
1,8 \\
1,0 \\
0,4 \\
0,3 \\
0,16\end{array}$ & $\begin{array}{r}12,0 \\
24,6 \\
37,6 \\
9,6 \\
3,9 \\
4,6 \\
4,1 \\
2,1 \\
0,24\end{array}$ & $\begin{array}{l}1,1 \\
0,6 \\
1,7 \\
1,4 \\
0,8 \\
0,6 \\
0,7 \\
0,5 \\
0,06\end{array}$ \\
\hline sum & 97.09 & & 98,74 & \\
\hline
\end{tabular}

Notes: see Table 4-7.

The results were completed by local analyses of matrix among crystals in the dependence on distance from the bottom block area. The matrix composition does not depend on the position in the block (see Annex $C_{4}$ ).

Local analysis of selected places was carried out to estimate $\mathrm{B}_{2} \mathrm{O}_{3}$ content (wave dispersive analyzer Microspec HDX-2A). The results are summarized in Table 4-13.

Table 4-13: A Summary of Local Determinations Results of the $\mathrm{B}_{2} \mathrm{O}_{3}$ Content in Selected Areas of the Samples of Glasses $1 / 5$ and $2 / 5$ (Microspec wDX-2A)

\begin{tabular}{|c|c|}
\hline Analyzed Area & $\begin{array}{c}\mathrm{B}_{2} \mathrm{O}_{3} \text { Content } \\
{[\text { In wt. } \%]}\end{array}$ \\
\hline Glass $1 / 5$ - Matrix & 15.00 \\
Glass 2/5 - Matrix & 8.95 \\
Glass 2/5 - Eucryptite & $<2 \sigma$ \\
\hline
\end{tabular}


Note:

It is probable that the analyses of tabular crystals (in clusters and isolated crystals, as well, include the surrounding area of crystals. It is caused by a very small thickness of respective crystals. Analogically, during the analyses of spherical particles and with respect to their size, there is probable a considerable participation of surrounding matrix on the analyses results.

The above described results were confirmed by independent experiments using superprobe JXA-133 with Kevex EDS analyser and scanning electron microscope JSM/25 SIII with Tracor EDS analyser in the laboratory of VschT.

The results of analysis obtained by EDS are shown in the following Table 4-14.

Table 4-14: Composition of selected Areas and Crystals in Samples $1 / 5$ and $2 / 5$

\begin{tabular}{|l|c|c|c|c|}
\hline \multicolumn{5}{|c|}{ Composition in wt. 8} \\
\hline Compound & $\begin{array}{c}\text { Bl } \\
\text { Eskolaite }\end{array}$ & $\begin{array}{c}1 / 5 \\
\text { Matrix }\end{array}$ & $\begin{array}{c}2 / 5 \\
\text { Particles }\end{array}$ & $\begin{array}{c}2 / 5 \\
\text { Eucryptite }^{3}\end{array}$ \\
\hline $\mathrm{Na}_{2} \mathrm{O}$ & - & 3.1 & 6.1 & - \\
$\mathrm{Al}_{2} \mathrm{O}_{3}$ & 7.8 & 15.8 & 20.6 & 31.8 \\
$\mathrm{SiO}_{2}$ & - & 49.1 & 32.4 & 54.3 \\
$\mathrm{Fe}_{2} \mathrm{O}_{3}$ & 2.3 & 1.9 & 12.1 & 2.0 \\
$\mathrm{Cr}_{3} \mathrm{O}_{3}$ & 89.9 & 1.4 & 13.7 & \\
$\mathrm{MnO}_{2}$ & & 0.5 & 5.8 & \\
$\mathrm{NiO}^{2}$ & & & 4.4 & \\
$\mathrm{ZnO}$ & & & 4.8 & \\
\hline
\end{tabular}

1) near bottom specimen; the matrix contains, besides large eskolaite crystals, small dark spheres with a very small crystal of eskolaite in the centre, probably due to nucleation at low temperature (see VŠCHT Rep. No. 3).

2) near surface specimen, small spherical particle with increased concentration of spinel forming compounds. Relatively high content of Si, Na and Al can be attributed to the excited volume in the vicinity of the small particle.

3 ) the higher content of $\mathrm{SiO}_{2}$ than the calculated one corresponds with the solid solution in the series $\mathrm{LiAlSiO}_{4}-\mathrm{SiO}_{2}$.

A comparison of the composition of small particles (spinel phase) and of the matrix of Glass $2 / 5$ is also shown in the graphical output of EDS analysis in Figure 4-40. 


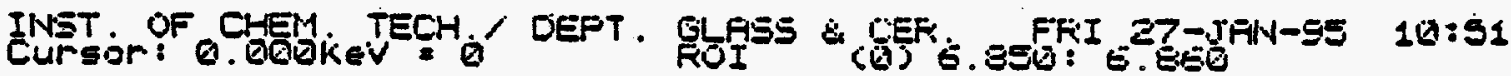

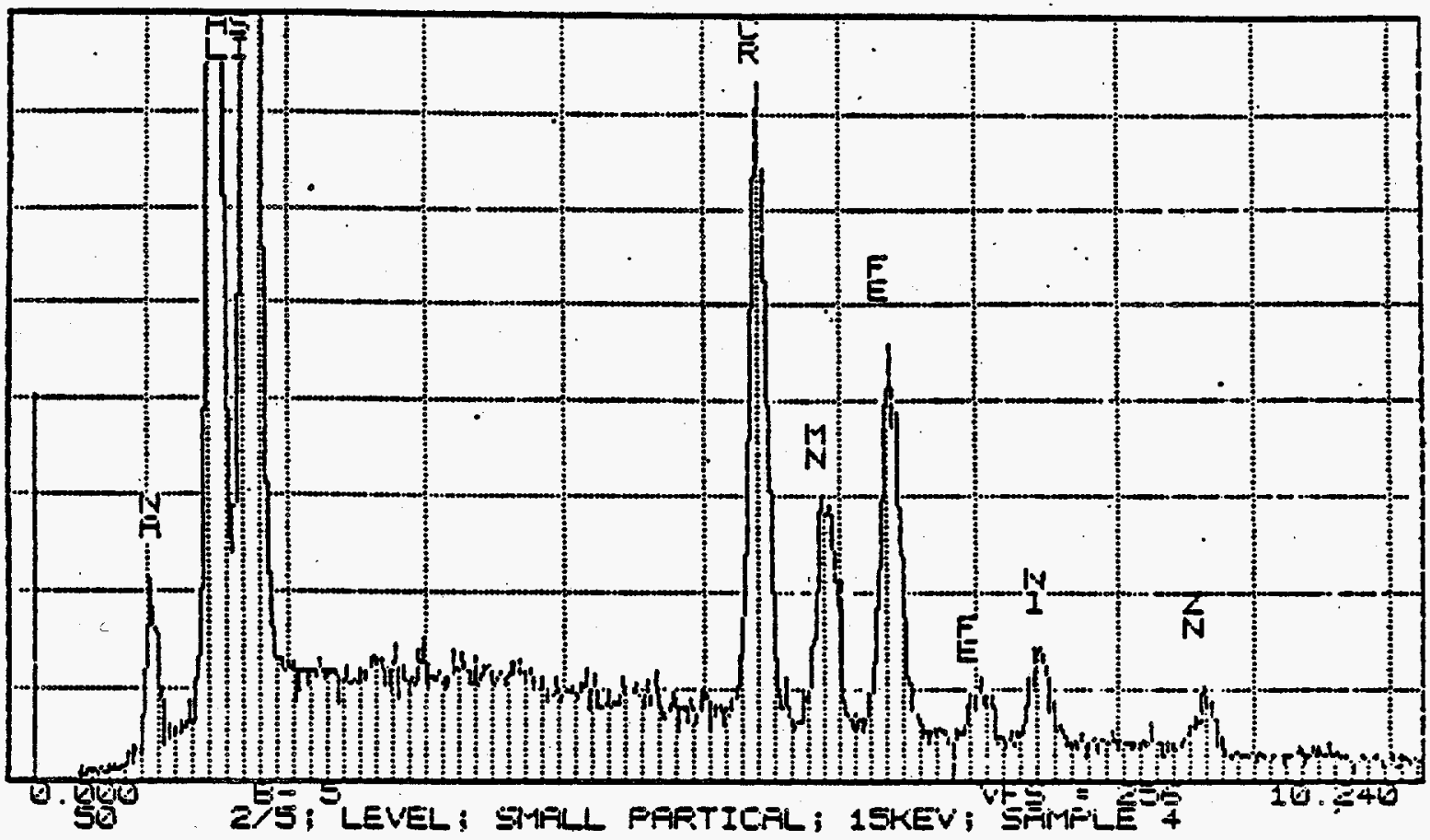

INET OF CHEM TECH

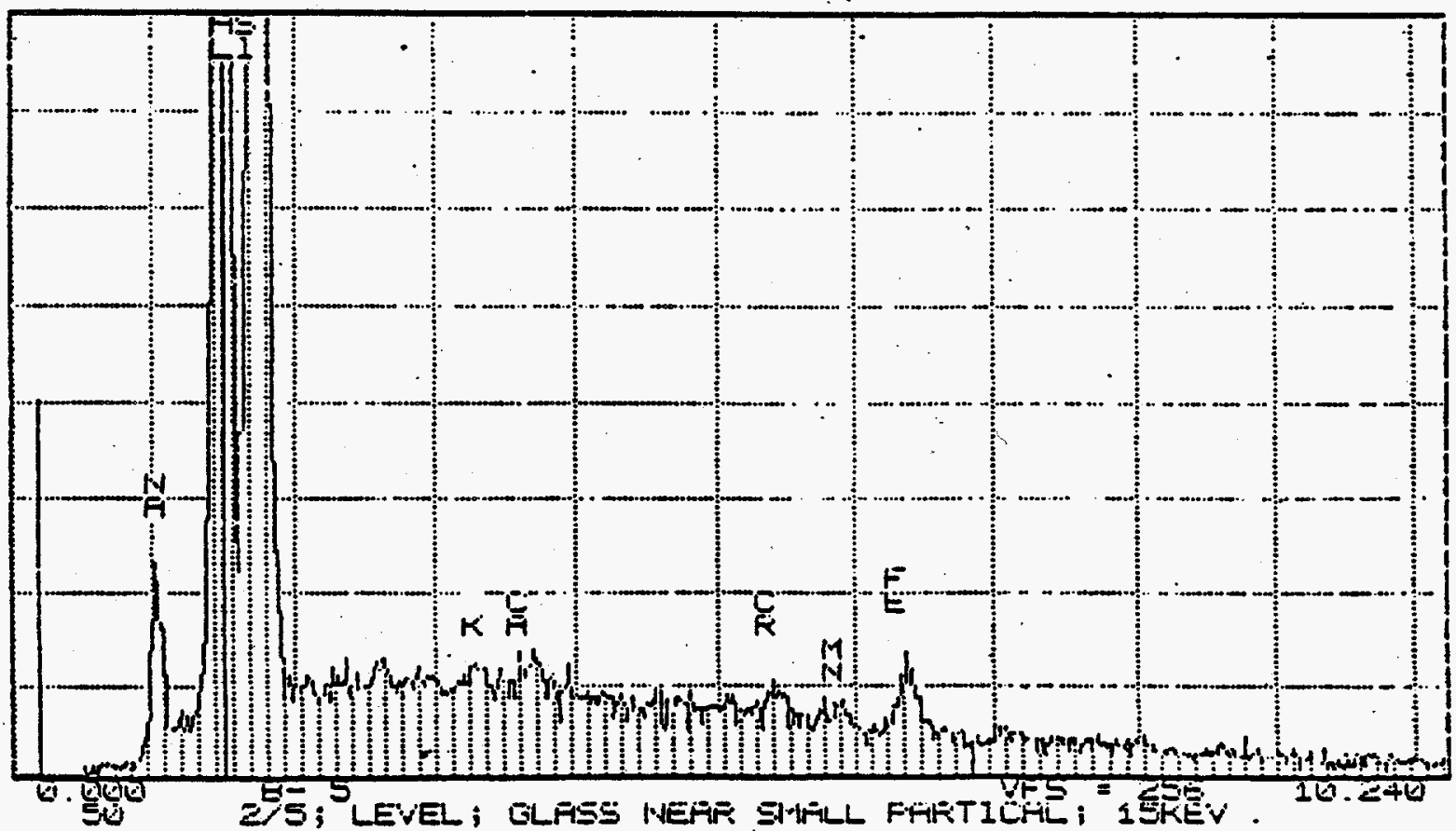

Figure 4-40: EDS Spectra of Glass 2/5: Upper Part-Particles

Lower Part-Glass Matrix 


\subsubsection{CONCLUSIONS}

1. Both Glasses $1 / 5$ and $2 / 5$ contain tabular crystals of eskolaite as well as agglomerates consisting also of eskolaite. apparently relicts of $\mathrm{Cr}(\mathrm{OH})_{3}$ particles infiltrated partly by the melt.

2. Crystals of eskolaite contain, besides of $\mathrm{Cr}_{2} \mathrm{O}_{3}$, also variable amounts of $\mathrm{Fe}_{2} \mathrm{O}_{3}$ and $\mathrm{Al}_{2} \mathrm{O}_{3}$, presumably in solid solution (but any shift of diffraction lines was not observed):

3. Whereas eskolaite is the only crystalline phase in Glass $1 / 5$, the phase composition of $2 / 5$ is more complicated and more sensitive to the conditions of preparation, i.e. thermal history, composition and homogeneity. Distinct differences in the phase composition were found between the samples taken from various parts of the cast blocks.

4. Following phases were found in Glass $2 / 5$ (quenched and annealed) :

Major phases: beta-eucryptite, eskolaite

Minor phases: nepheline, $\mathrm{Li}_{2} \mathrm{Al}_{2} \mathrm{Si}_{2} \mathrm{O}_{8}$, spinel $(\mathrm{Zn}, \mathrm{Ni}, \mathrm{Mn}$, Fe, Al, Cr)

Apparently, eskolaite crystals are active in heterogeneous nucleation of eucryptite and nepheline.

5. The spinel phase is present in the form of very small spherical particles (mostly 1 micron and less), non-uniformly distributed especially in the free space between large crystals of the other phases. Small diameter and high number per volume unit suggests the formation in lower temperature range, $i . e$. in the region of high nucleation rate and low rate of growth. Spinel particles are more concentrated in the bottom zone of Glass $2 / 5$. 
6. According to the above shown properties, glass $1 / 5$ is more stable, whereas glass $2 / 5$ is extremely sensitive to thermal history and concentration changes. Lower mecharical strength can be expected because beta-eucryptite is a phase hardly compatible with other phases due to different expansion coefficients.

7. A minor difference in the microanalysis results of eskolaite particles and their agglomerates indicates that the agglomerates correspond to areas where the melting of the initial particle of chromium hydroxide was already accomplished but the dissemination of chromium in the environment did not fully appear. such states of transformation are demonstrated in Annexes $c 2$ and $c 3$.

\subsubsection{PHYSICO-CHEMICAI PROPERTIES}

The major part of data on glass system properties, gained in this section, form a basis for the technology development and serve to the better understanding of glass system behavior during glass melting and product cooling.

\subsubsection{DENSITY}

Density of Glasses 1 and 2 was measured by ASTM C 693-84(88) "Standard testing method for determination of the glass density by the hydrostatic weighing".

Portions of specimens $1 / 5(6)$ and $2 / 5(6)$ which were cut to smaller parts were used for the measurements, three independent sample parts for each glass.

The numbers given in brackets mean special part of the specimen glass block, which is defined in the respective laboratory protocols.

The average density of Glass $1 / 5$ was $2472 \mathrm{~kg} \cdot \mathrm{m}^{-3}$.

The average density of Glass $2 / 5$ was $2550 \mathrm{~kg} \cdot \mathrm{m}^{-3}$.

Note: The samples quality does not correspond to the requirement of the sample homogeneity due to the presence of bubbles, splits and inhomogeneities. It is necessary to consider the results only as informative values. 


\subsubsection{TEMPERATURE DEPENDENCE OF VISCOSITY}

Determination of viscosity by rotary viscometer used czech and. ISO standard CSN ISO 7884-2 "Viscosity and reference viscosity points Part 2: viscosity determination by rotary viscometer".

Preparation of testing samples

Smaller parts of glass samples $1 / 5$ and $2 / 5$ in the form of cut off block parts were used for the measurements. The height of blocks was approximately $1 \mathrm{~cm}$. The necessary weight of the glass for sample $2 / 5$ was completed by a small portion of Glass $2 / 5(6)$.

The samples were cut off to the necessary size and melted-down in PtRh crucibles, diameter $35 \mathrm{~mm}$, height $55 \mathrm{~mm}$. The volume of both samples before melting-down was $33.7 \mathrm{~cm}^{3}$.

Experimental part

The samples were measured on searle type rotary viscometer. Description of the apparatus, procedure and calibration is in the Annex B4.

The Glass $1 / 5$ was melted down in a crucible at $1000{ }^{\circ} \mathrm{C}$. The temperature was increased up to $1152^{\circ} \mathrm{C}$ after immersing of the sphere. After stabilizing of conditions the measurement started from this temperature in intervals of $50{ }^{\circ} \mathrm{C}$ down to $786^{\circ} \mathrm{C}$.

At the end the viscosity at $1103^{\circ} \mathrm{C}$ was measured for control. The measured value corresponds very well with the value substracted from the curve $\log v$ versus temperature, see Table 4-15.

The Glass $2 / 5$ was melted-down in a crucible at $1350^{\circ} \mathrm{C}$ and the sphere was immersed at the same temperature. After 90 minutes stabilization, the temperature was decreased to $.1296{ }^{\circ} \mathrm{C}$ and the first value was measured. However, as it is seen from Table 4-16, even after this time the stabilization was not ideal and the measured value has quite a great deviation from the curve calculated according to the VFT equation (see below). Further on, there were measured viscosities towards lower temperatures at 
.first and after repeated stabilization at $1350^{\circ} \mathrm{C}$ towards higher temperatures.

For the description of viscosity temperature dependence, the Vogel-Fulcher-Tammann (VFT) equation was used. Viscosity values were used for the calculation of constants of VFT equation with the application of ADSTAT programme (modul of non-linear regression).

For the description of viscosity temperature dependence in the wide temperature range vogel-Fulcher-Tammann equation was used in the same way. The former calculation was completed by dilatometric transformation temperature $t_{g}$ to which the viscosity $10^{13.1}$ dPa.s was adjoined:

Testing results

The testing results are expressed in the form of Vogel-Fulcher-Tammann equations which describe the temperature viscosity dependence for tested samples in given temperature range (temperature dependences of viscosities are given in Annexes $\mathrm{C5}, \mathrm{C6}, \mathrm{C7}$ and $\mathrm{C8})$. The experimental values in the temperature range 1091 to $1192^{\circ} \mathrm{C}$, where the viscosity stabilization at constant temperature was not reached (continuously decreasing viscosity), were eliminated in calculation for glass 2/5. They are given, however, in the respective graph and tables for illustration. The comparison of experimental and calculated viscosity values are given in Tables 4-15 to 4-18.

VFT equations for Glass $1 / 5$ (only rotary viscometer):

$$
\begin{aligned}
& \log v=-2.434+5353.0 /(t-23.9) \\
& s=0.035, \quad r=0.9986 \text {, validity from } 786^{\circ} \mathrm{C} \text { to } 1152^{\circ} \mathrm{C} \\
& \text { where: } v \text {... viscosity [dPa.s] . s ... standard deviation } \\
& t \text {... temperature }\left[{ }^{\circ} \mathrm{C}\right] \quad r \text {... correlation coefficient }
\end{aligned}
$$


Table 4-15: Comparison of Experimental and Calculated Viscosity Values for Glass $1 / 5$ (Calculation only from Rotary Viscometer Data)

\begin{tabular}{|c|c|c|c|}
\hline Temperature $\left[{ }^{\circ} \mathrm{c}\right]$ & $\log v(\mathrm{~m})$ & $\log v(\mathrm{c})$ & Deviation \\
\hline 786 & 4.619 & 4.590 & 0.029 \\
831 & 4.168 & 4.199 & -0.031 \\
889 & 3.727 & 3.754 & -0.027 \\
937 & 3.434 & 3.429 & 0.005 \\
1002 & 3.041 & 3.039 & 0.002 \\
1058 & 2.783 & 2.743 & 0.040 \\
1102 & 2.552 & 2.532 & 0.020 \\
1103 & 2.539 & 2.527 & 0.012 \\
1152 & 2.261 & 2.312 & -0.051 \\
\hline
\end{tabular}

Note: $v(m) \ldots$ measured viscosity [dPa.s]

$v(c)$... calculated viscosity [dPa.s]

VFT equations for Glass $2 / 5$ (only rotary viscometer):

$$
\begin{aligned}
& \log v=-9.127+23952 /(t+777.2) \\
& s=0.027, r=0.9951, v a l i d i t y \text { from } 1243^{\circ} \mathrm{C} \text { to } 1420^{\circ} \mathrm{C}
\end{aligned}
$$

where: $v$... viscosity [dPa.s]

$t$.... temperature $\left[{ }^{\circ} \mathrm{C}\right]$

s ... standard deviation

$r$... correlation coefficient

Table 4-16: Comparison of Experimental and Calculated Viscosity Values for Glass $2 / 5$ (Calculation only from Rotary Viscometer Data)

\begin{tabular}{|c|c|c|c|}
\hline Temperature $\left[{ }^{\circ} \mathrm{C}\right]$ & $\log \mathrm{v}(\mathrm{m})$ & $\log v(\mathrm{c})$ & Deviation \\
\hline$\star 1091$ & $3.24-3.03$ & 3.694 & \\
$\star 1142$ & $3.03-3.01$ & 3.353 & \\
$\star 1192$ & $2.96-2.84$ & 3.036 & \\
1243 & 2.716 & 2.729 & -0.013 \\
1295 & 2.423 & 2.432 & -0.009 \\
1296 & 2.470 & 2.426 & 0.044 \\
1348 & 2.126 & 2.144 & -0.018 \\
1348 & 2.150 & 2.144 & 0.006 \\
1378 & 1.959 & 1.987 & -0.028 \\
1408 & 1.830 & 1.834 & -0.004 \\
1420 & 1.795 & 1.774 & 0.021 \\
\hline
\end{tabular}

Note: $v(m)$... measured viscosity [dPa.s]

$v(c)$... calculated viscosity [dPa.s.]

* ... values not used for the calculation

of VFT equation constants 
VFT equations for Glass $1 / 5$ (wide range temperature):

$$
\begin{aligned}
& \log v=-0.897+2868.2 /(t-268.1) \\
& s=0.045, \quad r=0.9999, \quad v a l i d i t y \text { from } 473^{\circ} \mathrm{C} \text { to } 1152{ }^{\circ} \mathrm{C}
\end{aligned}
$$

where: $v$...viscosity [dPa.s]

$t$... temperature $\left[{ }^{\circ} \mathrm{c}\right]$ s.... standard deviation

r... correlation coefficient

Table 4-17: Comparison of Experimental and Calculated Viscosity values for Glass $1 / 5$ (Wide Range Temperature Curve)

\begin{tabular}{|c|c|c|c|}
\hline Temperature [ $\left.{ }^{\circ} \mathrm{C}\right]$ & $\log v(\mathrm{~m})$ & $\log v(\mathrm{c})$ & Deviation \\
\hline 473 & 13.100 & 13.102 & -0.001 \\
786 & 4.619 & 4.641 & -0.022 \\
831 & 4.168 & 4.198 & -0.030 \\
889 & 3.727 & 3.722 & 0.005 \\
937 & 3.434 & 3.391 & 0.043 \\
1002 & 3.041 & 3.011 & 0.030 \\
1058 & 2.783 & 2.734 & 0.049 \\
1102 & 2.552 & 2.543 & 0.009 \\
1103 & 2.539 & 2.538 & 0.001 \\
1152 & 2.261 & 2.348 & -0.087 \\
\hline
\end{tabular}

Note: $v(m), \ldots$ measured viscosity [dPa.s]

$v(c)$... calculated viscosity [dPa.s]

VFT equations for Glass. $2 / 5$ (wide-range temperature):

$$
\begin{aligned}
& \log v=-6.184+13139 /(t+230.4) \\
& s=0.025, \quad r=0.9999, \quad \text { validity from } 1243{ }^{\circ} \mathrm{C} \text { to } 1420{ }^{\circ} \mathrm{C} \\
& \text { where: } \dot{v} \ldots \text { viscosity }[\text { dPa.s }] \\
& t \ldots \text { temperature }\left[{ }^{\circ} \mathrm{C}\right]
\end{aligned}
$$

Table 4-18: Comparison of Experimental and Calculated Viscosity values for Glass $2 / 5$ (Wide Range Temperature Curve)

\begin{tabular}{|c|c|c|c|}
\hline Temperature $\left[{ }^{\circ} \mathrm{C}\right]$ & $\log v(\mathrm{~m})$ & $\log v(\mathrm{c})$ & Deviation \\
\hline 451 & 13.100 & 13.098 & 0.002 \\
1091 & $3.24-3.03$ & 3.759 & \\
1142 & $3.03-3.01$ & 3.390 & \\
1192 & $2.96-2.84$ & 3.053 & \\
1243 & 2.716 & 2.734 & -0.018 \\
1295 & 2.423 & 2.430 & -0.007 \\
1296 & 2.470 & 2.424 & 0.046 \\
1348 & 2.126 & 2.140 & -0.014 \\
1348 & 2.150 & 2.140 & 0.010 \\
1378 & 1.959 & 1.985 & -0.026 \\
1408 & 1.830 & 1.835 & -0.005 \\
1420 & 1.795 & 1.777 & 0.018 \\
\hline
\end{tabular}


Note: $v(m) \ldots$ measured viscosity [dPa.s]

$v(c)$... calculated viscosity [dPa.s]

*.... values not used for the calculation

of VFT equation constants

Notes:

The measurement was not carried out above the melting temperature because of glass melts foaming during the heating above this temperature, which would lead to incorrect results.

The measurements were carried out with phase inhomogeneous glass melts, mostly under the liquidus temperature (see section 4.2.2.5.).Changes of crystalline phases content were supposed even during measurement in the dependence on the temperature and measuring time (directly confirmed with the glass $2 / 5$ in the temperature range from $1091^{\circ} \mathrm{C}$ to $1292^{\circ} \mathrm{C}$ ). With regard to these facts it is necessary to consider these results only as informative.

\subsubsection{TEMPERATURE DEPENDENCE OF ELECTRICAL CONDUCTIVITY}

In this section the determination of specific electric resistance of glass melts at high temperatures (instead of electrical conductivity) is described.

As standard and technical documents following documents were used:

Electrical conductivity measurement procedure. PSL-417-ELC, PNL, USA.

Boulos E.N., Smith J.W., Moynihan C.T.: Rapid and accurate measurements of electrical resistivity on glass melts. Glastechn. Ber., 56K, 1983, .s. 509 .

\section{Preparation of testing sample}

Melted-down samples were used for measurement after viscosity measurements (see section 4.2.2.2. of this Report).

Experimental part

Samples were measured on an apparatus delivered by VEzAs. Hradec Králové, which is similar to the apparatus described in PSL-417-ELC as far as construction. The furnace with control and temperature measurement is corresponding to the rotary viscometer (see 'Part 4.2.2.2. and Annex B5). 
The crucible with the melted-down glass $1 / 5$ was heated up to $1196^{\circ} \mathrm{C}$, the electrodes were immersed and after the stabilization of conditions the measurement was started from this temperature in intervals approximately $50^{\circ} \mathrm{C}$ down to the temperature $742^{\circ} \mathrm{C}$.

The crucible with the melted-down glass $2 / 5$ was heated up to $1451{ }^{\circ} \mathrm{C}$, the electrodes were immersed and after the stabilization of conditions the measurement started from this temperature in intervals approximately $50^{\circ} \mathrm{C}$ down to the temperature $742^{\circ} \mathrm{C}$.

For the description of the temperature dependence versus specific electric resistance the Vogel-Fulcher-Tammann equation was used. The VFT equation constants were calculated by the programme ADSTAT (modul of Nonlinear regression) from the measured values of resistance after the recalculation to the specific electric resistance.

Testing result

The testing results are VFT equations describing the temperature dependence of the specific electric resistance for tested samples in the given temperature range. For these dependences see the Annex $C$ ( $C 9$ and $C 10)$. The comparison of experimental and calculated values of specific electric resistance is given in Tables 4-19 and 4-20.

VFT equation for Glass $1 / 5$ :

$\log R_{V}=-1.281+1777.9 /(t-121.3)$

$s=0.014, r=0.9992$, validity from $742{ }^{\circ} \mathrm{C}$ to $1196{ }^{\circ} \mathrm{C}$

where: $R_{v} \ldots \ldots$ specific electric resistance [ $\left.\Omega . c m\right]$

$t \ldots \ldots$ temperature $\left[{ }^{\circ} \mathrm{C}\right]$

s..... standard deviation

r..... correlation coefficient 
Table 4-19: Comparison of Experimental and Calculated Values of the Specific Electric Resistance for Glass $1 / 5$

\begin{tabular}{|c|c|c|c|}
\hline Temperature $\left[{ }^{\circ} \mathrm{C}\right]$ & $\log \mathrm{R}_{\mathrm{v}}(\mathrm{m})$ & $\log R_{\mathrm{v}}(\mathrm{C})$ & Deviation \\
\hline 742 & 1.574 & 1.584 & -0.010 \\
793 & 1.369 & 1.366 & 0.003 \\
842 & 1.207 & 1.186 & 0.021 \\
894 & 1.049 & 1.020 & 0.029 \\
943 & 0.875 & 0.883 & -0.008 \\
993 & 0.759 & 0.759 & $(0)$ \\
1044 & 0.637 & 0.646 & -0.009 \\
1094 & 0.535 & 0.547 & -0.012 \\
1143 & 0.455 & 0.459 & -0.004 \\
1196 & 0.391 & 0.373 & 0.018 \\
\hline
\end{tabular}

Note: $R_{v}(m)$... measured specific electric resistance [ $\left.\Omega \mathrm{cm}\right]$ $R_{v}(c)$... calculated specific electric resistance $[\Omega \mathrm{cm}]$ * ... value not used for VFT equation constants calcul.

VFT equation for Glass 2/5:

$$
\begin{aligned}
& \log R_{v}=-2.488+3967.7 /(t+63.7) \\
& s=0.012, \quad r=0.9985, \quad \text { validity from } 1100{ }^{\circ} \mathrm{C} \text { to } 1451{ }^{\circ} \mathrm{C}
\end{aligned}
$$

where: $R_{v} \ldots \ldots \ldots$ specific electric resistance $[\Omega . c m]$

$$
\begin{aligned}
& t \ldots \ldots \ldots \ldots \text { temperature }\left[{ }^{\circ} \mathrm{C}\right] \\
& \mathbf{s} \ldots \ldots \ldots \ldots \text { standard deviation } \\
& r \ldots \ldots \ldots \text { correlation coefficient }
\end{aligned}
$$

Table 4-20: Comparison of Experimental and Calculated Values of the Specific Electric Resistance for Glass $2 / 5$

\begin{tabular}{|c|c|c|c|}
\hline Temperature $\left[{ }^{\circ} \mathrm{C}\right]$ & $\log R_{\mathbf{v}}(\mathrm{m})$ & $\log R_{\mathrm{v}}(\mathrm{c})$ & Deviation \\
\hline 1100 & 0.913 & 0.922 & -0.009 \\
1137 & 0.820 & 0.817 & 0.003 \\
1182 & 0.707 & 0.697 & 0.010 \\
1218 & 0.625 & 0.608 & 0.017 \\
1264 & 0.491 & 0.501 & -0.010 \\
1309 & 0.383 & 0.403 & -0.020 \\
1359 & 0.299 & 0.301 & -0.002 \\
1400 & 0.228 & 0.223 & 0.005 \\
1411 & 0.208 & 0.203 & 0.005 \\
1451 & 0.133 & 0.132 & 0.001 \\
\hline
\end{tabular}

Note: $R_{V}(m)$... measured specific electric resistance [ $\Omega . \mathrm{cm}$ ] $R_{v}(c) \ldots$ calculated specific electric resistance $[\Omega . c m]$ Note:

The measurement was not carried out above the melting temperature because of glass melts foaming during the heating above this temperature and, which could lead to incorrect results. 
The measurements were carried out with phase inhomogeneous glass melts, mostly bellow the liquidus temperature (see section 4.2.2.5. of this Report). Changes of crystalline phases content were supposed even during the measurement in the dependence on the temperature and measuring time (directly confirmed in case of the glass $2 / 5$ in the temperature range from $1091{ }^{\circ} \mathrm{C}$ to $1292{ }^{\circ} \mathrm{C}$ ). With regard to these facts it is necessary to consider these results only as informative.

\subsubsection{DIIATOMETRY}

Determination of mean coefficient of linear thermal expansion and dilatometric transformation temperature

Mean coefficient of linear expansion of glasses was measured using the czech standard:

CSN ISO 7991. Determination of mean coefficient of linear (thermal) expansion.

For transformation temperature $\left(t_{g}\right)$ measurements standard:

CSN ISO 7884-8 Viscosity and reference viscosity points. Determination of dilatometric

was used. transformation temperature $t_{g}$.

Preparation of testing samples

From the central part of the portion 1/5(6) of quenched and annealed block of glass $1 / 5$ there were cut off two prisms, dimensions $5 \times 5 \times 25 \mathrm{~mm}$, in parallel direction with the bottom area. Sample faces were ground in the plane perpendicular to the longitudinal axis.

From the portion $2 / 5(8)$ of quenched and annealed block of glass $2 / 5$ two prisms were cut off from the bottom zone, dimensions $5 \times 5 \times 25 \mathrm{~mm}$, in parallel direction with the bottom area (the prisms included a $2 \mathrm{~mm}$ glass layer from the central part of the sample), and further on, two prisms, dimensions $5 \times 5 \times 25 \mathrm{~mm}$, from the central part (the prisms centre was $6 \mathrm{~mm}$ from the surface area). 
The preparation of samples was complicated by cracking during the sample preparation: Sample faces were ground in the plane perpendicular to the longitudinal axis.

A $2 \mathrm{~mm}$ layer from the central part of the sample was ground off, after the first two measurements, from the prisms bottom zone. The measurement was then repeated.

Experimental part

Samples were measured using dilatometer No. 2 from Adamel Lhomargy according to the standard CSN ISO 7991 and CSN ISO 7884-8. Heating rate $4^{\circ} \mathrm{C} / \mathrm{min}$.

Unstandardized softening temperature $t_{d}$ was evaluated directly from the dilatometric curve as a temperature at which the elongation of measured sample was stopped due to the influence of the thrust mechanism pressure. Thrust force of the draw rod was adjusted on $18 \mathrm{cN}$.

Testing results

Testing results are given in Table 4-21 and selected typical dilatometric curves are given in the Annex C (C11, C12 and C13). The course of dilatometric curves of all samples $2 / 5$ above the temperature $t_{g}$ is characteristic for devitrified glasses, and in such a case it is not often possible to evaluate the temperature $t_{d}$.

While measuring samples $2 / 5$ the the respective prisms of samples deflected and the resulting thermal expansion values changed therefore with a change of the prisms position in the measuring apparatus. During repeated measurements, however, the $t_{g}$ value changed which can be explained by continual changes caused by crystallization due to the sample heating up to temperatures higher than $t_{g}$ (see temperatures $t_{\max }$ in Table 4-21). 
Table 4-21: Mean Coefficient of Linear Thermal Expansion, Dilatometric Transformation Temperature $t_{g}$ and Dilatometric softening Point $t_{d}$ of Glassés $1 / 5$ and $2 / 5$

\begin{tabular}{|c|c|c|c|c|}
\hline Sample & $\begin{array}{c}a(20-300){ }^{0} \mathrm{C} \cdot 10^{6} \\
{\left[K^{-1}\right]}\end{array}$ & $\begin{array}{c}t_{g} \\
{\left[{ }^{\circ} c\right]}\end{array}$ & $\begin{array}{c}t_{d} \\
{\left[{ }^{0} c\right]}\end{array}$ & $\begin{array}{l}t_{\text {max }} \\
{\left[{ }^{\circ} \mathrm{c}\right]}\end{array}$ \\
\hline $\begin{array}{l}\text { 1/5 lst prism } \\
\text { 2nd prism }\end{array}$ & $\begin{array}{l}8,05 \\
8,17\end{array}$ & $\begin{array}{l}473 \\
472\end{array}$ & $\begin{array}{l}514 \\
515\end{array}$ & \\
\hline $\begin{array}{l}\text { 2/5 bottom zone } \\
\text { 1st prism } \\
\text { 1st measur. } \\
\text { 2nd measur.b } \\
\text { 3rd measur.b } \\
\text { 2nd prism } \\
\text { 1st measur. } \\
\text { 2nd measur.b } \\
\text { 3rd measur.b }\end{array}$ & $\begin{array}{l}5,24 \\
5,89 \\
5,47 \\
5,60 \\
5,45 \\
5,28\end{array}$ & $\begin{array}{l}449 \\
426 \\
421 \\
\\
447 \\
424 \\
426\end{array}$ & $\begin{array}{l}\mathbf{a} \\
\mathbf{a} \\
\mathbf{a} \\
\mathbf{a} \\
\mathbf{a} \\
\mathbf{a}\end{array}$ & $\begin{array}{l}511 \\
500 \\
513 \\
520\end{array}$ \\
\hline $\begin{array}{l}\text { 2/5 central part } \\
\text { 1st prism } \\
\text { 1st measur. } \\
\text { 2nd measur. } \\
\text { 3rd measur. } \\
\text { 2nd prism } \\
\text { 1st measur. } \\
\text { 2nd measur. } \\
\text { 3rd measur. }\end{array}$ & $\begin{array}{l}7,19 \\
7,79 \\
7,18 \\
8,08 \\
8,02 \\
7,57\end{array}$ & $\begin{array}{l}450 \\
449 \\
442 \\
\\
451 \\
455 \\
445\end{array}$ & $\begin{array}{l}\mathbf{a} \\
\mathbf{a} \\
\mathbf{a} \\
\mathbf{a} \\
\mathbf{a} \\
\mathbf{a}\end{array}$ & $\begin{array}{l}492 \\
554 \\
494 \\
622\end{array}$ \\
\hline
\end{tabular}

$t_{\text {max }}$ - maximum reached temperature during measuring

$a^{\text {max }}$ - cannot be evaluated

b - after grinding off of glass residues from the central part

\subsubsection{LIQUIDUS TEMPERATURE}

Liquidus temperature of Glasses 1 and 2 was performed according to standard:

ASTM C 829-81(86) Standard method for measuring of liquidus temperature of glass by a method of gradient furnace.

Preparation of testing sample

There were used portions $1 / 5(5)$ and $2 / 5(7)$ for the test, crushed according to the ASTM C $829-81(86)$.

The test was carried out also with a Glass sample $A I / C r$ for comparison (see Annex A3). 
Experimental part

Samples were tempered in a gradient furnace during 24 hours in the temperature range $550-1100^{\circ} \mathrm{C}$. The test was repeated in the temperature range $830-1320^{\circ} \mathrm{C}$ (24 hours). The temperature $1320^{\circ} \mathrm{C}$ is the highest temperature adjustable in the used gradient furnace.

Testing results

Glass $1 / 5$

with respect to a very dark colour and the presence of eskolaite crystals there was not possible to determine the liquidus temperature of any other phase by optical microscope, as required by procedure according to the standard ASTM C 829 $-81(86)$.

The presence of crystals corresponding to a high temperature eucryptite (by chemical composition) even at $1320^{\circ} \mathrm{C}$ was confirmed using a local analysis in electron scanning microscope (for conditions see section 4.2.1.2. of this Report).

Glass $2 / 5$

with respect to a very dark colour and separated eskolaite crystals there was not possible to determine the liquidus temperature of any other phase by optical microscope, as required by procedure according to the standard ASTM C $829-81(86)$. The presence of crystals corresponding to a high temperature eucryptite (by chemical composition) even at $1320^{\circ} \mathrm{C}$ was confirmed using local analysis in electron scanning microscope (for conditions see section 4.2.1.2. of this Report).

\subsubsection{DISCUSSION AND CONCLUSIONS}

The above described measurements characterize the behavior of Glasses 1 and 2 from the point of view of the properties which are important for their production by melting (viscosity, electrical conductivity and liquidus temperature). Density, expansion coefficient and transformation temperature are the basic properties which contribute to a better understanding of the character of investigated glasses. 
Glass 1 exhibited regular, i.e. non-anomalous behaviour when individual properties were measured. Viscosity data as well as electrical conductivity were successfully interpreted, in a wide temperature range, using the vogel-Fulcher-Tammann equation. The coefficient of thermal expansion was well reproducible as well as the transformation temperature. Although the temperature of melting used in the case of Glass 1 was lower than that corresponding to the standard melting temperature given by the viscosity (100-60 dPa.s, whereas really attained viscosity value was about $200 \mathrm{dPa} . \mathrm{s}$ at $1150^{\circ} \mathrm{C}$ ), the product could be considered as a good glass not exhibiting apparent anomalies. Both the residual particles of the original $\mathrm{Cr}_{2} \mathrm{O}_{3}$ and secondary formed eskolaite crystals exhibited no apparent effect on physicochemical properties of the glass studied.

On the other hand, Glass $2 / 5$ (which has been melted at the temperature of viscosity lower than $6 \mathrm{~Pa} . \mathrm{s}$ ) exhibited non-regular properties due to its lower stability, i.e. crystallization of phases other than eskolaite even in the case of quenching (see chapter 4.2.1.4). Therefore, difficulties occured when measuring properties at higher temperatures, i.e. viscosity, electrical conductivity and thermal expansion. Continuing changes of the crystallinity were responsible for inadequate fit of viscosity data with the VFT equation as well as for inaccuracy of electrical conductivity measurements. From the same reason, poor reproducibility was found for thermal expansion measurements: distinct differences in the expansion coefficient were found in repeated measurements with the same sample, and also between the samples taken from the central and bottom part of the glass block. The last difference can be explained by different content of beta-eucryptite in respective specimens, in accord with crystallinity measurements (see chapter.4.2.1.4). Higher content of eucryptite, which is a phase exhibiting negative expansion coefficient, results in a considerable decrease of the coefficient. 
Thermal expansion measurements indicate that crystallinity changes in Glass 2 occur even at low temperatures, i.e. only slightly above the tranformation temperature. This finding corresponds with the observation of very small crystals found in glass 2/5, identified as spinel. Their small diameter and large number can be explained by a secondary formation in the region of high nucleation rate, i.e. at low temperatures.

\subsubsection{CHEMICAI PROPERTIES}

According to the Test Plan chemical analysis of studied glasses should explain the behavior of chromium or chromium compounds in the final vitrification products. Quantitative chemical analysis of produced glasses can explain some processes which take place during the chemical transformation of batches to the glass (e.g. volatilization of some constituents) and special analysis of tri- and hexavalent chromium should answer one of the important problems of this project: incorporation of chromium into the glass structure.

An attempt of nondestructive analysis of chromium in glass matrix was realized.

An orientation study of the respective glass products durability was performed, which was not expected from the Test Plan, but which could answer some important questions about the suitability of respective vitrification products for the technological realization.

\subsubsection{CHEMICAI ANALYSIS OF GLASSES}

Qualitative and semiqualitative optical emission spectrographic analysis

Laboratory of the Glass Institute, where a majority of chemical analyses were performed, used for the analyses:

Internal regulation cH-46-92 Qualitative optical emission spectroscopy. Spectrography. 
-Preparation of testing sample

Following portions of delivered samples were used for analyses:

$1 / 5$ portions $1 / 5(1), 1 / 5(2)$ and $1 / 5(4)$

$2 / 5$ portions $2 / 5(1), 2 / 5(2), 2 / 5(4)$ and $2 / 5(5)$

(Numbers in brackets indicate parts of respective glass blocks - description is given in special laboratory protocols).

The delivered samples were crushed to a grain size $<2 \mathrm{~mm}$. The crushed sample, weight about $0.2 \mathrm{~g}$ was hand ground in agate mortar.

Experimental part

The sample was transferred into a supporting spectral electrode sU 308. Further procedure was carried out according to the quoted Internal regulation.

Testing results

Testing results are summarized in Table 4-22.

Table 4-22: The Results of Optical Emission Spectrographic Analysis

\begin{tabular}{|l|c|c|}
\hline $\begin{array}{c}\text { Identificated } \\
\text { Component } \\
\text { (Expressed as } \\
\text { Oxide) }\end{array}$ & \multicolumn{2}{|c|}{ Concentration Estimate } \\
\cline { 2 - 3 } & $1 / 5$ & $2 / 5$ \\
\hline $\mathrm{SiO}_{2}$ & $\mathrm{MC}$ & $\mathrm{MC}$ \\
$\mathrm{B}_{2} \mathrm{O}_{3}$ & $\mathrm{SC}$ \\
$\mathrm{Cr}_{2} \mathrm{O}_{3}$ & $\mathrm{MC}$ & $\mathrm{SC}$ \\
$\mathrm{MnO}$ & $\mathrm{SC}$ & $\mathrm{AC}$ \\
$\mathrm{Na}_{2} \mathrm{O}$ & $\mathrm{AC}$ & $\mathrm{SC}$ \\
$\mathrm{IiO}_{2} \mathrm{SC}$ & $\mathrm{SC}$ \\
$\mathrm{Al} \mathrm{O}_{3}$ & $\mathrm{SC}$ & $\mathrm{MC}$ \\
$\mathrm{Fe} \mathrm{O}_{3}$ & $\mathrm{MC}$ & $\mathrm{SC}$ \\
$\mathrm{CaO}$ & $\mathrm{SC}$ & $\mathrm{AC}$ \\
$\mathrm{MoO}$ & $\mathrm{AC}$ & $\mathrm{AC}$ \\
$\mathrm{PbO}$ & $\mathrm{AC}$ & $\mathrm{AC}$ \\
$\mathrm{NiO}$ & $\mathrm{AC}$ & $\mathrm{AC}$ \\
$\mathrm{CuO}$ & $\mathrm{AC}$ & $\mathrm{AC}$ \\
$\mathrm{znO}$ & $\mathrm{AC}$ & $\mathrm{AC}$ \\
\hline
\end{tabular}

Note:

Symbol:

MC, main component

sc, secondary component

AC, accompanying component
Corresponding concentration range:

10 - 100 wt. ?

$1-10$ wt. 
Quantitative chemical analysis

A complex of quantitative chemical analyses of glasses was based on standards and technical documents, which are used for chemical analysis in the STL laboratory of the Glass Institute:

CSN 700621 Part 2. Chemical analysis of glass. Determination of silicon(IV) oxide at a presence of fluorides by gravimetric method.

CSN 700625 Part 1 . Determination of phosphorus oxide by photometric method using a molybdenum vanadium agent.

Internal regulation $\mathrm{CH}-01-92$ Testing method of glass. Determination of boron oxide by titration method.

Internal regulation CH-08-92 Testing method of glass. Determination of sulfur(VI) oxide by titration method after pyrolytic separation in the form of $\mathrm{SO}_{2}$.

Internal regulation $\mathrm{CH}-11 \mathrm{a}-92$ Testing method of glass. Determination of chlorides by the method of direct titration.

Internal regulation $\mathrm{CH}-15-94$ Determination of redox states of iron in glasses and glass ceramic materials.

Internal regulation $\mathrm{CH}-16-94$ Determination of redox states of chromium in glasses and glass ceramic materials.

Internal regulation $\mathrm{CH}-21 \mathrm{~b}-92$ Chemical analysis of glass. Methods of optical emission spectrometry with microwave generated capacity bonded plasma, CMP-OES. Determination of aluminium oxide.

Internal regulation $\mathrm{CH}-27 \mathrm{a}-92$ Testing method of glass. Methods of atomic absorption and emission flame spectrometry. Determination of magnesium oxide.

Internal regulation $\mathrm{CH}-29 \mathrm{a}-92$ Chemical analysis of glass. Methods of atomic absorption and emission flame spectrometry. Determination of calcium oxide.

Internal regulation CH-34a-92 Chemical analysis of glass. Methods of atomic absorption and emission flame spectrometry. Determination of zinc oxide.

Internal regulation $\mathrm{CH}-39 \mathrm{a}-92$ Chemical analysis of glass. Methods of atomic absorption and emission flame spectrometry. Determination of iron(III), chromium(III), manganese(II) and nickel(II) oxides. Determination of molybdenum.

Internal regulation $\mathrm{CH}-42 \mathrm{a}-92$ Testing method of glass. Chemical analysis of glass. Methods of atomic absorption and emission flame spectrometry. Determination of sodium, potassium and lithium oxides.

Preparation of testing samples.

Following portions of delivered samples were used for analyses: $1 / 5$ portions $1 / 5(1), 1 / 5(2)$ and $1 / 5(4)$

$2 / 5$ portions $2 / 5(1), 2 / 5(2), 2 / 5(4)$ and $2 / 5(5)$

$\mathrm{Al} / \mathrm{Cr}$. block part marked $\mathrm{Al} / \mathrm{Cr}$

$\mathrm{Bl} / \mathrm{Cr}$ block part marked $\mathrm{B} 1 / \mathrm{Cr}$ 
For the comparison purposes samples of special glasses $A I / C r$ and BI/Cr (see Annex A3) were also analyzed.

Delivered samples were crushed to a grain size $<2 \mathrm{~mm}$. The crushed sample was homogenized and changed to a powder form by hand grinding in an agate mortar to particles of diameter d $\leq 150 \mathrm{\mu m}$. Ground samples were dried at $110^{\circ} \mathrm{C}$ to a constant weight and transferred to a weighing bottle with a ground joint and located in dessicator.

Experimental part

The determinations were carried out according to the quoted standards and. Internal regulations. The determination of a sum $\left(\mathrm{Nd}_{2} \mathrm{O}_{3}+\mathrm{La}_{2} \mathrm{O}_{3}+\mathrm{ZrO}_{2}\right)$ is described in the Annex $\mathrm{B} 10$.

Testing results

1) Determination of chromium and iron redox states.

The results are summarized in Tables 4-23 and 4-24.

Table 4-23: The Results of Chromium Redox states Determination

\begin{tabular}{|c|c|c|c|}
\hline Sample & $\begin{array}{l}\text { Total Chromium } \\
\text { Expressed as } \\
\mathrm{Cr}_{2} \mathrm{O}_{3}[\mathrm{wt} . \mathrm{i}]\end{array}$ & $\begin{array}{l}\text { Chromium(VI) } \\
\text { Expressed as } \\
\text { Cro }_{3}[w t . \text { t] }\end{array}$ & Used Method \\
\hline $1 / 5$ & $(n=5, \quad s=0.045)$ & $\begin{array}{c}0.380 \star \\
(n=5, s=0.003) \\
0.367 * \star \\
(n=7, s=0.008)\end{array}$ & Int.Regul. $\mathrm{CH}-16-94$ \\
\hline $2 / 5$ & $\begin{array}{c}5.76 \\
(n=5, \quad s=0.10)\end{array}$ & $\begin{array}{c}0.357 \star \\
(n=5, s=0.002) \\
0.339 \star \star \\
(n=7, s=0.007)\end{array}$ & Int.Regul. $\mathrm{CH}-16-94$ \\
\hline $\mathrm{Al} / \mathrm{Cr}$ & 0.51 & $0.070 \star *$ & Int. Regul. $\mathrm{CH}-16-94$ \\
\hline $\mathrm{BI} / \mathrm{Cr}$ & 0.54 & NS & Int.Regul. CH-16-94 \\
\hline 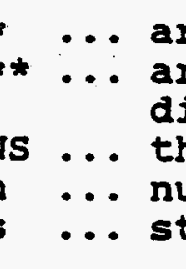 & $\begin{array}{l}\text { metic mean of } \\
\text { imetic mean of } \\
\text { enylcarbazide } \\
\text { iven componen } \\
\text { of determin }\end{array}$ & $\begin{array}{l}\text { trimetric re } \\
\text { pectrophotome } \\
\text { hod at prese } \\
\text { ras not deter } \\
\text { ons }\end{array}$ & $\begin{array}{l}\text { ts } \\
\text { c results with } \\
\text { of sodium azide } \\
\text { ed }\end{array}$ \\
\hline
\end{tabular}


Table 4-24: The Results of Iron Redox States Determination

\begin{tabular}{|l|l|l|l|}
\hline Sample & $\begin{array}{l}\text { Total Iron } \\
\text { Expressed as } \\
\text { Fe2 } \mathrm{O}_{3} \text { [wt. \&] }\end{array}$ & $\begin{array}{l}\text { Iron(II) } \\
\text { Expressed as } \\
\text { FeO [wt. \&] }\end{array}$ & Used Method \\
\hline $1 / 5$ & 1.34 & DL & Int.Regul.CH-15-94 \\
\hline $2 / 5$ & 2.08 & DL & Int.Regul.CH-15-94 \\
\hline $\mathrm{A} Y / \mathrm{Cr}$ & 1.43 & DI & Int.Regul.CH-15-94 \\
\hline $\mathrm{B} 1 / \mathrm{Cr}$ & 2.16 & DL & Int.Regul.CH-15-94 \\
\hline
\end{tabular}

DL: a content of determined component on a level of detection limit (DL) by using of given method. Event. presence of iron(II) content may be expected on levels of Feo $<0.01$ wt. \&.

2) Quantitative chemical analysis

The results are summarized in Table 4-25.

Table 4-25: The Results of Quantitative Chemical Analyses

\begin{tabular}{|c|c|c|c|c|}
\hline nent & $\begin{array}{l}\text { Sample 1/5 } \\
\text { [wt. \&] }\end{array}$ & $\begin{array}{l}\text { Sample } 2 / 5 \\
\text { [wt. \&] }\end{array}$ & $\begin{array}{l}\text { Sample } A I / C r \\
\text { [wt. \&] }\end{array}$ & Used Method \\
\hline 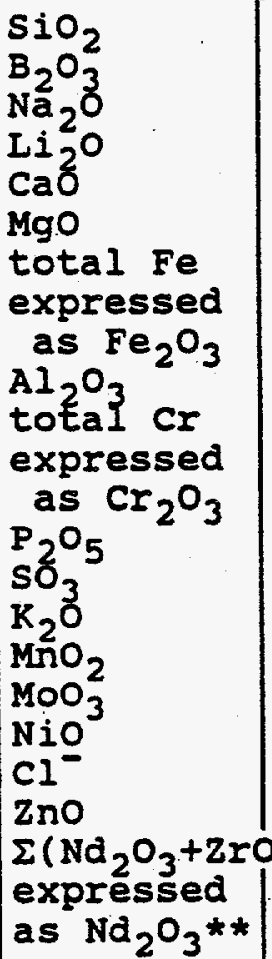 & $\begin{array}{c}3.60 \\
0.130 \\
0.069 \\
0.09 \\
0.38 \\
0.105 \\
0.09 \\
0.122 \\
0.15 \\
\left.+\mathrm{La}_{2} \mathrm{O}_{3}\right) \\
0.11\end{array}$ & $\begin{array}{l}5.70 \\
0.168 \\
0.083 \\
0.14 \\
0.55 \\
0.18 \\
0.11 \\
0.112 \\
0.26 \\
0.14\end{array}$ & \begin{tabular}{|c|c|}
0.45 \\
not determined \\
not determined \\
0.07 \\
0.42. \\
0.135 \\
0.10 \\
0.111 \\
0.18 \\
\\
0.12
\end{tabular} & $\begin{array}{l}\text { CSN } 700621 / 1 \\
\text { IR } C H-01-92 \\
\text { IR } C H-42 a-92 \\
\text { IR } C H-42 a-92 \\
\text { IR } C H-29 a-92 \\
\text { IR } C H-27 a-92 \\
\text { IR } C H-39 a-92 \\
\text { IR CH-21b-92 } \\
\text { IR CH-39a-92 } \\
\text { CSN } 700625 / 1 \\
\text { IR CH-08-92 } \\
\text { IR CH-42a-92 } \\
\text { IR CH-39a-92 } \\
\text { IR CH-39b-92 } \\
\text { IR CH-39a-92 } \\
\text { IR CH-11a-92 } \\
\text { IR CH-34a-92 } \\
\text { see Experimen- } \\
\text { tal Part }\end{array}$ \\
\hline
\end{tabular}


* The resulting value is an arithmetic mean from six determinations with a standard deviation $s=0.38$.

* Considering the decomposition method and not selective character of final determination method, the given values are only informative.

IR: Internal regulation

\subsubsection{NONDESTRUCTIVE ANALYSIS}

A special sample (from Nuclear Research Institute marked as $U J V-2-6)$ was polished under water, another sample of Glass $2 / 5$ was delivered in the form of a rod $12 \times 8 \times 50 \mathrm{~mm}$. This sample was broken just before the measurements in uHV to exclude the surface contamination. Photoelectron spectra were measured at room temperature by the ADES-400 VG spectrometer using MgR or AlK radiation $(1486.6 \mathrm{eV}, 1253.6 \mathrm{eV}, 110 \mathrm{w})$. The energy analyzer was operated in the constant energy mode at $50 \mathrm{eV}$ or $100 \mathrm{eV}$ pass energy. The instrument was calibrated by Au $4 f 7 / 2$ line at $83.8 \mathrm{eV}$. Photoelectron spectra were recorded in regions of Cr $2 \mathrm{p}$, 01s, Cls, and si2p lines at the normal take-off angle. All spectra were charge corrected with respect to the Cls line at. $285.0 \mathrm{ev}$.

\section{Chemical bonding of $C F$ atoms}

Sample UJV-2-6

The peak position of the cr2p line located at $577.0 \mathrm{eV}$ (see Figure 4-41) corresponds to $\mathrm{Cr}-\mathrm{O}$ bonding state in $\mathrm{Cr}_{2} \mathrm{O}_{3}$. An asymmetry of the line at higher binding energy indicates a presence of further bonding state $\left(\mathrm{CrO}_{3}\right)$. This bonding state contributes to the overall peak intensity by less than $10 \%$.

Sample $2 / 5$

The peak position of the Cr2p line located at binding energy of $577.0 \mathrm{eV}$ (charge corrected) corresponds to $\mathrm{Cr}$-0 bonding state in $\mathrm{Cr}_{2} \mathrm{O}_{3}$ (Capece, 1982). The peak is Gaussian with the FwHM of $3.8 \mathrm{eV}$. Chemical shift of expected $\mathrm{CrO}_{3}$ species is about 3 ev (Capece, 1982). From the above three facts it follows that only a little or no contribution of the $\mathrm{CrO}_{3}$ bonding state to the overall measured intensity is included (see Figure 4-42). 
From : 590.000 To: 570.000 in steps of -0.100505 scans. Dwell. 0.10 sec Region 6 of file :B:....NONE......

cr2p

sklovoda

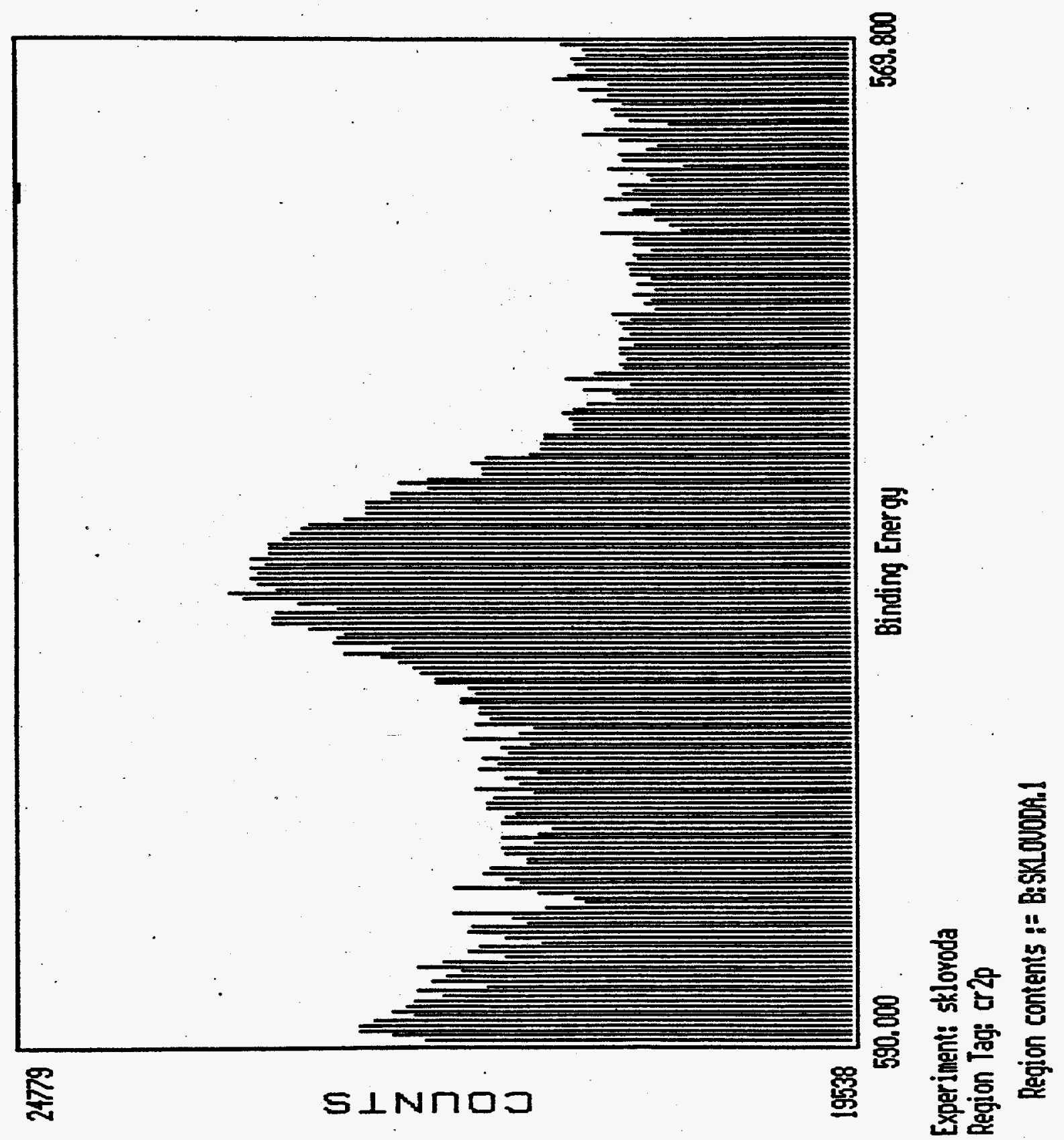

Figure 4-41: The Cr2p line of the sample UJV-2-6 


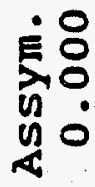

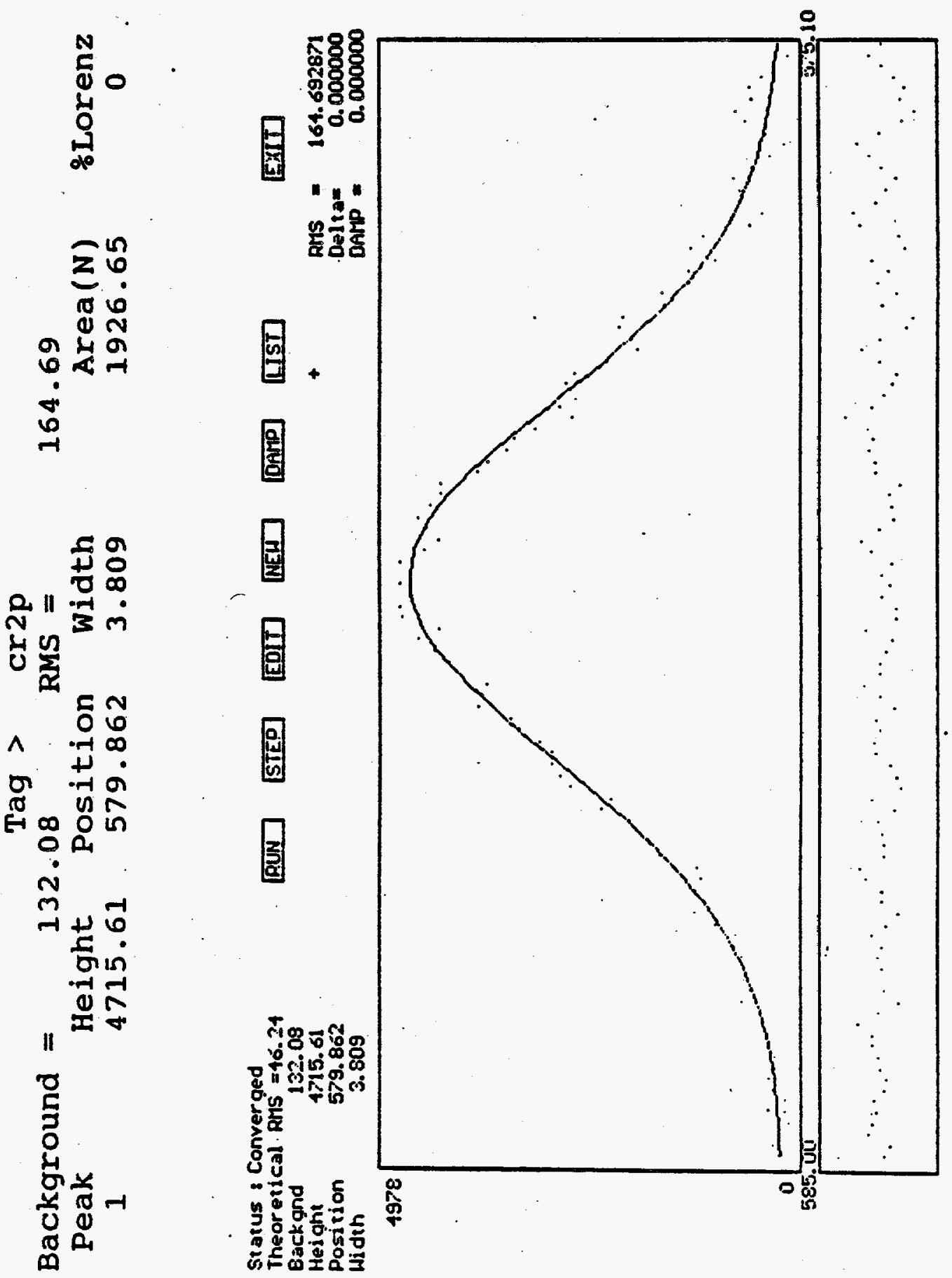

Figure 4-42: The Cr2p line of the sample 2/5 


\subsubsection{CHEMICAL DURABIIITY}

Chemical durability of glasses is one of several properties characterizing vitrification products and plays an important role in acceptance criteria for radioactive waste depositories.

In this project chemical durability was used for the comparison of glasses studied and in some cases the results of measurements supported information gained by other methods. This was e.g. the case of highly crystallized products.

For measurements of glass durability:

CSN ISO 719 Glass testing methods. Glass. Hydrolytic resistance of glass grains at $98^{\circ} \mathrm{C}$. Method of test and classification.

was used in the STL laboratory.

Preparation of testing sample

Following portions of samples were used for analyses:

$1 / 5$ portions $1 / 5(1), 1 / 5(2)$ and $1 / 5(4)$

$2 / 5$ portions $2 / 5(1), 2 / 5(2), 2 / 5(4)$ and $2 / 5(5)$

A2 block part marked $A 2$

B1 block part marked B1

B2 block part marked B2

The determination was performed also with samples labelled $A$ and $B$ for comparison (as described in Annex A2, Glasses $A$ and $B$ are very close to Glass 1 and 2 resp.). The samples were crushed to a grain size diameter $d=300-500 \mu m$ according to quoted standard.

Experimental part

The determination was carried out according to the mentioned standard procedure. The samples were treated one hour at $98{ }^{\circ} \mathrm{C}$ and the leachate was titrated by hydrochloric acid, $\mathrm{C}(\mathrm{HCl})$ $=0.01 \mathrm{~mol} / 1$.

Testing results

Testing results are summarized in the Table 4-26. The classification with regard to the resistance classes and limiting values of water resistance by grain method according to the quoted standard is summarized in the Table 4-27. 
Table 4-26: The Results of Hydrolytic Resistance of Tested Samples According to the CSN ISO 719

\begin{tabular}{|c|c|c|}
\hline $\begin{array}{l}\text { Sample } \\
\text { Marking }\end{array}$ & $\begin{array}{l}\text { Consumption of Hyarochloric } \\
\text { Acid } c(\text { HCI) }=0.01 \text { mol/l to } \\
1 \text { of Glass Grains [ml/g] }\end{array}$ & $\begin{array}{l}\text { Resistance } \\
\text { Class }\end{array}$ \\
\hline mean value & $\begin{array}{l}0.38 \\
0.37 \\
0.35 \\
0.37\end{array}$ & HGB 3 \\
\hline $2 / 5$ & $\begin{array}{l}44.1 \\
44.1 \\
43.7 \\
46.3 \\
44.6\end{array}$ & not classified \\
\hline average value & $\begin{array}{l}0.32 \\
0.25 \\
0.29\end{array}$ & HGB 3 \\
\hline Bl & $\begin{array}{l}30.3 \\
29.8 \\
29.8 \\
30.0\end{array}$ & not classified \\
\hline $\begin{array}{c}\text { B2 } \\
\text { average value }\end{array}$ & $\begin{array}{l}73.0 \\
82.0 \\
73.0 \\
71.7 \\
72.1 \\
72.3 \\
74.0\end{array}$ & not classified \\
\hline
\end{tabular}

Table 4-27: Classification of Tested Samples According to the CSN ISO 719

\begin{tabular}{|l|l|}
\hline Resistance Class & $\begin{array}{l}\text { Consumption of Hydrochloric Acid } \\
\text { c(HCI) } 0.01 \text { mol } / 1 \text { to } 1 \mathrm{~g} \\
\text { of Glass Grains }[\mathrm{ml} / \mathrm{g}]\end{array}$ \\
\hline HGB 1 & up to 0.10 through \\
HGB 2 & from 0.10 to 0.20 through \\
HGB 3 & from 0.20 to 0.85 through \\
HGB 4 & from 0.85 to 2.00 through \\
HGB 5 & from 2.00 to 3.50 through \\
\hline
\end{tabular}

Notes: The relatively high and irreproducible values of hydrolytic resistance for samples $2 / 5, \mathrm{B1}$ and $\mathrm{B} 2$ according to the quoted standard, reflect their inhomogeneous characters due to the presence of crystalline phases. 


\subsubsection{DISCUSSION OF RESULTS}

Quantitative chemical analysis has confirmed that the composition of Glasses 1 and 2 prescribed in the Test Plan was generally achieved by melting. The content of $\mathrm{Cr}_{2} \mathrm{O}_{3}$ is $0,3-0,5$ : lower and the content of $\mathrm{B}_{2} \mathrm{O}_{3}$ is slightly higher than required, but the differences found by the analysis cannot change the properties of the studied system to any considerable extent. The content of other elements is in.good agreement with the required composition.

Trivalent chromium is by order of magnitude higher than the concentration of the hexavalent form, in accord with the result described in chapter 4.2.3.2. The content of $\mathrm{Fe}^{2+}$ below the level of detection indicates that the spinel phase in glass 2 contains mainly $\mathrm{Ni}, \mathrm{Mn}$ and $\mathrm{Zn}$ in the positions of divalent cations.

The results of photoelectron spectroscopy of $\mathrm{Cr}$. redox state have shown the presence of a low content of $\mathrm{Cr}^{6+}$ in one of the samples, whereas in the sample $2 / 5$ the line is of gaussian form and only little or no contribution from $\mathrm{Cr}^{6+}$ bonding state is included. The method seems to be not sensitive enough for the determination of $\mathrm{Cr}^{6+} / \mathrm{Cr}$ (total) at the relatively low content of Cr in the samples.

Poor hydrolytic resistance according to Iso 719 of Glass 2 in contact with water apparently results from the crystallinity of the sample. Two possibilities come into consideration: the formation and presence of a higly soluble crystalline phase or/and, the presence of remaining interconnected glass phase rich in boric oxide and alkali oxides.

\subsubsection{BATCH HEAT TREATMENT}

The influence of time and temperature on the CrVI behavior during the heat treatment of respective batches has been studied by experiments in gradient furnace and constant temperature. Glass batches 1 and 2 marked Batch 1 and Batch 2 in amount of $500 \mathrm{~g}$ were prepared in svus laboratory and studied in the Glass Institute, STL laboratory. 


\subsubsection{GRADIENT FURNACE EXPERIMENTS}

\section{Preparation of testing samples}

Before weighing the batches were mixed by shaking in closed wide-mouth PE bottles. Weighing was carried out in analytical preweighing balances with precision $\pm 0.5 \mathrm{~g}$, then the bottle was closed as quickly and tightly as possible for preventing the air moisture penetration.

\section{Experimental part}

For tests the PtRhio boats, dimension $9.5 \times 12.7 \times 140 \mathrm{~mm}$, were used. Thermal treatment was carried out in the gradient resistance furnace for the determination of liquidus temperature, with precision $\pm 2^{\circ} \mathrm{C}$, maximum temperature $1320^{\circ} \mathrm{C}$. Temperature was measured by a calibrated $s$ type thermocouple with automatic temperature control in $5 \mathrm{~mm}$ intervals, temperature determination precision was $\pm 2{ }^{\circ} \mathrm{C}$.

The $10 \mathrm{~g}$ weight of batch was uniformly spread on the boat bottom. The boat with sample was inserted into the furnace with stabilized temperature, and after a certain time put out and spontaneously cooled.

Temperature distribution in the furnace tightly above the sample was measured during the test with the exception of tests with 1 hour thermal treatment. In such cases the temperature distribution in the furnace. was measured before inserting the boat with sample.

Tests were carried out in following temperature ranges using respective residence time:

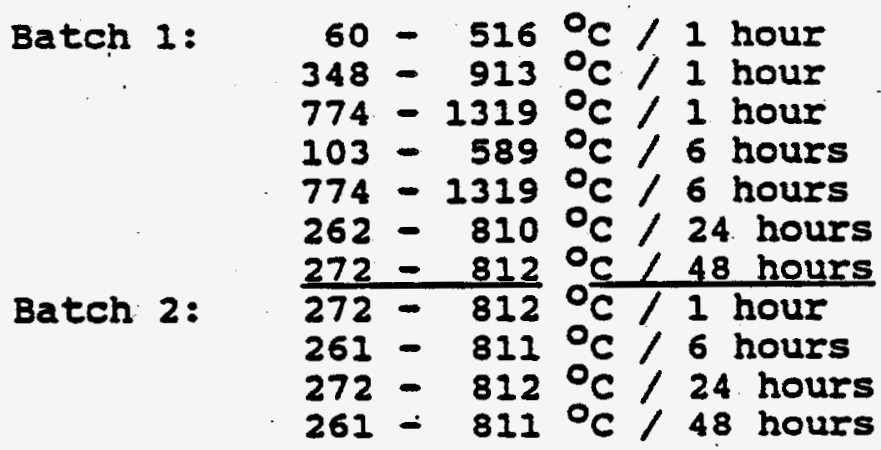




\section{Testing results}

The appearence of the boat after thermal treatment is shown in Figures 4-43 to 4-46. In Tables 4-27 and 4-28 the visual evaluation of temperatures, corresponding to certain changes in appearance (color- or other transitions) of thermally treated gradient boats in dependence on thermal treatment time, is shown. The precision of corresponding temperature reading is $\pm 10^{\circ} \mathrm{C}$ with regard to unclear transitions (with the exception of some marked temperatures which have lower precision because of a very unclear transition).

Legend for visual evaluation:

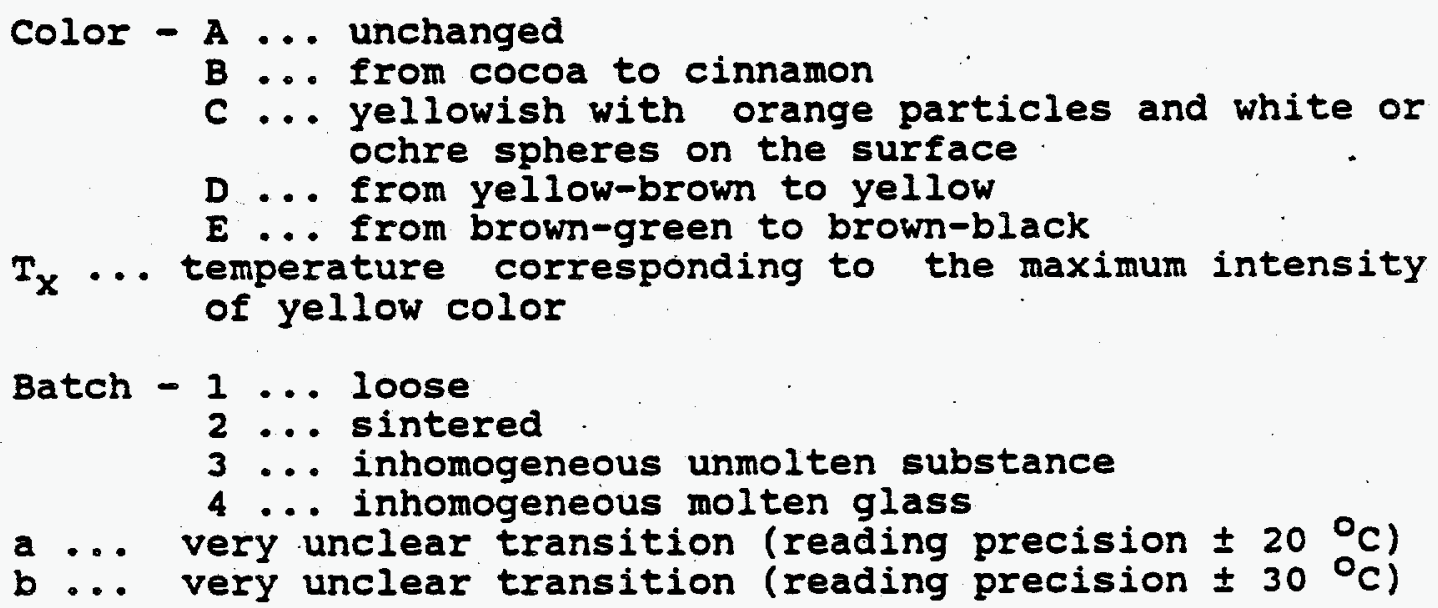

Table 4-28: Visual Evaluation of Specimen Appearance of the Batch 1 after Thermal Treatment (For Notes and Legend See Text)

\begin{tabular}{|c|c|c|c|c|c|c|}
\hline $\begin{array}{l}\text { Thermal } \\
\text { Treatment } \\
\text { Time }[\mathrm{h}]\end{array}$ & $\begin{array}{c}\mathrm{A}-\mathrm{B} \\
{\left[{ }^{\circ} \mathrm{C}\right]}\end{array}$ & $\begin{array}{l}\mathrm{B}-\mathrm{C} \\
{\left[{ }^{\circ} \mathrm{C}\right]}\end{array}$ & $\begin{array}{l}\mathrm{C}-\mathrm{D} \\
{\left[{ }^{\circ} \mathrm{C}\right]}\end{array}$ & $\begin{array}{l}\mathrm{D}-\mathrm{E} \\
2-3 \\
{\left[{ }^{\circ} \mathrm{C}\right]}\end{array}$ & $\begin{array}{l}3-4 \\
{\left[{ }^{\circ} \mathrm{C}\right]}\end{array}$ & $\begin{array}{l}\mathrm{T}_{\mathbf{X}} \\
{\left[{ }^{\circ} \mathrm{C}\right]}\end{array}$ \\
\hline 1 & $410 \mathrm{a}$ & 525 & 570 & $670 a$ & 710 & 620 \\
6 & $350 a$ & 515 & 550 & $670 a$ & 710 & 600 \\
24 & $320 a$ & 470 & 520 & $670 a$ & 710 & 560 \\
48 & $300 a$ & 450 & 500 & $670 a$ & 710 & 550 \\
\hline
\end{tabular}


Table 4-29: Visual Evaluation of Gradient Boats Appearance with Batch 2 after Thermal Treatment

(For Notes and Legend See Text)

\begin{tabular}{|c|c|c|c|c|c|}
\hline $\begin{array}{c}\text { Thermal } \\
\text { Treatment } \\
\text { Time [h] }\end{array}$ & $\begin{array}{c}\mathrm{A}-\mathrm{B} \\
{\left[{ }^{\circ} \mathrm{C}\right]}\end{array}$ & $\begin{array}{c}\mathrm{B}-\mathrm{C} \\
{\left[{ }^{\circ} \mathrm{C}\right]}\end{array}$ & $\begin{array}{c}\mathrm{C}-\mathrm{D} \\
{\left[{ }^{\circ} \mathrm{C}\right]}\end{array}$ & $\begin{array}{c}\mathrm{D}-\mathrm{E} \\
{\left[{ }^{\circ} \mathrm{C}\right]}\end{array}$ & $\begin{array}{c}\mathrm{T}_{\mathrm{X}} \\
{\left[{ }^{\circ} \mathrm{C}\right]}\end{array}$ \\
\hline 1 & $330 \mathrm{a}$ & $530 \mathrm{a}$ & 550 & $>810$ & 660 \\
6 & $300 \mathrm{~b}$ & $520 \mathrm{a}$ & 540 & $800 \mathrm{a}$ & 630 \\
24 & $300 \mathrm{~b}$ & $510 \mathrm{a}$ & 530 & 780 & 600 \\
48 & $300 \mathrm{~b}$ & $500 \mathrm{a}$ & 530 & 760 & 580 \\
\hline
\end{tabular}

F

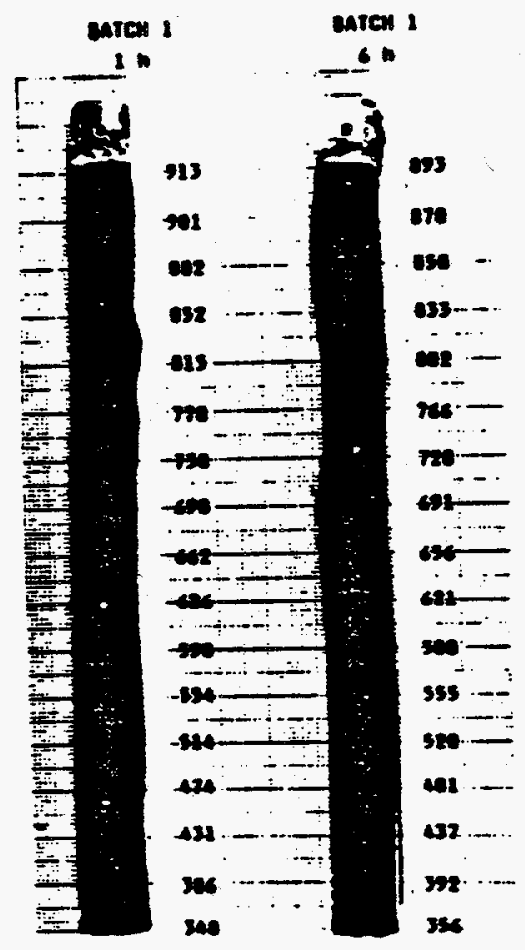

Figure 4-43: Appearance of the Boat with Batch 1 after Thermal Treatment in the Gradient Furnace during 1 and 6 Hours 


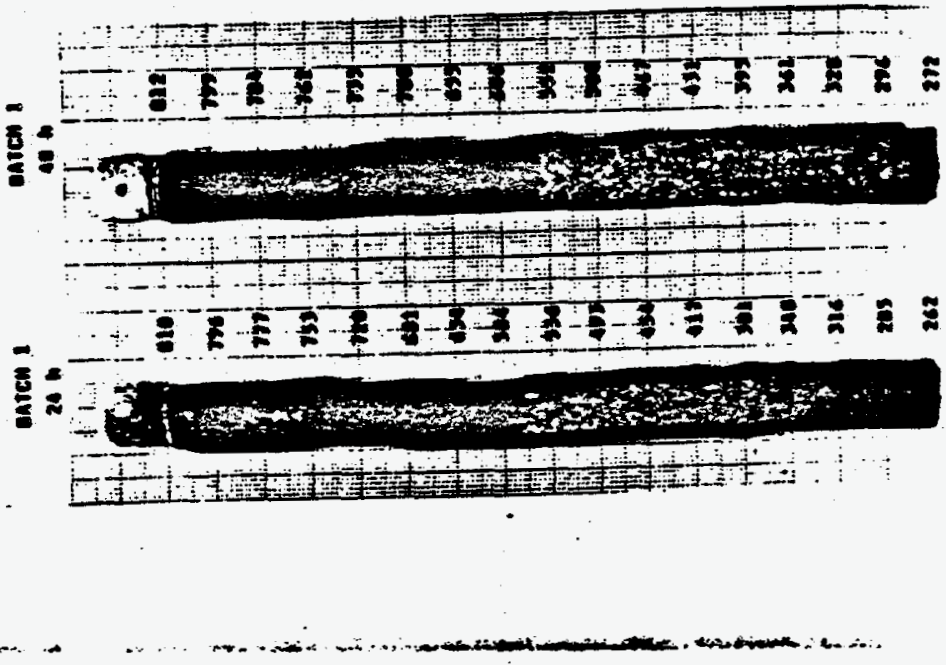

Figure 4-44: Appearance of the Boat with Batch 1 after Thermal Treatment in the Gradient Furnace during 24 and 48 Hours

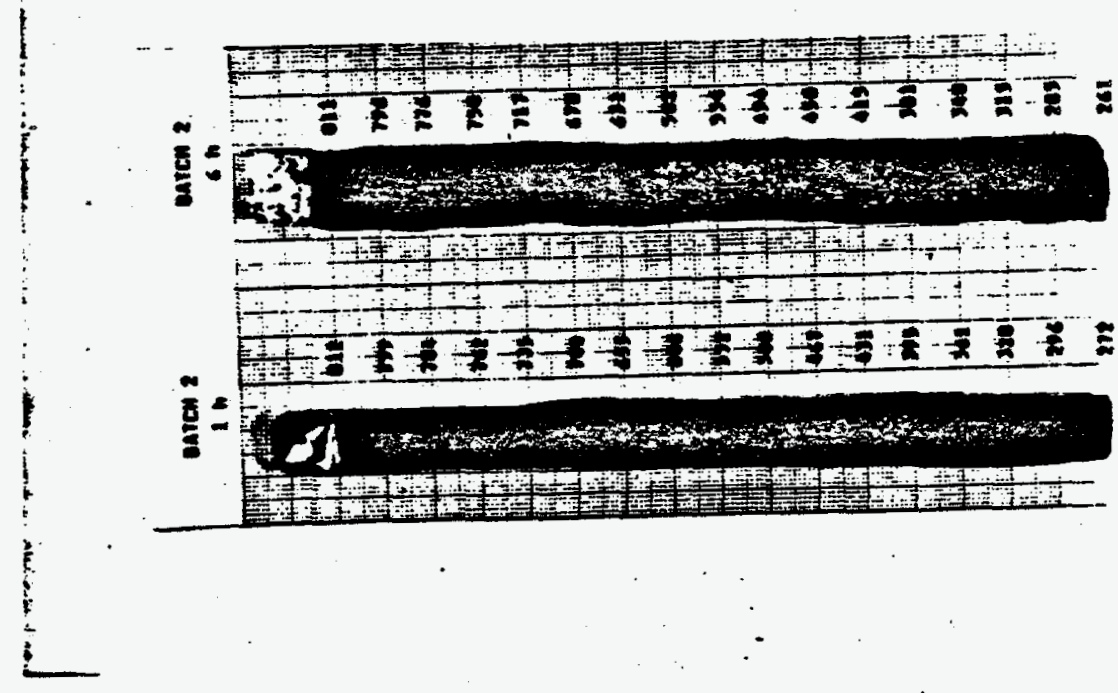

Figure 4-45: Appearance of the Boat with Batch 2 after Thermal Treatment in the Gradient Furnace during $I$ and 6 hours 


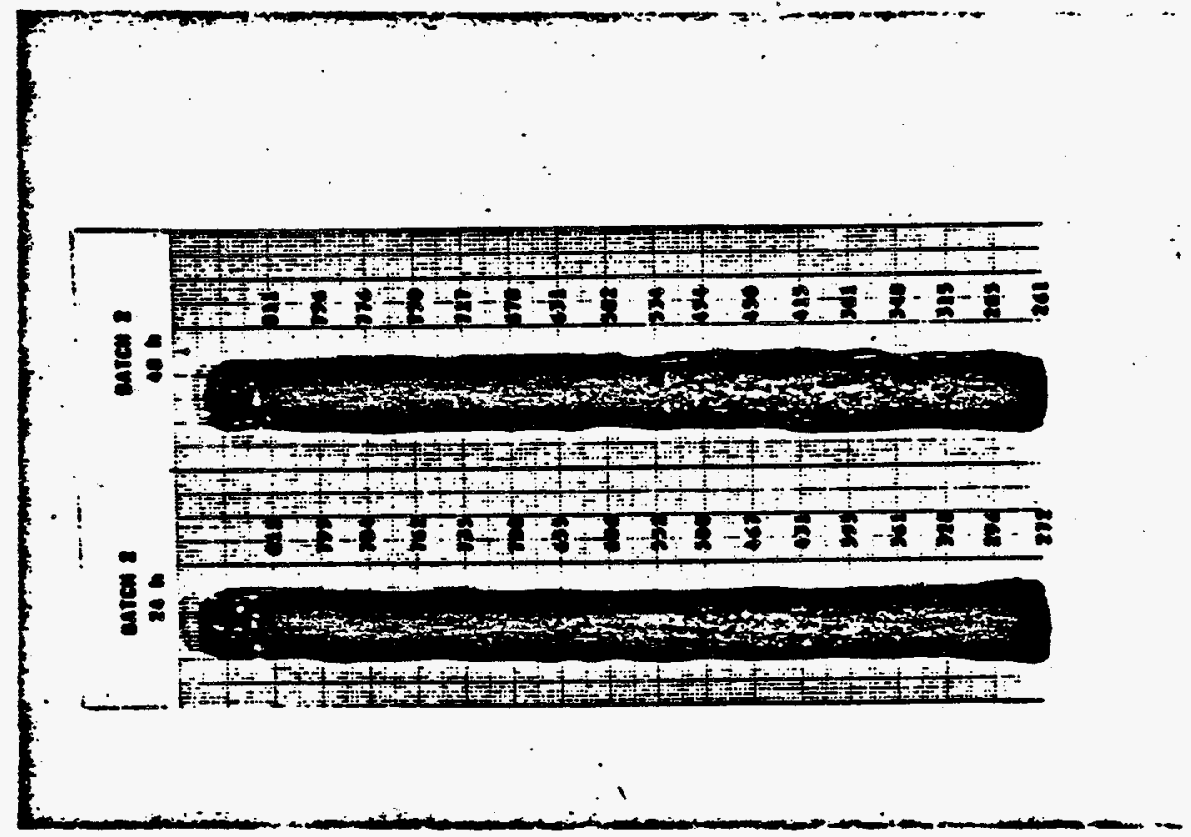

Figure 4-46: Appearance of the Boat with Batch 2 after Thermal Treatment in the Gradient Furnace during 24 and 48 Hours

\subsubsection{EXPERIMENTS AT CONSTANT TEMPERATURE}

Preparation of testing samples

Before weighing the batches were mixed by shaking in closed wide-mouth PE bottle. Weighing was carried out using analytical preweighing balances with precision $\pm 0.01 \mathrm{~g}$, then the bottle was closed as quickly and tightly as possible for preventing of air moisture penetration.

Experimental part

For test the Pt dishes, diameter $50 \mathrm{~mm}$, height $25 \mathrm{~mm}$, batch weight $5.00 \mathrm{~g}$ were used. The thermal treatment was carried out in a crucible furnace (producer szIKKTI Budapest, Hungary) with inner dimension: diameter $26 \mathrm{~cm}$, height $33 \mathrm{~cm}$, and a regulator Eurotherm (temperature control accuracy was $\pm 2{ }^{\circ} \mathrm{C}$ ). Temperature in the furnace close to the dish with sample was measured by a calibrated $K$ type thermocouple and read on the temperature indicator FLUKE. 
The dishes with samples (maximum 4 dishes at the same time in one test) were inserted into the preheated furnace. The temperature was stabilized in max. 5 minutes from inserting and a maximum deviation from the adjusted temperature was $\pm 5{ }^{\circ} \mathrm{C}$ during first 10 minutes of thermal treatment.

with the exception of first 10 minutes the temperature stability was $\pm 2^{\circ} \mathrm{C}$. After the determined thermal treatment time the dishes with samples were put out and inserted.into a muffle lehr preheated up to $250 \pm 5{ }^{\circ} \mathrm{C}$ where they were for 5 minutes for temperature stabilization. After this time the dishes were put out and the bottoms were quenched in the cold water. This procedure released the thermally treated sample from the dish bottom. The treatment was used in all tests with the exception of the thermal treatment at $200{ }^{\circ} \mathrm{C}$ when the dish bottom was quenched in water immediately after putting out from the muffle lehr.

During initial tests some deviations from this procedure (inserting of samples in the furnace) appeared and consequently a certain shift in $\mathrm{CrO}_{3}$ content in the resulted sample occurred (standard conditions were not sufficient). That is why these testing results were not included in final results and were considered only as preliminary. The following tests with exactly kept procedure were called main tests series. If any deviation from the standard procedure was supposed or in exceptional cases, when the determined $\mathrm{CrO}_{3}$ content value was considerably different from estimated dependences, the whole test was repeated.

Dishes with thermally treated samples were continuously delivered to the chemical laboratory for the $c r^{6+}$ determination. Note: During the possible oxidation of total $\mathrm{Cr}^{3+}$ to $\mathrm{Cr}^{6+}$ in case of two inserted dishes ( $5 \mathrm{~g}$ of Batch 1 and $5 \mathrm{~g}$ of Batch 2) $0.118 \mathrm{~g}$ of $\mathrm{O}_{2}$ would be consumed. With an inner volume of the crucible furnace $17.5 \mathrm{dm}^{3}$ it would cause a theoretical $\mathrm{O}_{2}$ content decrease in the furnace atmosphere by 9.7 rel. \% (calculation for $900^{\circ} \mathrm{C}$ ), or $6.8 \mathrm{rel} .8$ (calculation for $550^{\circ} \mathrm{C}$ ). 
The furnace is not, however, airtight and a certain change of air with the surrounding air occurs. When comparing results gained with a different number of dishes (reproducibility of results with Batch 1 during the thermal treatment at $550^{\circ} \mathrm{C} / 3 \mathrm{~h}$ ) the effect of the number of dishes on the resulted value was not detected. With regard to the supposed result accuracy of $\mathrm{Cr}^{6+}$ content determination in the sample at given experimental conditions, including all experimental effects and estimated to 5 - 10 rel. $t$, it is possible to neglect this effect.

Testing result

Tables 4-29 and 4-30 give a survey of tests with the respective visual evaluation. The legend of the visual evaluation is the same as in Section 4.2.4.1.:

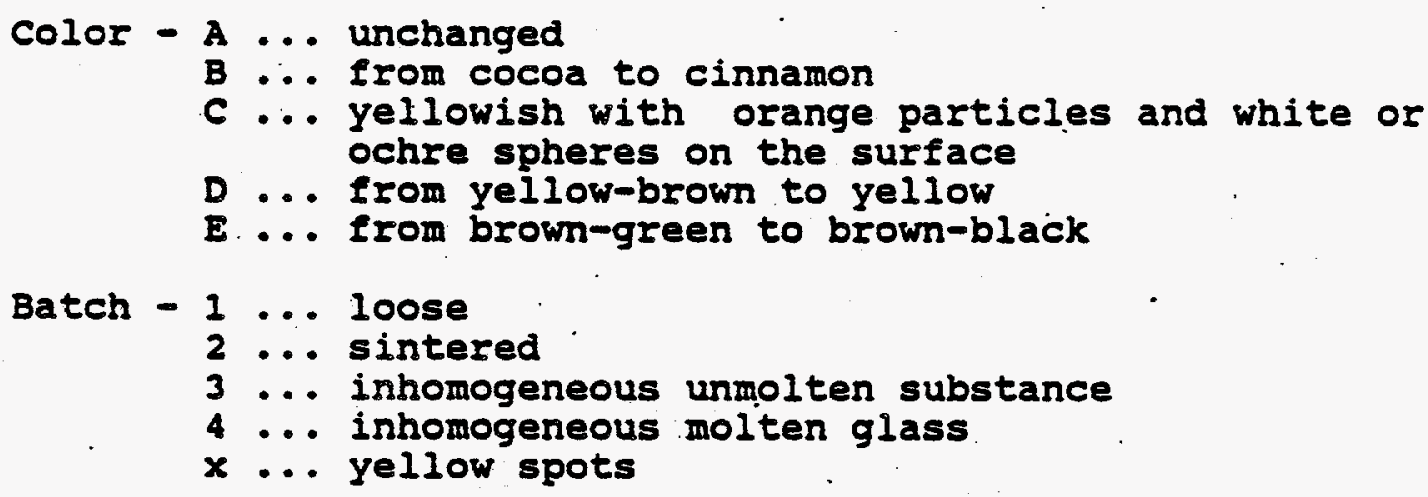

Table 4-30: Tests Survey with Thermally Treated Batch 1 at a Constant Temperature and their Visual Evaluation

\begin{tabular}{|c|c|c|c|c|c|c|c|}
\hline \multirow{2}{*}{$\begin{array}{r}\text { Temperature } \\
{\left[{ }^{\circ} \mathrm{C}\right]}\end{array}$} & & \multicolumn{4}{|c|}{ Time } & \multicolumn{2}{|c|}{$[h]$} \\
\hline & 0.25 & 0.5 & 1 & 3 & 6 & 24 & 48 \\
\hline $\begin{array}{l}900 \\
800 \\
700 \\
650 \\
600 \\
550 \\
500 \\
450 \\
400 \\
300 \\
200\end{array}$ & $\mathrm{BI}-2$ & $\begin{array}{c}\text { E4 } \\
\text { E4X } \\
\text { E3X } \\
\text { D2X } \\
\text { D2 } \\
\text { C2 } \\
\text { B1-2 } \\
\text { B1-2 } \\
\mathrm{A}-\mathrm{B} 1 \\
\mathrm{~A} 1 \\
\mathrm{~A} 1\end{array}$ & $\begin{array}{l}\text { E4X } \\
\text { E3X } \\
\text { D2X } \\
\text { D2 } \\
\text { C2 }\end{array}$ & $\begin{array}{c}\text { E4X } \\
\text { E3X } \\
\text { D2X } \\
\text { D2 } \\
\text { C2 } \\
\text { B1-2 } \\
\text { B1-2 } \\
\text { B1-2 } \\
\text { A1 } \\
\text { A1 }\end{array}$ & $\begin{array}{c}\text { E3X } \\
\text { D2X } \\
\text { D2 } \\
\text { C2 } \\
\text { B1-2 } \\
\text { B1-2 }\end{array}$ & D2 & D2 \\
\hline
\end{tabular}


Table 4-31: Tests survey with a Thermally Treated Batch 2 at a Constant Temperature and their Visual Evaluation

\begin{tabular}{|c|c|c|c|c|c|c|c|}
\hline \multirow{2}{*}{$\begin{array}{r}\text { Temperature } \\
{\left[{ }^{\circ} \mathrm{C}\right]}\end{array}$} & \multicolumn{5}{|c|}{ Time } & \multicolumn{2}{|c|}{$[\mathrm{h}]$} \\
\hline & 0.25 & 0.5 & 1 & 3 & 6 & 24 & 48 \\
\hline $\begin{array}{l}900 \\
800 \\
750 \\
700 \\
650 \\
600 \\
550 \\
500 \\
450 \\
400 \\
300 \\
200\end{array}$ & $\mathrm{~B}-\mathrm{Cl}$ & $\begin{array}{c}\text { E3X } \\
\text { D2 } \\
\text { D2 } \\
\text { D1-2 } \\
\text { D1-2 } \\
\text { D1-2 } \\
\text { C1 } \\
\text { B1 } \\
\text { B1 } \\
\text { B1 } \\
\text { A1 } \\
\text { A1 }\end{array}$ & $\begin{array}{c}\text { D2 } \\
\text { D2 } \\
\text { D2 } \\
\text { D1-2 } \\
C-D 1\end{array}$ & $\begin{array}{c}\text { E2X } \\
\text { D2 } \\
\text { D2 } \\
\text { D2 } \\
\text { D1-2 } \\
\text { C-D1 } \\
- \text { B1 } \\
\text { B1 } \\
\text { B1 } \\
\text { A1 } \\
\text { A1 }\end{array}$ & $\begin{array}{c}\text { D2 } \\
\text { D2 } \\
\text { D1-2 } \\
\text { C-D1 } \\
\text { B1 } \\
\text { B1 }\end{array}$ & $C-D I$ & $C-D 1$ \\
\hline
\end{tabular}

\subsubsection{CHEMICAL ANALYSIS OF BATCHES}

$\mathrm{Cr}^{6+}$ content in thermally treated batches

\section{Experimental procedure}

Sample in Pt dish was moistened with water and transferred to a heating plate with controlled. electric power input. $5 \mathrm{ml}$ of hydrofluoric acid, conc., $\mathrm{H}_{2} \mathrm{~F}_{2}=38-40$ wt. and $1 \mathrm{ml}$ of diluted sulfuric acid, $\mathrm{H}_{2} \mathrm{SO}_{4}(1+1)$ were added. Reaction mixture temperature was held at $50^{\circ} \mathrm{C}$ within 7 days. During the sample decomposition the hydrofluoric acid was added to the total volume of $30 \mathrm{ml} \mathrm{HF}$ while mixing the reaction mixture by Pt wire from time to time.

The decomposed sample was quantitatively transferred to a volumetric flask by $20 \mathrm{ml}$ of saturated boric acid solution. The sample stock solution prepared by this method was diluted with water up to. the mark and mixed.

The aliquot part of the stock solution was titrated by a volumetric solution of iron salt, $c\left(\mathrm{NH}_{4}\right)_{2} \mathrm{Fe}\left(\mathrm{sO}_{4}\right)_{2}=0.02 \mathrm{~mol} / \mathrm{l}$ at potentiometric indication of the equivalence point by a cell created by platinum and saturated calomel electrode. Factor of iron salt volumetric solution was determined by a standard solution of potassium dichromate. 
The results of $\mathrm{Cr}^{6+}$ determination in batches samples are expressed in the form of $\mathrm{CrO}_{3}$ wt. $z$.

\section{Disturbina effects}

The determination is disturbed by the presence of all.ions in higher oxidizing states which react with a volumetric solution of iron salt at the test conditions, e.g. manganese Ions $\mathrm{Mn}^{3+}, \mathrm{Mn}^{4+}, \mathrm{Mn}^{6+}, \mathrm{Mn}^{7+}$. However, no experimental groundworks exist for evidence of their presence in titration solution.

Testing result

Preliminary experiments

a) Blank experiment

Thermally untreated batches in amount $5 \mathrm{~g}$.

Batch 1:

0.014 wt. of $\mathrm{CrO}_{3}$

Batch 2:

0.013 wt. of $\mathrm{CrO}_{3}$

0.032 wt. of $\mathrm{CrO}_{3}$

0.032 wt. of $\mathrm{CrO}_{3}$

b) The effect of the amount of thermaliy treated batch Thermal treatment at $700{ }^{\circ} \mathrm{C} / 0.5 \mathrm{~h}$ within the preliminary tests, samples 1 and 2 were treated simultaneousiy

Batch 1: sample 1 (weight $3 \mathrm{~g}$ ) sample 2 (weight $5 \mathrm{~g}$ )

2.23 wt. of $\mathrm{CrO}_{3}$. 1.24 wt. of $\mathrm{CrO}_{3}$

Batch 2: sample 1 (weight $3 \mathrm{~g}$ ) sample 2 (weight $5 \mathrm{~g}$ )

4.09 wt. of $\mathrm{CrO}_{3}$ 4.31 wt. of $\mathrm{CrO}_{3}$

c) Reproducibility of determination of $\mathrm{Cr}^{6+}$ content in thermally treated batches

Batch 1: (thermal treatment at $550^{\circ} \mathrm{C} / 3 \mathrm{~h}$ within the main test series, samples 1 to 4 were thermally treated simultaneously, sample 5 separately) sample 1 sample 2

1.69 wt. of $\mathrm{CrO}_{3}$ sample 3 1.66 wt. of $\mathrm{CrO}_{3}$ sample 4 sample 5 1.65 wt. of $\mathrm{CrO}_{3}$ 1.69 wt. of $\mathrm{CrO}_{3}$ $\overline{\mathbf{x}}=1.67$ wt. of $\mathrm{CrO}_{3}$

1.66 wt. of $\mathrm{CrO}_{3}$ $s=0.02$ wt. of $\mathrm{CrO}_{3}$ 
Batch 1: (thermal treatment at $900{ }^{\circ} \mathrm{C} / 3 \mathrm{~h}$ within the preliminary tests, samples 1 and 2 were thermally treated simultaneously)

sample 1

sample 2

0.354 wt. \& of $\mathrm{CrO}_{3}$

0.334 wt. of $\mathrm{CrO}_{3}$

$\bar{x}=0.344$ wt. of of $\mathrm{CrO}_{3}$

Batch 2: (thermal treatment at $550{ }^{\circ} \mathrm{C} / 3 \mathrm{~h}$, samples 1 to 4 were thermally treated within the preliminary tests, sample 5 was treated separately within the main tests series)

sample 1

sample 2

1.79 wt. of $\mathrm{CrO}_{3}$

sample 3

1.74 wt. \& of $\mathrm{CrO}_{3}$

sample 4

1.77 wt. if of $\mathrm{CrO}_{3}$

1.84 wt. \& of $\mathrm{CrO}_{3}$

$\bar{x}=1.79$ wt. \& of $\mathrm{CrO}_{3}$

$s=0.04$ wt. of $\mathrm{CrO}_{3}$

sample 5

2.30 wt. \& of $\mathrm{CrO}_{3}$

Batch 2: (thermal treatment at $900{ }^{\circ} \mathrm{C} / 3 \mathrm{~h}$ within the preliminary tests, samples 1 and 2 were thermally treated simultaneously)

sample 1

2.47 wt. \& of $\mathrm{CrO}_{3}$

sample 2

2.32 wt. of $\mathrm{CrO}_{3}$

$\overline{\mathbf{x}}=2.40$ wt. of $\mathrm{CrO}_{3}$

\section{Main tests series}

The gained results are summarized in Tables 4-31 and 4-32.

Table 4-32: $\mathrm{Cr}^{6+}$ Content (Expressed as wt. of $\mathrm{CrO}_{3}$ )

in Thermally Treated Samples of Batch 1

(see Text for more Details)

\begin{tabular}{|c|c|c|c|c|c|c|c|}
\hline Temperature & \multicolumn{9}{|c|}{ Time } & \multicolumn{2}{c|}{ [h] } \\
\cline { 2 - 7 }$\left[{ }^{\circ} \mathrm{C}\right]$ & 0.25 & 0.5 & 1 & 3 & 6 & 24 & 48 \\
\hline 900 & & 0.288 & & & & & \\
800 & & 0.471 & 0.465 & 0.475 & & & \\
700 & & 0.992 & 1.01 & 1.14 & 1.14 & & \\
650 & & 1.54 & 1.87 & 2.09 & 2.33 & & \\
600 & & 1.44 & 1.67 & 2.42 & 3.10 & & \\
550 & 0.970 & 1.22 & 1.35 & 1.67 & 1.93 & 2.72 & 3.12 \\
500 & & 1.04 & & 1.45 & 1.58 & & \\
450 & & 0.697 & & 1.26 & & & \\
400 & & 0.583 & & 1.00 & 1.22 & & \\
300 & & 0.269 & & 0.576 & & & \\
200 & & 0.037 & & 0.065 & & & \\
\hline
\end{tabular}


Table 4-33: $\mathrm{Cr}^{6+}$ Content (Expressed as wt. of $\mathrm{Cro}_{3}$ )
in Thermally Treated Samples of Batch 2 (See Text for more Details)

\begin{tabular}{|c|c|c|c|c|c|c|c|}
\hline Temperature & \multicolumn{9}{|c|}{ Time } & \multicolumn{2}{c|}{ [h] } \\
\cline { 2 - 8 }$\left[{ }^{\circ} \mathrm{C}\right]$ & 0.25 & 0.5 & 1 & 3 & 6 & 24 & 48 \\
\hline 900 & & 1.97 & & & & & \\
800 & & 3.73 & 4.05 & 3.46 & & & \\
750 & 4.29 & & & 4.75 & & & \\
700 & & 3.67 & 4.61 & 4.99 & 5.19 & & \\
650 & & 2.74 & 3.81 & 4.67 & 5.04 & & \\
600 & & 2.00 & 2.50 & 3.50 & 4.56 & & 4.71 \\
550 & 1.27 & 1.55 & 1.86 & 2.30 & 2.82 & 3.85 & 4 \\
500 & & 1.42 & & 1.78 & 2.05 & & \\
450 & & 1.30 & & 1.57 & & & \\
400 & & 1.00 & & 1.43 & 1.69 & & \\
300 & & 0.662 & & 1.38 & & & \\
200 & & 0.046 & & 0.140 & & & \\
\hline
\end{tabular}

\subsubsection{MATHEMATICAL EVALUATION OF EXPERIMENTS}

The dependence of the $\mathrm{Cr}^{6+}$ content on thermal treatment conditions in Batches 1 and 2

The calculations of dependence of $\mathrm{Cr}^{6+}$ content, expressed as $\mathrm{CrO}_{3}$, (in wt. related to the weight of initial batch) on conditions of the thermal treatment were carried out on the basis of experimental values given in Tables 4-31 and 4-32. The program ADSTAT (Linear regression and Non-linear regression) was used for statistical calculations. For the mathematical description of particular dependences the selected types of functions (1inear, polynomial, power, hyperbolic and exponential) were used.

\section{Batch 1}

Mathematical evaluation was carried out separately for two temperature ranges differing in the character of mathematical dependences.

The range of low temperatures

This range covers temperatures from $200{ }^{\circ} \mathrm{C}$ to $650^{\circ} \mathrm{C}$. For thermal treatment temperatures $600^{\circ} \mathrm{C}$ and $650^{\circ} \mathrm{C}$ and for longer 
residence times (more than 1 hour) statistically important deviations from supposed course of dependence (i.e. great increase of $\mathrm{CrO}_{3}$ content at the temperature $600{ }^{\circ} \mathrm{C}$ and a strong decrease at the temperature $650^{\circ} \mathrm{C}$ ) were found. That is why these values were not included in final calculations.

For the description of time dependence of $\mathrm{CrO}_{3}$ content the most suitable was the power function. Linear regression was used. for the calculation in case of the temperature $550^{\circ} \mathrm{C}$. Following coefficients were obtained:

$$
\log y=A+B * \log t
$$

$$
\begin{array}{lll}
A=0.129(0) & s_{A}=0.006(1) \\
B=0.216(2) & s_{B}=0.006(5) \\
s=0.013(6) & r=0.9977 \\
n=7 & &
\end{array}
$$

where:

(area of validity: $0.25 \mathrm{~h}$ to $48 \mathrm{~h}$ )

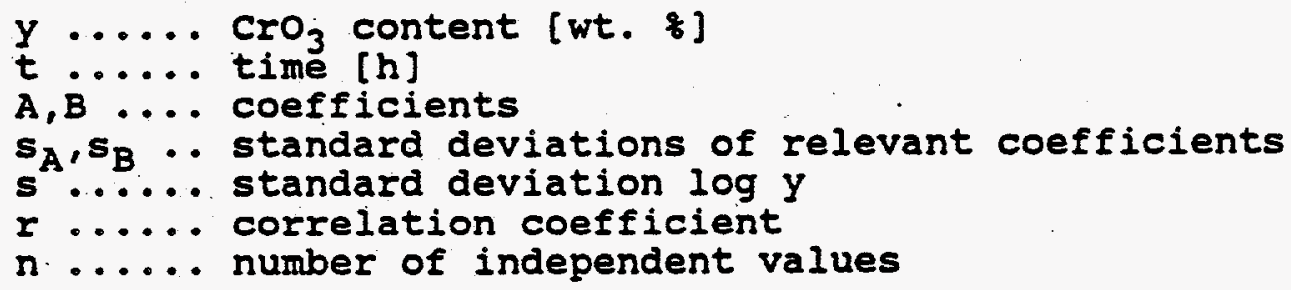

The correspondence of experimental values with a calculated course of the dependence according to the equation $/ 1 /$ is documented in a Figure (see Annex C18).

The equation(1) can be transformed:

$$
y=1.346 * t^{0.216}
$$

For the calculation of the temperature dependence of $\mathrm{CrO}_{3}$ content as the most suitable following function was found (Method of non-linear regression, calculation from all experimental values for $200{ }^{\circ} \mathrm{C}$ to $550{ }^{\circ} \mathrm{C}$ and further on from values for 600 ${ }^{\circ} \mathrm{C} / 0.5 \mathrm{~h}$ and $\mathrm{h}$, and $650{ }^{\circ} \mathrm{C} / 0.5 \mathrm{~h}$ and $1 \mathrm{~h}$ was used. For the purpose of the calculation the $\mathrm{CrO}_{3}$ content is converted to the time $t=1 \mathrm{~h}$, dividing the experimental value by the expression $\left.t^{0.216}\right)$ :

$$
y=A *(T-B)
$$




$$
\begin{aligned}
& A=0.00397(1) \\
& B=204 .(4) \\
& s=0.07(4)
\end{aligned}
$$

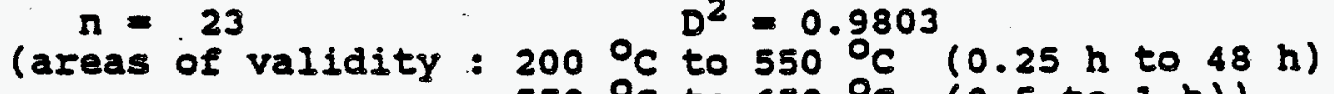

$$
\begin{aligned}
& \left.550{ }^{\circ} \mathrm{C} \text { to } 650{ }^{\circ} \mathrm{C} \quad(0.5 \text { to } 1 \mathrm{~h})\right)
\end{aligned}
$$

where:

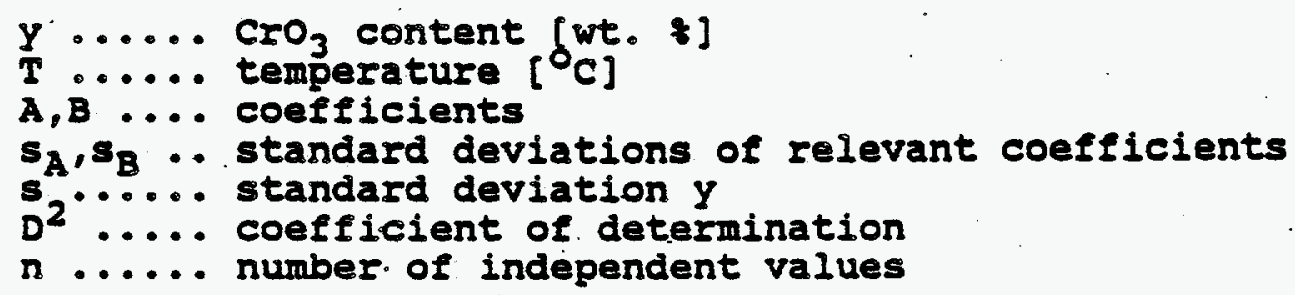

The correspondence of experimental values with calculated course of the dependence according to the relation / $/$ is documented in Figure (see Annex C19).

The relation used for the calculation of the dependence of $\mathrm{CrO}_{3}$ content on temperature and time of thermal treatment in the range of lower temperatures is following:

$$
y=0.00397 *(T-204) . t^{0.216}
$$

where:

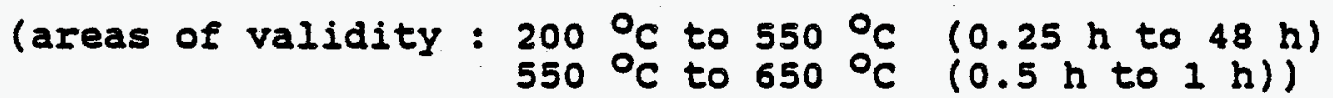

$$
\begin{aligned}
& y \ldots \ldots \text { Cro } \\
& \text { T } \ldots \ldots \text { content }[w t . ~ \\
& t \\
& t] . . .
\end{aligned}
$$

The comparison of experimental values with a calculated course of the dependence is shown in Figure 4-47.

\section{The range of high temperatures}

This area includes temperatures of thermal treatment higher than $650^{\circ} \mathrm{C}$ (experimentally verified up to $900^{\circ} \mathrm{C}$ ). In this range the effect of the time of thermal treatment was not found and the $\mathrm{CrO}_{3}$ content was dependent only on the temperature of the thermal treatment (at given experimental conditions).

For the description of the dependence of $\mathrm{CrO}_{3}$ content on the thermal treatment conditions in the area of high temperatures as most suitable following function was found (method of non-iinear 
regression, calculation from all experimental values for $800^{\circ} \mathrm{C}$ and $900^{\circ} \mathrm{C}$ and from a value for $700{ }^{\circ} \mathrm{C} / 6 \mathrm{~h}$ ).:

$$
Y=A+\frac{B}{T-C}
$$

$$
\begin{aligned}
A & =-0.030(8) & s_{A} & =0.021 \\
B & =87.6(1) & s_{B} & =5.7(1 \\
C & =625 .(2) & s_{C} & =3 .(6) \\
s & =0.005(0) & D^{2} & =0.999 \\
n & =5 & & D^{2}
\end{aligned}
$$

where:

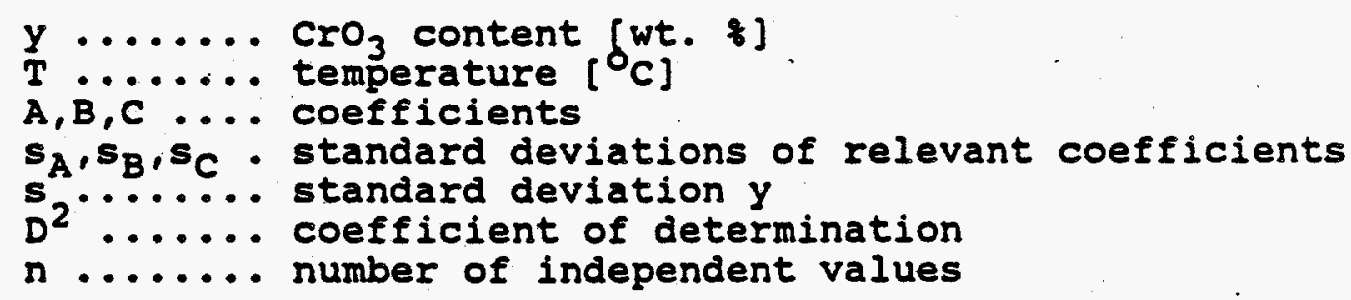

The correspondence of experimental values with calculated course of the dependence according to the equation /5/ is documented in Figure (see Annex c20).

Following equation was used for calculations:

$$
\begin{gathered}
Y=-0.031+\frac{87.6}{T-625} \\
\text { (area of validity: } 700^{\circ} \mathrm{C} \text { to } 900^{\circ} \mathrm{C} \text { ) }
\end{gathered}
$$

where:

$$
\underset{T}{Y} \ldots \ldots \text { cro } \mathrm{Cr}_{3} \text { content }[w t . q]
$$

The comparison of experimental values with the calculated course of the dependence is documented in Figure 4-47. 


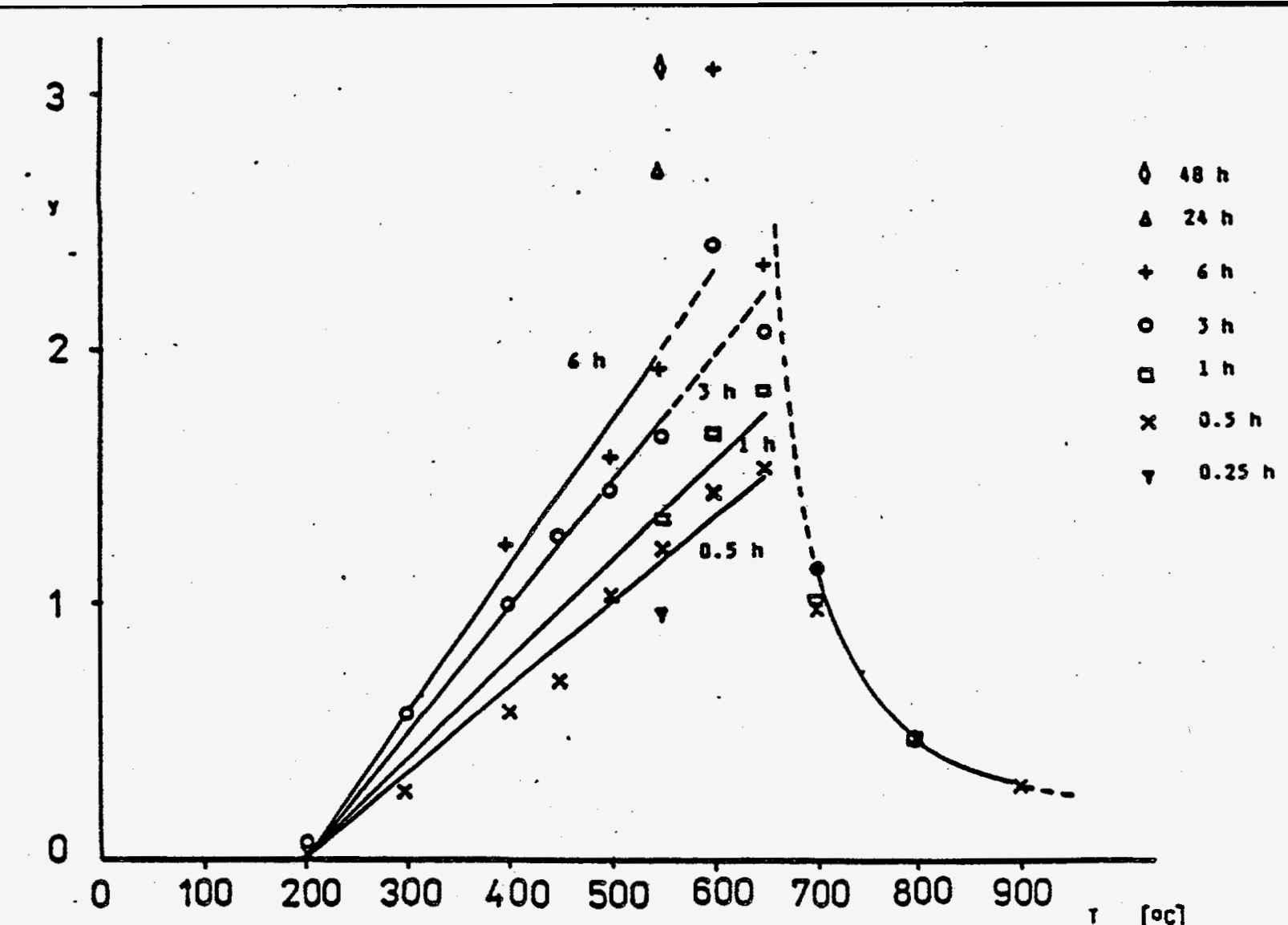

Figure 4-47: Comparison of experimental values with calculated dependence courses. for the Batch 1. See text for more details.

Batch 2

Mathematical processing of experimental results was carried out separately for three temperature ranges which differ in the character of dependences:

The dependences between the ranges of low and medium temperatures follow up each other at the temperature $550^{\circ} \mathrm{C}$. For this temperature the time dependence of the $\mathrm{CrO}_{3}$ content was determined which was further on used for the evaluation of temperature dependences in both adjoining temperature ranges.

For the description of time dependence of $\mathrm{CrO}_{3}$ content the power function was the most suitable. The coefficients for the temperature $550^{\circ} \mathrm{C}$ were gained by calculation using following equation for linear regression:

$$
\log Y=A+B * \log t
$$

$$
\begin{array}{ll}
A=0.257(7) & s_{A}=0.004(4) \\
B=0.243(1) & s_{B}=0.004(7) \\
s=0.009(9) & n=7 \\
r=0.9991 & \\
\text { (area of validity: } 0.25 \text { h to } 48 \mathrm{~h} \text { ) }
\end{array}
$$


where:

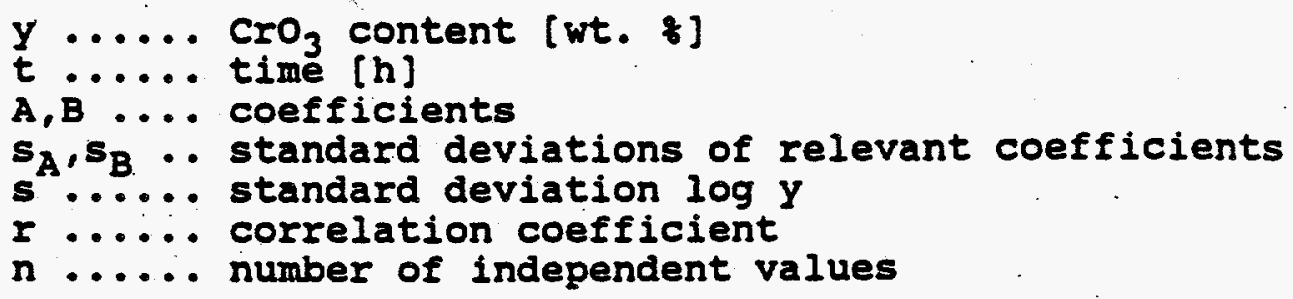

The correspondence of experimental values with a calculated course of the dependence according to the equation $/ 7 /$ is documented in Figure (see Annexex C21).

After a transformation:

$$
y=1.810 * t^{0.243}
$$

\section{The range of low temperatures}

This range includes temperatures from $200{ }^{\circ} \mathrm{C}$ to $550{ }^{\circ} \mathrm{C}$. From the final calculation the value for $300{ }^{\circ} \mathrm{C} / 3 \mathrm{~h}$ was eliminated (after preliminary calculations) for extreme deviation value.

For the calculation of the temperature dependence of $\mathrm{CrO}_{3}$ content the most suitable was following function (method of non-linear regression, calculation from all experimental values for $200^{\circ} \mathrm{C}$ to $550{ }^{\circ} \mathrm{C}$, with exception of $300^{\circ} \mathrm{C} / 3 \mathrm{~h}$, for the purpose of the calculation the $\mathrm{CrO}_{3}$ content is converted to the time $t=1 \mathrm{~h}$ by dividing of experimental value by the expression $\left.t^{0.243}\right):$

$$
y=A *(T-B)
$$

$$
\begin{aligned}
& A=0.00470(4) \\
& B=168 .(1) \\
& \mathrm{s}=0.11(9) \\
& n=18 \\
& \text { (area of validity: } 200{ }^{\circ} \mathrm{C} \text { to } 550^{\circ} \mathrm{C}(0.25 \mathrm{~h} \text { to } 48 \mathrm{~h}) \text { ) }
\end{aligned}
$$

where:

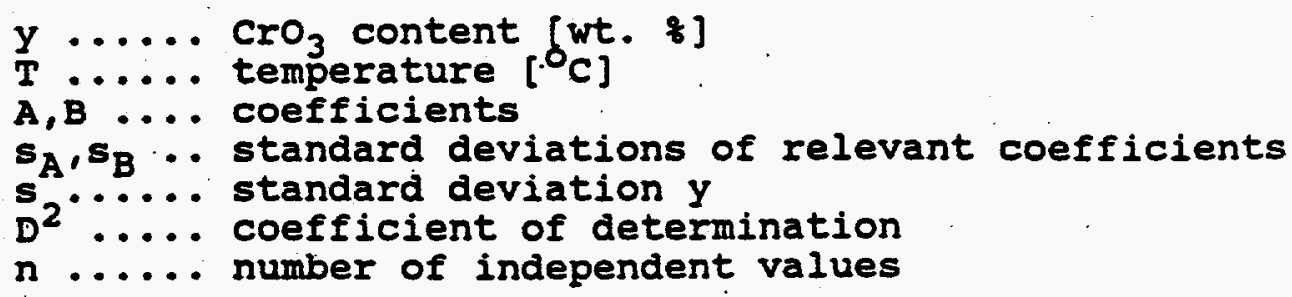


The correspondence of experimental values with calculated course of the dependence according to the relation $/ 9 /$ is documented in Figure (see Annex c22).

Following relation for the calculation of the dependence of $\mathrm{CrO}_{3}$ content on temperature and time of thermal treatment in the range of low temperatures was used:

$$
Y=0.00470 *(T-168) * t^{0.243}
$$

(area of validity: $200{ }^{\circ} \mathrm{C}$ to $550^{\circ} \mathrm{C}(0.25 \mathrm{~h}$ to $48 \mathrm{~h})$ )

where:

$$
\begin{aligned}
& y \ldots \ldots . \text { Cro }_{3} \text { content }[w t . \\
& \text { T } \ldots \ldots \text { temperature }\left[\delta_{C}\right] \\
& t \ldots \ldots \text { time }[h]
\end{aligned}
$$

The comparison of experimental values with a calculated course of dependence is given in Figure 4-48.

\section{The range of medium temperatures}

This range includes temperatures from $550^{\circ} \mathrm{C}$ to $700^{\circ} \mathrm{C}$. At the temperatures of thermal treatment $650^{\circ} \mathrm{C} / 6 \mathrm{~h}$ and $700^{\circ} \mathrm{C} / 3 \mathrm{~h}$ and $6 \mathrm{~h}$ statistically important deviations from supposed course of dependence (i.e. great decrease of $\mathrm{CrO}_{3}$ content) were found. That is why these values were not inciuded in final calculations.

For the calculation of the temperature dependence of $\mathrm{CrO}_{3}$ content the most suitable was following function (method of non-linear regression, calculation from all experimental values for $550^{\circ} \mathrm{C}$ to $650^{\circ} \mathrm{C}$, with exception of $650^{\circ} \mathrm{C} / 6 \mathrm{~h}$ and further on $700^{\circ} \mathrm{C} / 0.5 \mathrm{~h}$ and $1 \mathrm{~h}$, for the purpose of the calculation the $\mathrm{CrO}_{3}$ content is converted to the time $t=1 \mathrm{~h}$ by dividing the experimental value by the expression $t^{0.243}$ ):

$$
y=A *(T-B)
$$

$$
\begin{aligned}
& A=0.0176(2) \\
& B=448(3) \\
& S=0.17(2) \\
& n=16 \\
& \text { (areas of validity: }
\end{aligned}
$$

$$
\begin{aligned}
& \begin{array}{l}
s_{A}=0.0008(1) \\
s_{B}=7 .(4)
\end{array} \\
& D^{2}=0.9713 \\
& 550{ }^{\circ} \mathrm{C} \text { to } 600{ }^{\circ} \mathrm{C}(0.25 \mathrm{~h} \text { to } 6 \mathrm{~h}) \text {, } \\
& 600{ }^{\circ} \mathrm{C} \text { to } 650{ }^{\circ} \mathrm{C}(0.25 \mathrm{~h} \text { to } 3 \mathrm{~h}) \text {, } \\
& \left.650{ }^{\circ} \mathrm{C} \text { to } 700{ }^{\circ} \mathrm{C} \quad(0.25 \mathrm{~h} \text { to } 1 \mathrm{~h})\right\}
\end{aligned}
$$


where:

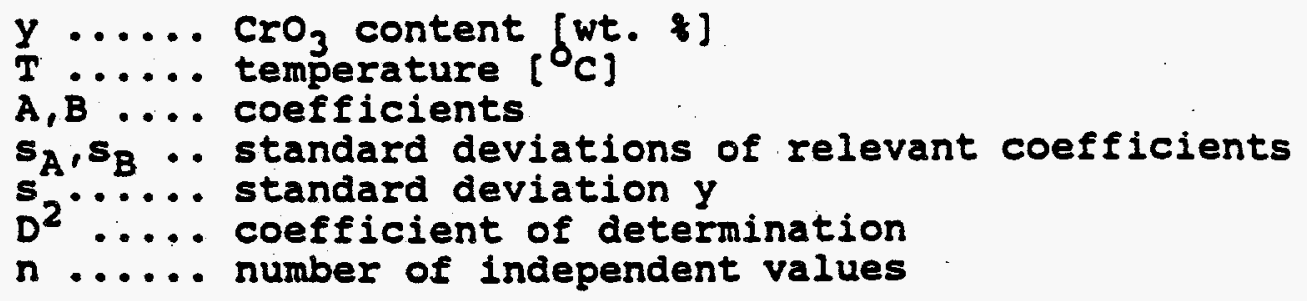

The correspondence of experimental values with calculated course of the dependence according to the relation / $11 /$ is documented in Figure (see Annex c23).

Following relation was used for the calculation of the dependence of $\mathrm{CrO}_{3}$ content on temperature and time of thermal treatment in the range of medium temperatures:

$$
Y=0.0176 *(T-448) * t^{0.243}
$$

(areas of validity: $550{ }^{\circ} \mathrm{C}$ to $600{ }^{\circ} \mathrm{C}(0.25 \mathrm{~h}$ to $6 \mathrm{~h})$,

$$
\begin{aligned}
& 600{ }^{\circ} \mathrm{C} \text { to } 650{ }^{\circ} \mathrm{C}(0.25 \mathrm{~h} \text { to } 3 \mathrm{~h}) ; \\
& 650{ }^{\circ} \mathrm{C} \text { to } 700{ }^{\circ} \mathrm{C} \quad(0.25 \mathrm{~h} \text { to } 1 \mathrm{~h}) ;
\end{aligned}
$$

where:

$$
\begin{aligned}
& y \ldots \ldots \text { cro }{ }_{3} \text { content }[w t . q] \\
& \text { T } \ldots \ldots \text { temperature }\left[\delta_{C}\right] \\
& t \ldots \ldots \text { time }[h]
\end{aligned}
$$

The comparison of experimental values with the calculated course of the dependence is documented in Figure 4-48.

The range of high temperatures

This range includes temperatures of thermal treatment higher than $750{ }^{\circ} \mathrm{C}$ (experimentally verified up to $900{ }^{\circ} \mathrm{C}$ ). In this range the effect of the time of thermal treatment was not found and the $\mathrm{CrO}_{3}$ content was dependent only on the thermal treatment temperature (at given experimental conditions).

For the description of the dependence of $\mathrm{CrO}_{3}$ content on the conditions of the thermal treatment in the range of high temperatures the most suitable function was found (direct calculation from three points, for the calculation the values for $900{ }^{\circ} \mathrm{C} / 0.5 \mathrm{~h}, 750{ }^{\circ} \mathrm{C} / 3 \mathrm{~h}$ and the mean from the values for $800^{\circ} \mathrm{C}$, were used. Statistical calculation using the method of non-linear regression with the use of all values for $800^{\circ} \mathrm{C}$ did not show suitable results with regard to a great dispersion variance): 


$$
Y=A+\frac{B}{T-C}
$$

$$
\begin{aligned}
& A=-20.523 \\
& B=30672 \\
& C=-463.6
\end{aligned}
$$

where:

$$
\text { (area of validity: } 750^{\circ} \mathrm{C} \text { to } 900^{\circ} \mathrm{C} \text { ) }
$$

$$
\begin{aligned}
& \text { Y. ...... CrO content }\{w t . ~ i] \\
& T \text {...... temperature }\left[{ }^{0} \mathrm{C}\right] \\
& A, B, C \text {.. coefficients }
\end{aligned}
$$

Following equation was used for calculations:

$$
y=-20.523+\frac{30672}{I+463.6}
$$

where:

(area of validity: $750^{\circ} \mathrm{C}$ to $900^{\circ} \mathrm{C}$ )

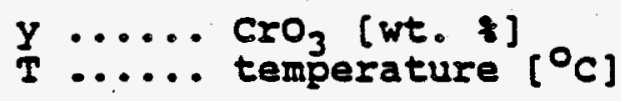

The comparison of experimental values with the calculated course of the dependence is documented in the. Figure 4-48.

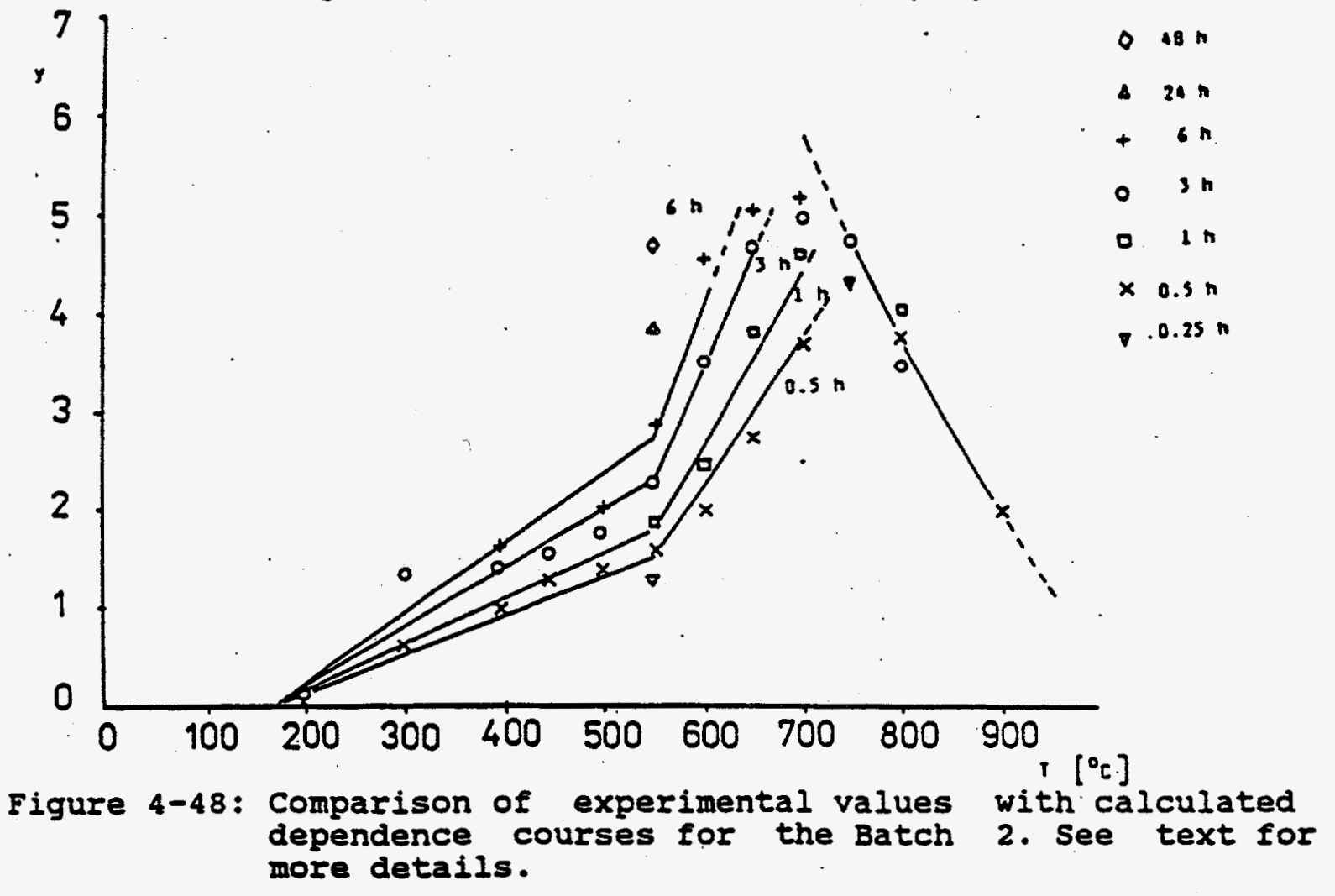




\subsubsection{DISCUSSION OF RESULTS}

A comparison of the behavior of the two batches of Glasses 1 and 2 allows to deduce several common features concerning $c r$ compounds reactions.

Oxidation of $\mathrm{Cr}^{3}$ to $\mathrm{Cr}^{6+}$ occurs at temperatures higher than 170 - $200^{\circ} \mathrm{C}$ due to a reaction of chromium hydroxide with sodium oxide under atmospheric oxygen access. The reaction rate increases with increasing temperature. At 600 and $550{ }^{\circ} \mathrm{C}$ (for glasses 1 and 2, respectively) an acceleration of the reaction was observed higher than expected from the empirical rate equation. The highest degree of conversion can be attained at the temperatures of $600-700^{\circ} \mathrm{C}(88 \%$ experimentally found in case of the batch 2 at $700{ }^{\circ} \mathrm{C}$ ).

During the initial stages of glass melting there exist conditions for oxidation processes and alkali chromate formation in quite a large extent. A decrease of the reaction rate at temperatures higher than $670-700^{\circ} \mathrm{C}$ can be attributed to the formation of the liquid phase which hinders the acces of oxygen from the atmosphere into the batch. Decreasing values of $\mathrm{CrO}_{3}$ content at higher temperatures (above 650 and $700^{\circ} \mathrm{C}$ resp.) as well as lower content of $\mathrm{CrO}_{3}$ in the final glass indicate that a backwards reaction, i.e. reduction of chromate occurs in the higher temperature range and that an optimum temperature for oxidation can be found differing according to melting conditions. The reaction between chromium hydroxide and alkali can be accelerated by alkali compounds adsorbed at the surface of hydroxide particles.

It can be concluded that - due to the high reaction rate - the formation of alkali chromates is unavoidable during melting in an oxydizing atmosphere. On the other hand, the occurence of sodium chromate during the early stage of melting did not produce - under the conditions of Glasses 1 and 2 preparation - harmful effects such as macroscopic phase separation of the chromate with a low melting point $\left(790^{\circ} \mathrm{C}\right.$ for $\left.\mathrm{Na}_{2} \mathrm{CrO}_{4}\right)$. 


\subsubsection{CONCLUSIONS}

Following conclusions can be made from experiments performed with Glasses 1 and 2 , with respect to melting behaviour and product properties:

Both glasses can be melted at technologically acceptable temperatures. Glass 1 was melted at $1150{ }^{\circ} \mathrm{C}$ corresponding to the additionally measured viscosity of about $20 \mathrm{~Pa} . \mathrm{s}$ which is a higher value than the optimal one. Higher viscosity and lower temperature are probably the reasons why agglomerates of $\mathrm{Cr}_{2} \mathrm{O}_{3}$ did not dissolve in the melt to such an extent as in Glass 2 which was melted at $1450^{\circ} \mathrm{C}$ and viscosity lower than $6 \mathrm{~Pa} . \mathrm{s}$.

Alkali chromate is formed inevitably within the medium range of temperatures in oxidizing conditions. With the method of melting used in this study, macroscopic liquid phase separation of sodium chromate was not observed although reducing agents were not introduced into the batch. Also the common experience with aventurine glasses indicates that melting of glasses containing chromium compounds exceeding the solubility limits can be mastered, but under unproper conditions difficulties can occur due to the formation of chromates in the initial stage of melting.

Agglomerates of $\mathrm{Cr}_{2} \mathrm{O}_{3}$ (eskolaite) were found in both glasses with particle size corresponding to the as-batched chromium hydroxide which apparently did not dissolve at the melting temperature. Individual crystals of eskolaite are formed during cooling from the supersaturated melt. The crystals of eskolaite do not disturb the regular behavior of the melt (see results of viscosity measurements of Glass 1 with relatively high content of eskolaite agglomerates) and presumably will. not influence considerably the required chemical and physical properties of the product.

on the other hand, irregularities occured in Glass 2 melt during viscosity and electrical conductivity measurements, and also considerable variation of expansion coefficient was found. 
These effects can be attributed to a high crystallization rate of other phases, esp. eucryptite.

The crystals were found in both glasses even after the highest temperature of treatment in the gradient furnace $1320{ }^{\circ} \mathrm{C}$. This result can be explained by very fast crystallization during cooling the samples or by a very high liquidus temperature which should implicate a very low viscosity at liquidus temperature. However, the presence of eucryptite crystals at the highest temperature $1320{ }^{\circ} \mathrm{C}$ indicates that the liquidus temperature is even higher. More detailed liquidus temperature measurement should require a modificaion of the method incl. more detailed study of the crystals morphology.

The crystallinity of Glasses 1 and 2 after quenching differs considerably. Generally, Glass 2 exhibits a higher crystallization ability displayed by a higher number and content of crystalline phases. In addition to eskolaite, eucryptite and nepheline, a new fine-grained phase was found in Glass 2 , with composition enriched by $\mathrm{Mn}, \mathrm{Zn}$ and $\mathrm{Ni}$, and also by $\mathrm{Cr}, \mathrm{Fe}$ and possibly $\mathrm{Al}$. The particles are very small and SEM microanalysis always encounters an undefined amount of the surrounding glass. Based on microanalysis, $\mathrm{X}$-ray diffraction and microscopy, the fine-grained phase was interpreted as a solid solution of spinel type structure although the form of crystals does not show relevant morphological characteristics at the magnification used in this study. More detailed study should be performed if Glasses 1 and 2 remain an object of further research.

When considering the suitability of Glasses 1 and 2 for waste vitrification, Glass 2 exhibits several undesirable properties: very high crystallization ability has unacceptable consequences in the physical properties (irregularities in viscosity and electrical conductivity, low mechanical strength) and esp. in hydrolytic resistance which is 2 orders of magnitude lower than that found for Glass 1. For future studies, changes of the composition of the glasses can be recommended in the direction of decreased $\mathrm{Ii}_{2} \mathrm{O}$ and $\mathrm{Al}_{2} \mathrm{O}_{3}$ and increased $\mathrm{SiO}_{2}$ content. 
Independent melting and properties measurements were performed with Glasses 1 and 2 using two separately prepared forms od chromium hydroxide (black or green due to different drying temperatures 150 and $105^{\circ} \mathrm{C}$, respectively). The results of both series of experiments are' in full agreement indicating that the type of hydroxide used does not affect nor the melting behavior nor the properties studied (see also Annex A2).

The attempt to determine the ratio of trivalent to hexavalent chromium resulted in a conclusion that the content of $\mathrm{Cr}^{6+}$ is by order of magnitude lower than that of $\mathrm{Cr}^{3+}$ in Glasses 1 and 2. This amount is sufficient to suppress the content of Feo (see Tables 4-23 and 4-24) to a negligible value, in agreement with redox equilibria in the systems containing polyvalent oxides. More detailed study of this problem should be useful. 


\section{GLASSES WITH SPECIAL THERMAL TREATMENT}

To simulate technological conditions of melting and the following cooling special heat treatment has been used to prepare samples close to real final products.

The Glasses 1 and 2 gained by the procedure described in Section 4.1. were heat treated according to the schedules shown in the Test Plan. The specimens marked Ccc (Canister Centerline cooling) were cooled in a manner simulating the real cooling conditions of the vitrified product, whereas specimens marked TEM simulated a long time thermal exposure which enabled indication of settling effects.

This section describes the preparation of such products and a detailed study of the crystal phases formation. $x$-ray diffraction analysis and optical microscopy was used for the identification of the macrostructure and specific crystal phases. To analyse possible settling, surface and bottom parts of samples were examined.

\subsection{PREPARATION OF GLASSES}

Glasses prepared in the Task 2 of the Test Plan, in the same way as samples described in section 4.1 . and labelled $1 / 6$ and $2 / 6$ were used for the preparation of glasses with a special thermal treatment, corresponding to the procedure requested by Task 5. The resulting samples of glasses were marked as 1/6/TEM, $2 / 6 /$ TEM, $1 / 6 /$ CCC and $2 / 6 /$ CCC.

The preparation of samples was performed in the laboratory of svus.

To reach the requested products (1/6/TEM, 1/6/CCC, 2/6/TEM and $2 / 6 / C C C$ ) glasses $1 / 6$ and $2 / 6$ were treated by following procedures :

Preparation of samples using TEM procedure $1 / 6 /$ TEM

Sample was heated up to the temperature $850^{\circ} \mathrm{C}$ (furnace KHS, temperature increase cca $225^{\circ} \mathrm{C} / \mathrm{h}$ ), transferred to furnace sK, 
heated for $20 \mathrm{~min}$ at $1150{ }^{\circ} \mathrm{C}$. transferred to the furnace with the temperature $1050{ }^{\circ} \mathrm{C}$, treated for 24 hours at this temperature and transferred again to the KHS furnace where the treatment continued for 2 hours at $500{ }^{\circ} \mathrm{C}$. An uncontrolled cooling followed. The scheme of cooling corresponded to the temperature decrease given iri Table 5-1:

Table 5-1: Uncontrolled Cooling of Samples Marked TaM

\begin{tabular}{|c|c|}
\hline Time Interval [hour] & Temperature Decrease $\left[{ }^{\circ} \mathrm{C} / \mathrm{h}\right]$ \\
\hline $0-2$ & 60 \\
$2-3$ & 40 \\
$3-6$ & 25 \\
$6-18$ & 12 \\
\hline
\end{tabular}

\section{$2 / 6 /$ TEM}

The procedure was similar to the treatment of the sample 1/6/TEM. Sample was heated up to $850^{\circ} \mathrm{C}$ (conditions the same as in the previous case), transferred to the furnace sk, heated for $20 \mathrm{~min}$ at $1450^{\circ} \mathrm{C}$, transferred to another furnace with the temp. $1350^{\circ} \mathrm{C}$ and treated for 24 hours. Then (because of the danger of crucible cracking) transferred to the sk furnace heated to $1170^{\circ} \mathrm{C}$ ( $30 \mathrm{~min}$ residence time). After this procedure heating 2 hours at $500{ }^{\circ} \mathrm{C}$ was followed by uncontrolled cooling (see the Table 5-1).

Preparation of samples using ccc cooling procedure

\section{$1 / 6 / \mathrm{CcC}$}

Sample $1 / 6$ was heated to the temperature $850^{\circ} \mathrm{C}$ in $\mathrm{kHS}$ furnace (temperature increase cca $225^{\circ} \mathrm{C} / \mathrm{h}$ ), transferred to sR furnace, heated to $1150^{\circ} \mathrm{C}$, residence time $20 \mathrm{~min}$., transferred to kHS furnace and heated for 1 hour at $872{ }^{\circ} \mathrm{C}$, followed by cooling according to the CCC scheme (see the Table 5-2).

\section{$2 / 6 / \operatorname{ccc}$}

Sample $2 / 6$ was heated to the temperature $850^{\circ} \mathrm{C}$ in $\mathrm{kHS}$ furnace (temperature increase cca $225^{\circ} \mathrm{C} / \mathrm{h}$ ), transferred to sK furnace, heated to $1450^{\circ} \mathrm{C}$, residence time $20 \mathrm{~min} .$, transferred 
to SK furnace and heated for 1 hour at $1172{ }^{\circ} \mathrm{C}$, followed by temperature decrease to $872^{\circ} \mathrm{C}$, transferred to kHs furnace (heated to $872{ }^{\circ} \mathrm{C}$ ) and cooling according to the CcC scheme (see the Table 5-2).

Table 5-2: Canister Centerline cooling (ccc) schedules

\begin{tabular}{|c|c|c|c|c|}
\hline For Glass $N$ & ing at $1150^{\circ} \mathrm{C}$ & For Glass & ing at 1450 & ${ }^{\circ} \mathrm{C}$ \\
\hline $\begin{array}{c}\text { Time } \\
\text { [hour] }\end{array}$ & $\underset{\left[{ }_{C}\right]}{\text { Temperature }}$ & $\begin{array}{l}\text { Time } \\
\text { [hour] }\end{array}$ & $\begin{array}{c}\text { Temperature } \\
{\left[{ }^{\circ} \mathrm{C}\right]}\end{array}$ & \\
\hline $\begin{array}{r}0 \\
1 \\
2 \\
3 \\
4 \\
5 \\
6 \\
7 \\
8 \\
9 \\
10 \\
11 \\
12 \\
13 \\
14 \\
15 \\
16 \\
17 \\
18 \\
19 \\
20 \\
21 \\
22 \\
23 \\
24 \\
25\end{array}$ & $\begin{array}{l}872 \\
872 \\
840 \\
810 \\
781 \\
752 \\
725 \\
698 \\
672 \\
647 \\
623 \\
600 \\
577 \\
556 \\
535 \\
516 \\
499 \\
483 \\
467 \\
451 \\
436 \\
421 \\
406 \\
392 \\
378 \\
365\end{array}$ & $\begin{array}{l}0 \\
1 \\
2 \\
3.42 \\
4.42 \\
5.42 \\
6.42 \\
7.42 \\
8.42 \\
9.42 \\
10.42 \\
11.42 \\
12.42 \\
13.42 \\
14.42 \\
15.42 \\
16.42 \\
17.42 \\
18.42 \\
19.42 \\
20.42 \\
21.42 \\
22.42 \\
23.42 \\
24.42 \\
25.42 \\
26.42 \\
27.42\end{array}$ & $\begin{array}{r}1172 \\
1172 \\
1048 \\
872 \\
840 \\
810 \\
781 \\
752 \\
725 \\
698 \\
672 \\
647 \\
623 \\
600 \\
577 \\
556 \\
535 \\
516 \\
499 \\
483 \\
467 \\
451 \\
436 \\
421 \\
406 \\
392 \\
378 \\
365\end{array}$ & - \\
\hline
\end{tabular}

All samples prepared in the above mentioned ways were cut and photographed (Archive suUs). One half of the crucible has been handed over to the V.SCHT laboratory for further examination. other part is archived in svus. 


\section{5:2. CHARACTERIZATION}

\subsubsection{VISUAL EVAIUATION OF SAMPLES}

Following sample evaluation was performed after their preparation in svus laboratory and using the cuts prepared for the analysis in the Glass Institute:

\section{$1 / 6 /$ TEM}

At the crucible bottom and on the surface hairline cracks were found. The cut shows small bubbles (diam. $0.5-3.0 \mathrm{~mm}$ ). The sample was compact, homogeneous and brittle. Foaming was observed during the melting procedure.

\section{$1 / 6 / C C C$}

The same hairline cracks at the bottom and on the surface as in the case of $1 / 6 / T g M$ were observed. The size of bubbles and their amount was smaller than in 1/6/TEM case.

The sample was compact, homogeneous, more brittle then 1/6/TEM. No foaming took place during the sample preparation.

\section{2/6/TEM}

Eracture surface has a character of glass. No bubbles were observed. Problems with the crucible material appeared. The experiences with the melting of glasses $B$ (see Annex A2) led to the use of a porcelaine crucible (material M1/168), even this material showed corrosion in the bottom and side parts of the crucible.

On the surface a brown layer was visible. The cut showed that the sample was compact, very brittle, with agate-like less colored stripes, especially near the bottom.

\section{$2 / 6 / C C C$}

Hairline cracks at the surface, tiny bubbles $(0.5-2 \mathrm{~mm})$. The surface of the glass was crystallized.

Whereas all previous samples exhibited glassy appearence on the fracture surface, this sample had a matte, rough fracture and Iow strength with a tendency to disintegration during mechanical operations. 


\subsubsection{CRYSTALLINITY}

\subsubsection{X-RAY DIFFRACTION. ANALYSIS}

The respective samples cooled according the TEM and CCC procedures, bearing labels 1/6/TEM, 1/6/CCC, 2/6/TEM and 2/6/CCC were supplied to the VSCHT laboratory as parts of ceramic crucibles containing the cooled melt of about $45 \mathrm{~mm}$ height. The visual appearence was dark greenish but certain differences could be observed (see cummulative information in previous section).

The method and apparatus used were the same as in the Section 4.2.1.1. The resulting diffraction patterns are shown in enclosed Figures 5-1 and.5-2.

Evaluation

Specimen $1 / 6 /$ Ccc - bottom

Large amount of the amorphous phase. Beta-eucryptite: is the dominant phase with slightly smaller lattice parameters compared with the tabulated values (No. 26-839). Distinct lines of crystalline eskolaite (No. 38-1479) with regular lattice parameters.

Specimen $1 / 6 / C c c$ - surface

slightly smaller amount of amorphous phase compared with the preceding case, beta-eucryptite is more distinct, no other difference compared with the bottom.

Specimen 1/6/TEM - bottom

Large amount of the amorphous phase, the only crystalline phase is $\mathrm{Cr}_{2} \mathrm{O}_{3}$ (eskolaite).

Specimen 1/6/TEM - surface

similar to $1 / 6$ TEM-bottom

Specimen $2 / 6 / C c c$ - bottom

The background which should characterize the amorphous phase is not present. Beta-eucryptite is the dominant crystalline phase with lattice parameters near to the tabulated values. Distinct lines of nepheline, weak lines of eskolaite. Two very weak lines $(d=4.79$ and 2.93 ) were not identified. 


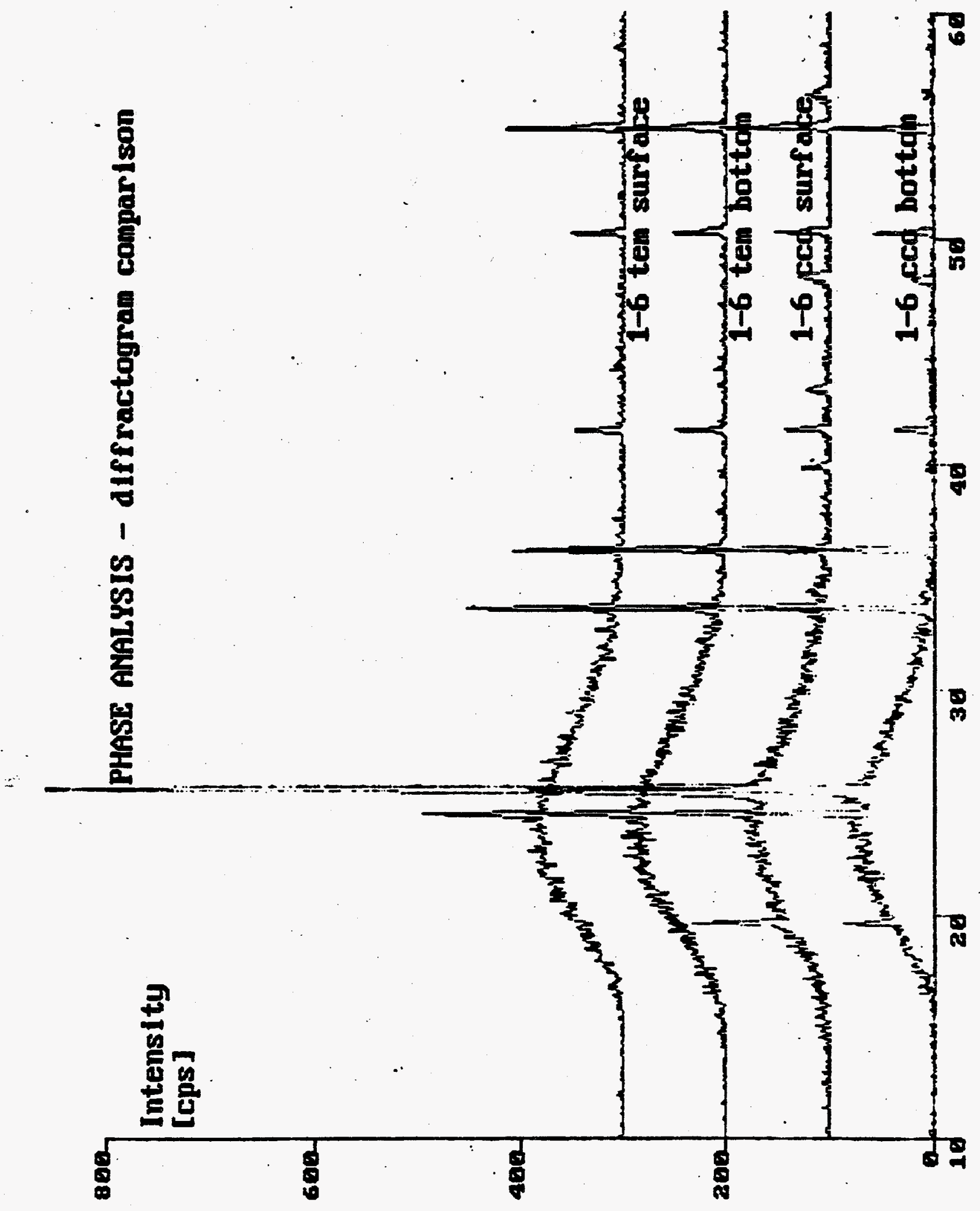

Figure 5-1: Diffractograms of Tempered Specimens of Glass 1 


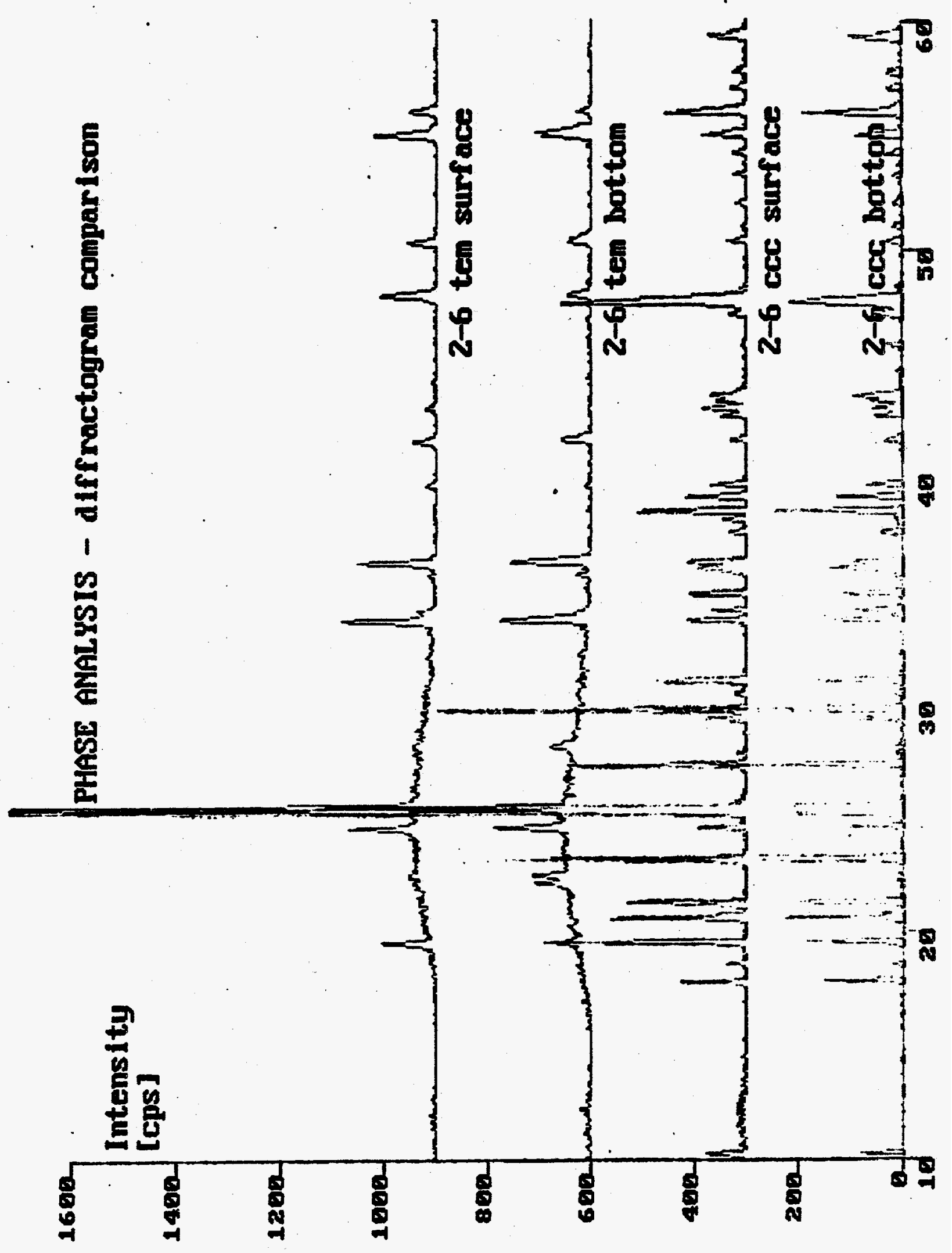

Figure 5-2: Diffractograms of Tempered Specimens of Glass 2 


\section{Specimen $2 / 6 / c c c$ - surface}

Not different from the bottom.

\section{Specimen 2/6/TEM - bottom}

Beta-eucryptite is the dominant phase with smaller lattice parameters, distinct lines of eskolaite and also of Li-Al-disilicate (No. 40-62). Relativeiy small proportion of the amorphous phase.

\section{Specimen 2/6/TEX - surface}

Similar to the bottom, less distinct lines of II-Al-disilicate.

\subsubsection{OPTICAI MICROSCOPY}

Samples of Glass 1 and 2 , marked $1 / 6$ and $2 / 6$ according to the sequence of melt, and TEM or CCC according to the previous thermal treatment (see section 5.1.), were examined by optical microscopy.

Thin sections for microscopic examination were prepared from the upper (near surface) part as well as from the lower (near bottom) part of the glass sample as received with the remainder of the ceramic melting crucible. A comparison of the surface and bottom part of the. samples was made in order to decide if some effects of settling (sedimentation) of crystalline phases occur in the system during melting.

Thin sections were prepared by the usual method in petroleum and examination was made in polarized light. Image analysis LUCIA was used for the evaluation. The results are shown in Tables 5-3 and 5-4 and in Figures 5-3 to 5-14.

\section{Specimen 1/6/TEM surface}

The specimen contains agglomerates of eskolaite $\left(\mathrm{Cr}_{2} \mathrm{O}_{3}\right)$. mostly in solid solution with $\mathrm{Fe}_{2} \mathrm{O}_{3}$, with mean diameter of 0 , $073 \mathrm{~mm}$ (see Table 5-3 and Figure 5-3) and irregular distribution of eskolaite plates again mostly with $\mathrm{Fe}_{2} \mathrm{O}_{3}\left(\mathrm{ES}_{\mathrm{Fe}}\right.$ ). The crystals of pure eskolaite (ES) have green colour, solid solution changes the colour to brown. The content of the dark phase evaluated from the surface area in Figure 5-3 is 31 , taken from a layer about $0.03 \mathrm{~mm}$ thick. A detail of the structure of a small agglomerate 
and of its surroundings is shown in Figure 5-4. There can be seen crystals of varying size and some of them have uneven boundaries. Glass is the prevailing phase.

\section{Specimen 1/6/TEM bottom}

The structure of the specimen is similar to that described above. The surface area of agglomerates is 0,$9 ;(0,3$ in the previous case), the content of the dark phase evaluated from the surface area is 32,6 (see Table 5-3). The detail of the structure is also similar to that shown in Figure 5-4.

\section{Specimen $1 / 6 / C c c$ surface}

Uniformly distributed crystals of $\mathrm{ES}_{\mathrm{Fe}}$ and $\mathrm{ES}$, agglomerates of $0,066 \mathrm{~mm}$ diameter, surface area of agglomerates $1.9 \%$, surface area of the dark phase is $33 \%$ (see Table 5-4 and Figure 5-5). With higher magnification (Figure 5-6), there were found crystals of dendritic appearance which could not be identified by optical microscopy. See section 5.3.

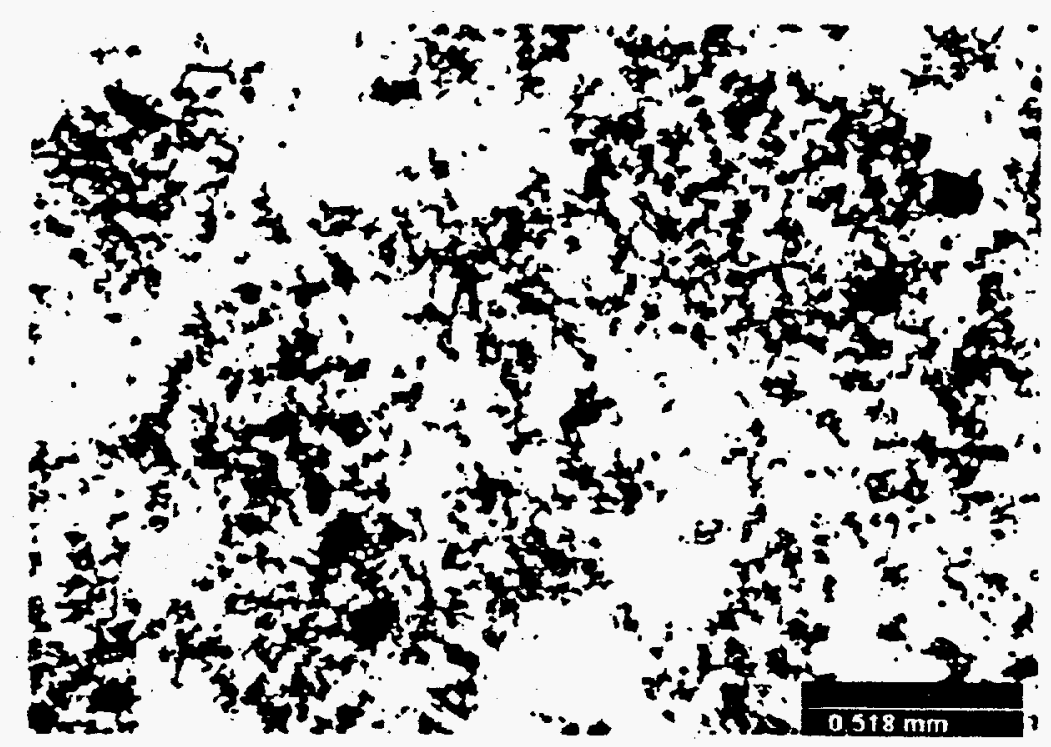

Figure 5-3: Glass 1/6/TEM Surface, Surface Area of the Dark Phase $31.3 \%$ 


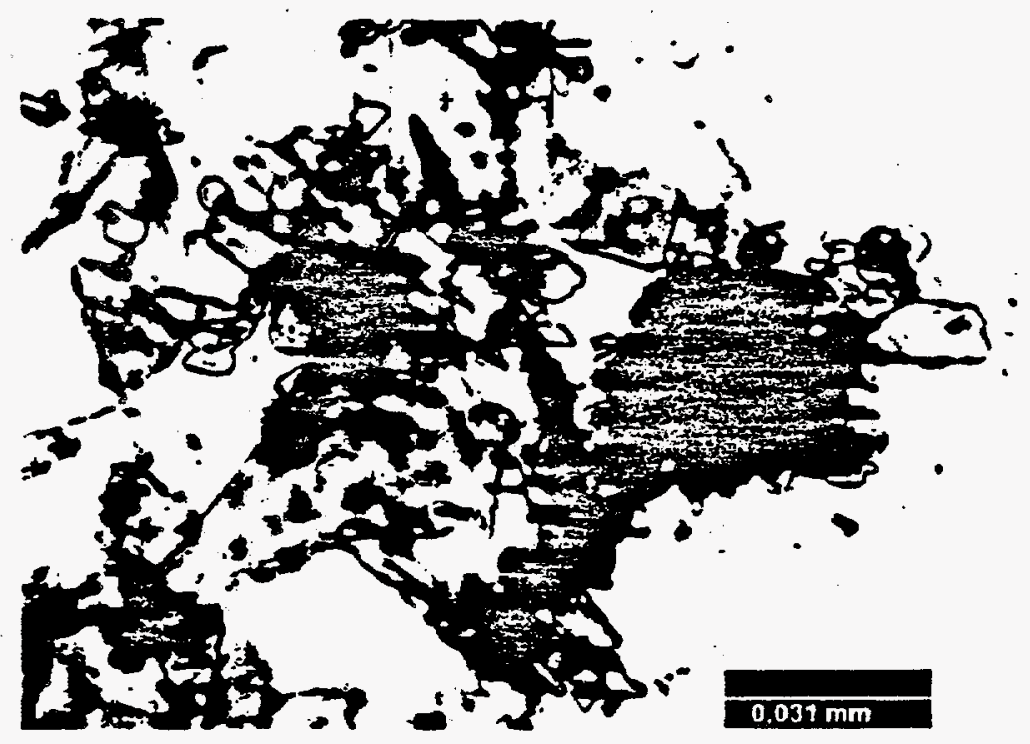

Figure 5-4: Glass 1/6/TEM Surface, Plates of Eskolaite, Detail of a Small Agglomerate and its Vicinity

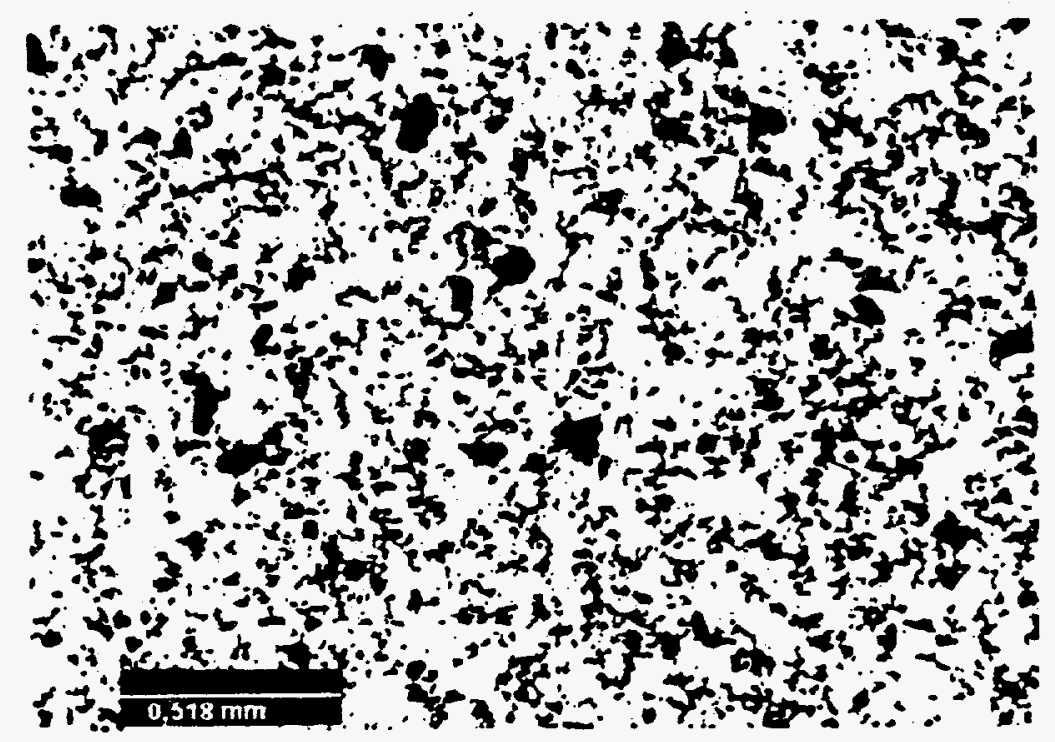

Figure 5-5: Glass $1 / 6 /$ CCC Surface, Surface Area of the Dark Phase 33\% 


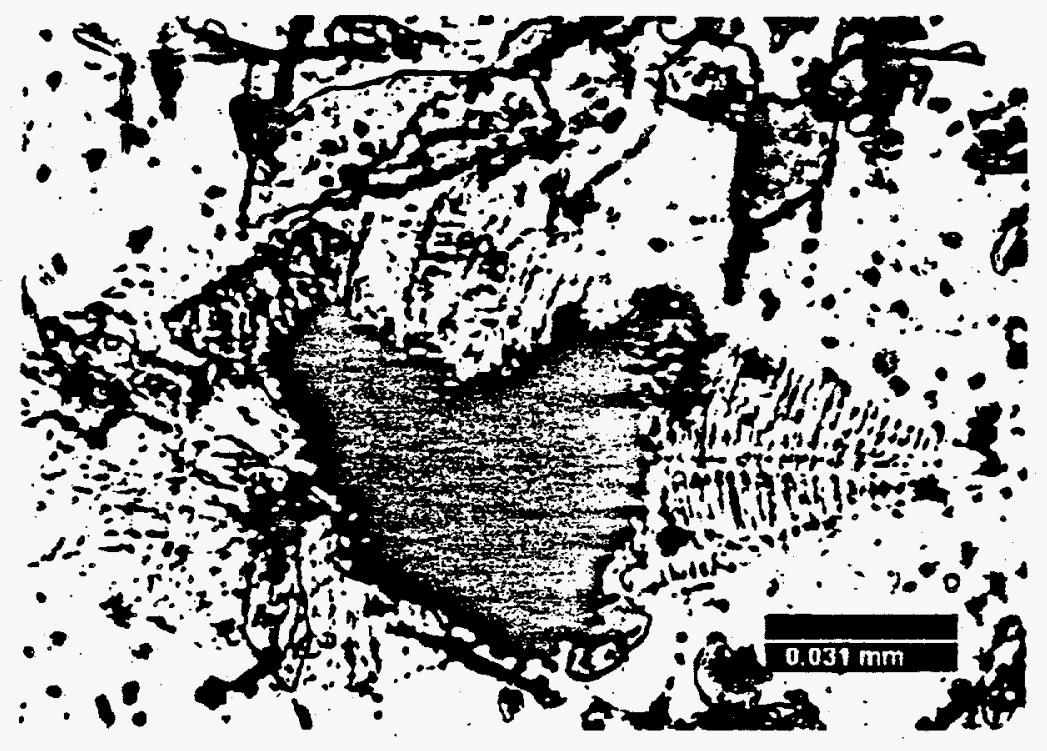

Figure 5-6: Glass 1/6/CCC Surface, Plates of Eskolaite and Crystals of Another Crystalline Phase of Dendritic Appearance

Specimen $1 / 6 / \mathrm{CCC}$ bottom

Eskolaite agglomerates of $0,069 \mathrm{~mm}$ diameter, surface area of agglomerates $1.5 \%$ (see. Table 5-4), surface area of the dark phase is $34.5 \%$. The microscopic structure is not shown in the figures because it is very similar to the previous specimen (surface), incl. the non-identified dendritic phase.

\section{Specimen 2/6/TEM surface}

Non-uniformly distributed crystals of $E_{F e}$ and $E S$ are present (see Figure 5-7). Therefore, it is difficult to identify individual agglomerates and only the content of the dark phase from the surface area was evaluated: 52 in the place of observation. Under higher magnification (see Figure 5-8), crystals of beta-eucryptite can be seen as well as dendrites similar to those in 1/6/CCC specimens. In comparison with previously described samples of Glass 1 , the content of crystaline phases is much higher and the content of the glass phase lower, but still well evident. . 


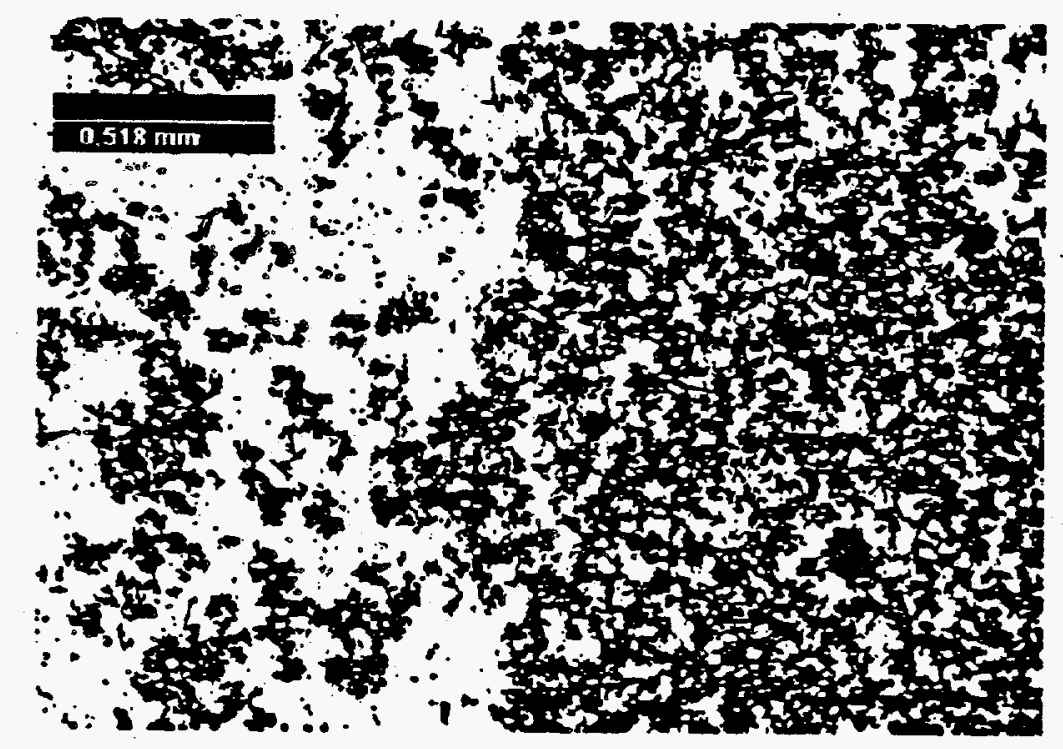

Figure 5-7: Glass 2/6/TEM Surface, Surface Area of the Dark Phase 52\%, Inhomogeneous Distribution of Eskolaite

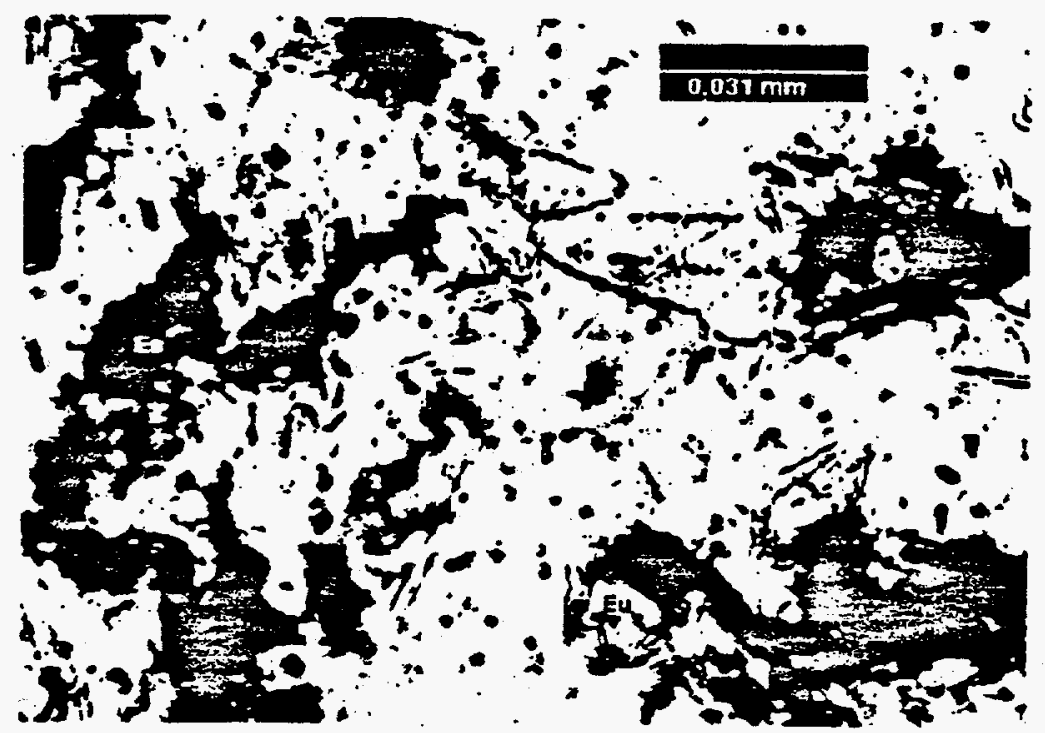

Figure 5-8: Glass 2/6/TEM Surface, Crystals of Eskolaite (Es) and beta-eucryptite (Eu), Glass Phase (GL) and New Dendritic Phase 
Specimen $2 / 6 /$ TEM bottom

Figure 5-9 shows again non-uniform distribution of $\mathrm{ES}_{\mathrm{Fe}}$ and ES crystals. Agglomerates cannot be clearly identified; the surface area of the dark phase is $35 \%$ High content of crystaliine phases was found of the same character as in the previous case. In detail, the structure is very similar to that in Figure 5-8.

\section{Specimen $2 / 6 / \mathrm{CCC}$ surface}

Non-uniformly distributed crystals of ESFe do not allow statistical evaluation of agglomerates the size of which is small (see Figure 5-10). Higher magnification (Figures 5-11 and 5-12) shows the presence of beta-eucryptite and nepheline. The two crystalline phases are difficult to distinguish one from the other by optical microscopy. The specimen is completely crystalline, only thin layers of greenish glass phase can be seen on crystal boundaries.

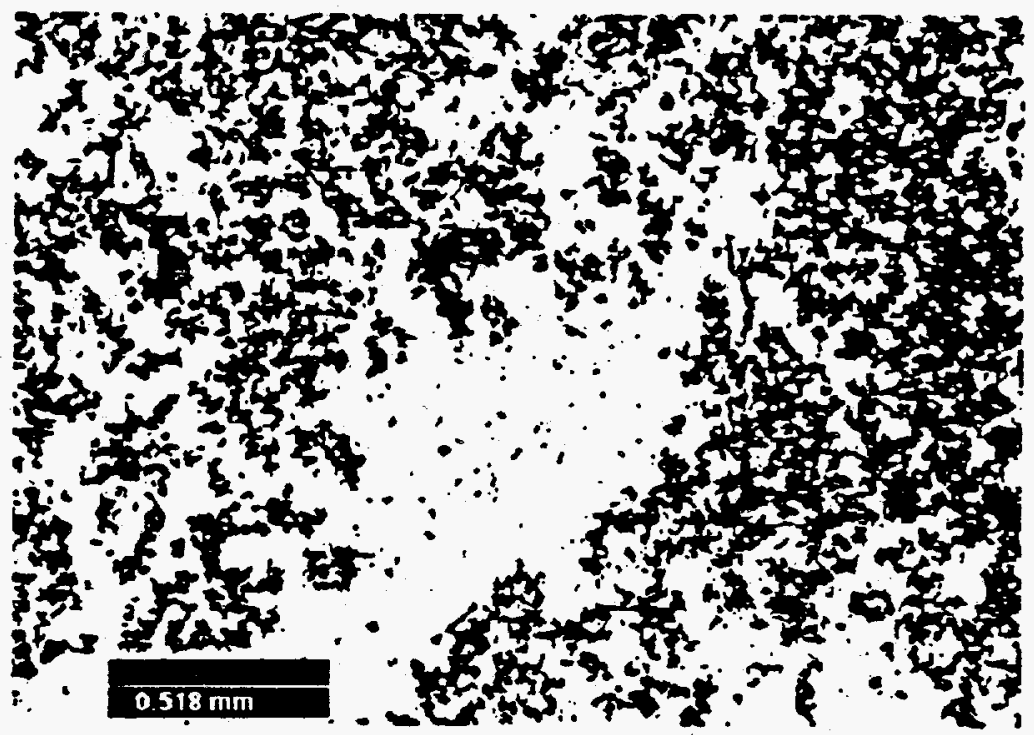

Figure 5-9: Glass 2/6/TEM Bottom, Surface Area of the Dark Phase $35 \%$, Inhomogeneous Distribution of Eskolaite 


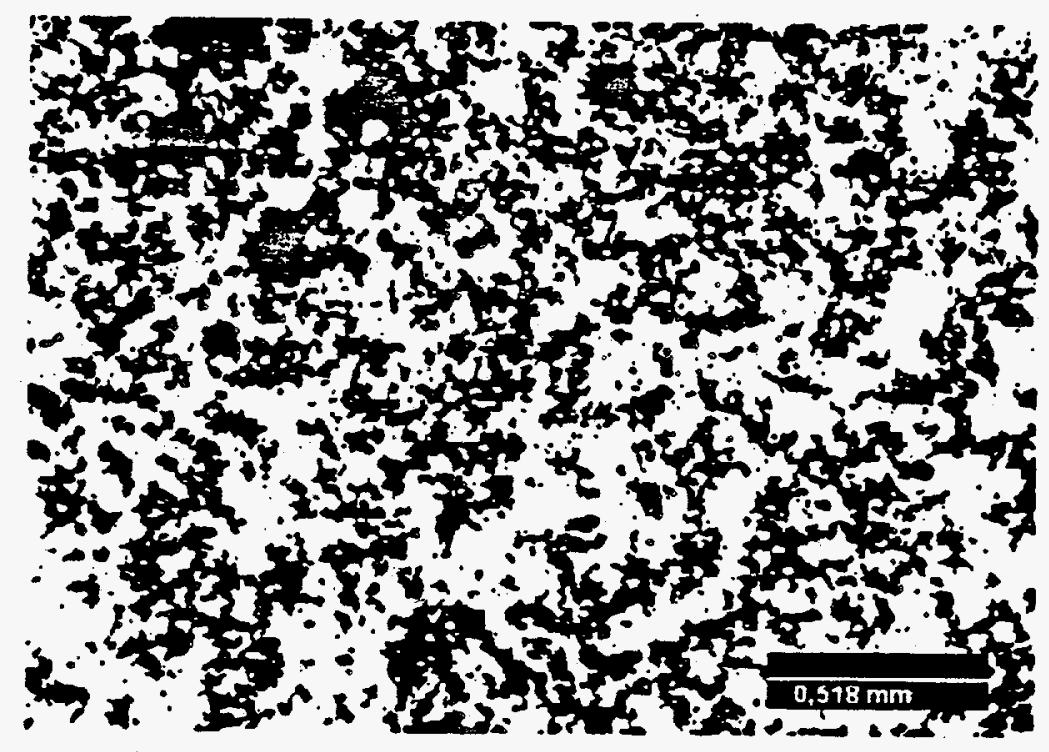

Figure 5-10: Glass 2/6/CCC Surface, Surface Area of the Dark Phase 40 \%, Inhomogeneous Distribution of Eskolaite (Other Phases not Apparent)

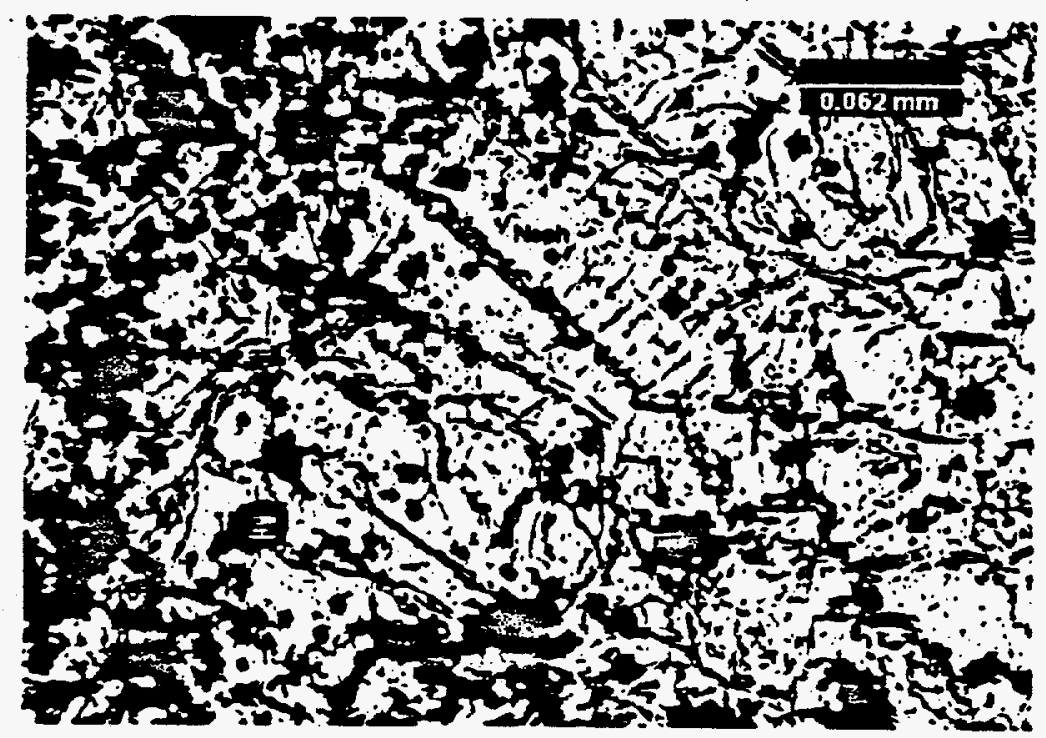

Figure 5-11: Glass 2/6/CCC Surface, Crystalline structure (Nepheline, Eskolaite, beta-eucryptite), only Small Amount of Glass Phase on Crystal Boundaries 


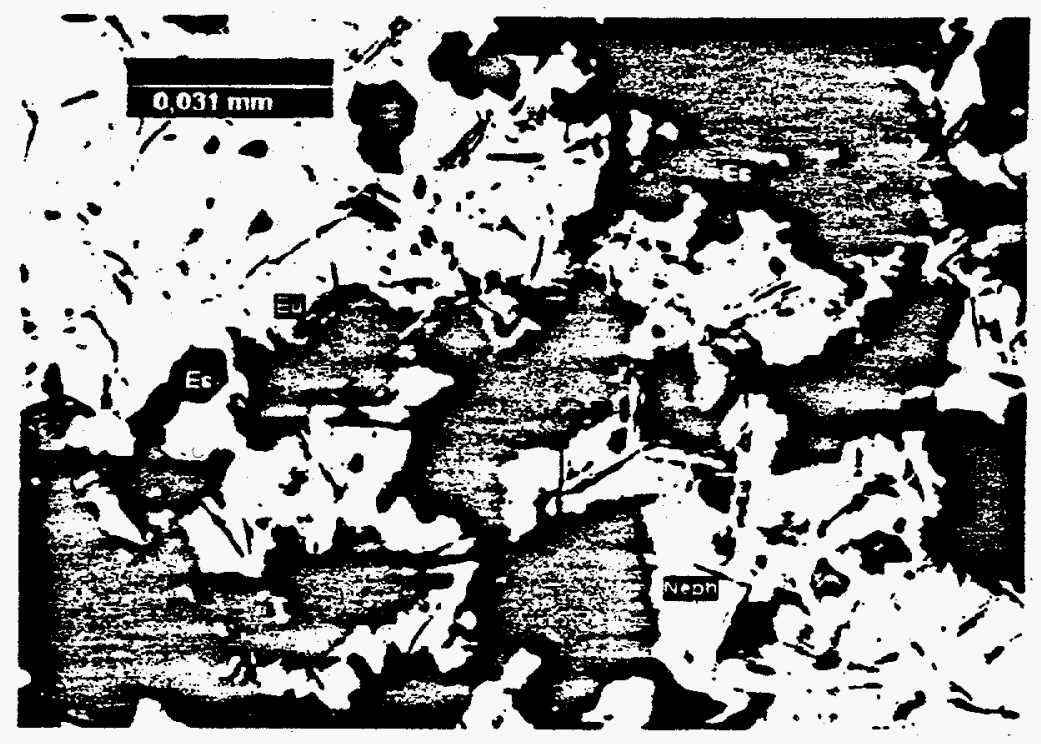

Figure 5-12: Glass 2/6/CCC surface at Higher Mágnification, Crystalline Structure with Small Amount of Intercrystalline Glass Phase

\section{specimen $2 / 6 / C C C$ bottom}

similar phase composition and structure to that of surface specimen. The crystalline structure is clearly evident from Figure 5-13 and also from Figure 5-14 which represents the same place in the specimen using crossed nicols arrangement. The dendrites of nepheline are obvious in the last figure. 


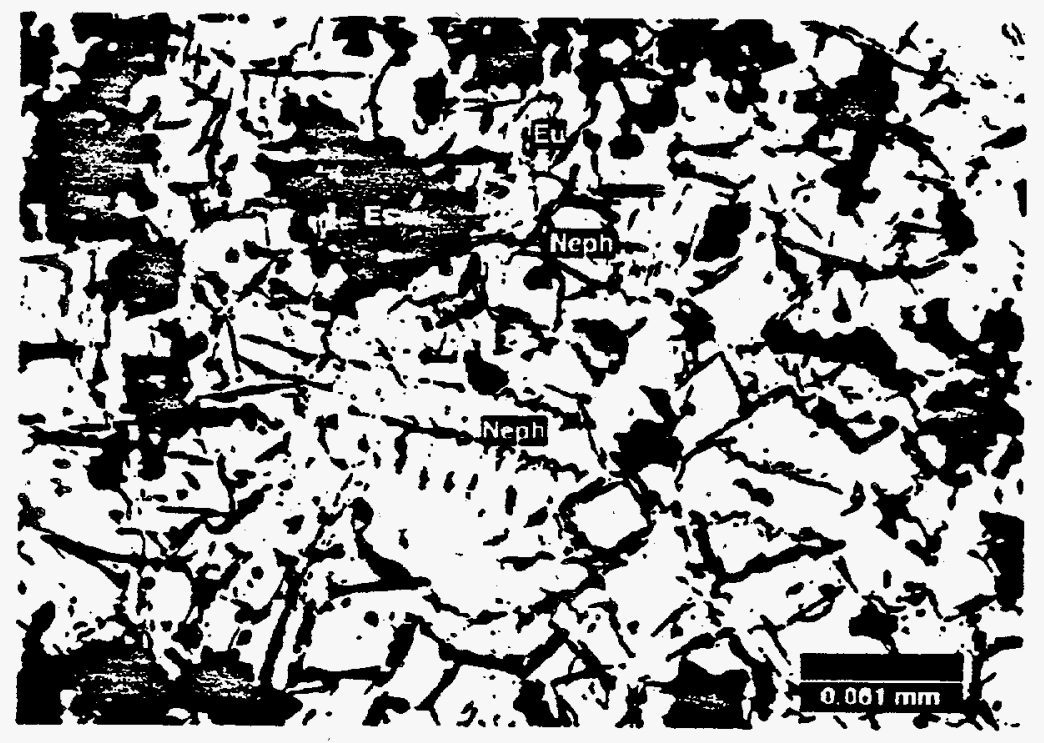

Figure 5-13: Glass 2/6/CCC Bottom, Crystalline Structure Composed of Eskolaite, Nepheline and beta-eucryptite, Small Amount of Glass phase at Interfaces

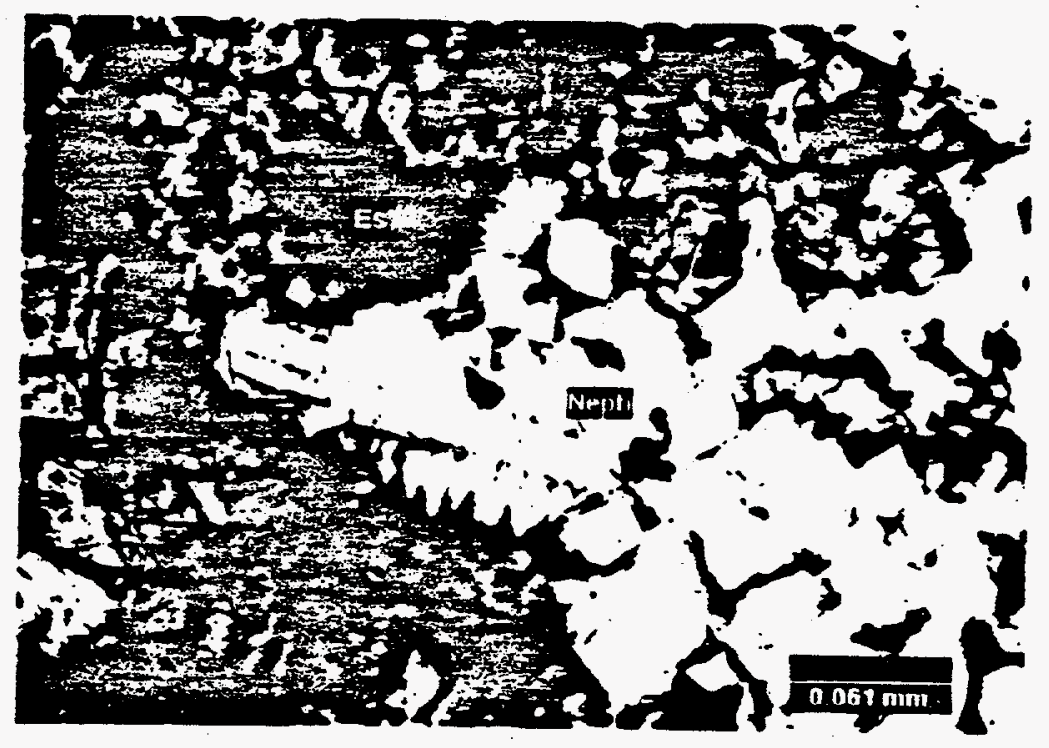

Figure 5-14: Glass 2/6/CCC Bottom, Crystalline structure of Figure 5-13 in Crossed Nicols 
Table 5-3: Statistical Evaluation of Large Agglomerates (1/6/TEM Surface, Bottom)

1/6 TEM surface

Number of Fields 1

Number of Objects 32

Objects per Field 32

Measured Area $\quad 3.93371\left[\mathrm{~mm}^{*} \mathrm{~mm}\right]$

Objects per Area $\quad 8.13481 /\left[\mathrm{mm}^{*} \mathrm{~nm}\right]$

Area Fraction 0.00315698

Surface area of the dark phase $31 \%$

$\begin{array}{llllll}\text { Feature } & \text { Mean } & \text { St.Dev } & \text { Minimum } & \text { Maximum } & \\ \text { EqDiameter } & 0.073286 & 0.020173 & 0.047565 & 0.12262 \mathrm{~min}\end{array}$

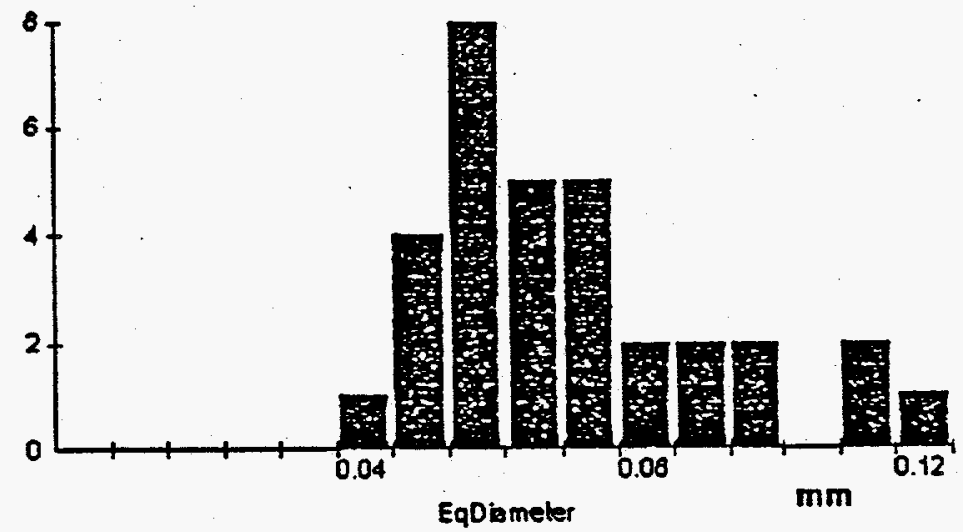

1/6 TEM boltom

Number of Fields 1

Number of Objects 34

Objects per Field $\quad 34$

Measured Area $\quad 3.93371\left[\mathrm{~mm}^{*} \mathrm{~mm}\right]$

Objects per Area $\quad 8.64324 /\left[\mathrm{mm}^{*} \mathrm{~mm}\right]$

Area Fraction 0.00937195

Surface area of the dark phase $32,6 \%$

$\begin{array}{llllll}\text { Feature } & \text { Mean } & \text { St.Dev } & \text { Minimum } & \text { Maximum } & \\ \text { EqDiameter } & 0.07293 & 0.019396 & 0.043955 & 0.1307 & \mathrm{~mm}\end{array}$

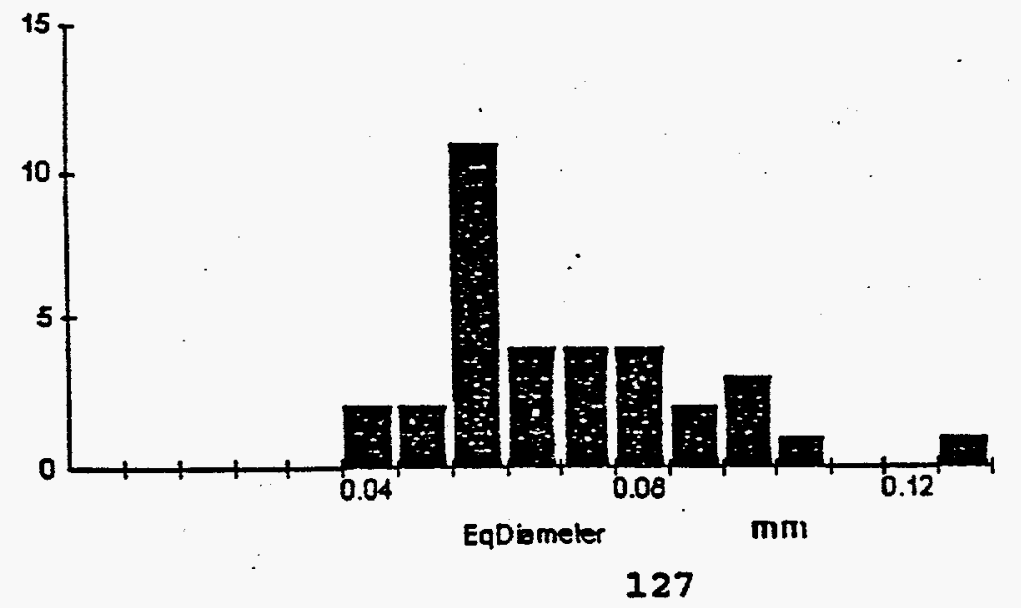


- Table 5-4: Statistical Evaluation of Large Agglomerates (1/6/CcC surface, Bottom)

$1 / 6 \mathrm{CCC}$ surface

Number of Fields 1

Number of Objects 46

Objects per Field 46

Measured Area $\quad 3.93371 .\left[\mathrm{mm}^{*} \mathrm{~mm}\right]$

Objects per Area $\quad 11.6938 /\left[\mathrm{mm}^{*} \mathrm{~mm}\right]$

Area Fraction 0.0185967

Surface area of the dark phase $33 \%$

$\begin{array}{llllll}\text { Feature } & \text { Mean } & \text { St.Dev } & \text { Minimum } & \text { Maximum } & \\ \text { EqDiameter } & 0.065295 & 0.018107 & 0.041116 & 0.11235 & \mathrm{~mm}\end{array}$

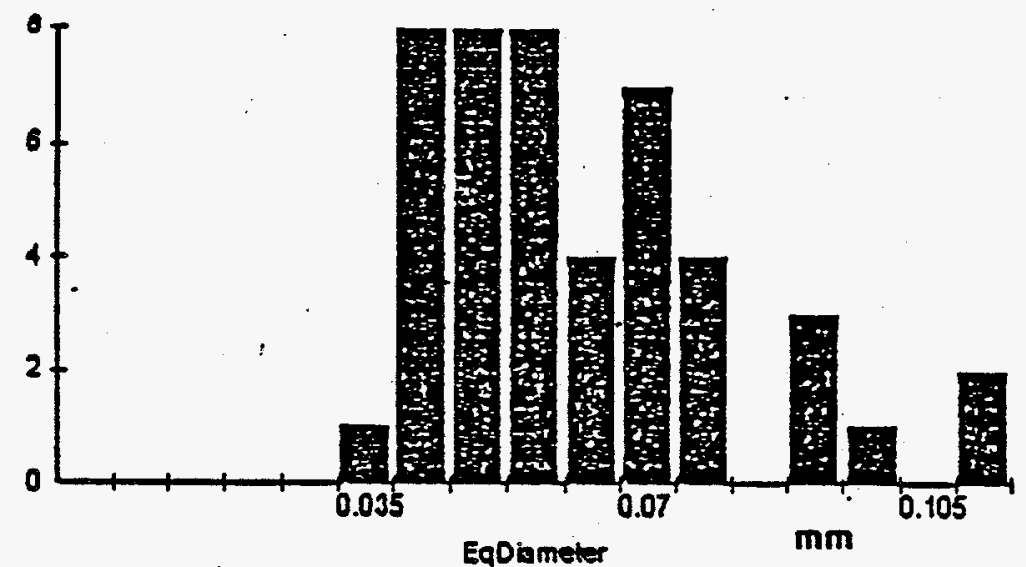

1/6 CCC bottom

Number of Fields 1

Number of Objects 39

Objects per Field 39

Measured Area $\quad 3.93371\left[\mathrm{~mm}^{*} \mathrm{~mm}\right]$

Objects per Area $\quad 9.9143 /\left[\mathrm{mm}^{*} \mathrm{~mm}\right]$

Area Fraction 0.0149423

Surface area of the dark phase $34,5 \%$

$\begin{array}{llllll}\text { Feature } & \text { Mean } & \text { St.Dev } & \text { Minimum } & \text { Maximum } & \\ \text { EqDiameter } & 0.068997 & 0.025111 & 0.045377 & 0.15796 & \mathrm{~mm}\end{array}$

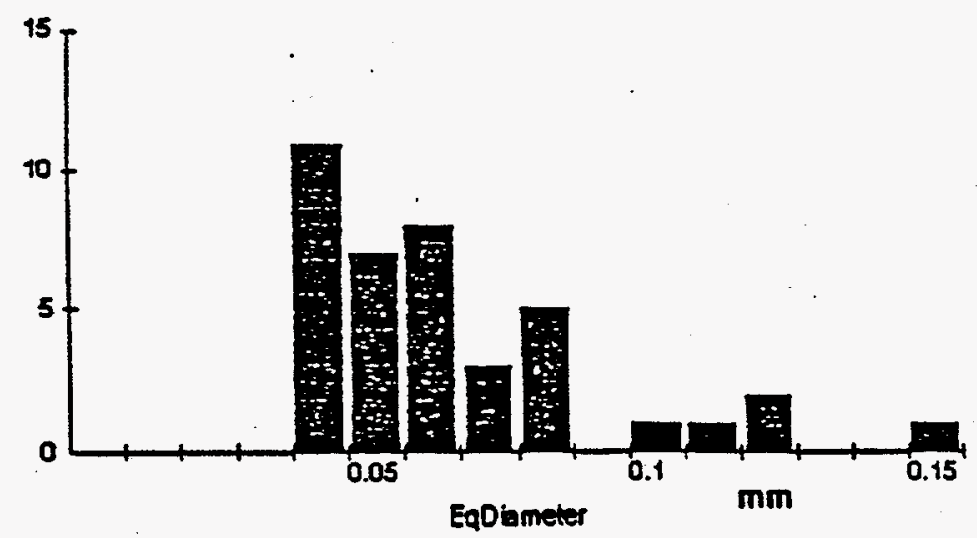




\subsection{DISCUSSION AND CONCLUSIONS}

\section{$x$-ray diffraction analysis}

There is a distinct difference between the phase composition of Glass 1 and Glass 2 before (quenched and annealed samples) as well as after thermal treatment. Glass 1 generally exhibits lower tendency to crystallization and a higher portion of the amorphous phase compared to similar samples of Glass 2 .

The samples cooled under the schedule CCC crystallize to a higher degree than TEM samples and the content of the amorphous phase is lower. For $2 / 6$ samples, Li-Al-disilicate is characteristic with TEM schedule and nepheline with CCC schedule of cooling. In $1 / 6$ samples, beta-eucryptite is present only with CCC schedule (not with TEM). Smaller lattice parameters mostly found for betaeucryptite, in comparison with tabulated values, can be explained by the formation of solid solutions with $\mathrm{SiO}_{2}$ ("stuffed" betaquartz, (see e.g. Strnad, 1986)).

There were not found effects of settling or segregation in the samples after long-time thermal treatment. Under the conditions of experiments that had been performed, no indication of concentration increase of phases with different densities was found in the upper or lower part of the melt.

optical analysis

No distinct differences between the phase composition near to the surface and to the bottom, which could be attributed to settling effects during melting, were found.

The amount of glass phase in specimens 1 was distinctly higher than in specimens 2. The CCC schedule implies a higher degree of crystallization than TEM schedule. The specimen $2 / 6 /$ Ccc was completely crystalline, excepting thin layers of glass on the crystal boundaries.

There were found dendritic crystals of unknown composition in specimens $1 / 6 / \mathrm{CCC}$ and $2 / 6 /$ TEM. It cannot be excluded that the dendrites represent morphologically different crystals. of beta- 
eucryptite found by $x$-ray diffraction. Additional examination by $X$-ray microanalysis was not succesful because of very small thickness of dendritic crystals.

The results of microscopic examination are in good agreement with the results of X-ray diffraction with the exception of betaeucryptite in $1 / 6 / \mathrm{CcC}$ which was found by $x$-ray, but not observed microscopically, probably due to unproper optical properties. A similar explanation can follow for the Ii-Al-disilicate phase.

\section{THE INFLUENCE OF. GLASS BASICITY AND CONTENT OF SOME} CONSTITUENTS ON THE CHROMIUN BEHAVIOR IN GLASSES

\subsection{INTRODUCTION}

The problem of incorporation of multi-valence elements into the final vitrification products is to guarantee such a valence state which leads to their maximum dissolution in the glass structure, and at the same time to the maximum chemical. resistance of the product (Schreiber, Hockman, 1987). The decisive role of redox processes in case of elements like chromium or uranium in the process of waste vitrification confirmed. Schreiber, Balazs, Kozak, (1983). This problem is complicated by the fact that the presence of several elements of this kind leads to the redox interactions and very often the optimum solution is not possible.

The main parameters affecting the ratio of hexa- and trivalent chromium are following:

- basicity of the melt (the glass composition)

- melting temperature

- oxygen fugacity in the furnace atmosphere

- mutual interaction of the redox elements

The melt composition

After the dissolution of a multivalent element in the glass melt, an equilibrium among its several valencies is established after a certain time: This equilibrium can be described as a solvolytic reaction regarding the fact that the melt itself 
plays a role in the redox process. One of the authors (schreiber, 1986) presents a possible equation:
$(m-2 x)$
$(m-n)$
2-
$4 \mathrm{MO}_{X}($ melt $)=4 M($ melt $)+(4 x-2 n)$
$O(\operatorname{melt})+n \mathrm{O}_{2}(\mathrm{~g})$

where $x$ is the number of oxygens associated with oxidized redox ion in the melt to form an oxo-anion, $\underline{n}$ is the number of electrons involved in the reduction and $m$ is the valence of the M element.

The equilibrium between $\operatorname{Cr}(V I)$ and $\operatorname{Cr}$ (III) can be described by following equation:

$$
4 \mathrm{CrO}_{4}^{2-}=4 \mathrm{Cr}^{3+}+10 \mathrm{O}^{2-}+3 \mathrm{O}_{2}
$$

It follows from the equation (1) that the ratio between the oxidized and reduced form of an element depends on the presence of free oxygen ions in the melt. The concentration of these ions (non-bridging oxygens) depends again on the depolymerization degree of the silicate or borate net, that is on the ratio of the concentration of net-forming elements to the concentration of modifiers (Volf, 1978).

In the glass praxis, a concept of acido-basicity has been introduced to enable a comparison of glasses of various compositions (Volf, 1984). Another concept was proposed (Lux, 1939) to express the concentration of oxygen ions in the melt - po (analogy to $\mathrm{pH}$ in aqueous solutions), because of the influence of oxygen ions on the acido-basicity of glasses (Volf, $1984)$.

In agreement with the equation (1), the content of redox element in its higher valence state increases when the basicity of the melt increases (decrease of po). On the contrary an increase of the glass acidity leads to the increase of the concentration of the redox element in its reduced state.

The acido-basicity of the glass can be calculated (Volf, 1984) using Duffy-Ingram formula: 


$$
p o=\sum \frac{{ }^{2} \dot{F}_{i}}{2 G_{i}}, \quad G=1.36(x-0.26)
$$

where:

$z_{i}$... the charge of ith electronegative element

$r_{i} \ldots$... the content of the element in ionic percents

$G_{i}$... the force affecting the basicity of th ith element

$x^{1}$... the electronegativity according to pauling

or formula of Sandersion:

$$
\mathrm{po}_{g}=\left(\prod \mathrm{x}_{i} \mathrm{~N}(i) . .5 .02 j \exp \left(1 /\left(1+\Sigma \mathrm{N}_{i}\right)\right)\right.
$$

where:

$$
\begin{aligned}
& x_{i} \text {... the Sanderson s electronegativity of ith atom, } \\
& N_{i} \text {... the } m \cdot W_{M} / \pi \text {. } W_{0} \text { ratio in the } M_{m} O_{n} \text { oxide ( } m \text { and } \underline{n} \text { are } \\
& \text { numbers of } M \text { and } O \text { atoms in the oxide: } \bar{w}_{M} \text { and } w_{O} \\
& \text { are their molecular weights). }
\end{aligned}
$$

(The latter formulae was used for the po(g) calculations in this section.)

In case when the concentration of the redox element increases to a certain extent, the redox element can contribute to the melt basicity and at the same time to some deviations from the redox equilibrium.

The effect of oxygen fugacity in the furnace atmosphere

On the basis of the equation (1), we can derive following dependence:

$$
\log \mathrm{fO}_{2}=(4 / n) \log \left(\mathrm{M}^{(\mathrm{m}-\mathrm{n})}+\right) /\left(\mathrm{M}^{\mathrm{m}+}\right)+B(2)
$$

The term $\underline{B}$ incorporates all quantities that are functions of temperature and/or base composition, and $\underline{n}$ represents the number of electrons transferred in the reaction.

It follows from the equation (2) that for a given melt composition and temperature the redox equilibrium depends, first of all, on the partial pressure of oxygen in the furnace atmosphere.

It is necessary to bear in mind the fact that the equilibrium in. the melt is in such a case affected by the diffusion of oxygen in the bulk of glass melt and that the 
equilibrium may be in some cases reached in tens of hours (depending on the amount of glass and dimensions and shape of the furnace). According to (Nath, Paul, Douglas, 1965), the real equilibrium with the furnace atmosphere is never reached in industrially operated furnaces.

In case of radioactive waste processing, the fugacity of oxygen is not generally directed by the furnace atmosphere but by suitable additives like carbon (coal or graphite),formic acid, nitrates, sulphates etc. The redox state of respective elements is thus directed by the melt composition and maximum process temperature. That was the reason why the main attention was given in this section to the effect of the glass composition (changes of the acidity) and to the CrVI/CrIII ratio.

\section{The glass melt temperature}

The reduction of a polyvalent element, as described in the equation (1), is an exothermic reaction (schreiber, 1986). The respective enthalpy change can be calculated from the clausiusclapeyron equation (Moore, 1981):

$$
\log \frac{\left[M^{(m-n)+}\right]}{\left[M^{m+}\right]}=\frac{-\Delta H}{2.303 R \cdot T} \cdot \frac{1}{T}+b
$$

where:

$$
\begin{aligned}
& \mathbf{R} \ldots \text { the ideal gas constant } \\
& \mathbf{T} \ldots \text { the temperature in } \mathrm{O}_{\mathrm{K}} \\
& \mathrm{H} \ldots \text { the enthalpy of reduction reaction } \\
& \mathrm{b} \ldots \text { a term that incorporates oxygen fugacity and } \\
& \text { composition dependencies. }
\end{aligned}
$$

It emerges from the equation that with the increase of the temperature the glass melt enables the reduction reactions and the redox elements tend to lower oxidation states. With the temperature changes during the cooling process, the redox equilibrium exhibits corresponding changes. This results in certain inhomogeneities in the melt. Even with glasses which were initially in the state of equilibrium, a shift in the equilibrium appears in the course of cooling when cooling was not sufficiently fast (Brückner, 1985). 
It is rather easy to cool a melt avoiding reactions between the melt and the atmosphere but it is almost impossible to cool it avoiding any reactions of oxygen inside of the melt. The mean diffusion path between all redox partners is much longer than the distance which the oxygen ions can cover during the cooling. Therefore it is necessary to reckon with a certain shift in the reaction equilibrium even when the cooling is very fast.

The behavior of chromium in silicate glasses during the cooling was studied e.g. by (Süssmilch, 1993), who checked the formation of yellow layer of alkali chromate during the cooling process. Quenched silicate glass (with high titanium content) was heated at temperatures and time given in the following table. The separated amount of chromate (in $\mathrm{mg}$ ) from the $10 \mathrm{~g}$ of the glass studied is given in following Table:

\begin{tabular}{|c|ccc|}
\hline $\begin{array}{c}\text { Temperature } \\
{\left[0_{\text {C] }}\right.}\end{array}$ & \multicolumn{3}{|c|}{ Time [hours] } \\
\hline 850 & 0.5 & 2 & 4 \\
900 & 0.05 & 1.52 & 11.9 \\
950 & 0.36 & 1.50 & 12.8 \\
1000 & 3.27 & 54.6 & 118.0 \\
1050 & 15.1 & 3.7 & 3.2 \\
\hline
\end{tabular}

The data indicated a danger of a slow cooling process which stimulate the CrVI formation at the temperature about $950{ }^{\circ} \mathrm{C}$. In cases of the formation of large blocks of glass a relatively inhomogeneous product is to be expected.

The mutual interactions of fedox elements in the melt

One of very important conclusions based on an extensive research (Schreiber, Balazs, 1982 and Schreiber, Balazs, Jamison, Schaeffer, 1982) was that the relative sequence of redox pairs in the melt is constant and independent of the melt composition. Individual redox values remain at the same time dependent of the glass composition and temperature. Such series copy the redox pair behavior in solutions with the exception of pairs in which the melt causes structural changes. 
It is necessary to distinguish between redox ratio and redox equilibrium (Brückner, 1985), for the redox equilibrium can be reached in a thermodynamic stable melt in case of sufficient long melting, depending on the melt viscosity and diffusion velocity. The equilibrium is generally reached after several decades of hours.

\subsection{EFFECT OF ACIDOBASICITY}

\subsubsection{INTRODUCTION}

The aim of the Task $6 a$ was to determine the effects of the acidobasicity changes on the incorporation of chromium into the glass phase by changing the contents of $\mathrm{Li}_{2} \mathrm{O}, \mathrm{SiO}_{2}$ and $\mathrm{B}_{2} \mathrm{O}_{3}$ added to the non-radioactive model waste with higher concentration of $\mathrm{Cr}$, defined in Table 1 of the Test Plan. Two levels of Cr concentration in waste were to be tested. Two main glasses were given: Glass 1 and Glass 2 with 30 and 45 resp. loading of waste (see the same Table). The range of glass composition to be examined was defined by following changes of concentrations of selected glass components added to the waste:

$\begin{array}{lrrrc} & \mathrm{Ii}_{2} \mathrm{O} & \mathrm{SiO}_{2} & \mathrm{~B}_{2} \mathrm{O}_{3} & \text { Label } \\ \text { Glass } 1 & 9.550 & 66.064 & 24.386 & \text { Z } \\ \text { l.Modification } & 5.000 & 70.614 & 24.386 & \text { Y } \\ \text { 2.Modification } & 5.000 & 66.064 & 28.936 & \text { X } \\ \text { Glass 2 } & 11.516 & 71.779 & 16.706 & \text { W } \\ \text { Modification } & 6.515 & 71.779 & 21.706 & \text { V }\end{array}$

(The numbers are given in wt. of the component in the varied oxide mixture.)

The proposed changes in the composition of glasses should decrease the basicity and thus to improve the incorporation of chromium in the vitrification product, shifting the redox equilibria crIII/CrVI to crIII. 


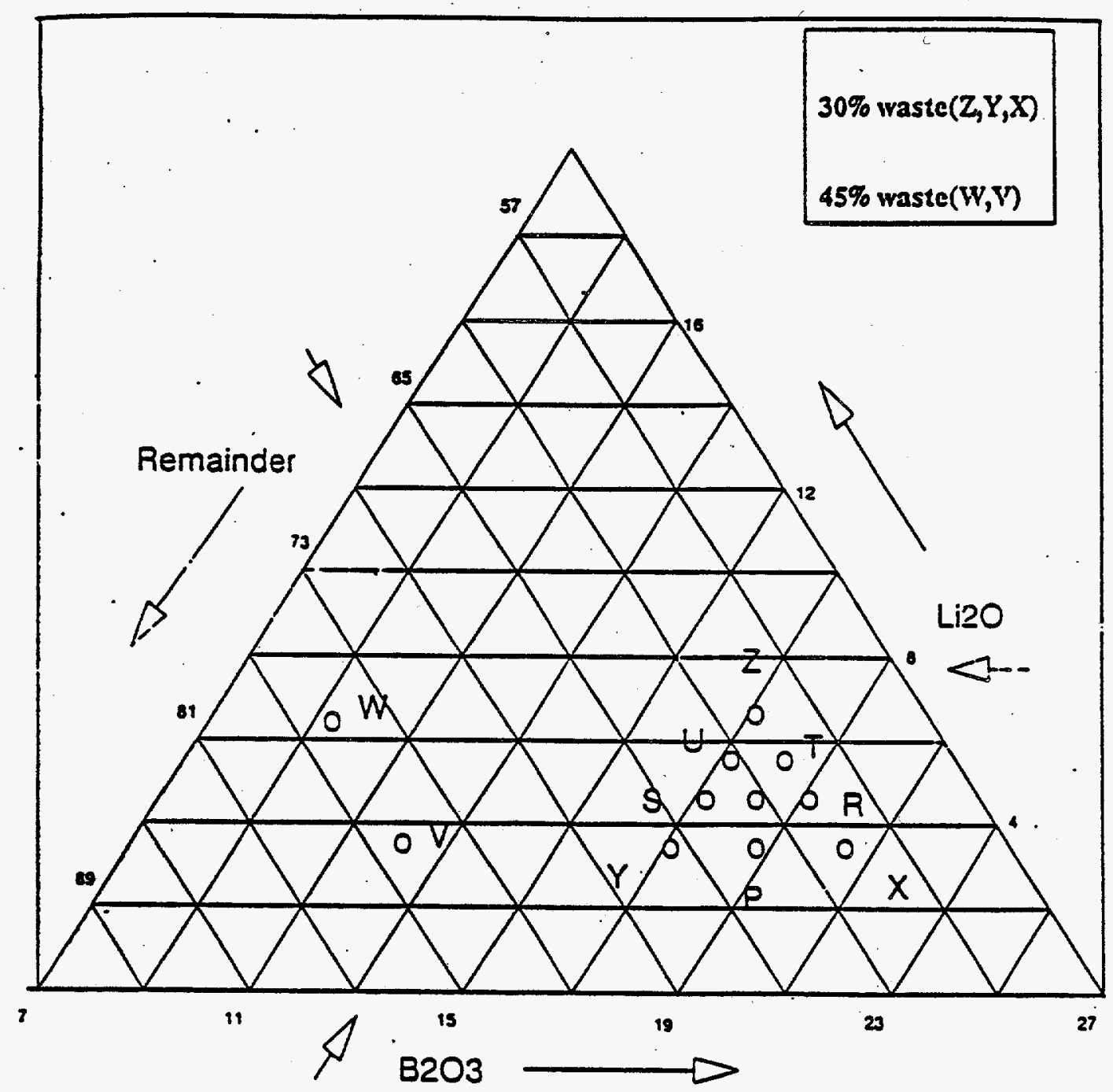

Figure 6-1: Variation of $\mathrm{B}_{2} \mathrm{O}_{3}$ and $\mathrm{Li}_{2} \mathrm{O}$ Content in Glasses Note: $\mathrm{SiO}_{2}$ is a Part of the "Remainder": Z-T-R-X Series $\left(46.7 \% \mathrm{SiO}_{2}\right), \mathrm{U}-\mathrm{Q}(47.8 \%), \quad \mathrm{P}(48.3 \%)$, $S(48.97), Y(49.9 \%), W-V(40.2 \%)$.

Glass Compositions: see Table $6-2 a, b$ and Table 6-3.

More detailed experimental scheme was chosen for the system corresponding to Glass 1 (two intermediate levels of $\mathrm{Li}_{2} \mathrm{O}$ content) to gain basic information about the proper melting temperature for the glass casting, to examine the relative hydrolytic resistance of the glass grains and to determine the chromate separated from the melt. Variation in $B$ and $L i$ oxides in 
glasses is shown in Figure 6-1. Changes of $\mathrm{SiO}_{2}$ content are hidden in the variation of the "remainder".

The changes of glass acidobasicities for chosen compositions are summarized in Table 6-1. Method of calculation of the Sanderson's acidobasicity and table of sanderson's atomic electronegativities are described elsewhere (Volf, 1984).

Table 6-1: Sanderson's Acidobasicity of Glasses

\begin{tabular}{|lrrrrrrrr|}
\hline Glass & Z & $Y$ & $X$ & W & V \\
\hline po [g] & 1.608 & 1.759 & 1.779 & 1.481 & 1.612 & \\
\hline Glass & U & $T$ & $S$ & $Q$ & $R$ & $P$ \\
\hline po [g] & 1.656 & 1.663 & 1.706 & 1.712 & 1.719 & 1.769 \\
\hline
\end{tabular}

To evaluate the differences in behavior of the melt when $\mathrm{cr}^{6+}$ is present in the first step of the heat treatment, sodium chromate instead of $\mathrm{Cr}$ hydroxide was used in the batch for the glass preparation.

Further problem of the task was to determine the changes of the $C r(V I) / t o t a l$ cr ratio with the composition changes of components added to the waste.

Results obtained served for the preparation of selected glasses which were prepared in greater amounts at svus and used for crucial experiments at the Glass Institute (see section 6.5).

\subsubsection{PREPARATION OF GLASSES}

In order to study changes in behavior and in leaching properties of glass products, batches were prepared for selected compositions which give $100 \mathrm{~g}$ of final glassy product. Compositions of giasses are given in Tables 6-2,6-3, and 6-4. Each product was assigned to one of the labels used in these tables and denoted by successive order numbers. The batches were weighed up from compounds mainly of analytical grade listed in Table 6-5. Chemical compounds were ground and mixed. 
Two special forms of hydrated chromium oxide were applied for the preparation of glasses. A black form of hydroxide (formed from Cr hydroxide I dried at $150^{\circ} \mathrm{C}$, see Annex Al) was used in the first period of experiments. A correct green form of hydroxide (dried at $105^{\circ} \mathrm{C}$, marked as $\mathrm{Cr}$ hydroxide $\mathrm{II}$ ) was applied in later experiments (see Tables $6-2,6-3$, and 6-4). Any significantly different behavior of the glass products was not observed by interchange of the chromium hydroxide forms.

The samples were melted in corundum crucibles (volume: $150 \mathrm{ml}$, height: $61 \mathrm{~mm}$, upper diameter: $68 \mathrm{~mm}$ ) in a resistance furnace Model Clasic SK1216 with $360 \mathrm{~cm}^{2}$ of the operating place. Because we did not know the proper melting temperature of the batches, we applied two or three temperatures for the glass preparation and tested the casting ability by weighing the cast part of glass (Annex B12). The effect of melting dwell was examined in some cases. The casting was performed onto a steel plate with a steel mould of the size $13 \times 85 \mathrm{~mm}$. A glass tape was pulled out after the casting procedure for visual examination. Then the cast sample was transferred into an other furnace (Model Clasic NR1013) which was preheated to $530^{\circ} \mathrm{C}$ and after 1 hour tempering, the furnace was switched off and the sample was cooled in the furnace to $50^{\circ} \mathrm{C}$.

The melting conditions (temperature and the residence time), calculated viscosities for the melting temperature and temperature $1150^{\circ} \mathrm{C}$, and proportion of the melt cast to the mould are included in Tables $6-6,6-7$ and 6-8. (Regression function for the Arrhenius equation, computed by Hrma et al., 1994, was used. Glasses prepared at temperature lower than $1300^{\circ} \mathrm{C}$ fulfill all constraints given for the model using Fulcher equation.) 
Table 6-2a: Composition of Prepared Glasses

Modification of Glass 1 ( 30 waste Loading), 1.Part [Units in Mass Fractions]

\begin{tabular}{|c|c|c|c|c|c|c|}
\hline $\begin{array}{r}\text { Glass } \\
\text { Component }\end{array}$ & $\mathbf{z}$ & $Y$ & $\mathbf{x}$ & [i] & {$[\notin]$} & [X] \\
\hline $\begin{array}{l}\mathrm{SiO}_{2} \\
\mathrm{~B}_{2} \mathrm{O}_{3} \\
\mathrm{Na}_{2} \mathrm{O} \\
\mathrm{Li}_{2} \mathrm{O} \\
\mathrm{CaO} \\
\mathrm{MgO} \\
\mathrm{Fe}_{2} \mathrm{O}_{3} \\
\mathrm{Al}_{2} \mathrm{O}_{3} \\
\mathrm{ZrO}_{2} \\
\mathrm{Cr}_{2} \mathrm{O}_{3} \\
\mathrm{P}_{2} \mathrm{O}_{5} \\
\mathrm{SO}_{3} \\
\mathrm{Na}_{2} \mathrm{O}_{3} \\
\mathrm{La}_{2} \mathrm{O}_{3} \\
\mathrm{~K}_{2} \mathrm{O}_{3} \\
\mathrm{~F} \\
\mathrm{MnO}_{2} \\
\mathrm{MOO}_{3} \\
\mathrm{NiO}_{\mathrm{Cl}} \\
\mathrm{CnO}\end{array}$ & $\begin{array}{l}0.4675 \\
0.1707 \\
0.0624 \\
0.0669 \\
0.0019 \\
0.0002 \\
0.0140 \\
0.1621 \\
0.0002 \\
0.0414 \\
0.0011 \\
0.0006 \\
0.0006 \\
0.0002 \\
0.0008 \\
0.0003 \\
0.0041 \\
0.0011 \\
0.0009 \\
0.0012 \\
0.0019\end{array}$ & $\begin{array}{l}0.4994 \\
0.1707 \\
0.0624 \\
0.0350 \\
0.0019 \\
0.0002 \\
0.0140 \\
0.1621 \\
0.0002 \\
0.0414 \\
0.0011 \\
0.0006 \\
0.0006 \\
0.0002 \\
0.0008 \\
0.0003 \\
0.0041 \\
0.0012 \\
0.0009 \\
0.0012 \\
0.0019\end{array}$ & $\begin{array}{l}0.4676 \\
0.2026 \\
0.0624 \\
0.0350 \\
0.0019 \\
0.0002 \\
0.0140 \\
0.1621 \\
0.0002 \\
0.0414 \\
0.0011 \\
0.0006 \\
0.0006 \\
0.0002 \\
0.0008 \\
0.0003 \\
0.0041 \\
0.0011 \\
0.0009 \\
0.0012 \\
0.0019\end{array}$ & $\begin{array}{l}0.4653 \\
0.1699 \\
0.0626 \\
0.0665 \\
0.0018 \\
0.0002 \\
0.0139 \\
0.1613 \\
0.0002 \\
0.0457 \\
0.0011 \\
0.0006 \\
0.0006 \\
0.0002 \\
0.0008 \\
0.0003 \\
0.0041 \\
0.0011 \\
0.0009 \\
0.0012 \\
0.0018\end{array}$ & $\begin{array}{l}0.4970 \\
0.1699 \\
0.0626 \\
0.0348 \\
0.0018 \\
0.0002 \\
0.0139 \\
0.1613 \\
0.0002 \\
0.0456 \\
0.0011 \\
0.0006 \\
0.0006 \\
0.0002 \\
0.0008 \\
0.0003 \\
0.0041 \\
0.0011 \\
0.0009 \\
0.0012 \\
0.0018\end{array}$ & $\begin{array}{l}0.4653 \\
0.2016 \\
0.0626 \\
0.0348 \\
0.0018 \\
0.0002 \\
0.0139 \\
0.1613 \\
0.0002 \\
0.0457 \\
0.0011 \\
0.0006 \\
0.0006 \\
0.0002 \\
0.0008 \\
0.0003 \\
0.0041 \\
0.0011 \\
0.0009 \\
0.0012 \\
0.0018\end{array}$ \\
\hline
\end{tabular}

Note: [1] $Z^{\prime}, Y^{\prime}$ and $X^{\prime}$ compositions with the black form of $C r$ hydroxide are used in experiments $7,9,10,13,14,15$ and 16 .

Table 6-2b: Composition of Prepared Glasses Modification of Glass 1 ( 30 Waste Loading), 2.Part [Units in Mass Fractions]

\begin{tabular}{|l|rrrrrr|}
\hline $\begin{array}{r}\text { Glass } \\
\text { Component }\end{array}$ & P & U & T & S & $R$ & $Q$ \\
\hline $\mathrm{SiO}_{2}$ & 0.4834 & 0.4784 & 0.4675 & 0.4889 & 0.4675 & 0.4782 \\
$\mathrm{~B}_{2} \mathrm{O}_{3}$ & 0.1866 & 0.1707 & 0.1816 & 0.1707 & 0.1921 & 0.1814 \\
$\mathrm{Na}_{2} \mathrm{O}$ & 0.0624 & 0.0624 & 0.0624 & 0.0624 & 0.0624 & 0.0624 \\
$\mathrm{Li}_{2} \mathrm{O}$ & 0.0350 & 0.0560 & 0.0560 & 0.0455 & 0.0455 & 0.0455 \\
$\mathrm{CaO}$ & 0.0019 & 0.0019 & 0.0019 & 0.0019 & 0.0019 & 0.0019 \\
$\mathrm{MgO}_{\mathrm{Fe}_{2} \mathrm{O}_{3}}$ & 0.0002 & 0.0002 & 0.0002 & 0.0002 & 0.0002 & 0.0002 \\
$\mathrm{Al}_{2} \mathrm{O}_{3}$ & 0.0140 & 0.0140 & 0.0140 & 0.0140 & 0.0140 & 0.0140 \\
$\mathrm{ZrO}_{2}$ & 0.0002 & 0.1621 & 0.1621 & 0.1621 & 0.1621 & 0.1621 \\
\hline
\end{tabular}

cont. 


\begin{tabular}{|c|c|c|c|c|c|c|}
\hline $\begin{array}{r}\text { Glass } \\
\text { Component }\end{array}$ & $\mathbf{P}$ & $\mathbf{U}$ & $\mathbf{T}$ & $\mathbf{s}$ & $\mathbf{R}$ & $Q$ \\
\hline $\begin{array}{l}\mathrm{SO}_{3}{ }^{3} \\
\mathrm{Na}_{2} \mathrm{O}_{3} \\
\mathrm{La}_{2} \mathrm{O}_{3} \\
\mathrm{~K}_{2} \mathrm{O} \\
\mathrm{F} \\
\mathrm{MnO}_{2} \\
\mathrm{MoO}_{3} \\
\mathrm{NiO} \\
\mathrm{Cl} \\
\mathrm{Zno}\end{array}$ & $\begin{array}{l}0.0414 \\
0.0011 \\
0.0006 \\
0.0006 \\
0.0002 \\
0.0008 \\
0.0003 \\
0.0041 \\
0.0011 \\
0.0009 \\
0.0012 \\
0.0019\end{array}$ & $\begin{array}{l}0.0414 \\
0.0011 \\
0.0006 \\
0.0006 \\
0.0002 \\
0.0008 \\
0.0003 \\
0.0041 \\
0.0011 \\
0.0009 \\
0.0012 \\
0.0018\end{array}$ & $\begin{array}{l}0.0414 \\
0.0011 \\
0.0006 \\
0.0006 \\
0.0002 \\
0.0008 \\
0.0003 \\
0.0041 \\
0.0011 \\
0.0009 \\
0.0012 \\
0.0019\end{array}$ & $\begin{array}{l}0.0414 \\
0.0011 \\
0.0006 \\
0.0006 \\
0.0002 \\
0.0008 \\
0.0003 \\
0.0041 \\
0.0011 \\
0.0009 \\
0.0012 \\
0.0019\end{array}$ & $\begin{array}{l}0.0414 \\
0.0011 \\
0.0006 \\
0.0006 \\
0.0002 \\
0.0008 \\
0.0003 \\
0.0041 \\
0.0011 \\
0.0009 \\
0.0012 \\
0.0019\end{array}$ & $\begin{array}{l}0.0414 \\
0.0011 \\
0.0006 \\
0.0006 \\
0.0002 \\
0.0008 \\
0.0003 \\
0.0041 \\
0.0011 \\
0.0009 \\
0.0012 \\
0.0019\end{array}$ \\
\hline
\end{tabular}

Table 6-3: Composition of Prepared Glasses Modification of Glass 2 ( 45 \%aste Loading) [Units in Mass Fractions]

\begin{tabular}{|c|c|c|c|c|}
\hline $\begin{array}{r}\text { Glass } \\
\text { Component }\end{array}$ & $W$ & $v$ & [1] & {$[1]$} \\
\hline $\begin{array}{l}\mathrm{SiO}_{2} \\
\mathrm{~B}_{2} \mathrm{O}_{3} \\
\mathrm{Na}_{2} \mathrm{O} \\
\mathrm{Li}_{2} \mathrm{O} \\
\mathrm{CaO} \\
\mathrm{MgO} \\
\mathrm{Fe}_{2} \mathrm{O}_{3} \\
\mathrm{Al}_{2} \mathrm{O}_{3} \\
\mathrm{ZrO}_{2} \\
\mathrm{Cr}_{2} \mathrm{O}_{3} \\
\mathrm{P}_{2} \mathrm{O}_{5} \\
\mathrm{SO}_{3} \\
\mathrm{Na}_{2} \mathrm{O}_{3} \\
\mathrm{La}_{2} \mathrm{O}_{3} \\
\mathrm{~K}_{2} \mathrm{O} \\
\mathrm{F} \\
\mathrm{MnO} \\
\mathrm{MOO} \\
\mathrm{NiO}_{3} \\
\mathrm{Cl} \\
\mathrm{ZnO}\end{array}$ & $\begin{array}{l}0.4024 \\
0.0919 \\
0.0937 \\
0.0633 \\
0.0028 \\
0.0003 \\
0.0210 \\
0.2432 \\
0.0003 \\
0.0622 \\
0.0016 \\
0.0009 \\
0.0009 \\
0.0003 \\
0.0011 \\
0.0004 \\
0.0062 \\
0.0016 \\
0.0013 \\
0.0018 \\
0.0028\end{array}$ & $\begin{array}{l}0.4024 \\
0.1194 \\
0.0937 \\
0.0358 \\
0.0028 \\
0.0003 \\
0.0210 \\
0.2432 \\
0.0003 \\
0.0622 \\
0.0016 \\
0.0009 \\
0.0009 \\
0.0003 \\
0.0011 \\
0.0004 \\
0.0062 \\
0.0016 \\
0.0013 \\
0.0018 \\
0.0028\end{array}$ & $\begin{array}{l}0.3995 \\
0.0912 \\
0.0936 \\
0.0629 \\
0.0028 \\
0.0003 \\
0.0208 \\
0.2414 \\
0.0003 \\
0.0683 \\
0.0016 \\
0.0009 \\
0.0009 \\
0.0003 \\
0.0011 \\
0.0004 \\
0.0061 \\
0.0016 \\
0.0013 \\
0.0018 \\
0.0028\end{array}$ & $\begin{array}{l}0.3995 \\
0.1185 \\
0.0936 \\
0.0356 \\
0.0028 \\
0.0003 \\
0.0208 \\
0.2414 \\
0.0003 \\
0.0683 \\
0.0016 \\
0.0009 \\
0.0009 \\
0.0003 \\
0.0011 \\
0.0004 \\
0.0061 \\
0.0016 \\
0.0013 \\
0.0018 \\
0.0028\end{array}$ \\
\hline
\end{tabular}

Note: [1] $W^{\prime}$ and $V^{\prime}$ compositions with black form of $c r$ hydroxide are used in experiments 11,12 
Table 6-4: Composition of Glasses Prepared from Waste with Doubled Content of Chromium [Units in Mass Fractions]

\begin{tabular}{|l|lllll|}
\hline $\begin{array}{r}\text { Glass } \\
\text { Component }\end{array}$ & $\mathrm{Z}^{\prime \prime}$ & $\mathrm{Y}^{\prime \prime}$ & $\mathrm{X}^{\prime \prime}$ & $\mathrm{w}^{\prime \prime}$ &. \\
\hline $\mathrm{SiO}_{2}$ & 0.4669 & 0.4988 & 0.4669 & 0.4015 & 0.4015 \\
$\mathrm{~B}_{2} \mathrm{O}_{3}$ & 0.1707 & 0.1707 & 0.2026 & 0.0919 & 0.1194 \\
$\mathrm{Na}_{2} \mathrm{O}$ & 0.0548 & 0.0548 & 0.0548 & 0.0823 & 0.0823 \\
$\mathrm{Li}_{2} \mathrm{O}$ & 0.0668 & 0.0350 & 0.0350 & 0.0633 & 0.0358 \\
$\mathrm{CaO}$ & 0.0016 & 0.0016 & 0.0016 & 0.0024 & 0.0024 \\
$\mathrm{MgO}$ & 0.0002 & 0.0002 & 0.0002 & 0.0002 & 0.0002 \\
$\mathrm{Fe}_{2} \mathrm{O}_{3}$ & 0.0123 & 0.0123 & 0.0123 & 0.0184 & 0.0184 \\
$\mathrm{Al}_{2} \mathrm{O}_{3}$ & 0.1425 & 0.1425 & 0.1425 & 0.2137 & 0.2137 \\
$\mathrm{ZrO}_{2}$ & 0.0002 & 0.0002 & 0.0002 & 0.0003 & 0.0003 \\
$\mathrm{Cr}_{2} \mathrm{O}_{3}$ & 0.0728 & 0.0728 & 0.0728 & 0.1092 & 0.1092 \\
$\mathrm{P}_{2} \mathrm{O}_{5}$ & 0.0010 & 0.0010 & 0.0010 & 0.0014 & 0.0014 \\
$\mathrm{SO}_{3}$ & 0.0005 & 0.0005 & 0.0005 & 0.0008 & 0.0008 \\
$\mathrm{Na}_{2} \mathrm{O}_{3}$ & 0.0005 & 0.0005 & 0.0005 & 0.0008 & 0.0008 \\
$\mathrm{La}_{2} \mathrm{O}_{3}$ & 0.0002 & 0.0002 & 0.0002 & 0.0003 & 0.0003 \\
$\mathrm{~K}_{2} \mathrm{O}$ & 0.0007 & 0.0007 & 0.0007 & 0.0010 & 0.0010 \\
$\mathrm{~F}$ & 0.0002 & 0.0002 & 0.0002 & 0.0004 & 0.0004 \\
$\mathrm{MnO}_{2}$ & 0.0036 & 0.0036 & 0.0036 & 0.0054 & 0.0054 \\
$\mathrm{MOO}_{3}$ & 0.0010 & 0.0010 & 0.0010 & 0.0014 & 0.0014 \\
$\mathrm{NiO}_{\mathrm{Cl}}$ & 0.0008 & 0.0008 & 0.0008 & 0.0012 & 0.0012 \\
$\mathrm{ZnO}$ & 0.0011 & 0.0011 & 0.0011 & 0.0016 & 0.0016 \\
\end{tabular}

Table 6-5: Chemical Compounds Used for Preparation of Glasses

\begin{tabular}{|c|c|c|}
\hline Chemical compound & Purity & Producer \\
\hline $\begin{array}{l}\mathrm{SiO}_{2} \cdot g l a s s \text { sand } \\
\mathrm{H}_{3} \mathrm{BO}_{3} \\
\mathrm{Na}_{2} \mathrm{CO}_{3} \\
\mathrm{Li}_{2} \mathrm{CO}_{3} \\
\mathrm{CaO} \\
\mathrm{MgO}-\text { light } \\
\mathrm{Fe}_{2} \mathrm{O}_{3} \\
\mathrm{Al}_{2} \mathrm{O}_{3} \\
\mathrm{ZrO}\left(\mathrm{NO}_{3}\right)_{2} \cdot 2 \mathrm{H}_{2} \mathrm{O} \\
\mathrm{Cr}_{2} \mathrm{O}_{3} \cdot \mathrm{nH}_{2} \mathrm{O} \\
\mathrm{NaH}_{2} \mathrm{PO}_{4} \mathrm{H}_{2} \mathrm{O} \\
\mathrm{Na}_{2} \mathrm{SO}_{4} \\
\mathrm{Nd}_{2} \mathrm{O}_{3} \\
\mathrm{La}_{2} \mathrm{O}_{3} \\
\mathrm{~K}_{2} \mathrm{CO}_{3}\end{array}$ & $\begin{array}{l}99.85 \\
\text { pure } \\
\text { pure } \\
\text { p.a. } \\
\text { p.a. } \\
\text { pure } \\
\text { p.a. } \\
\text { p.a. } \\
\text { p.a. } \\
\text { p.a. } \\
\text { p.a. } \\
\text { pure } \\
\text { pure } \\
\text { pure }\end{array}$ & $\begin{array}{l}\text { Deposit strelec, CR } \\
\text { LACHEMA } \\
\text { LACHEMA } \\
\text { LACHEMA } \\
\text { LACHEMA } \\
\text { LACHEMA } \\
\text { LACHEMA } \\
\text { LACHEMA } \\
\text { SOjuzChimexport, Moscow } \\
\text { Sklárský. ustav (Annex Al) } \\
\text { LACHEMA } \\
\text { LACHEMA } \\
\text { FLUKA AG BUCHs sG, Swiss } \\
\text { AUSTRANAL-Präparate, } \\
\text { LOBA-CHEMIE, wien } \\
\text { LACHEMA. }\end{array}$ \\
\hline
\end{tabular}

cont. 


\begin{tabular}{|c|c|c|}
\hline Chemical Compound & Purity & Producer \\
\hline $\begin{array}{l}\mathrm{NaF} \\
\mathrm{MinO} \\
\mathrm{MOO}_{3} \\
\mathrm{Ni}\left(\mathrm{NO}_{3}\right)_{2} \cdot 6 \mathrm{H}_{2} \mathrm{O} \\
\text { 2no } \\
\mathrm{NaCl}\end{array}$ & $\begin{array}{l}\text { p.a. } \\
\text { pure } \\
\text { p.a. } \\
\text { p.a. } \\
\text { p.a. } \\
\text { pure }\end{array}$ & $\begin{array}{l}\text { LACHEMA } \\
\text { Riedel-De Haen AG. } \\
\text { Seelze-Hannover } \\
\text { IACHEMA } \\
\text { ANALAR The British Drog } \\
\text { HOUSES ITD. } \\
\text { B.D.H.Labor.Chem.Divis. } \\
\text { LACHEMA } \\
\text { LACHEMA }\end{array}$ \\
\hline
\end{tabular}

Table 6-6: Melting and Casting List of Glass 1 Modifications ( 30 Waste Loading)

\begin{tabular}{|c|c|c|c|c|}
\hline Sample & $\begin{array}{c}\text { Melt:Temp:/Dwell } \\
{\left[{ }^{\left.{ }^{\circ} \mathrm{C} / \mathrm{h}\right]}\right]}\end{array}$ & $\begin{array}{c}\text { Calc. Visc } \\
1150^{\circ} \mathrm{C} \\
{[\mathrm{Pa} . \mathrm{s}]}\end{array}$ & $\begin{array}{l}\text { sity at } \\
\text { MeIt.T. } \\
{[\text { [a.s] }}\end{array}$ & $\begin{array}{c}\text { Cast } \\
\text { Proportion } \\
{[w t .8]}\end{array}$ \\
\hline $\begin{array}{r}Z \cdot 7 \\
28 \\
X \cdot 9 \\
Y \cdot 10 \\
X \cdot 13 \\
X \cdot 14 \\
Y \cdot 15 \\
Y \cdot 16 \\
U 19 \\
U 20 \\
T 21 \\
T 22 \\
S 23 \\
S 24 \\
R 25 \\
R 26 \\
Q 31 \\
U 32 \\
U 33 \\
S 34 \\
P 35 \\
P 36 \\
Y 37 \\
Y 38 \\
Y 39 \\
Y 40 \\
Z 41 \\
Z 42 \\
X 63 \\
X 64\end{array}$ & $\begin{array}{l}1150 / 2[1] \\
1150 / 2[1] \\
1150 / 2 \\
1150 / 2 \\
1350 / 2 \\
1350 / 2+1400 / 0.5 \\
1350 / 2 \\
1350 / 2+1400 / 0.5 \\
1150 / 2 \\
1150 / 2 \\
1150 / 2 \\
1150 / 2+1200 / 0.5 \\
1150 / 2 \\
1150 / 2+1250 / 0.5 \\
1150 / 2 \\
1150 / 2+1250 / 0.5 \\
1200 / 2+1250 / 0.5 \\
1200 / 2 \\
1200 / 2+1250 / 0.5 \\
1400 / 3 \\
1400 / 3 \\
1400 / 3 \\
1350 / 2 \\
1350 / 2 \\
1350 / 2+1400 / 0.5 \\
1350 / 2+1400 / 0.5 \\
1150 / 3 \\
1150 / 3 \\
1400 / 3 \\
1400 / 3\end{array}$ & $\begin{array}{r}6.66 \\
6.78 \\
16.30 \\
26.24 \\
16.30 \\
16.30 \\
26.24 \\
26.24 \\
10.84 \\
10.84 \\
9.20 \\
9.20 \\
17.07 \\
17.07 \\
12.39 \\
12.39 \\
14.53 \\
10.84 \\
10.84 \\
17.07 \\
21.15 \\
21.15 \\
26.87 \\
26.87 \\
26.87 \\
26.87 \\
6.78 \\
6.78 \\
16.66 \\
16.66\end{array}$ & $\begin{array}{r}6.66 \\
6.78 \\
16.30 \\
26.24 \\
3.18 \\
2.25 \\
4.88 \\
3.41 \\
10.84 \\
10.84 \\
9.20 \\
6.03 \\
17.07 \\
7.21 \\
12.39 \\
5.33 \\
6.19 \\
7.07 \\
4.74 \\
2.40 \\
2.84 \\
2.84 \\
5.00 \\
5.00 \\
1.70 \\
1.70 \\
6.78 \\
6.78 \\
2.30 \\
2.30\end{array}$ & $\begin{array}{r}46 \\
49 \\
0 \\
0 \\
41 \\
48 \\
37 \\
37 \\
33 \\
38 \\
41 \\
46 \\
18 \\
38 \\
35 \\
46 \\
42 \\
41 \\
50 \\
51 \\
50 \\
48 \\
40 \\
37 \\
45 \\
44 \\
44 \\
39 \\
46 \\
47\end{array}$ \\
\hline
\end{tabular}

Note: [1] Equivalent amount of $\mathrm{Na}_{2} \mathrm{CrO}_{4}$ was used in the sample 28 , substituting the $C r$ hydroxide weighed out in other cases. 
Table 6-7: Melting and Casting List of Glass 2 Modifications (45 * Waste Loading)

\begin{tabular}{|c|c|c|c|c|}
\hline Sample & $\begin{array}{c}\text { Melt. Temp. / Dwell } \\
{\left[{ }^{\circ} \mathrm{C}\right] /[\mathrm{h}]}\end{array}$ & $\begin{array}{c}\text { Calc. Visc } \\
1150^{\circ} \mathrm{C} \\
{[\mathrm{Pa} . \mathrm{s}]}\end{array}$ & $\begin{array}{l}\text { sity at } \\
\text { Melt.T. } \\
{[\mathrm{Pa} \text { s] }]}\end{array}$ & $\begin{array}{c}\text { Cast } \\
\text { Proportion } \\
\text { [wt: } t]\end{array}$ \\
\hline $\begin{array}{r}w \cdot 11 \\
V \cdot 12 \\
w 17 \\
V 18 \\
\text { W27 } \\
V 28 \\
\text { W47 } \\
\text { W48 } \\
V 52\end{array}$ & $\begin{array}{l}1450 / 2 \\
1450 / 2 \\
1450 / 4 \\
1450 / 4 \\
1450 / 2 \\
1450 / 2 \\
1450 / 3 \\
1450 / 3 \\
1450 / 3\end{array}$ & $\begin{array}{l}11.2 \\
24.1 \\
11.5 \\
24.3 \\
11.5 \\
24.3 \\
11.5 \\
11.5 \\
25.0\end{array}$ & $\begin{array}{l}1.4 \\
2.5 \\
1.4 \\
2.6 \\
1.4 \\
2.6 \\
1.4 \\
1.4 \\
2.6\end{array}$ & $\begin{array}{r}37 \\
0 \\
44 \\
23 \\
{[1] \text { kel }} \\
{[1]_{\mathrm{kel}}} \\
48 \\
49 \\
29\end{array}$ \\
\hline
\end{tabular}

Note: $[1]_{\text {kel }}=$ melt is cooled in the crucible

Table 6-8: Melting and Casting List of Glasses with Doubled Cr content in Waste

\begin{tabular}{|c|c|c|c|c|}
\hline Sample & $\begin{array}{c}\text { Melt. Temp. /Dwell } \\
{\left[{ }^{\circ}\right] /[\mathrm{h}]}\end{array}$ & $\begin{array}{c}\text { Calc: Visce } \\
1150^{\circ} \mathrm{C} \\
{[\mathrm{Pa} \cdot \mathrm{s}]}\end{array}$ & $\begin{array}{l}\text { sity at } \\
\text { MeIt.T. } \\
\text { [Pa.s] }\end{array}$ & $\begin{array}{c}\text { Cast } \\
\text { Proportion } \\
{[w t . q] .}\end{array}$ \\
\hline $\begin{array}{l}Z " 43 \\
X^{\prime \prime} 46 \\
W^{\prime \prime} 49 \\
Y " 54\end{array}$ & $\begin{array}{l}1150 / 3+1200 / 0.5 \\
1400 / 3+1450 / 0.5 \\
1450 / 4 \\
1450 / 3\end{array}$ & $\begin{array}{r}5.77 \\
14.19 \\
9.03 \\
22.88\end{array}$ & $\begin{array}{l}3.81 \\
1.37 \\
1.08 \\
2.07\end{array}$ & $\begin{array}{l}34 \\
34 \\
26 \\
23\end{array}$ \\
\hline
\end{tabular}

A thin section was cut from the bulk of glass sample for further microscopic examination. About $10 \mathrm{~g}$. piece was cut to prepare a glass powder fraction for water leaching procedures. The remainder and crucible fractions with adhered glass was stored in boxes placed in Lab No. 15 of NRI (Iist of archived samples is in Annex D2). The detailed instructions for the batch preparation, the melting procedure and the preparation of samples for analysis are included in the Manual NRI-403-941130/4. 


\subsubsection{ANAIYSIS OF IEACHATES}

Because no yellow layer of chromate was detected on the surface of prepared glasses, a fraction between 46 and $56 \mu \mathrm{m}$ of glass particles was prepared for each glass product according to the MRI-403-941130/4 Manual (translated part in Annex B13). Such a Iine fraction was selected in order to enable to dissolve not only the surface part of the possible separated chromate but also the part which could occupy small holes and bubbles dispersed through the bulk of glass. Two methods of leaching of $0.5 \mathrm{~g}$ samples in $50 \mathrm{ml}$ water were applied,-a hot one, half-an-hour leaching close to the boiling temperature and a cold one lasting for 24 hours (an equilibrium of leachates electric conductivity was reached after $24 \mathrm{~h}$ ). The hot procedure was found to be better correlated with composition changes and the $C r$ concentration gained by the cold procedure of tested glass was under the detection limit. Therefore, the hot procedure was used for evaluation of leaching results.

Detailed description of methods is given in Annex B13 and B2.

Chemical analysis of total $C r$ and $C r$ (VI) content was performed on the same day as the leachate was prepared. An auxiliary measurement of the leachate electric conductivity was carried out, after the leaching procedure has been finished, for a better preliminary concentration adjustment of calibration solutions used for the $C r$ determination. A relationship between the leachate electric conductivity and the $c r$ concentration in leachates is given in Annex 017.

The results of the leachate analyses were collected in Tables 6-9, 6-10 and 6-11. 
Table 6-9: Results of Leachate Analyses for Glass 1 Modifications with 30 \& Waste Loading

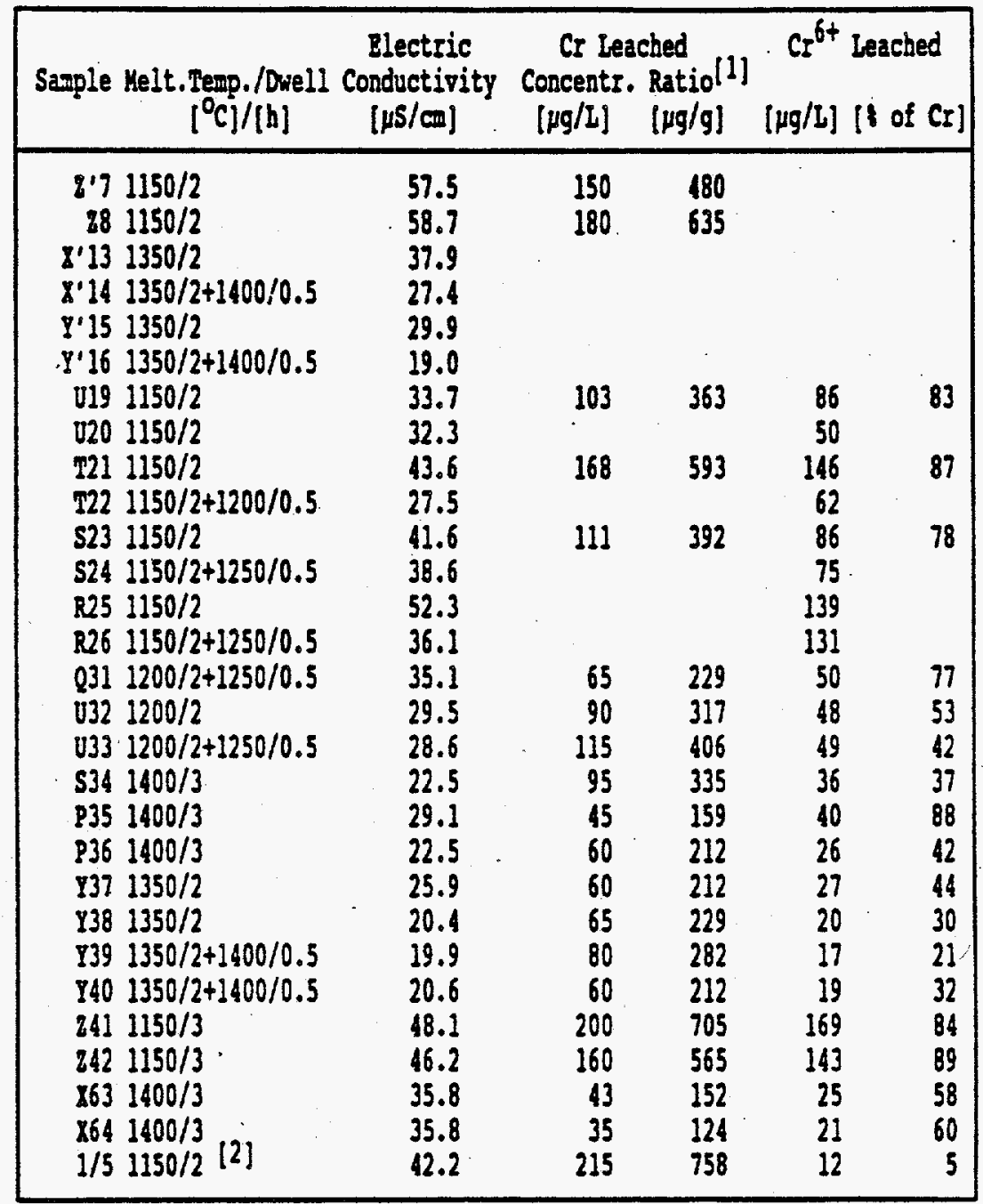

Notes: [1] Proportion of as-batched chromium

[2] Measured for comparison (glass prepared in svus)

Table 6-10: Results of Leachate Analyses for Products of Glass 2 Modifications with 45 \& Waste Loading

\begin{tabular}{|c|c|c|c|c|c|}
\hline $\begin{array}{l}\text { Sample Melt. Temp./Dwell } \\
\left.\qquad{ }^{\circ} \mathrm{C}\right] /[\mathrm{h}]\end{array}$ & $\begin{array}{c}\text { Electric } \\
\text { Conductivity } \\
\text { [HS/cm] }\end{array}$ & $\begin{array}{l}\text { CI Lea } \\
\text { Concentr. } \\
{[\mu \mathrm{g} / \mathrm{L}]}\end{array}$ & $\begin{array}{l}\text { ched } \\
\text { Ratio }[1] \\
{[\mu g / g]}\end{array}$ & $\begin{array}{c}\mathrm{Cr}^{6+} \\
{[\mu \mathrm{g} / \mathrm{L}]}\end{array}$ & $\begin{array}{l}\text { Leached } \\
\text { [ lof CI] }\end{array}$ \\
\hline 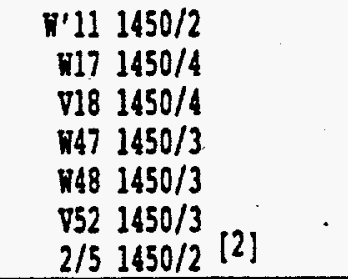 & $\begin{array}{r}40.0 \\
31.4 \\
26.8 \\
49.6 \\
46.4 \\
34.1 \\
379.3\end{array}$ & $\begin{array}{r}161 \\
104 \\
49 \\
196 \\
189 \\
58 \\
1630 \\
\end{array}$ & $\begin{array}{r}345 \\
244 \\
115 \\
461 \\
444 \\
136 \\
3833 \\
\end{array}$ & $\begin{array}{r}135 \\
74 \\
27 \\
142 \\
122 \\
25 \\
1275 \\
\end{array}$ & $\begin{array}{l}84 \\
71 \\
55 \\
72 \\
65 \\
43 \\
78\end{array}$ \\
\hline
\end{tabular}


Table 6-11: Results of Leachate Analyses

(Doubled Cr Content in Waste)

\begin{tabular}{|c|c|c|c|c|c|}
\hline $\begin{array}{l}\text { Sample Helt. Temp. } / \text { owell } \\
\qquad\left[{ }^{\circ} \mathrm{C} \mid /[\mathrm{h}]\right.\end{array}$ & $\begin{array}{c}\text { Blectric } \\
\text { Conductivity } \\
\text { [ } \mu \mathrm{s} / \mathrm{ail}]\end{array}$ & $\begin{array}{l}\text { Cr le } \\
\text { Concentr } \\
\text { [ug/L] }\end{array}$ & $\begin{array}{l}\text { ched } \\
\text { Ratio [1] } \\
{[\mu g / g]}\end{array}$ & $\begin{array}{l}c^{6+} \\
{[\mu g / L]}\end{array}$ & $\begin{array}{l}\text { Leached } \\
\text { [lof } \mathrm{Cr} \text { ] }\end{array}$ \\
\hline $\begin{array}{l}z=13150 / 3+1200 / 0.5 \\
x=461400 / 3+1450 / 0.5 \\
T=491450 / 4 \\
T=541450 / 3\end{array}$ & $\begin{array}{l}56.6 \\
29.1 \\
12.3 \\
18.9\end{array}$ & $\begin{array}{r}235 \\
36 \\
166 \\
80\end{array}$ & $\begin{array}{l}172 \\
181 \\
222 \\
120\end{array}$ & $\begin{array}{r}145 \\
22 \\
105 \\
30\end{array}$ & $\begin{array}{l}62 \\
60 \\
63 \\
50\end{array}$ \\
\hline
\end{tabular}

Note for Tables $6-10$ and 6-11 see Table 6-9.

6.3. EFFECT OF LOWER AI CONTENT AND OMISSION OF LI FROM ADDITIVES

\subsubsection{INTRODUCTION}

Test plan for the Task $6 \mathrm{~b}$ expected the study of the aluminium effect on the properties of the vitrification products.

In addition to that, new information from PNL confirmed expected lower concentration of $A l$ and higher concentration of alkali elements in the composition of wastes.

The effect of aluminium content on the glass properties is not unambiguous. The higher concentration of $\mathrm{Al}_{2} \mathrm{O}_{3}$ in glasses can decrease the viscosity at high temperatures (e.g. in case of E-type glasses (15\%), glasses for discharge lamps (up to $24 \%$ ) (Volf 52)). The above glasses contain higher concentrations of $\mathrm{CaO}$ and $\mathrm{MgO}$. The concentrations of $\mathrm{Al}_{2} \mathrm{O}_{3}$ in glasses above 12 to 16 decrease the chemical resistance of glasses against acid solutions.

Also the $\mathrm{R}_{2} \mathrm{O} / \mathrm{Al}_{2} \mathrm{O}_{3}$ molar ratio in alkali-aluminium-silicate glasses is important. If this ratio exceeds the value 1 , the coordination number of all Al atoms is 4 and all Al ions form a part of a continuous space lattice. In such a case, the structure contains only bridging oxygen atoms and the structure should be very rigid. Decreasing the above mentioned ratio, the $\mathrm{AlO}_{6}$ coordination polyhedra are formed and the presence of non-bridging oxygens (bonds of Si-O-R type) leads to the weakening of the glass network. 
The formation of $\beta$-eucryptite in glasses (see section 4.2.1. and 5.2.2.) led to some negative effects on the glass stability. This was the reason why the omission of Li was studied in this section besides the effect of aluminium.

\subsubsection{PREPARATION OF GLASSES}

Two effects were studied on Glass 1 modifications:

a) decrease of Al concentration in the waste,

b) omission of $\mathrm{LI}$ oxide from the mixture of oxides chosen for addition to the waste.

The mass defect was compensated by $\mathrm{Na}_{2} \mathrm{O}$ in both cases.

Two levels of $\mathrm{Al}_{2} \mathrm{O}_{3}$ substitution by $\mathrm{Na}_{2} \mathrm{O}$ was used:

- Level 1 (13.09: $\left.\mathrm{Al}_{2} \mathrm{O}_{3}\right)$ :

The $\mathrm{Na}_{2} \mathrm{O}$ content in the waste was $50 \%$ higher than on the standard level (composition labelled as " $M$ ").

- Level 2 (9.97 $\left.\mathrm{Al}_{2} \mathrm{O}_{3}\right)$ :

The $\mathrm{Na}_{2} \mathrm{O}$ content in the waste was doubled (composition labelled as "O").

Three glasses without addition of $\mathrm{Li}$ were prepared (Glass 1 contains $6.68 \%$ of $\mathrm{Li}$ ), one on each level, labelled as " $K$ " for standard level, " $L$ " for level" 1 , and " $N$ " for level 2 . compositions of glasses are given in Table 6-12.

Table 6-12: Composition of Glasses with Lower Al and Li Content Simultaneously Compensated by Increase of $\mathrm{Na}$ Content [Units in Mass Fractions]

\begin{tabular}{|l|rrrrr|}
\hline $\begin{array}{c}\text { Glass } \\
\text { Component }\end{array}$ & $\mathrm{O}$ & $\mathrm{N}$ & $\mathrm{M}$ & $\mathrm{I}$ & $\mathrm{K}$ \\
\hline $\mathrm{SiO}_{2}$ & 0.4675 & 0.4675 & 0.4675 & 0.4675 & 0.4675 \\
$\mathrm{~B}_{2} \mathrm{O}_{3}$ & 0.1707 & 0.1707 & 0.1707 & 0.1707 & 0.1707 \\
$\mathrm{Na}_{2} \mathrm{O}$ & 0.1249 & 0.1918 & 0.0937 & 0.1606 & 0.1293 \\
$\mathrm{Li}_{2} \mathrm{O}$ & 0.0668 & 0.0000 & 0.0669 & 0.0000 & 0.0000 \\
$\mathrm{CaO}$ & 0.0019 & 0.0019 & 0.0019 & 0.0019 & 0.0019 \\
$\mathrm{MgO}$ & 0.0002 & 0.0002 & 0.0002 & 0.0002 & 0.0002 \\
$\mathrm{Fe}_{2} \mathrm{O}_{3}$ & 0.0140 & 0.0140 & 0.0140 & 0.0140 & 0.0140 \\
$\mathrm{Al2} \mathrm{O}_{3}$ & 0.0997 & 0.0997 & 0.1309 & 0.1309 & 0.1621 \\
$\mathrm{ZrO}_{2}$ & 0.0002 & 0.0002 & 0.0002 & 0.0002 & 0.0002 \\
\hline
\end{tabular}

cont. 


\begin{tabular}{|l|cccccc|}
\hline $\begin{array}{r}\text { Glass } \\
\text { Component }\end{array}$ & 0 & $N$ & $M$ & $I$ & $K$ \\
\hline $\mathrm{Cr}_{2} \mathrm{O}_{3}$ & 0.0414 & 0.0414 & 0.0414 & 0.0414 & 0.0414 \\
$\mathrm{P}_{2} \mathrm{O}_{5}$ & 0.0011 & 0.0011 & 0.0011 & 0.0011 & 0.0011 \\
$\mathrm{SO}_{3}$ & 0.0006 & 0.0006 & 0.0006 & 0.0006 & 0.0006 \\
$\mathrm{Nd}_{2} \mathrm{O}_{3}$ & 0.0006 & 0.0006 & 0.0006 & 0.0006 & 0.0006 \\
$\mathrm{La}_{2} \mathrm{O}_{3}$ & 0.0002 & 0.0002 & 0.0002 & 0.0002 & 0.0002 \\
$\mathrm{~K}_{2} \mathrm{O}^{\mathrm{F}}$ & 0.0008 & 0.0008 & 0.0008 & 0.0008 & 0.0008 \\
$\mathrm{MnO}_{2}$ & 0.0003 & 0.0003 & 0.0003 & 0.0003 & 0.0003 \\
$\mathrm{MoO} \mathrm{O}_{3}$ & 0.0041 & 0.0041 & 0.0041 & 0.0041 & 0.0041 \\
$\mathrm{NiO}$ & 0.0011 & 0.0011 & 0.0011 & 0.0011 & 0.0011 \\
$\mathrm{Cl}$ & 0.0009 & 0.0009 & 0.0009 & 0.0009 & 0.0009 \\
$\mathrm{ZnO}$ & 0.0012 & 0.0012 & 0.0012 & 0.0012 & 0.0012 \\
& 0.0019 & 0.0019 & 0.0019 & 0.0019 & 0.0019 \\
\hline
\end{tabular}

The batch preparation and melting were performed in the same way as in the section 6.2.2. The proportions of glass cast to the mould and calculated viscosities, are shown in Table 6-13.

Table 6-13: Melting and Casting

(List of Glasses with Lower $\mathrm{Al}, \mathrm{Li}$ and Higher Na)

\begin{tabular}{|c|c|c|c|c|}
\hline Sample & $\begin{array}{c}\text { Melt. Temp. / Dwell } \\
{\left[{ }^{\circ} \mathrm{C}\right] /[\mathrm{h}]}\end{array}$ & $\begin{array}{c}\text { Calc. Vis } \\
1150^{\circ} \mathrm{C} \\
{[\mathrm{Pa} . \mathrm{s}]}\end{array}$ & $\begin{array}{l}\text { osity at } \\
\text { Melt.T. } \\
{[\mathrm{Pa} . \mathrm{s}]}\end{array}$ & $\begin{array}{c}\text { Cast } \\
\text { Proportion } \\
{[w t .8]}\end{array}$ \\
\hline $\begin{array}{l}050 \\
\text { N51 } \\
\text { M55 } \\
\text { L56 } \\
\text { L57 } \\
\text { K58 } \\
\text { K59 } \\
\text { K60 }\end{array}$ & $\begin{array}{l}1150 / 2 \\
1150 / 2 \\
1150 / 2 \\
1150 / 2 \\
1150 / 2+1250 / 1 \\
1150 / 2 \\
1150 / 2+1250 / 1 \\
1300 / 2\end{array}$ & $\begin{array}{r}1.80 \\
8.81 \\
3.49 \\
17.10 \\
17.10 \\
33.20 \\
33.20 \\
33.20\end{array}$ & $\begin{array}{r}1.80 \\
8.81 \\
3.49 \\
17.10 \\
7.05 \\
33.20 \\
13.26 \\
8.75\end{array}$ & $\begin{array}{r}64 \\
60 \\
55 \\
32 \\
5.2 \\
0 \\
0 \\
30\end{array}$ \\
\hline
\end{tabular}

\subsubsection{ANALYSIS OF LEACHATES}

The leaching procedures and analyses of the leachates followed the same methods as in the section 6.2.3. Results of the analyses carried out on leachates are given in Table 6-14. 
Table 6-14: Results of Leachate Analyses

(Lower $\mathrm{Al}, \mathrm{Ii}$ and Higher $\mathrm{Na}$ )

\begin{tabular}{|c|c|c|c|c|c|}
\hline$\frac{\begin{array}{c}\text { Sample Kelt.Temp./Drell } \\
{\left[{ }^{0} \mathrm{C}\right] /[\mathrm{h}]}\end{array}}{0501150 / 2}$ & $\begin{array}{c}\begin{array}{c}\text { Blectric } \\
\text { Conductivity } \\
\text { [ } \mu \mathrm{S} / \mathrm{cm}]\end{array} \\
290.6\end{array}$ & \multicolumn{2}{|c|}{$\begin{array}{l}\text { CI Leached } \\
\text { Concentr. Ratio }[1] \\
{[\mu g / L] \quad[\mu g / g]}\end{array}$} & \multicolumn{2}{|c|}{$\begin{array}{l}\text { CrVI Leached } \\
{[\mu g / \mathrm{L}][\text { lof } \mathrm{CI}]}\end{array}$} \\
\hline $\begin{array}{l}0501150 / 2 \\
1511150 / 2 \\
11551150 / 2 \\
L 561150 / 2 \\
L 57 \quad 1150 / 2+1250 / 1 \\
\mathbb{R 6 0} 1300 / 2\end{array}$ & $\begin{array}{r}290.6 \\
125.3 \\
82.6 \\
12.0 \\
51.7 \\
28.0\end{array}$ & $\begin{array}{r}2450 \\
1600 \\
550 \\
660 \\
445 \\
90\end{array}$ & $\begin{array}{r}8648 \\
5648 \\
1941 \\
2330 \\
1571 \\
318\end{array}$ & $\begin{array}{r}1971 \\
1445 \\
452 \\
612 \\
143 \\
66\end{array}$ & $\begin{array}{r}80 \\
90 \\
82 \\
93 \\
100 \\
73\end{array}$ \\
\hline
\end{tabular}

Hote: [1] see Table $6-9$.

\subsection{ANALYSIS OF GLASSES}

Main glasses with composition through the whole range of the Glass 1 modifications containing $30 \%$ of the waste were analyzed for the total $C r$ and $\operatorname{Cr}(V I)$ content. The powder sample was dissolved using the procedure described in Annex-B2. The total $\mathrm{Cr}$ was determined by AAS (Annex-BII) and $\operatorname{cr}(V I)$ by spectrophotometric method with diphenylcarbazide indicator (Annex B2). In some cases, the total $\mathrm{Cr}$ concentration was in addition determined by spectrophotometry of alkali chromate (Annex B2). Results of the chemical analysis are given in Table 6-15. Table 6-15: Chemical Analysis of Glass 1 Modifications (Concentration of Total $\mathrm{Cr}$ and $\mathrm{Cr}^{6+}$ in wt. $\%$ )

\begin{tabular}{|c|c|c|c|c|c|c|c|c|}
\hline \multirow[t]{2}{*}{ Sample } & \multirow{2}{*}{$\frac{\text { Melt.Temp. / Dwell }}{\left.{ }^{\circ} \mathrm{C}\right] /[\mathrm{h}]}$} & \multirow{2}{*}{\begin{tabular}{|l|} 
Acid-bas \\
$\mathrm{p} 0[g]$
\end{tabular}} & \multicolumn{3}{|c|}{ Total Cr } & \multicolumn{2}{|c|}{$\mathrm{Cr}^{6+}$ Content } & \multirow{2}{*}{$\begin{array}{l}\mathrm{Cr}^{6+} / \mathrm{Cr} \\
\text { Ratio } \\
\text { [wt l] }\end{array}$} \\
\hline & & & As-batch & Anal. & RSD & Anal. & RSD & \\
\hline $\begin{array}{l}241 \\
242 \\
1 / 5 \\
032 \\
033 \\
031 \\
225 \\
R 26 \\
264\end{array}$ & $\begin{array}{l}1150 / 3 \\
1150 / 3 \\
1150 / 2 \\
1200 / 2 \\
1200 / 2+1250 / 0.5 \\
1200 / 2+1250 / 0.5 \\
1150 / 2 \\
1150 / 2+1250 / 1 \\
1400 / 3\end{array}$ & $\begin{array}{l}1.608 \\
1.608 \\
1.608 \\
1.656 \\
1.656 \\
1.712 \\
1.719 \\
1.719 \\
1.743\end{array}$ & $\begin{array}{l}2.84 \\
2.84 \\
2.84 \\
2.84 \\
2.84 \\
2.84 \\
2.84 \\
2.84 \\
2.84\end{array}$ & $\begin{array}{l}3.12 \\
2.96 \\
2.70 \\
2.86 \\
2.96 \\
2.87 \\
2.66 \\
2.79 \\
2.87\end{array}$ & $\begin{array}{l}3.6 \\
1.9 \\
2.1 \\
1.2 \\
5.3 \\
0.6 \\
0.8 \\
2.2 \\
5.0\end{array}$ & $\begin{array}{c}0.22 \\
0.28 \\
0.23 \\
0.22 \\
0.20 \\
0.14 \\
0.14\end{array}$ & $\begin{array}{r}8.3 \\
1.9 \\
4.6 \\
18.6 \\
20.6 \\
10.1 \\
1.8\end{array}$ & $\begin{array}{l}9.0 \\
9.6 \\
8.4 \\
7.9 \\
6.7 \\
4.9 \\
5.3\end{array}$ \\
\hline
\end{tabular}

cont. 


\begin{tabular}{|c|c|c|c|c|c|c|c|c|}
\hline \multirow[t]{2}{*}{ Sample } & \multirow{2}{*}{\begin{tabular}{|c|} 
Helt. Temp. / Dwell \\
$\left.{ }^{\circ} \mathrm{c}\right] /[\mathrm{b}]$
\end{tabular}} & \multirow{2}{*}{$\frac{\text { Acid-bas }}{\mathrm{pO[g]}}$} & \multicolumn{3}{|c|}{ Total Cr } & \multicolumn{2}{|c|}{$\mathrm{Cr}^{\text {ot }}$ Content } & \multirow{2}{*}{$\begin{array}{l}\mathrm{Cr}^{6+} / \mathrm{Cl} \\
\text { Ratio } \\
{[\text { [utl] }}\end{array}$} \\
\hline & & & As-batch & Anal. & RSD & Anal. & RSD & \\
\hline $\begin{array}{l}737 \\
738 \\
739 \\
740 \\
835 \\
836\end{array}$ & $\begin{array}{l}1350 / 2 \\
1350 / 2 \\
1350 / 2+1400 / 0.5 \\
1350 / 2+1400 / 0.5 \\
1400 / 3 \\
1400 / 3\end{array}$ & $\begin{array}{l}1.759 \\
1.759 \\
1.759 \\
1.759 \\
1.769 \\
1.769\end{array}$ & $\begin{array}{l}2.84 \\
2.84 \\
2.84 \\
2.84 \\
2.84 \\
2.84\end{array}$ & $\begin{array}{l}2.92 \\
3.10 \\
2.73 \\
2.89 \\
2.99 \\
2.79\end{array}$ & $\begin{array}{l}1.9 \\
1.0 \\
0.8 \\
3.6 \\
3.8 \\
4.1\end{array}$ & $\begin{array}{l}0.10 \\
0.07 \\
0.08 \\
0.10 \\
0.08\end{array}$ & $\begin{array}{r}24.1 \\
1.9 \\
21.1 \\
12.6 \\
5.5\end{array}$ & $\begin{array}{l}3.6 \\
2.2 \\
2.8 \\
3.6 \\
2.7\end{array}$ \\
\hline $\begin{array}{l}z=43 \\
x=46 \\
y=54\end{array}$ & $\begin{array}{l}1150 / 3+1200 / 0.5 \\
1400 / 3+1450 / 0.5 \\
1450 / 3\end{array}$ & $\begin{array}{l}1.615 \\
1.795 \\
1.805\end{array}$ & $\begin{array}{l}4.98 \\
4.98 \\
4.98\end{array}$ & $\begin{array}{l}5.18 \\
3.13 \\
4.25\end{array}$ & $\begin{array}{l}1.1 \\
4.6 \\
1.1\end{array}$ & $\begin{array}{l}0.25 \\
0.10 \\
0.10\end{array}$ & $\begin{array}{r}7.5 \\
20.8 \\
1.9\end{array}$ & $\begin{array}{l}1.8 \\
2.9 \\
2.4\end{array}$ \\
\hline $\begin{array}{c}2 / 5 \\
\mathrm{~A} 1 / \mathrm{Cr}\end{array}$ & $\begin{array}{l}1450 / 2 \\
1150 / 2\end{array}$ & 1.481 & $\begin{array}{l}4.25 \\
0.36\end{array}$ & $\begin{array}{l}3.95 \\
0.36\end{array}$ & $\begin{array}{l}0.1 \\
6.6\end{array}$ & 0.16 & 0.5 & 4.1 \\
\hline
\end{tabular}

Note: RSD means relative standard deviation in

\subsection{PHYSICO-CHEMICAI PROPERTIES OF GLASSES}

Four glasses were selected from the range of composition studied. Compositions $R$ and $X$ represent the glasses with lower $\mathrm{Li}_{2} \mathrm{O}$ content (Glass 1: 6.7 \%; $\mathrm{R}: 4.45 \%$; $\mathrm{X}: 3.50$ \%) substituted for $\mathrm{B}_{2} \mathrm{O}_{3}$ by weight (the complete compositions are in Table 6-2). Compositions $M$ and $I$ contain less $\mathrm{Al}_{2} \mathrm{O}_{3}$ and more alkali oxides than Glass $1 \quad \mathrm{Al}_{2} \mathrm{O}_{3}: 16.2$ for Glass 1 and 13.1 for compositions $M$ and $L ;$ alkali oxides: $13.0 \%$ for Glass $I$ and 16.1 for compositions $M$ and $L$ ). Complete substitution of $\mathrm{Li}_{2} \mathrm{O}$ for $\mathrm{Na}_{2} \mathrm{O}$ is realized in composition $L$.

Glasses $X, R, M$ and $L$ were prepared in higher amounts $(500 \mathrm{~g})$ in svus and the analyses of their crystallinity and physico-chemical properties were performed in Glass Institute, STL. The density, Cr redox state and temperature dependence of viscosity were determined for specimens of Glasses $X$ and $R$. Determination of water resistance was performed for all glasses prepared.

Determination of density

For the test, the samples of Glasses $X$ and $R$ were cut to smaller parts of suitable size. 
The samples were tested according to the ASTM C 693-84(88) "Standard testing method for determination of the glass density by the hydrostatic weighing". The density for a given sample was measured on three independent sample parts.

Testing results

The average density of Glass $\mathrm{X}: 2404 \mathrm{~kg} \cdot \mathrm{m}^{-3}$.

The average density of Glass $R$ : $2428 \mathrm{~kg} \cdot \mathrm{m}^{-3}$.

Note:

The samples quality does not correspond to the requirement of the sample homogeneity due to the presence of bubbles, splits and inhomogeneities. Therefore, it is necessary to consider the results only as informative values.

Determination of viscosity by rotary viscosimeter

CSN ISO 7884-2 standard "Viscosity and reference viscosity points. Part 2: Viscosity determination by rotary viscosimeter" has been used.

Parts of Glass $X$ and Glass $R$ samples used for the density measurement were applied to viscosity determination.

The samples were measured on searle type rotary viscometer. Description of the apparatus, procedure and calibration is in the Annex B4.

The Glass $X$ was melted down in a crucible at $1340^{\circ} \mathrm{C}$. The temperature was increased up to $1436^{\circ} \mathrm{C}$ after immersing of the sphere. After stabilizing of conditions (approx. $25 \mathrm{~min}$ ) the measurement started from this temperature in intervals by the approx. $50{ }^{\circ} \mathrm{C}$ down to $1061{ }^{\circ} \mathrm{C}$. Finally, the viscosity at $1342{ }^{\circ} \mathrm{C}$ and $1387^{\circ} \mathrm{C}$ was measured for control. The measured value corresponds to the course of the curve in the beginning of the measurement (see Table 6-16).

The Glass $R$ was melted down in a crucible at $12000^{\circ} \mathrm{C}$. The temperature was increased up to $1382^{\circ} \mathrm{C}$ after immersing of the sphere. After stabilizing of conditions (approx. 60 min.) the measurement started from this temperature in intervals by approx. $50{ }^{\circ} \mathrm{C}$ down to $1051{ }^{\circ} \mathrm{C}$. 
- For the description of viscosity temperature dependence, the vogel-Fulcher-Tammann (VFT) equation was used. From measured viscosity values the constants of VFT equations with the application of ADSTAT programme (modul of Non-linear regression) were calculated.

\section{Testing results}

Vogel-Fulcher-Tammann equations are the testing result, describing the temperature viscosity dependence for tested samples in given temperature range where:

$$
\begin{aligned}
& v \ldots \ldots \text { viscosity }[\mathrm{dPa} . \mathrm{s}] \\
& t \ldots \ldots \text { temperature }\left[{ }^{\circ} \mathrm{C}\right] \\
& \mathrm{s} \ldots \ldots \text { standard deviation } \\
& \mathrm{D}^{2} \ldots \ldots \text {... coefficient of determination }
\end{aligned}
$$

\section{VFT equations for Glass $X:$}

$$
\begin{gathered}
\log v=-4.940+14439.0 /(t+707.8) \\
s=0.013+D^{2}=0.9995 \\
\text { validity from } 1061{ }^{\circ} \mathrm{C} \text { to } 1436{ }^{\circ} \mathrm{C}
\end{gathered}
$$

\section{VFT equations for Glass $R$ :}

$$
\begin{gathered}
\log v=-26.660+207220 /(t+5897.9) \\
s=0.014 \quad D^{2}=0.9994 \\
\text { validity from } 1051{ }^{\circ} \mathrm{C} \text { to } 1382{ }^{\circ} \mathrm{C}
\end{gathered}
$$

The comparison of experimental and calculated viscosity values are given in Tables 6-16 and 6-17. 
Table 6-16: Comparison of Experimental and Calculated Viscosity Values for Glass $x$

\begin{tabular}{|c|c|c|r|}
\hline Temperature $\left[{ }^{\circ} \mathrm{C}\right]$ & $\log \mathrm{v}(\mathrm{m})$ & $\log \mathrm{v}(\mathrm{c})$ & Deviation \\
\hline 1061 & 3.198 & 3.223 & -0.025 \\
1062 & 3.233 & 3.218 & 0.015 \\
1062 & 3.223 & 3.218 & 0.005 \\
1107 & 3.012 & 3.016 & -0.004 \\
1107 & 3.017 & 3.016 & 0.001 \\
1158 & 2.809 & 2.798 & 0.011 \\
1208 & 2.601 & 2.596 & 0.005 \\
1254 & 2.427 & 2.420 & 0.007 \\
1295 & 2.262 & 2.269 & -0.007 \\
1340 & 2.102 & 2.111 & -0.009 \\
1342 & 2.100 & 2.104 & -0.004 \\
1387 & 1.934 & 1.952 & -0.018 \\
1387 & 1.959 & 1.952 & 0.007 \\
1436 & 1.811 & 1.795 & 0.016 \\
\hline
\end{tabular}

Table 6-17: Comparison of Experimental and Calculated Viscosity Values for Glass $R$

\begin{tabular}{|c|c|c|c|}
\hline Temperature $\left[{ }^{\circ} \mathrm{C}\right]$ & $\log \mathrm{v}(\mathrm{m})$ & $\log \mathrm{v}(\mathrm{c})$ & Deviation \\
\hline 1051 & 3.154 & 3.161 & -0.007 \\
1051 & 3.143 & 3.161 & -0.018 \\
1095 & 2.991 & 2.974 & 0.017 \\
1144 & 2.756 & 2.768 & -0.012 \\
1188 & 2.586 & 2.585 & 0.001 \\
1225 & 2.442 & 2.433 & 0.009 \\
1263 & 2.274 & 2.279 & -0.005 \\
1303 & 2.134 & 2.118 & 0.016 \\
1346 & 1.957 & 1.947 & 0.010 \\
1382 & 1.799 & 1.806 & -0.007 \\
\hline & $\mathrm{v}$ & Notes: $\mathrm{v}(\mathrm{m})$... measured viscosity [dPa.s] \\
$\mathrm{v}$ calculated viscosity [dPa.s]
\end{tabular}

x-ray diffraction identification of crystalline phases

Internal regulation F-12-93 "X-ray diffraction analysis on the apparatus siemens U 13-008" has been used.

Samples of Glasses $X, R, M$ and $L$ were crushed and ground in a grinding equipment with hard metal lining.

$X$-ray diffraction analysis was carried out on the apparatus Siemens $U$ 13-008 according to the Internal regulation F-12-93 using $C u K$ alpha radiation, $N i$ filter. 
Testing result

By comparison with a data file ASTM (JCPDS) the eskolaite $\mathrm{Cr}_{2} \mathrm{O}_{3}$ (ASTM 6-0504) as the only crystalline phase in all samples was identified.

Photodocumentation and analysis in electron scanning microscope

Internal regulation F-18-94 "Methods of nondestructive analysis of solid substances in the apparatus complex Camscan 4-DV-LINR AN 10000 - Microspec WDX-2A" has been used.

For investigating in electron scanning microscope, all delivered samples were used, representing the perpendicular sections through blocks. The section surface was polished on polishing device at first and then on an equipment by a free diamond (DSM 2/1 Pramet and PWD 3-1 Wolters) on a brass support plate.

Before inserting into apparatus, surfaces of samples were coated by carbon in a high vacuum equipment B 302 .

Samples. Were located in a chamber of electron scanning microscope camscan 4-DV with energy dispersive analyzer IINK AN 10000 .

Images in BSE and. EDX spectra were taken using conditions described in Annex $B 9$.

Note:

The supplement of analyses up to 100 wt. is created by minor components (in particular cases statistically unprovable, the values are lower than $2 \sigma$ ) and $\mathrm{B}_{2} \mathrm{O}_{3}$ and $\mathrm{Li}_{2} \mathrm{O}$ which cannot be determined by the used method of analysis.

Testing results

Glass $X$ and Glass $R$

only two types of texture motives were detected in the whole analyzed area. The typical examples of grained irregular particles are shown in Figures $6-2$ and 6-3. The area analysis results are given in Tables 6-18 and 6-19. The results indicate that the grains are composed of eskolaite particles. 


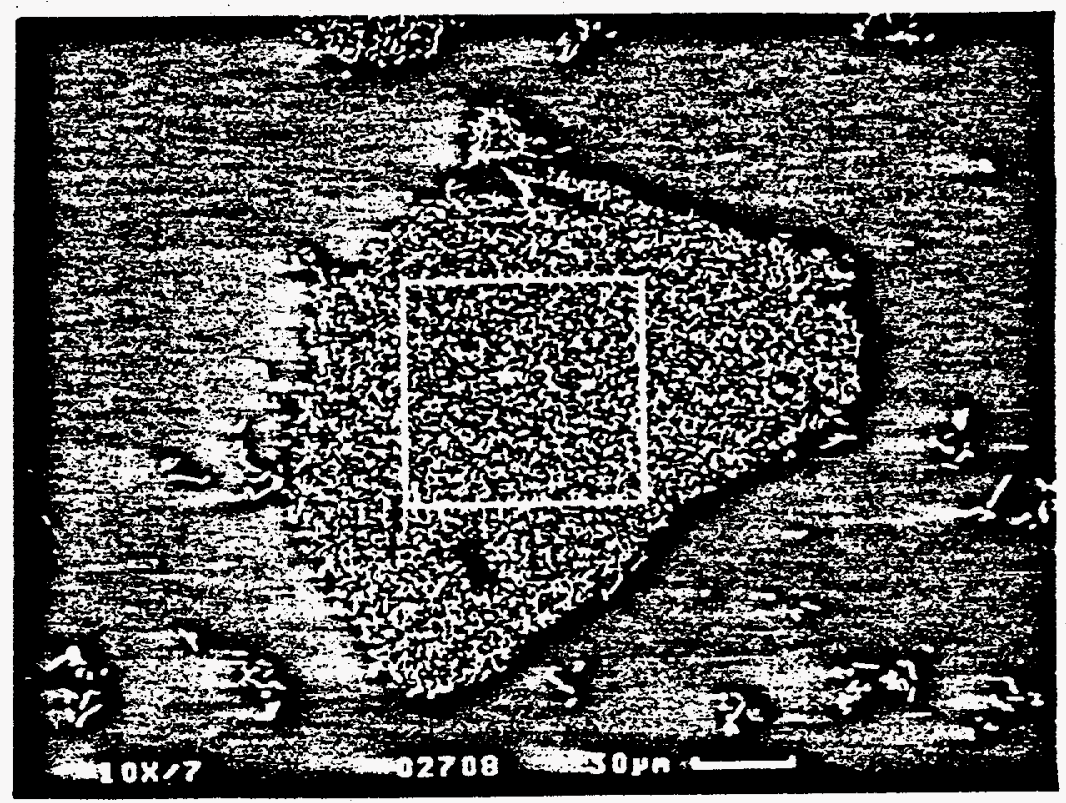

Figure 6-2: Glass X. Grain Irregular Particle with

Marked Area Analysis. Normal section $(0-4 \mathrm{~mm})$. Microscope Camscan 4-DV, BEI.

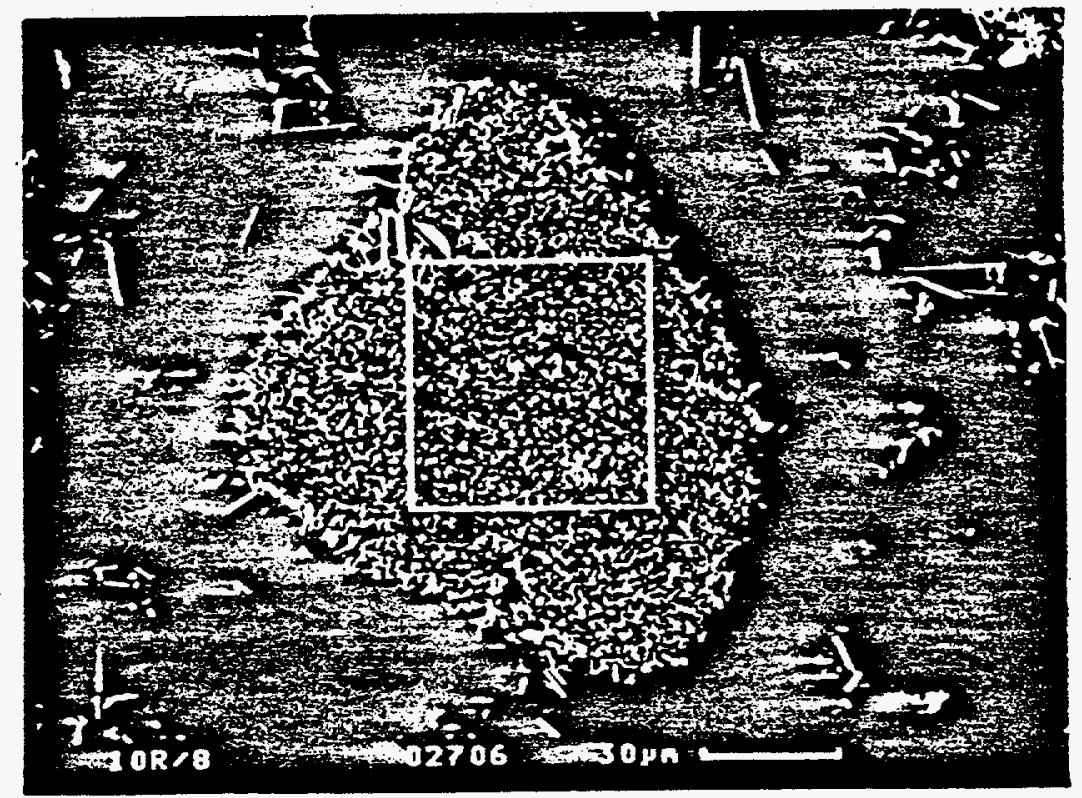

Figure 6-3: Glass R. Grain Irregular Particle with Marked Area Analysis. Normal Section (0-4 mm). Microscope Camscan 4-DV, BEI. 
Table 6-18: Survey of Analyses Results of the Glass X (IINK AN 10000, Expressed in wt. i)

\begin{tabular}{|c|c|c|c|c|c|}
\hline $\begin{array}{l}\text { Analyzed } \\
\text { Area }\end{array}$ & $\begin{array}{l}\text { Grain } \\
\text { (Area }\end{array}$ & $\begin{array}{l}\text { Particles } \\
\text { Analysis) }\end{array}$ & $\begin{array}{l}\text { Isolated Eskolaite } \\
\text { Crystals }\end{array}$ & \multicolumn{2}{|c|}{ Matrix } \\
\hline $\mathbf{n}$ & & 1 & 1 & \multicolumn{2}{|c|}{3} \\
\hline & & $x$ & $\dot{x}$ & $\overline{\boldsymbol{x}}$ & $\sigma$ \\
\hline $\begin{array}{l}\mathrm{Na}_{2} \mathrm{O} \\
\mathrm{Al}_{2} \mathrm{O}_{3} \\
\mathrm{Siọ}_{2} \\
\mathrm{Fe}_{2} \mathrm{O}_{3} \\
\mathrm{Cr}_{2} \mathrm{O}_{3} \\
\mathrm{MnO}_{3} \\
\mathrm{NiO}_{2} \\
\mathrm{ZnO}\end{array}$ & & $\begin{array}{c}5.0 \\
10.4 \\
26.3 \\
2.2 \\
37.3 \\
0.66 \\
a \\
a\end{array}$ & $\begin{array}{c}3.6 \\
9.4 \\
17.1 \\
5.8 \\
63.2 \\
a \\
a \\
a\end{array}$ & $\begin{array}{c}7.4 \\
17.8 \\
51.2 \\
1.3 \\
0.30 \\
\text { a } \\
\text { a } \\
a\end{array}$ & $\begin{array}{l}0.3 \\
(0) \\
0.3 \\
0.1 \\
0.03 \\
a \\
a \\
a\end{array}$ \\
\hline sum & & 81.86 & 99.1 & 78.00 & \\
\hline
\end{tabular}

Table 6-19: Survey of Analyses Results of the Glass $R$ (LINK AN 10000; Expressed in wt. \%)

\begin{tabular}{|c|c|c|c|c|}
\hline $\begin{array}{c}\text { Analyzed } \\
\text { Area }\end{array}$ & $\begin{array}{c}\text { Grain } \\
\text { (Area Aarticles } \\
\text { Analysis) }\end{array}$ & $\begin{array}{c}\text { Isolated Eskolaite } \\
\text { Crystals }\end{array}$ & \multicolumn{2}{|c|}{ Matrix } \\
\hline $\mathrm{Na}_{2} \mathrm{O}$ & 6.0 & 4.6 & 7.9 & 7.2 \\
$\mathrm{Al}_{2} \mathrm{O}_{3}$ & 13.2 & 11.2 & 19.7 & 18.9 \\
$\mathrm{SiO}_{2}$ & 34.2 & 22.0 & 56.4 & 57.1 \\
$\mathrm{Fe}_{2} \mathrm{O}_{3}$ & 2.8 & 5.9 & 1.4 & 1.4 \\
$\mathrm{Cr}_{3} \mathrm{O}_{3}$ & 37.6 & 54.8 & 0.45 & 0.30 \\
$\mathrm{MnO}_{2}$ & $\mathrm{a}$ & 1.0 & $\mathrm{a}$ & 0.47 \\
$\mathrm{NiO}_{\mathrm{ZnO}}$ & $\mathrm{a}$ & $\mathrm{a}$ & $\mathrm{a}$ & $\mathrm{a}$ \\
\hline Sum & $\mathrm{a}$ & $\mathrm{a}$ & $\mathrm{a}$ & $\mathrm{a}$ \\
\hline
\end{tabular}

See Table 6-18 for notes.

In the whole sample area, the isolated crystals of eskolaite were observed. Their character is similar as documented in Figures 4-19. The crystal and surrounding glass (matrix) analysis results are summarized in the same Tables $6-18$ and $6-19$. By $X$-ray diffraction analysis and local analyses, eskolaite as the only crystalline phase in Glasses $X$ and $R$ was confirmed. 


\section{Glass L}

The texture motives (grains, isolated crystals) in the whole analyzed area of Glass $L$ are similar as in the Glass $1 / 5$ but without the eskolaite crystal clusters. Any dependence of the texture motives concentration on a distance from the bottom block area was not detected. A typical example of grain particles is shown in Figure 6-4. The examples of isolated crystal clusters can be seen in the same Figure.

The results of the area analysis of grain particles, and local analysis of the surrounding glass (matrix) are summarized in Table 6-20. The analysis indicates the presence of fine eskolaite particles within the grains.

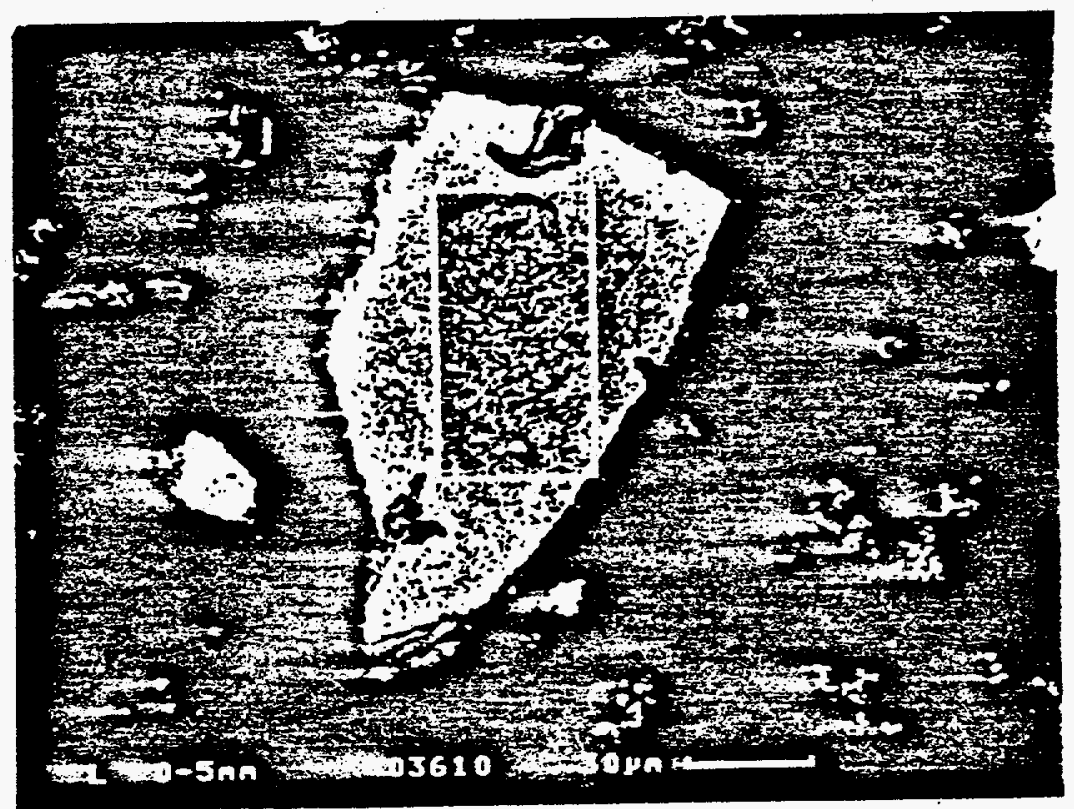

Figure 6-4: Glass L. Grain Particle with Marked Area Analysis. Normal Section $(0-5 \mathrm{~mm})$. Microscope Camscan 4-DV, BEI. 
Table 6-20: Survey of Analyses Results of I Glass Sample (IINK AN 10000 , Expressed in wt. $\%$ )

\begin{tabular}{|c|c|c|c|c|}
\hline Area & \multicolumn{2}{|c|}{ Grain Particles } & \multicolumn{2}{|c|}{ Matrix } \\
\hline $\mathbf{n}$ & \multicolumn{2}{|c|}{6} & \multicolumn{2}{|c|}{10} \\
\hline & $\overline{\boldsymbol{x}}$ & $\sigma$ & $\overline{\mathbf{x}}$ & $\sigma$ \\
\hline $\begin{array}{l}\mathrm{Na}_{2} \mathrm{O} \\
\mathrm{CaO} \\
\mathrm{Al}_{2} \mathrm{O}_{3} \\
\mathrm{SiO}_{2} \\
\mathrm{Fe}_{2} \mathrm{O}_{3} \\
\mathrm{Cr}_{2} \mathrm{O}_{3} \\
\mathrm{MnO}_{2}\end{array}$ & $\begin{array}{c}8.9 \\
0.20 \\
6.7 \\
22.7 \\
.1 .5 \\
46.3 \\
\text { a. }\end{array}$ & $\begin{array}{l}0.6 \\
0.02 \\
0.4 \\
1.6 \\
0.2 \\
3.0 \\
a\end{array}$ & $\begin{array}{c}12.8 \\
0.22 \\
12.9 \\
45.2 \\
1.3 \\
0.86 \\
0.48\end{array}$ & $\begin{array}{l}0.9 \\
0.04 \\
0.3 \\
0.8 \\
0.1 \\
0.10 \\
0.10\end{array}$ \\
\hline sum & 86.30 & & 73.76 & \\
\hline
\end{tabular}

See Table 6-18 for notes.

\section{Glass M}

Three texture motives of the Glass $M$ analyzed area are documented in Figures 6-5 (grains, clusters, isolated crystals). Any dependence of the texture motives concentration on a distance from the bottom block area was not detected.

The typical examples of grain particles are shown in Figures 6-6 and 6-7. Crystal clusters and isolated crystals are similar to the Glass $1 / 5$. 


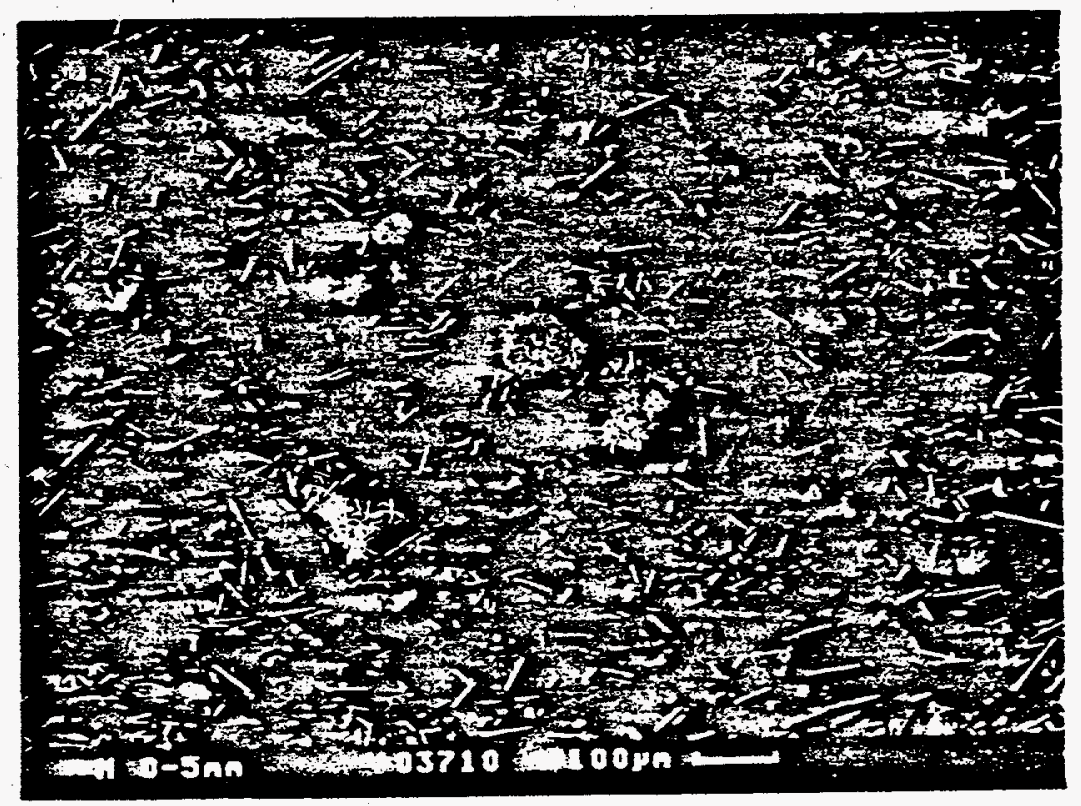

Figure 6-5: Glass M. Detail Section View in a Bottom Block Part $(0-5 \mathrm{~mm})$. Microscope Camscan 4-DV, BEI.

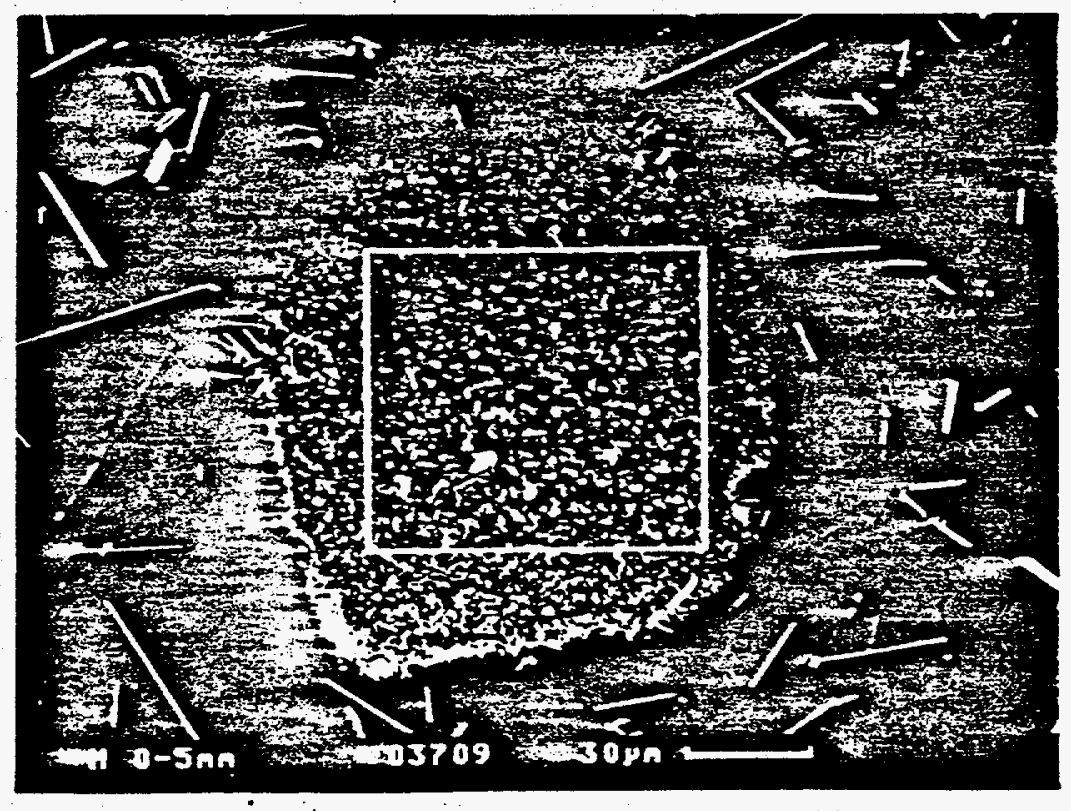

Figure 6-6: Glass M. Grain Particle with Marked Area Analysis. Normal Section $(0-5 \mathrm{~mm})$. Microscope Camscan 4-DV, BEI. 


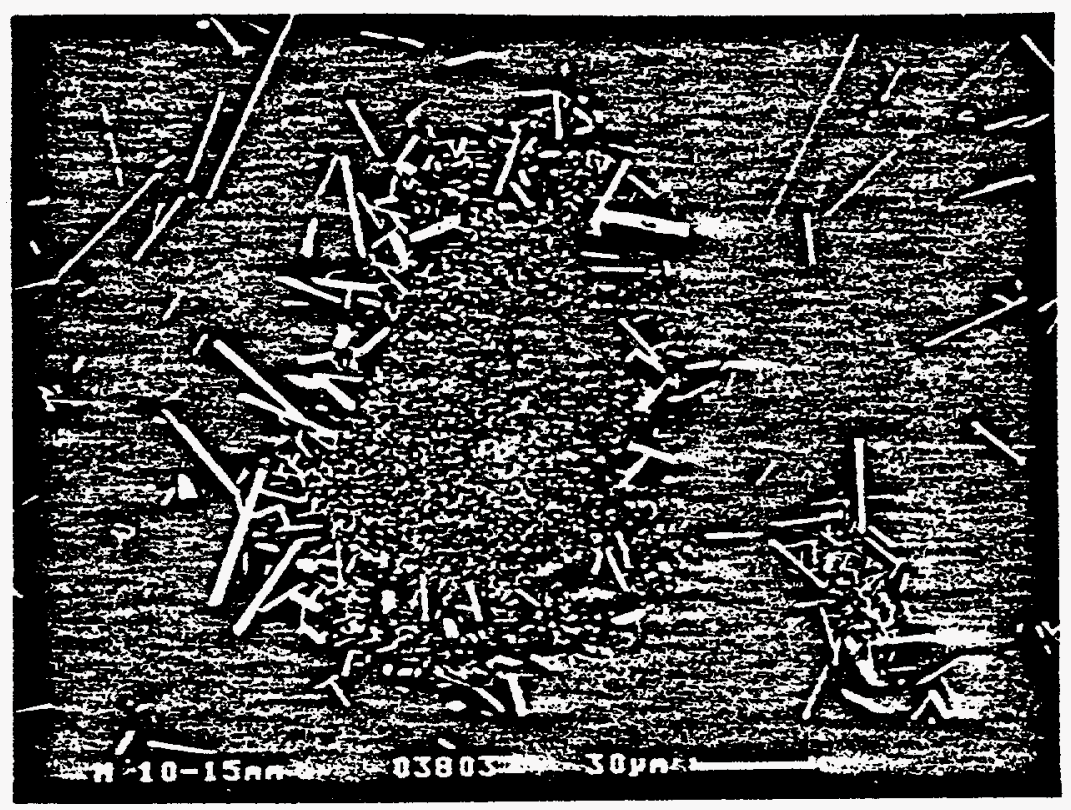

Figure 6-7: Glass M: Grain Particle. Normal Section (10-15 mm). Microscope Camscan 4-DV, BEI.

The results of the area analyses of the grain particles and crystals in clusters are summarized in Table 6-21. The results of local analyses of isolated crystals and the surrounding glass (matrix) are summarized in Table 6-22. Grain particles and crystal clusters do not differ in composition considerably. Local analysis confirms the presence of eskolaite enriched by $\mathrm{Fe}_{2} \mathrm{O}_{3}$.

Table 6-21: Survey of Area Analyses Results of Glass $M$ (IINK AN 10000, Expressed in wt. $\%$ )

\begin{tabular}{|c|c|c|c|c|}
\hline Area & \multicolumn{2}{|c|}{ Grain Particles } & Crystal Clusters \\
\hline $\mathrm{n}$ & \multicolumn{2}{|c|}{3} & \multicolumn{2}{|c|}{3} \\
& $\overline{\mathbf{x}}$ & $\sigma$ & $\overline{\mathbf{x}}$ & $\sigma$ \\
\hline $\mathrm{Na}_{2} \mathrm{O}$ & 7.0 & 0.5 & 7.8 & 0.9 \\
$\mathrm{CaO}_{\mathrm{Al}} \mathrm{O}_{3}$ & $\mathrm{a}$ & $\mathrm{a}$ & $\mathrm{a}$ & $\mathrm{a}$ \\
$\mathrm{SiO}_{3}$ & 29.6 & 0.6 & 9.0 & 0.9 \\
$\mathrm{Fe}_{2} \mathrm{O}_{3}$ & 1.7 & 1.5 & 29.2 & 3.5 \\
$\mathrm{Cr}_{2} \mathrm{O}_{3}$ & 33.7 & 0.2 & 2.0 & 0.5 \\
$\mathrm{MnO}_{2}$ & $\mathrm{a}$ & $\mathrm{a}$ & 32.2 & 6.8 \\
\hline $\mathrm{Sum}$ & 80.3 & & $\mathrm{a}$ & $\mathrm{a}$ \\
\hline
\end{tabular}

See Table 6-18 for notes. 
Table 6-22: Survey of Local Analyses Results of Glass $M$ (LINK AN 10000, Expressed in wt. $\&$ )

\begin{tabular}{|l|c|c|c|c|}
\hline Area & \multicolumn{2}{|c|}{ Isolated Crystals } & \multicolumn{2}{c|}{ Matrix } \\
\hline$n$ & \multicolumn{2}{|c|}{3} & \multicolumn{2}{|c|}{9} \\
& $\bar{x}$ & $\sigma$ & $\bar{x}$ & $\sigma$ \\
\hline & 1.9 & 0.9 & 9.6 & 0.4 \\
$\mathrm{Na}_{2} \mathrm{O}$ & $\mathrm{a}$ & $\mathrm{a}$ & 0.26 & 0.04 \\
$\mathrm{CaO}^{2}$ & 3.6 & 0.7 & 13.2 & 0.3 \\
$\mathrm{Al}_{2} \mathrm{O}_{3}$ & 9.7 & 2.2 & 46.2 & 0.7 \\
$\mathrm{SiO}_{2}$ & 9.1 & 0.8 & 1.4 & 0.2 \\
$\mathrm{Fe}_{2} \mathrm{O}_{3}$ & 3.1 & 6.2 & 0.86 & 0.11 \\
$\mathrm{Cr}_{2} \mathrm{O}_{3}$ & 66.7 & $\mathrm{a}$ & 0.47 & 0.07 \\
$\mathrm{MnO}_{2}$ & $\mathrm{a}$ & $\mathrm{a}$ & 71.99 & \\
\hline $\operatorname{sum}$ & 85.0 & & & \\
\hline
\end{tabular}

See Table 6-18 for notes.

Notes:

A considerable participation of the surrounding matrix crystals is probable during the analysis of eskolaite crystals with respect to their very small thickness.

The eskolaite crystal clusters i.e. loose agglomerates of relatively large crystals typical for glasses $1 / 5$ and $2 / 5$ (described in the section 4.2.1.3) were observed neither in samples of Glass $X$ and $R$ nor in Glass $L$.

The increased scatter of the sum of separate components from theoretical value $100 \mathrm{wt}$. \& in crystals is caused by irregularity of geometric conditions in the place of analysis (the difficulty of grinding of very hard crystals to the plane of surrounding glass).

Determination of water resistance at $98{ }^{\circ} \mathrm{C}$

CSN ISO 719 standard "Glass testing methods. Glass. Water resistance of the glass cullet at $98^{\circ} \mathrm{C}$. Method of dividing and testing to classes" has been used.

The Glass $M$ and Glass $I$ samples were prepared for testing and the determination was carried out according to quoted standards. 
Testing result

Testing results are summarized in Table 6-23.

The limiting values of water resistance by grain method according to CSN ISO 719 are summarized in Table 6-24.

Table 6-23: The Results of Determination of Water Resistance of Glasses $X, R, L$ and $M$ at $98^{\circ} \mathrm{C}$

\begin{tabular}{|c|c|c|c|}
\hline Sample & $\begin{array}{c}\text { Determination } \\
\text { No. }\end{array}$ & $\begin{array}{l}\text { Consumption of Hydrochloric } \\
\text { Acid } c(\mathrm{HCl})=0.01 \mathrm{~mol} / \mathrm{l} \text { to } 1 \mathrm{~g} \\
\text { of Crushed Material }[\mathrm{ml} / \mathrm{g}]\end{array}$ & $\begin{array}{c}\text { Average } \\
\text { value }\end{array}$ \\
\hline$x$ & $\begin{array}{l}1 \\
2 \\
3\end{array}$ & $\begin{array}{l}0.23 \\
0.24 \\
0.26\end{array}$ & 0.24 \\
\hline $\mathbf{R}$ & $\begin{array}{l}1 \\
2 \\
3\end{array}$ & $\begin{array}{l}0.27 \\
0.27 \\
0.26\end{array}$ & 0.27 \\
\hline$I$ & $\begin{array}{l}1 \\
2 \\
3\end{array}$ & $\begin{array}{l}0.32 \\
0.29 \\
0.33\end{array}$ & 0.31 \\
\hline $\mathbf{M}$ & $\begin{array}{l}1 \\
2 \\
3\end{array}$ & $\begin{array}{l}0.57 \\
0.54 \\
0.62\end{array}$ & 0.57 \\
\hline
\end{tabular}

Table 6-24: Limiting Values of Water Resistance by Grain Method According to the CSN ISO 719

\begin{tabular}{|c|c|}
\hline Resistance Class & $\begin{array}{l}\text { Consumption of Hydrochloric Acid } \\
\text { c(HCl) }=0.01 \text { mol } / 1 \text { to } 1 \text { g of crushed } \\
\text { material }[\mathrm{m}] / \mathrm{g}]\end{array}$ \\
\hline HGB 3 & from 0.20 to 0.85 through \\
\hline
\end{tabular}

All glasses belong to the HGB 3 resistance class.

Determination of $C r$ redox state in Glasses $X$ and $R$

Results of Cr redox state determination are summarized in Table 6-25. Analyzed data are consistent with the data obtained for glasses prepared in lower amount. 
Table 6-25: Chromium Redox State in Glasses $X$ and $R$

\begin{tabular}{|c|c|c|c|c|}
\hline Sample & $\begin{array}{c}\text { Total Cr } \\
{[w t .8]}\end{array}$ & $\begin{array}{r}C^{6+} \\
{[w t .8]}\end{array}$ & $\begin{array}{c}C r^{6+} / \text { Total Cr } \\
{[w t .8]}\end{array}$ & See ${ }^{\text {(1] }}$ \\
\hline $10 X / 7$ & 2.98 & 0.034 & 1.15 & 1.053 \\
$10 R / 8$ & 2.98 & 0.099 & 3.31 & 1.052 \\
\hline
\end{tabular}

Note [1]: Analyzed Cr/ As-batched Cr ratio

\subsection{DISCUSSION AND CONCLUSIONS}

Results of experiments performed in the Task $6 \mathrm{a}$ and Task $6 \mathrm{~b}$ were divided to several sections:

a) experiments on Glass 1 modifications containing $30 \%$ waste

b) experiments on Glass 2 modifications containing 45 waste

c) a study of the effect of doubled $\mathrm{Cr}$ concentration in the waste

d) a study of effects caused by lower Al and higher Na content in the waste, and by the $\mathrm{Li}_{2} \mathrm{O}$ omission from the mixture of varied oxides composition

e) analyses of total $\mathrm{Cr}$ and $\mathrm{Cr}$ (VI) content in Glass 1 modifications with 30 \& of the waste.

f) evaluation the properties of glasses prepared in higher amount

\section{a) Glass 1 modifications with 30 of wastes}

Minimum operating temperatures determined for the casting of sufficient amount of the melt ( 40 was estimated as sufficient) of all compositions studied are indicated in Figure 6-8. The figure shows the assumed trend of a decrease of the casting temperature with the $\mathrm{B}_{2} \mathrm{O}_{3}$ addition on the same level of alkali content and similarly with the alkali addition on the same level of $\mathrm{B}_{2} \mathrm{O}_{3}$ content. The changes of minimum operating temperature determined in these experiments resemble to variations of the viscosity values calculated for $1150^{\circ} \mathrm{C}$ (see Table 6-6). The values of viscosity calculated for $1150^{\circ} \mathrm{C}$ lower than $10 \mathrm{~Pa} . \mathrm{s}$ say the melt will be cast easily at $1150^{\circ} \mathrm{C}$. The values higher than 
$.16 \mathrm{~Pa} . \mathrm{s}$ belong to the melts which cannot at all be cast at $1150{ }^{\circ} \mathrm{C}$. The viscosity limits given above will be the lower, the higher the temperatures of casting will be used (see the same Table). Interesting relationship was deduced from the measurement of cast proportion of the melt. More details are given in Annex, B12.

The cast bulk of glass has usually small number of bubbles and great number of crystal inclusions not homogeneously dispersed in glassy material. The surface was smooth. Chromium leached from the glass powders followed roughly the trend in basicity of the prepared products. The lower is the basicity, the lower is the amount of chromium leached (Figure 6-9). Deviations from this dependence are high because of low Cr concentration measured in leachates ( 25 to $200 \mathrm{\mu g} / \mathrm{L}$ ). The same holds for the measurement of $\mathrm{Cr}^{6+}$ concentration (15 to $169 \mu \mathrm{g} / \mathrm{L}$ ).

The ratio of total chromium leached from glass grains varies from 124 to $705 \mathrm{\mu g} / \mathrm{g}$ of as-batched cr. The highest values are found for the basic composition $(\mathrm{z})$ : $705 \mathrm{\mu g} / \mathrm{g}$ for 241-black cr hydroxide; $.565 \mathrm{~kg} / \mathrm{g}$ for 242 -green $C r$ hydroxide. The glasses from the lowest level of $\mathrm{Ii}$ possess the lowest Cr-leaching ratio: from 124 to $282 \mathrm{\mu g} / \mathrm{g}$. The glasses from the intermediate levels of $\mathrm{Li}$ show the ratios between 159 and $406 \mu \mathrm{g} / \mathrm{g}$. We can conclude generally that $C r$ leaching is low and the leaching rate is indirectly proportional to the Li content. 


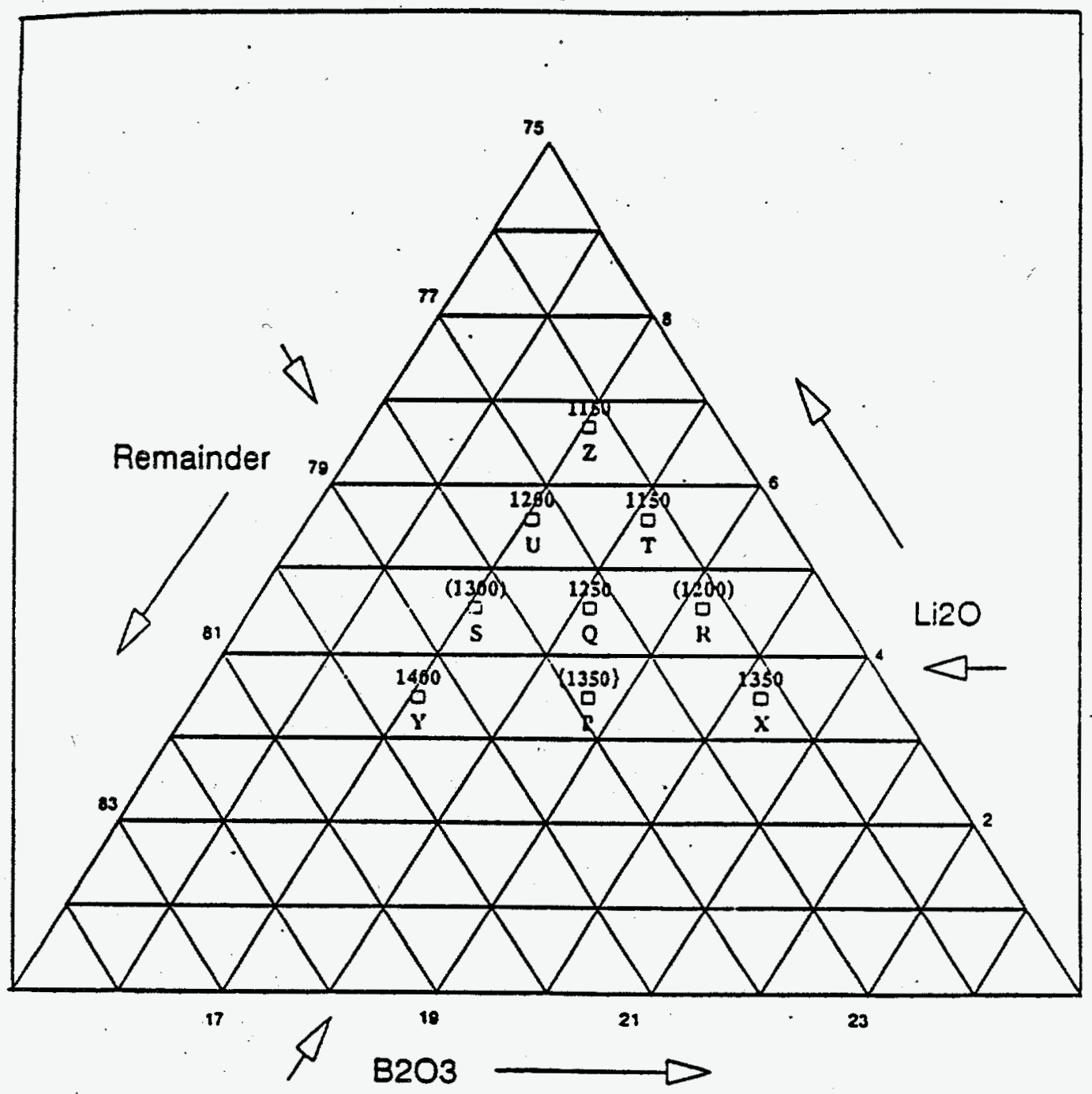

Figure 6-8: Temperature Ranges for Glass Casting

Note: Numbers indicate the minimum melting temperature necessary for casting of sufficient amount of glass. Numbers in brackets are interpolated from experiments performed. 


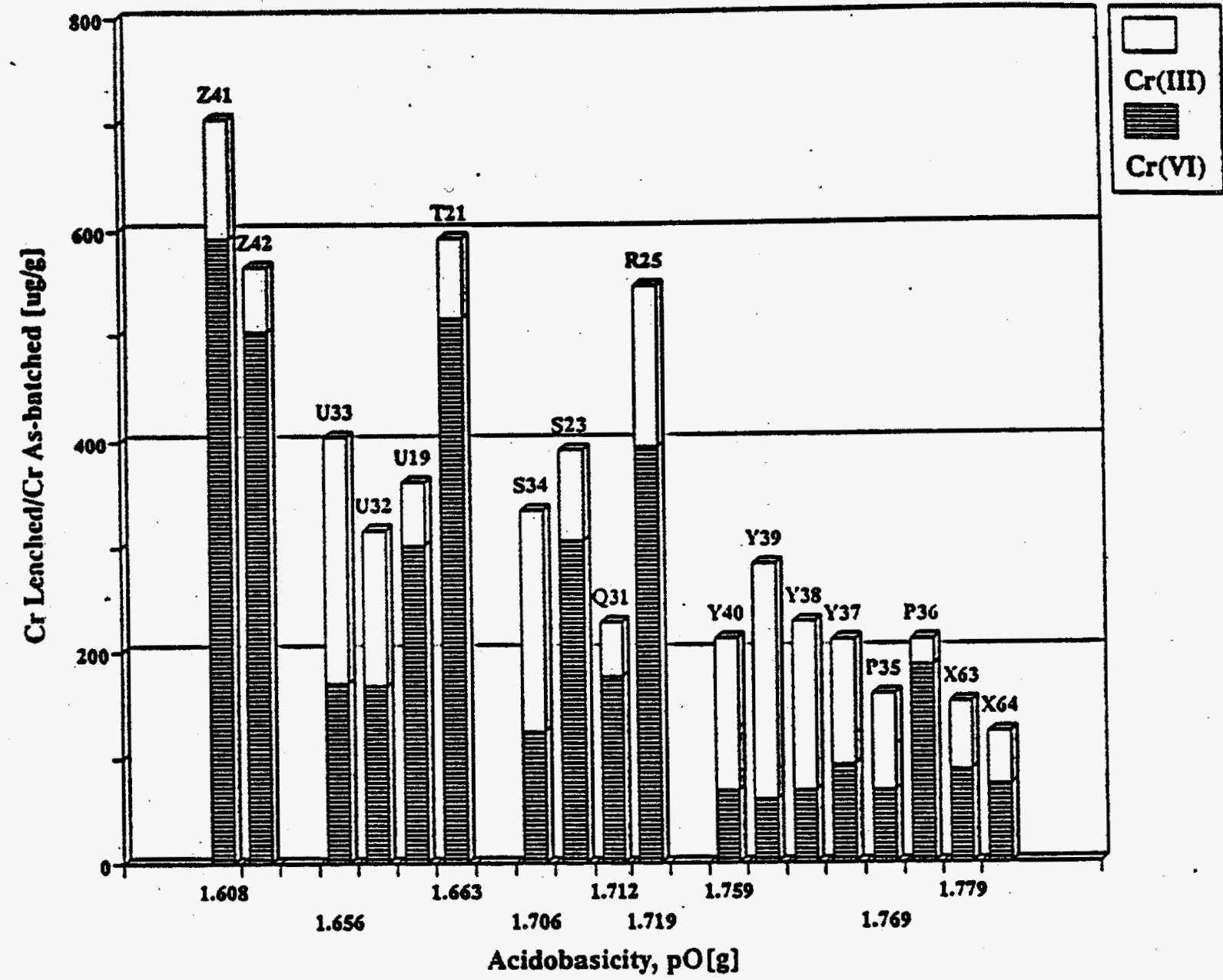

Figure 6-9: Cr Leached from Grains of Glass 1 Modifications ( 30 Waste Loading)

Effect of the decreasing basicity connected with the weight substitution of $\mathrm{Li}_{2} \mathrm{O}$ for $\mathrm{SiO}_{2}$ is documented in Figure 6-10, and with the $\mathrm{Li}_{2} \mathrm{O}$ substitution for $\mathrm{B}_{2} \mathrm{O}_{3}$ in Figure 6-il.

Almost for all compositions, the $\mathrm{Cr}^{6+} / \mathrm{Cr}$ ratio decreases with the growing temperature of melting (see Figure 6-10).

The ratio of $\mathrm{Cr}^{6+}$. to total $\mathrm{Cr}$ in the leachate varies from 25 to 89 without any pronounced dependence on composition. 


\section{$B=$ const $; \mathrm{Li}$ decrease; $\mathrm{Si}$ increase}

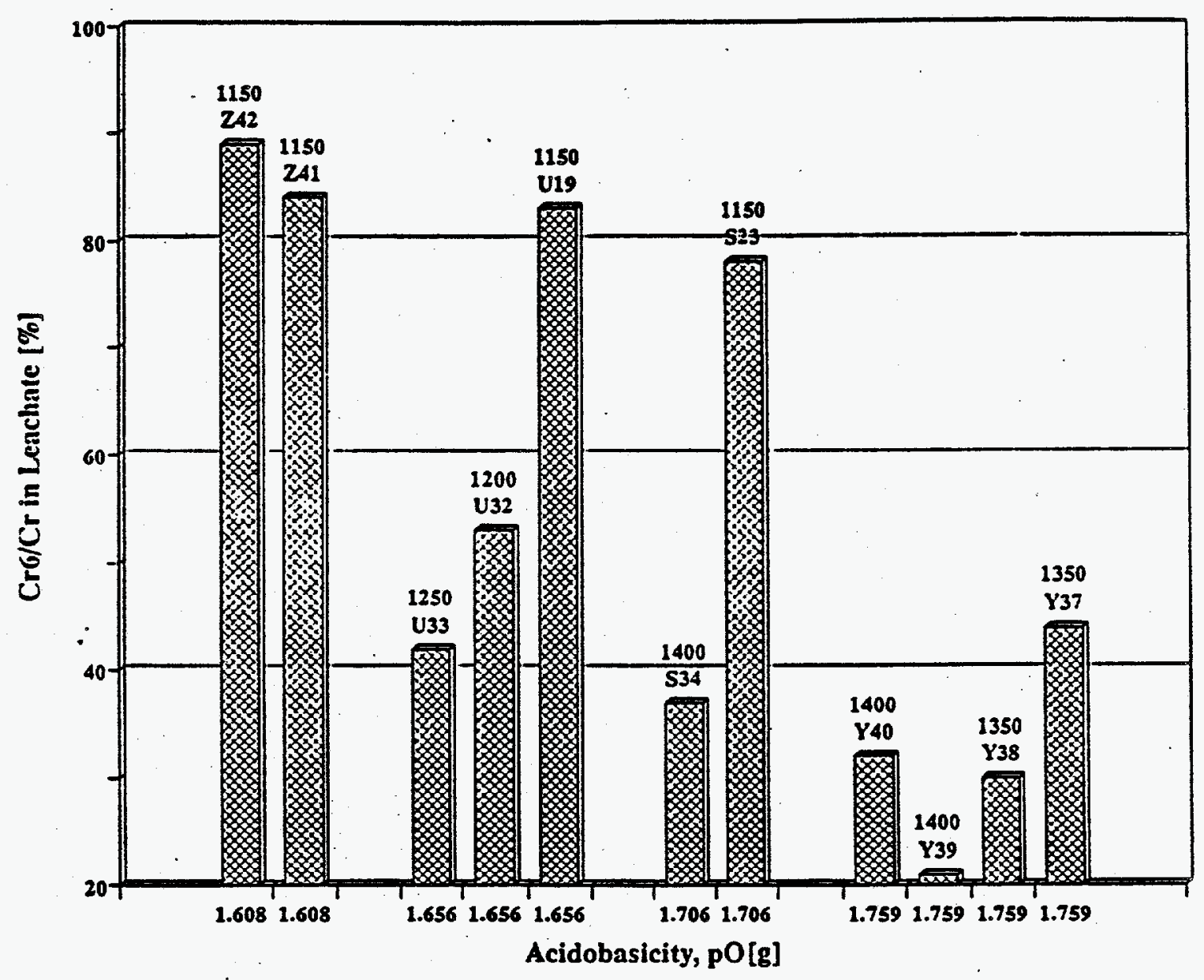

Figure 6-10: Relationship between $\mathrm{Cr}^{6+} / \mathrm{Cr}$ Ratio in Leachate and Basicity for the $Z-U-S-Y$ Series of Composition 


\section{$\mathrm{Si}=$ const Li decrease $; \mathrm{B}$ increase}

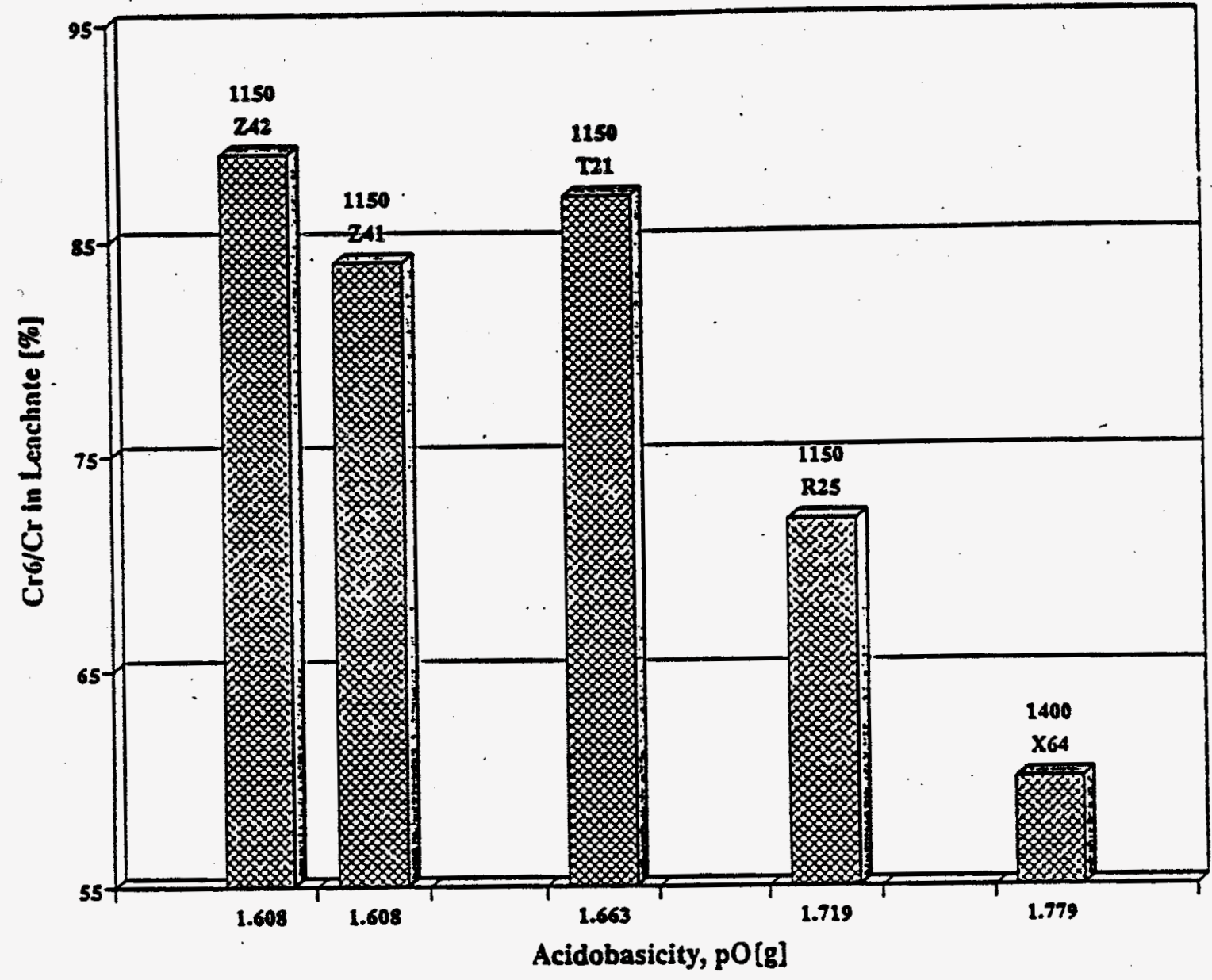

Figure 6-11: Relationship between $\mathrm{Cr}^{6+} / \mathrm{Cr}$ Ratio in Leachate and Basicity for the $\mathrm{Z}-\mathrm{T}-\mathrm{R}-\mathrm{X}$ Series of Composition

Analysis of the leachate of glass powder prepared from the batch containing sodium chromate (28). instead of Cr hydroxide proved that the substitution has only little effect on the $\mathrm{Cr}$ leaching $(635 \mathrm{~kg} / \mathrm{g})$.

b) Glass 2 modifications with 45 of waste

Casting ability of $45 \%$ waste-loaded melts is much worse than for the glasses loaded by 30 \%. It is not possible to use the above mentioned regression equation for viscosity calculations because it is out of the treated range. Nevertheless, the 
calculated values are included together with the casting estimates in Table 6-7. The casting of the melt with the basic composition (W) was good but the glass with low Li level (V) could be cast only after two hours of dwell time at the temperature $1450{ }^{\circ} \mathrm{C}$ in spite of a higher content of $\mathrm{B}_{2} \mathrm{O}_{3}$. The prolongation of the dwell time to 4 hours improved the casting behavior of both melts, however, the casting of glass $V$ was poor. The cast glasses with 45 of waste showed orange stripes on their surface. In order to test if the stripes are dispersed in the whole bulk of glass, we repeated the 2 hours melting and kept the melts in crucibles to cool. We found the orange spots through the whole glass body. As was stated in section 4.2.1.1.. crystaline chromate phase was not present in the Glass $2 / 5$ (glass with the same composition, but prepared at the svus under rather different conditions) in spite of a high $c r$ content found in the hot leachate of its grains.

Cr content in leachates, prepared by glass grain leaching, and electric conductivity of the leachates are of the same order as for the leachates of glass prepared with the basic composition represented by the 30 waste loading $(z)$. Generally, the values for Glass type $V$ are lower than for type $w$. The lowest value is probably caused by longer dwell time of melting ( 4 hours for w17).

The leached proportion of $C r$ was determined as 115 and $136 \mathrm{\mu g} / \mathrm{g}$ of as-batched $\mathrm{Cr}$ for type $V$ and from 244 to $461 \mathrm{\mu g} / \mathrm{g}$ for $W$ type (Figure 6-12). Cr concentration in the leachates varied from 50 to $200 \mathrm{\mu g} / \mathrm{L}$ that is of the same order as for glasses with 30 \% waste loading.

The $C r(V I)$ content to total $\mathrm{Cr}$ content ratio determined in leachates for the composition. $V(43$ and $55 \%)$ is lower than the values for the standard composition $W(65$ to 71 \%).

No significant difference was determined by applying two different forms of $C r$ hydroxide (black and green).

It can be concluded that the decrease of acidobasicity. caused by a decrease of Ii content with a simultaneous increase 
of $\mathrm{B}$ content, improves the leaching properties of glass but the viscosity of the melt at $1450^{\circ} \mathrm{C}$ is too high for a proper casting. summarized results are presented in Figure 6-12.

\section{$\mathrm{Si}=$ const; Li decrease; $\mathrm{B}$ increase}

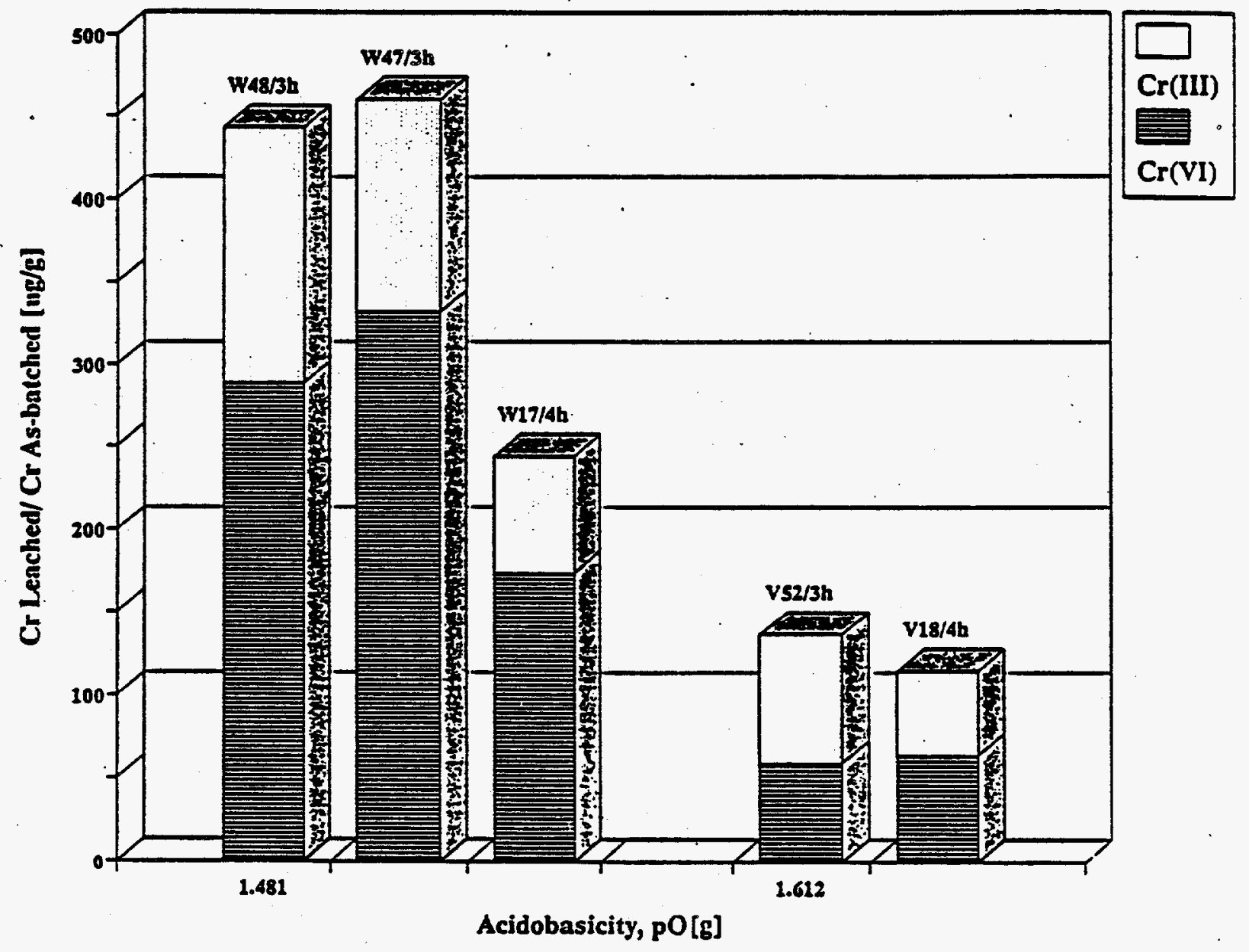

Figure 6-12: Results of Leachate Analyses (45 Waste Loading)

Note: Dwell time of the melting is indicated in hours [h].

c) Effect of doubled Cr concentration in waste

An attempt was made to prepare glasses with the waste containing doubled $\mathrm{Cr}$ concentration. Only the melt with the $v$ composition of additives could not be cast. In all cases of compositions, the cast proportion was poorer than for the melts 
with the waste of lower $C r$ content. This does not agree with calculated viscosities (see Tables 6-8, 6-7 and 6-6). It should be noted that a $50{ }^{\circ} \mathrm{C}$ higher casting temperature was used for the preparation of these glasses with higher content of $\mathrm{Cr}$ (for 30 of waste loading).

As concerned to the ( $\mathrm{Cr}$ leached)/(Cr as-batched) ratio, it decreases in all cases studied (Figure 6-13).

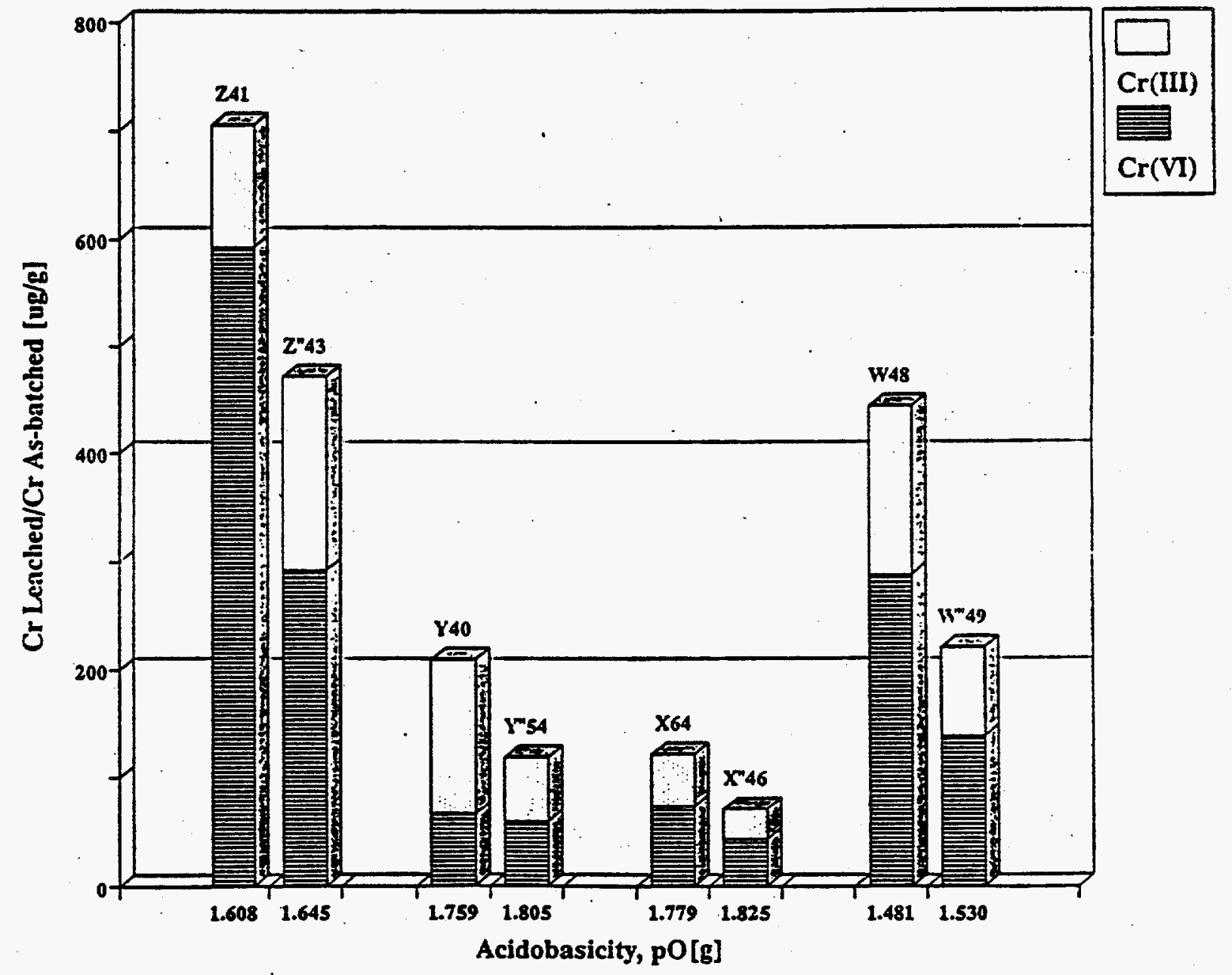

Figure 6-13: Effect of $\mathrm{Cr}$. Doubling in Waste Note: Double commas denote glasses with higher $\mathrm{Cr}$ concentration 
d) Effect of lower Al content in glass and omission of Ii from mixture added to waste

The casting ability of melts containing the lowest Al content and the highest $\mathrm{Na}$ concentration ( $O$ and $N$ mixture) was excellent at $1150^{\circ} \mathrm{C}$. Also the $M$ glass was melted excellently but the casting temperature of I glass (without $L i$ ) at the same level of Al needs to be raised to $1250^{\circ} \mathrm{C}$ to get the similar result. The $K$ composition was well cast at $1300^{\circ} \mathrm{C}$.

The glass with the same composition but containing Li oxide (" $\mathrm{Zn}^{\text {") }}$ was cast at $1150^{\circ} \mathrm{C}$ easily.

The ratio of (Cr leached)/(Cr as-batched) in the leachate increases with the decrease of Al content and with simultaneous increase of $\mathrm{Na}$ (see Figure 6-14). The proportion of $\mathrm{Cr}$ leached from the glass grains is one order higher than for the composition of Glass 1 .

The substitution of $\mathrm{LI}$ by $\mathrm{Na}$ decreases the above mentioned ratio for the lowest concentration of $\mathrm{Al}_{2} \mathrm{O}_{3}$ and the highest concentration of $\mathrm{Na}_{2} \mathrm{O}$ (compositions $\mathrm{O}$ and $\mathrm{N}$ ) without the change of melting temperature ( $\left.1150^{\circ}{ }^{\circ} \mathrm{C}\right)$. The glasses with higher content of $\mathrm{Al}_{2} \mathrm{O}_{3}$ (13.1 \%; $\mathrm{M} 55$ and 256 ) increase the leached part of $\mathrm{Cr}$ by substitution of $\mathrm{L} i$ by $\mathrm{Na}$ at constant melting temperature $\left(1150^{\circ} \mathrm{C}\right)$. Only the composition $\mathrm{L}\left(1250^{\circ} \mathrm{C} ; \mathrm{L} 57\right)$ with higher melting temperature leads to a leached Cr proportion lower than for the glass containing Li (M55). Similar result was observed for the higher content of $\mathrm{Al}_{2} \mathrm{O}_{3}$ (compositions $\mathrm{Z}$ and $\mathrm{K}$ ). The leached proportion of $\mathrm{Cr}$ is lower for the glass $\mathrm{K} 60(318 \mathrm{\mu g} / \mathrm{g})$ than for the glass $242(565 \mu \mathrm{g} / \mathrm{g})$ or $241(705 \mathrm{\mu g} / \mathrm{g})$ but the $\mathrm{K} 60$ melting temperature is $1300^{\circ} \mathrm{C}$ (it could not be cast at lower temperature) and for $\mathrm{z}$ 's only $1150{ }^{\circ} \mathrm{C}$. 


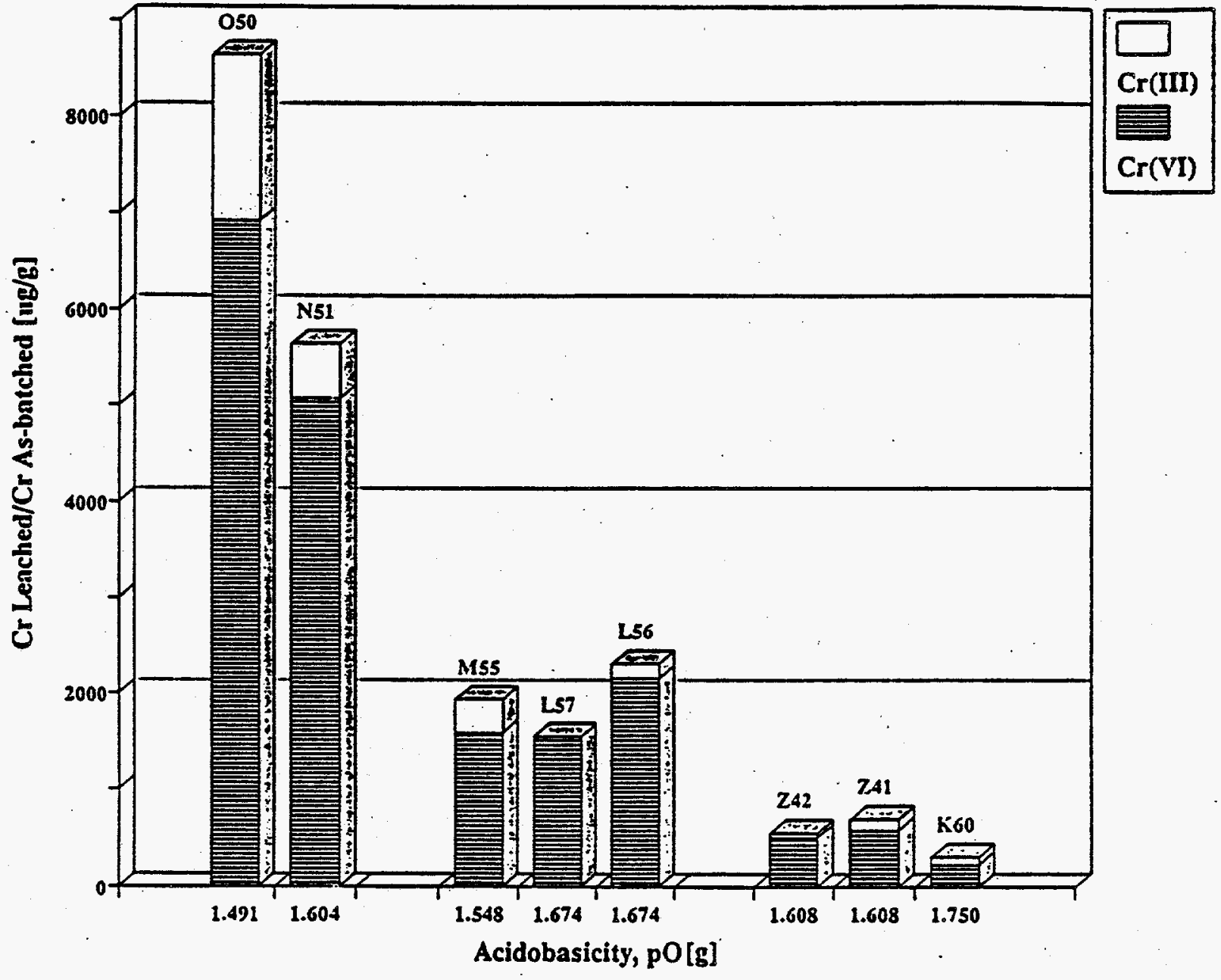

Figure 6-14: Results of Leachate Analyses (Lower Al,Li;Higher Na) Note: Content [wt. $z$ ] of the changed components in glass are as follows:

\section{Composition}

Label

$\begin{array}{lllllll}0 & N & M & \text { L } & Z & K\end{array}$

$\mathrm{Al}_{2} \mathrm{O}_{3}$

$\begin{array}{llllll}10.0 & 10.0 & 13.4 & 13.4 & 16.2 & 16.2\end{array}$

Alkali Oxides

$\begin{array}{llllll}19.3 & 19.3 & 16.1 & 16.1 & 13.0 & 13.0\end{array}$

$\mathrm{Li}_{2} \mathrm{O}$

6.70 .0

6.7

0.0

6.7

0.0 


\section{e) Analysis of glasses}

The ratio of total $\mathrm{Cr}$ content in the glass determined by analysis to the as-batched $C r$ content (only the products containing 30 \& of waste oxides are tested) varies from 0.93 to 1.10, except for the sample 454. Variation of standard deviation for the given determinations lies between 0.4 and 6.6 *

There is a tendency of the increase of $\mathrm{Cr}^{6+}$ proportion in the total Cr content in glass with the increase of $\mathrm{Li}$ content and simultaneous decrease of Si or/and B content (Figure 6-15). These changes are connected with the increase of po(g). The highest value of 9.6 $\mathrm{Cr}^{6+}$ holds for the upper $\mathrm{Li}$ level $(z)$. The values from 2 to 4.5 of $\mathrm{Cr}^{6+}$ in glass were determined for the lowest Ii level ( $Y$ and $X$ ). Analysis of the intermediate $I i$ levels gives from 4.9 to 7.8 of $\mathrm{Cr}^{6+}$.

similar effect was determined for the glasses with higher chromium content (Figure 6-16). Matter of interest is the half value of $\mathrm{Cr}^{6+} / \mathrm{Cr}$ for the highest $\mathrm{Li}$ level (2"43 vs. $\mathrm{Z42}$ and $\mathrm{Z41}$ ).

A partial substitution of $\mathrm{Al}_{2} \mathrm{O}_{3}\left(16.2 \rightarrow 13.1\right.$ \%) for $\mathrm{Na}_{2} \mathrm{O}$ leads to a considerable increase of hexavalent portion of chromium in glass (Figure $6-17 ; Z \rightarrow M$ ) that is in agreement with higher basicity of the substituted glass. However, the lower basicity connected with the complete substitution of $\mathrm{Li}_{2} \mathrm{O}$ for $\mathrm{Na}_{2} \mathrm{O}(Z \rightarrow M ; M \rightarrow L)$ does not support the higher $\mathrm{Cr}^{6+} / \mathrm{Cr}$ ratio determined for composition $L$. Only the value for $K$ composition is lower than expected. 


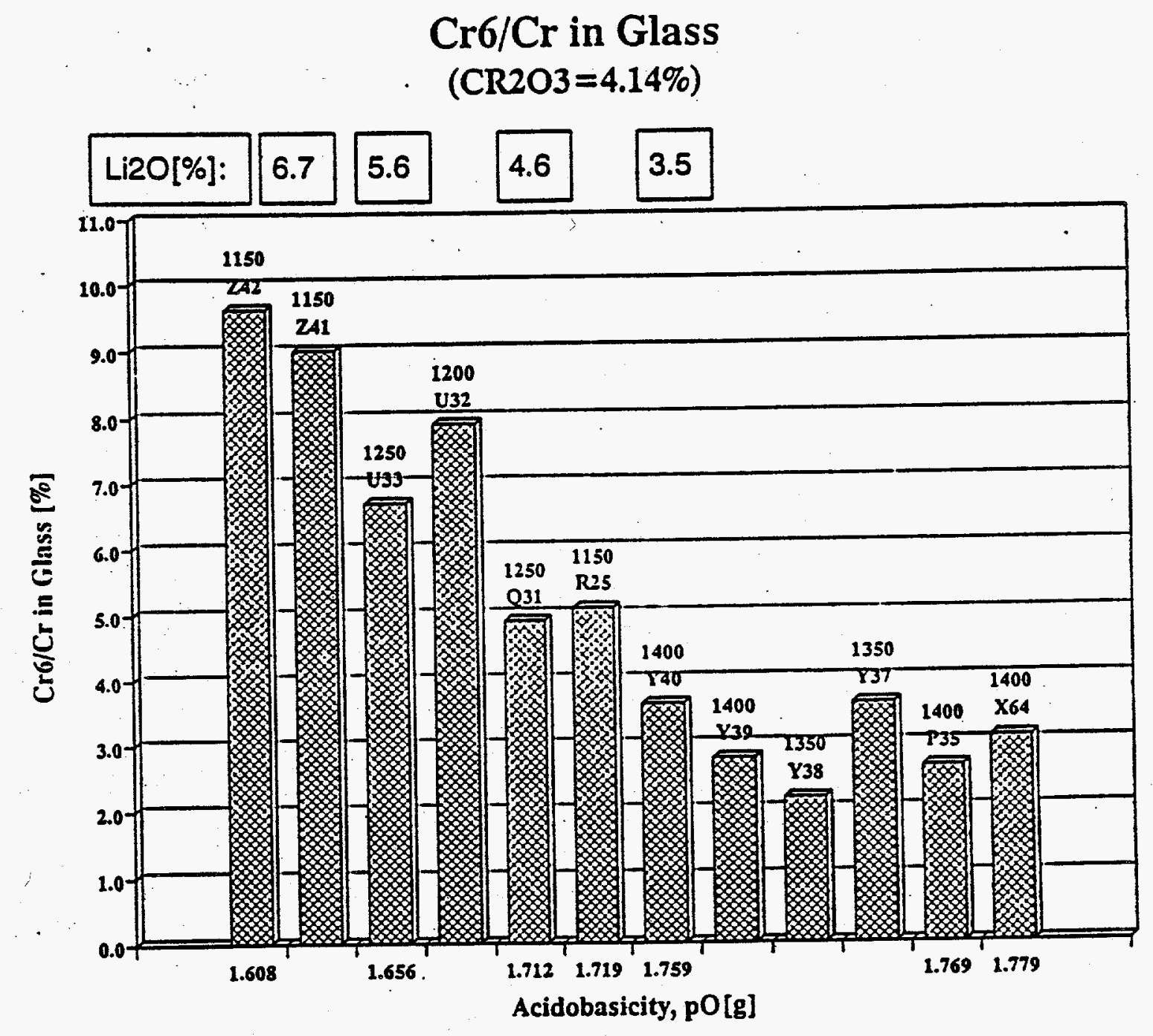

Figure 6-15: Cr Analysis in Glass (4.14 of $\mathrm{Cr}_{2} \mathrm{O}_{3}$ )

Note: Melting temperatures and labels are written on the top of columns 


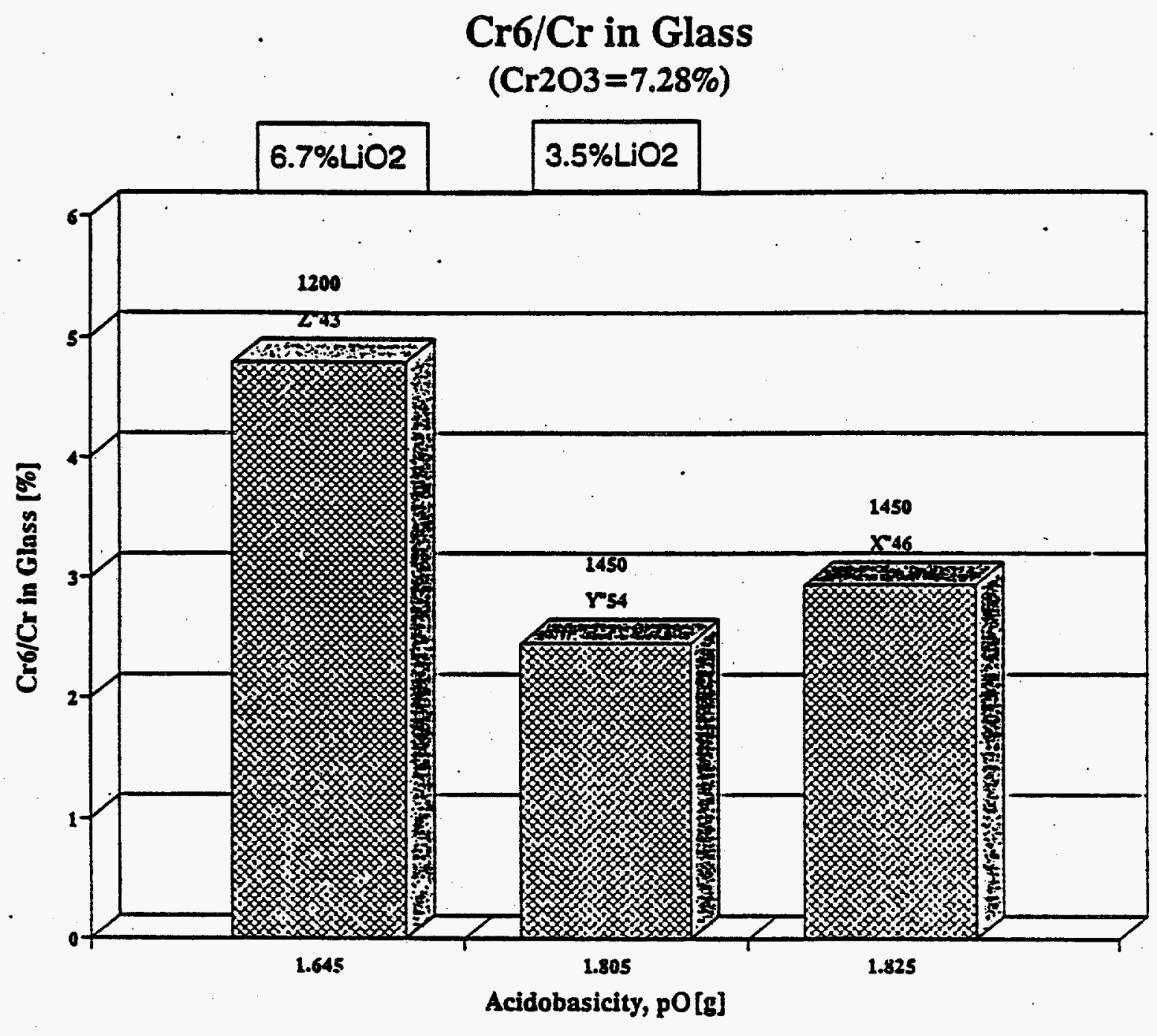

Figure 6-16: Cr Analysis in Glass (7.28 of $\mathrm{Cr}_{2} \mathrm{O}_{3}$ )

Note: Melting temperatures and labels are written on the top of columns 


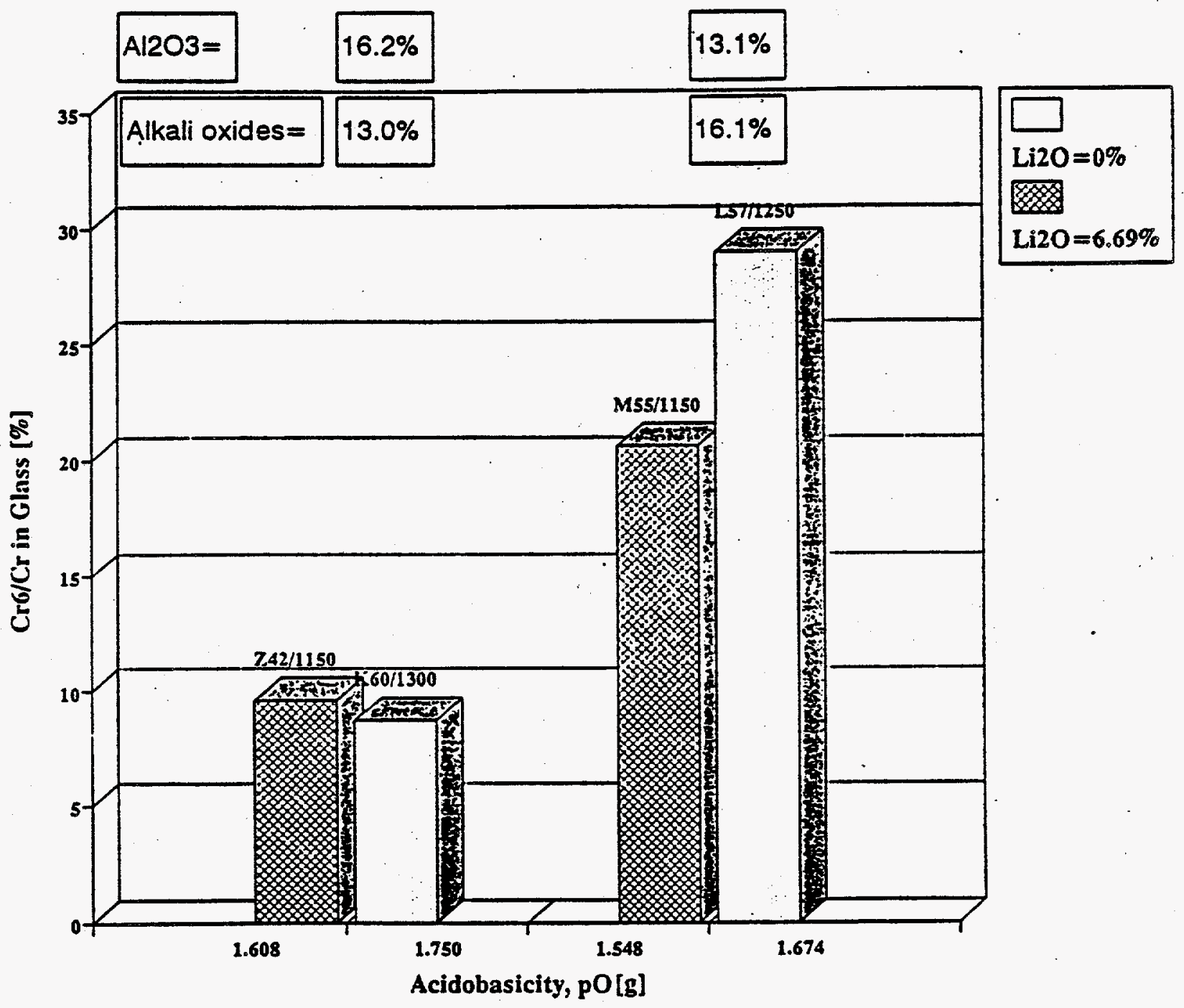

Figure 6-17: Cr Analysis of Glass with Partial $\mathrm{Al}_{2} \mathrm{O}_{3}$ Substitution and/or Complete Substitution of $\mathrm{Li}_{2} \mathrm{O}^{2}$ for $\mathrm{Na}_{2} \mathrm{O}$

Note: Melting temperatures and labels are written on the top of columns 
f) Evaluation of Glasses $X, R, M$ and $L$

All glasses of selected compositions $X, R, M$, and $L$ prepared in larger amount in svus and tested in Glass Institute, STL exhibit similar properties to those of the base-line Glass 1 . The only crystalline phase found in the quenehed and annealed samples was $\mathrm{Cr}_{2} \mathrm{O}_{3}$ - eskolaite appearing in various forms: from dense fine-grained agglomerates to loose agglomerates (clusters) of relatively large crystals, and to individual non-agglomerated crystals.

Whereas in Glasses $X, R$ and $L$, dense grains were the prevailing form, clusters were characteristic for $R$ glass. Melting temperatures of Glasses $X$ and $R$ are relatively high, about $1390^{\circ} \mathrm{C}$ and $1450^{\circ} \mathrm{C}$ respectively (for viscosity of $6 \mathrm{~Pa} . \mathrm{s}$ ), as a result of $\mathrm{Li}_{2} \mathrm{O}-\mathrm{B}_{2} \mathrm{O}_{3}$ substitution.

Characteristics of the viscosity curve (temperature dependence) of glass $X$ corresponds to common glasses. Any anomaly was not observed by viscosity measurement. The slope of the viscosity curve of glass $R$ is nearly linear that is an anomaly behavior from the point of view of common glasses. The calculated coefficients of VFT equation differ by an order comparing to common glasses. Experimental data, however, fit very well the theoretical equation. Any significant differences caused by developing crystallization were not observed.

According to chemical durability, quenched and annealed Glasses $X, R, M$ and $I$ fall within the HGB 3 resistance class. Substitution of $\mathrm{Al}_{2} \mathrm{O}_{3}$ for $\mathrm{Na}_{2} \mathrm{O}$ sets a little worse chemical durability but substitution of $\mathrm{Ii}_{2} \mathrm{O}$ for $\mathrm{Na}_{2} \mathrm{O}$ did not affect the hydrolytic resistance considerably. However, final conclusion can be made only after crystaliization induced by CCC cooling schedule.

Determinated $c r$ redox state confirmed its dependence on the glass basicity. The $\mathrm{Cr}^{6+} / \mathrm{Cr}$ ratio gets lower with the decrease of basicity caused by substitution of $\mathrm{Li}_{2} \mathrm{O}$ for $\mathrm{B}_{2} \mathrm{O}_{3}$. 
7. THE EFFECT OF Fe, Mn, Ni AND Zr ON SPECIAL GLASS PROPERTIES 7.1. PREPARATION OF GLASSES OF SERIES $C$

The preparation of glasses in the $C$ series followed procedures required by PNL and contained in the mail dated $3 / 8 / 95$ and cleared in following e-mail exchange.

The five glasses containing a base-line Glass $\mathrm{Cl}$, and four other glasses with higher amount of $\mathrm{Fe}, \mathrm{Mn}, \mathrm{Ni}$ and $\mathrm{Zr}$, glasses C2, C3, C4, and C5, were prepared on the basis of raw materials equivalent to chemicals used in the preparation of Glasses 1 and 2 (see section 4.1. ). The respective compositions are given in Table 7-1.

Table 7-1: As-batched Compositions of Glasses C1, C2, C3, C4 and C5 (Weight of Resp. Oxides)

\begin{tabular}{|l|r|r|r|r|r|}
\hline Component & \multicolumn{1}{|c|}{$\mathrm{Cl}$} & \multicolumn{1}{c|}{$\mathrm{C} 2$} & \multicolumn{1}{c|}{$\mathrm{C3}$} & \multicolumn{1}{c|}{$\mathrm{C} 4$} & \multicolumn{1}{c|}{$\mathrm{C5}$} \\
\hline $\mathrm{SiO}_{2}$ & 52.150 & 50.133 & 51.182 & 51.698 & 50.698 \\
$\mathrm{~B}_{2} \mathrm{O}_{3}$ & 9.070 & 8.719 & 8.902 & 8.991 & 8.817 \\
$\mathrm{Na}_{2} \mathrm{O}$ & 14.736 & 14.226 & 14.478 & 14.614 & 14.365 \\
$\mathrm{Li}_{2} \mathrm{O}$ & 2.270 & 2.182 & 2.228 & 2.250 & 2.207 \\
$\mathrm{CaO}$ & 0.320 & 0.309 & 0.314 & 0.317 & 0.312 \\
$\mathrm{MgO}$ & 0.030 & 0.029 & 0.029 & 0.030 & 0.029 \\
$\mathrm{Fe}_{2} \mathrm{O}_{3}$ & 3.399 & 7.000 & 3.340 & 3.371 & 3.314 \\
$\mathrm{Al}_{2} \mathrm{O}_{3}$ & 11.337 & 10.945 & 11.138 & 11.243 & 11.052 \\
$\mathrm{ZrO}_{2}$ & 3.399 & 3.282 & 3.340 & 3.371 & 6.000 \\
$\mathrm{Cr}_{2} \mathrm{O}_{3}$ & 1.130 & 1.091 & 1.110 & 1.120 & 1.101 \\
$\mathrm{P}_{2} \mathrm{O}_{5}$ & 0.180 & 0.174 & 0.177 & 0.178 & 0.175 \\
$\mathrm{SO}_{3}$ & 0.100 & 0.097 & 0.098 & 0.099 & 0.097 \\
$\mathrm{Nd}_{2} \mathrm{O}_{3}$ & 0.100 & 0.097 & 0.098 & 0.099 & 0.097 \\
$\mathrm{La}_{2} \mathrm{O}_{3}$ & 0.040 & 0.039 & 0.039 & 0.040 & 0.039 \\
$\mathrm{~K}_{2} \mathrm{O}$ & 0.130 & 0.125 & 0.128 & 0.129 & 0.127 \\
$\mathrm{~F}$ & 0.050 & 0.048 & 0.049 & 0.050 & 0.049 \\
$\mathrm{MnO}_{2}$ & 0.700 & 0.676 & 2.500 & 0.694 & 0.682 \\
$\mathrm{MoO}$ & 0.180 & 0.174 & 0.177 & 0.178 & 0.175 \\
$\mathrm{NiO}$ & 0.150 & 0.145 & 0.147 & 1.000 & 0.146 \\
$\mathrm{Cl}$ & 0.210 & 0.203 & 0.206 & 0.208 & 0.205 \\
$\mathrm{ZnO}$ & 0.320 & 0.309 & 0.320 & 0.317 & 0.312 \\
\hline
\end{tabular}

\section{Preparation of Glasses C1 to $C 5$}

First five glasses were prepared as "quenched and annealed" using the same procedure for all five glasses. Details of the 
preparation is in the respective Report of svus (Report No. 7) and the type of the furnaces, crucibles and other accessories were the same as in the case of Glass 1 and 2 preparation (see section 4.1 .1 .

Glasses $C$ were prepared at $1300^{\circ} \mathrm{C}$, batch corresponded to $1000 \mathrm{~g}$ of glass and the respective heat treatment was equivalent to the procedure for the preparation of Glasses 1 and 2 . The loading of batches and sampling corresponded to the procedure given in Table 4-4 (Section 4.1.). Casting of glasses of series $c$ was performed in a mould dimensions of which were $12 \times 12$ $x 2 \mathrm{~cm}$, the rest of melt filled a mould $5 \times 5 \times 1 \mathrm{~cm}$.

Annealing of samples followed the same procedure which was used for the preparation of glasses 1 and 2 (see section 4.1.). Mean yield of glasses was $809 \mathrm{~g}$.

visual evaluation

Glasses of the $C$ series were seed-free and refined.

Glass C1

The sample fibers gained during the melting contained residues of the batch in the form of cca $0.1 \mathrm{~mm}$ batch stones of black colour, colour of fibers was yelow-green. The surface of the glass bars was bright and vitreous, in the bulk of glass golden like crystals were visible. A small brown layer was non significant.

Glass C2

The dimensions of batch stones found in fibres was similar as in case of Glass $\mathrm{Cl}$. The same was also the colour of the fibre. The fibres contained distinct black feathers. The appearance of the glass block was bright, vitreous, in the bottom area distinct brown layer was found.

Glass c3

The fibre which was sampled after 15 min of melting contained only small amount of solid particles, after $45 \mathrm{~min}$ of melting the fibres were smooth. The colour of fibres was dark brown. The block surface was smooth, vitreous, no crystals were 
observed. The brown layer was not present in the bottom area and also not on the block edges.

\section{Glass C4}

The appearance of fibres and of blocks was similar to the Glass Cl. Only the fibre colour was dark. Brown feathers were on the block edge.

\section{Glass C5}

The appearance of the Glass 65 was identical to Glass $\mathrm{Cl}$.

The fibres of above glasses were examined by optical microscopy (magnif. $6.5 \mathrm{x}$ ) for the batch stones number visible on the $3 \mathrm{~cm}$ length of the fibre.

Following sequence was gained:

Glass $C 3$
Glass $C 1$
Glass $C 4$ and $C 5$
Glass $C 2$

1 batch stone 60 batch stones 120 - 180 batch stones 80 batch stones plus brown feathers

Resulting Glasses $C 1$ to $C 5$ were subject for the study of the temperature dependence of viscosity and transformation temperature, which values were necessary for the proposal of the respective heat treatments. Measurements of the physico-chemical. properties and the results are described in the section 7.2 .

\section{Preparation of Glasses $C-C 1$ to $c-C 5$}

For the preparation of Glasses $C-C 1$ to $C-C 5$ Glasses $C 1$ to C5 were used.

Loading was performed in $10 \mathrm{~min}$ intervals, using $240 \mathrm{~g}$ of glass in a load. The remelting was performed at melting temperatures corresponding to the values of viscosity $6 \mathrm{~Pa} . \mathrm{s}$. The values of remelting temperatures are given for each glass in Table 7-2. The residence time at these temperatures was 24 hours.

The melt was casted in moulds, dimensions of which were $8 x$ $7 \times 1 \mathrm{~cm}$ and the resulted blocks were cooled on the basis of data given for each glass in Table 7-2. The average yield of Glasses C-C1 to C-C5 was $173 \mathrm{~g}$. 
Table 7-2: Melting Conditions for the Preparation of Glasses $C-C 1$ to $C-C 5$ and $D-C 1$ to $D-C 5$

\begin{tabular}{|l|c|c|c|c|}
\hline Glass & $\begin{array}{c}\text { Time of } \\
\text { Loading } \\
\text { [hours] }\end{array}$ & $\begin{array}{c}\text { Time of } \\
\text { Melting } \\
\text { [hours] }\end{array}$ & $\begin{array}{c}\text { Remelting } \\
\text { Temper. } \\
\text { [OC] }\end{array}$ & $\begin{array}{c}\text { Cooling } \\
\text { Temper. } \\
\text { [OC] }\end{array}$ \\
\hline C-C1 & 0.33 & 24 & 1326 & 503 \\
$C-C 2$ & 0.33 & 24 & 1300 & 495 \\
$C-C 3$ & 0.33 & 24 & 1316 & 499 \\
$C-C 4$ & 0.33 & 24 & 1314 & 500 \\
$C-C 5$ & 0.33 & 24 & 1328 & 507 \\
\hline D-C1 & 0.33 & 24 & 1226 & 503 \\
$D-C 2$ & 0.33 & 24 & 1200 & 495 \\
$D-C 3$ & 0.33 & 24 & 1216 & 499 \\
$D-C 4$ & 0.33 & 24 & 1214 & 500 \\
$D-C 5$ & 0.33 & 24 & 1228 & 507 \\
\hline
\end{tabular}

The appearance of the cut of blocks was dark, no brown layer was found.

Visual evaluation of glass fibres $c-c 2, c-c 3, c-c 4$ and $c-c 5$ : $\mathrm{C}-\mathrm{C2}$

The batch stones smaller than 0.1 m prevailed. In the comparison with the Glass $c 2$ the number of batch stones 0.1 $-0.3 \mathrm{~mm}$ is considerably smaller.

$c-c 3$

The appearance does not differ from the glass fibre of $c 3$. Fibre is smooth, isolated batch stones.

$\mathrm{C}-\mathrm{CA}_{4}$

Smaller number of batch stones greater than 0.3 but greater number of batch stones bellow $0.1 \mathrm{~mm}$.

c- $\mathrm{C5}$

In the comparison with the Glass c5 the number of batch stones above $0.3 \mathrm{~mm}$ is smaller, the number bellow $0.1 \mathrm{~mm}$ increased.

Preparation of Glasses $D-C I$ to $D-C 5$

For the preparation of Glasses D-Cl to D-C5 Glasses CI to C5 were used. 
Loading was performed in 10 min intervals, using $250 \mathrm{~g}$ of glass in a load. The higher value of the loads was used because of expected higher viscosities at lower remelting temperatures and the request to gain approx. the same amount of melt as in the case of glasses $\mathrm{C}-\mathrm{Cl}$ to $\mathrm{C}-\mathrm{C5}$.

The remelting was performed at the temperature $100^{\circ} \mathrm{C}$ below the melting temperatures corresponding to the values of viscosity $6 \mathrm{~Pa} . \mathrm{s}$. The values of temperatures used for the heat treatment are given also in Table $7-2$. The residence time at the respective temperature was 24 hours.

The casting and annealing was identical to the process used in case of Glasses $C-C$. The main yield of glass, was in this case $167 \mathrm{~g}$, cut of blocks was dark, no brown layer at the bottom was visible.

Visual evaluation of glass fibres of samples D-C2 to D-C5:

$\underline{D-C 2}$

The appearance and the dimensions of batch stones were similar to the Glass C-C2, but their number was greater.

$\underline{D-C 3}$

Fibre was very smooth, only individual very small batch stones were visible.

$\underline{D-C 4}$

The content of batch stones bellow $0.1 \mathrm{~mm}$ was significantly higher than in case of Glass C-C4.

$\underline{D-C 5}$

Dimensions and the number of batch stones bellow $0.1 \mathrm{~mm}$ were higher than in case of Glass C-C5.

It can be stated that during the heat treatment at the melting temperature (corresp. to $6 \mathrm{~Pa} . \mathrm{s}$ ) glasses with smaller batch stones were prepared (the number of stones smaller than $0.1 \mathrm{~mm}$ increased). The process of glass preparation which used the temperature $100^{\circ} \mathrm{C}$ lower than the melting temperature led to glasses with considerably higher number of fine batch stones than 
in case of Glasses C-C. Both heat treatment processes of Glass c3 resulted in glasses with individual batch stones.

\subsection{PHYSICO-CHEMICAL PROPERTIES OF GLASSES}

Physico-chemical properties of Glasses C1 to C5 were studied to enable preparation of glasses with special heat treatment.

The measurement of the temperature dependence of viscosity and the $T_{g}$ temperature was used for the heat treatment of glasses with $C$ and $D$ procedures (Glasses $C-C$ and $D-C$ ). Description of the measurements and resulting data are given in detail in the Closing Report STL No.91/95.

Determination of density

ASTM C 693-84(88) "Standard testing method for determination of the glass density by the hydrostatic weighing" was used for density determination.

Samples marked $\mathrm{Cl}, \mathrm{C2}, \mathrm{C3}, \mathrm{C4}$ and $\mathrm{C5}$ were cut to smaller parts of suitable size and three independent sample parts were measured.

Testing results

The average density of Giass $C 1$ is $2565 \mathrm{~kg} \cdot \mathrm{m}^{-3}$. The average density of Glass $\mathrm{C2}_{2}$ is $2596 \mathrm{~kg} \cdot \mathrm{m}^{-3}$. The average density of Glass $c 3$ is $2588 \mathrm{~kg} \cdot \mathrm{m}^{-3}$. The average density of Glass $C 4$ is $2580 \mathrm{~kg} \cdot \mathrm{m}^{-3}$. The average density of Glass $\mathrm{CS}_{5}$ is $2595 \mathrm{~kg} \cdot \mathrm{m}^{-3}$.

Note: The samples quality does not correspond to the requirement of full homogeneity due to the presence of bubbles, splits and inhomogeneities. Therefore, it is necessary to consider the results only as informative values.

Determination of viscosity by rotary viscometer

Viscosity of Glasses series $C$ was performed using standard:

CSN ISO 7884-2 Viscosity and reference viscosity points. Part 2: Viscosity determination by rotary viscometer.

The samples were cut off to the necessary size and melted down in PtRh crucibles, diameter $35 \mathrm{~mm}$, height $55 \mathrm{~mm}$. The 
volume of all samples before melting down was $33.7 \mathrm{~cm}^{3}$. The samples were measured on searle type rotary viscometer with the use of a PtRh10 spherical element (description of the apparatus, procedure and calibration is in Annex B4).

The Glass Cl was melted down in a crucible at $1285^{\circ} \mathrm{C}$. The temperature was increased up to $1324^{\circ} \mathrm{C}$ after immersing of the sphere. After stabilizing of conditions (approx. $30 \mathrm{min.}$ ) the measurement started at the above temperature in approx. $50{ }^{\circ} \mathrm{C}$ intervals down to $974^{\circ} \mathrm{C}$.

The Glass $\mathrm{C2}$ was melted down in a crucible at $1200^{\circ} \mathrm{C}$. The temperature was increased up to $1304^{\circ} \mathrm{C}$ after immersing of the sphere. After stabilizing of conditions (approx. $30 \mathrm{~min}$ ) the measurement started from this temperature in approx. $50{ }^{\circ} \mathrm{C}$ intervals down to $962^{\circ} \mathrm{C}$.

The Glass C3 was melted down in a crucible at $1290^{\circ} \mathrm{C}$. The temperature was increased up to $1311^{\circ} \mathrm{C}$ after immersing of the sphere. After stabilizing of conditions (approx. $30 \mathrm{~min}$ ) the measurement started from this temperature in approx. $50{ }^{\circ} \mathrm{C}$ intervals down to $998^{\circ} \mathrm{C}$. In the end the viscosity at $1314^{\circ} \mathrm{C}$ was measured for control. The measured value corresponds to the course of the curve in the beginning of the measurement.

The Glass $\mathrm{C}_{4}$ was melted down in a crucible at $1200^{\circ} \mathrm{C}$. The temperature was increased up to $131{ }^{\circ} \mathrm{C}$ after immersing of the sphere. After stabilizing of conditions ( 30 min.) the measurement started from this temperature in approx. $50^{\circ} \mathrm{C}$ intervals down to $1044^{\circ} \mathrm{C}$.

The Glass C5 was melted down in a crucible at $1250^{\circ} \mathrm{C}$. The temperature was increased up to $1292^{\circ} \mathrm{C}$ after immersing of the sphere. After stabilizing of conditions (approx. 60 in.) the measurement started from this temperature in approx. $50{ }^{\circ} \mathrm{C}$ down to $1021{ }^{\circ} \mathrm{C}$. In the end the viscosity at $1332^{\circ} \mathrm{C}$ was measured for control. The measured value corresponds to the course of the curve in the beginning of the measurement. 
For the description of viscosity temperature dependence, the Vogel-Fulcher-Tammann (VFT) equation was used. From measured viscosity values, the constants of VFT equations with the application of ADSTAT programme (modul of Non-linear regression) were calculated.

Testing results

Temperature dependencies for the Glasses CI to C5 are illustrated in the Annexes $\mathrm{C24}$ to $\mathrm{C28}$. The comparison of experimental and calculated viscosity values are given in Tables 7-3 to $7-7$.

VFT equations for Glass CI:

$$
\begin{aligned}
& \log v=-3.390+7134.7 /(t+55.0) \\
& s=0.015 \quad D^{2}=0.9996 \\
& \text { (validity from } \left.974^{\circ} \mathrm{C} \text { to } 1324^{\circ} \mathrm{C}\right)
\end{aligned}
$$

where: $v \ldots \ldots$ viscosity $[\mathrm{dPa} . \mathrm{s}]$

$t \ldots .$. temperature $\left[{ }^{\circ} \mathrm{c}\right]$

s $\ldots \ldots$ standard deviation

$D^{2} \ldots \ldots$ coefficient of determination

Table 7-3: Comparison of Experimental and Calculated Viscosity Values for Glass $C l$

\begin{tabular}{|c|c|c|c|}
\hline Temperature $\left[{ }^{\circ} \mathrm{c}\right]$ & $\log v(\mathrm{~m})$ & $\log v(\mathrm{c})$ & Deviation \\
\hline 974 & 3.530 & 3.544 & -0.014 \\
1015 & 3.292 & 3.278 & 0.014 \\
1017 & 3.279 & 3.266 & 0.013 \\
1051 & 3.043 & 3.061 & -0.018 \\
1100 & 2.799 & 2.787 & 0.012 \\
1150 & 2.535 & 2.531 & 0.004 \\
1201 & 2.284 & 2.291 & -0.007 \\
1254 & 2.040 & 2.061 & -0.021 \\
1307 & 1.856 & 1.848 & 0.008 \\
1308 & 1.841 & 1.845 & -0.004 \\
1324 & 1.795 & 1.784 & 0.011 \\
\hline
\end{tabular}

Notes: $v(m) \ldots$ measured viscosity [dPa.s]

$v(c)$... calculated viscosity [dPa.s]

VFT equations for Glass C2:

$$
\log v=-5.258+12042.0 /(t+411.0)
$$




$$
\begin{array}{ll}
s=0.002 & D^{2}=0.9999 \\
\text { (validity from } 962{ }^{\circ} \mathrm{C} \text { to } 1304{ }^{\circ} \mathrm{C} \text { ) }
\end{array}
$$

where: $v \ldots \ldots$ viscosity [dPa.s]

$t \ldots \ldots$ temperature $\left[{ }^{\circ} \mathrm{C}\right]$

s..... standard deviation

$D^{2} \ldots \ldots$ coefficient of determination

Table 7-4: Comparison of Experimental and Calculated Viscosity Values for Glass $\mathrm{C2}$

\begin{tabular}{|c|c|c|c|}
\hline Temperature $\left.{ }^{\circ} \mathrm{C}\right]$ & $\log \mathrm{v}(\mathrm{m})$ & $\log \mathrm{v}(\mathrm{c})$ & Deviation \\
\hline 962 & 3.512 & 3.513 & -0.001 \\
1007 & 3.236 & 3.235 & 0.001 \\
1058 & 2.940 & 2.940 & $(0)$ \\
1108 & 2.668 & 2.670 & -0.002 \\
1158 & 2.418 & 2.417 & 0.001 \\
1208 & 2.178 & 2.180 & -0.002 \\
1259 & 1.957 & 1.953 & 0.004 \\
1304 & 1.762 & 1.764 & -0.002 \\
\hline
\end{tabular}

Notes: $v(m) \ldots$ measured viscosity [dPa.s]

$v(c)$... calculated viscosity [dPa.s]

VFT equations for Glass C3:

$$
\begin{aligned}
& \log v=-1.227+2869.9 /(t-361.2) \\
& s=0.019 \quad D^{2}=0.9993 \\
& \text { (validity from } \left.998{ }^{\circ} \mathrm{C} \text { to } 1314{ }^{\circ} \mathrm{C}\right) \\
& v \ldots \ldots \text { viscosity }[\text { dPa.s] } \\
& t \ldots \ldots \text { temperature }\left[{ }^{\mathrm{C}}\right] \\
& \mathrm{s}^{2} \ldots \ldots \text { standard deviation } \\
& \mathrm{D}^{2} \ldots \ldots \text { coefficient of determination }
\end{aligned}
$$

where: $v \ldots \ldots$ viscosity [dPa.s]

Table 7-5: Comparison of Experimental and Calculated Viscosity Values for Glass $\mathbf{C 3}$

\begin{tabular}{|c|c|c|c|}
\hline Temperature [ $\left.{ }^{\circ} \mathrm{C}\right]$ & $\log v(\mathrm{~m})$ & $\log v(\mathrm{c})$ & Deviation \\
\hline 998 & 3.302 & 3.280 & 0.022 \\
1026 & 3.058 & 3.090 & -0.032 \\
1113 & 2.592 & 2.591 & 0.001 \\
1163 & 2.366 & 2.353 & 0.013 \\
1214 & 2.141 & 2.139 & 0.002 \\
1265 & 1.945 & 1.949 & -0.004 \\
1311 & 1.795 & 1.795 & $(0)$ \\
1314 & 1.782 & 1.785 & -0.003 \\
\hline
\end{tabular}

Notes: $v(m) \ldots$ measured viscosity [dPa.s]

$v(c)$... calculated viscosity [dPa.s] 
VFT equations for glass C4:

$$
\begin{aligned}
& \log v=-3.206+6736.3(t+37.1) \\
& s=0.009 \quad D^{2}=0.9997 \\
& \text { (validity from } \left.104{ }^{\circ} \mathrm{C} \text { to } 131{ }^{\circ} \mathrm{C}\right) \\
& v \ldots \ldots \text { viscosity }[\mathrm{dPa} s] \\
& t \ldots \ldots \text { temperature }\left[\mathrm{o}_{\mathrm{C}]}\right. \\
& s \ldots \ldots \text { standard deviation } \\
& \mathrm{D}^{2} \ldots \ldots \text { coefficient of determination }
\end{aligned}
$$

where: $v \ldots \ldots$ viscosity [dPa.s]

Table 7-6: Comparison of Experimental and Calculated Viscosity Values for Glass C4

\begin{tabular}{|c|c|c|c|}
\hline Temperature $\left[{ }^{\circ} \mathrm{c}\right]$ & $\log v(\mathrm{~m})$ & $\log v(\mathrm{c})$ & Deviation \\
\hline 1044 & 3.019 & 3.025 & -0.006 \\
1069 & 2.890 & 2.884 & 0.006 \\
1115 & 2.641 & 2.641 & $(0)$ \\
1164 & 2.410 & 2.402 & 0.008 \\
1214 & 2.172 & 2.178 & -0.006 \\
1265 & 1.957 & 1.967 & -0.010 \\
1311 & 1.799 & 1.791 & 0.008 \\
\hline
\end{tabular}

Notes: $v(m) \ldots$ measured viscosity [dPa.s]

$v(c)$... calculated viscosity [dPa.s]

VFT equations for Glass C5:

$$
\begin{aligned}
& \log v=-3.519 \quad+\quad 7140.5 /(t+19.9) \\
& s=0.004 \quad D^{2}=0.9999 \\
& \text { (validity from } \left.1021{ }^{\circ} \mathrm{C} \text { to } 1332^{\circ} \mathrm{C}\right)
\end{aligned}
$$

where: $v \ldots \ldots$ viscosity [dPa.s]

$t \ldots .$. temperature [ ${ } c]$

s ...... standard deviation

$D^{2} \ldots \ldots$ coefficient of determination 
Table 7-7: Comparison of Experimental and Calculated viscosity Values for Glass C5

\begin{tabular}{|c|c|c|c|}
\hline Temperature $\left[{ }^{\circ} \mathrm{C}\right]$ & $\log \mathrm{v}(\mathrm{m})$ & $\log \mathrm{v}(\mathrm{c})$ & Deviation \\
\hline 1021 & 3.342 & 3.341 & 0.001 \\
1052 & 3.140 & 3.143 & -0.003 \\
1086 & 2.941 & 2.938 & 0.003 \\
1125 & 2.715 & 2.718 & -0.003 \\
1168 & 2.498 & 2.492 & 0.006 \\
1212 & 2.274 & 2.278 & -0.004 \\
1254 & 2.087 & 2.087 & $(0)$ \\
1292 & 1.922 & 1.924 & -0.002 \\
1332 & 1.765 & 1.763 & 0.002 \\
\hline
\end{tabular}

Notes: $v(m) \ldots$ measured viscosity [dPa.s]

$v(c)$... calculated viscosity [dPa.s]

Determination of mean coefficient of linear thermal expansion and dilatometric transformation temperature

Following standards, technical documents, internal regulations and other sources were used:

CSN ISO 7991 Determination of mean coefficient of linear (thermal) expansion.

CSN ISO 7884-8 Viscosity and reference viscosity points. Determination of dilatometric transformation temperature $t_{g}$.

The samples marked $C_{1}, C_{2}, C_{3}, C_{4}$ and $C_{5}$ in the form of prisms, dimension $5 \times 5 \times 25 \mathrm{~mm}$ were were ground in the plane perpendicular to the longitudinal axis.

Samples were measured on dilatometer No. 2 from Adamel Lhomargy according to the above standards, heating rate $4^{\circ} \mathrm{c} / \mathrm{min}$ was used.

Unstandardized softening temperature $t_{d}$ was evaluated directly from the dilatometric curve as a temperature at which the elongation of measured sample was stopped due to the influence of the thrust mechanism pressure. Thrust force of the draw rod was adjusted on $18 \mathrm{cN}$.

Testing results are given in following Table 7-8. 
Table 7-8: Determination Results of Medium Coefficient of Iinear Thermal Expansion, Dilatometric Transformation Temperature $t_{g}$ and Dilatometric softening Point $t_{d}$ of Glasses $C 1$ to $C 5$.

\begin{tabular}{|c|c|c|c|}
\hline Sample & ${ }^{\alpha}(20-300){ }_{[k}^{c} c=10^{6}$ & $t_{g}\left[{ }^{o} c\right]$ & $t_{d}{ }_{0}$ \\
\hline $\begin{array}{l}\text { C1 } \\
\text { 1st prism } \\
\text { 2nd prism }\end{array}$ & $\begin{array}{l}9.60 \\
9.30\end{array}$ & $\begin{array}{l}503 \\
502\end{array}$ & $\begin{array}{l}548 \\
550\end{array}$ \\
\hline $\begin{array}{l}\text { C2 } \\
\text { 1st prism } \\
\text { 2nd prism }\end{array}$ & $\begin{array}{r}9.39 \\
9.26\end{array}$ & $\begin{array}{l}500 \\
488\end{array}$ & $\begin{array}{l}550 \\
531\end{array}$ \\
\hline $\begin{array}{l}\text { C3 } \\
\text { 1st prism } \\
\text { 2nd prism }\end{array}$ & $\begin{array}{l}9.18 \\
9.51\end{array}$ & $\begin{array}{l}498 \\
500\end{array}$ & $\begin{array}{l}545 \\
549\end{array}$ \\
\hline $\begin{array}{l}\text { C4 } \\
\text { 1st prism } \\
\text { 2nd prism }\end{array}$ & $\begin{array}{l}9.23 \\
9.35\end{array}$ & $\begin{array}{l}502 \\
498\end{array}$ & $\begin{array}{l}549 \\
544\end{array}$ \\
\hline $\begin{array}{l}\text { C5 } \\
\text { 1st prism } \\
\text { 2nd prism }\end{array}$ & $\begin{array}{l}8.93 \\
9.05\end{array}$ & $\begin{array}{r}508 \\
. \quad 506\end{array}$ & $\begin{array}{l}573 \\
568\end{array}$ \\
\hline
\end{tabular}

Average values:

$\begin{array}{lll}\text { Glass C1 } & \alpha_{(20-300){ }^{\circ} \mathrm{C}=9.45 \cdot 10^{-6} \mathrm{~K}^{-1}} & t_{g}=503{ }^{\circ} \mathrm{C} \\ \text { Glass C2 } & \alpha_{(20-300){ }^{\circ} \mathrm{C}=9.33 \cdot 10^{-6} \mathrm{~K}^{-1}} & t_{g}=494{ }^{\circ} \mathrm{C} \\ \text { Glass C3 } & \alpha_{(20-300){ }^{\circ} \mathrm{C}=9.35 \cdot 10^{-6} \mathrm{~K}^{-1}} & t_{\mathrm{g}}=499{ }^{\circ} \mathrm{C} \\ \text { Glass C4 } & \alpha_{(20-300){ }^{\circ} \mathrm{C}=9.29 \cdot 10^{-6} \mathrm{~K}^{-1}} & t_{g}=500{ }^{\circ} \mathrm{C} \\ \text { Glass C5 } & \alpha_{(20-300){ }^{\circ} \mathrm{C}=8.99 \cdot 10^{-6} \mathrm{~K}^{-1}} & t_{g}=507{ }^{\circ} \mathrm{C}\end{array}$

Note: The variance of experimental values a(20-300)oc shows a significant inhomogeneity of measured glasses. The maximum difference of values $\alpha(20-300) 0 \mathrm{C}$ between two paralel determinations in homogeneous glasses is 0.1 .

\subsection{STRUCTURAL CHARACTERISTICS OF GLASSES}

Glasses prepared according to procedures described in Section 7.1, (glasses C-CI to $C-C 5$ and $D-C 1$ to $D-C 5$ ) were studied by $x$-ray diffraction analysis, electron microanalysis and optical microscopy. 
X-ray diffraction identification of crystalline phases

Internal regulation $F-12-93 \quad x-r a y$ diffraction analysis on the apparatus siemens $U$ 13-008

was used for the samples investigation.

Sample parts marked $C-C 1, D-C 1, C-C 2, D-C 2, C-C 3, D-C 3$, $C-C 4, D-C 4, C-C 5$ and $D-C 5$ were crushed and ground in a grinding equipment with hard metal lining.

$X$-ray diffraction analysis was carried out using $C u K$ alpha radiation, Ni filter.

\section{Testing results}

\section{Sample $C-C 1$}

The presence of crystalline phase was not proved.

Sample $D-C l$

By comparison with the data file ASTM (JCPDS) the eskolaite $\mathrm{Cr}_{2} \mathrm{O}_{3}$ (ASTM 6-0504) in minor amount as the only crystalline phase in the sample was identified.

Sample $C-C 2$

By comparison with the data file ASTM (JCPDS) the eskolaite $\mathrm{Cr}_{2} \mathrm{O}_{3}$ (ASTM 6-0504) in minor amount (on a limit of evidence) as the only crystalline phase in the sample was identified.

\section{Sample D-C2}

By comparison with the data file ASTM (JCPDS) the eskolaite $\mathrm{Cr}_{2} \mathrm{O}_{3}$ (ASTM 6-0504) in minor amount as the only crystalline phase in the sample was identified:

\section{Sample $C-C 3$}

The presence of crystaline phase was not proved.

Sample $D-C 3$

By comparison with the data file ASTM (JCPDS) a crystalline phase with a spinel structure, chromite type Feo - $\mathrm{Cr}_{2} \mathrm{O}_{3}$ (ASTM 3-0873) as a minor phase was identified in the sample. A very thin diffraction line $d=3.47 \cdot 10^{-10} \mathrm{~m}$ was not identified. 
Sample $c-c 4$

By comparison with the data file ASTM (JCPDS) the eskolaite $\mathrm{Cr}_{2} \mathrm{O}_{3}$ (ASTM 6-0504) in minor amount (on a limit of evidence) as the only crystalline phase in the sample was identified.

\section{Sample D-C4}

By comparison with the data file ASTM (JCPDS) a crystalline phase with a spinel structure, chromite type Feo - $\mathrm{Cr}_{2} \mathrm{O}_{3}$ (ASTM 3-0873) as a minor phase was identified in the sample. A presence of a very small amount of eskolaite is probable in the sample (only the main diffraction line was proved).

\section{Sample C-C5}

The content of crystalline phase is very small. The presence of a very small amount of eskolaite is probable (only the main diffraction line was proved).

\section{Sample D-CS}

By comparison with the data file ASTM (JCPDS) the eskolaite $\mathrm{Cr}_{2} \mathrm{O}_{3}$ (ASTM 6-0504) in minor amount (on a limit of evidence) as the only crystalline phase in the sample was identified.

Photodocumentation and analysis in scanning electron microscope

Internal regulation F-18-94 Methods of nondestructive analysis of solid substances in the apparatus complex Camscan 4-DV LINK AN 10000 - Microspec WDX-2A

was used for crystalline phases documentation.

Preparations of testing samples

Cutting surfaces of plates representing the perpendicular sections through blocks of samples ( $C-C 1, D-C 1, C-C 2, D-C 2$, $C-C 3, D-C 3, C-C 4, D-C 4, C-C 5$ and $D-C 5$ were used for the investigation by SEM. The section surface was polished on polishing device and then on an equipment by free diamond (DSM 2/1 Pramet and PWD 3-1 Wolters) on a brass support plate.

Before inserting into apparatus, samples were coated by carbon in a high vacuum equipment B 302. Measurements were carried out with the use of electron scanning microscope camscan 4-DV with energy dispersive analyzer LINK AN 10000. 
Pictures taken in back scattered electrons (BSE) were carried out using following conditions: accelerating voltage $20 \mathrm{kV}$, working distance $29 \mathrm{~mm}$, shield 2 , resolution 4 .

Typical texture motives detected in analyzed glasses were documented and analyzed. The dependence of the presence of structural motives on a distance from the bottom block area was investigated in samples. This distance from the lower edge of the picture is given in $\mathrm{mm}$. The upper edge of the picture corresponds to the upper edge of the block. The distance range given in respective pictures or tables corresponds to the area taken from the bottom part of the sample.

Further on, the EDX spectra of selected areas of texture motives and matrix by energy dispersive analyzer IINK AN 10000 were made. Either area analyses (the dimension of analyzed area is documented in respective pictures) or local analyses (the diameter of analyzed place was approx. $1.5 \mu$ ) were carried out. The spectra gained were quantitatively evaluated by a correction program ZAF-4/FLS.

The complement of analyses to $100 \mathrm{wt.} f$ is formed by minor components (in particular cases statistically unprovable, the values are lower than $2 \sigma$ and $\mathrm{B}_{2} \mathrm{O}_{3}$ and $\mathrm{Ii}_{2} \mathrm{O}$ which cannot be determined by the method used. The $X$-ray distribution of selected elements $\mathrm{Cr}, \mathrm{Fe}, \mathrm{Si}, \mathrm{Na}, \mathrm{Al}, \mathrm{Ni}$ and $\mathrm{Zn}$ were made, using the program MAPPING.

Testing results

\section{Glass $\mathrm{C}-\mathrm{Cl}$}

Small magnification of this sample does not give any significant information. Respective picture is presented in the Closing Report STL No. 91/95. (this is also the case of other glasses studied in this section - pictures with lower information values are only in the above mentioned report).

The dependence of the texture motives concentration on a distance from the bottom block area was not found. Typical examples of crystal clusters are shown in Figures 7-1 and 7-2. 
The result of the local analysis of a crystal in cluster is given in Table 7-9.

In the whole sample area the isolated crystals of eskolaite were observed. Their character is documented in Figure 7-3. The isolated crystal and surrounding glass (matrix) local analysis results are summarized in Table 7-9.

Both X-ray diffraction analysis and local analysis confirmed the presence of eskolaite as the only crystalline phase in Glass $\mathrm{C}-\mathrm{Cl}$.

Glass D-C1

Typical example of a crystal cluster and its transition form to recrystallized grain particle is shown in Figure 7-4. The result of the local analysis of crystal in cluster is given in Table 7-10.

In the whole sample area the isolated crystals of eskolaite were observed. Their character is documented in Figure 7-5. The result of local analyses of isolated crystal and surrounding glass (matrix) are sumnarized in Table 7-10.

$x$-ray diffraction analysis and local analysis confirmed eskolaite as the only crystalline phase in glass D-Cl.

\section{Glass $\mathrm{C}-\mathrm{C2}$}

The dependence of texture motives concentration on a distance from the bottom block area was not detected in this Glass.

Typical example of a crystal cluster is shown in Figure 7-6. The result of local analysis of the crystal in cluster is given in Table 7-11.

In the whole sample area isolated crystals of eskolaite were observed. Their character is documented in Figure 7-7. The isolated crystal and surrounding glass (matrix) local analysis results are summarized in Table 7-11.

$X$-ray diffraction analysis and local analysis confirmed eskolaite as the only crystalline phase in Glass c-c2. 


\section{Glass D-C2}

The dependence of the texture motives concentration on a distance from the bottom block area was not detected.

Typical examples of recrystallized grain particles or crystal clusters are shown in Figures 7-8 and 7-9. Results of local analysis of a crystal in cluster is given in Table 7-12.

In the whole sample area isolated crystals of eskolaite were observed. Their. character is documented in Figure 7-10. The crystal and surrounding glass (matrix) local analyses results are summarized in Table 7-12.

$X$-ray diffraction analysis and local analysis confirmed eskolaite as the only crystalline phase in Glass D-C2.

The total concentration of recrystallized grain particles or clusters and isolated crystals in sample D-C2 is significantly higher than in the sample C-C2.

\section{Glass $\mathrm{C}-\mathrm{C} 3$}

Texture motives were not found even at a greater magnification in the $c-c 3$ glass (pictures are presented only in the respective closing Report, see comment at the description of of the characteristics of glass $\left.C-C_{1}\right)$. The absence of crystalline phases was confirmwed also by the respective $x$-ray diffraction analysis.

The results of local analyses of surrounding glass (matrix) are summarized in Table 7-13.

\section{Glass D-C3}

In the whole analyzed area of the sample the only texture motive - isolated crystals - was detected. The dependence of isolated crystals concentration on the distance from the bottom block area was not found.

Typical examples of isolated crystals are shown in Figures 7-11 and 7-12. The results of local analyses of selected isolated crystals and surrounding glass (matrix) are given in Table 7-i3. 
$X$-ray diffraction analysis and local analyses confirmed only one crystalline phase of chromite type spinel structure with a substitution of $\mathrm{di}$ - and trivalent ions of $\mathrm{Ni}, \mathrm{Zn}, \mathrm{Mn}, \mathrm{Fe}, \mathrm{Cr}$ and $A l$.

\section{Glass $C-C_{4}$}

A typical example of crystal cluster found in this glass is shown in the Figure 7-13. Results of local analyses of a crystal in cluster is given in Table 7-14.

In the whole sample area isolated crystals of eskolaite were observed. Their character is documented in Figure 7-14. The isolated crystal and surrounding glass (matrix) local analysis results are summarized in Table 7-14.

$X$-ray diffraction analysis and local analysis, confirmed eskolaite as the only crystalline phase in glass $\mathrm{C}-\mathrm{C} 4$. The dependence of texture motives concentration on a distance from the bottom block area was not detected.

\section{Glass D-C4}

Typical examples of crystal clusters are shown in Figure 7-15. Figure 7-16 presents not only crystal cluster but also a grain particle and isolated isometric crystal. $x$-ray distribution of $\mathrm{Si}, \mathrm{Cr}, \mathrm{Fe}, \mathrm{Na}, \mathrm{Al}, \mathrm{Ni}$ and $\mathrm{zn}$ in the area documented in Figure $7-16$ is shown in Figures $7-17$ and $7-18$. The results of the analyses of the grain particle, crystal in cluster, isolated isometric crystal and surrounding glass (matrix) are summarized in Table 7-15.

$x$-ray diffraction analysis and local analysis confirmed the content of two different crystalline phases in glass D-C4. The phase with a chromite type spinel structure with substitution of di- and trivalent ions of $\mathrm{Ni}, \mathrm{Zn}, \mathrm{Mn}, \mathrm{Fe}, \mathrm{Cr}$ and $\mathrm{Al}$ is in a form of isolated isometric crystals, and in a form of grain irregular particles. Eskolaite is present in a form of crystal clusters.

The dependence of the texture motives concentration on a distance from the bottom block area was not detected. 


\section{Glass C-C5}

Typical examples of grain recrystallized particles are shown in Figure 7-19, an example of crystal clusters is documented in Figure 7-20. The results of local analyses of crystal in clusters and the surrounding glass (matrix) are summarized in Table 7-16.

The results of $X$-ray diffraction analysis and local analyses confirmed the content of eskolaite as the only crystalline phase in glass $\mathrm{C}-\mathrm{C}$.

The dependence of texture motives concentration on a distance from the bottom block area was not detected.

\section{Glass D-C5}

Examples of recrystallized grain particles are shown in Figures 7-21 and 7-22, the examples of crystal clusters in Figure 7-23 and examples of isolated crystals in Figure 7-24.

The results of the area analysis of the recrystallized grain particle, local analysis of crystal in cluster, local analysis of isolated crystal and the surrounding glass (matrix) are summarized in Table 7-17.

The results of $\mathrm{X}$-ray diffraction analysis and local analysis confirmed the content of eskolaite as the only crystaline phase in Glass D-C5. The total concentration of recrystallized particles, clusters and isolated crystals in sample D-C5 is significantly higher than in sample $c-c 5$.

The dependence of the texture motives concentration on a distance from the bottom block area was not detected.

Note: It was possible that during the analysis of eskolaite tabular crystals considerable amount of crystal surrounding matrix participated in the elements detection due to a very small thickness of these crystals.

The deviation of a sum from theoretical value 100 wt. found in the analyses of crystals was caused by a complicated observance of geometric conditions in the place of analysis (the difficulty of grinding of very hard crystals to the plane of surrounding glass). 


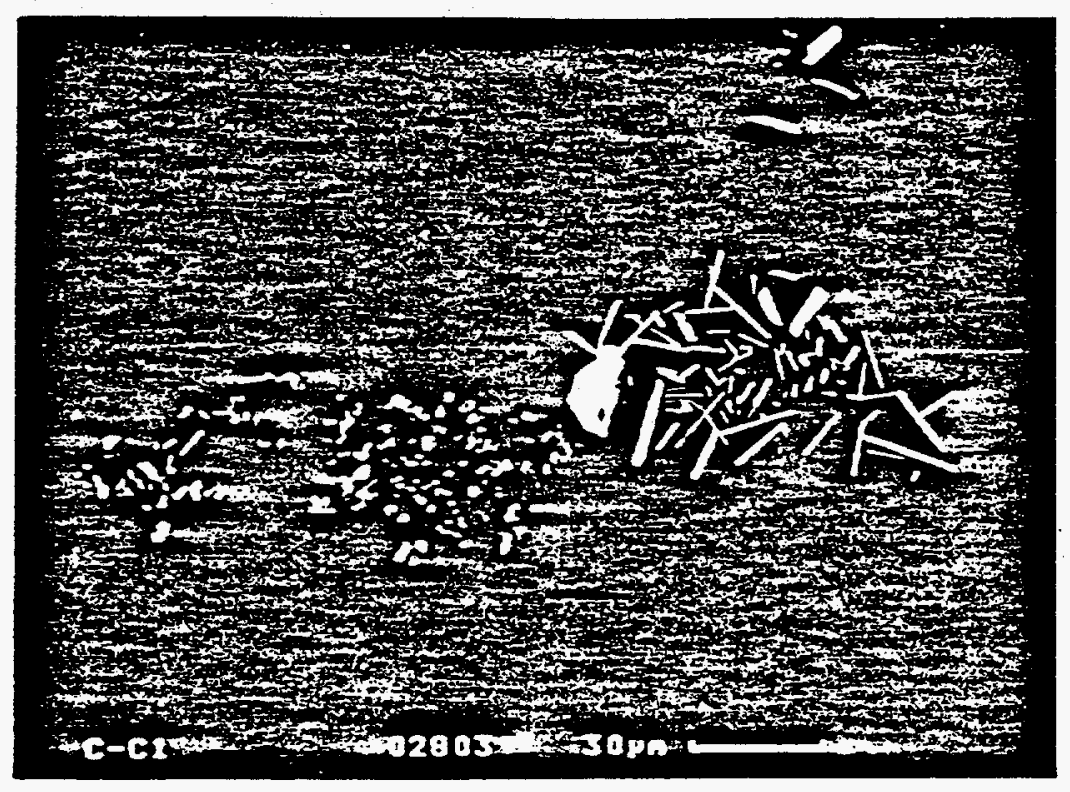

Figure 7-1: Glass C-C1. Detail section View in a Central Block Part (6-10 mm). Microscope Camscan 4-DV, BSE.

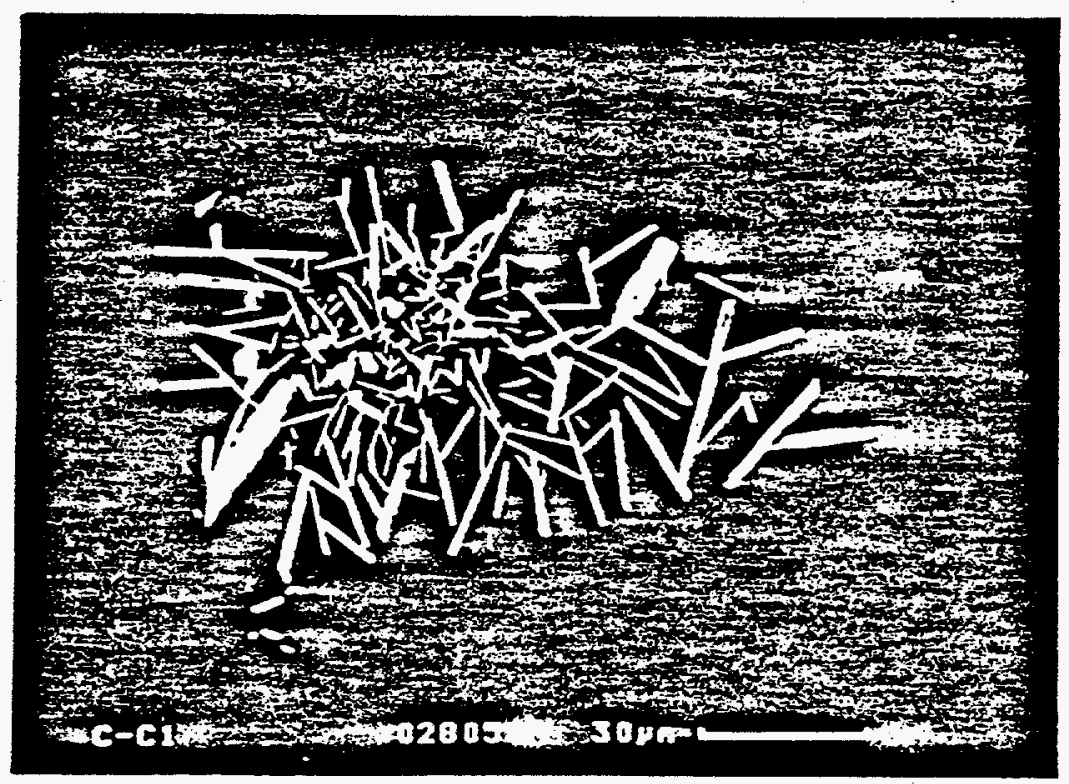

Figure 7-2: Glass C-C1. Crystal Cluster with Marked Local Analysis. Normal section $(6-10 \mathrm{~mm})$. Microscope Camscan 4-DV, BSE. 


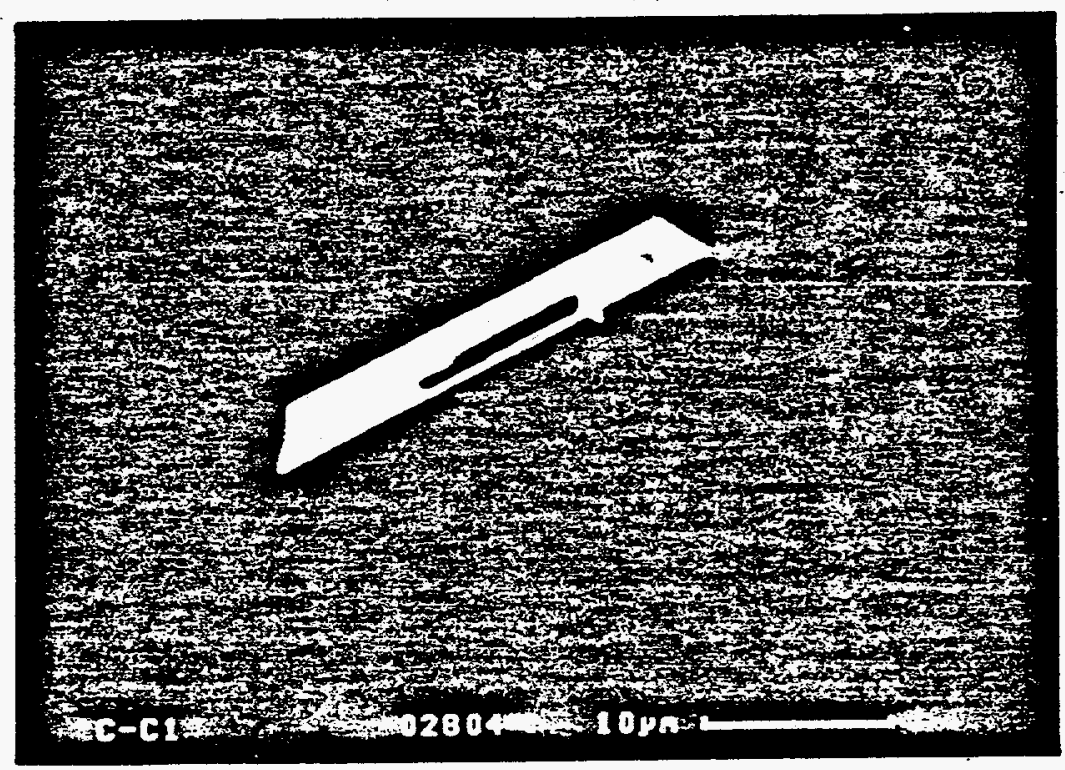

Figure 7-3: Glass C-CI. Isolated Eskolaite Crystal with Marked Local Analysis. Normal Section (6-10 mm). Microscope Camscan 4-DV, BSE.

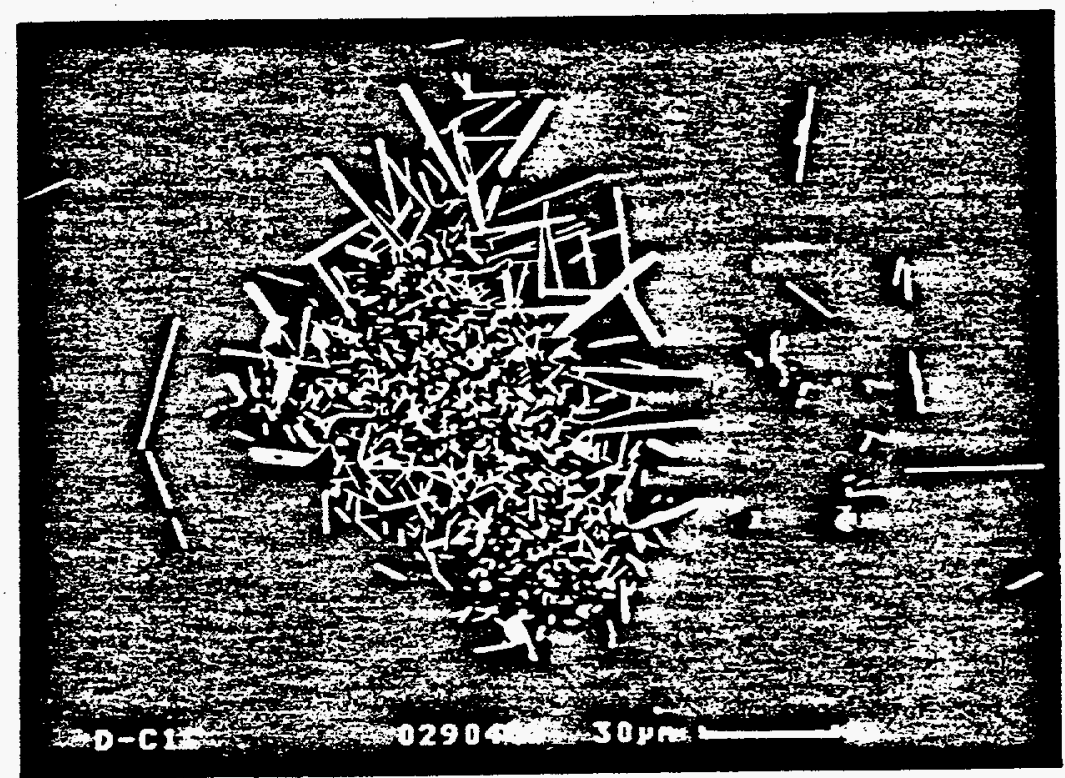

Figure 7-4: Glass D-Cl. Crystal Cluster. Normal Section (6-10 mm). Microscope Camscan 4-DV, BSE. 


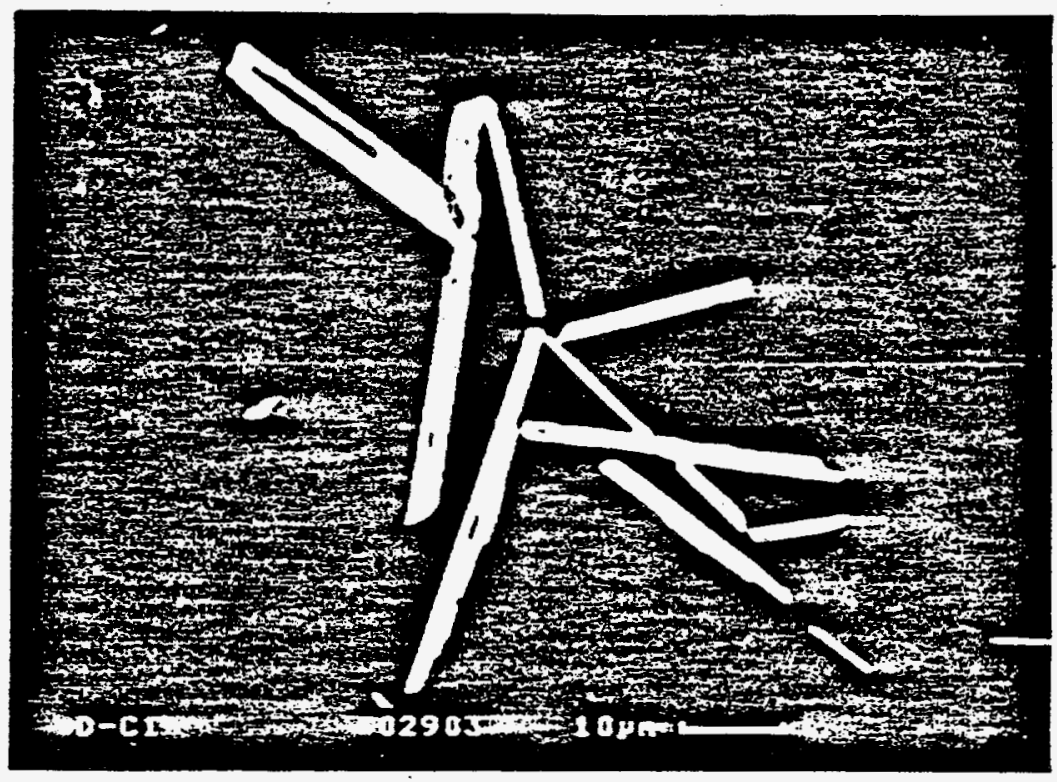

\section{Figure 7-5: Glass D-CI. Isolated Eskolaite Crystals with Marked Local Analysis. Normal Section (6-10 mm). Microscope Camscan 4-DV, BSE.}

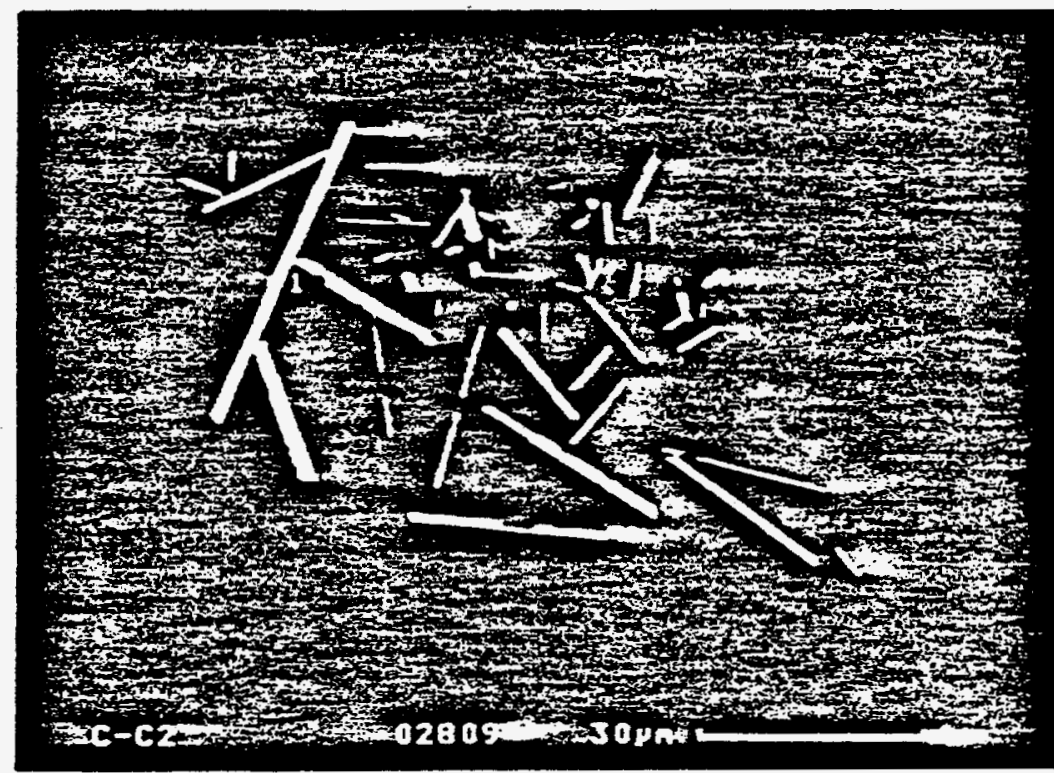

Figure 7-6: Glass C-C2. Crystal Cluster with Marked Local Analysis. Normal Section $(6-10 \mathrm{~mm})$. Microscope Camscan 4-DV, BSE. 


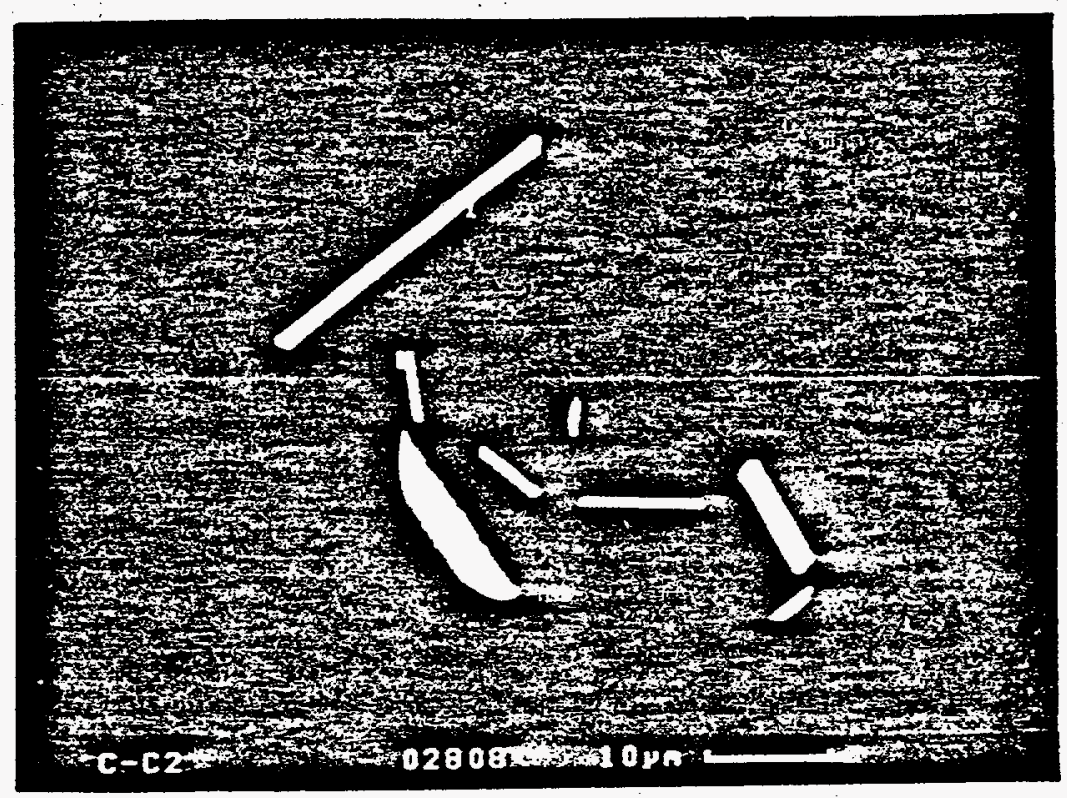

Figure 7-7: Glass C-C2. Isolated Eskolaite Crystals with Marked Local Analysis. Normal Section $(6-10 \mathrm{~mm})$. Microscope Camscan 4-DV, BSE.

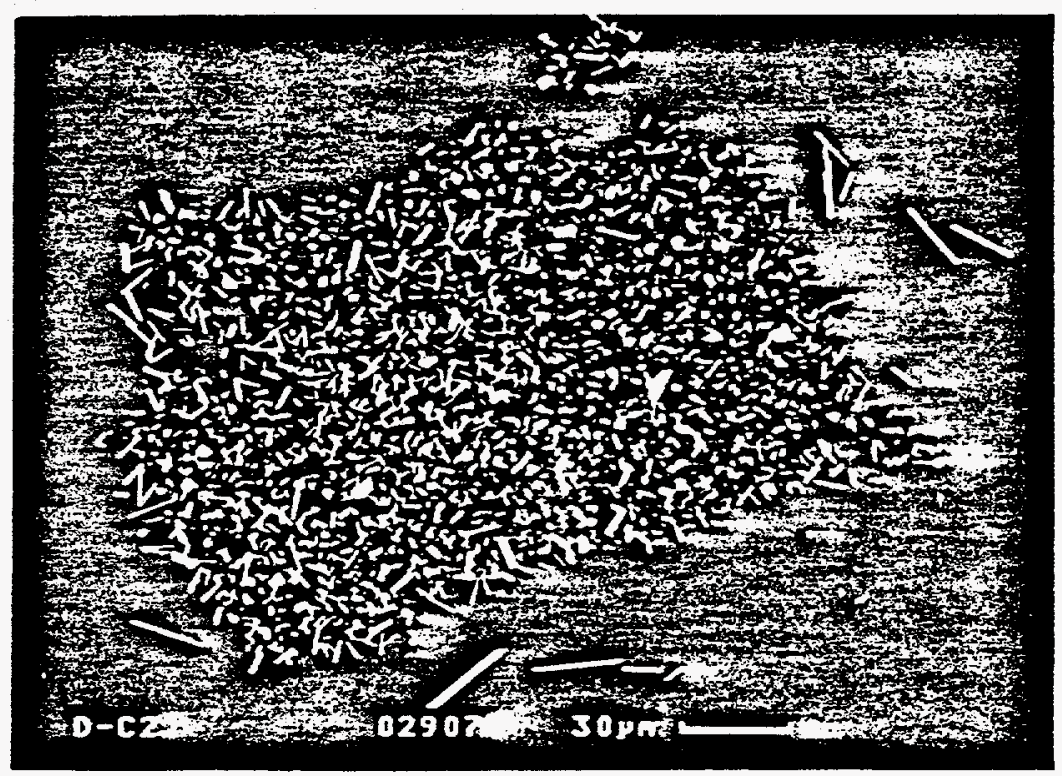

Figure 7-8: Glass D-C2. Recrystallized Grain Particle. Normal Section (6-10 mm). Microscope Camscan 4-DV, BSE. 


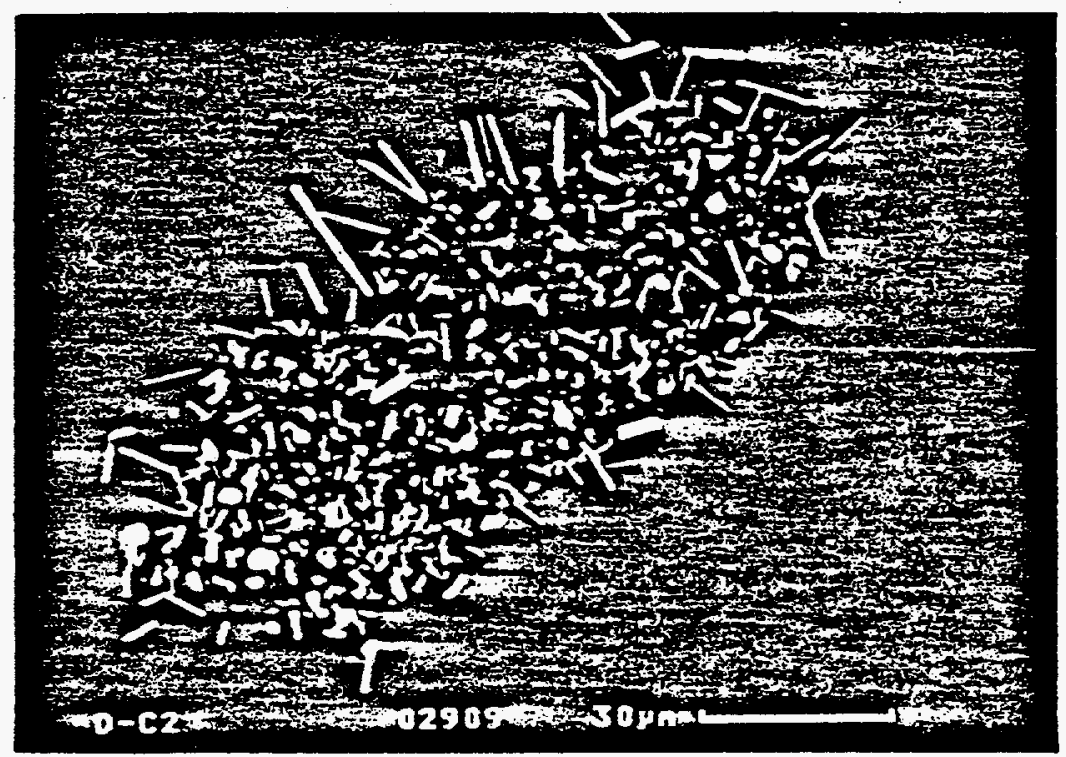

Figure 7-9: Glass D-C2. Recrystallized Grain Particle. Normal Section $(6-10 \mathrm{~mm})$. Microscope Camscan 4-DV, BSE.

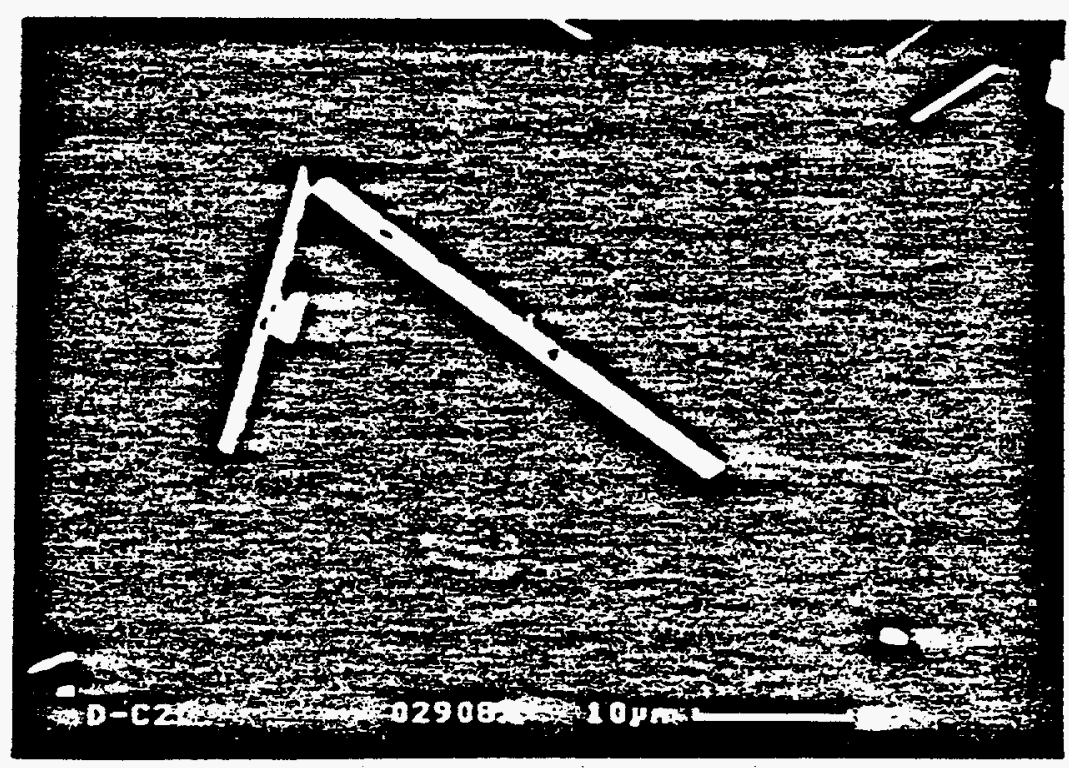

Figure 7-10: Glass D-C2. Isolated Eskolaite Crystals with Marked Local Analysis. Normal Section $(6-10 \mathrm{~mm})$. Microscope Camscan 4-DV, BSE. 


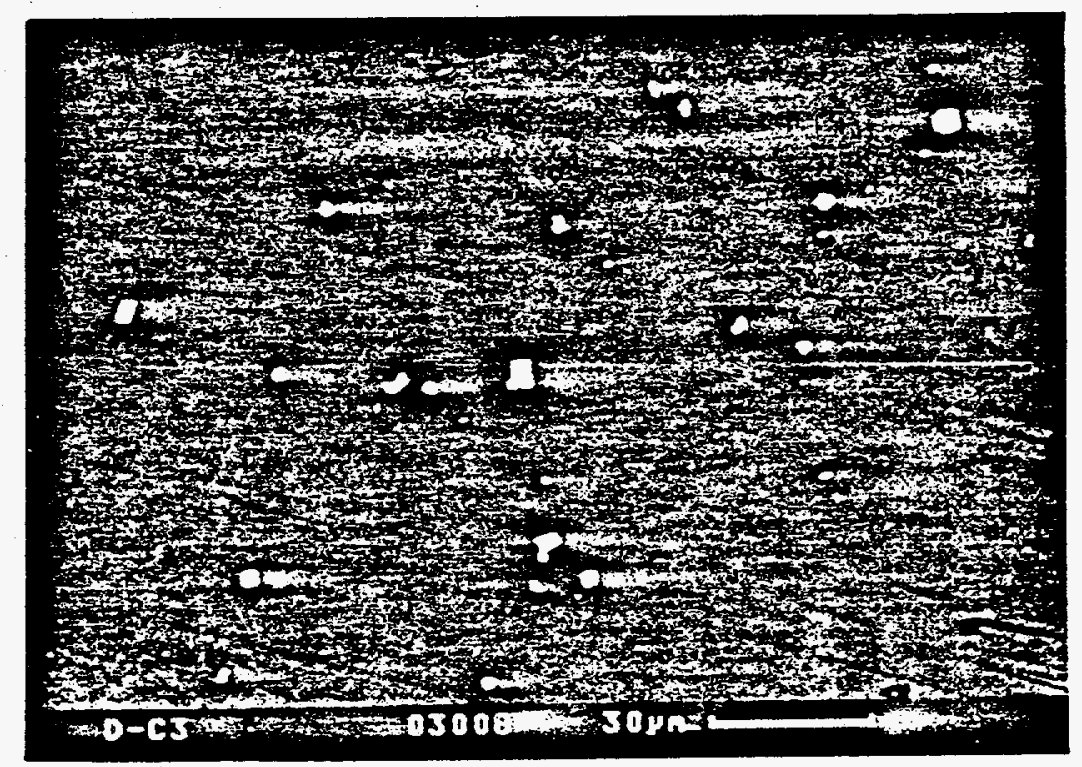

Figure 7-11: Glass D-C3. Spinel Phase Crystals in a Central Block Part (6-10 mm). Microscope Camscan 4-DV, BSE.

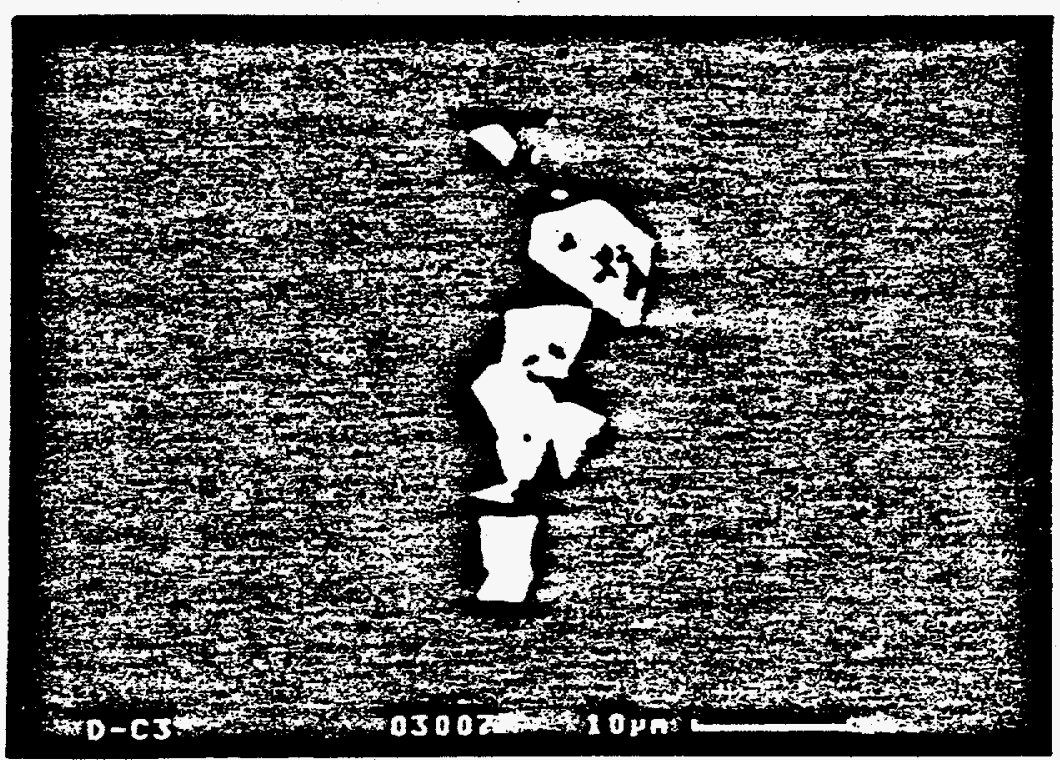

Figure 7-12: Glass D-C3. Spinel Phase Crystals in a Central Block Part with Marked Local Analys is (6-10 mm). Microscope Camscan 4-DV, BSE. 


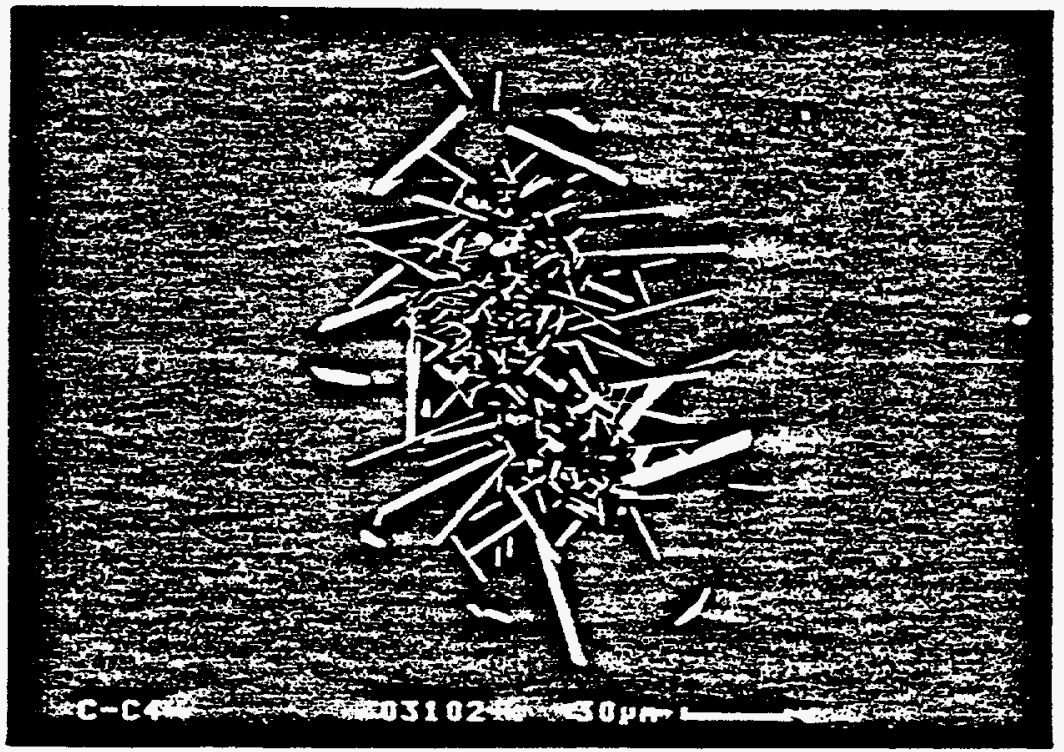

Figure 7-13: Glass C-C4. Crystal Cluster. Normal

Section (6-10 mm). Microscope Camscan 4-DV, BSE.

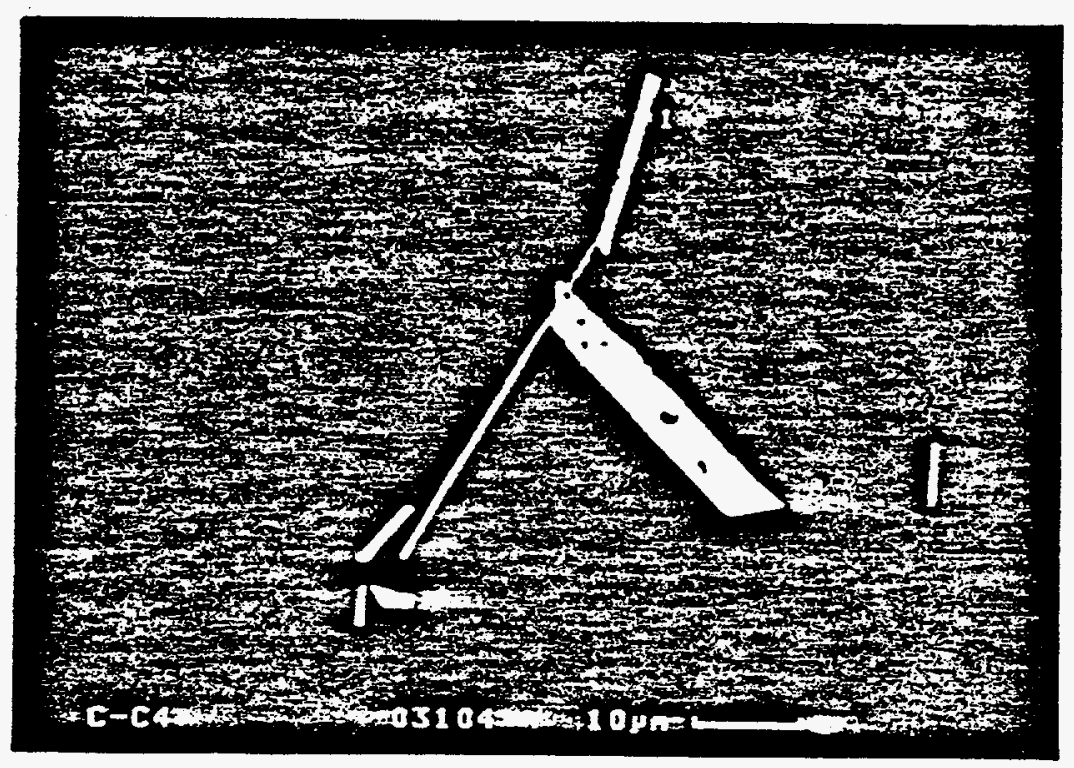

Figure 7-14: Glass C-C4. Isolated Eskolaite Crystals with Marked Local Analysis. Normal Section (6-10 mm). Microscope Camscan 4-DV, BSE. 


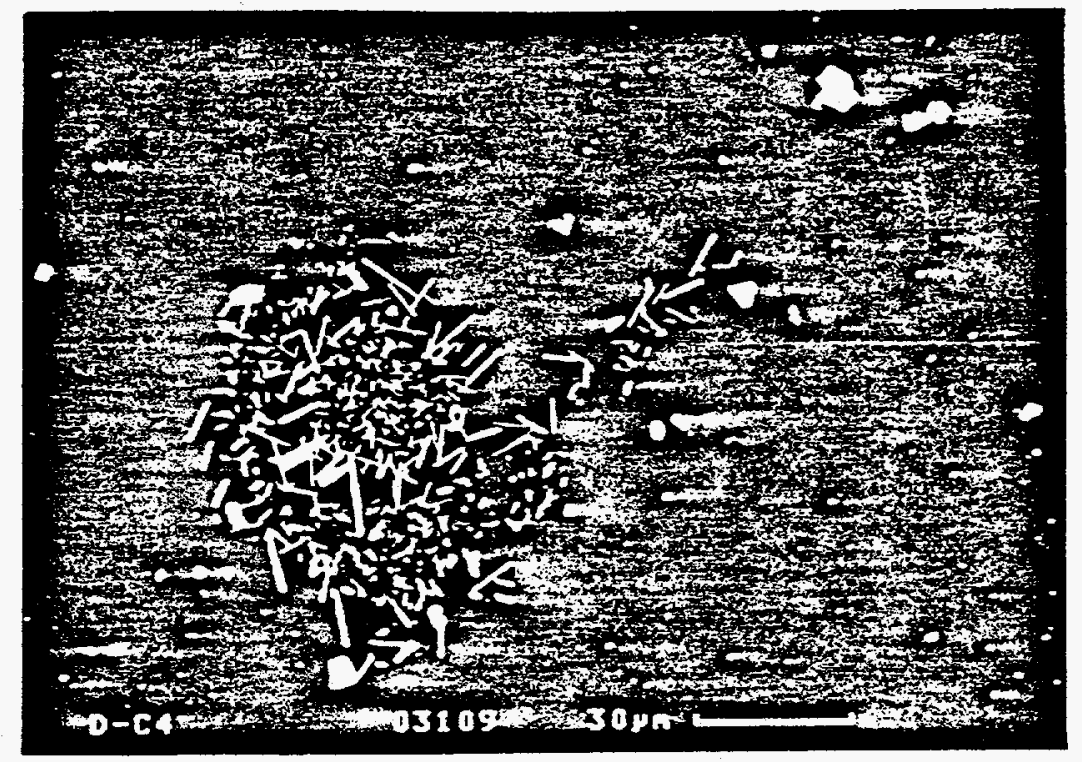

Figure 7-15: Glass D-C4. Eskolaite Crystal Cluster and Spinel Phase Crystals in a Central Block Part $(6-10 \mathrm{~mm})$. Microscope Camscan 4-DV, BSE.

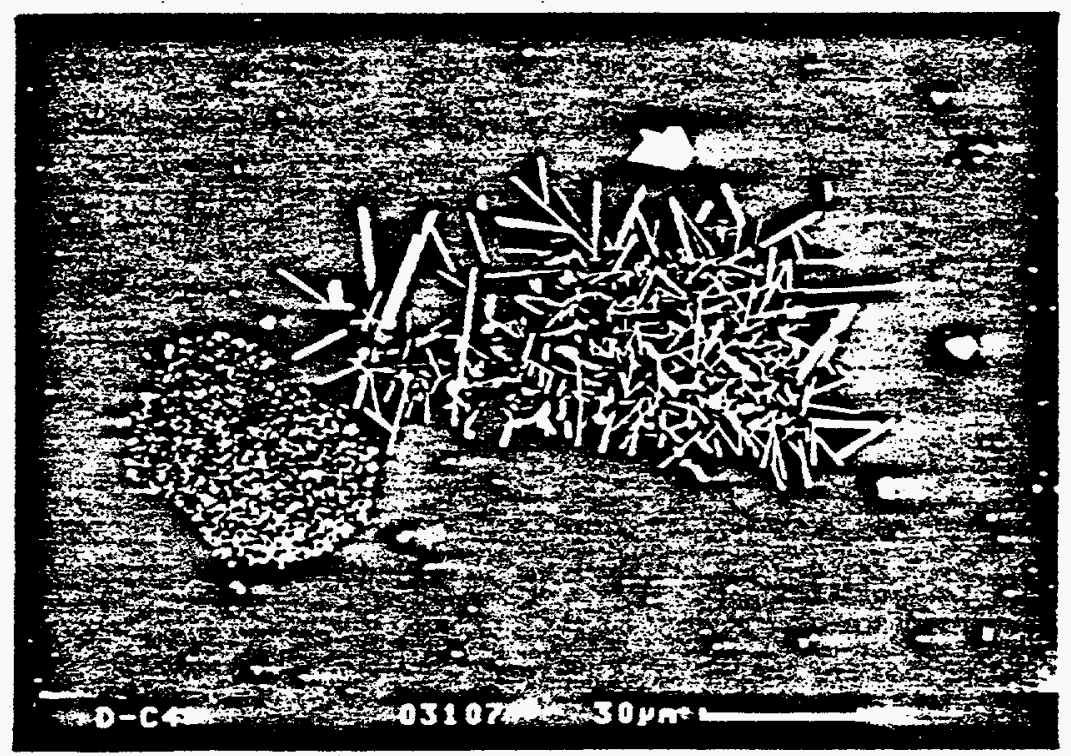

Figure 7-16: Glass D-C4. Grain Particle, Eskolaite Crystal Cluster and Isolated Spinel Phase Crystals in a Central Block Part (6-10. $\mathrm{mm})$. Microscope Camscan 4-DV, BSE. 


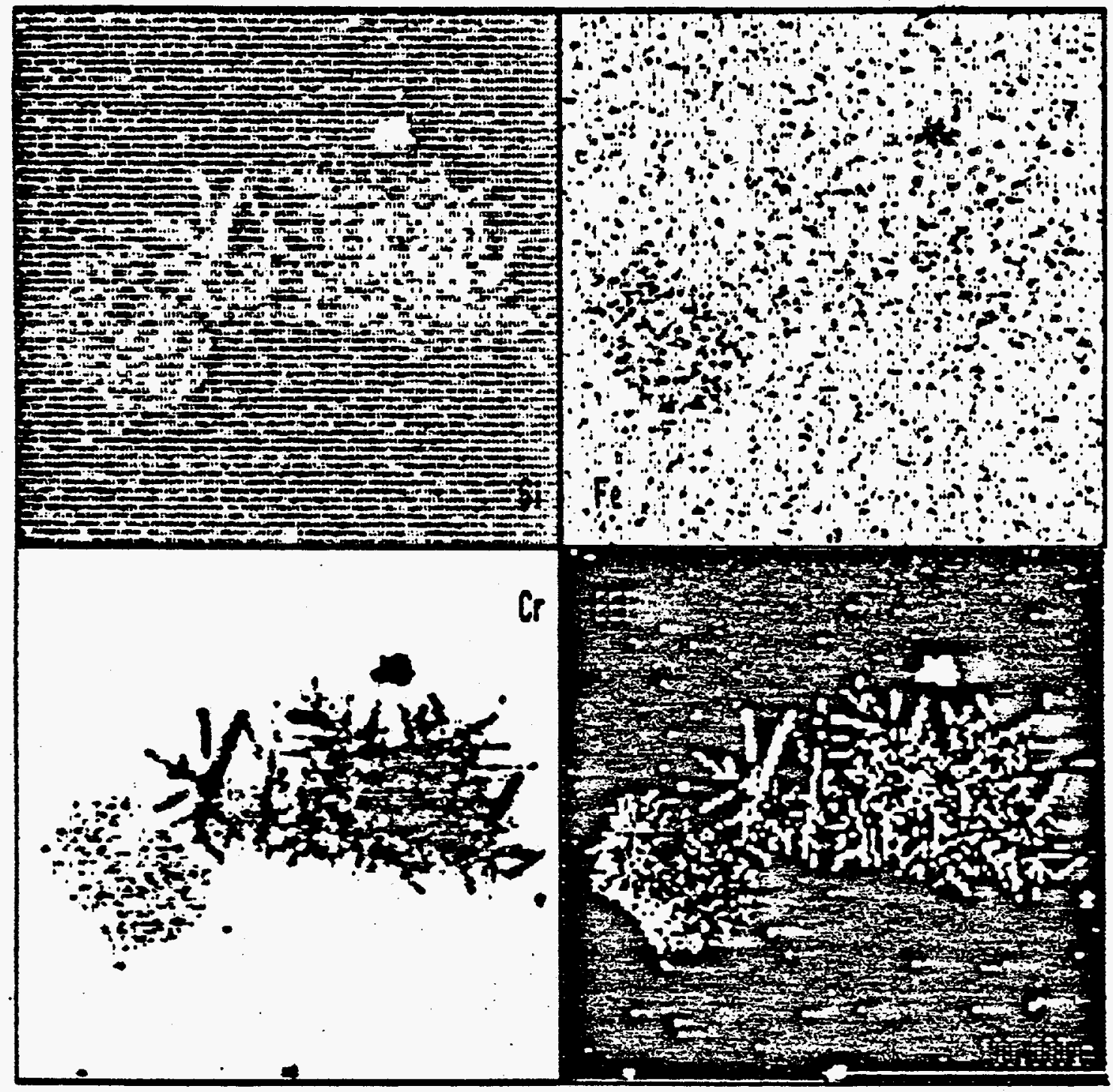

Figure 7-17: Glass D-C4. Grain Particle, Eskolaite Crystal Cluster and Isolated Spinel Phase Crystals. $X$-Ray Distribution of $C r, F e$ and $S i$ in the Area Given in Figure 7-16. Normal section (6-10 mm). Microscope Camscan 4-DV, MAPPING Programme. 


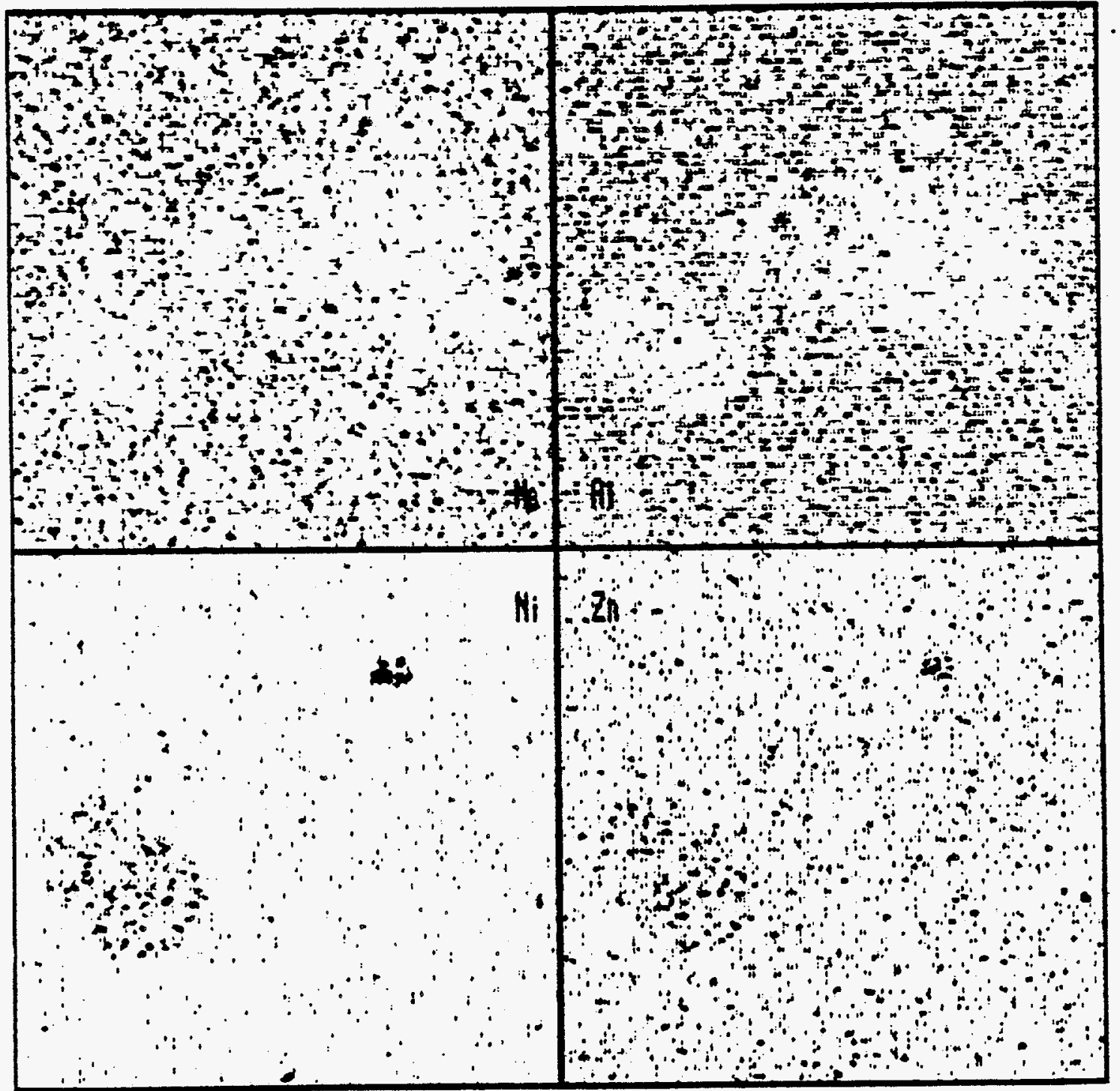

Figure 7-18: Glass D-C4. Grain Particle, Eskolaite Crystal Cluster and Isolated Spinel Phase crystals. $\mathrm{X}$-Ray Distribution of $\mathrm{Na}, \mathrm{Al}, \mathrm{Zn}$ and $\mathrm{Ni}$ in the Area Given in Figure 7-16. Normal section (6-10 $\mathrm{mm}$ ). Microscope Camscan 4-DV, MAPPING Programme. 


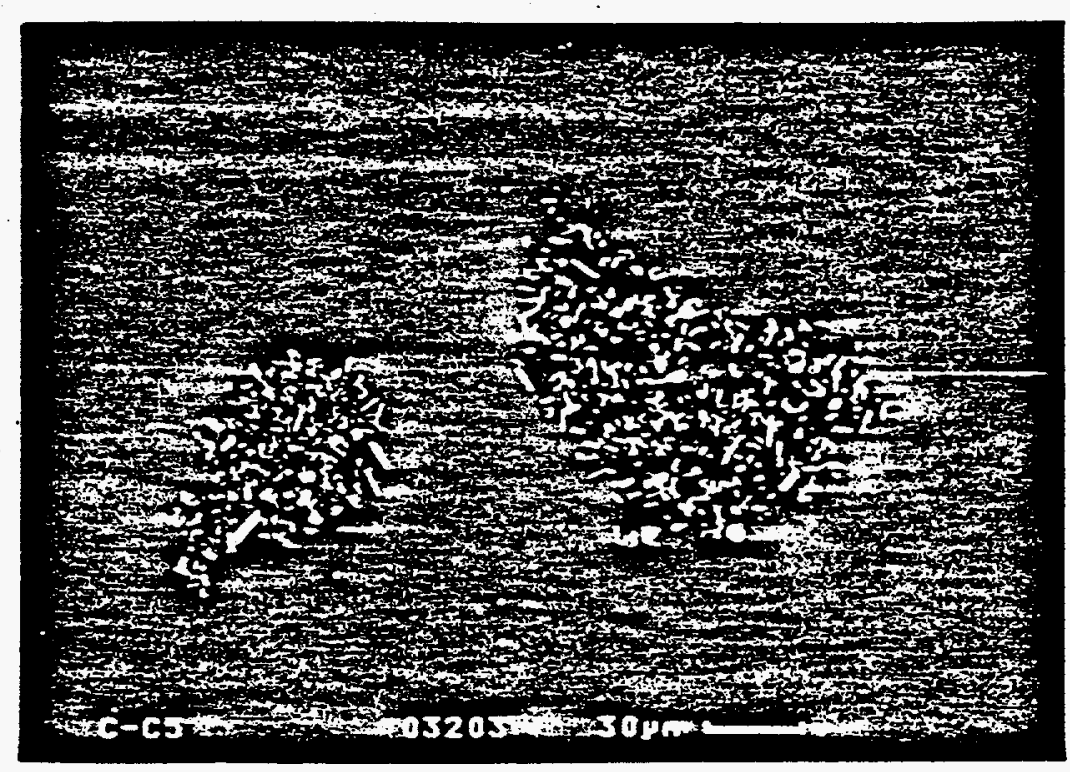

Figure 7-19: Glass C-C5. Grain Recrystallized Particles. Normal section $(6-10 \mathrm{~mm})$.

Microscope Camscan 4-DV, BSE.

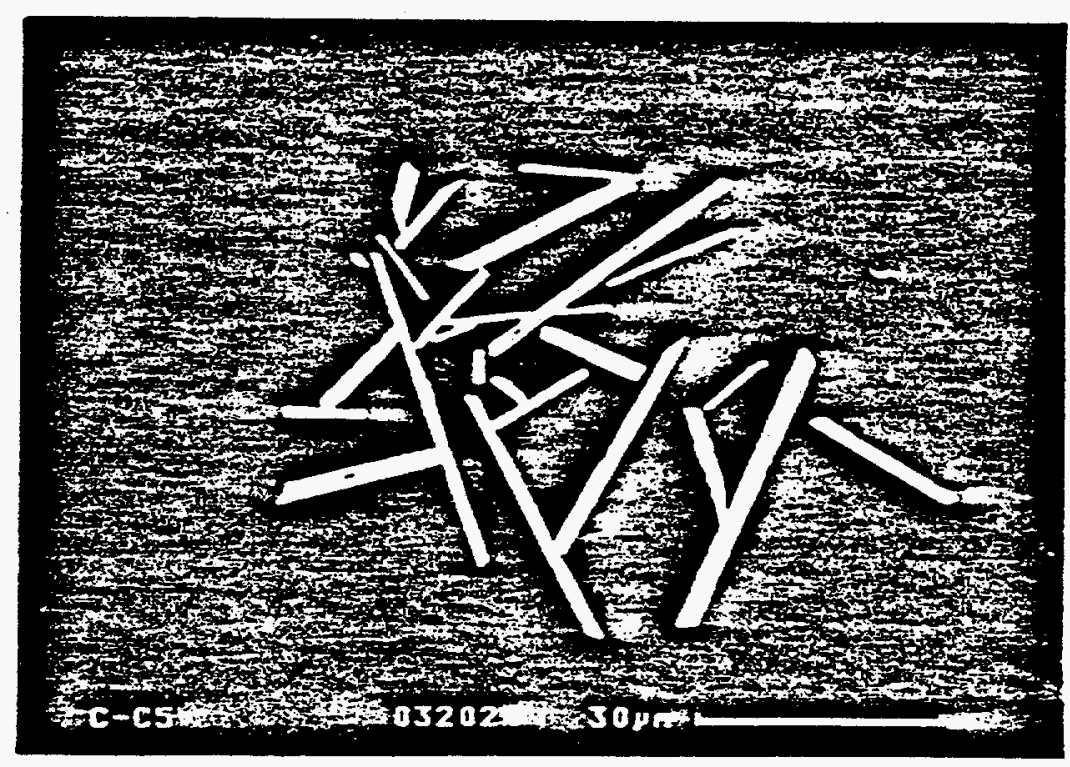

Figure 7-20: Glass C-C5. Crystal Cluster. Normal section $(6-10 \mathrm{~mm})$. Microscope Camscan 4-DV, BSE. 


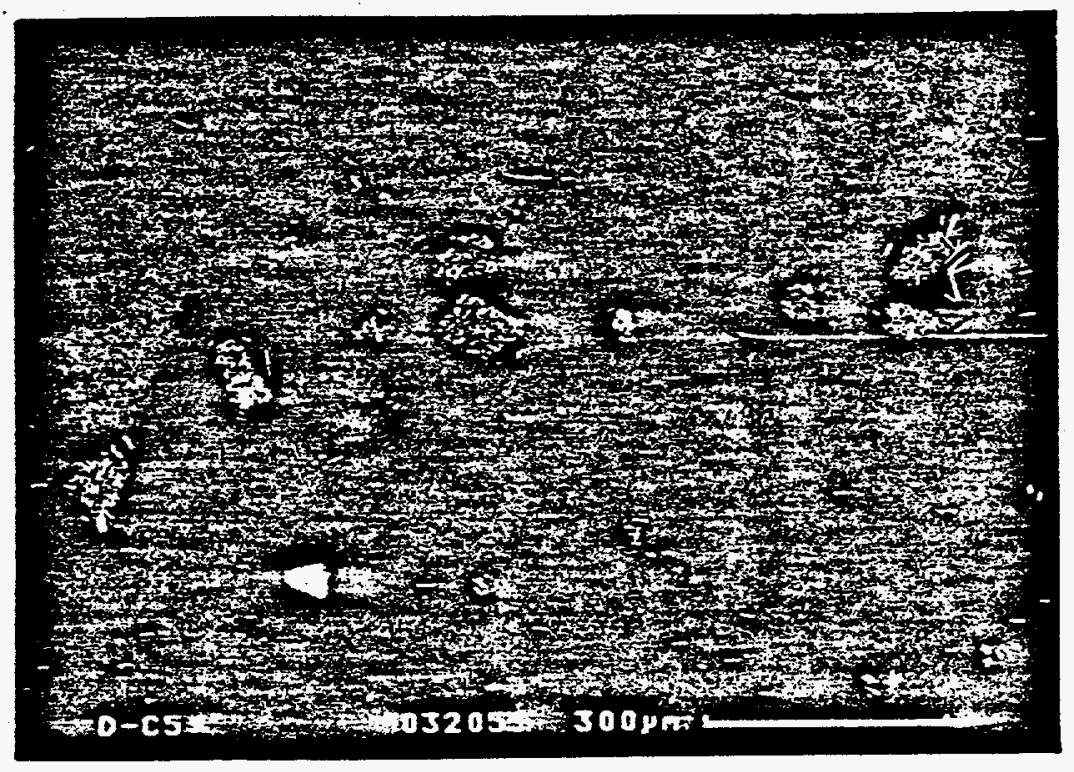

Figure 7-21: Glass D-C5. Detail Section View in a Central Block Part (6-10 mm). Microscope Camscan 4-DV, BSE.

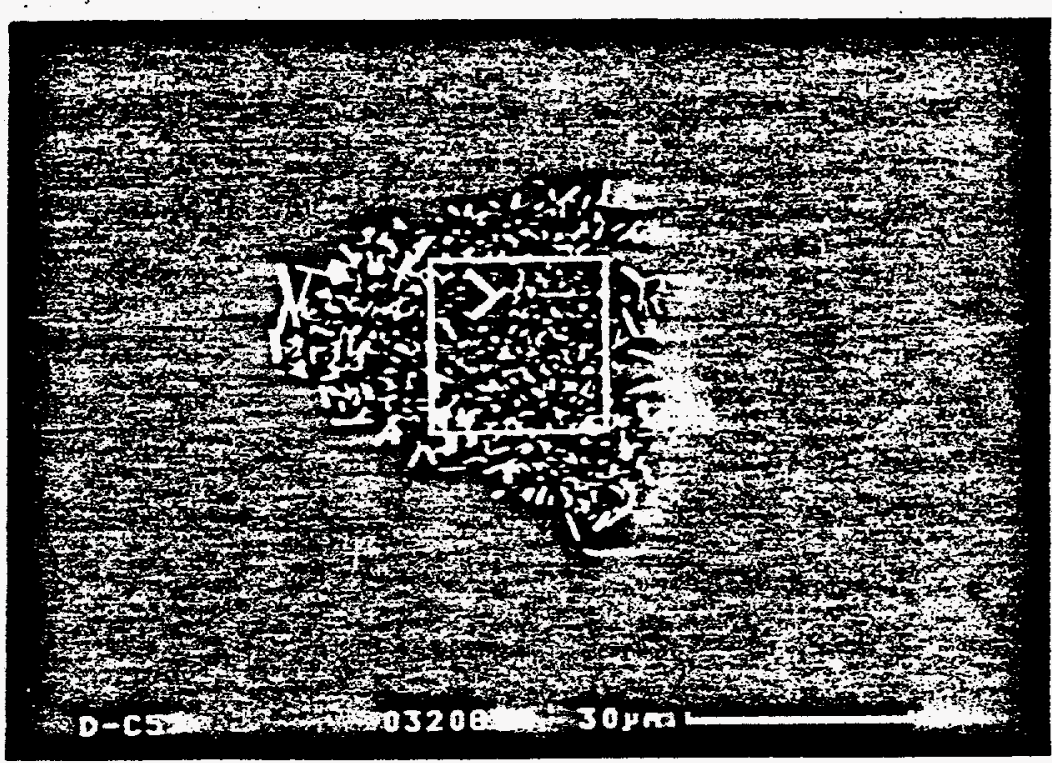

Figure 7-22: Glass D-C5. Recrystallized Grain Particle with Marked Local Analysis. Normal Section (6-10 mm). Microscope Camscan 4-DV, BSE. 


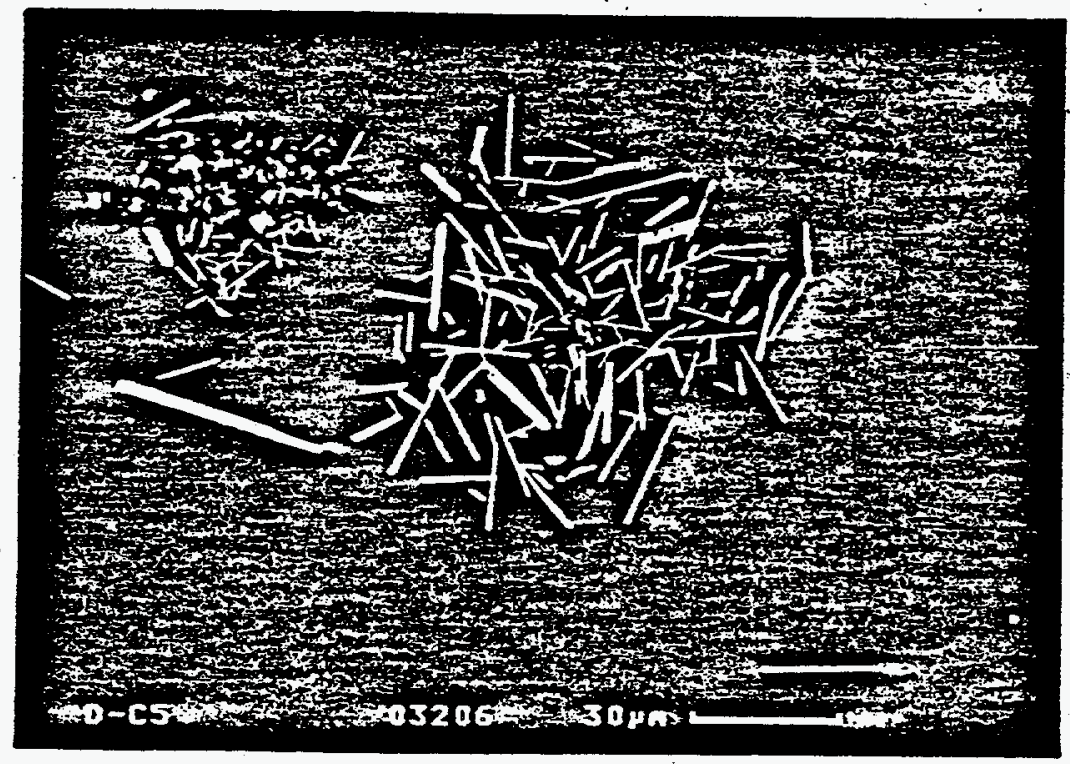

Figure 7-23: Glass D-C5. Crystal Cluster.

Normal Section $(6-10 \mathrm{~mm})$.

Microscope Camscan 4-DV, BSE.

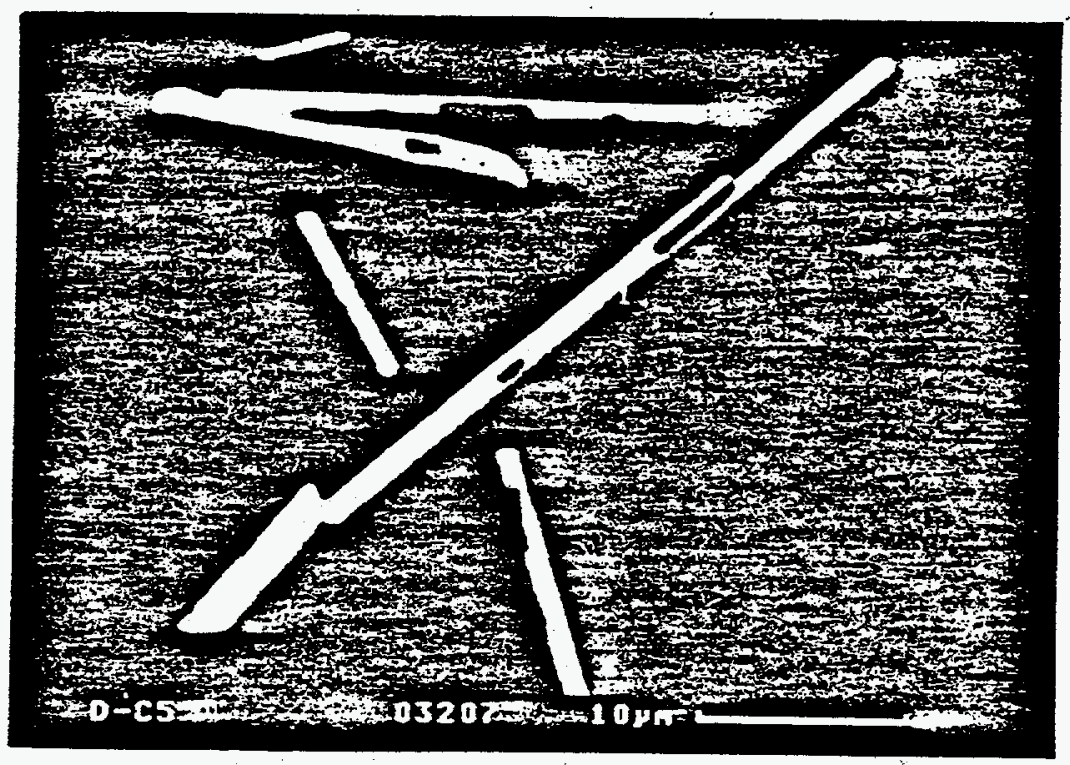

Figure 7-24: Glass D-C5. Isolated Eskolaite Crystals with Marked Local Analysis. Normal Section $(6-10 \mathrm{~mm})$. Microscope Camscan 4-DV, BSE. 
Table 7-9: Survey of Analyses Results of the Glass Sample C-C1 (IINK AN 10000, Expressed in wt. \%)

\begin{tabular}{|c|c|c|c|c|}
\hline Area & $\begin{array}{c}\text { Crystal in } \\
\text { cluster }\end{array}$ & $\begin{array}{l}\text { Isolated } \\
\text { Crystal }\end{array}$ & \multicolumn{2}{|c|}{ Matrix } \\
\hline $\mathbf{n}$ & 1 & 1 & \multicolumn{2}{|c|}{5} \\
\hline & $x$ & $x$ & $\overline{\mathbf{x}}$ & $\boldsymbol{\sigma}$ \\
\hline $\begin{array}{l}\mathrm{Na}_{2} \mathrm{O} \\
\mathrm{CaO} \\
\mathrm{Al}_{2} \mathrm{O}_{3} \\
\mathrm{SiO}_{2} \\
\mathrm{ZrO}_{2} \\
\mathrm{Fe}_{2} \mathrm{O}_{3} \\
\mathrm{Cr}_{2} \mathrm{O}_{3} \\
\mathrm{MnO}_{2} \\
\mathrm{NiO} \\
\mathrm{ZnO}\end{array}$ & $\begin{array}{c}1.2 \\
a \\
0.78 \\
1.2 \\
a \\
6.6 \\
85.0 \\
a \\
a \\
a\end{array}$ & $\begin{array}{c}3.8 \\
0.21 \\
2.9 \\
8.9 \\
a \\
5.5 \\
84.0 \\
a \\
a \\
a\end{array}$ & $\begin{array}{c}12.4 \\
0.30 \\
10.9 \\
52.2 \\
3.0 \\
3.4 \\
0.76 \\
0.71 \\
\text { a } \\
\text { a }\end{array}$ & $\begin{array}{l}0.2 \\
0.04 \\
0.3 \\
1.6 \\
0.2 \\
0.2 \\
0.13 \\
0.09 \\
\text { a } \\
\text { a }\end{array}$ \\
\hline sum & 94.78 & 105.31 & 83.67 & \\
\hline
\end{tabular}

Notes: $n$... number of independent analyses

$x$... measured value $\overline{\mathbf{x}}$.... arithmetical mean

$\sigma \ldots$ standard deviation $a$... value less than 20

Table 7-10: Survey of Analyses Results of the Glass Sample D-Cl (IINK AN 10000, Expressed in wt. f)

\begin{tabular}{|c|c|c|c|c|}
\hline Area & $\begin{array}{c}\text { Crystal in } \\
\text { Cluster }\end{array}$ & $\begin{array}{c}\text { Isolated } \\
\text { Crystal }\end{array}$ & \multicolumn{2}{|c|}{ Matrix } \\
\hline $\mathrm{n}$ & 1 & 1 & \multicolumn{2}{|c|}{5} \\
\hline & $\mathrm{x}$ & $\mathrm{x}$ & $\overline{\mathrm{x}}$ & $\sigma$ \\
\hline $\mathrm{Na}_{2} \mathrm{O}$ & 5.5 & 7.3 & 13.2 & 0.4 \\
$\mathrm{CaO}_{\mathrm{Al} \mathrm{O}_{3}}$ & 0.29 & 0.23 & 0.35 & 0.03 \\
$\mathrm{SiO}_{2}$ & 3.5 & 4.4 & 11.0 & 0.3 \\
$\mathrm{ZrO}_{2}$ & 12.3 & 17.0 & 52.3 & 1.1 \\
$\mathrm{Fe}_{2} \mathrm{O}_{3}$ & $\mathrm{a}$ & 0.91 & 3.0 & 0.2 \\
$\mathrm{Cr}_{2} \mathrm{O}_{3}$ & 5.6 & 5.8 & 3.6 & 0.2 \\
$\mathrm{MnO}_{2}$ & 69.0 & 62.3 & 0.55 & 0.10 \\
$\mathrm{NiO}^{2}$ & $\mathrm{a}$ & $\mathrm{a}$ & 0.69 & 0.13 \\
$\mathrm{ZnO}$ & $\mathrm{a}$ & $\mathrm{a}$ & $\mathrm{a}$ & $\mathrm{a}$ \\
\hline $\mathrm{Sum}$ & $\mathrm{a}$ & $\mathrm{a}$ & $\mathrm{a}$ & $\mathrm{a}$ \\
\hline
\end{tabular}

See Table 7-9 for notes. 
Table 7-11: Survey of Analyses Results of the Glass Sample C-C2 (IINK AN 10000, Expressed in wt. *)

\begin{tabular}{|c|c|c|c|c|}
\hline Area & $\begin{array}{c}\text { Crystal in } \\
\text { Cluster }\end{array}$ & $\begin{array}{c}\text { Isolated } \\
\text { Crystal }\end{array}$ & \multicolumn{2}{|c|}{ Matrix } \\
\hline $\mathrm{n}$ & 1 & 1 & \multicolumn{2}{|c|}{4} \\
\hline & $\mathbf{x}$ & $\mathrm{x}$ & $\overline{\mathbf{x}}$ & 0 \\
\hline $\mathrm{Na}_{2} \mathrm{O}$ & 2.5 & 4.7 & 12.6 & 0.7 \\
$\mathrm{CaO}_{\mathrm{Al} \mathrm{O}_{3}}$ & 0.19 & $\mathrm{a}$ & 0.35 & 0.09 \\
$\mathrm{SiO}_{2}$ & 2.2 & 3.1 & 10.7 & 0.5 \\
$\mathrm{ZrO}_{2}$ & 7.1 & 9.7 & 49.9 & 1.4 \\
$\mathrm{Fe}_{2} \mathrm{O}_{3}$ & 11.2 & 0.76 & 2.9 & 0.2 \\
$\mathrm{Cr}_{3} \mathrm{O}_{3}$ & 58.0 & 10.7 & 6.9 & 0.1 \\
$\mathrm{MnO}_{2}$ & 0.74 & 55.2 & 0.60 & 0.11 \\
$\mathrm{NiO}$ & $\mathrm{a}$ & $\mathrm{a}$ & 0.61 & 0.12 \\
$\mathrm{ZnO}^{n}$ & $\mathrm{a}$ & $\mathrm{a}$ & $\mathrm{a}$ & $\mathrm{a}$ \\
\hline $\mathrm{Sum}$ & 81.93 & $\mathrm{a}$ & $\mathrm{a}$ & $\mathrm{a}$ \\
\hline
\end{tabular}

See Table 7-9 for notes.

Table 7-12: Survey of Analyses Results of the Glass Sample D-C2 (IINK AN 10000, Expressed in wt. *)

\begin{tabular}{|c|c|c|c|c|}
\hline Area & crystal in & Isolated & \multicolumn{2}{|c|}{ Matrix } \\
\hline $\mathbf{n}$ & 1 & 1 & \multicolumn{2}{|c|}{7} \\
\hline & $x$ & $x$ & $\bar{x}$ & $\boldsymbol{\sigma}$ \\
\hline $\begin{array}{l}\mathrm{Na}_{2} \mathrm{O}^{\circ} \\
\mathrm{CaO} \\
\mathrm{Al}_{2} \mathrm{O}_{3} \\
\mathrm{SiO}_{2} \\
\mathrm{ZrO}_{2} \\
\mathrm{Fe}_{2} \mathrm{O}_{3} \\
\mathrm{Cr}_{2} \mathrm{O}_{3} \\
\mathrm{MnO}_{2} \\
\mathrm{NiO}^{2} \\
\mathrm{ZnO}\end{array}$ & $\begin{array}{c}6.2 \\
a \\
4.0 \\
14.8 \\
1.4 \\
16.0 \\
57.9 \\
a \\
a \\
a\end{array}$ & $\begin{array}{c}7.7 \\
a \\
4.6 \\
15.1 \\
1.2 \\
14.2 \\
57.9 \\
a \\
a \\
a\end{array}$ & $\begin{array}{c}13.6 \\
0.30 \\
11.4 \\
50.1 \\
3.1 \\
7.6 \\
0.53 \\
0.72 \\
a \\
a\end{array}$ & $\begin{array}{l}0.4 \\
0.08 \\
0.4 \\
0.7 \\
0.3 \\
0.2 \\
0.10 \\
0.12 \\
a \\
a\end{array}$ \\
\hline sum & 100.30 & 100.70 & 87.35 & \\
\hline
\end{tabular}

See Table 7-9 for notes. 
Table 7-13: Survey of Analyses Results of the Glass Samples C-c3 and D-C3 (LINK AN 10000, Expressed in wt. \&)

\begin{tabular}{|c|c|c|c|c|c|c|}
\hline Area & \multicolumn{2}{|c|}{$\begin{array}{c}c-c 3 \\
\text { Matrix }\end{array}$} & \multicolumn{2}{|c|}{$\begin{array}{c}D-C 3 \\
\text { Crystals }\end{array}$} & \multicolumn{2}{|c|}{$\begin{array}{c}D-C 3 \\
\text { Matrix }\end{array}$} \\
\hline $\mathbf{n}$ & \multicolumn{2}{|c|}{5} & \multicolumn{2}{|c|}{2} & \multicolumn{2}{|c|}{5} \\
\hline & $\overline{\mathbf{x}}$ & $\boldsymbol{\sigma}$ & $x$ & $x$ & $\overline{\mathbf{x}}$ & $\sigma$ \\
\hline $\begin{array}{l}\mathrm{Na}_{2} \mathrm{O} \\
\mathrm{CaO} \\
\mathrm{Al}_{2} \mathrm{O}_{3} \\
\mathrm{SiO}_{2} \\
\mathrm{ZrO}_{2} \\
\mathrm{Fe}_{2} \mathrm{O}_{3} \\
\mathrm{Cr}_{2} \mathrm{O}_{3} \\
\mathrm{MnO}_{2} \\
\mathrm{NiO} \\
\mathrm{ZnO}\end{array}$ & $\begin{array}{c}12.8 \\
0.36 \\
11.9 \\
53.7 \\
2.8 \\
3.6 \\
0.93 \\
2.7 \\
\text { a } \\
\text { a }\end{array}$ & $\begin{array}{l}0.2 \\
0.06 \\
0.2 \\
0.5 \\
0.3 \\
0.2 \\
0.05 \\
0.1\end{array}$ & $\begin{array}{c}8.5 \\
a \\
4.1 \\
11.5 \\
0.90 \\
7.1 \\
51.9 \\
17.2 \\
1.6 \\
5.5\end{array}$ & $\begin{array}{c}10.7 \\
.2 \\
6.2 \\
22.8 \\
1.1 \\
6.6 \\
39.1 \\
13.5 \\
1.4 \\
4.4\end{array}$ & $\begin{array}{l}13.4 \\
0.32 \\
11.8 \\
52.6 \\
3.3 \\
3.6 \\
0.77 \\
2.6 \\
\text { a } \\
\text { a }\end{array}$ & $\begin{array}{l}0.9 \\
0.10 \\
0.3 \\
0.5 \\
0.3 \\
0.2 \\
0.05 \\
0.20\end{array}$ \\
\hline sum & 88.79 & & 108.30 & 105.8 & 88.39 & - \\
\hline
\end{tabular}

See Table 7-9 for notes.

Table 7-14: Survey of Analyses Results of the Glass Sample C-C4. (IINK AN 10000, Expressed in wt. $\%$ )

\begin{tabular}{|c|c|c|c|c|}
\hline Area & $\begin{array}{c}\text { Crystal in } \\
\text { cluster }\end{array}$ & $\begin{array}{r}\text { Isolated } \\
\text { Crystal }\end{array}$ & \multicolumn{2}{|c|}{ Matrix } \\
\hline $\mathbf{n}$ & 1 & 1 & \multicolumn{2}{|c|}{5} \\
\hline & $x$ & $x$ & $\overline{\mathbf{x}}$ & $\sigma$ \\
\hline $\begin{array}{l}\mathrm{Na}_{2} \mathrm{O} \\
\mathrm{CaO} \\
\mathrm{Al}_{2} \mathrm{O}_{3} \\
\mathrm{SiO}_{2} \\
\mathrm{ZrO}_{2} \\
\mathrm{Fe}_{2} \mathrm{O}_{3} \\
\mathrm{Cr}_{2} \mathrm{O}_{3} \\
\mathrm{MnO}_{2} \\
\mathrm{NiO} \\
\mathrm{ZnO}\end{array}$ & $\begin{array}{c}11.4 \\
0.18 \\
7.1 \\
28.2 \\
1.6 \\
4.7 \\
44.7 \\
0.72 \\
1.2 \\
a\end{array}$ & $\begin{array}{c}11.6 \\
a \\
7.8 \\
27.9 \\
2.0 \\
5.1 \\
45.3 \\
a \\
0.60 \\
a\end{array}$ & $\begin{array}{c}12.8 \\
0.35 \\
11.5 \\
52.1 \\
3.3 \\
3.3 \\
0.79 \\
0.75 \\
1.0 \\
a\end{array}$ & $\begin{array}{l}0.4 \\
0.06 \\
0.3 \\
0.5 \\
0.3 \\
0.1 \\
0.07 \\
0.16 \\
0.1 \\
a\end{array}$ \\
\hline sum & 99.80 & 100.30 & 85.89 & \\
\hline
\end{tabular}

See Table 7-9 for notes. 
Table 7-15: Survey of Analyses Results of the Glass Sample D-C4 (IINK AN 10000, Expressed in wt. t)

\begin{tabular}{|c|c|c|c|c|c|}
\hline Area & $\begin{array}{l}\text { Grain } \\
\text { Particle }\end{array}$ & $\begin{array}{r}\text { Isolated } \\
\text { Crystal }\end{array}$ & $\begin{array}{l}\text { Crystal in } \\
\text { Cluster }\end{array}$ & \multicolumn{2}{|c|}{ Matrix } \\
\hline $\mathbf{n}$ & 1 & 1 & 1 & \multicolumn{2}{|c|}{5} \\
\hline & $\mathbf{x}$ & $x$ & $\mathbf{x}$ & $\overline{\mathbf{x}}$ & 0 \\
\hline $\begin{array}{l}\mathrm{Na}_{2} \mathrm{O} \\
\mathrm{CaO} \\
\mathrm{Al}_{2} \mathrm{O}_{3} \\
\mathrm{SiO}_{2} \\
\mathrm{ZrO}_{2} \\
\mathrm{Fe}_{2} \mathrm{O}_{3} \\
\mathrm{Cr}_{2} \mathrm{O}_{3} \\
\mathrm{MnO}_{2} \\
\mathrm{NiO} \\
\mathrm{ZnO}\end{array}$ & $\begin{array}{c}12.8 \\
0.20 \\
8.4 \\
36.6 \\
1.9 \\
6.2 \\
21.9 \\
2.0 \\
6.3 \\
2.4\end{array}$ & $\begin{array}{c}6.0 \\
a \\
2.3 \\
6.1 \\
a \\
10.1 \\
57.4 \\
5.1 \\
14.0 \\
5.8\end{array}$ & $\begin{array}{c}5.9 \\
a \\
4.0 \\
14.2 \\
1.0 \\
5.5 \\
70.0 \\
a \\
0.98 \\
a\end{array}$ & $\begin{array}{c}12.7 \\
0.41 \\
11.5 \\
52.7 \\
3.4 \\
3.5 \\
0.61 \\
0.81 \\
1.0 \\
a\end{array}$ & $\begin{array}{l}0.7 \\
0.10 \\
0.2 \\
0.6 \\
0.4 \\
0.3 \\
0.14 \\
0.09 \\
0.2 \\
a\end{array}$ \\
\hline Sum & 98.70 & 106.8 & 101.58 & 86.63 & \\
\hline
\end{tabular}

See Table 7-9 for notes.

Table 7-16: Survey of Analyses Results of the Glass Sample $\dot{C}-c 5$ (IINK AN 10000, Expressed in wt. \%)

\begin{tabular}{|l|c|c|c|}
\hline Area & $\begin{array}{c}\text { Crystal in } \\
\text { Cluster }\end{array}$ & \multicolumn{2}{|c|}{ Matrix } \\
\hline$n$ & 1 & \multicolumn{2}{|c|}{5} \\
\hline & $\dot{x}$ & $\bar{x}$ & 0 \\
\hline $\mathrm{Na}_{2} \mathrm{O}$ & 4.4 & 12.6 & 0.4 \\
$\mathrm{CaO}_{\mathrm{Al} \mathrm{O}_{3}}$ & 0.23 & 0.39 & 0.04 \\
$\mathrm{ZrO}_{2}$ & 3.1 & 12.1 & 0.3 \\
$\mathrm{Fe}_{2} \mathrm{O}_{3}$ & 1.4 & 6.4 & 0.3 \\
$\mathrm{Cr}_{2} \mathrm{O}_{3}$ & 5.3 & 3.7 & 0.2 \\
$\mathrm{MnO}_{2}$ & 77.8 & 0.83 & 0.02 \\
$\mathrm{NiO}$ & $\mathrm{a}$ & 0.75 & 0.12 \\
$\mathrm{ZnO}$ & $\mathrm{a}$ & $\mathrm{a}$ & $\mathrm{a}$ \\
\hline $\mathrm{Sum}$ & $\mathrm{a}$ & $\mathrm{a}$ & $\mathrm{a}$ \\
\hline
\end{tabular}

See Table 7-9 for notes. 
Table 7-17: Survey of Analyses Results of the Glass Sample D-C5 (IINK AN 10000, Expressed in wt. i)

\begin{tabular}{|c|c|c|c|c|c|}
\hline Area & Grain & Isolated & Crystal in & \multicolumn{2}{|c|}{ Matrix } \\
\hline $\mathbf{n}$ & 1 & 1 & 1 & \multicolumn{2}{|c|}{5} \\
\hline & $\mathbf{x}$ & $\mathbf{x}$ & $\mathbf{x}$ & $\overline{\mathbf{x}}$ & $\boldsymbol{\sigma}$ \\
\hline $\begin{array}{l}\mathrm{Na}_{2} \mathrm{O} \\
\mathrm{CaO} \\
\mathrm{Al}_{2} \mathrm{O}_{3} \\
\mathrm{SiO}_{2} \\
\mathrm{ZrO}_{2} \\
\mathrm{Fe}_{2} \mathrm{O}_{3} \\
\mathrm{Cr}_{2} \mathrm{O}_{3} \\
\mathrm{MnO}_{2} \\
\mathrm{NiO}_{2} \\
\mathrm{ZnO}\end{array}$ & $\begin{array}{c}10.3 \\
0.22 \\
7.1 \\
30.2 \\
4.1 \\
4.8 \\
43.0 \\
0.67 \\
a \\
a\end{array}$ & $\begin{array}{c}5.5 \\
a \\
4.3 \\
14.9 \\
2.1 \\
7.1 \\
64.4 \\
a \\
0.68 \\
a\end{array}$ & $\begin{array}{c}5.5 \\
a \\
3.0 \\
12.1 \\
0.95 \\
2.0 \\
81.2 \\
a \\
a \\
a\end{array}$ & $\begin{array}{c}12.8 \\
0.37 \\
11.6 \\
53.3 \\
6.3 \\
3.5 \\
0.64 \\
0.74 \\
a \\
a\end{array}$ & $\begin{array}{l}0.7 \\
0.06 \\
0.3 \\
0.7 \\
0.3 \\
0.2 \\
0.08 \\
0.18 \\
a \\
a\end{array}$ \\
\hline sum & 100.39 & 98.98 & 104.75 & 89.25 & \\
\hline
\end{tabular}

See Table 7-9 for notes.

Characterization of series $\mathbf{C}$ glasses by optical microscopy

Samples of glasses of series $C$ were cut from parts of blocks, namely from the central parts not affected by the surface. Thin sections were prepared in petroleum and microscopic examination was performed using image analysis system Lucia for evaluation of size distributions.

The results are shown in Figures 7-25 to 7-33 and in Table 7-18. The results resemble, in general, the crystallinity of Glasses 1 and 2 described in Chapter 4, esp. due to the presence of $\mathrm{Cr}_{2} \mathrm{O}_{3}$.

Glass C-C1 (Figure 7-25)

Agglomerates of eskolaite crystals $\left(\mathrm{Cr}_{2} \mathrm{O}_{3}\right)$ are embedded in the glass matrix as well as rare individual crystals of the same substance. The size of the agglomerates indicates that they originate from the particles of chromium hydroxide used for glass melting. The size of eskolaite thin plates is comparable with the above mentioned glasses 1 and 2 . The crystals exhibit brown 
color, presumably due to the presence of $\mathrm{Fe}_{2} \mathrm{O}_{3}$ in solid solution with eskolaite. In the center of the agglomerates greenish colour can be observed indicating lower content of $\mathrm{Fe}_{2} \mathrm{O}_{3}$ supplied from the infiltrating melt.

Note: small dark points in the Figures are relicts of the polymer used for thin section preparation and therefore, they are not considered in the evaluations.

Glass D-C1 (Figure 7-26)

The agglomerates of eskolaite are composed of brown crystals which are larger in size than in C-Cl. Individual,isolated hexagonal plates of the same color also have larger dimensions and their number per unit volume is higher than in C-cl. Unidirectional orientation of individual eskolaite crystals can be seen in the lower part of Figure 7-26 (cross sections of plates are visible as short lines).

Glass C-C2 (Figure 7-27)

Brown agglomerates as well as individual crystals of eskolaite are present, the latter being more numerous in comparison with $\mathrm{C}-\mathrm{Cl}$. The area fraction of individual crystals is negligible compared to the area fraction of agglomerates.

Glass D-C2 (Flgure 7-28)

Agglomerates of large eskolaite crystals indicate the growth of crystals from the infiltrating melt. Some agglomerates are composed of small crystals in the center whereas large crystals appear on the periphery. The color of crystals is brown. Individual crystals of eskolaite are more numerous and larger compared to C-C2. Preferred orientation of individual crystals is apparent in Figure 7-28.

Glass C-C3

No crystalline phase has been found.

Glass D-C3 (Figure 7-29)

In contrast to the precedent samples eskolaite crystals were not found. Only small crystals of cubic symmetry are present with mean diameter of about 1 micron (see the size distribution in 
Table 7-18). The crystals are dark, mostly non-transparent, not exhibiting birefringence, which indicates to the expected spinel phase.

Glass C-C4 (Figure 7-30)

The sample contains agglomerates as well as rare individual crystals of eskolaite exhibiting brown colour.

Glass D-C4 (Figure 7-31)

Agglomerates of eskolaite are present, individual crystals of eskolaite are less numerous and colored brown. Furthermore, numerous crystals of a cubic, presumably spinel phase are embedded in the glass. The size distribution of the latter crystals is shown in Table 7-18.

Glass C-C5 (Figure 7-32)

Brown agglomerates of eskolaite are present with only rare individual crystals of the same substance. Small dark points which are artefacts from the polymer were eliminated in Figure 7-32 using the method of image analysis. Therefore, the background is white in Figure 7-32 and only eskolaite crystals are visible. Voluminous agglomerates composed of large eskolaite crystals are apparent in the Figure.

Glass D-C5 (Figure 7-33)

Agglomerates of brown eskolaite crystals are present as well as individual crystals exhibiting larger size (compared to C-C5) and preferred orientation. Also the concentration of individual crystals is higher than in C-C5. A fine-grained agglomerate and an agglomerate composed of larger crystals are shown in Figure 7-33. 
Table 7-18: Size Distribution of the spinel Phase in a) D-C3 and

b) $D-C 4$

a) D-C3

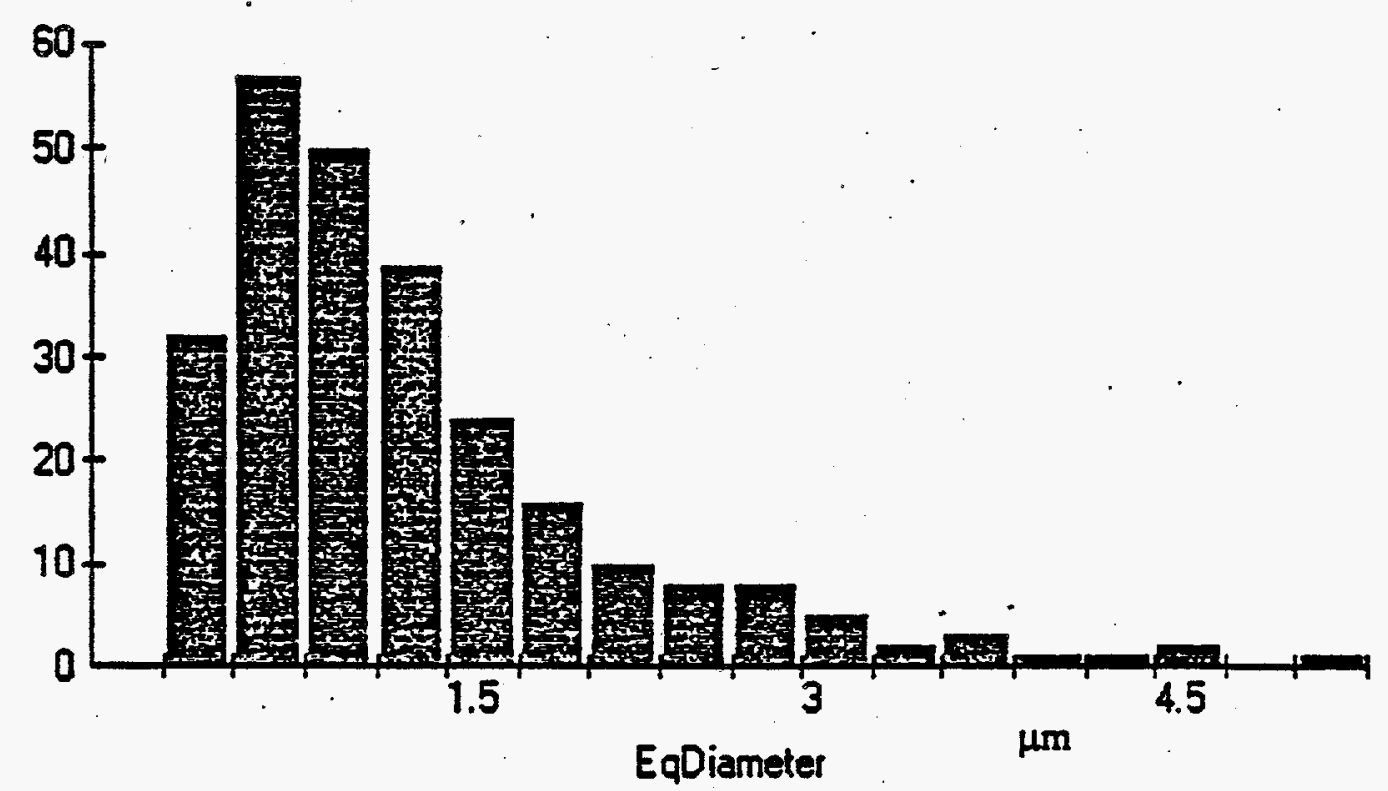

b) D-C4

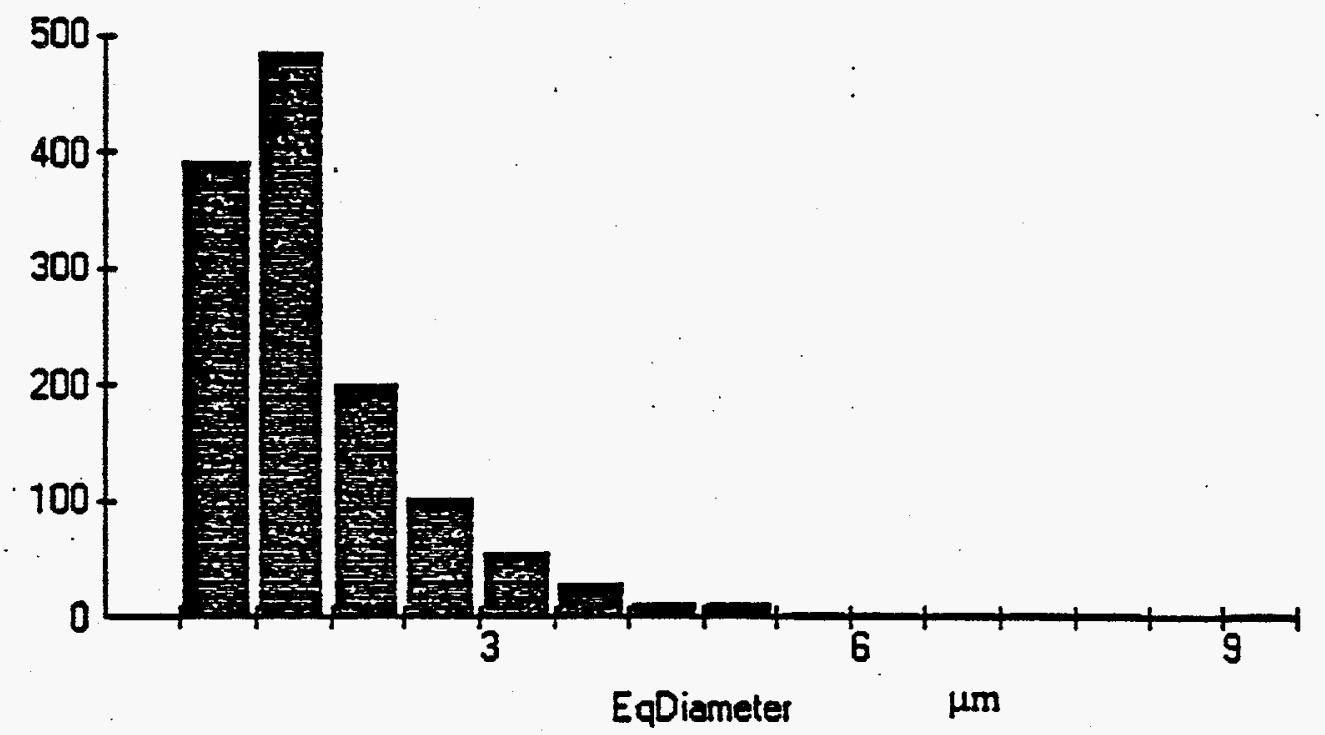




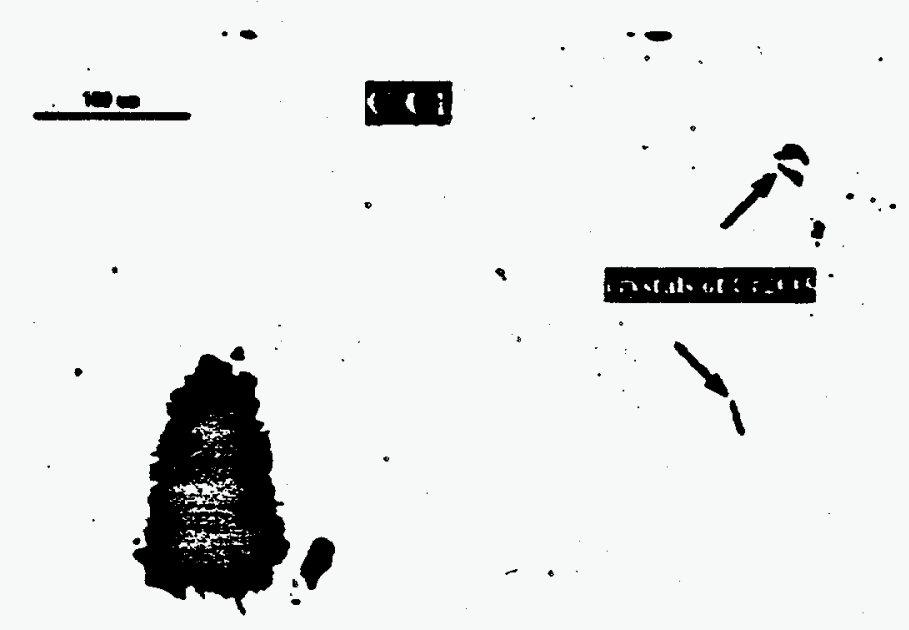

$+$

Figure 7-25: Glass C-CI, Isolated Crystals and an Agglomerate of Eskolaite (Area Fraction of Agglomerates $3 \%$ )

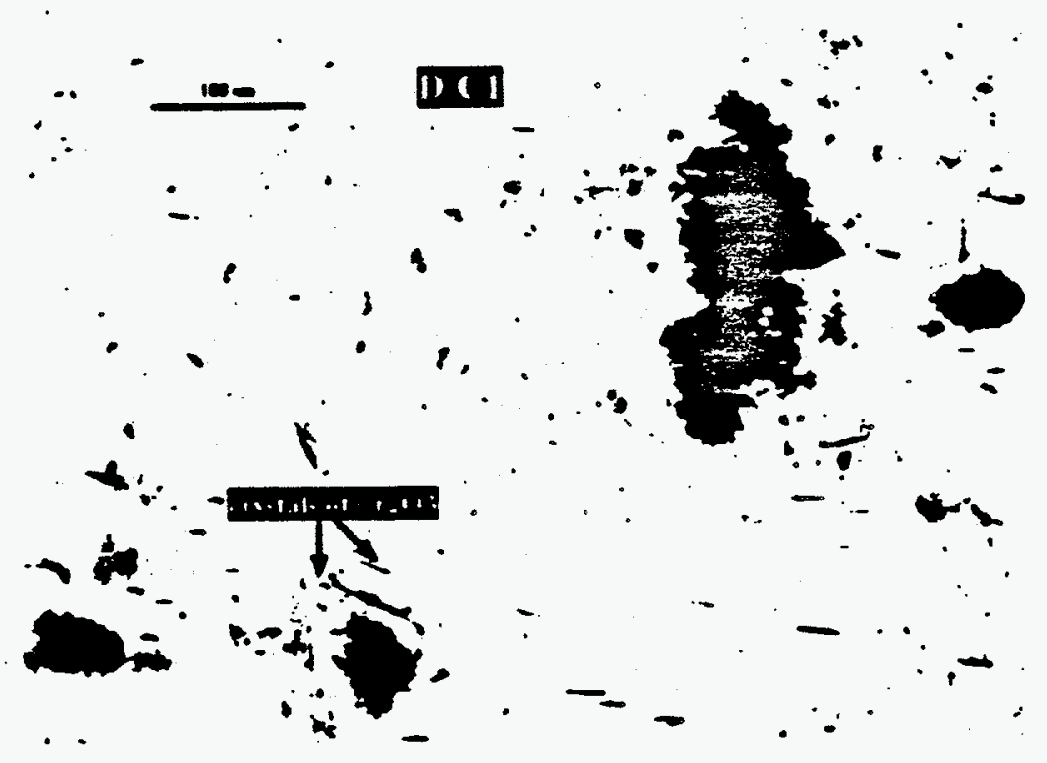

Figure 7-26: Glass D-Cl, Eskolaite Crystals and Agglomerates $(5 \%)$, Preffered Horizontal orientation of Isolated Eskolaite Crystals 


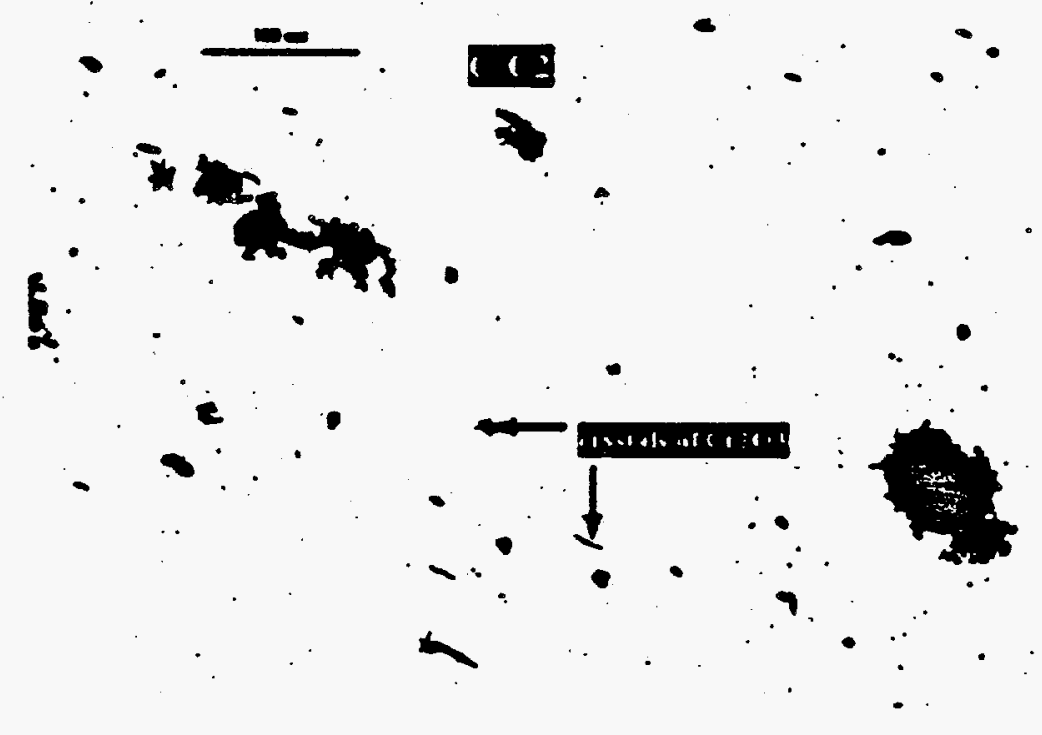

Figure 7-27: Glass C-C2, Eskolaite Crystals and Agglomerates, (Area Fraction of Agglomerates 2.5 \%)

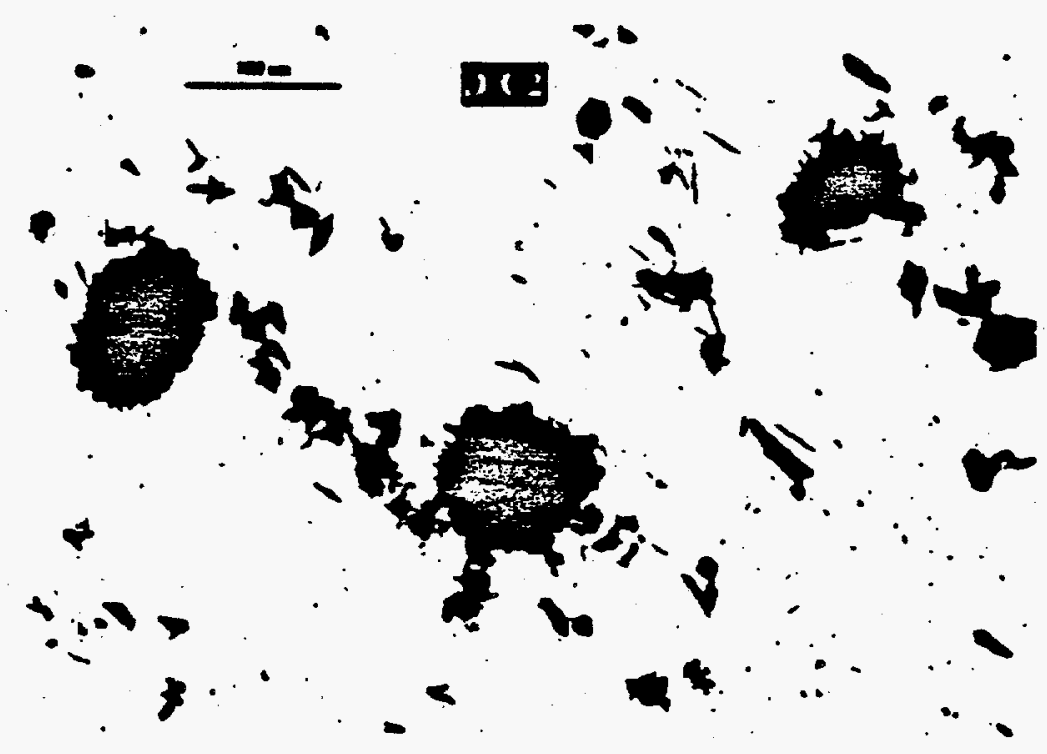

Figure 7-28: Glass D-C2, Eskolaite Crystals and Agglomerates, (Area Fraction of the Dark Phase $12 t$ ) 


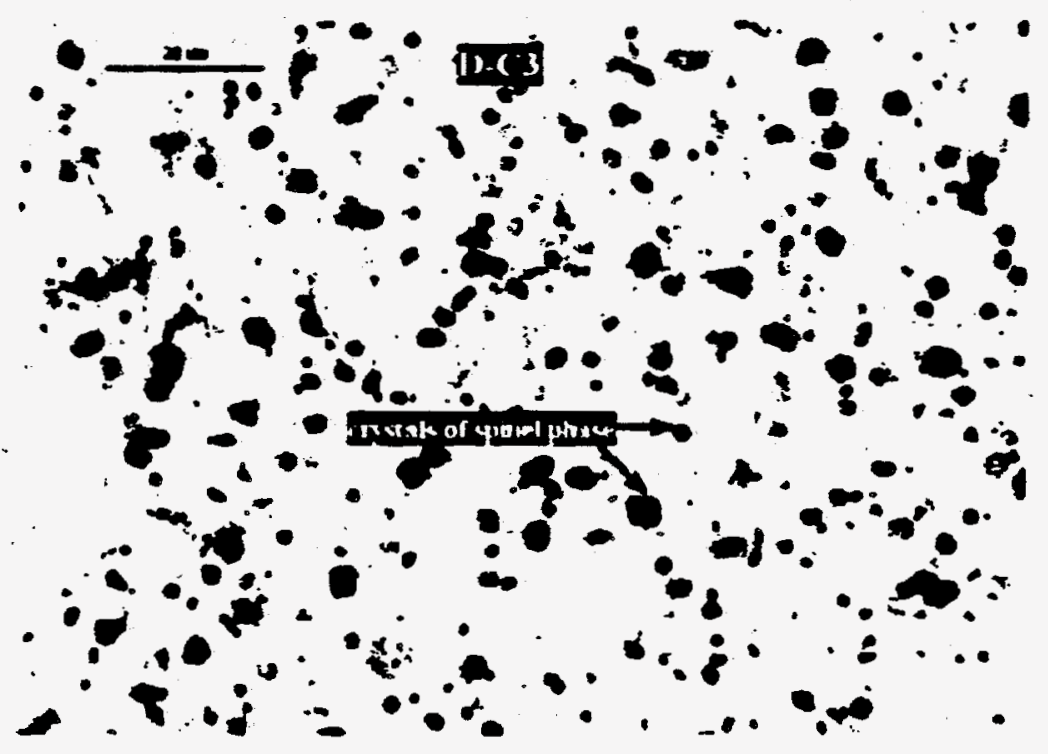

Figure 7-29: Glass D-C3, Crystals of a Spinel Phase, (Area Fraction $4.7 \%$ )
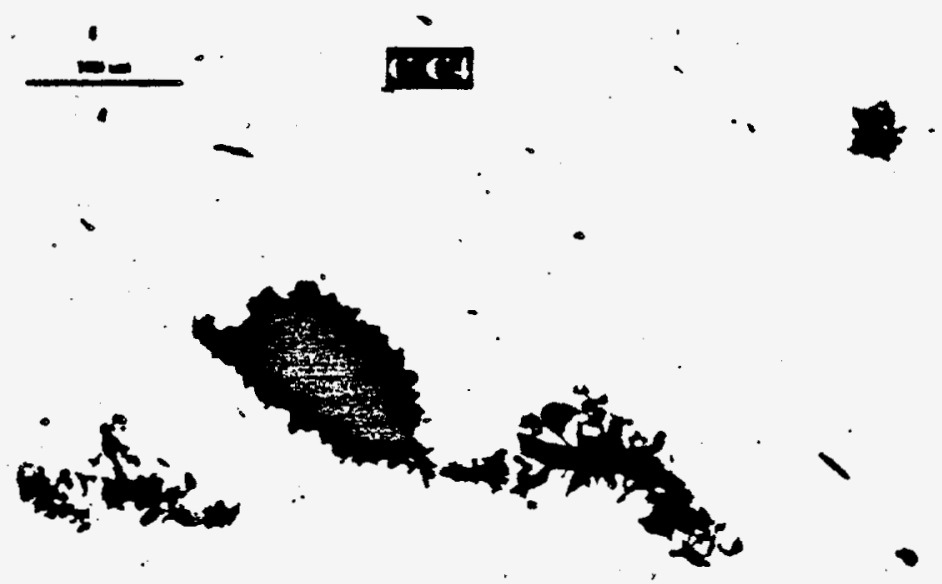

Figure 7-30: Glass C-C4, Eskolaite Crystals and Agglomerates, (Area Fraction of the Dark Phase $8 \mathrm{f}$ ) 


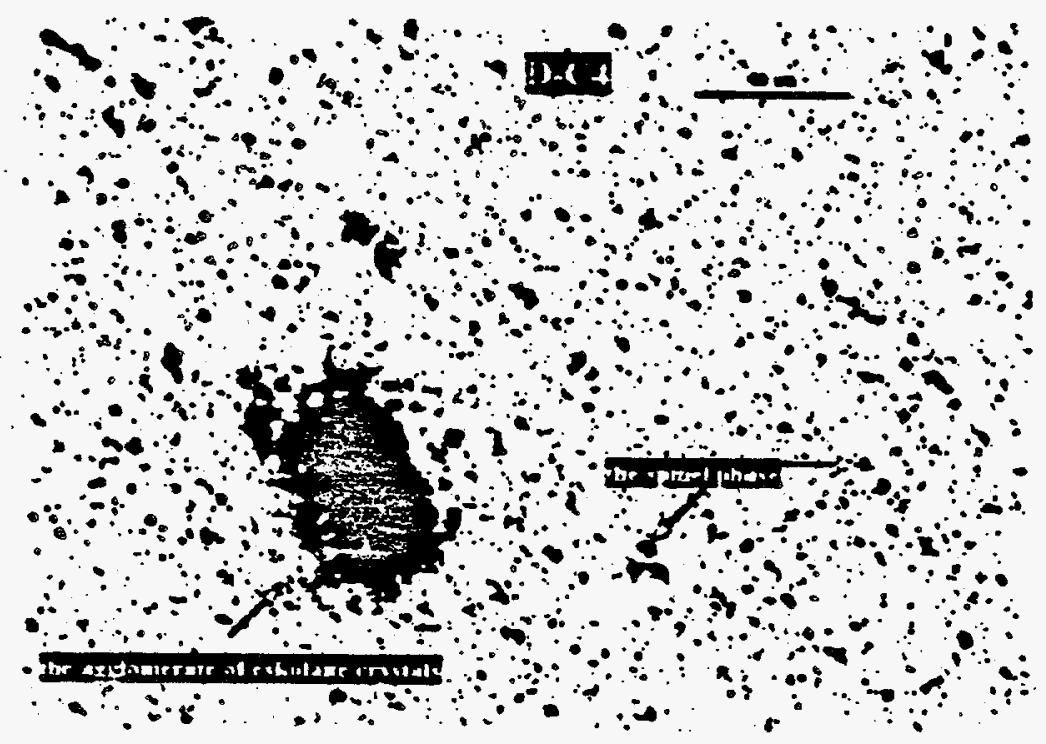

Figure 7-31: Glass D-C4, an Agglomerate of Eskolaite Crystals and Crystals of a spinel Phase (Area Fraction of the Dark Phase $10 *$ )

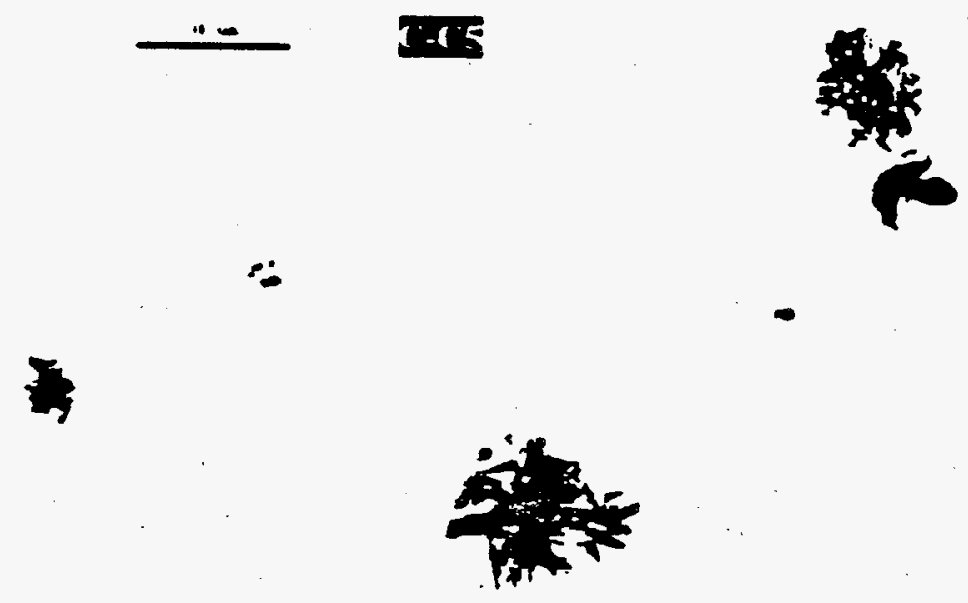

Figure 7-32: Glass C-C5, Agglomerates and Crystals of Eskolaite 


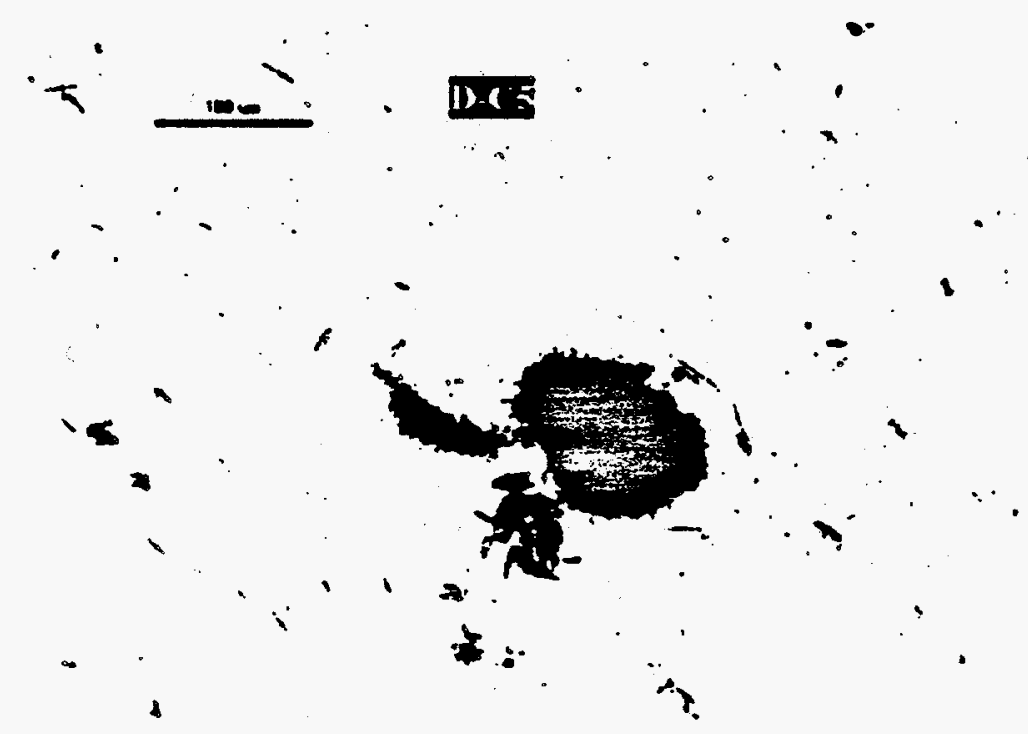

Figure 7-33: Glass D-C5, Agglomerates and Isolated Crystals of Eskolaite

\subsection{DISCUSSION AND CONCLUSIONS}

Glasses of modified compositions C1 - C5 were studied to obtain basic information on melting behavior, physical properties and crystallinity.

The glasses can be melted at relatively low temperatures: the viscosity of 10 or $6 \mathrm{~Pa} . \mathrm{s}$ was attained at temperatures of about 1250 or $1320^{\circ} \mathrm{C}$, respectively, with only small deviations within the series. Two problems should be studied in more detail additionally if the project will continue: the reason of inhomogeneity stated. in section 7.2. and the extent of vaporization during melting (presumably of $\mathrm{NaBO}_{2}$ ).

The glasses of the series $C$ apparently withstand crystallization much better than Glasses 1 and 2 studied earlier. In the base-line glass $C l$ only small amount of eskolaite crystals was found after the 24 hours dwell at the melting temperature (the crystals could not be identified by $x$-ray diffraction but 
stated by microscopic examination). No crystalline phase was found in glass c-c3 containing mo after $24 \mathrm{~h}$ treatment at the melting temperature and after exposure $100{ }^{\circ} \mathrm{C}$ bellow the melting temperature only small crystals of a spinel phase were identified. Eskolaite agglomerates as well as individual crystals were not present in this case, 1.e. all as-batched chromium hydroxide was fully dissolved in the melt. The spinel crystals were found also in the glass D-C4, in this case together with eskolaite agglomerates and less numerous individual plates. In both glasses D-C3 and D-C4 the spinel phase was identified by $X$-ray diffraction, 'SEY microanalysis and optical-microscopy. It can be assumed that the main sources of divalent cations are oxides of manganese, nickel and zinc whereas $\mathrm{Cr}$, Fe and possibly also Al (the last can be estimated from the ratio of $s i$ to Al in the microvolume analyzed) are present in the trivalent state. If some part of. Cr introduced into the glas is present in the hexavalent state, the presence of divalent $F e$ is highly improbable (see section 2 ).

In most cases the crystals within eskolaite agglomerates grow to a larger size during exposure at lower temperature (the D samples), presumably via liquid phase transport. This phenomenon is similar to that known from the studies dealing with the stones in glasses originating from chromium containing colorants (non-published studies, VScHT).

Relatively large size of eskolaite agglomerates may result in an increased tendency to settling which, however, was not observed in this study and to which attention should be paid later. On the other hand, the occurance of agglomerates can be diminished or eliminated by technological means during batch preparation. From the point of view of the size of crystals separated from the melt, individual crystals of eskolaite have equivalent sphere or cube diameter of at least several microns compared to about 1 micron size of spinel crystals found in D-C3 and D-C4. When considering also the density of both crystals ( 5.22 and $3.6-5.2$ respectively), an estimate can be made that 
particles of eskolaite will participate in settling to a larger extent at the same viscosity of the melt. However, the sedimentation velocity of individual eskolaite crystals will be decreased due to their non-isometric shape.

The general conclusion is that glasses of $c$ series represent a very promising type of glass for waste vitrification. However, it should be necessary to perform more detailed studies of the following problems:

a) Iiquidus temperature, crystallization ability and viscosity changes induced by changes of the base-line composition C1 with the aim to optimize the properties. special attention should be paid to the participation of divalent cations (incl. $\mathrm{Mg}$ ) on the spinel formation.

b) Crystallinity after heat ttreatment at high as well as at lower temperatures (ccc-type schedule) with respect to possible settling effects and to the effect of phase composition on chemical durability and mechanical properties.

c) Melting behavior of batches, including volatilization, homogenization, redox reactions and conditions for the reduction of chromates.

d) Chemical durability tests and studies of long-time interactions of glass with aqueous solutions for as prepared glass as well as for crystallized products, preferably using continuous dynamic (flow-through) tests. 


\section{REFERENCES}

Bamford, C.R. 1977. Colour Generation and Control in Glass, Elsevier.

Beyersdorfer, P. 1943. Studien über das Aventuringlas, Glastechnische Berichte, Vol.21 (1), p. $152-177$.

Brückner, R. 1985. Redox Ratios Shifts and Electrical Transport properties in Redox Pair Containing Glasses, Journal of Non Crystalline Solids, Vol. 71, p. 49-57.

Capece F.M. et al. 1982. J. Electron Spectrosc, Relat. Phenom. 27, p. 119.

Hrma, P. 1994. Property/Composition Relationships for Hanford High-Level Waste Glasses Melting at $1150^{\circ} \mathrm{C}$, PNL-10359, UC-721, Battelle, December 1994.

Kocik J., Nebrenský J. Barveni skla (The Colouring of Glass). Praha 1962. 2nd ed. with I. Fanderlik 1978.

Kühl, C., H. Rudow, and W. Weyl. 1938. Verhalten der Sauerstoffspender in Glase. Glastechnische Berichte, Vol.16 (2), p.37-51.

Lux, H. 1939: Electrochem., Vol.45, p. 303.

Moore, พ.J. 1981. Fyzikálni chemie (Physical Chemistry), Praha.

Nath, P., A. Paul, and R.W.Douglas. December 1965. Physical and Chemical Estimation of Trivalent and Hexavalent Chromium in Glasses. Physics and Chemistry of Glasses, Vol. 6 (6), p.203-206.

Polyushkin, V.I. 1979. Stroit. mat. konstr.. Vol.21 (32).

Polyushkin, V.I. 1983. Steklo i keramika, No.1, p. 30.

Folyushkin, V.I. 1983. Steklo i keramika, No.7, p. 30 .

Schreiber, H.D., and G.B. Balazs. 1982. The Chemistry of Uranium in Borosilicate Glasses. Part 1. Simple Base Compositions Relevant to the Immobilisation of Nuclear Wastes, Physics and Chemistry of Glasses, Vol. 23, p. 139-146.

Schreiber, H.D., G.B. Balazs, P.L. Jamison, and A.P. Shaffer. 1982. The Chemistry of Uranium in Borosilicate Glasses. Part 2. Base Compositions Containing Titanium Relevant to the Immobilisation of Nuclear Wastes, Physics and Chemistry of Glasses, Vol.23, p. 147-153.

Schreiber, H.D., G.B. Balazs, and S.J.Kozak. May 1983. Chemistry of Uranium in Glass-Forming Melts: Redox Interactions of Uranium with Chromium and Iron in Aluminosilicates. Journal of the American Ceramic Society, Vol. 66(5), p.340-6. 
Schreiber, H.D. 1986. Redox Processes in Glass-Forming Melts, Journal of Non Crystalline Solids, Vol. 84, p. 129-141.

Schreiber, H.D., S.J.Kozak, A.L. Fritschman, D.S. Goldman, and H.A. Schaeffer. 1986. Redox Kinetics and Oxygen Diffusion in a Borosilicate Melt, physics and Chemistry of Glasses, vol.27 (4), p.152-177.

Schreiber, H.D., and A.I. Hockman. 1987. Redox Chemistry in Candidate Glasses for Nuclear Wastes Immobilization, Journal of the American Ceramic Society, vol. 70, p. 591-594.

Strnad, Z. 1986. Glass-Ceramic Materials, Elsevier 1986.

Süssmilch, J. 1993. Thesis, NRI Rez near Prague.

Volf, M.B. 1952. Taveni skla (Glass Melting), Praha.

Volf, M.B. 1978. Chemie skla (Chemistry of Glass), Praha.

Volf, M.B. 1984. Chemical Approach to Glass, Elsevier.

Volf, M.B. 1984. Sklo ve vípoctech (Glass in Calculations), Praha. Weyl, W.M. 1951. Coloured Glasses, Sheffield.

(Other References:)

Allied Analytical System. 1983. Methods Manual, IL Video 11 and 12 , USA.

Bickford, D.F., and R.B. Diemer Jr. 1986. Redox Control of Electric Melters with Complex Feed Compositions. I.Analytical Methods and Models, Journal of Non Crystalline solids, Vol. 84, p. 276-284.

Bickford, D.F., R.B. Diemer Jr., and D.C. Iverson. 1986. Redox Control of Electric Melters with Complex Feed Composi- tions. II. Preliminary Iimits for Radioactive Waste Melters, Journal of Non Crystalline Solids, Vol.84, p. 285-291.

Goel, N.K. 1968. Thesis, Banaras Hindu University, Varanasi-5, India.

Irmann, F. 1952. A study of Molten Borates with the $\mathrm{Cr}^{6+}-\mathrm{Cr}^{3+}$ indicators, Journal of the American Ceramic Society, Vol.74 (19), p. $4767-70$.

Johnston, W.D. 1964. Journal of the American Ceramic society, Vol.48, p.185. 
Kramer, F.W. 1991. Contribution of Basicity of Technical Glass Melts in Relation to Redox Equilibria and Gas Solubities, Glastechnische Berichte, Vol.64 (3), p. 71-79.

Nath, P. i R.W. Douglas. December 1965. $\mathrm{Cr}^{6+}-\mathrm{Cr}^{3+}$ Equilibrium in Binary Alkali Silicate Glasses, Physics and Chemistry of Glasses, Vol.6 (6), p. 197-202.

Nath, P. 1966. $\mathrm{Cr}^{3+}-\mathrm{Cr}^{6+}$ Equilibrium in Binary Alkali Borate Melts, Cent. Glass Ceram. Res. Inst. Bulletin, vol.13 (4), p. 94-101.

Paul, A. 1982. Chemistry of Glasses, Chapman Hall London, p.134-148.

Price, W.J. 2983. Spectrochemical Analysis by Atomic Absorption, John Willey and Sons, New York.

Plodinec, M.S. 1976. Sclent. Basis Nucl. Waste Management, vol.1. p.31.

Rawson, H. 1967. Inorganic Glass-Forming System, Acad. Press.

Rennie, M.S., D.D. Howat, and P.R. Jochens. August 1972 . The Effects of Chromium Oxide, Iron oxide and Calcium oxide on the Liquidus Temperatures, Viscosities and Electrical Conductivities of Slag in the System MgO-Al $\mathrm{O}_{3}-\mathrm{SiO}_{2}$, Journal of the South ffican Institute of Mining and Metallurgy, vol.73 (1), p. 1-9.

Scholze, H. 1988. Glas, Springer.

Schreiber, H.D., H.V. Lauer, and T. Thanyasiri. 1980. Oxidation-Reduction Equilibria of Iron and Cerium in silicate Glasses: Individual Redox Potentials and Mutual Interactions, Journal of Non Crystalline Solids, Vol.38 (39), p. 785-790.

Schreiber, H.D., and G.B. Balazs, August 1981. Mutual Interactions of $T i, C r$ and Eu Redox Couples in Silicate Melts, physics and Chemistry of Glasses, Vol. 22 (4), p. 99-103.

Schreiber, H.D. 1983. The Chemistry of Uranium in Glass- Forming Aluminosilicate Melts, Journal Less-Common-Metals, Vol.91, p. 129-147.

Suissmilch, J. 1993. The Vitrification of Accident Wastes from the Nuclear Power Plant A-1 in slovakia, Proceedings of the International conference on Nuclear waste Management and Environmental Remediation, Vol. 3, p. 849-50, September 5-11, Prague.

Tress, H.J. 1960. A Thermodynamic Approach to Redox Equilibria in Glasses, Physics and Chemistry of Glasses, Vol.1 (6), p. 196-200. 
Tupý, R. 1985. Zpracováni radioaktivnich odpadú $z$ atomových elektráren (Treatment of Radioactive Wastes from Nuclear Power Plants), Final Report No. 163.081 .080 (NRI-AKTO), SVús, Hradec Králové.

Tupý, R. 1986. Výzkum technologie vitrifikace odpadú z jaderných elektráren (Research of Waste Technology Vitrification from Nuclear Power Plants).- Partial Final Report Task NRI-1, svís. Hradec Králové.

Tupý, R. 1987. Výzkum technologie vitrifikace odpadú z jaderných elektráren (Research of Waste Technology Vitrification from Nuclear Power Plants), Partial Final Report, Contract No. 162.296.086, Task NRI-1, svús, Hradec Králové.

Tupý, R. 1988. Výzkum technologie vitrifikace odpadú 2 jaderných elektráren (Research of Waste Technology Vitrification from Nuclear Power Plants), Partial Final Report, Contract No. 162.296.086, Task NRI-1, svứs, Hradec Králové.

Tupý, R. 1989. Výzkum technologie vitrifikace odpadú z jaderných elektráren (Research of waste Technology Vitrification from Nuclear Power Plants), Final Report of Contract No. 162.296.086. Task NRI-1, svús, Hradec Králové.

Tyagi, B.S. 1969. Thesis, Banaras Hindu University, Varanasi-5, India.

Tyagi, B.S. and P. Nath. 1972. $\mathrm{Cr}^{3+}-\mathrm{Cr}^{6+}$ Equilibrium in Binary and Ternary Aluminoborate Glasses Containing Oxides of Zinc, Cadmium and Lead, Cent. Glass Ceram. Res.Inst. Bulletin, Vol.19 (2), p. 31-40.

Volf, M.B. 1988. Mathematical Approach to Glass, Elsevier.

Weyl, W.M. and Marboe E.C. 1962. The Constitution of Glasses II. 1. Intersci. 
9. QUALITY ASSURANCE

The QA system of the NRI is in conformity with the QA principles and requirements of Czech Nuclear Safety Regulations No. $436 / 90$ and IAEA Code 50-C-QA. It is also in conformity with the ISO 9000 .

The work on " The effect of chromium on the properties of simulated nuclear waste glasses" has been performed by the Department of Radioactive Waste Solidification (a department of the Nuclear Research Institute Rez plc, Czech Republic) as the main Contractor. The institutions: Department of Glass and ceramics of the University of Chemical Technology, Prague and svus ple, Hradec Králové and Glass Institute, State Testing Laboratory, Hradec Králové cooperated as subcontractors .

The above task has been coordinated by the respective department of the NRI Rez (the main coordinator being Mr Josef süssmilch, head of the department). The major part of the laboratory work, especially the preparation of greater mass samples and special measurements have been performed in laboratories of svus and Glass Institute, state Testing Laboratory.

Methods and instrumentation:

Methods and instrumentation are described in individual Sections and some methods are presented in the Annex $B$ of the report. Detailed data on the equipment used in this project were given in the Test Plan.

The system of work of state Testing Laboratory, methods and procedures, quality assurance, rules of metrology, system of control is described in the Quality Assurance Manual of the Laboratory No. 237.

Methods and procedures corresponding to CSN, EN, ASTM or ISO standards were used with advantage, sometimes were completed by internal rules. These rules are the subject of the respective QA Manual. 
This laboratory possesses the function of an Institute $s$ metrologist (B. Trefna, eng.).

The svus Institute was responsible for the preparation of the majority of samples. The instrumentation for the measurement (such as balances, thermocouples) is checked by the state Inspectorate for Metrology in Brno, CR.

svus is responsible for the archivation of the majority of samples which have been prepared during the course of the project. Samples prepared in the connection with the performance of the Task 6 are archived in the NRI.

9.1 NRI QA system documentation for quality assurance planning, management, implementation, and verification

In accordance with NRI QA system the QA scheme includes following documentation (in czech):

A. Permanent Documentation of Universal Use in QA

(a) NRI Manual

It describes NRI role, quality policy, QA system, QA process, organization, responsibilities and procedures.

(b) Standard Work Procedures and Instructions

Procedural documents describing methods and procedures relevant to standard works carried out.

B. Documentation Specifically Prepared for QA of PNL Project

It references broadly to the $Q A$ manuals and $Q A$ procedures.

(a) Overall QA programme for PNL project

It consists of constituent QA programmes developed for tasks.

(b) Specific Work Procedures and Instructions

Procedural documents, specific for the given tasks, describing methods and procedures relevant to work carried out. 


\subsection{Staff}

The team responsible for the project 209344-A-FI consists of representatives of four institutions. The leading position is held by The Nuclear Research Institute (NRI Rez plc) in Rez, the Contractor of the project: cooperating institutions are:

- . Svus ple, Hradec Králové

-- Glass Institute, state enterprise, Hradec Králové, State Testing Laboratory No. 237

-- University of Chemical Technology, Department of Glass and Ceramics, Praha

All staff members from the respective institutions are properly trained and .their knowledge periodically examined regarding the safety handling with toxic materials, inflammable materials, aggressive materials (such as acids and lyes) and with radioactive materials (the last training is accomplished only in the NRI).

\subsection{Testing equipment}

The testing equipment used and relating to specific experiments is given in respective sections. Detailed description was presented in the Test Plan.

\subsection{Physical output}

The physical output of the activities relating to this project consist of:

- test plan

- samples of glasses

- protocols of experiments and measurements

- laboratory diaries

- reports: monthly reports, final report incl. appropriate draft.

Samples of glasses, protocoles of their preparation, laboratory diaries, protocoles of analysis are archived at respective laboratories (SVUS, VŠCHT and NRI) for the whole period of research and at least one year after. The archivation time can be changed according to the request of PNL, Battelle. 
The results of analysis were used for the preparation of monthly reports and for Final Report. Some important protocoles were enclosed to monthly reports (for the consultation purposes).

special procedures for the sample preparation, for analysis are kept in respective laboratories and in NRI kez according to the special Manual of QA prepared by NRI for the purpose of this task.

9.5 Science control of task

General activities (planning, control of the work progress. solution of problems) were supervised by the "steering committee" of the project, which consisted of 8 members (two from each institution).

Scientific level of tasks was checked and controlled by the "Scientific council", which used to gather at "ad hoc" opportunities and consisted of top specialists from all participating institutions. 
ANREXES A

EXPERIMENTS NOT INCLUDED IN THE TEST PIAN

ANREX AI

PREPARATION AND PROPERTIES OF CHROMIUM HYDROXIDE I

During the preparatory and orientation phase of experiments a batch of chromium hydroxide was prepared, which was further used for the preparation of glasses called in this report glass $A, B, A / T E M, B / T E M, A / C C C$ and $B / C C C$.

- The preparation of this hydroxide was performed according to the procedure given in the Test Plan ("Procedure for $\mathrm{Cr}_{2} \mathrm{O}_{3} \cdot \mathrm{n} \mathrm{H}_{2} \mathrm{O}$ or $\mathrm{Cr}(\mathrm{OH})_{3}$ preparation" and is described in the closing Report STL No. 199/94. This chromiun hydroxide is in this report marked Chromium hydroxide I.

Properties of the Chromium hydroxide I are described in the Closing report STL No. 200/94.

During the preparation of batches for further glass melting the Chromium hydroxide I was dried at the temperature $150^{\circ} \mathrm{C}$ instead of $105{ }^{\circ} \mathrm{C}$, the resulting hydroxide changed some properties and its composition. This chromium hydroxide is called chromium hydroxide-black form (its properties are given in the Closing Report STL No. 59/95) and was used for the preparation of the above mentioned glasses.

The chromium hydroxide and the resulting glass materials served for orientation experiments, on one side, and served also for comparison of results which are described in the Final Report text, on the other side.

PREPARATION OF CHROMIUM HYDROXIDE I

As in the case of chromium hydroxide II preparation (see section 3.1.) chromium nitrate was used as the initial chromium compound. Procedure of hydroxide preparation was identical to the same given for chromium hydroxide II and is not repeated in this Annex. 
Powdered and homogeneous product was marked "Chromium hydroxide I, prepared in the Glass Institute as chromium hydroxide I, $\mathrm{Cr}_{2} \mathrm{O}_{3} \times \mathrm{nH}_{2} \mathrm{O}$, Sept. 16, $1994^{\prime \prime}$, weight $9025 \mathrm{~g}$.

PROPERTIES OF CHROMIUM HYDROXIDE I

The properties of the Chromium hydroxide. I are described in the closing report STL No. $200 / 94$.

The density of the chromiun hydroxide I was measured using helium pycnometer AUTOPYCNOMETER 1320 according to Internal regulation F-12-93.

The sample density: $2.584 \mathrm{~g} \cdot \mathrm{cm}^{-3}$.

The granulometric analysis (according to internal regulations F-09-93) was performed by sedimentation method using Micromeritics, USA apparatus, SEDIGRAPH 5100. The sample was dispersed in ethanol in a ultrasonic probe Laborette 19 for 3 minutes.

Results of granulometry are presented in the Table Al-1 andin Figures $A I-1$ and $A 1-2$.

Specific surface of the product was determined by nitrogen adsorption with the use of the apparatus FLOWSORB II 2300 (Micromeritics, USA). Specific surface of the sample:

$$
24.5 \mathrm{~m}^{2} \mathrm{~g}^{-1} \text { (range was } 0.6 \mathrm{~m}^{2} \mathrm{~g}^{-1} \text { ). }
$$

$x$-ray diffraction analysis of the sample powder (Internal regulation $F-12-93$ ) was carried out with the use of an apparatus siemens $U$ 13-008, using $\mathrm{Cu} K$ a radiation, $\mathrm{Ni}$ filter.

The sample of Chromium hydroxide I was roentgenographically amorphous. In spite of an adjustment of experimental conditions to a maximum sensitivity no diffraction lines were gained.

Qualitative and semiqualitative optical emission spectrographic analysis of the sample (Internal regulation, $\mathrm{CH}-46-92$ ). showed that the content of chromium oxide was higher than 10 wt:, aluminium oxide less than 1 wty and sodium oxide between $I$ and 10 wt 8 . 


\section{Table Al-1: Granulometry of Chromiun Hydroxide I}

SediGraph S10G VE.Ge

GRANULDMETFIE

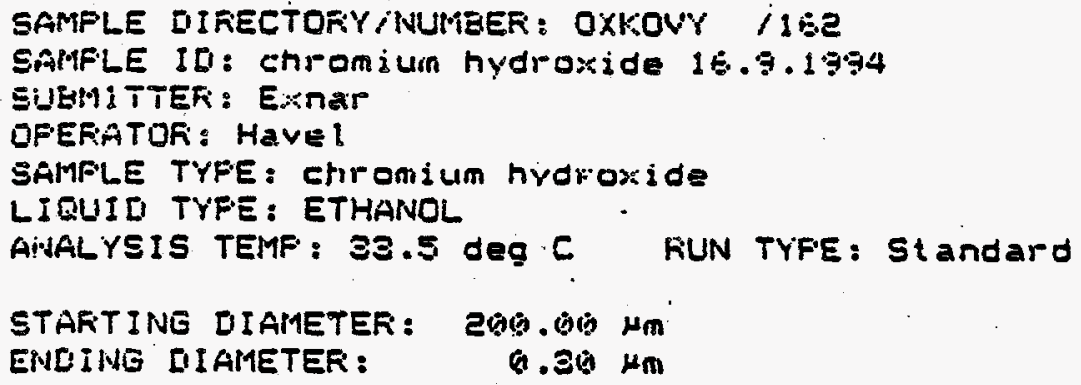

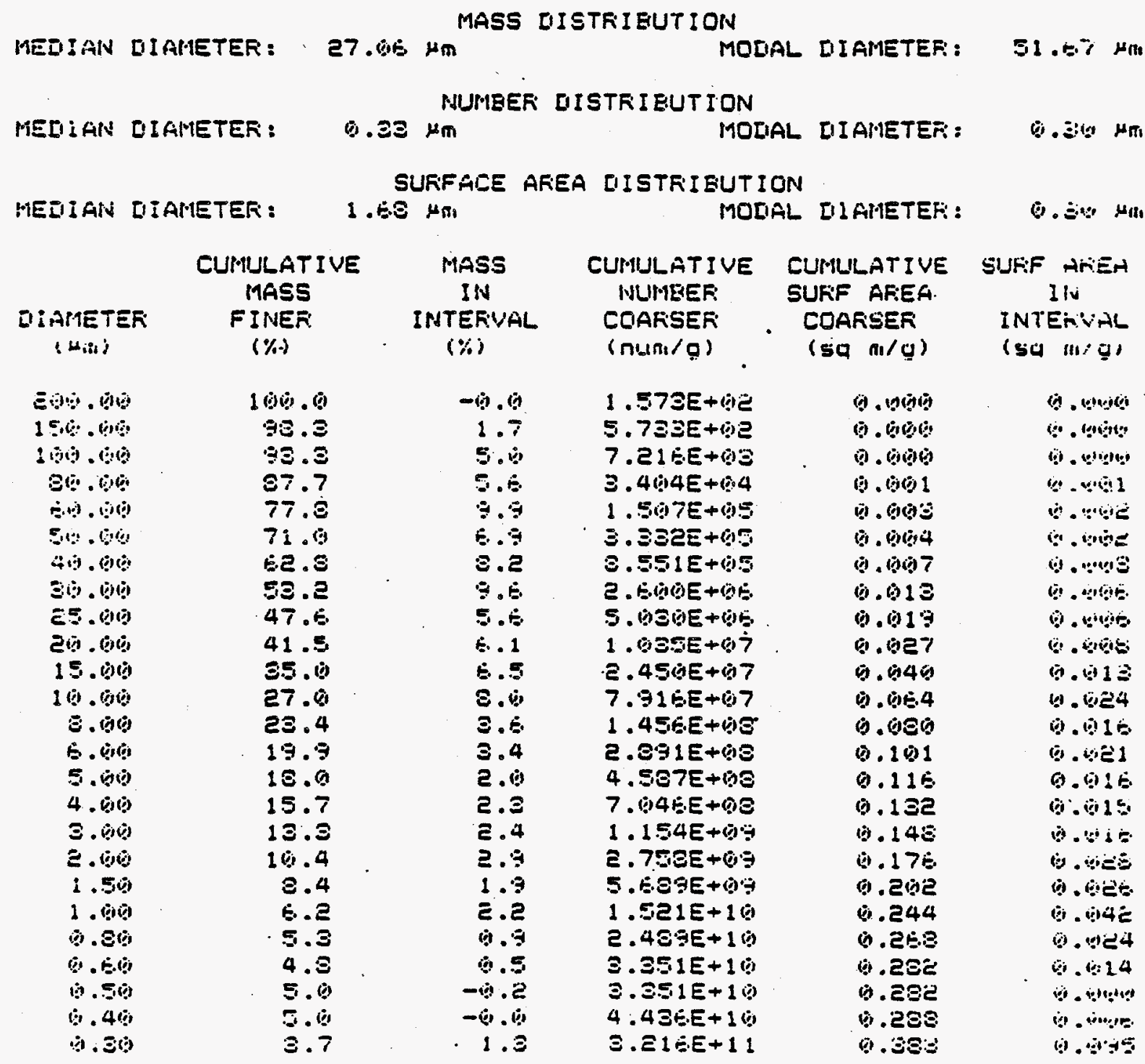

UINIT NUMEEF: : 1

STAFT $14: 59: 59$ G9/27, REFRT 10:20: : TOT RUNA TIME $\because: S T:$ : SAIM DEINS : .. . SE4: 016 LIQ LENS: 9.7T7E JILL LIQ VISC: .039 nit 5

REYNOLDS NUMEEF: : FULL SCALE MASS \%: $1 \%$ 


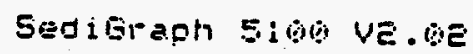

G FIA A UL'OMETFIIE

SAMFLE IIRECTOFY/NUMEEK: OXKOUY /16.2

SAMFLE III: chromiLm hydroxide 16.9 .1994

SUERIITTEF: Exnar

OFERATOF: Have?

SAMFLE TYFE: chromiLm hydroxide

LIQUILI TYFE: ETHANOL

ANALYSIS TEMF: $3 \Xi .5$ deg $C$ hUN TYFE: Standard

EUMULATIVE MASS PERCENT FINER VS. DIAMETEF:

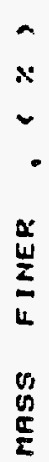

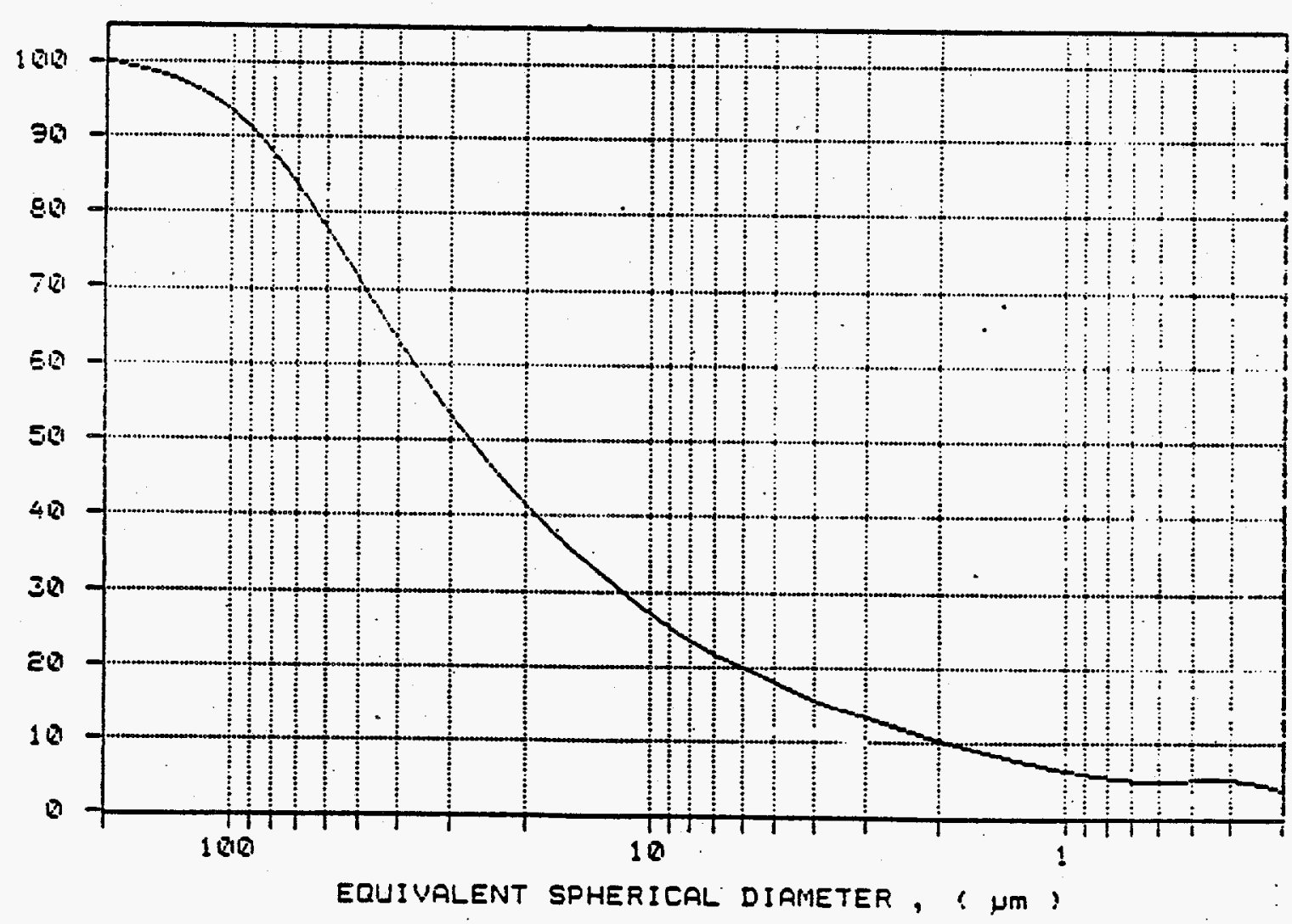

Figure A1-1: Cumulative Mass Percent Finer vs. Diameter, for the Chromium Hydroxide I 
SediGraph 51000 ye.

SAMFLE [IFECTOFY/NUMEER: OXKOVY /1EZ

SAMPLE ID: chromium hydroxide 15.9.1994

SUEMITTER: Exnar

OFEFATQR: HaVel

SAMFLE TYFE: chromium hydroxide

LIQUID TYFE: ETHANOL

ANALYSIS. TEMF: 33.5 deg $C$. RUN TYFE: Standard
FAGE :

UNIT NUMEEF: : 1

START 14:59:59 001E:.:4 FEFFT $15: 20: 030 \% / 2 \div / 9 \%$ TOT RUN TIME C::5: :

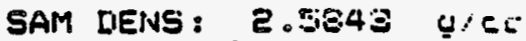
LIQ DENS: 9.7776 a/C6 LIQ VISC: $0.93 \%$ inter =

MASS POPULATION US. DIAMETER

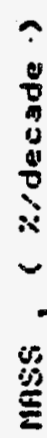

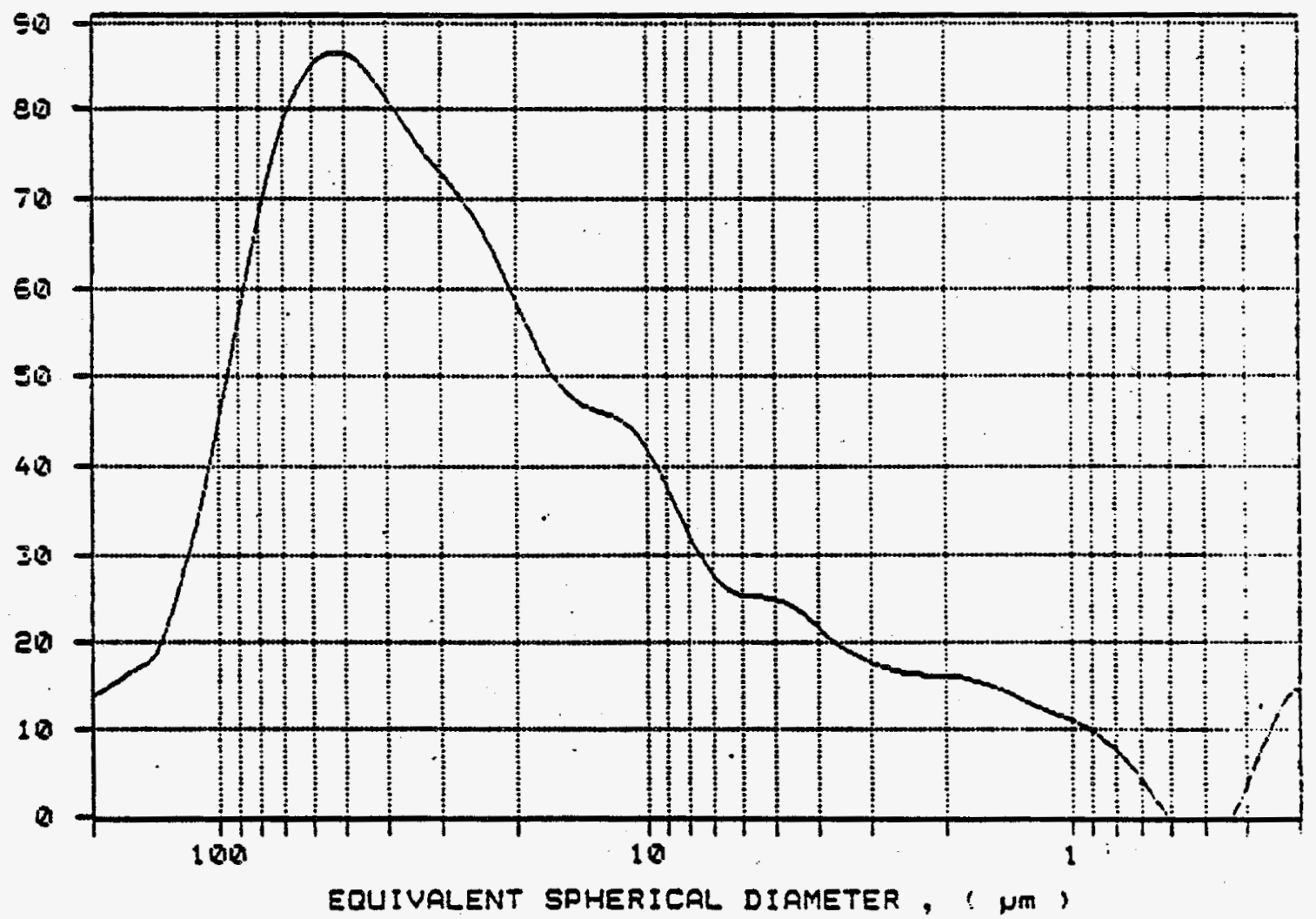

Figure A1-2: Mass Population vs. Diameter for the Preparation of Chromium Hydroxide I 
Quantitative chemical analysis of chromium hydroxide I Czech standards:

CSN 720103

Basic method of silicate analysis, Determination of the loss by ignition,

ČsN 720108 Basic method of silicate analysis. Determination of oxides of ammonia group by a gravimetric method

and Glass Institute Internal regulations:

Internal regulation $\mathrm{CH}-42 \mathrm{a}-92$ Testing method. Methods of atomic absorption and emission flame spectrometry. Determination of sodium oxide.

Internal regulation $\mathrm{CH}-10-94$ Determination of nitrates by ion selective nitrate electrode.

led to following results:

Table Al-2: Results: of Chromium Hydroxide I Quantitative Analysis

\begin{tabular}{|l|c|c|}
\hline $\begin{array}{l}\text { Determined } \\
\text { Component }\end{array}$ & $\begin{array}{c}\text { Chromium } \\
\text { Hydroxide } \\
\text { [wt\%] }\end{array}$ & $\begin{array}{c}\text { Number of } \\
\text { Determinations }\end{array}$ \\
\hline Loss by ignition & & \\
(1100 ${ }^{\mathrm{C} \text { to }}$ & & \\
constant weight) & 27.8 & 4 \\
$\mathrm{Cr}_{2} \mathrm{O}_{3}$ & 62.7 & 4 \\
$\mathrm{Na}^{-}$ & 4.55 & 4 \\
$\mathrm{NO}_{3}$ & 10.25 & 4 \\
\hline
\end{tabular}

- the results given are an mean value from 4 parallel determinations.

- the analyzed product shows hygroscopic properties.

- the leachate by deionized water shows an alkaline reaction on litmus paper.

Detailed description of the respective quantitative analytical methods is given in section 3.2..

PROPERTIES OF THE CHROMIUM HYDROXIDE-BLACK FORM

As mentioned above, the chromium hydroxide-black form has been used for the preparation of several glasses, properties of which were used for comparison with glasses described in the text of the Final Report.

This is the reason why the properties of this hydroxide were studied. It was not expected that the changes in concentration of chromium in glasses could change their properties, but the 
modification of the chromium hydroxide-black form could influence kinetics of glass melting and in certain cases the properties of the vitrification product.

\section{Density determination}

As in the case of Chromium hydroxide I and chromium hydroxide II density determinations according to the procedure:

Internal regulation F-11-93 Density determination was used.

$$
\text { on AUTOPYCNOMETER } 1320 \text { (MICrOmeritics, USA) }
$$

Sample density of Chromium hydroxide - black form: $2.800 \mathrm{~g} \cdot \mathrm{cm}^{-3}$.

$$
X-r a y \text { identification of crystal phases }
$$

Internal regulation F-12-93 X-ray diffraction analysis on the apparatus Siemens $U$ 13-008

The sample of Chromium hydroxide-black form was roentgenographically amorphous. In spite of an adjustment of experimental conditions to a maximum sensitivity no. diffraction line was found.

\section{Partial quantitative chemical analysis}

Following standards were used:

CSN 720103 Basic method of silicate analysis. Determination of the loss by ignition

CSN 720108 Basic method of silicate analysis. Determination of oxides of ammonia group by a gravimetric method

Testing results are summarized in Table A1-3.

Table A1-3: Results of Quantitative Chemical Analysis

\begin{tabular}{|c|c|}
\hline $\begin{array}{l}\text { Determined } \\
\text { Component }\end{array}$ & $\begin{array}{l}\text { Content } \\
\text { [wt. *] }\end{array}$ \\
\hline $\begin{array}{l}\text { Loss by ignition } \\
(1100 \cdot \mathrm{C} \text { to the } \\
\text { const. weight) } \\
\text { sum } \mathrm{R}_{2} \mathrm{O}_{3}+\mathrm{RO}_{2} \\
\text { expressed as } \mathrm{Cr}_{2} \mathrm{O}_{3}\end{array}$ & $\begin{array}{l}24.1 \\
69.9\end{array}$ \\
\hline
\end{tabular}
of Chromium Hydroxide - Black Form

Notes: - Test results are related to a sample dried at $150{ }^{\circ} \mathrm{C}$ to a constant weight.

- The given value of loss by ignition is informative only considering that there are not known forms and time stability of nitrates at given temperature. 
ANNEX A2

PREPARATION AND PROPERTIES OF GLASSES A, $B, A / T E M, A / C C C$, B/TEM AND B/CCC

PREPARATION OF GLASSES A AND B

Glasses $A$ and $B$ (corresponding to Glass 1 and Glass 2 resp.) were prepared in the laboratory of svus using thre same procedure for the glass preparation described in the section 4.1. The only difference was the use of the chromium hydroxide-black form for the batch preparation. This difference led to the minor change in the Glass $A$ and $B$. composition. As-batched compositions are for all four glasses given in Table A2-1. The behaviour of batches during the melting process did not differ from the behaviour of Glasses 1 and 2 preparation.

Table A2-1: As-batched Compositions of Glasses 1, A, 2 and B [wt. \% ]

\begin{tabular}{|l|r|r|r|r|}
\hline Component & Glass 1 & Glass A & Glass 2 & Glass B \\
\hline $\mathrm{SiO}_{2}$ & 46.752 & 46.515 & 40.239 & 39.949 \\
$\mathrm{~B}_{2} \mathrm{O}_{3}$ & 17.070 & 16.983 & 9.188 & 9.122 \\
$\mathrm{Na}_{2} \mathrm{O}$ & 6.245 & 6.294 & 9.367 & 9.365 \\
$\mathrm{Li}_{2} \mathrm{O}$ & 6.685 & 6.651 & 6.334 & 6.289 \\
$\mathrm{CaO}$ & 0.186 & 0.185 & 0.279 & 0.277 \\
$\mathrm{MgO}$ & 0.018 & 0.018 & 0.027 & 0.027 \\
$\mathrm{Al}_{2} \mathrm{O}_{3}$ & 1.399 & 1.392 & 2.099 & 2.083 \\
$\mathrm{ZrO}_{3}$ & 16.213 & 16.131 & 24.319 & 24.144 \\
$\mathrm{Cr}_{2} \mathrm{O}_{3}$ & 0.021 & 0.021 & 0.032 & 0.032 \\
$\mathrm{P}_{2} \mathrm{O}_{5}$ & 4.143 & 4.563 & 6.215 & 6.830 \\
$\mathrm{SO}_{3}$ & 0.108 & 0.107 & 0.162 & 0.161 \\
$\mathrm{Na}_{2} \mathrm{O}_{3}$ & 0.057 & 0.045 & 0.086 & 0.079 \\
$\mathrm{La}_{2} \mathrm{O}_{3}$ & 0.060 & 0.060 & 0.090 & 0.089 \\
$\mathrm{~K}_{2} \mathrm{O}$ & 0.021 & 0.021 & 0.032 & 0.032 \\
$\mathrm{~F}$ & 0.075 & 0.075 & 0.113 & 0.112 \\
$\mathrm{MnO}_{2}$ & 0.411 & 0.027 & 0.041 & 0.041 \\
$\mathrm{MOO}_{3}$ & 0.108 & 0.109 & 0.617 & 0.613 \\
$\mathrm{NiO}$ & 0.090 & 0.090 & 0.162 & 0.161 \\
$\mathrm{CnO}$ & 0.123 & 0.122 & 0.185 & 0.134 \\
$\mathrm{ZnO}$ & 0.186 & 0.185 & 0.279 & 0.184 \\
\hline
\end{tabular}

PROPERTIES OF GLASSES A AND B

Properties of Glasses $A$ and $B$ (namely $A I$ and $B I$ ) are presented in the closing Report STL No. 254/94 and VSCHT Report No. 1 in detail. 
Determination of medium coefficient of linear thermal expansion and dilatometric transformation temperature

Following Czech standards were used:

CSN ISO 7991 Determination of medium coefficient of linear (thermal) expansion.

CSN ISO 7884-8 Viscosity and reference viscosity points. Determination of dilatometric transformation temperature $t_{g}$

Testing results are given in the Table A2-2. The course of dilatometric curve of the sample BI is typical for devitrificated or crystallizing glasses and, in this case, it is not usually possible to evaluate the temperature $t_{d}$.

Table A2-2: Results of Determinations of Medium Coefficient of Iinear. Thermal Expansion, Dilatometric Transformation Temperature $t_{g}$ and Dilatometric Softening Point $t_{d}$ of Experimental Glasses

\begin{tabular}{|c|c|c|c|}
\hline Sample & $a(20-300){ }^{\circ} \mathrm{C} \cdot 10^{6}\left[\mathrm{~K}^{-1}\right]$ & $t_{\mathrm{g}}\left[{ }^{\circ} \mathrm{C}\right]$ & $t_{\mathrm{d}}\left[{ }^{\circ} \mathrm{C}\right]$ \\
\hline $\mathrm{Al}$ & 8,15 & 476 & 521 \\
& 8,33 & 476 & 523 \\
\hline $\mathrm{BI}$ & 8,01 & 444 & $\mathrm{a}$ \\
& 7,92 & 444 & $\mathrm{a}$ \\
\hline
\end{tabular}

Note: a $\ldots$ the evaluation was not possible

X-Ray Diferaction

The $X$-ray powder patterns were measured with seifert $x-r a y$ diffractometer and evaluated using PDF-2 Database. The most developed crystalline phase is eskolaite (PDF 38-1479) in both samples $A I$ and $B I$.

The diffractograme for BI sample is, however, more complicated. There is a strong line at $d=3,49 \mathrm{~A}$ which corresponds to beta-LiAlSio 4 (JCPDS 26-839: pseudohexagonal triclinic phase with the structure of high-temperature quartz). The diffractogramme also exhibits highly diffusive bands at d values corresponding to the mineral eucryptite with very small coherent regions.

The $X$-ray analysis performed in the laboratory of GI-STL confirmed the presence of eskolaite in both glasses, 
beta-eucryptite and a spinel-type compound corresponding to chromite (ASTM 3-0873) in Glass. B. Several thin diffraction lines, belonging to other unidentified phases, were also present. Further investigation confirmed the presence of nepheline and Li-Al-disilicate. The diffraction analysis results of Glasses $A$ and $B$ are identical to the analysis of Glasses 1 and 2 (see Section 4.2 .1 .1 .1 .

optical microscopy (phase composition, crystalline phases)

Two kinds of observations were performed, with polished sections (incident light) and with thin sections.

a) Measurements with polished sections

The AI specimen contained inhomogeneities of circular shape of about $100 \mu \mathrm{m}$ mean diameter, which were smaller and less distinct in B1. The inhomogeneities are presumably composed of eskolaite crystals. Both samples contained numerous individual crystals (plates) of the same substance, with the ratio of width to thickness about 10.

b) Measurements with thin sections

Thin sections were prepared by grinding and polishing under petroleum. The results (figures) of image analysis are in vSCHT Report No. 1.

Conclusions :

- A higher number of agglomerates of circular shape is present in Al compared with B1 (the ratio $28: 11$ in the fields of observation) and the size of agglomerates is larger in $A I$.

- The agglomerates are composed of eskolaite plates.

- The thickness of eskolaite plates is about 1 micron or less.

- The total content of eskolaite as estimated from the area is approx. 1,5 times higher in AI than in B1.

- Individual plates of eskolaite randomly distributed in the mass of the samples are probably of secondary origin, i.e. they were formed by crystallization from the melt, whereas agglomerates represent, presumably, pseudomorphosis of the particles of the raw material. 


\section{X-ray microanalysis and scanning electron microscopy}

Sample Al

In the dark glass matrix many individual crystals like needles are accompanied by much larger agglomerates of circular or oval shape with the diameter of about 100 microns. The individual needles are cross sections of eskolaite plates. The body of the agglomerate is formed by many small crystals of eskolaite and the shape of the agglomerate represents probably the relicts of the original particles $\left.\mathrm{Cr}_{(\mathrm{OH}}\right)_{3}$ in the batch.

$X$-ray energy spectrum of the crystal showed small peaks of Al, Si, Ca and Fe beside the very strong peak of Cr. This is caused by small size of crystals comparable with the analyzed volume under the electron probe. Some elements might not be present in escolaite like si, $\mathrm{Na}, \mathrm{K}$ or $\mathrm{Ca}$ - they come from surrounding glass but $A l$ and $F e$ are at least disputable.

\section{Sample BI}

Besides individual crystals of approximately the same size as in previous sample the agglomerates having thinner structure then agglomerates of Al sample are present..

The crystals in agglomerate are bigger and more developed. The spectrum taken from a well developed crystal shows that no $\mathrm{Si}, \mathrm{Na}, \mathrm{K}$ and $\mathrm{Ca}$ peaks are present but $\mathrm{Al}$ and $\mathrm{Fe}$ peaks are present even in smaller extent. This might indicate that $\mathrm{Fe}$ and Al atoms can be embedded in eskolaite structure. Standardiess EDS analysis of this crystal confirmed the above mentioned speculation. At higher magnification 10000 in BSE mode small droplets of phase separated glass in the matrix of $B I$ sample appeared. Unfortunately these droplets were so small that microprobe analysis was not possible.

Feature analysis of $A I$ and $B 1$ sections by Revex program gave following results: Agglomerate area in Al was $3.86 \%$ of the field scanned, in BI was this area only 0.57 of the field scanned.

A very detailed electron microanalysis results are presented in the Closing Report of STL No. 254/94) accompanied by a series 
of BSE pictures and EDX spectra. The results of the matrix, agglomerate and separate crystal analysis are presented in Tables A2-3 to A2-8.

Table A2-3: Summary of Analyses Results of Annealed Glass A1

\begin{tabular}{|c|c|c|c|c|c|c|}
\hline $\begin{array}{c}\text { Analyzed } \\
\text { Area }\end{array}$ & \multicolumn{2}{|c|}{$\begin{array}{c}\text { Grained } \\
\text { Particles }\end{array}$} & \multicolumn{2}{c|}{$\begin{array}{c}\text { Isolated } \\
\text { Crystals }\end{array}$} & \multicolumn{2}{c|}{ Matrix } \\
\hline $\mathrm{n}$ & \multicolumn{2}{|c|}{7} & \multicolumn{2}{|c|}{3} & \multicolumn{2}{c|}{15} \\
\hline & $\overline{\mathbf{x}}$ & $\sigma$ & $\overline{\mathbf{x}}$ & $\sigma$ & \multicolumn{2}{|c|}{$\bar{\sigma}$} \\
\hline $\mathrm{Na}_{2} \mathrm{O}$ & 5,4 & 0,6 & 2,0 & 0,8 & 7,59 & 0,22 \\
$\mathrm{Al}_{2} \mathrm{O}_{3}$ & 11,5 & 0,7 & 7,2 & 1,5 & 17,9 & 0,6 \\
$\mathrm{SiO}_{2}$ & 30,7 & 1,6 & 7,2 & 2,2 & 51,4 & 1,1 \\
$\mathrm{Fe}_{2} \mathrm{O}_{3}$ & 1,9 & 0,2 & 2,8 & 0,6 & 1,36 & 0,10 \\
$\mathrm{Cr}_{2} \mathrm{O}_{3}$ & 32,0 & 2,1 & 80,8 & 7,2 & 0,78 & 0,08 \\
$\mathrm{MnO}_{2}$ & $\mathrm{a}$ & & $\mathrm{a}$ & & 0,42 & 0,11 \\
\hline sum & 81,5 & & 100,0 & & 79,45 & \\
\hline
\end{tabular}

Notes:

$n$... number of independent analyses $\sigma .$. standard deviation

$\overline{\mathbf{x}}$... arithmetical mean

a ... value less than $2 \sigma$

Table A2-4: Summary of Analyses Results of Crystal Clusters in Annealed Glass Al

\begin{tabular}{|c|c|c|c|c|c|c|}
\hline $\begin{array}{c}\text { Analyzed } \\
\text { Area }\end{array}$ & \multicolumn{2}{|c|}{$\begin{array}{l}\text { Area } \\
\text { Analysis }\end{array}$} & \multicolumn{2}{|c|}{ Crystals } & \multicolumn{2}{|c|}{$\begin{array}{c}\text { Intercrystal } \\
\text { space }\end{array}$} \\
\hline n & \multicolumn{2}{|c|}{7} & \multicolumn{2}{|c|}{8} & \multicolumn{2}{|c|}{7} \\
\hline & $\bar{x}$ & $\boldsymbol{\sigma}$ & $\overline{\mathbf{x}}$ & $\boldsymbol{\sigma}$ & $\overline{\mathbf{x}}$ & $\sigma$ \\
\hline $\begin{array}{l}\mathrm{Na}_{2} \mathrm{O} \\
\mathrm{Al}_{2} \mathrm{O}_{3} \\
\mathrm{SiO}_{2} \\
\mathrm{Fe}_{2} \mathrm{O}_{3} \\
\mathrm{Cr}_{2} \mathrm{O}_{3} \\
\mathrm{MnO}_{2}\end{array}$ & $\begin{array}{r}6,6 \\
13,2 \\
34,7 \\
2,5 \\
29,7 \\
a\end{array}$ & $\begin{array}{l}0,8 \\
0,7 \\
1,8 \\
0,2 \\
2,5\end{array}$ & $\begin{array}{c}2,3 \\
5,1 \\
8,8 \\
4,3 \\
71,7 \\
a\end{array}$ & $\begin{array}{l}0,8 \\
0,9 \\
3,8 \\
1,4 \\
8,4\end{array}$ & $\begin{array}{r}7,1 \\
16,7 \\
46,0 \\
1,4 \\
5,2 \\
a\end{array}$ & $\begin{array}{l}0,6 \\
1,1 \\
1,9 \\
0,2 \\
2,1\end{array}$ \\
\hline sum & 86,7 & & 92,2 & & 76,4 & \\
\hline
\end{tabular}

Notes: see Table A2-3. 
Table A2-5: Summary of Analyses Results of Crystal Clusters in the Lower Part of the Block (NS $0-2 \mathrm{~mm}$ ) of Annealed Glass BI

\begin{tabular}{|c|c|c|c|c|c|c|}
\hline $\begin{array}{l}\text { Analyzed } \\
\text { Area }\end{array}$ & \multicolumn{2}{|c|}{$\begin{array}{c}\text { Area } \\
\text { Analysis }\end{array}$} & \multicolumn{2}{|c|}{ Crystals } & \multicolumn{2}{|c|}{$\begin{array}{c}\text { Intercrystal } \\
\text { space }\end{array}$} \\
\hline $\mathbf{n}$ & \multicolumn{2}{|c|}{3} & \multicolumn{2}{|c|}{3.} & \multicolumn{2}{|c|}{3} \\
\hline & $\overline{\mathbf{x}}$ & $\boldsymbol{\sigma}$ & $\overline{\mathbf{x}}$ & $\sigma$ & $\overline{\mathbf{x}}$ & $\sigma$ \\
\hline $\begin{array}{l}\mathrm{Na}_{2} \mathrm{O} \\
\mathrm{Al}_{2} \mathrm{O}_{3} \\
\mathrm{SiO}_{2} \\
\mathrm{Fe}_{2} \mathrm{O}_{3} \\
\mathrm{Cr}_{2} \mathrm{O}_{3} \\
\mathrm{MnO}_{2}\end{array}$ & $\begin{array}{r}5,3 \\
17,2 \\
23,5 \\
3,0 \\
43,7 \\
a\end{array}$ & $\begin{array}{l}0,1 \\
1,0 \\
2,0 \\
0,2 \\
3,8\end{array}$ & $\begin{array}{r}2,1 \\
11,7 \\
8,1 \\
4,4 \\
75,9 \\
a\end{array}$ & $\begin{array}{l}0,4 \\
1,0 \\
1,0 \\
0,7 \\
2,5\end{array}$ & $\begin{array}{r}6,3 \\
23,5 \\
37,0 \\
2,0 \\
15,9 \\
a\end{array}$ & $\begin{array}{l}3,5 \\
2,2 \\
5,3 \\
0,5 \\
5,4\end{array}$ \\
\hline sum & 92,7 & & 102,2 & & 84,7 & \\
\hline
\end{tabular}

Notes: see Table A2-3.

Table A2-6: Summary of Analyses Results of Crystal Clusters in the Upper Part of the Block (NS 6-20 mm) of Anealed Glass B1

\begin{tabular}{|c|c|c|c|c|c|c|}
\hline $\begin{array}{c}\text { Analyzed } \\
\text { Area }\end{array}$ & \multicolumn{2}{|c|}{$\begin{array}{c}\text { Area } \\
\text { Analysis }\end{array}$} & \multicolumn{2}{c|}{ Crystals } & \multicolumn{2}{c|}{$\begin{array}{c}\text { Intercrystal } \\
\text { Space }\end{array}$} \\
\hline $\mathrm{n}$ & \multicolumn{2}{|c|}{6} & \multicolumn{2}{c|}{5} & \multicolumn{2}{c|}{3} \\
\hline & $\overline{\mathbf{x}}$ & $\sigma$ & $\overline{\mathrm{x}}$ & $\sigma$ & $\overline{\mathrm{x}}$ & $\sigma$ \\
\hline $\mathrm{Na}_{2} \mathrm{O}_{0}$ & 2,2 & 0,5 & 0,6 & 0,6 & 2,2 & 1,2 \\
$\mathrm{Al}_{2} \mathrm{O}_{3}$ & 17,6 & 1,8 & 7,4 & 1,4 & 24,5 & 3,2 \\
$\mathrm{SiO}_{2}$ & 23,2 & 3,7 & 2,0 & 1,0 & 40,0 & 4,0 \\
$\mathrm{Fe}_{2} \mathrm{O}_{3}$ & 2,9 & 0,4 & 3,2 & 1,5 & 1,6 & 0,3 \\
$\mathrm{Cr}_{3} \mathrm{O}_{3}$ & 37,2 & $\mathbf{8 , 6}$ & 78,0 & 5,3 & 4,2 & 0,7 \\
$\mathrm{MnO}_{2}$ & $\mathrm{a}$ & & $\mathrm{a}$ & & $\mathrm{a}$ & \\
\hline sum & 83,1 & & 91,2 & & 72,5 & \\
\hline
\end{tabular}

Notes: see Table $\mathrm{A} 2-3$. 
Table A2-7: Summary of Analyses Results of the Matrix in Annealed Glass Bl

\begin{tabular}{|c|c|c|c|c|}
\hline $\begin{array}{c}\text { Analyzed } \\
\text { Area }\end{array}$ & \multicolumn{2}{|c|}{ Matrix } & \multicolumn{2}{c|}{ Matrix } \\
\hline $\mathrm{n}$ & \multicolumn{2}{|c|}{5} & \multicolumn{2}{|c|}{ NS 6 - 20 mm } \\
\hline & $\overline{\mathrm{x}}$ & $\sigma$ & $\overline{\mathrm{x}}$ & $\sigma$ \\
\hline $\mathrm{Na}_{2} \mathrm{O}$ & 15,8 & 0,5 & 13,2 & 0,4 \\
$\mathrm{Al}_{2} \mathrm{O}_{3}$ & 25,1 & 0,5 & 25,3 & 0,4 \\
$\mathrm{SiO}_{2}$ & 42,3 & 0,6 & 42,2 & 0,8 \\
$\mathrm{Fe}_{2} \mathrm{O}_{3}$ & 1,98 & 0,07 & 1,92 & 0,16 \\
$\mathrm{Cr}_{2} \mathrm{O}_{3}$ & 1,25 & 0,08 & 0,84 & 0,13 \\
$\mathrm{MnO}_{2}$ & 0,76 & 0,16 & 0,63 & 0,15 \\
\hline sum & 87,19 & & 84,09 & \\
\hline
\end{tabular}

Notes: see Table A2-3.

Table A2-8: Summary of Analyses Results of Spherical Particles from the Lower Part of the Block (NS $0-2 \mathrm{~mm}$ ) and Isolated Crystal

\begin{tabular}{|c|c|c|c|c|}
\hline $\begin{array}{c}\text { Analyzed } \\
\text { Area }\end{array}$ & \multicolumn{2}{|c|}{$\begin{array}{c}\text { Spherical } \\
\text { Particles } \\
\text { NS } 0-2 \mathrm{~mm}\end{array}$} & \multicolumn{2}{c|}{$\begin{array}{c}\text { Isolated } \\
\text { Crystals }\end{array}$} \\
\hline $\mathrm{n}$ & \multicolumn{2}{|c|}{5} & \multicolumn{2}{|c|}{3} \\
\hline & $\overline{\mathbf{x}}$ & 0 & $\overline{\mathbf{x}}$ & $\sigma$ \\
\hline $\mathrm{Na}_{2} \mathrm{O}$ & 13,2 & 1,0 & 0,7 & 0,2 \\
$\mathrm{Al}_{2} \mathrm{O}_{3}$ & 22,6 & 0,4 & 7,1 & 2,3 \\
$\mathrm{SiO}_{2}$ & 35,3 & 1,1 & 2,9 & 3,5 \\
$\mathrm{Fe}_{2} \mathrm{O}_{3}$ & 4,72 & 0,28 & 5,1 & 0,5 \\
$\mathrm{Cr}_{2} \mathrm{O}_{3}$ & 6,6 & 1,4 & 74,9 & 3,7 \\
$\mathrm{MnO}_{2}$ & 2,45 & 0,13 & $\mathrm{a}$ & \\
$\mathrm{NiO}_{\mathrm{ZnO}}^{1,19}$ & 0,15 & $\mathrm{a}$ & \\
\hline sum & 2,03 & 0,33 & $\mathrm{a}$ & \\
\hline
\end{tabular}

Notes: see Table A2-3.

Chemical durability of Glasses $A$ and $B$ using ćsN-Iso standard was presented in the section 4.2.3.3., Table 4-26. 
PREPARATION OF GLASSES A/TEM, B/TEM, A/CCC AND B/CCC

Glasses $A$ and $B$ prepared in the Task 2 were treated according the procedure requested by Task 5 .

Specimens with the labels $\mathrm{A3}$ and B3 were treated by the following procedures:

A3/TEY

Sample was heated. up to the temperature $850^{\circ} \mathrm{C}$ (furnace Kas), transferred to furnace $\mathrm{SK}$, heated for 20 min at $1150^{\circ} \mathrm{C}$, - transferred to the furnace with the temperature $1050^{\circ} \mathrm{C}$, treated for 24 hours and transferred again to the kHs furnace where the treatment continued 2 hours at $500^{\circ} \mathrm{C}$. An uncontrolied cooling sollowed.

\section{B3/TEM}

The procedure was similar to the treatment of the sample A3. Sample was heated up to $850^{\circ} \mathrm{C}$, transferred to the furnace sk, heated for $20 \mathrm{~min}$ at $1450{ }^{\circ} \mathrm{C}$, transferred to another furnace with the temperature. $1350^{\circ} \mathrm{C}$ and treated for 24 hours. Then (because of the danger of crucible cracking) transferred to the sk furnace heated to $1170{ }^{\circ} \mathrm{C}$ ( $30 \mathrm{~min}$ residence time). After this procedure heating 2 hours at $500^{\circ} \mathrm{C}$ was followed by uncontrolled cooling.

Preparation of samples with ccc cooling:

\section{3/CCC}

Heating to the temperature $850^{\circ} \mathrm{C}$ in $\mathrm{kHS}$ furnace, transfer to SK furnace heated to $1150^{\circ} \mathrm{C}$, residence time $20 \mathrm{~min}$., transfer to kHS furnace with 1 hour heating at $87 .{ }^{\circ} \mathrm{C}$, then cooling according to the CCC scheme.

\section{B3/CCC}

Heating to the temperature $850^{\circ} \mathrm{C}$, transfer to the sk furnace ( $1450{ }^{\circ} \mathrm{C}$ ) residence time $20 \mathrm{~min}$, transfer to $\mathrm{sK}$ furnace heated to $1172^{\circ} \mathrm{C}$, cooling to $872^{\circ} \mathrm{C}$ and transfer to the KHs furnace for the cooling according to the CCC scheme.

All samples prepared in the above mentioned ways were cut and photographed. 


\section{Visual evaluation of samples}

\section{A3/TEM}

At the crucible bottom hairline cracks were found. The cut shows small bubbles (diam. $0.5-3.0 \mathrm{~mm}$ ). Foaming was observed during the melting procedure.

\section{A3/CCC}

Hairline cracks at the bottom and on the surface as in the previous case were found. The size of bubbles and their amount was smaller than in A3/TEM case. No foaming.

\section{B3/TEM}

Break surface has character of glass. No bubbles. There were problems with the crucible material. Corundum, quartz and graphite were not found suitable for the experiment. Porcelain MI/168 (after heat treatment at $1500{ }^{\circ} \mathrm{C}$ ) has been used. Even this material was slightly corroded. For measurments only the inner part will be used. No bubbles in the glass have been observed.

\section{B3/CCC}

Hairline cracks were on the surface, small bubbles bellow $1 \mathrm{~mm}$ in the bulk of glass. The surface of the glass is crystallized.(Report svus No. 4 contain photographs of the cuts of glasses. 
ANTEX A3

PREPARATION OF GLASSES WITH LOWER CONTENT OF CHROMIUM OXIDE

PREPARATION OF GLASSES AI/Cr AND B1/Cr

Table A3-1: As-batched Compositions of Glasses $\mathrm{Al} / \mathrm{Cr}$ and $\mathrm{BI} / \mathrm{Cr}$

\begin{tabular}{|c|c|c|}
\hline component & Glass Composition & [Weight $*$ ] \\
\hline & $\mathrm{A} 1 / \mathrm{Cr}$ & $\mathrm{BI} / \mathrm{Cr}$ \\
\hline $\begin{array}{l}\mathrm{SiO}_{2} \\
\mathrm{~B}_{2} \mathrm{O}_{3} \\
\mathrm{Na}_{2} \mathrm{O} \\
\mathrm{Li}_{2} \mathrm{O} \\
\mathrm{CaO} \\
\mathrm{MgO} \\
\mathrm{Fe}_{2} \mathrm{O}_{3} \\
\mathrm{Al}_{2} \mathrm{O}_{3} \\
\mathrm{ZrO}_{2} \\
\mathrm{Cr}_{2} \mathrm{O}_{3} \\
\mathrm{P}_{2} \mathrm{O}_{5} \\
\mathrm{SO}_{3} \\
\mathrm{Na}_{2} \mathrm{O}_{3} \\
\mathrm{La}_{2} \mathrm{O}_{3} \\
\mathrm{~K}_{2} \mathrm{O}_{3} \\
\mathrm{~F} \\
\mathrm{MnO} \\
\mathrm{MOO}_{3} \\
\mathrm{NiO} \\
\mathrm{Cl} \\
\mathrm{ZnO}\end{array}$ & $\begin{array}{r}46.752 \\
17.070 \\
6.245 \\
6.685 \\
0.186 \\
0.018 \\
1.399 \\
16.213 \\
0.021 \\
0.500 \\
0.108 \\
0.057 \\
0.060 \\
0.021 \\
0.075 \\
0.027 \\
0.411 \\
0.108 \\
0.090 \\
0.123 \\
0.186\end{array}$ & $\begin{array}{l}40.239 \\
9.188 \\
9.367 \\
6.334 \\
0.279 \\
0.027 \\
2.099 \\
24.319 \\
0.032 \\
0.500 \\
0.162 \\
0.086 \\
0.090 \\
0.032 \\
0.113 \\
0.041 \\
0.617 \\
0.162 \\
0.135 \\
0.185 \\
0.279\end{array}$ \\
\hline
\end{tabular}

PROPERTIES OF GLASSES $\mathrm{Al} / \mathrm{Cr}$ and $\mathrm{BI} / \mathrm{Cr}$

Glass AI/CI

Liquidus temperature of the glass $A I / C r$ was evaluated according to the standard ASTM C $829-81(86)$. Even at the highest tested temperature the tabular crystals were found in the tempered glass. Since the concentration of crystals at $1320^{\circ} \mathrm{C}$ was not sufficient for $X$-ray identification a part of the gradient boat in the range 1220 - $1250^{\circ} \mathrm{C}$ containing the greater part of microscopic similar crystals for $x$-ray analysis was used. As the only crystalline phase a high temperature eucryptite (see 
Section 4.2.1.1. of this Report) was identified. The presence of crystals corresponding to a high temperature eucryptite (even at $\left.1320^{\circ} \mathrm{C}\right)$ was confirmed using a local analysis of chemical composition in electron scanning microscope (for conditions see Section 4.2.1.2. of this Report).

\section{Glass BI/Cr}

A spinel-type compound corresponding to chromite Feo. $\mathrm{Cr}_{2} \mathrm{O}_{3}$ (ASTM 3-0873) was found as the only crystalline phase by a data file (JCPDS). It is possible to conclude, according to diffraction intensity, that its content is in $\mathrm{m} / \mathrm{m}$ units.

\section{Electron microanalysis}

Samples of both glasses were analyzed by Electron Scanning Microscope Camscan 4-DV with energy-dispersive Analyzer LINK AN 10000 .

only normal polished sections through the block from. Glasses $\mathrm{Al} / \mathrm{Cr}$ and $\mathrm{BI} / \mathrm{Cr}$ were prepared. Before inserting into apparatus, samples have been coated by carbon in high vacuum deposition equipment B 302 .

No texture motives have been observed in sample Al/Cr. In Table A3-2 there is a summary of results of matrix analysis.

In the Glass BI/Cr spherical particles have been found (Figures $A 3-1$ and $A 3-2$ ) in total volume. The upper block surface had a different appearance, and therefore, it has been analyzed separately. The summary of analyses results is given in the Table $A 3-3$

It was probable that during the analysis of tabular crystals (in clusters and isolated crystals as well), considering their very small thickness, surroundings of the crystal could partially interfere in the analysis results. Analogically, during the analysis of spherical particles (considering their size), participation of surrounding matrix could appear in the analysis as we11. 
Table A3-2: Summary of Analytical Results of Glass Al/Cr and Comparison with As-batched Composition

\begin{tabular}{|c|c|c|c|}
\hline $\begin{array}{c}\text { Analyzed } \\
\text { Area }\end{array}$ & \multicolumn{2}{|c|}{ Matrix } & As-batched \\
\hline $\mathbf{n}$ & \multicolumn{2}{|c|}{9} & \\
\hline & $\bar{x}$ & 0 & \\
\hline $\mathrm{Ma}_{2} \mathrm{O}$ & 7,31 & 0,50 & 6,48 \\
$\mathrm{Al}_{3} \mathrm{O}_{3}$ & 17,9 & 0,6 & 16,83 \\
$\mathrm{SiO}_{2}$ & 50,2 & 1,9 & 48,52 \\
$\mathrm{Fe}_{2} \mathrm{O}_{3}$ & 1,56 & 0,14 & 1,45 \\
$\mathrm{Cr}_{2} \mathrm{O}_{3}$ & 0,55 & 0,10 & 0,50 \\
$\mathrm{MnO}_{2}$ & 0,47 & 0,09 & 0,43 \\
\hline sum & 77,99 & & 74,21 \\
\hline
\end{tabular}

Notes: n ... number of independent analyses

$\overline{\mathbf{x}}$... arithmetical mean

$\sigma$... standard deviation

a ... value less than $2 \sigma$

Table A3-3: Summary of Analyses Results of Annealed Glass BI/Cr

\begin{tabular}{|c|c|c|c|c|c|c|}
\hline $\begin{array}{c}\text { Analyzed } \\
\text { Area }\end{array}$ & \multicolumn{2}{|c|}{ Matrix } & \multicolumn{2}{c|}{$\begin{array}{c}\text { Spherical } \\
\text { Particles }\end{array}$} & \multicolumn{2}{c|}{ Upper surface } \\
\hline $\mathrm{n}$ & \multicolumn{2}{|c|}{8} & \multicolumn{2}{|c|}{4} & \multicolumn{2}{c|}{3} \\
\hline & $\overline{\mathbf{x}}$ & $\sigma$ & $\overline{\mathbf{x}}$ & $\sigma$ & $\overline{\mathbf{x}}$ & $\sigma$ \\
\hline $\mathrm{Na}_{2} \mathrm{O}$ & 10,4 & 0,6 & 9,9 & 0,6 & 9,3 & 0,2 \\
$\mathrm{Al}_{2} \mathrm{O}_{3}$ & 26,1 & 1,9 & 24,0 & 1,1 & 24,5 & 0,7 \\
$\mathrm{SiO}_{2}$ & 41,4 & 2,7 & 34,0 & 1,7 & 40,4 & 1,0 \\
$\mathrm{Fe}_{2} \mathrm{O}_{3}$ & 2,43 & 0,22 & 9,5 & 1,1 & 2,91 & 0,27 \\
$\mathrm{Cr}_{2} \mathrm{O}_{3}$ & 0,60 & 0,17 & 5,67 & 0,85 & 0,46 & 0,10 \\
$\mathrm{MnO}_{2}$ & 0,74 & 0,15 & 2,30 & 0,28 & 0,98 & 0,13 \\
$\mathrm{NiO}^{2}$ & $\mathrm{a}$ & & 2,16 & 0,33 & $\mathrm{a}$ & \\
$\mathrm{ZnO}$ & $\mathrm{a}$ & & 2,20 & 0,42 & $\mathrm{a}$ & \\
\hline sum & 81,67 & & 89,73 & & 78,55 & \\
\hline
\end{tabular}

Notes: see the above Table 


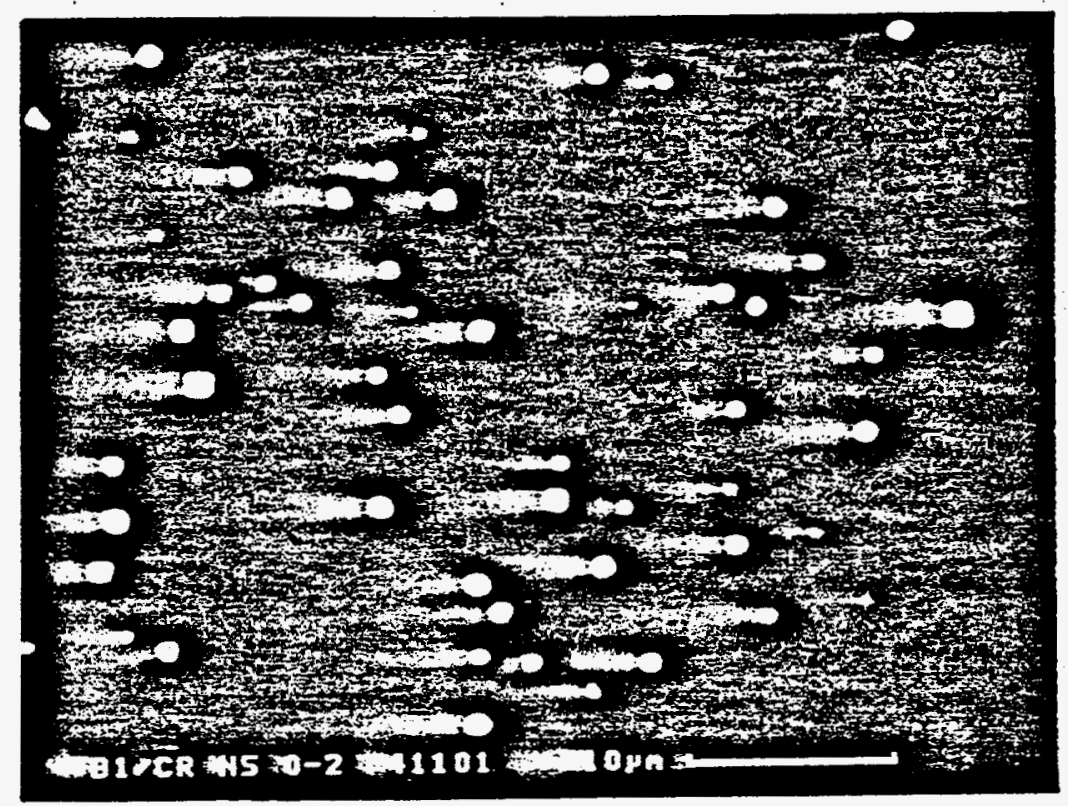

Figure A3-1: B1/Cr. Normal section (NS 0-2 mm). Microscope Camscan 4-DV, BSE.

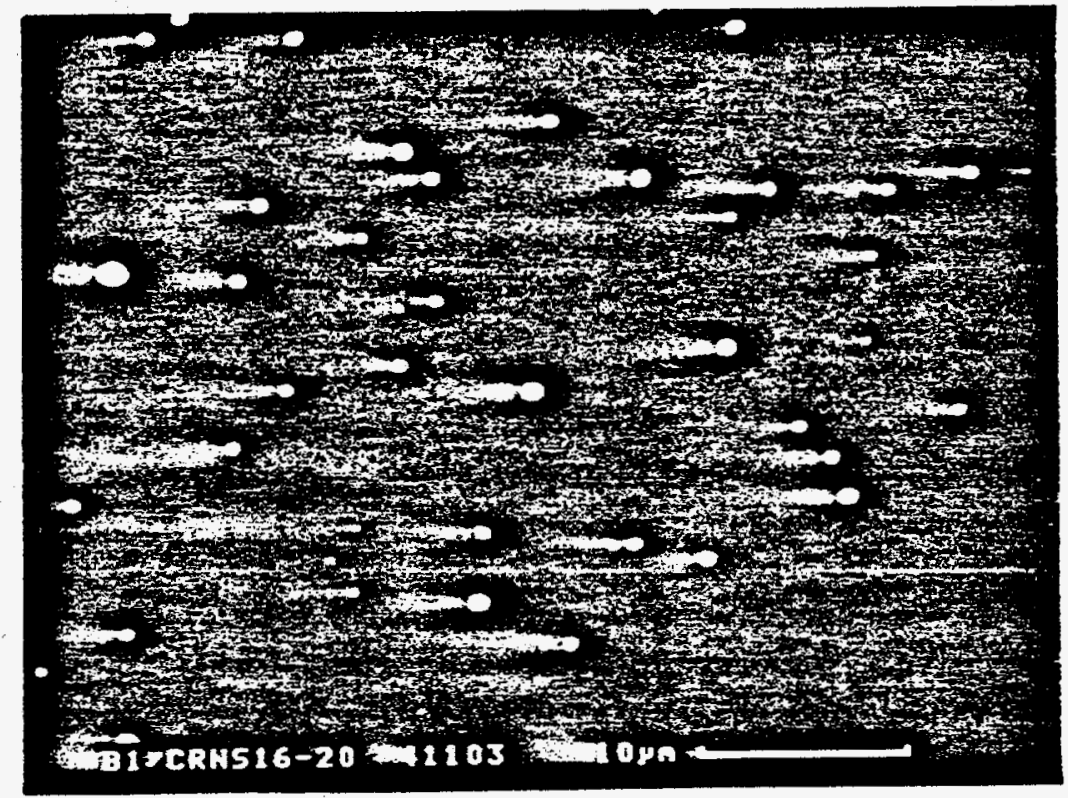

Figure $A 3-2: B 1 / C R$. Normal section (NS 16-20 mm). Microscope Camscan 4-DV, BSE. 


\section{ANNEXES B}

METHODS AND PROCEDURES

AMIEX 81

QUANTITATIVE CHEMICAL ANAIYSES OF CHROMIUY HYDROXIDE:

Yethods used in Glass Institute, STL

\section{Preparation of testing sample}

From a container with ground and homogenized chromium hydroxide app. $100 \mathrm{~g}$ of a sample was taken and dried at $105 \pm 2^{\circ} \mathrm{C}$ to a constant weight. Dried sample transferred to a weighing bottle with a ground-glass joint and located in desiccator.

Experimental part

The content of chromium oxide, $\mathrm{Cr}_{2} \mathrm{O}_{3}$ (wt., ) determined by

a) a gravimetric method according to the standard CSN 720108 after a dissolution of the sample in hydrochloric acid, $c(\mathrm{HCl})=6 \mathrm{~mol} / \mathrm{l}$.

b) redox titration using ferrous salt after a catalytic oxidation of chromium Cr(III) to chromium $\operatorname{Cr}(\mathrm{VI})$ in acidic medium according to the following procedure:

The sample weight about $0.25 \mathrm{~g}$ differentially weighed with a precision of $0.1 \mathrm{mg}$ to an app. $250 \mathrm{ml}$ beaker and dissolved in hydrochloric acid $c(\mathrm{HCl})=6 \mathrm{~mol} / \mathrm{l}$ while boiling. The excess of hydrochloric acid removed by fuming on heating plate at presence of $5 \mathrm{ml}$ of sulfuric acid, $\mathrm{c}\left(\mathrm{H}_{2} \mathrm{SO}_{4}\right)=8 \mathrm{~mol} / 2$. Then the solution diluted by water to a volume app. $75 \mathrm{ml}, 1 \mathrm{ml}$ of silver nitrate, $c\left(\mathrm{ANO}_{3}\right)=0.02 \mathrm{~mol} / \mathrm{l}$ and $0.5 \mathrm{~g}$ of potassium peroxodisulfate were added. Reaction mixture heated to a boiling point and boiled during 15 minutes. After cooling the solution quantitatively transferred to $100 \mathrm{ml}$ volumetric flask and diluted with deionized water up to the mark. In the aliquot part of a sample stock solution the $C r(+V I)$ concentration determined by titration with diammonium iron (II) bissulfate hexahydrate, $\left.c\left(\left(\mathrm{NH}_{4}\right)_{2} \mathrm{Fe}\left(\mathrm{SO}_{4}\right)_{2} \times 6 \mathrm{H}_{2} \mathrm{O}\right)\right)=0.1 \mathrm{~mol} / 1$ at potentiometric indication of equivalent point. 
The content of sodium oxide (wt. i) determined by spectrometric method according to Internal regulation $\mathrm{CH}-42 \mathrm{a}-92$ in an extract prepared according to the following procedure:

The sample of chromium hydroxide with weight app. $0.1 \mathrm{~g}$ weighed with a precision of $0.1 \mathrm{mg}$ to a $150 \mathrm{ml}$ beaker and extracted 2 times, every time with app. $20 \mathrm{ml}$ of hot deionized water. After sedimentation of a precipitate the liquid part transferred on a filter, blue ribbon (dense, slow filtering). The filtrate collected into a $100 \mathrm{ml}$ volumetric flask up to the volume app. $60 \mathrm{ml}$. In the end of the extraction the precipitate transferred quantitatively from the beaker on filter by hot deionized water and washed by such water volume until the total filtrate volume was approx. $80 \mathrm{ml}$. The filtrate acidified by hydrochloric acid, $c(\mathrm{HCl})=6 \mathrm{~mol} / \mathrm{l}$ on indicator methylorange $(\mathrm{pH}=3.1)$ and after cooling to laboratory temperature diluted with water up to the mark.

In the aliquot part of a stock solution the sodium oxide concentration determined according to the Internal regulation CH-42a-92 using the calibration curve method. Calibration solutions in the range $0-4 \mathrm{mg} / 1 \mathrm{Na}$ prepared by diluting of a sodium nitrate stock solution ( $1 \mathrm{ml}=1 \mathrm{mg} \mathrm{Na}$ ) to the concentration $(1 \mathrm{ml}=0.1 \mathrm{mg} \mathrm{Na})$ with following pipetting of aliquot parts $0.0-4.0 \mathrm{ml}$ to $100 \mathrm{ml}$ volumetric flasks and diluting with water up to the mark.

The content of nitrates $\mathrm{NO}_{3}^{-}$(wt. \&) determined using a ion selective nitrate electrode (ISE $\mathrm{NO}_{3}{ }^{-}$) in extract prepared according to the following procedure:

The sample of chromium hydroxide in weight app. $1 \mathrm{~g}$ weighed in precision of $0.1 \mathrm{mg}$ to a $100 \mathrm{ml}$ beaker and extracted by $50 \mathrm{ml}$ of deionized water while boiling during 5 minutes. After sedimentation the clear liquid transferred on a filter, white ribbon (high-rate filtering) and the filtrate collected into a $250 \mathrm{ml}$ beaker. $50 \mathrm{ml}$ of deionized water added to the precipitate and the extraction and decantation operations repeated. In the end of extraction $50 \mathrm{ml}$ of potassium sulfate, 
$\mathrm{K}_{2} \mathrm{SO}_{4}=1$ wt. $\%$ added to the precipitate in the beaker. Reaction mixture heated to the boiling point and boiled during 5 minutes. Then the content of the beaker quantitatively transferred on filter. The precipitate on filter washed by three parts of hot distilled water, every part in volume app. $10 \mathrm{ml}$ and filtrate collected to the $250 \mathrm{ml}$ beaker, which contained former decanted parts. After cooling $2 \mathrm{~g}$ of solid potassium sulfate added to the solution. The pH of extracts adjusted to indicator methylorange to the value 3.1 by adding of diluted sulphuric acid. The solution shortly boiled for decomposition of event. present carbonates. - After cooling the solution quantitatively transferred to a $250 \mathrm{ml}$ volumetric llask and diluted by deionized water up to the mark. The aliquot part of the stock solution pipetted to a $100 \mathrm{ml}$ beaker and diluted by potasium sulfate, $\mathrm{K}_{2} \mathrm{SO}_{4}=1 \mathrm{wt}$. $\%$, to the final volume $50 \mathrm{ml}$. The concentration (activity) of nitrate ions measured by the calibration curve method using the ion-selective nitrate electrode. Calibration solutions with concentration $0-1000 \mathrm{\mu g}$ $\mathrm{NO}_{3}{ }^{-}$in $50 \mathrm{ml}$ prepared from the stock solution of sodium nitrate ( $1 \mathrm{ml}=1 \mathrm{mg} \mathrm{NO}_{3}{ }^{-}$) by. pipetting of aliquot parts to $100 \mathrm{ml}$ beakers and diluting to final volume $50 \mathrm{ml}$ by pipetting of the potassium sulphate, $\mathrm{K}_{2} \mathrm{SO}_{4}=1$ wt. $z$.

The contents of aluminium and iron(III) oxides (wt. \&)

determined according to quoted documents after transferring of the sample to a solution by dissolving in hydrochloric acid, $c(\mathrm{HCl})=6 \mathrm{~mol} / \mathrm{l}$. 


\section{AMNEX B2}

METHODS FOR THE DETERMINATION OF TOTAL AND HEXAVALENT CHROMIUM IN CHROMIUM GLASSES AND LEACHING SOLUTIONS

\section{Nuclear Research Institute}

\section{Determination of total chromium}

Principle:

The method consists of two steps. In the first step, all chromium was oxidized to soluble chromate. After leaching with water, the chromium content was determined spectrophotometrically as chromate or by AAs method.

\subsection{Sample dissolution}

The glass samples were homogenized by powdering in an agate mortar. The weight aliquots (100-200mg) were weighed into a porcelain crucible and thoroughly mixed with a $\mathrm{Na}_{2} \mathrm{CO}_{3}+\mathrm{NaNO}_{3}$ mixture $(3+2)$. The mixture was fused using a gas-burner at first and then in an electrical furnace $\left(800^{\circ} \mathrm{C}\right)$. After the fusion ( $60 \mathrm{~min}$ ), the melt was cooled and leached with a hot distilled water. The extract was collected in a $50 \mathrm{ml}$ volumetric flask and after cooling, the volume was adjusted up to mark. This stock solution served for the total chromium content determination.

\section{2 spectrophotometic determination of total chromium}

The aliquots of stock solution $(1.0-2.0 \mathrm{ml})$, containing about $250 \mathrm{ug}$ of $\mathrm{Cr}$, were pipetted into $25 \mathrm{ml}$ volumetric flask. Them $4.0 \mathrm{ml}$ of $2.5 \mathrm{M} \mathrm{NaOH}$ were added and the volume was made up to mark with redistilled water. After mixing, the absorbance of chromate was measured in $1 \mathrm{~cm}$ cells at $380 \mathrm{~nm}$ against a blank. The chromium content was determined with the aid of a calibration graph. The calibration dependence was obtained by measurement of the standard solution of potassium bichromate under the same conditions as for the samples. The standard solution of bichromate was prepared by weighing of standard Reference Material (SRM) NBS-136d $\left(\mathrm{K}_{2} \mathrm{Cr}_{2} \mathrm{O}_{7}\right.$ of 99,9931 wt purity). 
-1.3 Determination of chromium content with AAs method

See The method of total Cr determination in water leachates of glass grains using the flame AAS, MRI-140-94403/ACr [ANNEX BII].

2. Determination of hexavalent chromium

Principle:

The glass samples were heated with sodium hydroxide under higher temperature and pressure. The hexavalent chromium released into solution as chromate was determinated spectrophotometrically.

\subsection{Sample treatment}

The weight aliquots (100-200 $\mathrm{mg}$ ) of well homogenized samples of chromium glasses were transferred into teflone containers. Then $4.0 \mathrm{ml}$ of dearized $1.5 \mathrm{M}$ NaOH was added to each aliquot. The containers with samples were introduced into a pressure dissolution apparatus. The samples were treated under pressure at $170-180^{\circ} \mathrm{C}$ for 24 hours. After cooling, the mixture was quantitatively transferred together with $0,5 \mathrm{M} \mathrm{NaOH}$ into a $50 \mathrm{ml}$ volumetric flask. After adjusting up to mark, the aliquots for hexavalent chromium determination were taken from the solution.

2.2 Chromium (VI) determination

The aliquots containing between $10-40 \mathrm{\mu g}$ of $\mathrm{Cr}$ (VI) were pipetted into a $50 \mathrm{ml}$ volumetric flasks. After dilution with redistilled water, the samples were neutralized with phosphoric acid $(\mathrm{pH}=7)$. Then, $1.0 \mathrm{ml}$ of diluted phosphoric acid $(7+3)$ and $1.0 \mathrm{ml}$ of diphenylcarbazide (DPC) solution $(1 \mathrm{~g} \mathrm{DPC} / 100 \mathrm{ml}$ of Acetone) were pipetted and redistilled water was added up to $50 \mathrm{ml}$. After 30 minut of standing (when the color intensity is constant) the absorbance was measured at $550 \mathrm{~nm}$ in $1 \mathrm{~cm}$ cells against blank. The calibration graph (between 2.5 - $40 \mathrm{\mu g}$ of Cr(VI) was constructed from standard solutions of potassium bichromate $(100 \mu \mathrm{g} / \mathrm{ml})$. The standard solution was prepared by weighing of SRM NBS-136d (99.9931t of purity).

Note: The leaching solution of chromium glasses were analyzed with the aid of methods described above. 
Methods used in the Glass Institute, State Testing Laboratory: (B3 to BiO)

\section{ANNEX B3}

\section{DETERMINATION OF LIOUIDUS TEMPERATURE}

The determination was carried out according to the standard ASTM C 829-81 (86) and the evaluation method was completed by electron scanning microscopy, microanalysis and $x-r a y$ diffraction with regard to a very dark colour of samples and escolaite crystal abundance which did not allow a standard evaluation by optical microscope.

The used procedure is similar to the Direct Crystallization Test GDL-IQT but with following differences:

a) a sample granulometry below $0.85 \mathrm{~mm}$ used according to the ASTM C 829-81 (86) (according to the GDL-LQT 1 - $3 \mathrm{~mm}$ ),

b) the treated boat not annealed again (according to the GDI-LQT the boat is annealed again at $500-525^{\circ} \mathrm{C}$ ),

c) the investigation carried.out in a tempered sample after lifting from PtRh boat without cutting to sections, the fracture surfaces of fragments used in the electron scanning microscope (according to the GDL-LQT sections are prepared).

We do not suppose that any of procedure differences could cause a change in the results.

\section{Specification of used procedure:}

PtRh10\% boats $(9.5 \times 12.7 \times 140 \mathrm{~mm})$ in gradient resistance furnace with accuracy of temperature control $\pm 2^{\circ} \mathrm{C}$, maximum temperature $1320^{\circ} \mathrm{C}$, standard tempering time 24 hours, temperature measured by a calibrated thermocouple, type $s$, with automatic temperature registration in intervals by the $5 \mathrm{~mm}$, two independent measurements, accuracy of liquidus temperature determination (of normal glasses) is better than $10^{\circ} \mathrm{C}$. Evaluation by electron scanning microscope and microanalyzer. 


\section{ANNEX B4}

\section{DETERMINATION OF VISCOSITY BY ROTARY VISCOMETER}

The determination was carried out according to the standard ĆSN ISO 7884-2 (the translation of International standard Iso 7884-2.).

There are following differences in comparison with GDL-VIS:

a) the sample melted-down in the greatest possible pieces (limitation of bubble forming) and not washed by ethanol,

b) the measuring procedure simplified with regard to inhomogeneous glasses for limiting the crystallization effect as much as possible.

\section{Specification of used procedure}

Searle type rotary viscometer with use of a spherical element from PtRhlo\%, diameter $12 \mathrm{~mm}$. The measuring range of the apparatus is $5.10^{2}-5.10^{4}$ dPa.s, maximum temperature $1550{ }^{\circ} \mathrm{C}$. PtRhlo crucibles, diameter $35 \mathrm{~mm}$, height $55 \mathrm{~mm}$. Sample volume before melting down $33.7 \mathrm{~cm}^{3}$. The apparatus calibration carried out on a standard glass NBS 711 in the temperature range $837{ }^{\circ} \mathrm{C}$ to $1236^{\circ} \mathrm{C}$. The calibrated thermocouple, typ $\mathrm{B}$, used for temperature measurement was situated $5 \mathrm{~mm}$ above the melt surface. The furnace temperature controlled by a controller Eurotherm 94 with precision $\pm 1{ }^{\circ} \mathrm{C}$. The precision of temperature determination is $\pm 2^{\circ} \mathrm{C}$, the accuracy of viscosity determination by used apparatus corresponds to $\pm 3^{\circ} \mathrm{C}$ in the measured viscosity range.

The sample was melted down at a temperature lower than melting point, after melting down a sphere was immersed and the temperature was increased up to the melting point. After stabilizing of conditions the viscosity was measured in intervals by the approx. $50{ }^{\circ} \mathrm{C}$ down to lower temperatures as long as the measurement was possible.

For the description of viscosity temperature dependence, the Vogel-Fulcher-Tammann (VFT) equation was used. From measured viscosity values the constants of VFT equations with the application of ADSTAT programme (modul of Non-linear regression) were calculated. 
Notes: The measurement with a standard NBS 711 was carried out up to the temperature $1328{ }^{\circ} \mathrm{C}$. Above $1250^{\circ} \mathrm{C}$ an intensive volatilization of lead compounds was found, which caused a change of the glass melt composition and viscosity, as well.

The viscosity is given in dPa.s (it corresponds to the earlier used Poise). For converting the $10 \mathrm{dPa} . \mathrm{s}=1 \mathrm{~Pa} . \mathrm{s}$.

\section{ANNEX $\mathbf{B 5}$}

DETERMINATION OF ELECTRIC CONDUCTIVITY OR SPECIFIC ELECTRIC RESISTANCE OF GLASS MELTS AT HIGH TEMPERATURES

There was measured a specific electric resistance which is a reciprocal value of electric conductivity.

Samples were measured on an apparatus delivered by VEzAs, Hradec Králové, which is similar to the apparatus described in PSL-417-ELC as for the construction. The furnace with control and temperature measurement is corresponding to the rotary viscometer. The measuring part consists of two plate PtRh10\% electrodes, height $30 \mathrm{~mm}$, width $10 \mathrm{~mm}$, distance $7.8 \mathrm{~mm}$, which are immersed to the glass melt to the depth $15 \mathrm{~mm}$. The glass melt was melted-down in PtRh10 crucible, diameter $35 \mathrm{~mm}$, height $55 \mathrm{~mm}$. Calibrated thermocouple, type $B$, was located $5 \mathrm{~mm}$ under the glass melt level.

The evaluating unit, constructed by vezAs is connected to electrodes by a pair of shielded cabels, the inside conductors of which are connected to one electrode and the shielding to the other. During the measurement a constant alternating current $20 \mathrm{~mA}$, frequence $\mathrm{l} \mathrm{kHz}$, passes through a current circuit. A voltage on electrodes, dependent on a glass melt resistance, is measured in a parallel measuring circuit in a current-free stage by a precise voltmeter MT 100 with high plate resistance. The effect of the resistance change of lead-in wires with temperature is eliminated by this. In the measuring circuit a logarithmic converter is connected, that means that to the resistance change by 1 order corresponds the output voltage change by $2 \mathrm{v}$. 
The evaluating unit is calibrated to a number of calibrated resistors in the range 0.1 - $500 \Omega$. The cell constant is determined by a calibrating measurement of the glass NBS 711. A supposed accuracy of the specific electric resistance determination (or its reciprocal value, i.e. conductivity) is \pm 5 .

The measurement procedure was similar to the viscosity measurement. The melted down samples were used for measurement after viscosity measurement.

For the description of the temperature dependence of the specific electric resistance was used the Vogel-Fulcher-Tammann (VFT) equation. The VFT equation constants were calculated by the programine ADSTAT (modul of Non-linear regression) from the measured values of resistance after the recalculation to the specific electric resistance.

Notes:

a) A new melted down glass sample NBS 711 was used for calibration. This glass is not very suitable as a standard. regarding its intensive volatilization at higher temperatures.

b) The resistivity was measured by the use of harmonic AC at frequency $1 \mathrm{kHz}$. The polarization effects, in that case, are negligible. If lower frequencies (less than $500 \mathrm{~Hz}$ ) are applied, the polarization process begins its important influence of the measured resistivity value. This fact was verified by impedance analyser HP 4192A. The measuring frequency is not stated in PSL-417-ELC.

\section{ANNEX $\mathrm{B6}$}

\section{DETERMINATION OF DENSITY}

The samples of glasses were tested according to the ASTM C $693-84(88)$ by a method of double measuring in distilled water. Helium pycnometer AUTOPYCNOMETER 1320 and the Internal Regulation F-11-93 were used for the measurements. The result density value is an average of three independent measurements. 
ANNEX B7

DETERMINATION OF MEAN COEFFICIENT OF LINEAR THERMAI EXPANSION AND DILATOMETRIC TRANSFORMATION TEMPERATURE

The determination was carried out according to the standard CSN ISO 7991 and CSN ISO 7884-8 which are the translations of International standards ISO 7991 and ISO 7884-8.

The measurement was carried out on dilatometer DI 22 from Adamel Lhomargy. Heating rate $4^{\circ} \mathrm{C} / \mathrm{min}$, samples in the form of prisms, dimensions $5 \times 5 \times 25 \mathrm{~mm}$. Sample faces were ground in the plane perpendicular to the longitudinal axis. The accuracy of temperature $\mathrm{Tg}$ determination is $\pm 3^{\circ} \mathrm{C}$.

Unstandardized softening temperature $t_{d}$ was evaluated directly from the dilatometric curve as a temperature at which the elongation of measured sample was stopped due to the influence of the thrust mechanism pressure. Thrust force of the draw rod was adjusted on $18 \mathrm{cN}$.

ANNEX B8

X-RAY DIFFRACTION IDENTIFICATION OF CRYSTALLINE PHASES

$x$-ray diffraction analysis was carried out on the apparatus siemens $U$ 13-008 (diffractometer with a record on recorder), using $\mathrm{Cu} \mathrm{K}$ alpha radiation, $\mathrm{Ni}$ filter.

Samples were crushed and ground in a grinding equipment with a hard metal lining. In the sample holder they were fixed with an addition of pure vaseline. The evaluation was carried out by comparison with a data file ASTM (JCPDS). 
ANTEX 89

PHOTODOCUMENTATION AND ANALYSIS IN ELECTRON SCANNING

MICROSCOPE

Photodocumentation and analysis were carried out on electron scanning microscope Camscan 4-DV from Cambridge Instruments with energy dispersive analyzer LINR AN 10000 and wave dispersive analyzer Microspec WDX-2A.

The samples surface was polished on a polishing device and then on an equipment by a free diamond (DSM $2 / 1$ Pramet or PWD 3-1 Wolters) on a brass support plate. Before inserting into apparatus, samples were coated by carbon in a high vacuum (steaming) equipment B 302 .

Photodocumentation was carried out in back electrones (BSE) or secondary electrones (SEI). Taking of snaps was carried out in the following conditions: accelerating voltage $20 \mathrm{kV}$, working distance $29 \mathrm{~mm}$, shield 2 , resolution 4.

The EDX spectra of selected areas were made by energy dispersive analyzer IINK AN 10000. The gained spectra were quantitatively evaluated by a correction programme ZAF-4/FIS, which is a part of programme equipment of analyzer, and statistically evaluated. Using the MAPPING programme there were made $x$-ray distributions of selected elements.

The wave dispersive analyzer Microspec WDX-2A was used for verification of $\mathrm{B}_{2} \mathrm{O}_{3}$ presence in selected samples areas. Bibliography:

ASTM C 829-81(86) Standard method for measuring of liquidus temperature of glass by a method of gradient furnace. (See Annex B3).

¿SN ISO 7884-2 Viscosity and reference viscosity points. Part 2: viscosity determination by rotary viscometer. (See Annex B4).

ASTM C 693-84(88) standard testing method for determination of the glass density by the hydrostatic weighing. (See Annex B6). 
CSN ISO 7991 Determination of medium coefficient of linear

(thermal) expansion. (See Annex B7).

CSN ISO 7884-8 Viscosity and reference viscosity points. Determination of dilatometric transformation temperature $t_{g}$ (See Annex $B 7$ ).

ANNEX B1O

DETERMINATION OF THE SUM OF Nd ${ }_{2} \mathrm{O}_{3}+\mathrm{La}_{2} \mathrm{O}_{3}+\mathrm{ZrO}_{2}$

The sample decomposed by an action of hydrofluoric and perchloric acid at increased temperature and atmospheric pressure. To the evaporation residue $0,5 \mathrm{ml}$ of conc. perchloric acid was added, diluted by water and quantitatively transferred to a $150 \mathrm{ml}$ beaker. Reaction mixture was heated up to the boiling point and shortly boiled. After cooling, the undissolved part was filtered off, the filtrate collected to a $100 \mathrm{ml}$ volumetric flask and diluted with water up to the mark.

From the sample stock solution prepared by this procedure an aliquot part was pipetted and the sum $\left(\mathrm{Nd}_{2} \mathrm{O}_{3}+\mathrm{La}_{2} \mathrm{O}_{3}+\mathrm{ZrO}_{2}\right)$ was determined spectrophotometrically using arsenaso III agent according to a procedure by Marczenko Z.: Separation and Spectrophotometric Determination of Elements, Ellis Horwood Limited, 1986, pp. 468-470.

The calibration curve was prepared on a basis of neodymium(III) chloride solution in a weight range up to $40 \mathrm{\mu g}$ of $\mathrm{Na}_{2} \mathrm{O}_{3}$. The absorbance of solutions was measured at a wavelength $650 \mathrm{~nm}$. 
ANREX B11

Nuclear Research Institute

TOTAL CHROMIUY DETERYINATION IN WATER-GLASS LEACHATES USING

FLAME-AAS

Atomic absorption spectrometry, with flame atomization according to the standard method as described in the Method $s$ Manual (Allied Analytical System, 1983). was used to determine total chromium in the water leachates. Basic instrumental parameters are reproduced in the Part $A$. A higher $\mathrm{N}_{2} \mathrm{O} / \mathrm{C}_{2} \mathrm{H}_{2}$ ratio with lower red cone (cca $5 \mathrm{~mm}$ ) of the flame was used in order to eliminate an influence of the chromium oxidation state as described in literature (Price, 1983) and to get on optimal signal/noise ratio.

Commercial chromium standard. solution ( $1000 \mathrm{mg} . \mathrm{I}^{-1}$ ) was. used to prepare calibration solutions $\left(1.0-2.5-5.0 \mathrm{mg} .1^{-1}\right)$ in cca 0.1 mol.1 $\mathrm{I}^{-1} \mathrm{HNO}_{3}$. All the leachates measured were acidified with concentrated $\mathrm{HNO}_{3}$ to the same value. An example of the calibratin curve is given in the part B. Limit of detection of the method was $30 \div 40 \mathrm{~kg} \mathrm{Cr.1}-1$.

\section{Materials}

- Nitric acid, 65 \%, analytical grade (LACHEMA).

- Chromium standard solution (1000 $\mathrm{g} . \mathrm{I}^{-1}$ ) SPECTROSOL (BDH CHEMICALS Ltd.).

- Deionized water.

Instruments

- Atomic absorption spectrometr, IL VIDEO 12 (INSTRUMENTATION LABORATORY).

- Water demineralizer, MIILI Q (MILIIPORE). 
STANDARD ATOMIC ABSORPTION CONDITIONS

\section{Cr DETERMINATION BY FLAME ATOMIZATION}

\section{INSTRUMENTAL PARAMETERS}

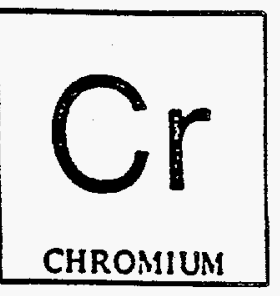

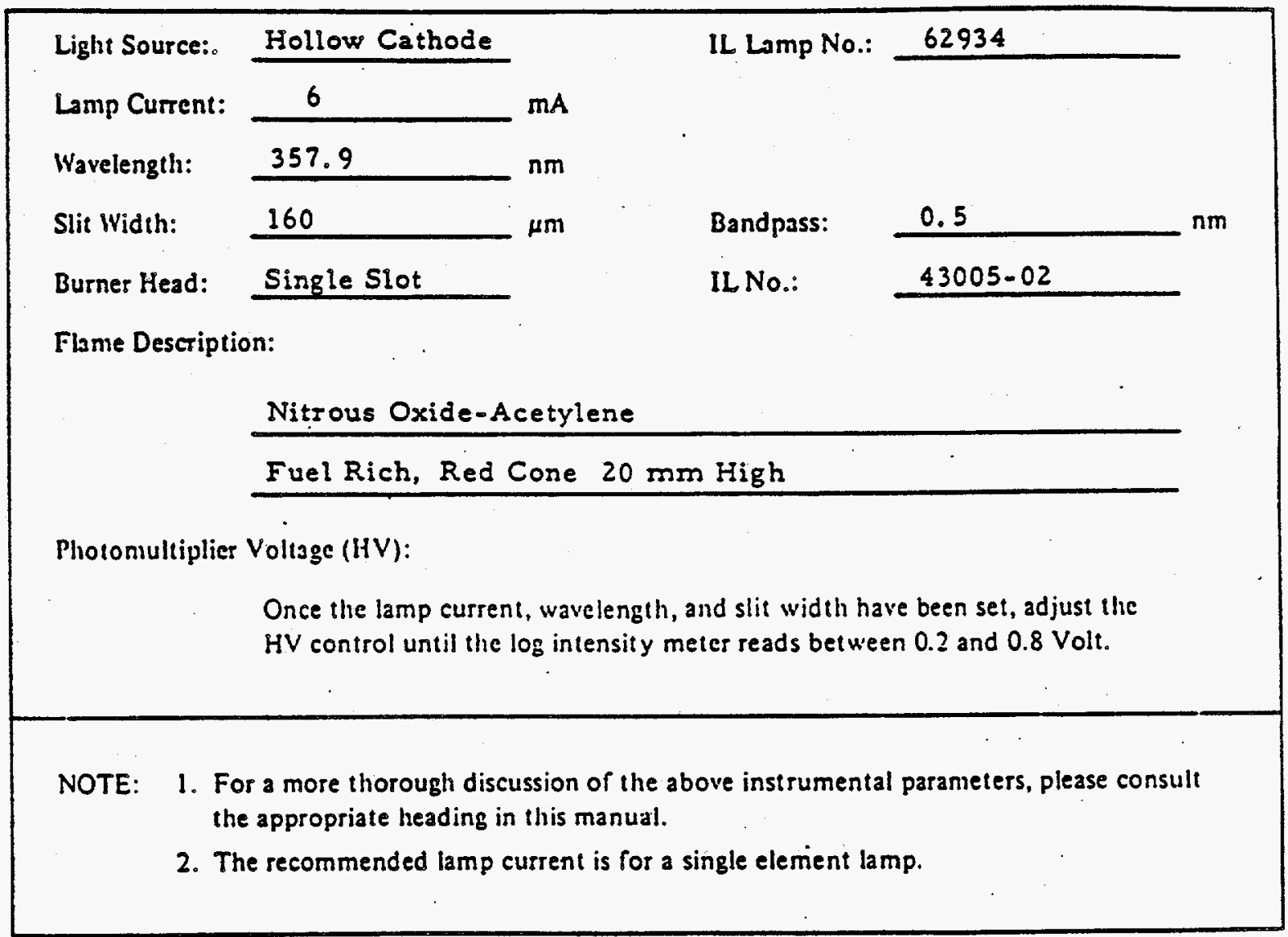

Sensitivity

The sensitivity (at 0.0044 Absorbance $=1 \%$ Absorption) is about $0.06 \mu \mathrm{g} / \mathrm{ml}$ for the instrumental parameters described above.

A standard containing _ 1 $\mu \mathrm{g} / \mathrm{ml}$ of $\mathrm{Cr}_{\mathrm{r}}$ will give a reading of approximately $0.1 \mathrm{~A}$.

\section{Linear Range}

The working range for $\mathrm{Cr}$ is linear up lo a concentration of approximately $5 \mu \mathrm{g} / \mathrm{m}$ l (when using an aqueous solution and the instrumental parameters deseribed above). 
PART A (cont.)

\author{
STANDARD ATOMIC ABSORITION CONDITIONS \\ CEDETERMINATION BY FLAME ATOMIZATION
}

Preparation of Standard Solution:

Dissolve 1.0000 gram of metallic chromium in $50 \mathrm{ml}$ of $1: 1$ hydrochloric acid with gentle heating. Cool and dilute quantitatively to a volume of 1 liter. Final concentration is $1000 \mu \mathrm{g} / \mathrm{ml} \mathrm{C}_{5}$.

Alternate Analytical Lines:

\section{Wavelength (nin)}

357.9

359.4

360.5

425.4

427.5

428.9

520.8

520.5
Approximate Sensitivity ( $\mu \mathrm{g} / \mathrm{mn})$

0.06

0.10

0.13

0.20

0.23

0.50

12.0

30.0
Slit Widtls $(\mu \mathrm{m}) / \mathrm{SBW}(\mathrm{nm})$

$160 / 0.5$

$160 / 0.5$

$160 / 0.5$

$160 / 0.5$

$160 / 0.5$

$160 / 0.5$

$40 / 0.15$

$40 / 0.15$

Interferences:

Chromium absorption is suppressed by cobalt, iron and nickel in an air-acetylene flame. especially in the presence of perchloric acid. The signal suppression can also be overcome by use of a nitrous oxide-acetylene flame. No ionization suppressant is necessary.

In addition, the iron interference can be minimized by the addition of $2 \%(w / v) \mathrm{NF}_{4} \mathrm{Cl}$ to the samples and standard solutions.

Several investigators have found interference from copper, barium, aluminum, magnesium, and calcium in an air-acetylene flame. The extent of this interference is strongly dependent on flame stoiehiometry. Use of a nitrous oxide-acetylene name will eliminate the interference.

Flame Emission:

The most sensitive emission wavelength for $C r$ is $425.4 \mathrm{~nm}$. A nitrous oxideacetylene flame having a red leather height of $8 \mathrm{~mm}$ is recommended. Alternate emission wavelengths for $C_{5}$ are $429.0 \mathrm{~nm}, 427.5 \mathrm{~nm}, 360^{2} .5 \mathrm{~nm}, 359.4 \mathrm{~nm}$ and $357.9 \mathrm{~nm}$, respectively. 


\section{PART B}

Flame Conditigns:

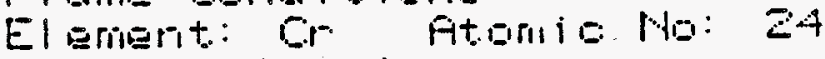
HCL $B$ mas $s i g$ )

Mitraus Opidericetylene

Fiaducing: (Fuel Fieh)

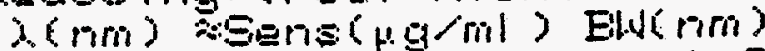
357.9
425.4
428.3
Q.
‥ 20
6. 50
1. 0
․․

Interferences:

Ghemical: See Methods Manual

Standard 0

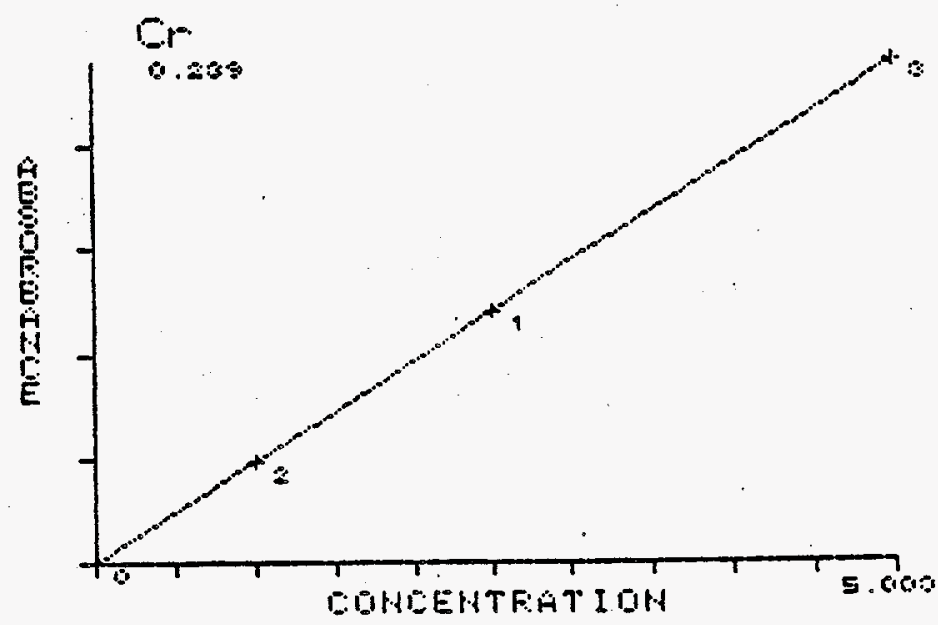

CALIBRATE A STD CONC

0.000

MEAN

0.000

12.500

1.000

0.120

0.048

APP CONC

0.239

STD $0 \quad 0.000$

STD 12.505

STD 20.995

STD $3 \quad 5.001$

A.UTO ZERO

10: $16: 47$

Fri 24 FEB 1995 


\section{ANNEX B12}

Nuclear Research Institute

MEASUREMENT OF CASTING ABILITY

In. order to get a simple scale of the casting ability for prepared glasses the proportion of cast glass was weighed. The procedure was used only for comparison of batches which should give $100 \mathrm{~g}$ of product. Two members of staff were trained to cut the casting glass approximately in the moment of similar apparent viscosity.

A well pronounced linear. relationship between the estimated casting ability and calculated viscosity, using Arrhenius equation and regression coefficients published by Hrma (2994) for temperature range from 950 to $1250^{\circ} \mathrm{C}$, is given in Figure B12-1.

Indicated points include the measurements of glasses for Glass 1 modification which were prepared at NRI in the range of temperature from 1150 to $1250^{\circ} \mathrm{C}$. Two outliers, N5I and I56, belonge to the series without any $L i$ content and with low concentration of Al. Points resulting from the measurement of glasses prepared at higher temperature (e.g. modifications of Glass 2) are located bellow the indicated part for the range under $1250^{\circ} \mathrm{C}$. They are not included in the figure.

A regression relationship was found for an estimate of castability from the following predicators: $S 1$, Li and $T$, where the predicators express the content of corresponding oxides in glass and $T$ means the casting temperature in $C$. The relation Cast [wt. $\%]=-2.68 * S i+7.43 * \mathrm{Li}+0.107 * \mathrm{~T}$

has following statistical parameters for 24 observations: $R^{2}$ (adj.) $=0.994$, standard error of estimate $=3.43$ (residual std.error), F-statistics $=1236$, Iesidual average $=-3.0 \mathrm{E}-3$, residual variance $=11.8$. 


\section{Casting Ability vs. Arrh.Viscosity \\ Melt.Temp. 1150 - 1250 'C}

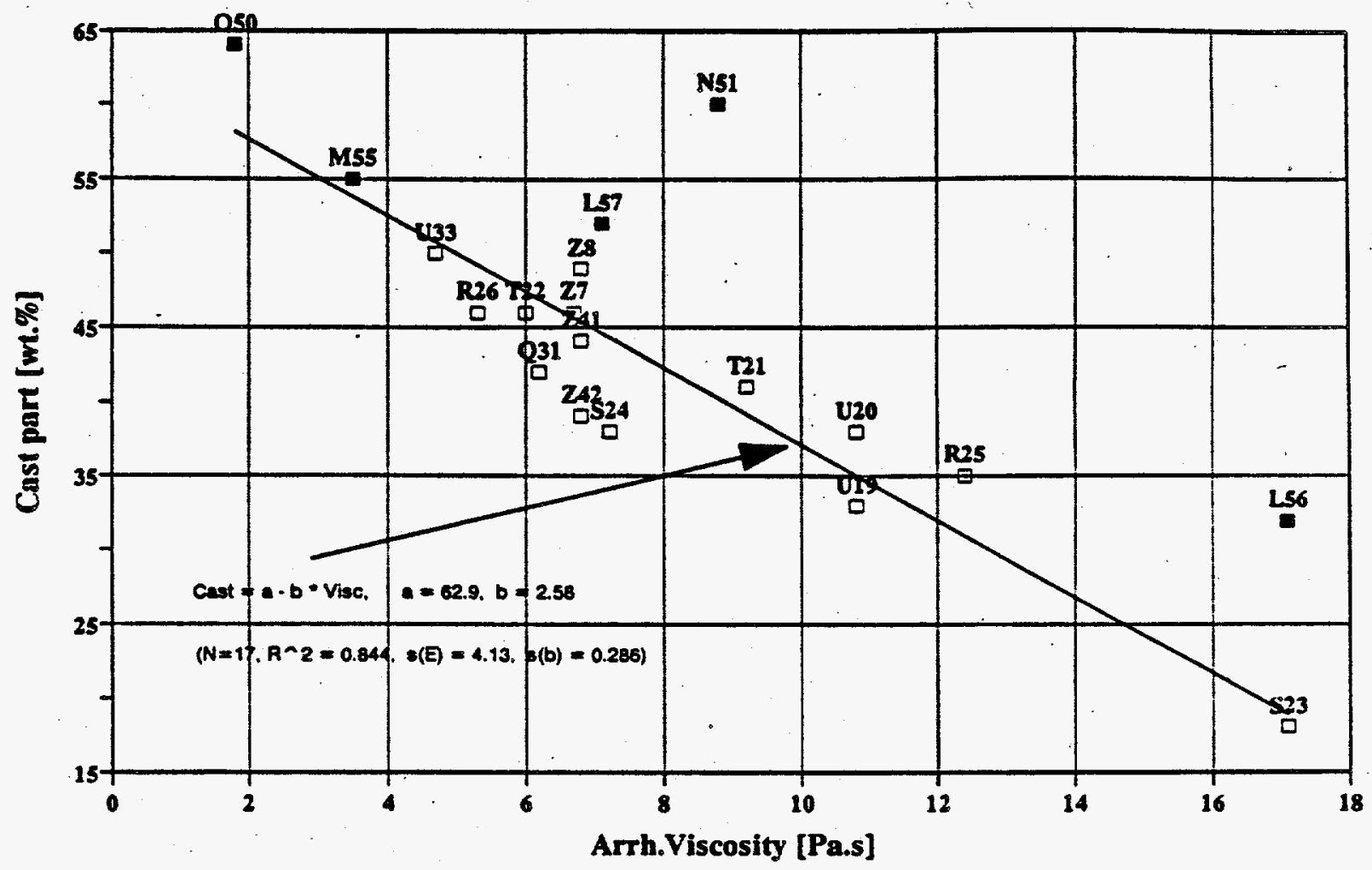

Figure B12-1: Dependence of Casting Ability on Calculated Viscosity

ANNEX B13

Nuclear Research Institute PREPARATION AND LEACHING OF CRUSHED GLASS

1) About $10 \mathrm{~g}$ piece is cut from the cast glass product.

2) Crushing is performed in a steel mortar by a steel pestle per several parts of the cut piece of glass. 
3) The divided part is inserted into the mortar and the pestle is hit by a $600 \mathrm{~g}$ hammer two or three times to produce minimum amount of grains under $40 \mathrm{\mu m}$.

4) The crushed part is got to the upper $56 \mu \mathrm{m} \mathrm{sieve}$ of a sieving set 56 and $40 \mathrm{\mu m}$ sieves completed with a bottom part.

5) The sieving set is vibrated on a Fritch vibrating device for one minute.

6) The remainder on the $56 \mathrm{\mu m}$ sleve is returned to the mortar and the procedures 3 to 6 are repeated until we get 19 of a eraction between 40 and $56 \mathrm{~km}$.

7) The last sieving is prolonged to 5 minutes.

8) Two $0.5 \mathrm{~g}$ aliquots of 40-56 $\mathrm{\mu m}$ fraction are weighed out and each added to $50 \mathrm{ml}$ boliling redistilled water in beakers.

9) The contents of the beakers are kept half an hour at mild boiling using an electric heater. Beakers are covered by lids.

10). Fine solid particles are separated from the suspension immediately after the leaching has been finished.

11) A centrifuge is used for the separation at $6000 \mathrm{rpm}$.

12) After cooling to about $25{ }^{\circ} \mathrm{C}$. the lost water is compensated and electric conductivity of leachate is measured using Conductometer Model IF2000C. Temperature of the leachate is measured.

13) The value of electric conductivity is used for the estimate of $\mathrm{Cr}$ calibration standard adjustment.

14) Concentrations of the total $c r$ and $c r^{6+}$ contents are performed according to procedures described in the Annex B2 or $B 11$.

Some conclusions followed from the measurement of electric conductivity of leachates and relationship between these values and concentration of $C r$ determined in leachates are summarized in Annex 017 . 


\section{ANNEXES C}

\section{TABLES AND FIGURES NOT INCLUDED IN THE TEXT OF FINAL REPORT}

The text of the Final Report includes the most important data (tables, pictures etc.) which demonstrate experimental results and are used to support and to explain statements used in respective discussions and conclusions. To include all data (tables and figures) in the text would complicate the reading and therefore some data are ncluded in this Annex. Some others are in the closing Reports, which were sent with respective Monthly Reports.

some other data form a part of Laboratory Reports archived in laboratories of cooperating institutions.
ANNEX C1
Glass $1 / 5$
Glass $2 / 5$
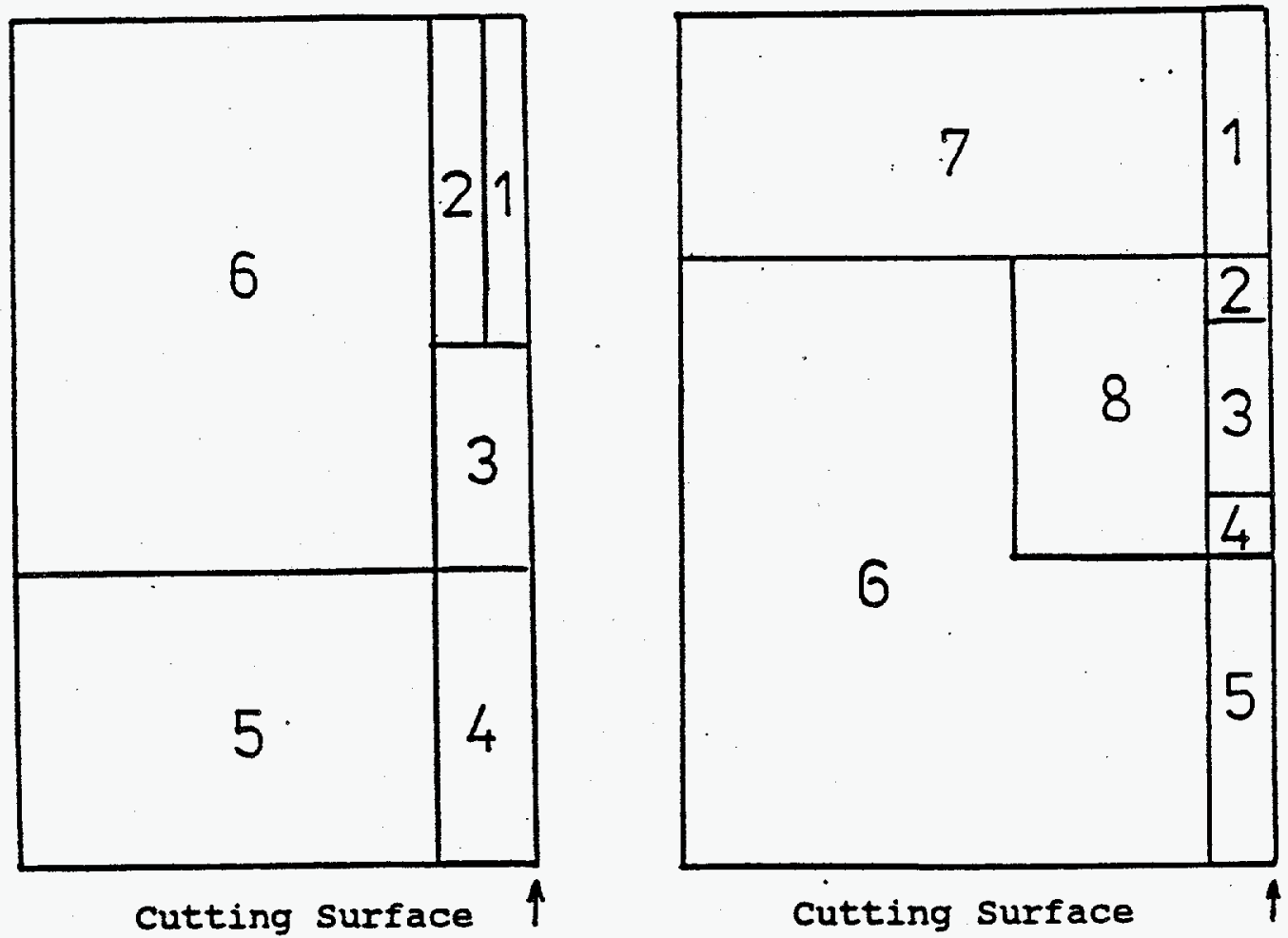

Figure: Scheme of cutting off of Great Sample Parts (Blocks) of Glasses $1 / 5$ and $2 / 5$ to Separate Portions for Various Tests (Surface Area)

The description of samples used for specific tests in the text of the Final Report uses the respective parts as sublabel (e.g. sample $2 / 5(8)$ ). 
ANNEX $C_{2}$

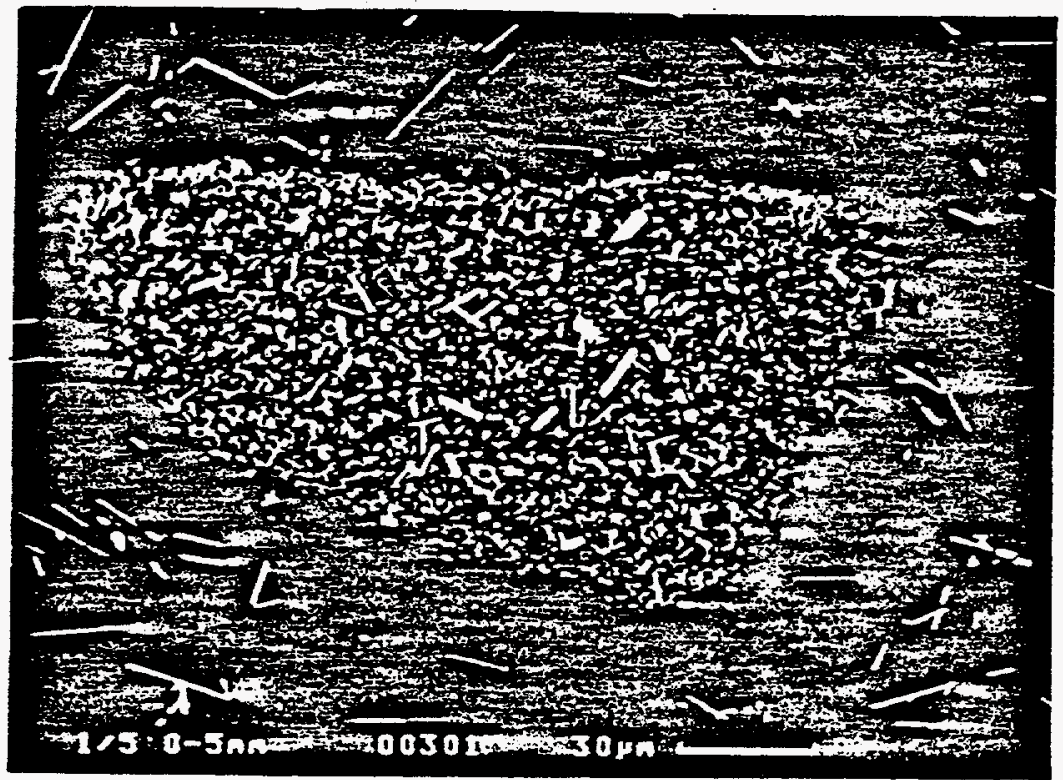

Figure: Glass 1/5. Transition Particle Type.

Normal Section $(0-5 \mathrm{~mm})$. Microscope Camscan 4-DV, BSE.

ANNEX C3

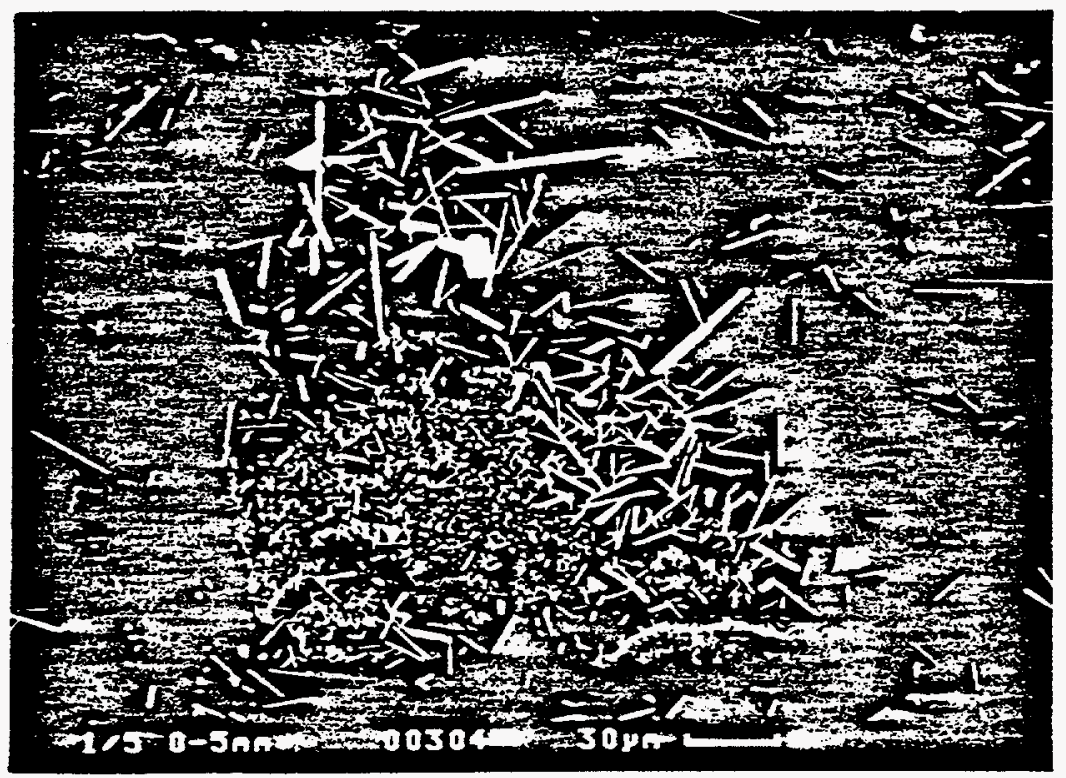

Figure: Glass 1/5. Transition Particle Type.

Normal Section $(0-5 \mathrm{~mm})$. Microscope CamScan 4-DV, BSE. 


\section{ANNEX C4}

Table: A Summary of Local Analyses Results of the Matrix Among Crystals in the sample of the Glass $2 / 5$ (LINK AN 10000, Expressed in wt. t)

\begin{tabular}{|c|c|c|c|c|c|c|}
\hline $\begin{array}{l}\text { Analyzed } \\
\text { Area }\end{array}$ & \multicolumn{2}{|c|}{$0^{\text {Matrix }}$} & \multicolumn{2}{|c|}{$1^{M a t r i x}$} & \multicolumn{2}{|c|}{$\begin{array}{l}\text { Matrix } \\
6-20 \mathrm{~mm}\end{array}$} \\
\hline n & \multicolumn{2}{|c|}{10} & \multicolumn{2}{|c|}{10} & \multicolumn{2}{|c|}{15} \\
\hline & $\bar{x}$ & $\sigma$ & $\bar{x}$ & $\sigma$ & $\bar{x}$ & $\sigma$ \\
\hline $\begin{array}{l}\mathrm{Na}_{2} \mathrm{O} \\
\mathrm{Al}_{2} \mathrm{O}_{3} \\
\mathrm{SiO}_{2} \\
\mathrm{Fe}_{2} \mathrm{O}_{3} \\
\mathrm{Cr}_{2} \mathrm{O}_{3} \\
\mathrm{MnO}_{2} \\
\mathrm{NiO} \\
\mathrm{ZnO} \\
\mathrm{CaO}\end{array}$ & $\begin{array}{l}12,8 \\
24,1 \\
40,4 \\
1,9 \\
0,87 \\
0,61 \\
a \\
a \\
0,39\end{array}$ & $\begin{array}{l}1,2 \\
0,7 \\
1,3 \\
0,2 \\
0,17 \\
0,12 \\
0,09\end{array}$ & $\begin{array}{l}12,9 \\
24,4 \\
41,4 \\
1,8 \\
0,76 \\
0,63 \\
a \\
a \\
0,29\end{array}$ & $\begin{array}{l}2,1 \\
0,4 \\
0,9 \\
0,2 \\
0,18 \\
0,15 \\
\\
0,07\end{array}$ & $\begin{array}{l}12,8 \\
25,0 \\
41,8 \\
1,8 \\
0,59 \\
0,74 \\
a \\
a \\
0,32\end{array}$ & $\begin{array}{l}0,6 \\
0,4 \\
0,6 \\
0,1 \\
0,11 \\
0,12 \\
0,07\end{array}$ \\
\hline sum & 81,07 & & 82,18 & & 83,05 & \\
\hline
\end{tabular}

Notes: see Table 4-7 in Section 4.2.1.3. 


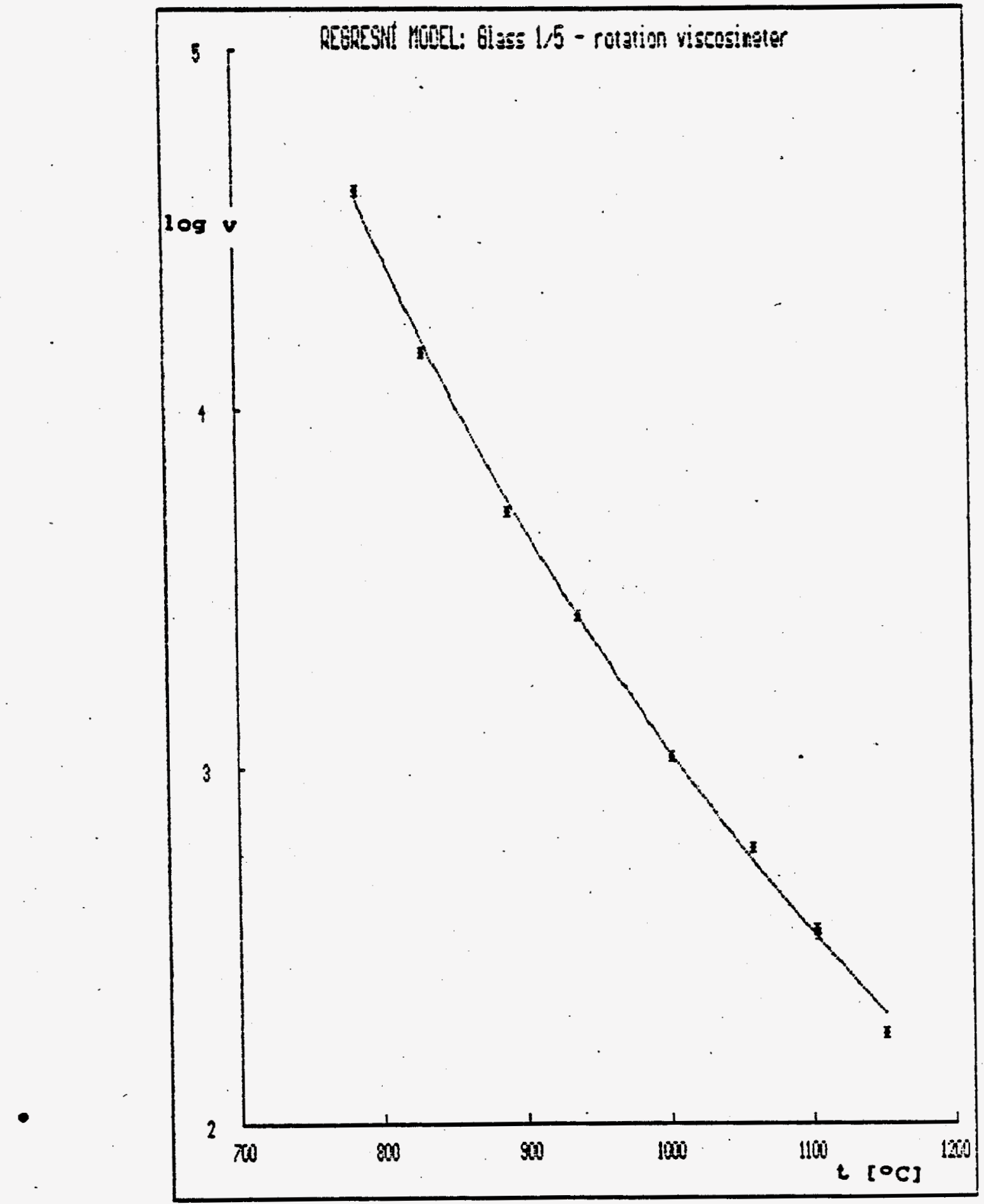

Figure: Temperature Dependence of Glass $1 / 5$ Viscosity 
ANNEX 66

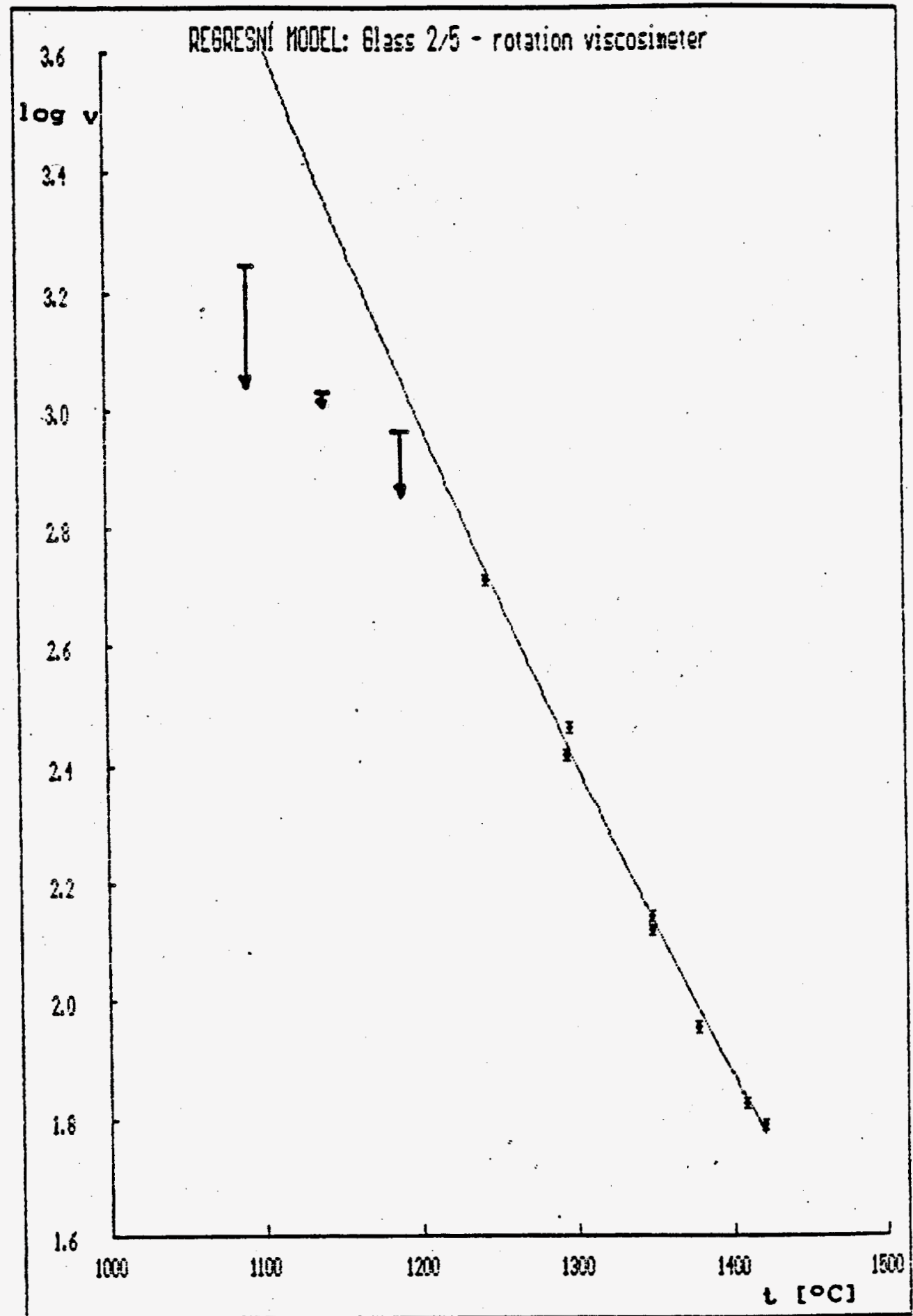

Figure: Temperature Dependence of Glass $2 / 5$ Viscosity 
ANIEX C7

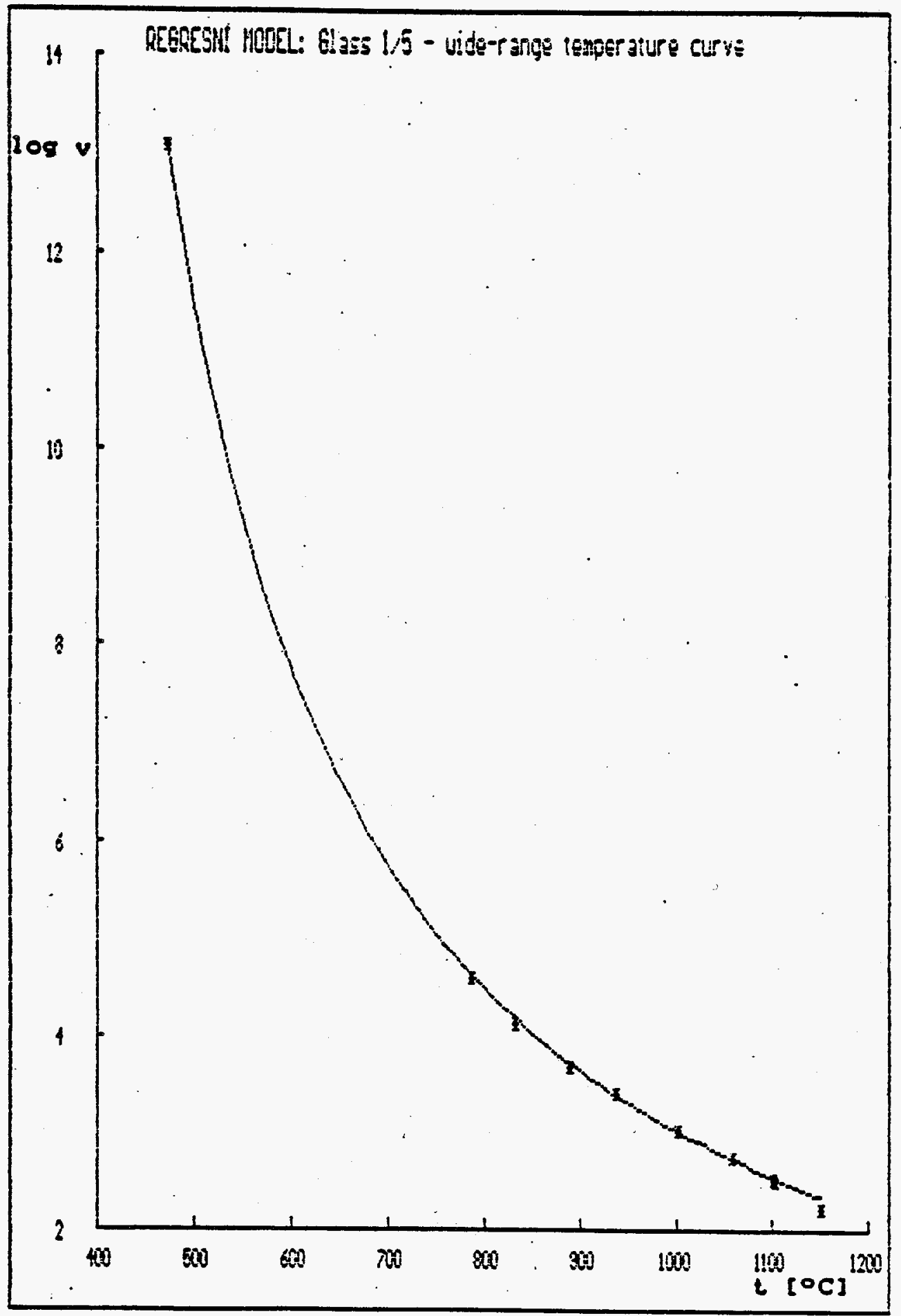

Figure: Wide Range Temperature Curve, Viscosity of Glass 1/5 


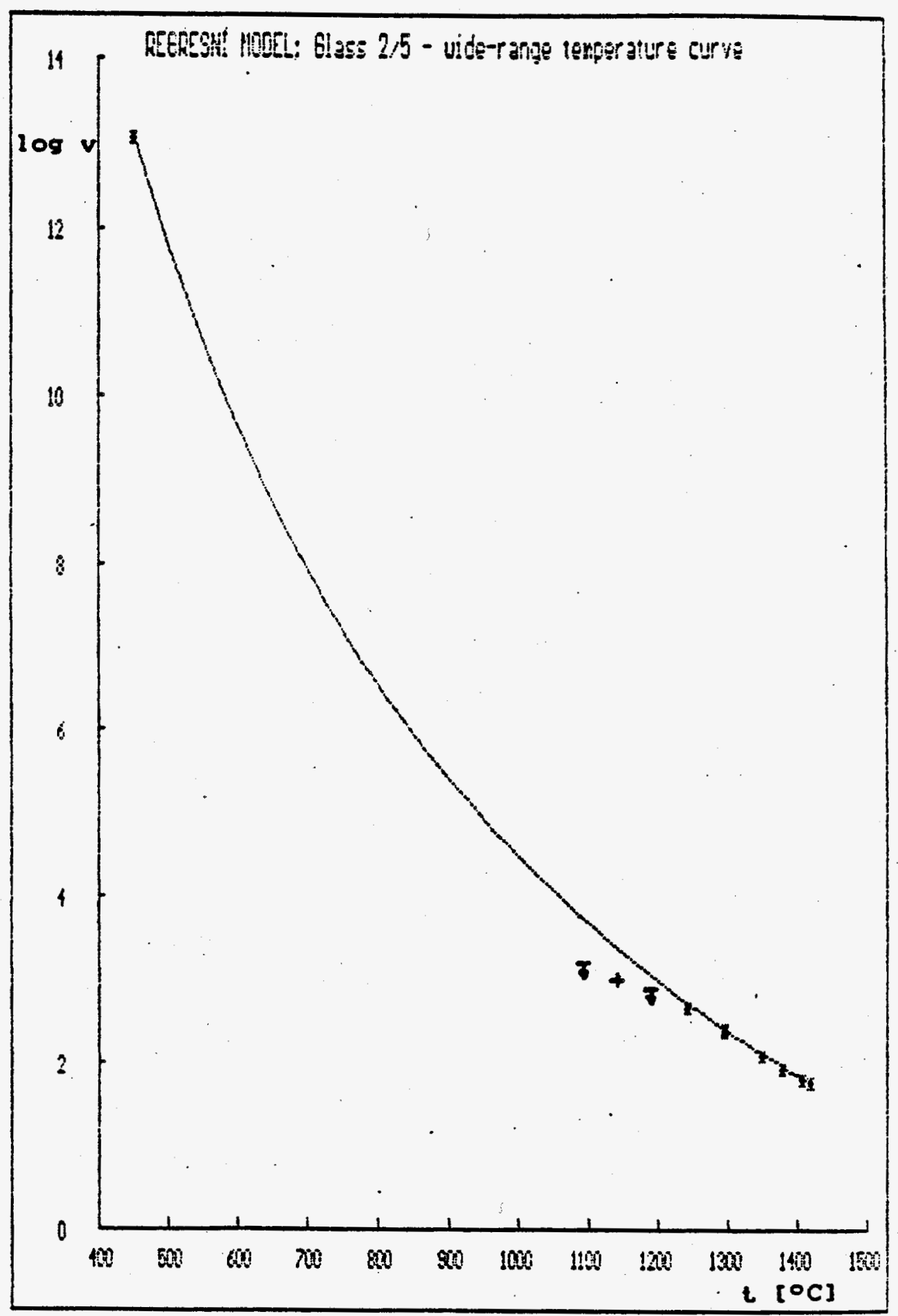

Figure: Wide Range Temperature Curve, Viscosity of Glass $2 / 5$ 
ANNEX C9

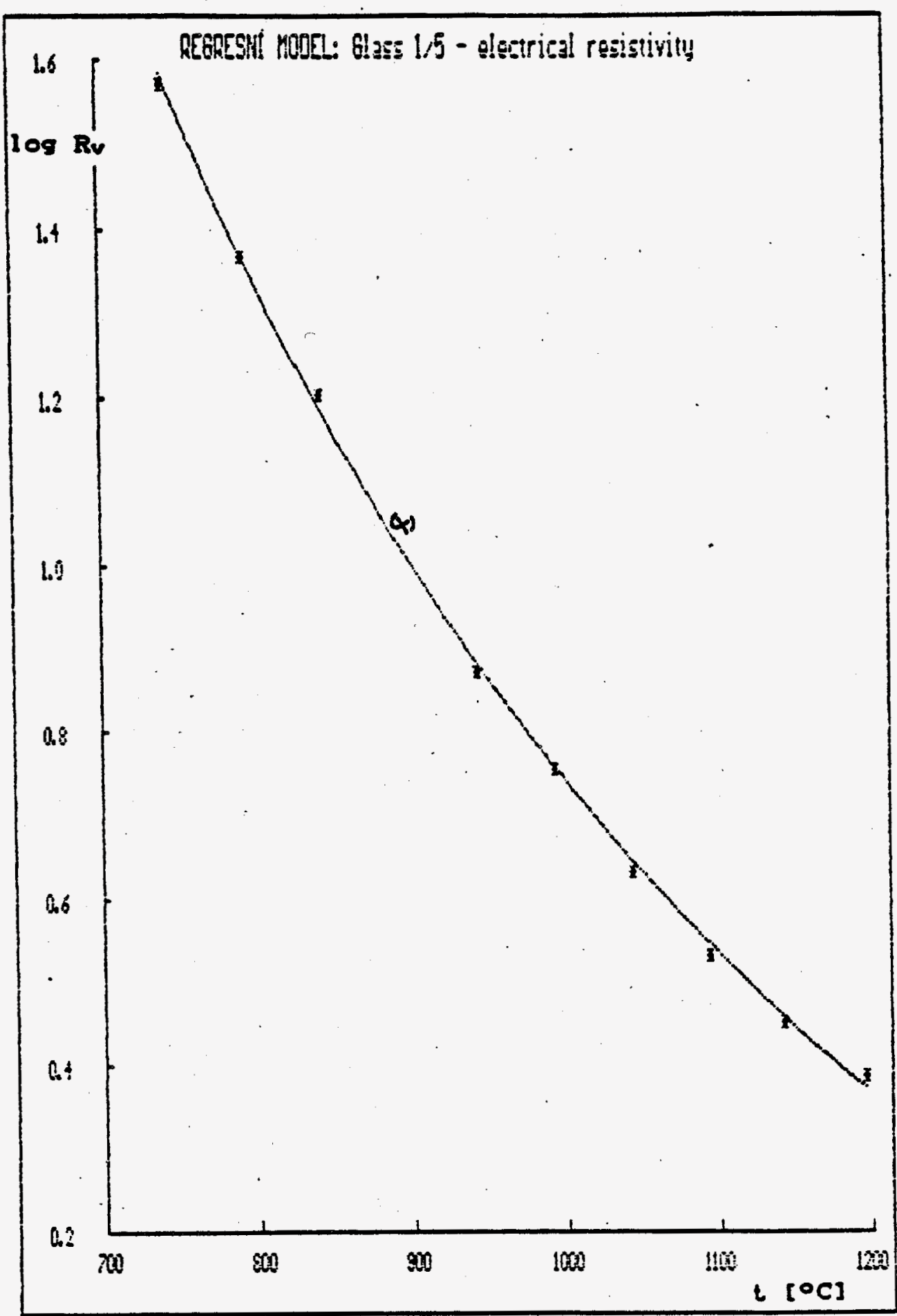

Figure: Temperature Dependence of Electrical Resistivity of Glass $1 / 5$. 


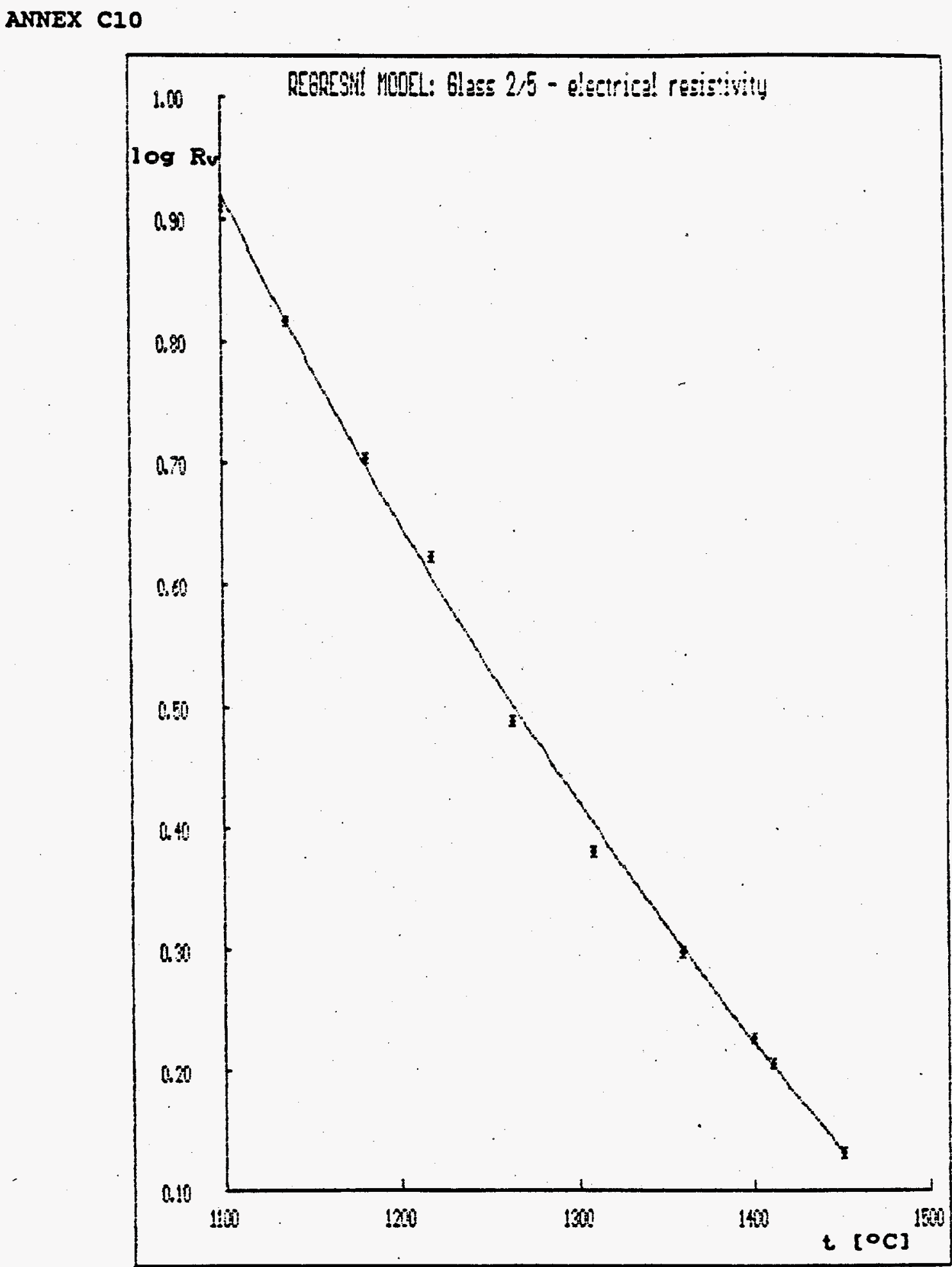

Figure: Temperature Dependence of Electrical Resistivity of Glass $2 / 5$ 


\section{ANNEX C11}
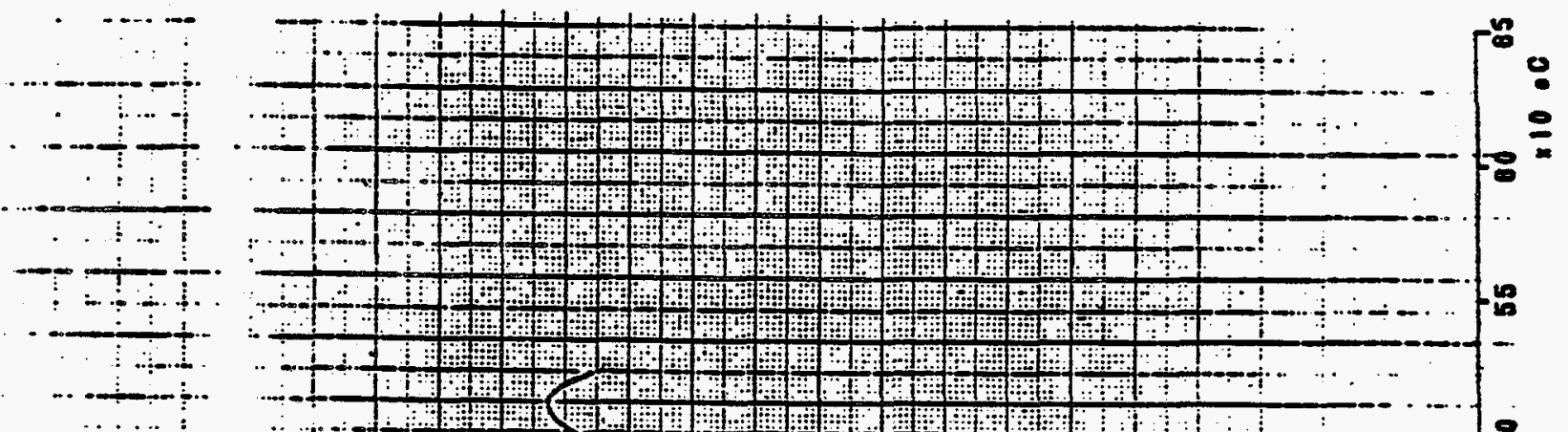

……-

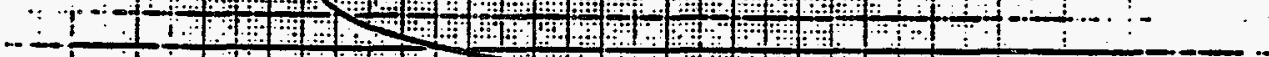

- +1 -

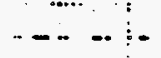

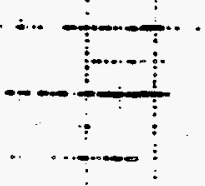

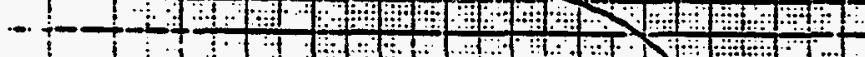

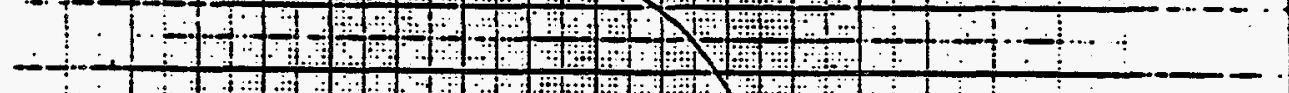

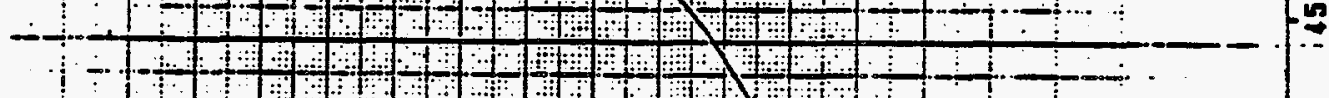

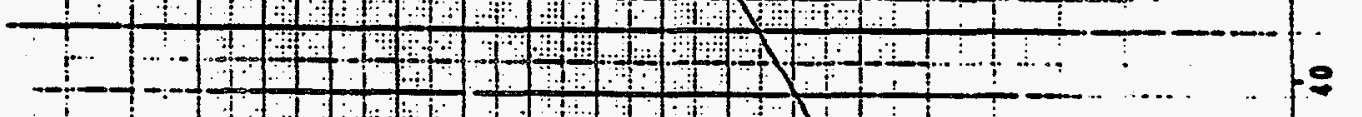

- .

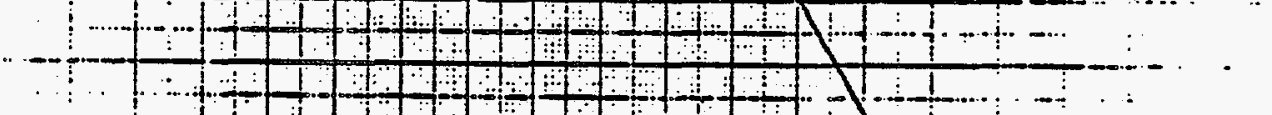

$\therefore=-\frac{1}{3}$
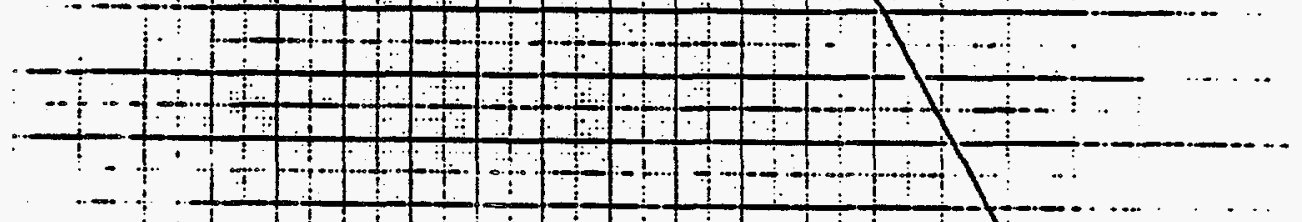

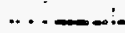

- i...
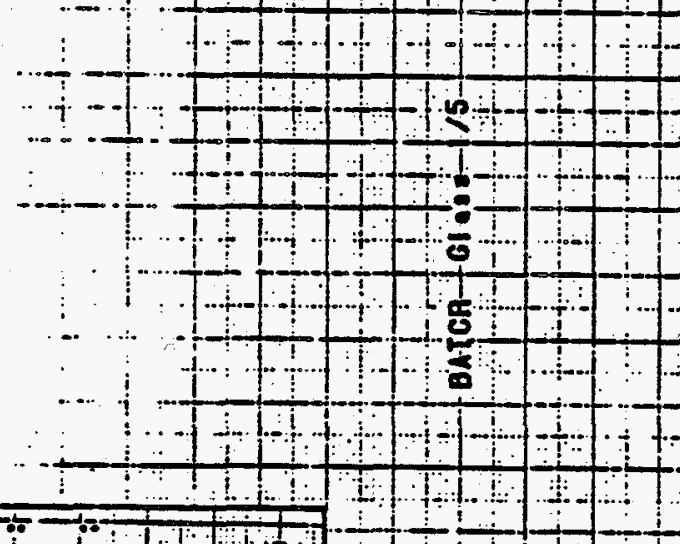


\section{ANNEX CI2}

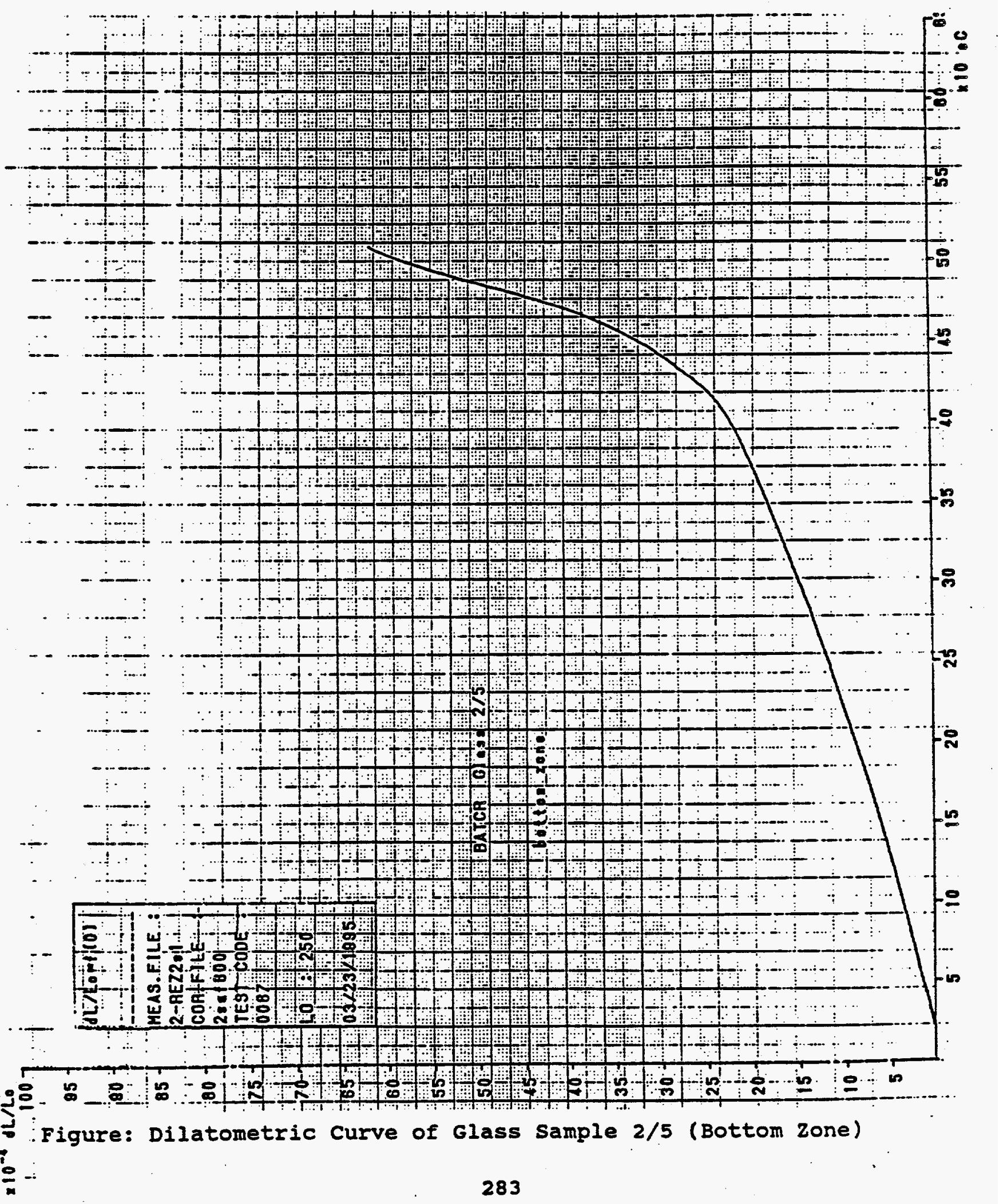




\section{ANMEX 013}

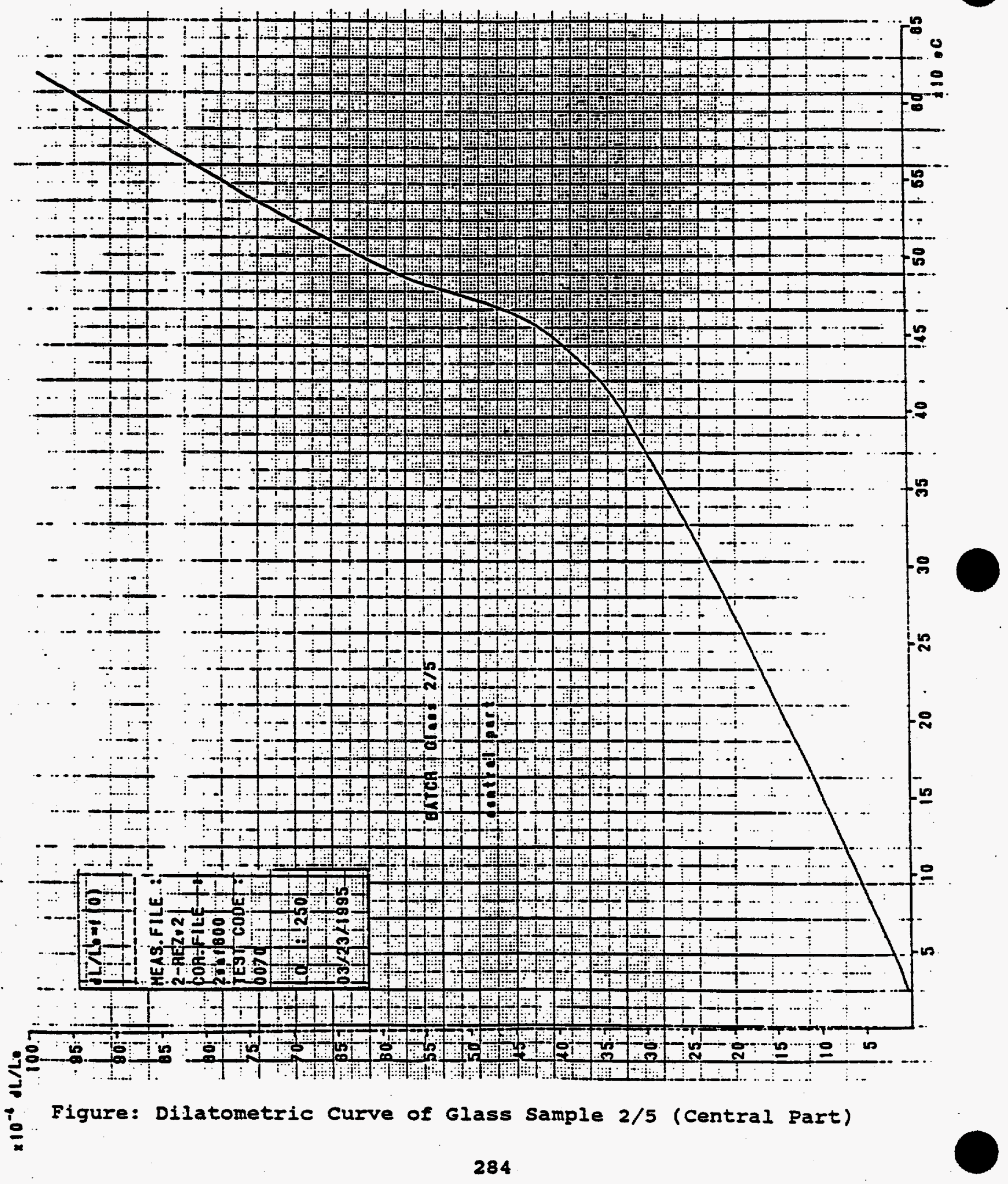


Table: Granulometry of the Chromium Hydroxide II

SediGraph 5100 V2.02

GRANULOHETR I E

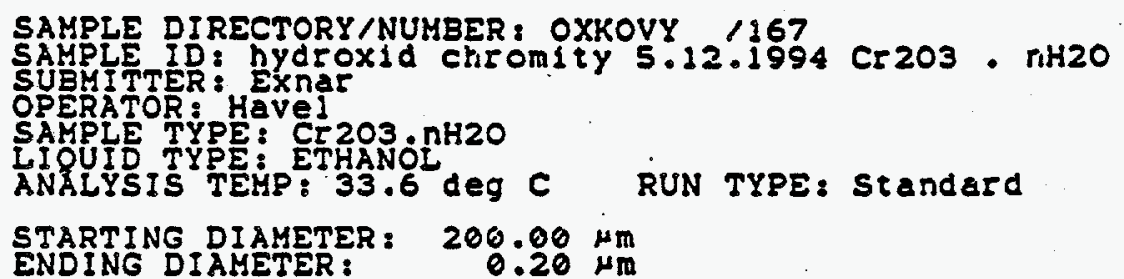

UNIT NUMBER:

PR्GE 1

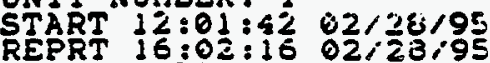

TOT RUN TIME $01: 22: 2$ :

SAM DENS: $2.5510^{\circ}$ Q

II VISC: 0.9375 mPax

REYNOLUS NUMBER: 0.63

ENDING DIAMETER: $\quad 0.20 \mu \mathrm{m}$

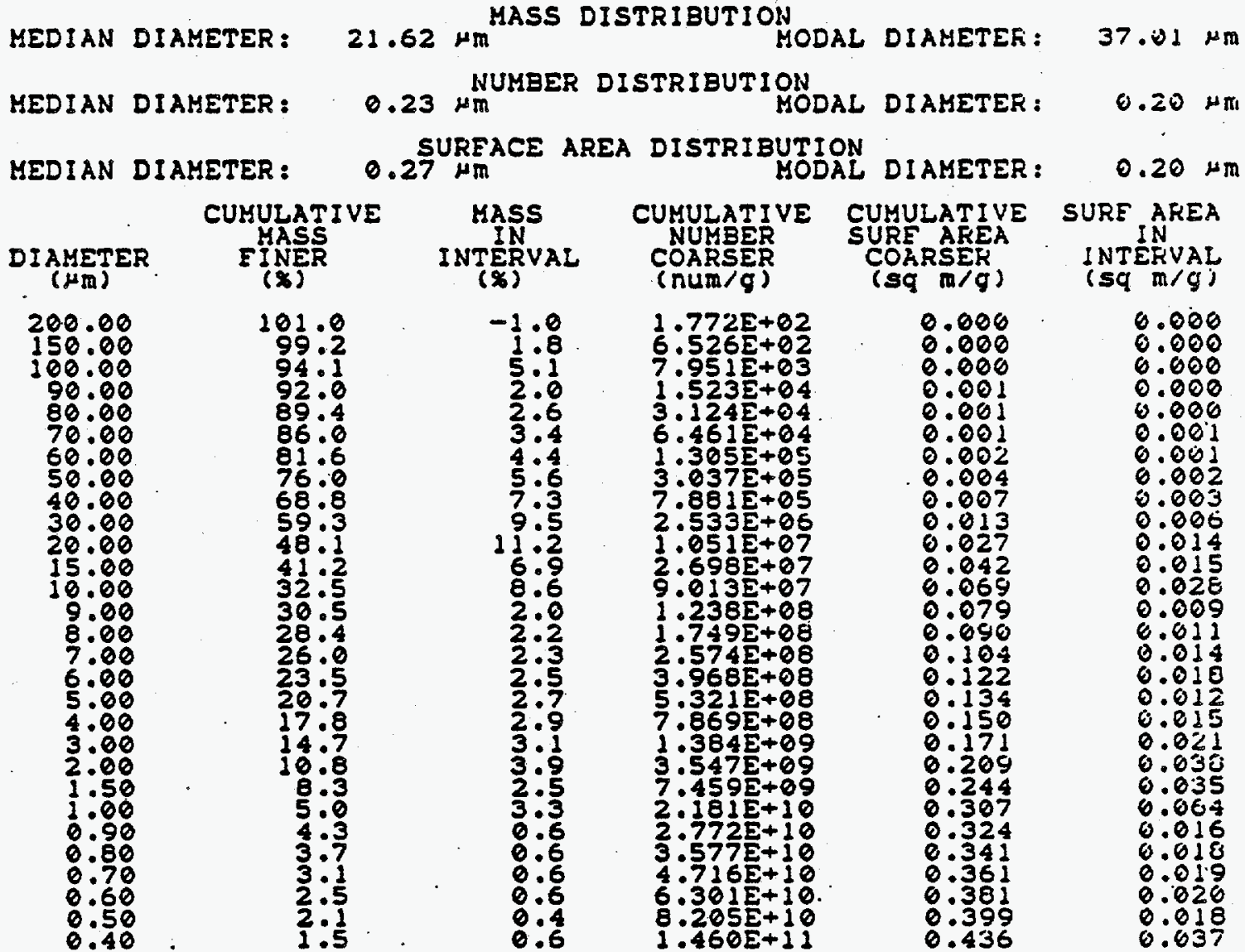


ANNEX C15

SediGraph 5100 V2.02

GRANULOHETRIE

YAGE 2

SAMPLE DIRECTORY/NUMEER: OXKOVY /167

SAMPLE ID: BYdrOXId ChrOmItY 5.12.1994 Cr203 . nH2O SU번 TTER : EXnac

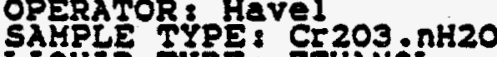

LIOUID TYPE: ETHANÓ

ANALYSIS TEMP-: 33.6 deg C RUN TYPE: Standard

UNIT NUKBER : $\frac{1}{2} \quad 02 / 28 / 95$

REPRT 16:02:16 02/28/95

TOT RUN TIHE $1: 22: 23$

SAM DENS: 2.5516 9/CC

LIO DENS: 0.7775 . g'es

GUMULATIVE MASS PERCENT FINER US. DIAMETER

눌

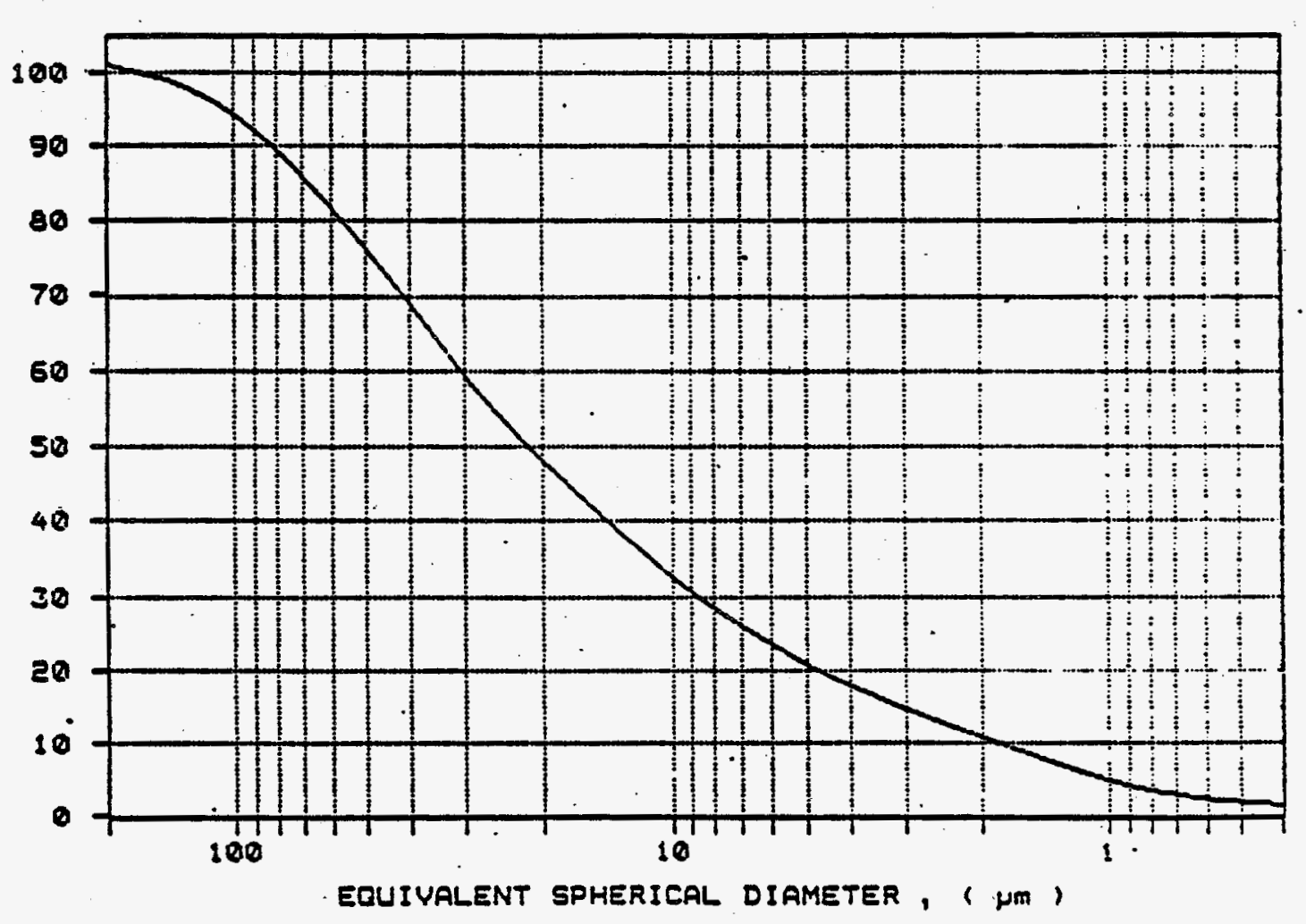

Figure: Cumulative Mass Percent Finer vs. Diameter of Particles for the Chromium Hydroxide II. 
SediGraph 5100 V2.02 GRA N U L O HETRIE

SAMPLE DIRECTORY/NUMBER: OXKOVY /167

SAMPLE ID: hydroxid chromity 5.12.1994 SUBMITTER: EXnar OPERATOR: HaVel

SAMPLE TYPE: Cr203.nH2O

LIQUID TYPE: ETHANOL

ANALYSIS TEMP: 33.6 deg C RUN TYPE: Standard
Cr203

Cr203 $\cdot$ nht20

UNIT NUMBER: 1

START 12:01:42 02/28/95 REPRT 16:12:04 02/28/95 TOT RUN TIHE $1: 22: 23$

SAH. DENS: $2.5510 \mathrm{~g} / \mathrm{CC}$ LIO DENS: $0.7775 \mathrm{~g} / \mathrm{CC}$ LIQ VISC: 0.9375 MPax:

MASS POPULATION VS. DIAMETER

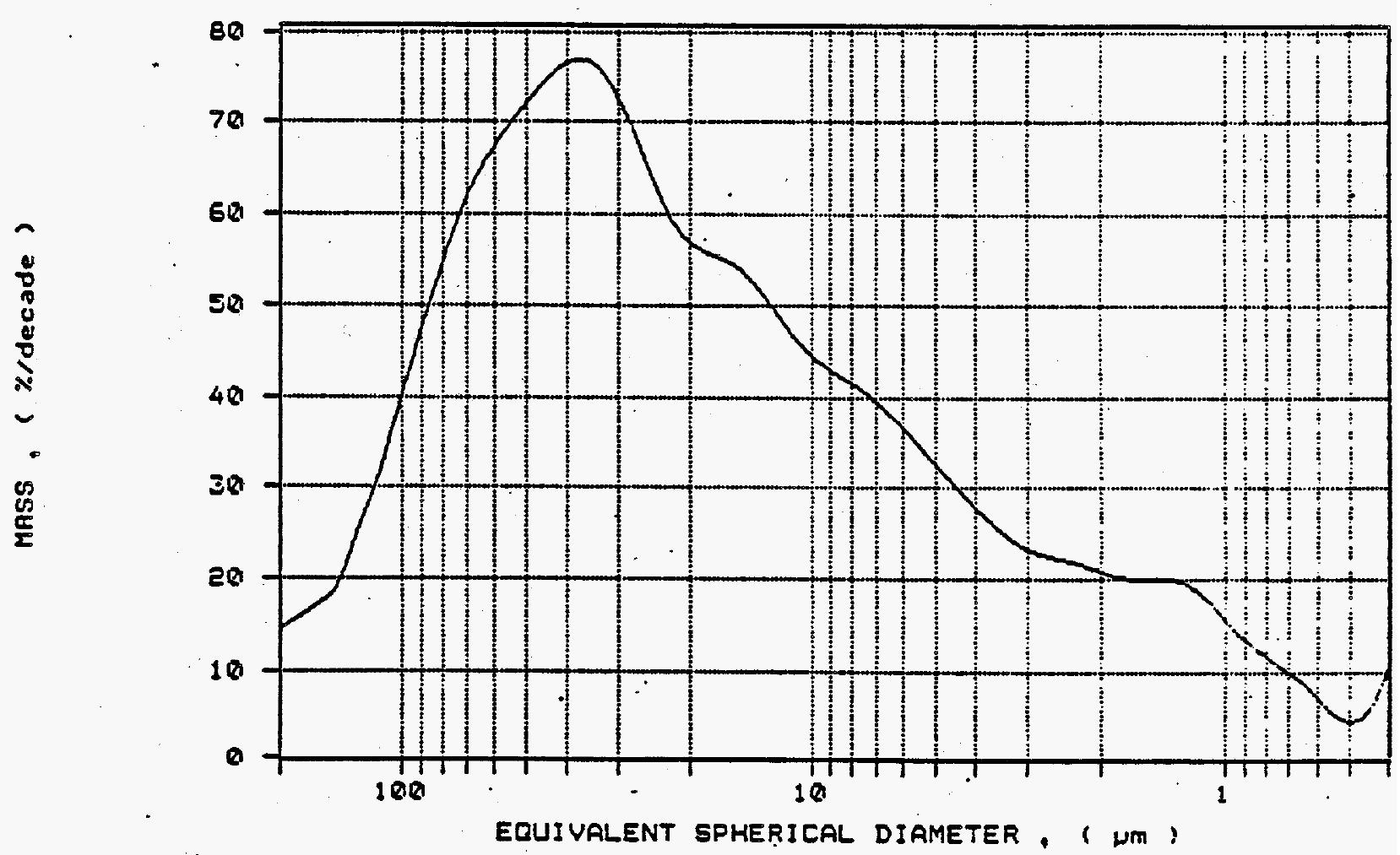

Figure: Mass Population vs. Particle Diameter, Chromium Hydroxide II 


\section{ANNEX Cl7}

MEASUREMENT OF LEACHATES ELECTRIC CONDUCTIVITY

Measurement of leachates electric conductivity was used as an auxiliary method for preliminary adjustment of concentration ranges for the calibration standard.

Relatively good lit was found for the leachate electric conductivity and $C r$ concentration (hot procedure described in Annex B13) dependence

(See log - $\log$ dependence in the Figure).

The best function for an estimate of electric conductivity of hot leachate was found in the regression equation:

$$
[\mu s / c m]=b_{1} \star B+b_{2} \star L i^{2}+b_{3} \star L i * T+b_{4} \star B * S i^{2} \text {, }
$$

where $B, I i$ and $S i$ are wt.t of corresponding oxide in the glass and $T$ is the casting temperature in ${ }^{\circ} \mathrm{C}$. The calculated regression coefficients are: 2.107 for $b_{1}, 2.86$. for $b_{2},-0.0209$ for $b_{3}$, and 0.00128 for $\mathrm{b}_{4}$.

The statistical parameters of this regression equation are as follows (number of observations are 24):

$R^{2}$ (adj) $=0.972$, standard error of estimate $=6.19$ (residual std.error), F-statistics $=200$, residual average $=3.6 \mathrm{E}-3$, residual variance $=38.4$. 


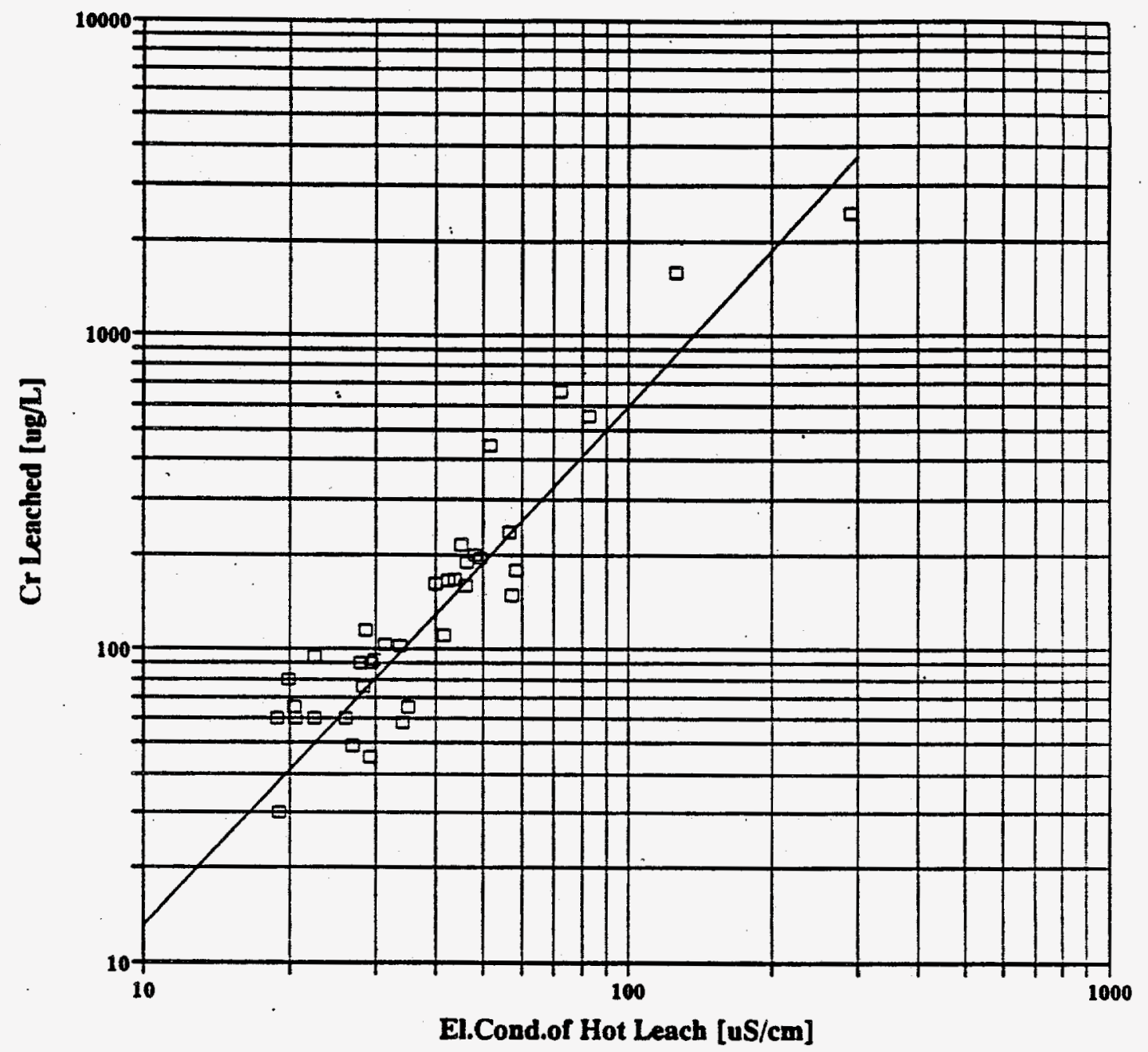

Figure: Correlation Between Leachate Electric Conductivity and Chromium concentration in Leachate 


\section{ANNEX C18}

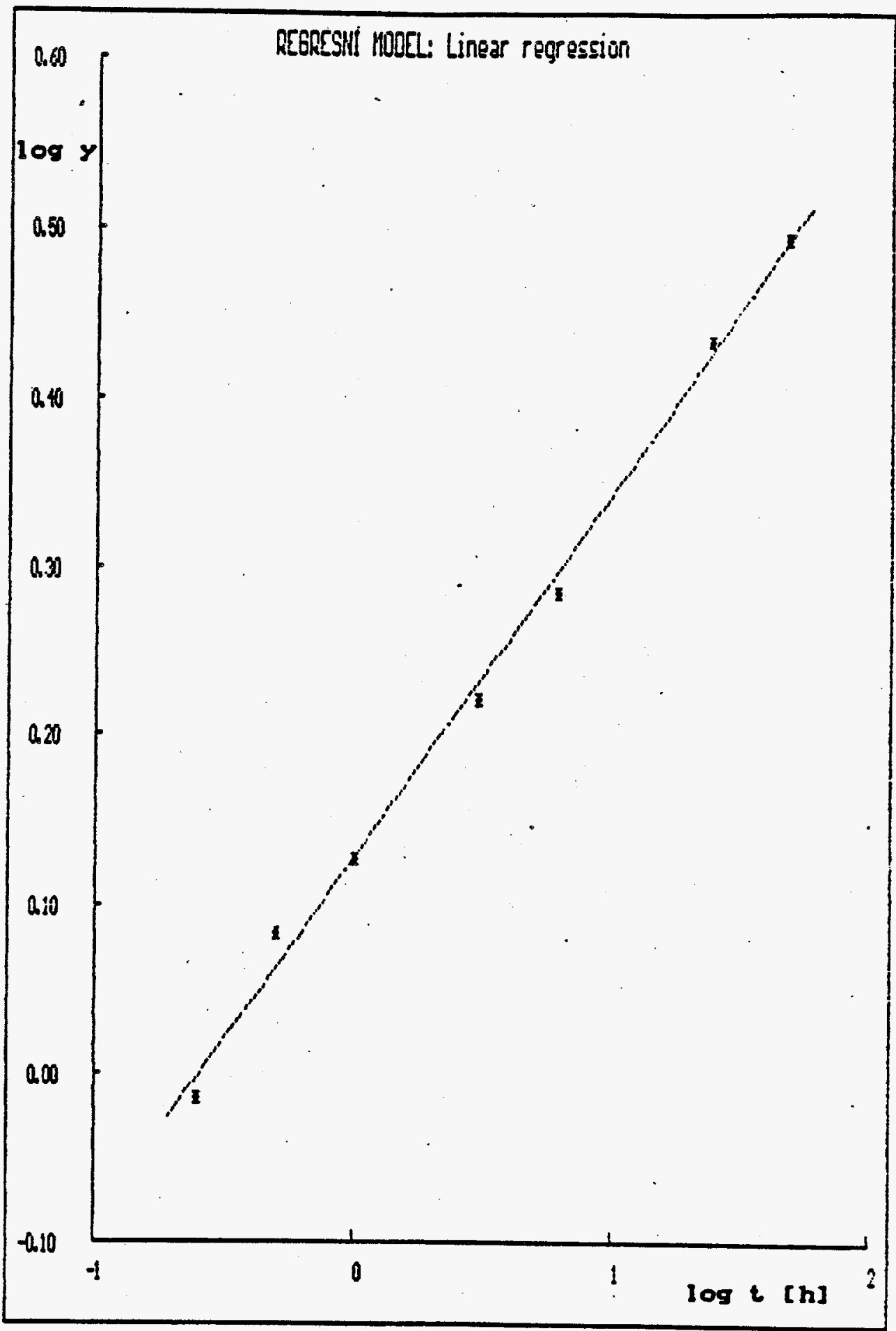

Figure: Verification of the Correspondence of the Calculated Time Dependence of the $\mathrm{CrO}_{3}$ Content According to the Relation 11 (see section 4.2.4.4 ) with Experimental Results (Batch 1, Temperature $550^{\circ} \mathrm{C}$ ). 


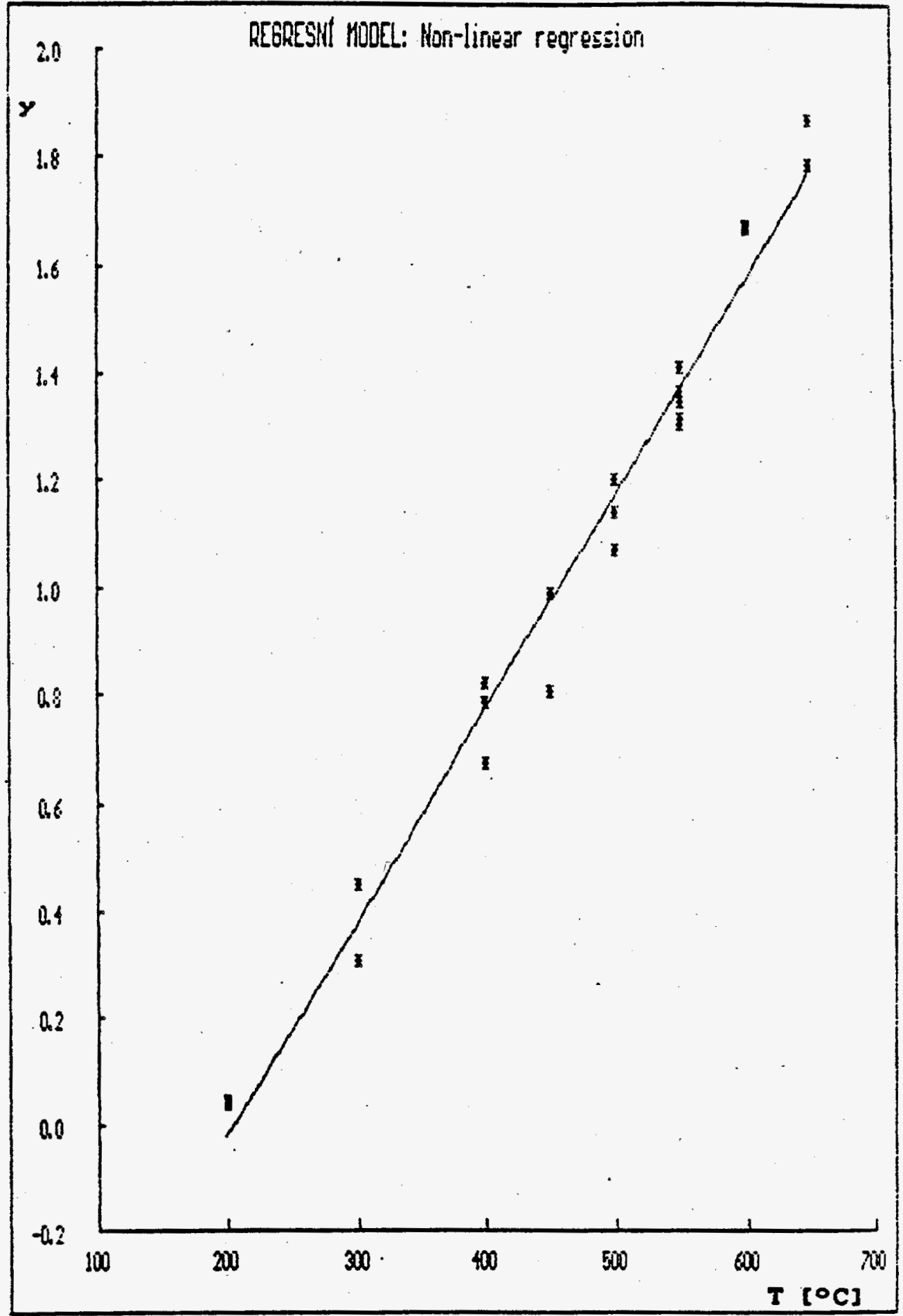

Figure: Verification of the Correspondence of the Calculated Temperature Dependence of the $\mathrm{CrO}_{3}$ Content According to the Relation /3/ (see Section 4.2.4.4.) with Experimental Results (Batch 1, Low Temperatures). 
ANNEX C2O

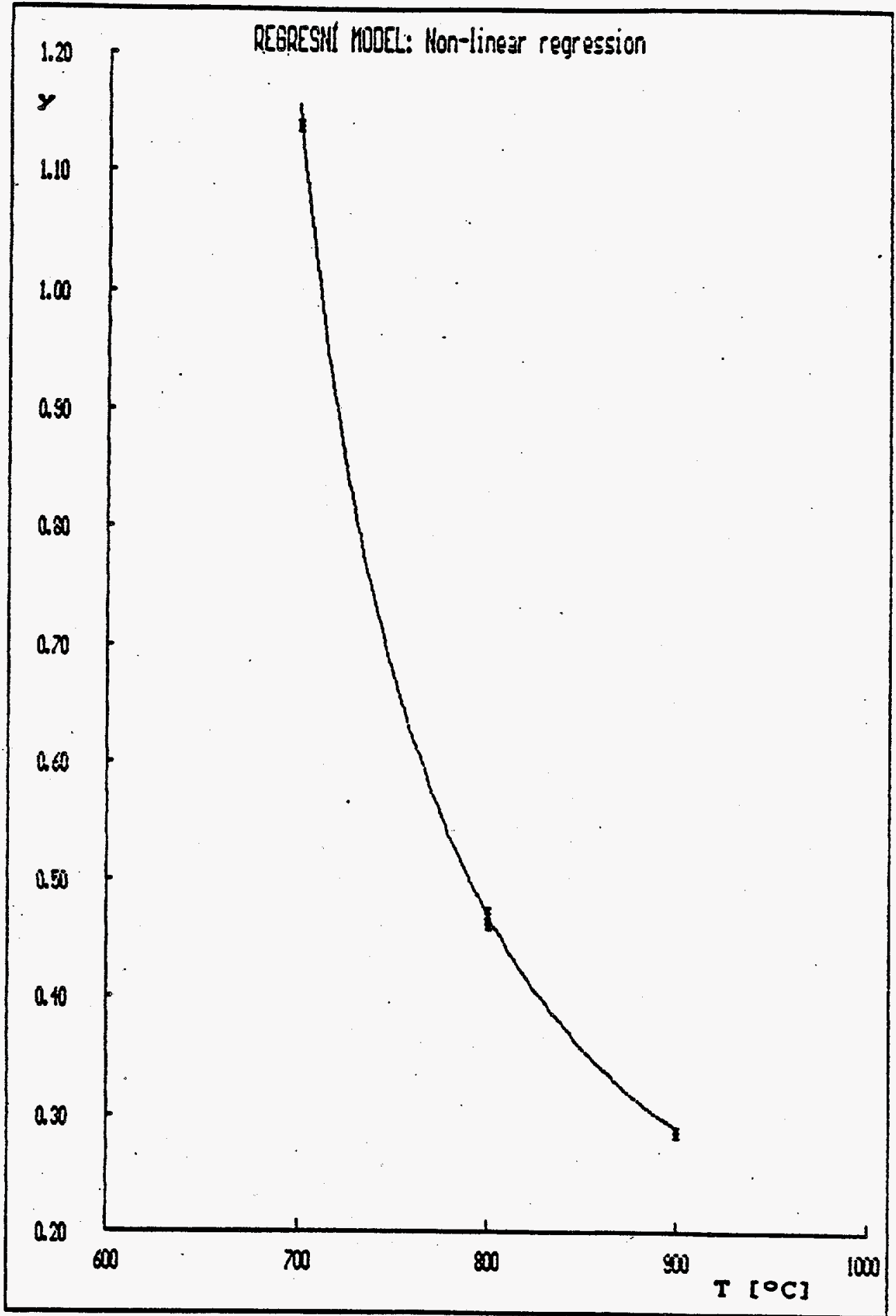

Figure: Verification of the correspondence of the Calculated Temperature Dependence of the $\mathrm{CrO}_{3}$ Content According to the Relation /5/. (see Section 4.2.4.4.) with Experimental Results (Batch 1, High Temperatures). 
ANNEX C21

!

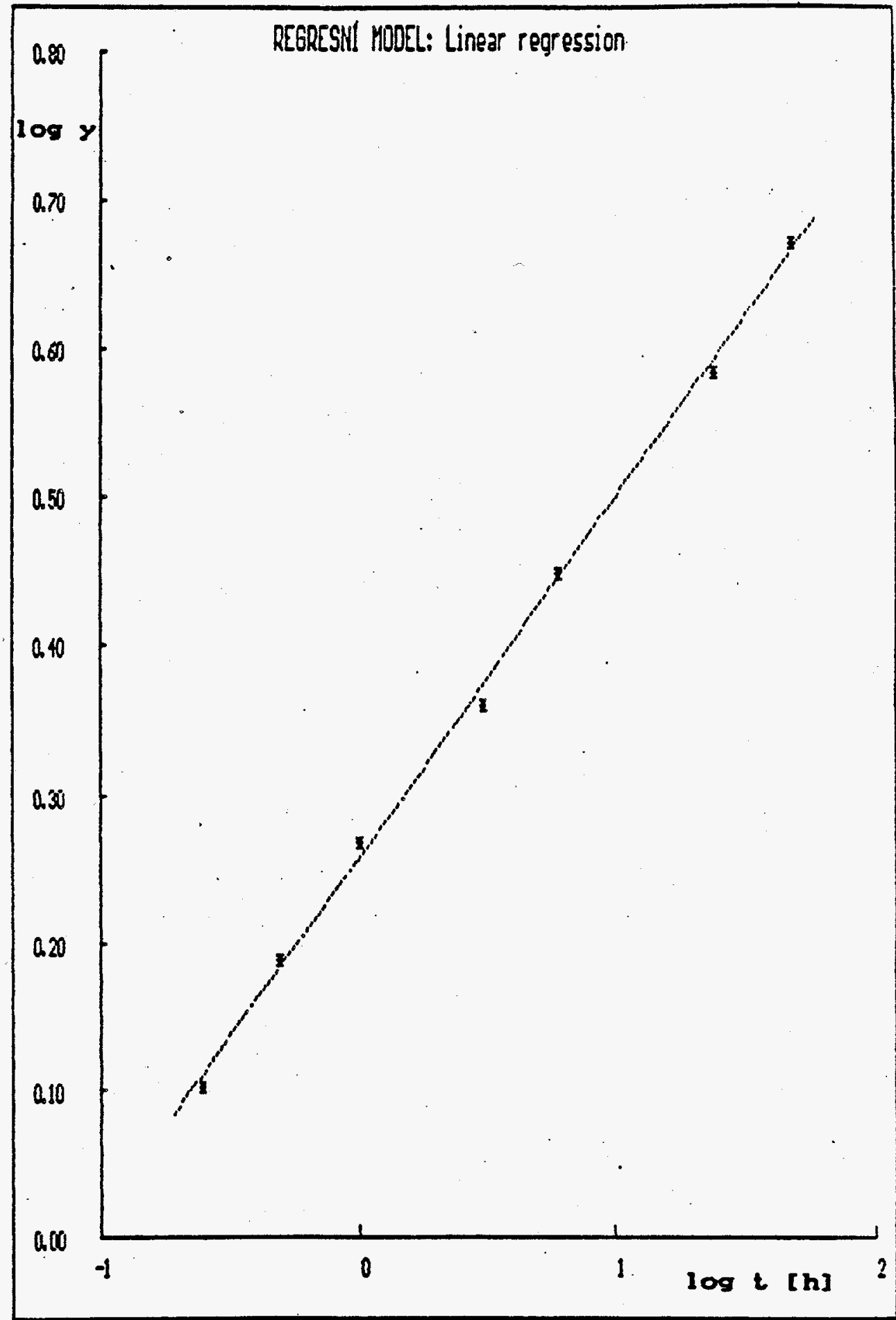

Figure: Verification of the Correspondence of the Calculated Time Dependence of the $\mathrm{CrO}_{3}$ Content According to the Relation $/ 7 /$ (see Section 4.2.4.4.) with Experimental Results (Batch 2, Temperature $550^{\circ} \mathrm{C}$ ). 


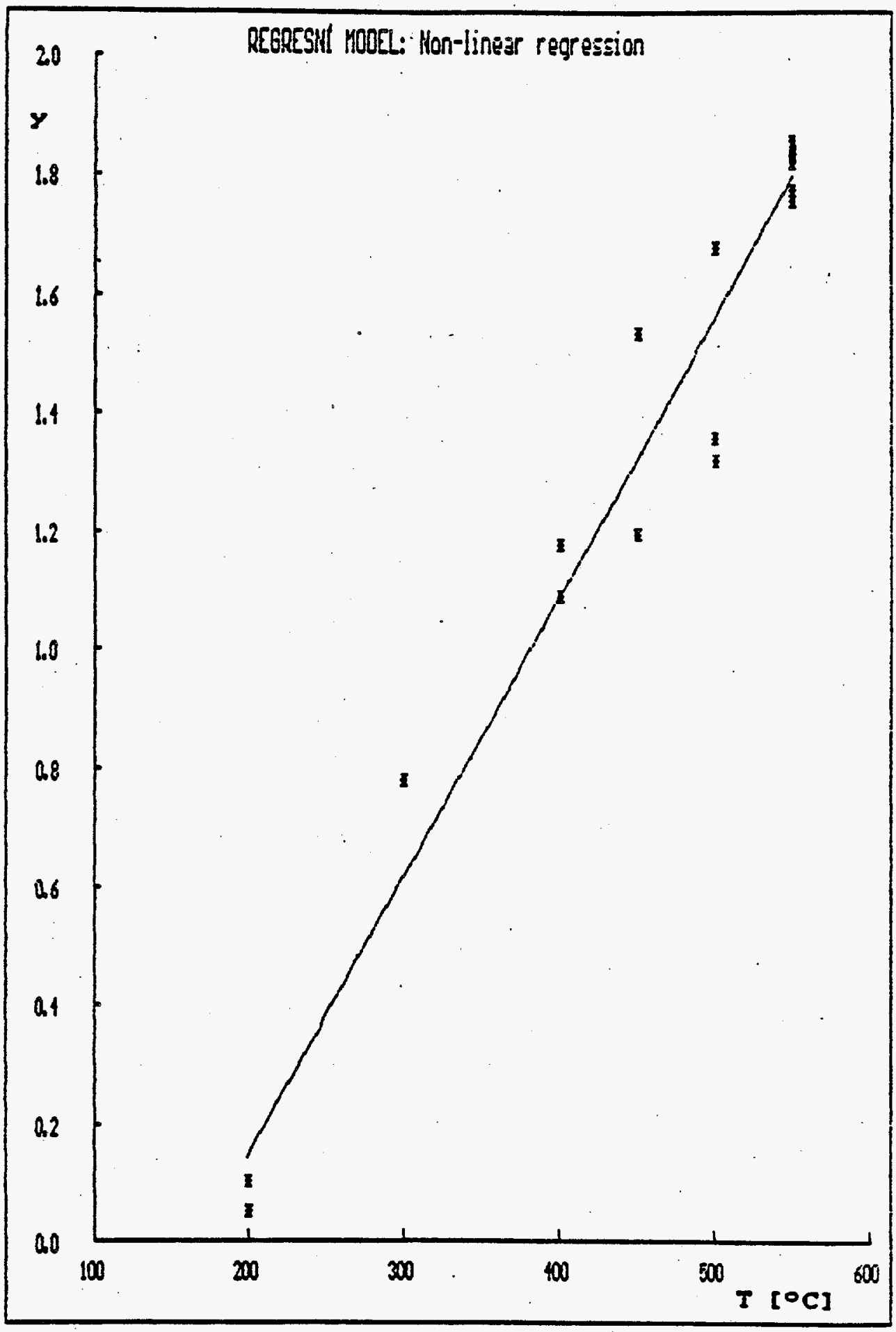

Figure: Verification of the Correspondence of the Calculated Temperature Dependence of the $\mathrm{CrO}_{3}$ Content According to the Relation $/ 9 /$ (see Section 4.2.4.4.) with Experimental Results (Batch 2, Low Temperatures). 


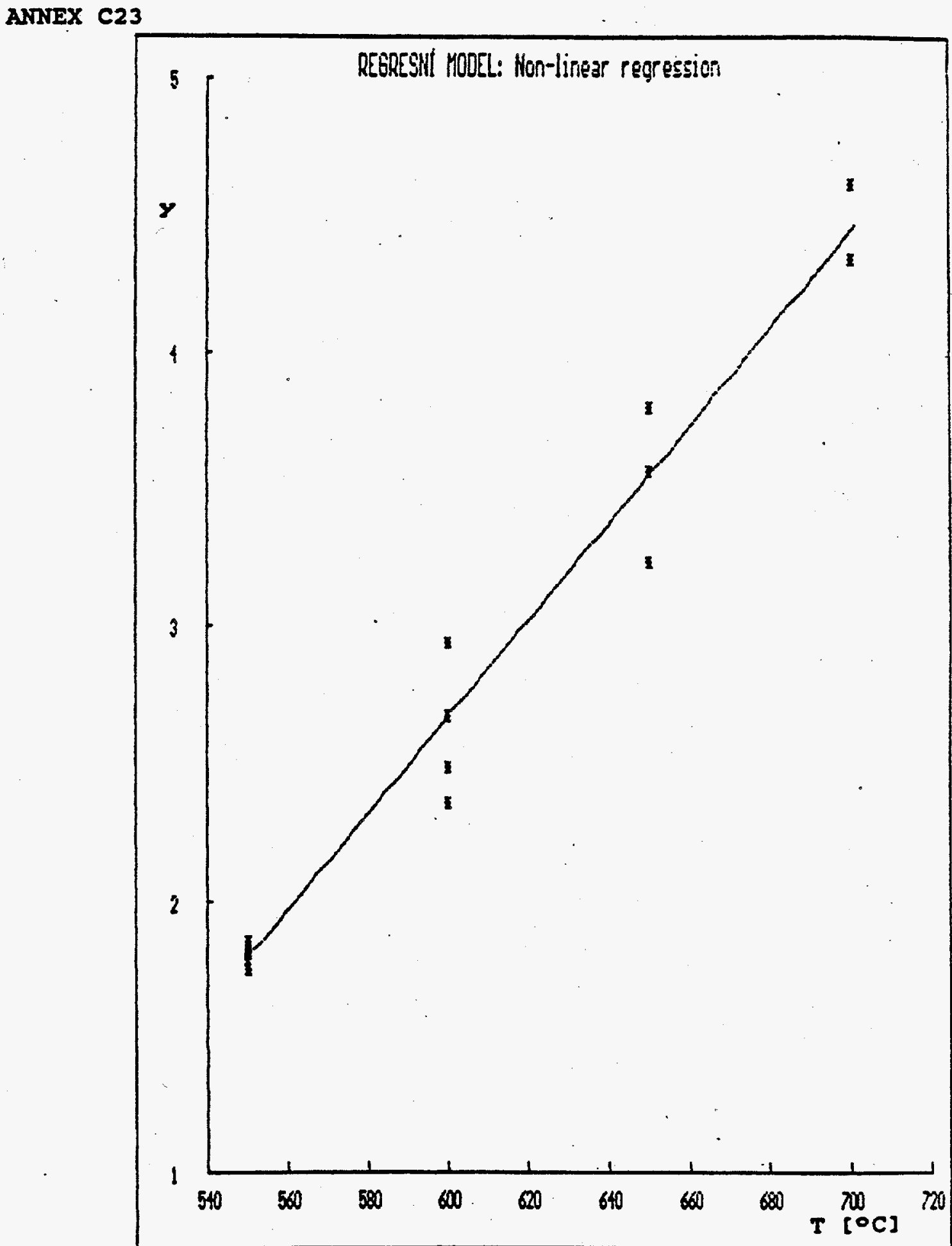

Figure: Verification of the Correspondence of the Calculated Temperature Dependence of the $\mathrm{CrO}_{3}$ Content According to the Relation $/ 11 /($ see section 4.2 .4 .4$.$) with Experimental$ Results (Batch 2, Medium Temperatures). 
ANNEX C24

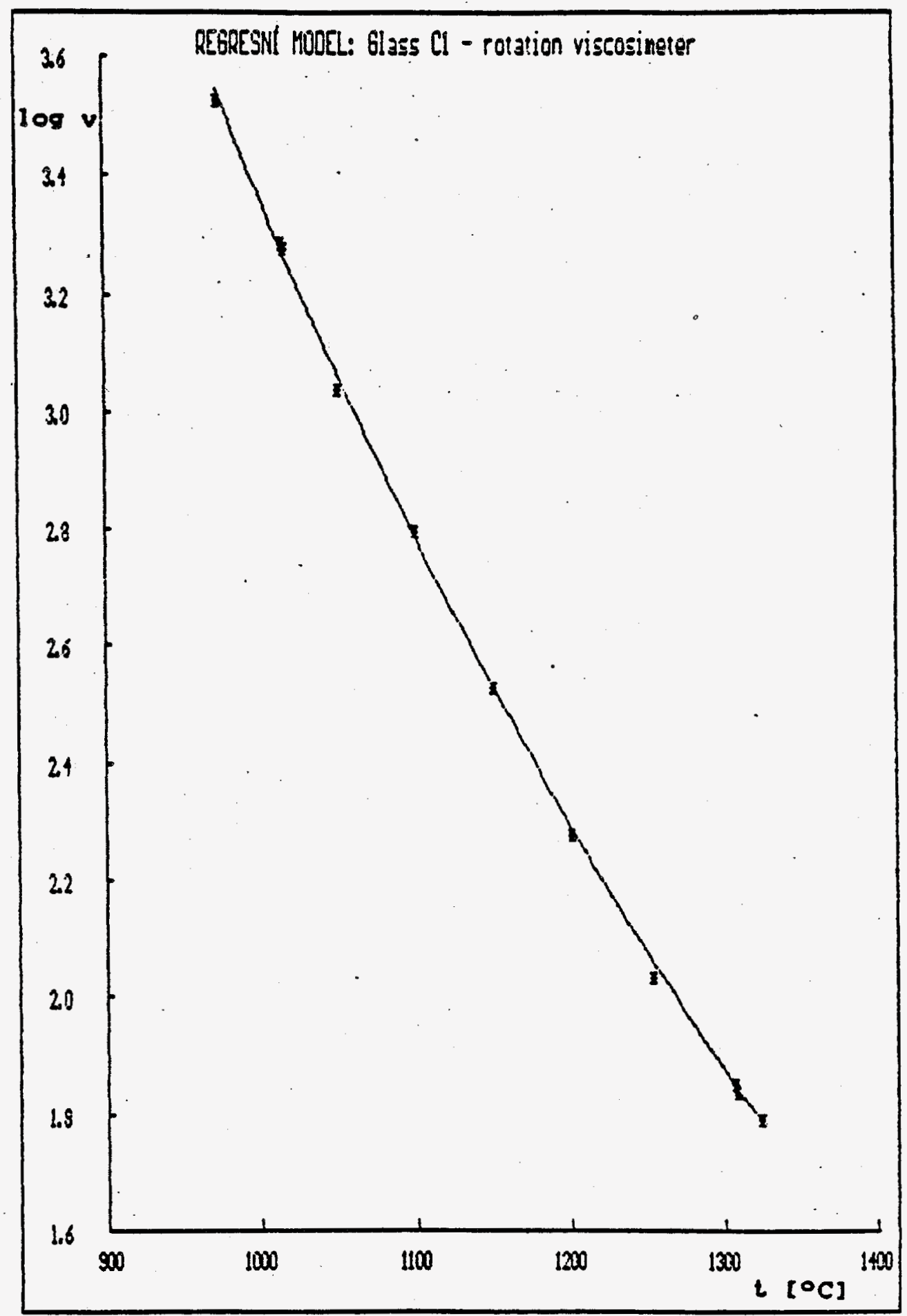

Figure: Temperature Dependence of Glass Cl Viscosity 


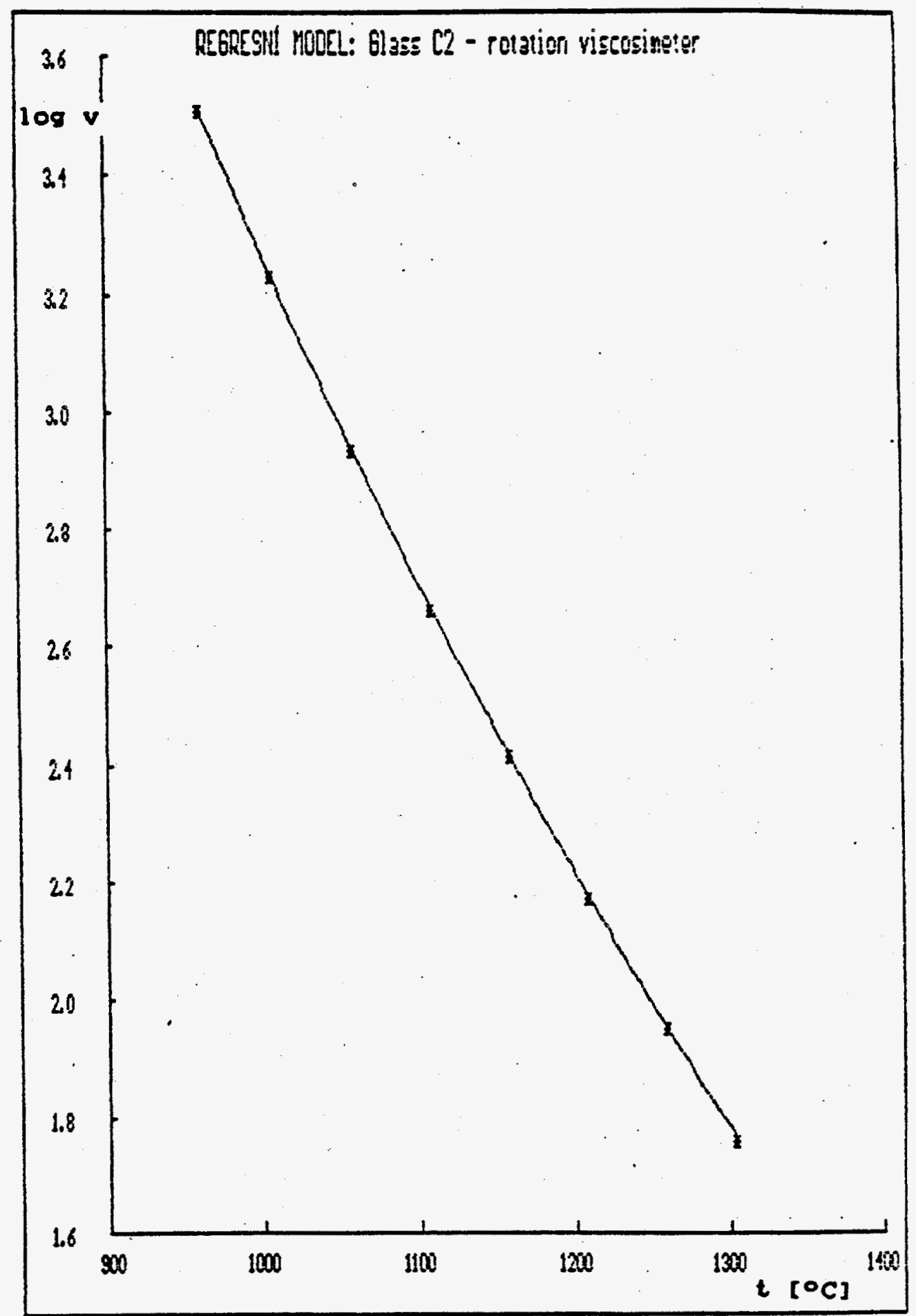

Figure: Temperature Dependence of Glass C2 Viscosity 


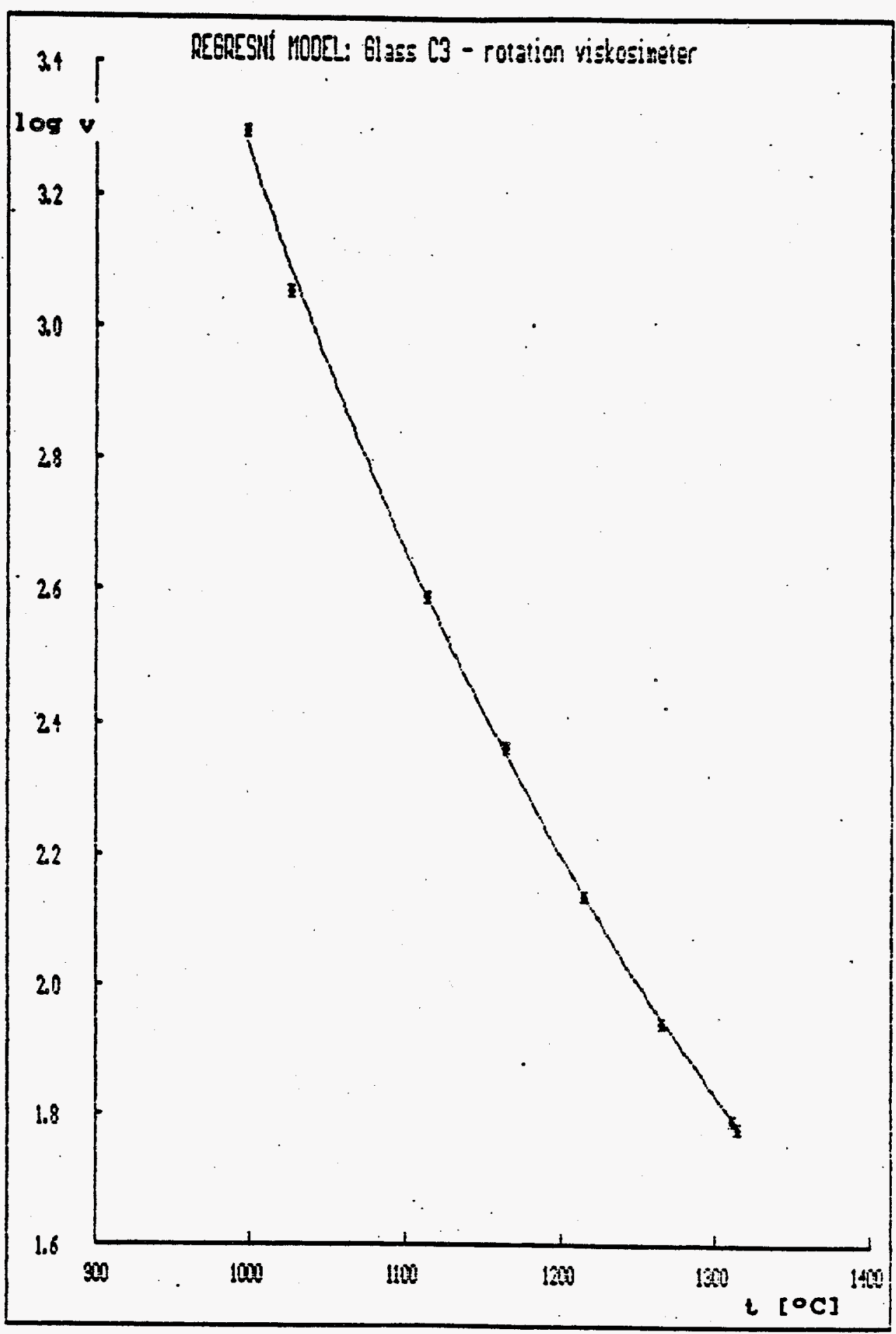

Figure: Temperature Dependence of Glass $c_{3}$ Viscosity 


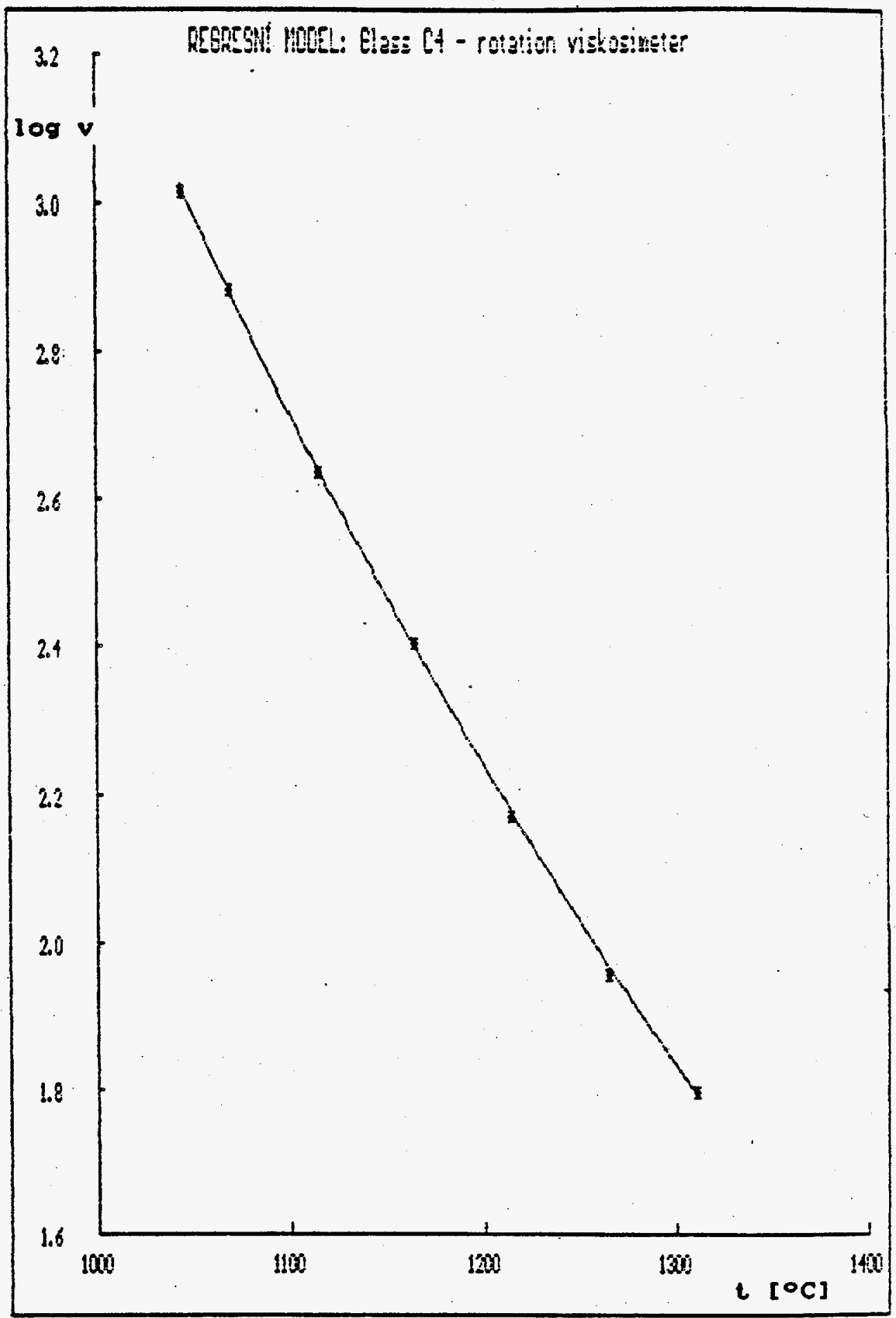

Figure: Temperature Dependence of Glass C4 Viscosity 
ANNEX $\mathbf{C 2 8}$

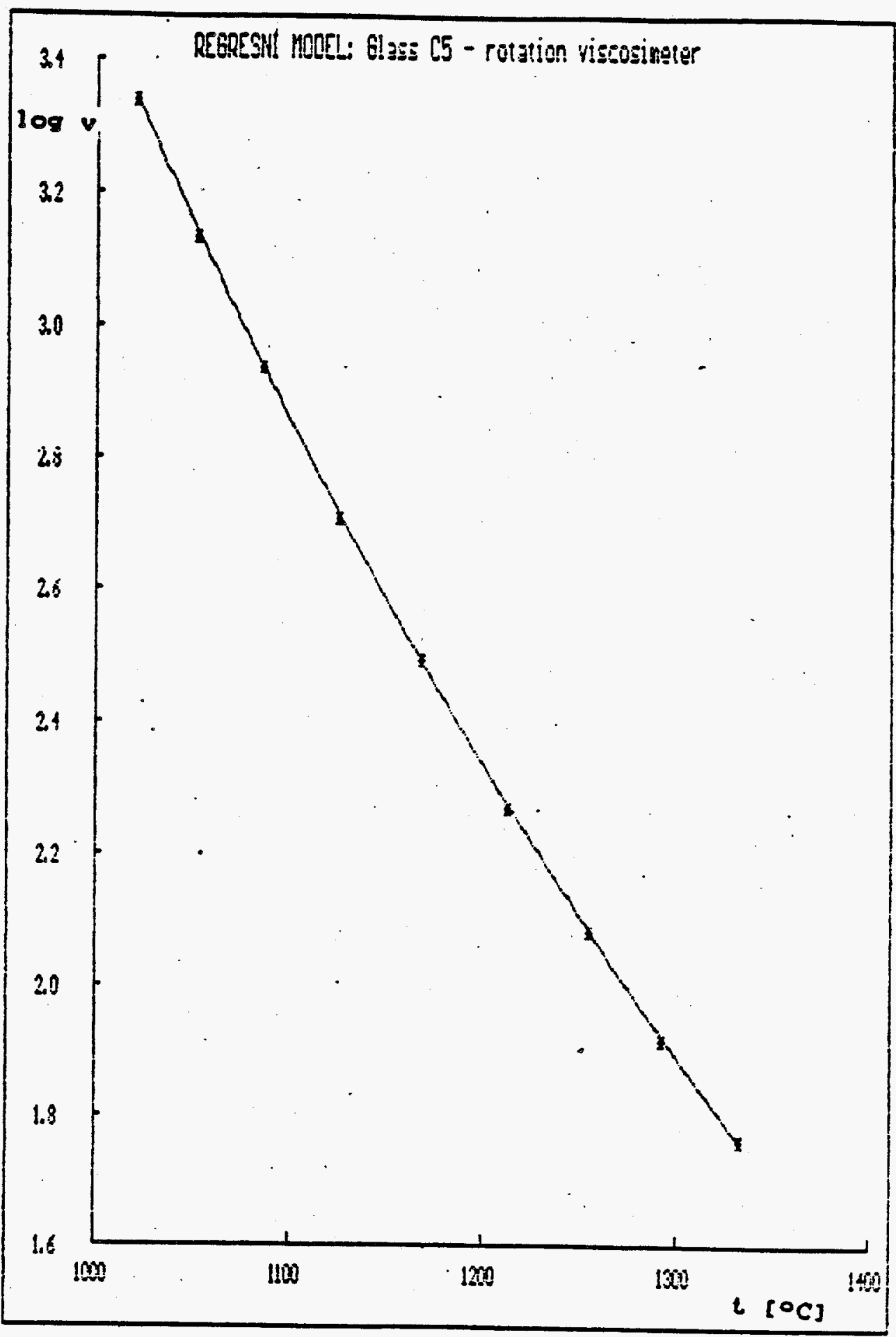

Figure: Temperature Dependence of Glass C5 Viscosity 
ANNEXES D

IISTS OF DOCUNIENTS AND SAMPLES

ANNEX DI

LIST OF CLOSING REPORTS

This list represents all closing Reports which were in their English version sent to Battelle with respective monthly reports and form a fix part of the Final Report. These reports document data all of which are not included in the Final Report, but which may give more information to the reader.

czech versions of reports are archived in the Nuclear Research Institute, laboratory reports (in czech) are at the disposal in respective cooperating laboratories.

\section{Glass Institute, State Testing Laboratory}

Closing Report STL No.180/94

Selected properties of experimental glasses

Closing Report STI No.199/94

Preparation of chromium hydroxide

Closing Report STL No.200/94

Properties of chromium hydroxide

Closing Report STI No.254/94

Selected properties of glasses $\mathrm{Al}, \mathrm{B1}, \mathrm{Al} / \mathrm{Cr}$ and $\mathrm{BI} / \mathrm{Cr}$

Closing Report STL No.1/95

Preparation of chromium hydroxide II

Closing Report STL No.2/95

Properties of chromium hydroxide II

Closing Report STL No.37/95

Selected properties of glasses $1 / 5$ and $2 / 5$

Closing Report STL No.38/95

Thermal treatment of glass batches 1 and 2 
Closing Report STL No.59/95

Properties of chromium hydroxide - black form

Closing Report STL No.90/95

Physical properties of glasses $10 X / 7$ and $10 R / 8$

Closing Report STL No.91/95

Physical properties of series C glasses

Closing Report STL No. $92 / 95$

Physical properties of $I$ and $M$ glasses

Chemical Oniversity, Department of Glass and Ceramics VSCHT-Battelle Report No.1

Characterization of specimens Al and BI (results of measurements)

vSCHT-Battelle Report No.2

Characterization of glasses 1 and 2 by $x$-ray diffraction

VSCHT-Battelle Report No.3

Characterization of glasses $1 / 5$ and $2 / 5$ by optical microscopy. $x$-ray microanalysis and scanning electron microscopy

VSCHT-Battelle Report No. 4

Characterization of glasses $1 / 6$ and $2 / 6$ by optical microscopy

VSCHT-Battelle Report No.5

Characterization of series C glasses by optical microscopy 
ANNEX D2

LIST OF ARCHIVED SAMPLES

ARCHIVE OF SAMPLES

(svus, Hradec Králové)

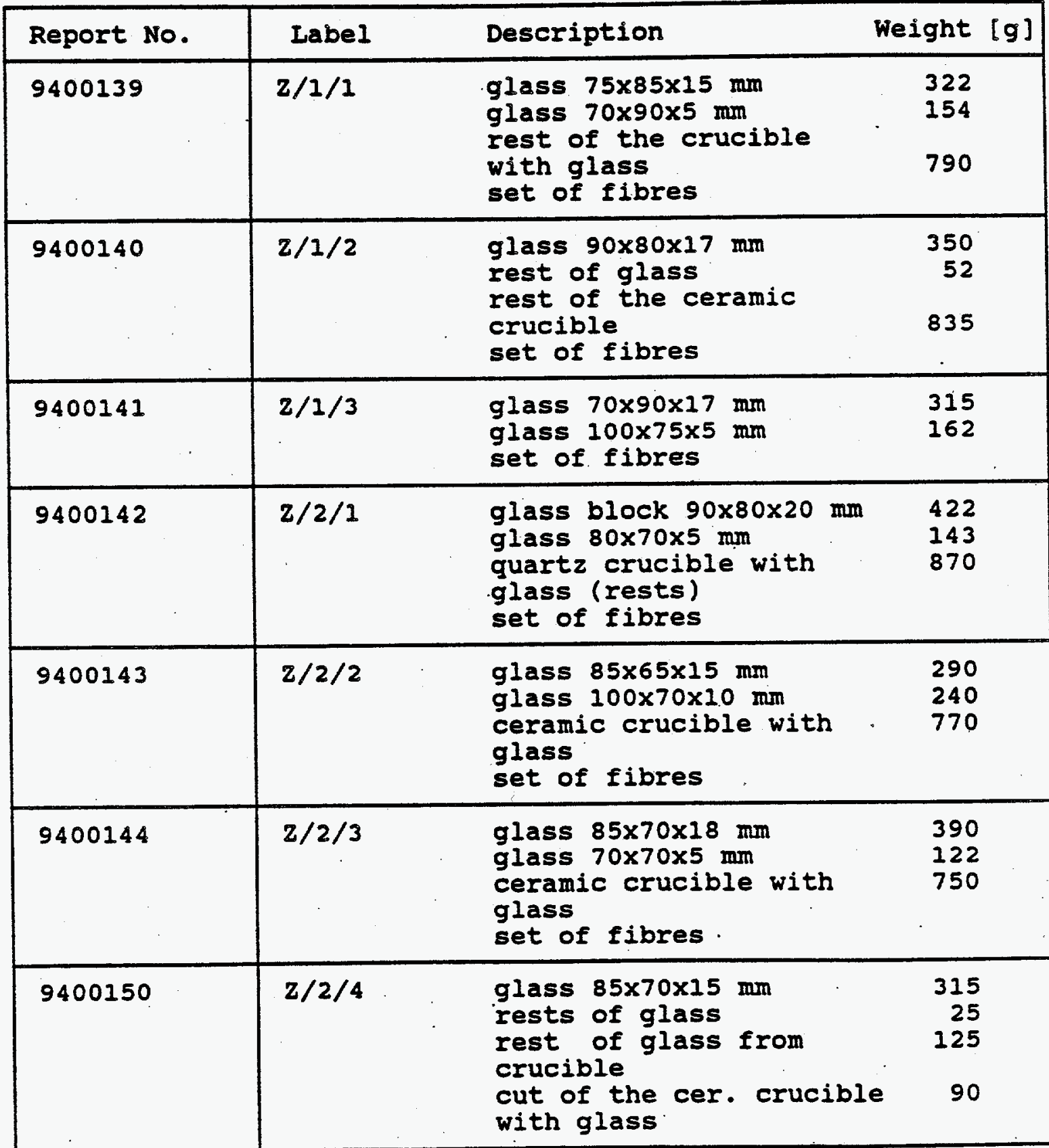

(cont.) 


\begin{tabular}{|c|c|c|c|}
\hline Report No. & Label & Description & Weight [g] \\
\hline 9400154 & $2 / 2 / 4$ & $\begin{array}{l}\text { rest of glass from Pt } \\
\text { crucible } \\
\text { glass } 80 \times 90 \times 12 \mathrm{~mm} \\
\text { get of fribres } \\
\text { cut of the cer. crucible } \\
\text { with glass }\end{array}$ & $\begin{array}{r}145 \\
300 \\
75\end{array}$ \\
\hline 9400233 & A 1 & $\begin{array}{l}2 \text { samples of glass } \\
40 \times 40 \times 15 \mathrm{~mm} \\
\text { rest of glass }\end{array}$ & $\begin{array}{r}120 \\
28\end{array}$ \\
\hline 9400234 & A 2 & $\begin{array}{l}2 \text { samples of glass } \\
40 \times 40 \times 15 \mathrm{~mm} \\
\text { rest of glass }\end{array}$ & $\begin{array}{r}125 \\
28\end{array}$ \\
\hline 9400235 & B 1 & $\begin{array}{l}2 \text { samples } 40 \times 40 \times 10 \mathrm{~mm} \\
\text { rest of gláss }\end{array}$ & $\begin{array}{l}92 \\
25\end{array}$ \\
\hline 9400236 & B 2 & $\begin{array}{l}2 \text { samples, } 40 \times 40 \times 13 \mathrm{~mm} \\
\text { rest of glass }\end{array}$ & $\begin{array}{r}120 \\
30\end{array}$ \\
\hline 9400237 & A 3 & $\begin{array}{l}\text { glass } 50 \times 100 \times 10 \mathrm{~mm} \\
\text { glass } 50 \times 50 \times 10 \mathrm{~mm} \\
\text { cuts of glass }\end{array}$ & $\begin{array}{r}170 \\
80 \\
160\end{array}$ \\
\hline 9400238 & A 4 & $\begin{array}{l}\text { glass } 100 \times 100 \times 22 \mathrm{~mm} \\
\text { glass } 95 \times 45 \times 10 \mathrm{~mm} \\
\text { glass } 45 \times 45 \times 10 \mathrm{~mm}\end{array}$ & $\begin{array}{r}615 \\
180 \\
90\end{array}$ \\
\hline 9400239 & B 3 & glass $45 \times 45 \times 8 \mathrm{~mm}$ & 80 \\
\hline 9400240 & B 4 & $\begin{array}{l}\text { block } d=25 \mathrm{~mm} \text { (irreg.) } \\
\text { block } 95 \times 45 \times 10 \mathrm{~mm} \\
\text { glass } 50 \times 45 \times 10 \mathrm{~mm}\end{array}$ & $\begin{array}{l}455 \\
210 \\
100\end{array}$ \\
\hline 9400241 & A $3 / \mathrm{CCC}$ & $\begin{array}{l}\text { cut cer. crucible with } \\
\text { glass } 1 / 2\end{array}$ & 163 \\
\hline 9400242 & A 3/TEM & $\begin{array}{l}\text { cut } 1 / 2 \text { cer. crucible } \\
\text { with glass }\end{array}$ & 163 \\
\hline 9400243 & B $3 / \mathrm{CCC}$ & $\begin{array}{l}\text { parts of cer. crucible } \\
\text { with glass } 1 / 2 \text { (cut) }\end{array}$ & 170 \\
\hline 9400244 & B 3/TEM & $\begin{array}{l}\text { rests of cer. crucible } \\
\text { with glass }\end{array}$ & 160 \\
\hline 9400245 & B $4 /$ TEM $/ 2$ & $\begin{array}{l}\text { rests of cer. crucible } \\
\text { with glass }\end{array}$ & 350 \\
\hline
\end{tabular}

(cont.) 


\begin{tabular}{|c|c|c|c|}
\hline Report No. & Label & Description & Weight $[g]$ \\
\hline 9400246 & B 4/TEM/3 & $\begin{array}{l}\text { rests of cer. crucible } \\
\text { with glass }\end{array}$ & 358 \\
\hline 9400247 & B $1 / C r$ & $\begin{array}{l}\text { block of glass } \\
95 \times 45 \times 15 \mathrm{~mm} \\
\text { glass } 45 \times 45 \times 12 \mathrm{~mm}\end{array}$ & $\begin{array}{r}193 \\
95\end{array}$ \\
\hline 9400248 & $\mathrm{~A} I / \mathrm{Cr}$ & $\begin{array}{l}\text { block of glass } \\
95 \times 45 \times 16 \mathrm{~mm} \\
\text { glass } 50 \times 45 \times 16 \mathrm{~mm}\end{array}$ & $\begin{array}{l}166 \\
110\end{array}$ \\
\hline 9400249 & B $3 / \mathrm{TEM} / 4$ & $\begin{array}{l}\text { rests of cer. crucible } \\
\text { with glass }\end{array}$ & 239 \\
\hline 940050 & $1 / 5$ & $\begin{array}{l}\text { glass } 100 \times 23 \times 15 \mathrm{~mm} \\
\text { glass } 45 \times 45 \times 10 \mathrm{~mm}\end{array}$ & $\begin{array}{l}85 \\
60\end{array}$ \\
\hline 9400251 & $1 / 6$ & $\begin{array}{l}\text { block of glass } \\
95 \times 50 \times 15 \mathrm{~mm} \\
\text { glass } 50 \times 50 \times 10 \mathrm{~mm} \\
\text { glass } 100 \times 30 \times 20 \mathrm{~mm} \\
\text { rests of glass }\end{array}$ & $\begin{array}{r}202 \\
82 \\
151 \\
13\end{array}$ \\
\hline 9400252 & $2 / 5$ & rests of glass & 148 \\
\hline 9400253 & $2 / 6$ & $\begin{array}{l}\text { block of glass } \\
100 \times 50 \times 12 \mathrm{~mm} \\
\text { glass } 50 \times 50 \times 12 \mathrm{~mm} \\
\text { rests of glass }\end{array}$ & $\begin{array}{r}191 \\
82 \\
127\end{array}$ \\
\hline 9400254 & $1 / 6 / \operatorname{ccc}$ & $\begin{array}{l}\text { cut cer. crucible } \\
\text { with glass }\end{array}$ & 134 \\
\hline 9400255 & $1 / 6 /$ TEM & $\begin{array}{l}\text { cut cer. crucible } \\
\text { with glass }\end{array}$ & 128 \\
\hline 9400256 & $2 / 6 / \operatorname{ccc}$ & $\begin{array}{l}\text { rests cer. crucible } \\
\text { with glass }\end{array}$ & 192 \\
\hline 9400257 & 2/6/TEM & $\begin{array}{l}\text { rests cer. crucible } \\
\text { with glass }\end{array}$ & 270 \\
\hline 940260 & $10 x / 7$ & $\begin{array}{l}\text { block of glass } \\
100 \times 50 \times 10 \mathrm{~mm} \\
\text { glass } 50 \times 50 \times 10 \mathrm{~mm}\end{array}$ & $\begin{array}{r}155 \\
77\end{array}$ \\
\hline 9400261 & $10 R / 8$ & $\begin{array}{l}\text { block of glass } \\
100 \times 50 \times 10 \mathrm{~mm} \\
\text { glass } 50 \times 50 \times 10 \mathrm{~mm}\end{array}$ & $\begin{array}{r}155 \\
80\end{array}$ \\
\hline
\end{tabular}

(cont.) 


\begin{tabular}{|c|c|c|c|}
\hline Report No. & Label & Description & Weight [g] \\
\hline 9400262 & c 1 & glass $50 \times 50 \times 10 \mathrm{~mm}$ & 76 \\
\hline 9400263 & C 2 & glass $50 \times 50 \times 10 \mathrm{~mm}$ & 80,6 \\
\hline Report No & Label & Description & Weight $[g]$ \\
\hline 9400264 & C 3 & glass $50 \times 50 \times 10 \mathrm{~mm}$ & 77 \\
\hline 9400265 & C 4 & glass $50 \times 50 \times 10 \mathrm{~mm}$ & 82 \\
\hline 9400266 & c 5 & glass $50 \times 50 \times 10 \mathrm{~mm}$ & 78 \\
\hline 9400267 & $c-c 1$ & $\begin{array}{l}\text { dice of crucible } \\
\text { block } 80 \times 30 \times 10 \mathrm{~mm} \\
\text { cut - off }\end{array}$ & $\begin{array}{r}35 \\
65 \\
7\end{array}$ \\
\hline 9400269 & $c-c 2$ & $\begin{array}{l}\text { dice of crucible } \\
\text { block } 70 \times 30 \times 12 \mathrm{~mm} \\
\text { cut of } \\
\text { set of fibres }\end{array}$ & $\begin{array}{l}60 \\
65 \\
69\end{array}$ \\
\hline 9400271 & $C-C 3$ & $\begin{array}{l}\text { dice of crucible } \\
\text { block } 70 \times 30 \times 12 \mathrm{~mm} \\
\text { cut off } \\
\text { set of fibres }\end{array}$ & $\begin{array}{l}50 \\
62 \\
13\end{array}$ \\
\hline 9400273 & $c-c 4$ & $\begin{array}{l}\text { dice of crrucible } \\
\text { block } 80 \times 30 \times 11 \mathrm{~mm} \\
\text { cut off } \\
\text { set of fibress }\end{array}$ & $\begin{array}{r}55 \\
75 \\
6\end{array}$ \\
\hline 9400275 & $\mathrm{c}-\mathrm{cs}$ & $\begin{array}{l}\text { dice of crucible } \\
\text { block } 70 \times 30 \times 11 \mathrm{~mm} \\
\text { set of fibres }\end{array}$ & $\begin{array}{l}60 \\
75\end{array}$ \\
\hline 9400268 & $D-C 1$ & $\begin{array}{l}\text { dice of crucible } \\
\text { block } 70 \times 30 \times 11 \mathrm{~mm} \\
\text { cut - off }\end{array}$ & $\begin{array}{l}63 \\
67 \\
14\end{array}$ \\
\hline 9400.270 & $D-C 2$ & $\begin{array}{l}\text { dice of crucible } \\
\text { block } 65 \times 32 \times 11 \mathrm{~mm} \\
\text { cut - off } \\
\text { set of fibres }\end{array}$ & $\begin{array}{r}70 \\
71 \\
6\end{array}$ \\
\hline 9400272 & $D-C 3$ & $\begin{array}{l}\text { dice of crucible } \\
\text { block } 70 \times 30 \times 11 \mathrm{~mm} \\
\text { cut - off } \\
\text { set of fibres }\end{array}$ & $\begin{array}{r}65 \\
55 \\
2\end{array}$ \\
\hline
\end{tabular}

(cont.) 


\begin{tabular}{|c|c|c|c|}
\hline Report No. & Label & Description & Weight [g] \\
\hline 9400274 & $D-C 4$ & $\begin{array}{l}\text { dice of crucible } \\
\text { block } 75 \times 30 \times 12 \mathrm{~mm} \\
\text { cut - off } \\
\text { set of fibres }\end{array}$ & $\begin{array}{r}65 \\
65 \\
5\end{array}$ \\
\hline 9400276 & $D-C 5$ & $\begin{array}{l}\text { dice of crucible } \\
\text { block } 75 \times 35 \times 11 \mathrm{~mm} \\
\text { set of fibres }\end{array}$ & $\begin{array}{l}70 \\
75\end{array}$ \\
\hline
\end{tabular}

ARCHIVE OF SAMPLES

(NRI, Reż)

SAMPLES ARCHIVED IN LAB NO. 15 OF NRI

\begin{tabular}{|c|c|c|c|c|c|c|c|c|}
\hline Sample & $\begin{aligned} & \text { Date of } \\
& \text { Prepar. }\end{aligned}$ & $\begin{array}{c}\text { Melt. Temp. / Dwe }] \\
{[\cdot \mathrm{C}] /[\mathrm{h}]}\end{array}$ & $\begin{array}{l}1 \mathrm{~B} \\
\text { PCS }\end{array}$ & $\begin{array}{l}\text { Buik of } \\
\text { s wt. }[g]\end{array}$ & $\begin{array}{l}\text { Glass } \\
\text { Grains }\end{array}$ & Tapes & $\begin{array}{l}\text { Thn } \\
\text { Plt }\end{array}$ & Rem \\
\hline $\begin{array}{l}A-Z 7 \\
A D Z 8 \\
A-X 9 \\
A-Y 10 \\
B-W 11 \\
B-V 12 \\
A-X 13 \\
A-X 14 \\
A-Y 15 \\
A-Y 16 \\
B O W 17 \\
B O V 18 \\
A O U 19 \\
A O U 20 \\
A O T 21 \\
A O T 22 \\
A O S 23 \\
A O S 24 \\
A O R 25 \\
A O R 26\end{array}$ & $\begin{array}{l}03.11 .94 \\
03.11 .94 \\
11.11 .94 \\
11.11 .94 \\
15.11 .94 \\
15.11 .94 \\
22.11 .94 \\
22.11 .94 \\
22.11 .94 \\
22.11 .94 \\
29.11 .94 \\
29.11 .94 \\
07.12 .94 \\
07.12 .94 \\
07.12 .94 \\
07.12 .94 \\
14.12 .94 \\
14.12 .94 \\
14.12 .94 \\
14.12 .94\end{array}$ & $\begin{array}{l}1150 / 2 \\
1150 / 2 \\
1150 / 2 \\
1150 / 2 \\
1450 / 2 \\
1450 / 2 \\
1350 / 2 \\
1350 / 2+1400 / 0.5 \\
1350 / 2 \\
1350 / 2+1400 / 0.5 \\
1450 / 4 \\
1450 / 4 \\
1150 / 2 \\
1150 / 2 \\
1150 / 2 \\
1150 / 2+1200 / 0.5 \\
1150 / 2 \\
1150 / 2+1250 / 0.5 \\
1150 / 2 \\
1150 / 2+1250 / 0.5\end{array}$ & $\begin{array}{l}1 \\
1 \\
1 \\
1 \\
1 \\
1 \\
1 \\
1 \\
5 \\
5 \\
5\end{array}$ & $\begin{array}{r}18 \\
18 \\
35 \\
40 \\
28 \\
31 \\
35 \\
16 \\
9 \\
24 \\
17 \\
26 \\
\\
12 \\
5 \\
27\end{array}$ & $\begin{array}{l}+ \\
+ \\
+ \\
+ \\
+ \\
+ \\
+ \\
+ \\
+ \\
+ \\
+ \\
+ \\
+ \\
+ \\
+\end{array}$ & $\begin{array}{l}+ \\
+ \\
+ \\
+ \\
+ \\
+ \\
+ \\
+ \\
+ \\
+ \\
+ \\
+\end{array}$ & $\begin{array}{l}+ \\
+\end{array}$ & $\begin{array}{l}\star \star 7 g \\
\star \star 2 g\end{array}$ \\
\hline
\end{tabular}

(cont.) 


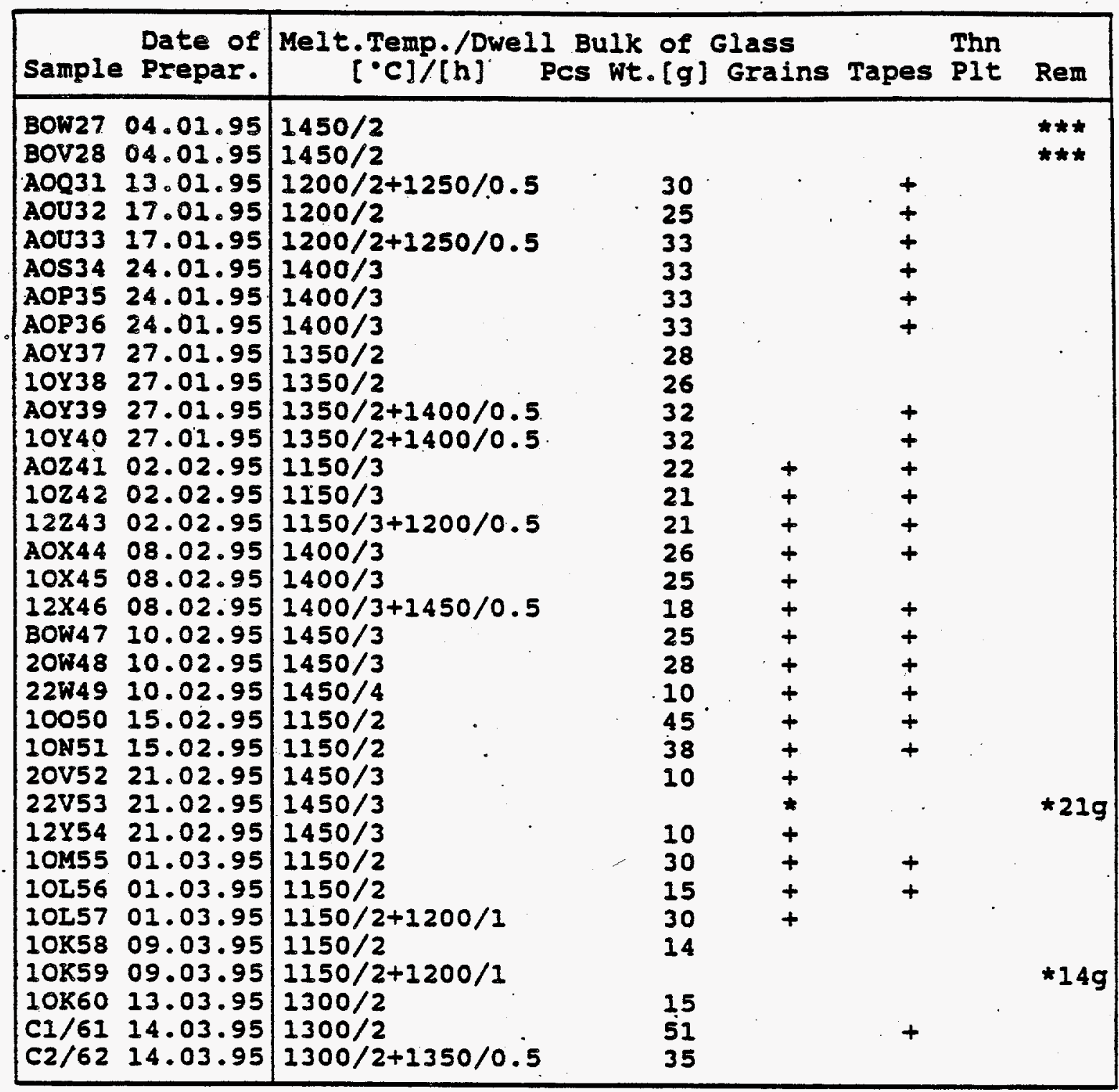

Notes:

Pcs $\quad \ldots$ Pieces

ThnPlt ... Thin plates (sections)

Rem ... Remarks: * weight of glass adhered on crucible walls

** weight of pieces of glass inhomogenized

*** the whole sample on crucible (broken) 


\section{Statement of Kork}

\section{Backoround}

Battelle, Pacific Northwest Laboratory (PII), has a requirement for a Contractor to determine the effect of chromium oxide on the properties of simulated nuclear waste glasses applicable to High Level h'aste (HL') melter.

The HLK' malter shall convert high level nuclear wastes to aluminoborosilicate glasses using slurry-fed electrical melters. Some wiestes planned for vitrification contain high concentrations of chromium oxide $\left(\mathrm{Cr}_{2} \mathrm{O}_{2}\right)$. Because of the limited solubility of $\mathrm{Cr}_{2} \mathrm{O}_{3}$ in borosilicate glasses, Haste loading in the glass (i.E., wiaste form) is limited by the chromium oxide content in tive haste:

It is our concern to ioentify what affects the incorporation of $\mathrm{C}_{-} \mathrm{O}_{3}$ in simulated nuciear hizste giasses, and how redox chemistiry, composition of giass and weste, and the iormation and setiling of aoglomerates afiect the processability of the waste giass in electrical continuous melters. Another concern is to oetermine the exient chromium oxios or chromiun spinel a fiect melt homogeneity, viscosity, electrical conouctivity, eno liquidus tempereiure.

Cinromium can be present in gizss zs Cr(III) or Cr(VI). di is ziso our concern

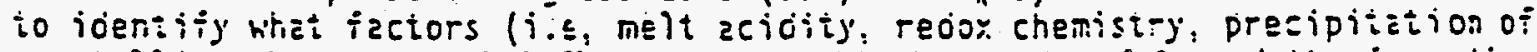
crysialiine phases, eic.) iniulunes the oxication siate oi (r and the iormetion

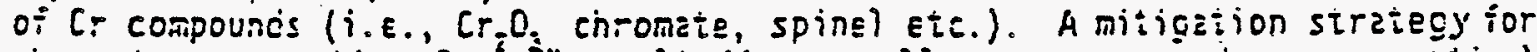
chromate segregation irom the nelt (j.e., yellow or orenge phizse separetion) neecis to de joentified.

\section{Obiective}

The Contractor stiall oetemine the eifest of enromium on the properties o: simulateo nuelear weste glasses and ioentify wiet aifests ine incorporition of cr into simuieced nuclear viaste giesses. The properties that are to be evaiviate are inhomogeneities in the gizss and the melt, crysiellizesion of Cr conteifing phases, and settling of. crystals ano aggiomerates.

To perrorm the above, PNL shall provide the Contractor with the waste composition (see Exnibit 1) and directions for preparing the kiaste. PN! shiall aiso provios ine gizss composition. The work will ioentify jactors that aiject the incorporation $0 * \mathrm{Cr}$ in olass and ioentify technical oificulties encountered when preparing giasses with $\mathrm{Cr}$. In addition, a strategy and method for the mitigation of chromate segregation shall be oeveloped. Recommenoations for a more in oepth focus of the problems for future research shall be made.

Note 1: The following tasks are to be followed in order as some steps are interopendent. 
PRP 110.209344

Enclosure 3

Hote 2: The detailed Quality Assurance (QR) sections ealled out in the majority of the tasks are provided so that the contractor can include the appropriate technical detail required for first. deliverable, the Test plan. .

Iast 1 Prepare $\mathrm{Cr}_{2} \mathrm{O}_{3}$ source as specified by PNL directions. The $\mathrm{Cr}$ (III) source is essentially $\mathrm{Cr}(\mathrm{OH})_{3}$ prepared from the mixing of $\mathrm{Cr}\left(\mathrm{NO}_{3}\right)_{3}$ and $\mathrm{H}_{2} \mathrm{OH}$.

Task 2 Prepare two glasses with precipitated $\mathrm{Cr}(\mathrm{OH})_{3}$ made in Task l. Glass 1 and Glass 2 will have compositions as specified in Exhibit 1 . It is not necessary to prepare frit. Standard chemicals may be used (e 9.. $\mathrm{H}_{3} \mathrm{BO}_{3}, \mathrm{Li}_{2} \mathrm{CO}_{3}$, and $\mathrm{SiO}_{2}$ ). The method and chenicals used for preparing glasses shall be specified in the final report. Joentify any problems associated with melting (i.e., foaming, scum formation, seitling of erystais, ete.). Meli Glass 1 at il50 ${ }^{\circ} \mathrm{C}$. Melt Glass 2 at $1450^{\circ} \mathrm{C}$. Glasses sinall be melted for 2 hours and mectianicaliy stirred every 20 minutes. Quench the olass on a meial piate or pour into bars as necessary for future tasks.

QA: Provide some means of sample control (1abeling, tagging, scribing) to ensure that the identification of melts and olass (sampies) is mainiejned at ell times so 25 to avoid mixing of sempies/melis. [escribe your sample/oizss icentificztion methocs, for this anc the other izsks in the Tes: pian. Piace tiris oescription in the Test pien whers it is mosi Suitedie.

iast 3 Make observations and oetermine any iniöomogeneities in the giasses and the melts, erystallization, agolomeration of ciysiais, ano setiling of crysizls and zgoiomerzies. Deiermine setzling and 2gglomeration of cinromiun coriteining prieses as a Tuhetion of tine and temperature. Crystallite and zgoiomerace size, composition, zad type shafi also be oetermined. Precare microslioes oí sampies and examine them using optical microscopy and scanning eieziron microscopy (SEM). For the optisal micrescopy exanirietion, use transmitied and reflected light to examine the sampies. Photograph and characterize gliss.

O\&: Deseribe how you will oosumen: your osserva:ions, and provioe a oescription of your opticel microscopy and SEM prosedures in the Tes: Pian.

Iesk 4 The viscosity and conouctivity of both molten glasses as a function of temperature shall be determined. The temperature shall includs, but is not limited, to the range in which settling and agglomeration occurs. The glass transition temperature and liquidus temperatures (For phases other then $\mathrm{C}_{2} \mathrm{O}_{3}$ ) shall be oetermined for both olzsses. PNL's procedures for viscosity, conductivity, and iliquious temperature shall be provioed to the contractor as guicance, but the Contractor is iree to use their own procedure. The metiod for tine 
RFP No. 209344

Enclosure 3

measurement of glass transition temperature and the temperature history of each glass shall be specified with the glass transition temperature.

OA: In the Test Plan that you will be preparing, describe which PNL provided procedures you will be using, and or your methods for determining viscosity, conductivity and liquidus temperature.

Iask 5 Volume or mass fraction of crystals (i.e., erystalline state fraction) shall be determined in Glass I and Glass 2, by optical examination of thin sections, for two different cooling schedules (as follows). Glass samples (from glasses prepared in Task 2) will be heated to the melting temperature, helo for 20 minutes, and cooled by the following edoling scheoules: 1) hold for 24 hrs at a temperature $100^{\circ} \mathrm{C}$ below the melting temperature and then anneal samples at $\approx 500^{\circ} \mathrm{C}$ for 2 hours, let furnace cool zo room lemperature and 2) cool samples to initial centerline canisier cooied (CCC) scheoule temperature, hold for I hour, and then cool following the scheoule, (see Appendix for blass I CCC scheoule, Giass 2's CCC schedule will be provided later. Glass 2's CCC scheoule is similar to Giass 1 schedule). X-ray diffraction (XRD) can be used as a rough estimate of crystalline state fraction, but optical examination method is necessary for accyrats oetermination.

QA: in the iest pizn, oescribe the proseoures for determining mess cr voiume iraction oi crysieis. Frovios osiajis of your opiticel exienineition methods, XRD, ano glass melting technique. In this izsk ano others, when using instruments for oetermining - temperature, weigtit or other measurements, ensure that they are calibrateo to known physical constants, ior example, national stancaros, stancard reference materials. Ii this is no: possibie, oescribe the method to assure accurate mezsuremen:s. $1 \%$ siancarcis cannot $D E$ provioed by the contractor, netity tne PNL iecnnicel Aaminiszrazor. Some stancaros may de provioed by PN!. if mezsuring eouipment is found to be out of calibration, frovios an eveiuation of the imeact to work periormeo under inis contrest, to the PN: iesnnice! Aoministrator.

introduction to Task 6: Determine what affects the incorporation oi $C r$ in olass by preparing several oizsses (see Tasks $\epsilon_{\bar{c}}, 6 b$, and $6 c$ ). in particuiar, determine the relationship of meli acidizy/besicity, mejor oless componenis, and reoox to cinromete formetion. The method for mezsurement and decermination of Cr(VI)/Cr(III) ratio shall be oescribed and error limits given in the fina? report.

Tesk $\sigma_{a}$ For melt acidity experiments, Na $\mathrm{O}$ can be substituted for $\mathrm{Li}_{2} \mathrm{O}, \mathrm{B}_{2} \mathrm{O}_{3}$ or $\mathrm{SiO}_{2}$ (frit components) to change the basicity of the meli. Other $^{3}$ components may be substituted for the frit components to increase or oecrease the basicity of the melt as appropriate. Kramer (1091) plotted $\mathrm{Cr}$ (VI)/Cr(III) as a function of basicity number for simpie binary alkali-silicate systems based on a stuoy by Nath and Dougias 
RFP No. 209344

Enclosure 3

(1965). The correlation between basicity number and chromate formation shall be expanded for the glasses prepared for this subeontract.

OA: Describe in the Test. Plan the technical procedures that will be used for determining what affects $\mathrm{Cr}$ has in glasses. Provide enough details to enable the results to be verified and reproduced. In the Test Plan, describe the method that will be used for determining $\operatorname{Cr}(V I) / C r(I I I)$ ratio.

Task 6b In addition, the effect of selected other components (e.g., $\mathrm{Al}_{3} \mathrm{O}_{3}$ ) in the glass on the incorporation of $\mathrm{Cr}$ and the $\mathrm{Cr}$ (VI)/Cr(III) stiati be explored. Specify the selected components and their basis for selection in the final report.

OA:: in the Test Plan, describe the method that will be usec for oetermining Cr(VI)/Cr(III) ratio. Specify the selesied components and their basis for seiection in the Test plan.

Tesk ic For redox experiments, adoitions of reductants (e.g., organics such as sugar or formate) and oxidants (i.e., nitrate) can be made to develop a relationship between adoitive and chromate formation and Cr(VI)/Cr(III). Aodition of reouetants and cxicianis stiaii be racis without changing glass composition when comearing the sits:: $0 \%$ adoitives in glass 1 and giass 2 compositions.

08:- Describe in the Test Plan how this and other task testing activi:ies will be documented. Piace this informetion in the iest pian where it is best suited, for exampie, locate these methocs with ine various iestine methods being used.

iask I Determine the temperature range at which chromaies forn (it any) in baich material (i.e. taich material used to make siass I anc filass 2) and the extent of ehromate formetion as a function of temperature and time. Besause nuciear waste gizsses will $D E$ prodused in a izrọe scale melier system we are coneerned with the fo.tmation of enromicies in the coid cap (i.e., bezch bianket)... The beich material is likeiy to experience a range of temperatures before besoming a giass. Tne formation of chromates shall be therefore silucied by ine hea: treatment of the batej material. (not glasses already prepzrac in Tesk 2)

QA: Provide details in the Test Plan of this procejure, such tha: the method is cocumented, and the results can be reproouced.

izsk 8 Develop mitigation strategy for chromate formation during meliing. implement strategy on gless composition which exhibits chromete segregation. Choose a glass from Task o or Ciass I or 2 . Report results. 
R.FP No. 209344

Enclosure 3

OA: Identify in the Test Plan how this work will be documented (recorded in lab.). The results are to be provided in the deliverable Report.

Task 9 Write and provide draft report which includes mechanisms for the behavior of $\mathrm{Cr}$ in glass and recommendations for future research. The data shall support the proposed mechanisms. Deliver draft report to PNL.

\section{Deliverables}

The following items and documentation are to be provided by the Contractor and oelivered to PNL:

- Test plan and schedule with enoing dates for individual tasks for PRI review and approval. The Test plan stall incluos the following izems: an introouction, scope stitement, oeiailec discussion of how the tasks are 20 be accomplished, test scheouie, ioentification of siaff who will be working on contract, calibration, data collection requirements, dais reouction, how datz is to be reviewed (nomally a peer review), and references. Incluoe those items noted in the above task's also. The test plan sections can be combined if that is more logical, ano the orcer of the sections is at the Contractor's diseretion. The Tesi Pian stieil show epprovel by the Contracior's authorized pariles. lipon receipt ci the ies:

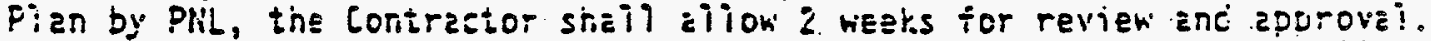

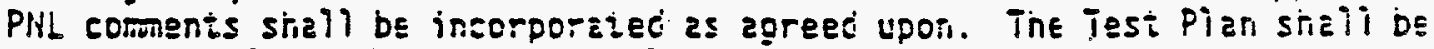
approved by PNI prior io siari of work.

- Monthiy progress reports. Jescribe prooress for ezch of the izske, end oeliverables on a percerizage basis. The estimaie oi percent comple ie is tesed or physical compiezion of ezch task. Technical orogress stiell be inoicated by ineluoing tine eppropriate technicai taiz, onservecions, enc conclusions. lif it zodez:s the scheoule will not be compieied as origineily plenned, an estimate of compietion is reouired in ine progress report. The progress repori is oue by the 15 th oay foilowing the moner being reporied.

- Test cata including Taboratory record book notes ano primery teta acouisition files. This inciuoes strip charts, comeuter prifizolis: calibration ciata/certificetion of insiruments (weight, temperzture, ELc), resumes of siaft working on contreet, laboratory recoro notebooks, photographs, and oocumentation of chemical analysis/certifications. This is not a complete list, but covers the basic types. The intent is for the contractor to forward copies of all primary (raw) test ciata. This information shall be ioentified with the contract number, ciate and name of the person who generaied the data. Test data shall show evidence of tecinical review by the contractors authorized party.

- Glass samples and microslioes, from all applicable tasks, with accurate and descriptive labels. The samples shall include ioentitication of the 
RFP No. 209344

Enclosure 4

glass/composition, date and Contractor's name. The method of identification shall not adversely affect the sampies.

A draft report is due 10 months after the start date of work. The draft report shall be reviewed by PNL and returned for the incorporation of comments. The final report, with incorporated comments as appropriate, are due 12 months after the start date of the work. The draft and final reports shall include a literature review summarizing the present state of knowledge regarding the incorporation of $\mathrm{Cr}$ into glass and its effect on properties, description of experimental procedures, results, discussion, and references. The report shall be signed by the contractor's authorized representative.

PNL shall provide the simulant preparation procedure, PNL procedures for viscosity, electrical conductivity and liquidus temperature measurement, and glass 2's CCC schedule to the contractor within thirty days of contract award.

One copy of all deliverables is to be forwarded to the PNL Technical Administrator. Technical Administrator shall al so be provided with the physical samples, glasses and slides prepared in support of this work scope.

\section{PREAWARD SURVEY OF PROSPECTIVE SUPPLIER/SUBCONTRACTORS}

When deemed necessary by Battelle, a preaward survey will be conducted of a prospective Contractor's technical, quality assurance, production, or financial capability. Evaluation of documented management controls applicable to materials to be produced or services to be performed by the prospective contractor or subcontractor(s) may include, but shall not be limited to inspection and test controls, calibration of measuring and test equipment, special process controls, material storage and handling, and change controls.

\section{References (attached)}

Kramer, F. H. 1991. "Contribution to basicity of technical glass melts in relation to redox equilibria and gas solubilities." Glastech. Ber. 64 (3): 71 80.

Nath, P. and R. W. Douglas. 1965. " $\mathrm{Cr}^{3+}-\mathrm{Cr}^{6+}$ equilibrium in binary alkali silicate glasses." Phys. and Chem. of Glasses. 6 (6):197-202. 